ANISLEY SUÁREZ OLIVA

TESIS DOCTORAL

2017

\title{
SÍNTESIS DE INDOLES Y CARBAZOLES FUNCIONALIZADOS: CATÁLISIS CON COMPLEJOS DE Au(III) Y ÁCIDOS DE BRØNSTED
}

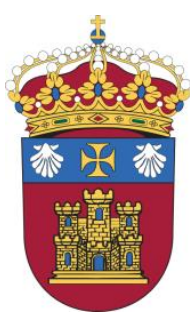

UNIVERSIDAD DE BURGOS

Departamento de Química

Área de Química Orgánica 



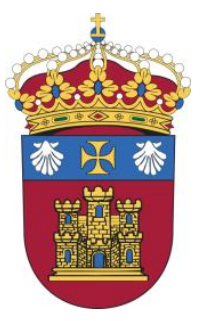

ROBERTO SANZ DIEZ, Catedrático de Química Orgánica del Departamento de Química de la Universidad de Burgos

\section{INFORMA:}

Que la presente Memoria titulada "Síntesis de Indoles y Carbazoles Funcionalizados: Catálisis con Complejos de $\mathrm{Au}(\mathrm{III})$ y Ácidos de Brønsted" ha sido realizada en el Departamento de Química de la Universidad de Burgos bajo su dirección, por la licenciada Anisley Suárez Oliva y autoriza su presentación para que sea calificada como Tesis Doctoral.

Burgos, Diciembre 2016

Fdo.: Roberto Sanz Diez 



\section{AGRADECIMIENTOS}

En primer lugar, quisiera agradecer a mi director Roberto Sanz, por haberme dado la oportunidad de realizar esta tesis bajo su supervisión. Por el apoyo recibido durante este tiempo y por trasmitirme su pasión por la Síntesis Orgánica.

Agradezco a Manu y a Patricia su por su ayuda en mis primeros pasos en el laboratorio y por la colaboración en este trabajo. También a Marta, Pilar y Jacinto sus consejos y su colaboración.

A mis compañeros de laboratorios porque sin ellos esta etapa no hubiera sido lo mismo. A Estela, Ana, Rocío y Miri por lo bien que lo hemos pasado juntas, y por todo el apoyo en los momentos más difíciles. A Elsa y Andrea por su energía positiva y su optimismo. A Saúl, Danidoc y Rubén por hacerme reír. A Samu por sus consejos en la recta final. A los pequeños (Cintia, Claudia, Fernando, Noelia, Carlos, Marta y Sergio).

A Nuria por ser un ejemplo de optimismo y valentía para todos.

A Blanca y a María, por todo lo que me habéis apoyado este último año.

A mis amigos, en especial a Karina y Juan.

A Pepi, Carlos, Juankar y la tía Nines por tratarme siempre como una más de la familia.

A Vicente, por estar siempre a mi lado, por todo su apoyo y confianza y por toda su ayuda en los momentos más duros.

A mi familia, en especial a mi madre y a mi hermana por todo por su confianza, su infinita paciencia y su apoyo incondicional. 

A mi madre. 

The Oak Tree

by Johnny Ray Ryder Jr.

A mighty wind blew night and day.

It stole the Oak Tree's leaves away.

Then snapped its boughs

and pulled its bark

until the Oak was tired and stark.

But still the Oak Tree held its ground while other trees fell all around.

The weary wind gave up and spoke,

"How can you still be standing Oak?"

The Oak Tree said, I know that you can break each branch of mine in two, carry every leaf away,

shake my limbs and make me sway.

But I have roots stretched in the earth, growing stronger since my birth.

You'll never touch them, for you see they are the deepest part of me.

Until today, I wasn't sure

of just how much I could endure.

But now I've found with thanks to you, I'm stronger than I ever knew. 



\section{ÍNDICE DE ABREVIATURAS}

$\beta$-CD $\quad \beta$-ciclodextrina

AcOEt Acetato de etilo

Alq alquilo

Ar arilo

BARAC Biarilazaciclooctinona

Bn bencilo

Boc: $\quad t$-butoxicarbonilo

CAN Nitratoamónicocérico

Cat catalizador genérico

Cat* catalizador genérico quiral

COD 1,5-Ciclooctadieno

DBSA Ácido dinitrobencenosulfónico

DCE: 1,2-dicloroetano

DCM Diclorometano

DMF Dimetilformamida

DMSO Dimetilsulfóxido

$\mathrm{E}^{+} \quad$ electrófilo genérico

H-mont Montmorillonita ácida

$\mathrm{HNTf}_{2} \quad$ Bistrifluorometanosulfinimida

IBX Ácido 2-yodoxibenzoico

IPr 1,3-bis(2,6-diisopropilfenil)imidazol-2-ilideno

KHMDS Hexametildisilazida de sodio

LDA Diisopropilamiduro de litio

LiHMDS Hexametildisilazida de litio

MS tamiz molecular

$\mathrm{NaBAr}_{4}$ Tetrafenilborato sódico 
NBS $N$-bromosuccinimida

NMP N-metil-2-pirrolidona

$\mathrm{NuH}$ nucleófilo genérico

OTf trifluorometanosulfonato

PPA Ácido polifosfórico

PTSA Ácido $p$-toluensulfónico

Py Piridina

TBHP $t$-butilhidroperóxido

TBF Formiato de $t$-butilo

TEA Trietanolamina

TFE 2,2,2-Trifluoroetanol

$\mathrm{TfOH}$ Ácido tríflico

THF Tetrahidrofurano

TMS trimetilsililo

TMSOTf Trimethylsilyl trifluoromethanesulfonate

Ts $\quad p$-toluensulfonilo/ tosilo

US ultrasonic sonication

XPhos 2-diciclohexilfosfino-2', 4', 6'-triisopropilbifenilo 


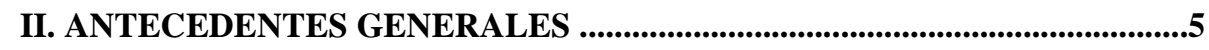

1. Indoles 3-funcionalizados: el indol como nucleófilo...............................................

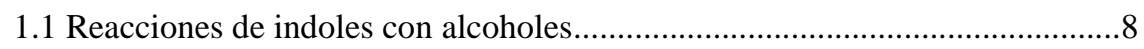

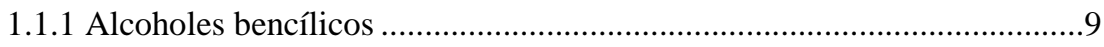

1.1.2 Alcoholes alílicos ............................................................................ 10

1.1.3 Alcoholes propargílicos......................................................................11

1.2 Reacciones de indoles con aldehídos.......................................................12

1.2.1 Síntesis de 3,3'-bisindolilmetanos (3,3'-BIMs) ......................................13

1.2.2 Síntesis de 3 -indolilmetanoles...............................................................15

1.3 Reacciones intramoleculares de indoles y alquinos catalizadas por complejos

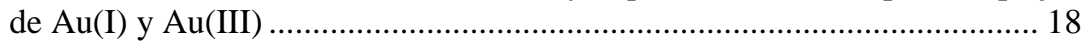

1.3.1 Reactividad de 2 y 3-(but-3-inil)-1H-indoles: Síntesis de carbazoles

1.3.2 Reactividad de 3-propargilindoles ........................................................28

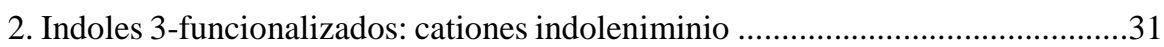

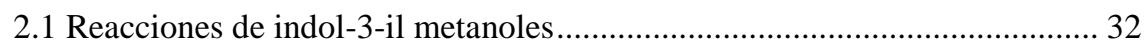

2.2 Reacciones de 3-sulfonilindoles............................................................. 33

\section{DISCUSIÓN DE RESULTADOS .................................................................... 37}

Capítulo 1 Reacciones de alquilación intramolecular de indoles con alcoholes

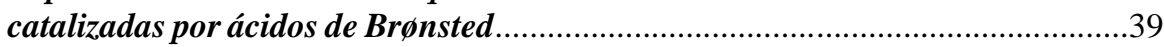

1.1 Antecedentes: Reacciones intramoleculares de sustitución nucleofílica directa

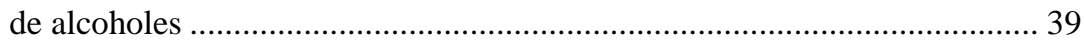

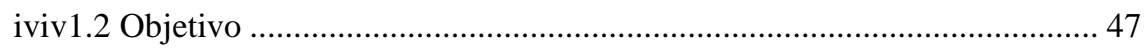

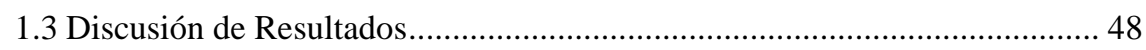

1.3.1 Síntesis de los indoles hidroxifuncionalizados de partida.......................48

1.3.2 Reacción de ciclación intramolecular de indoles con alcoholes catalizada por ácido de Brønsted................................................................................53

1.3.2.1 Síntesis de 5,10 dihidroindeno[ $1,2-b]$ indoles...................................53

1.3.2.2 Síntesis de 6,11-dihidro-5H-benzo[ $b]$ carbazoles.............................58

1.3.2.3 Síntesis de 6,11-dihidroindolo[1,2-b]isoquinolinas.........................60

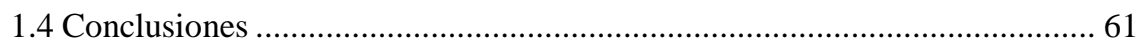

Capítulo 2 Síntesis de a-indolilcetonas funcionalizadas por sustitución nucleofílica de $\alpha$-indolilaciloínas....................................................................6.

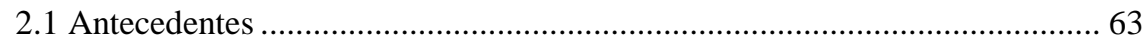

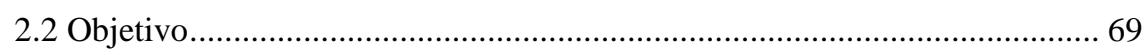

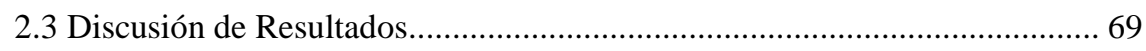

2.3.1 Síntesis de las $\alpha$-indolilaciloínas 18...................................................69

2.3.2 Reacción de $\mathrm{S}_{\mathrm{N}}$ directa de las aciloínas $\mathbf{1 8}$ catalizada por ácidos...........70 
2.3.2.1 Reacción de $\mathrm{S}_{\mathrm{N}}$ directa de $\mathbf{1 8}$ con nucleófilos carbonados. .71

2.3.2.1.1 Indoles como nucleófilos: Síntesis de 2,2-bis(indol-3-il)-1ariletanonas asimétricas 21 ..................................................... 71

2.3.2.1.2 Otros heteroarenos como nucleófilos.........................................74

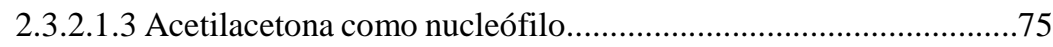

2.3.2.1.4 Otros compuestos 1,3-dicarbonílicos como nucleófilos..............76

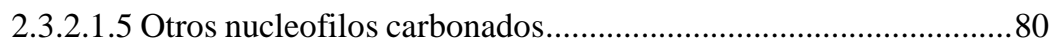

2.3.2.2 Reacción de $\mathrm{S}_{\mathrm{N}}$ de aciloínas $\mathbf{1 8}$ con nucleófilos heteroatómicos......80

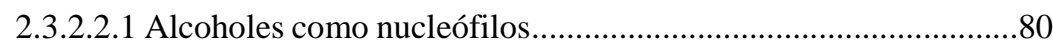

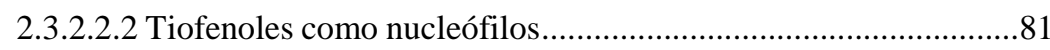

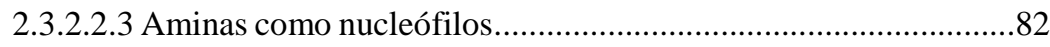

2.3.3 Aplicaciones sintéticas de las $\alpha$-indolilcetonas preparadas......................84

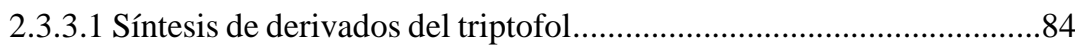

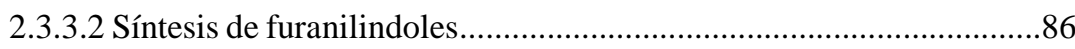

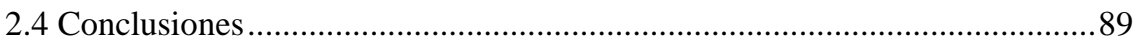

Capitulo 3 Síntesis de benzo[b]carbazoles por reacción de indoles con acetales de benzaldehído o-hidroxialquil funcionalizados......................................................91

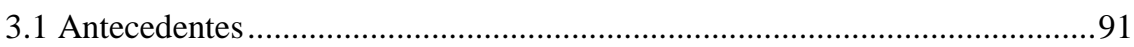

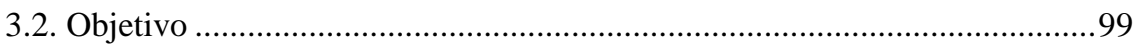

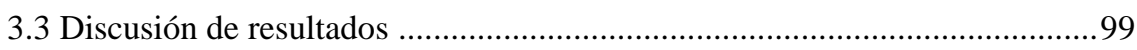

3.3.1 Síntesis de los hidroxiacetales de partida 32 ........................................99

3.3.2 Estudio de la reactividad de los acetales hidroxialquil funcionalizados con

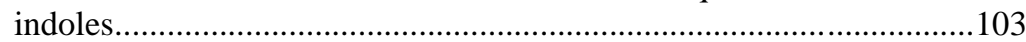

3.3.2.1 Pruebas preliminares........................................................................ 103

3.3.2.2 Mecanismo de formación del carbazol 41, el isobenzofurano 42 y el

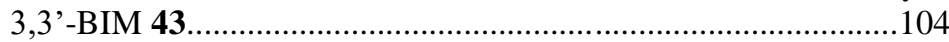

3.3.2.3 Optimización de las condiciones de reacción..................................107

3.3.2.4 Alcance de la reacción: Síntesis de los benzo[ $b]$ carbazoles 41......108

3.3.2.5 Reactividad de los acetales de 5-metoxibenzaldehído 2-hidroxialquil funcionalizados 33 con indoles.................................................111

3.3.2.6 Reacciones de los dietilacetales de $o$-(hidroxialquil)benzaldehído con grupos hidroxilo terciarios 32 m-t .............................................. 114

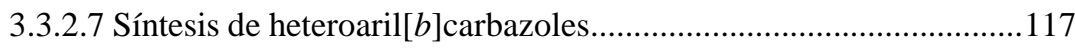

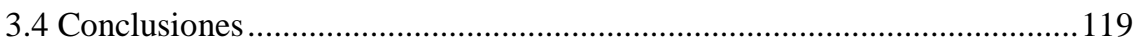

Capítulo 4 Reacciones de alquinoles a-indolilmetil funcionalizados catalizadas

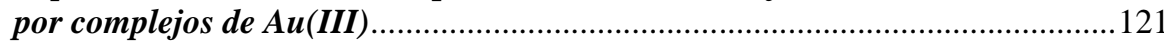

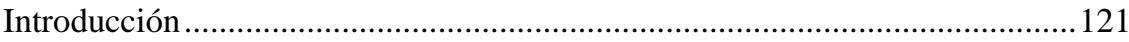

4.1 Estudio de la reactividad de alquinoles $\alpha$-bisindolilmetil sustituídos en presencia de catalizadores de $\mathrm{Au}(\mathrm{III})$....................................................... 123

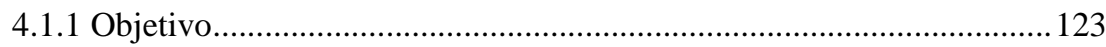

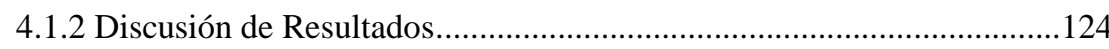


4.1.2.1 Síntesis de los alcoholes propargílicos $\alpha$-bisindol-3-yl-metil sustituídos 53

4.1.2.2 Reacciones de los alquinoles propargílicos $\alpha$-bisindolilmetil sustituídos 53 frente a complejos de Au(III) ................................126

4.1.2.2.1 Pruebas preliminares y optimización......................................126

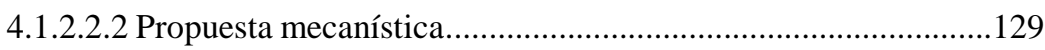

4.1.2.2.3 Evaluación del alcance de la reacción........................................130

4.1.2.2.4 Cálculos teóricos....................................................................134

4.2 Reacciones de yodociclación de alquinoles $\alpha$-bisindolilmetil sustituídos...137

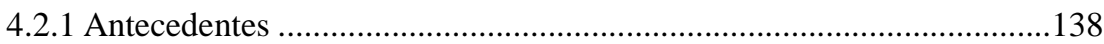

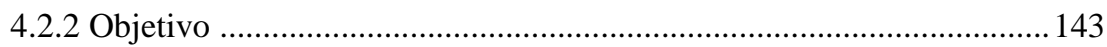

4.2.3 Síntesis de 1-indolil-3-yodocarbazoles................................................144

4.2.3.1 Pruebas preliminares y evaluación inicial del alcance de la

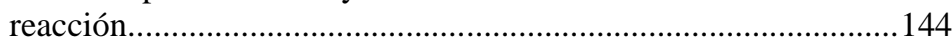

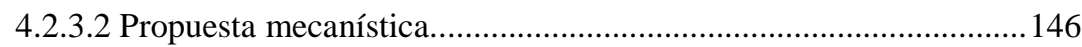

4.3 Reactividad de alquinoles $\alpha$-tioalquil funcionalizados frente a catalizadores de

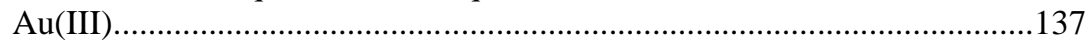

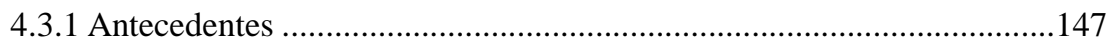

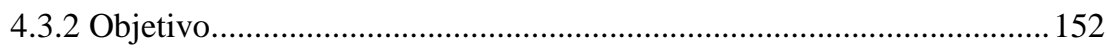

4.3.3 Discusión de Resultados...................................................................153

4.3.3.1 Síntesis de alquinoles propargílicos $\alpha$-ariltioalquilfuncionalizados

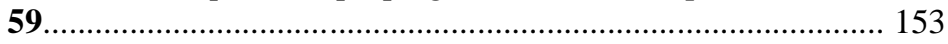

4.3.3.2 Síntesis de los indol-3-il-1,2-dioles 60........................................154

4.3.3.3 Estudio de la reactividad de los alquinoles propargílicos $\alpha$-tioalquil

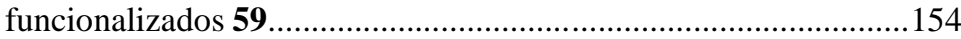

4.3.3.4 Propuesta mecanística..................................................................... 156

4.3.3.5 Reacción de los 1,2-dioles propargílicos 60 y tiofenoles catalizada por

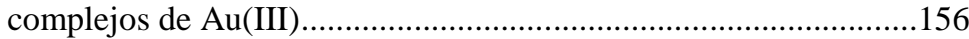

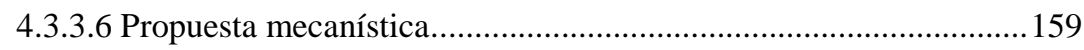

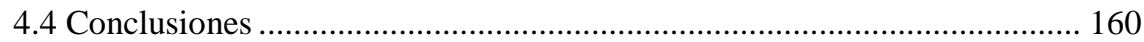

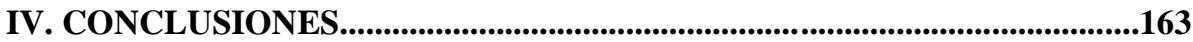

V. EXPERIMENTAL SECTION .................................................................. 165

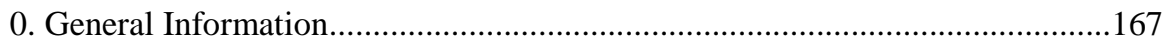

1. Synthesis of Fused Polycyclic Indoles...........................................................169

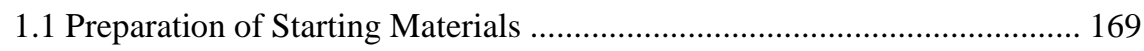

1.1.1. Synthesis of Indole Derivatives 1-4 ...................................................169

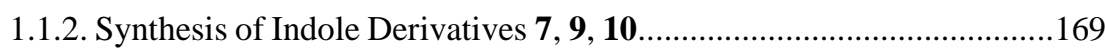

1.1.3 Syntesis of Alcohol Derivatives 5, 6, 11, and 12...............................171

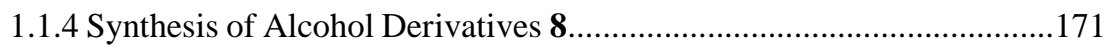

1.2 Synthesis of Polycyclic Adducts 13-17 .................................................. 180 


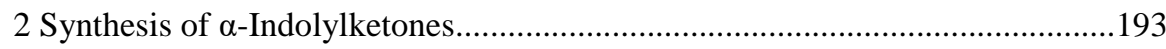

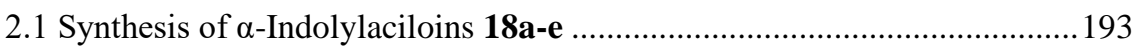

2.2 Synthesis of $\alpha$-(Indol-3-yl) Carbonyl Compounds 21 ...............................193

2.3 Synthesis of $\alpha$-(Indol-3-yl) Carbonyl Compounds 23 ...............................198

2.4 Synthesis of Tricarbonyl Compounds 25 ................................................200

2.5 Synthesis of Furanylindoles 26 .................................................................204

2.6 Synthesis of $\alpha$-(Trimethoxyphenyl) Carbonyl Compound 27a .................206

2.7 Synthesis of $\alpha$-(Indol-3-yl) Carbonyl Compounds 28.................................206

2.8. Synthesis of $\alpha$-(Indol-3-yl) Carbonyl Compounds 29 ........................... 210

2.9 Synthesis of Tryptophol Derivatives 30................................................211

3. Synyhesis of Benzo[ $b]$ carbazoles and Heteroaryl $[b]$ carbazoles.......................213

3.1 Preparation of Starting Materials ..............................................................213

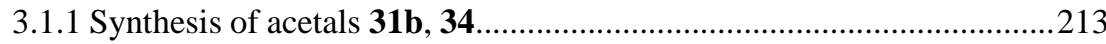

3.1.2 Synthesis of acetals 36a-d..............................................................213

3.1.3 Synthesis of hydroxy-functionalized acetals $\mathbf{3 2}, \mathbf{3 3}, \mathbf{3 5 a}, \mathbf{3 8}$ and/or cyclic

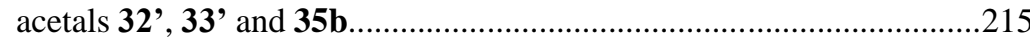

3.1.4 Synthesis of hydroxy-functionalized acetals 36a, 37, 40 and/or cyclic

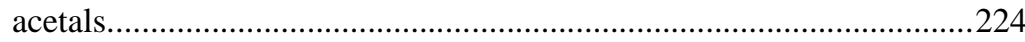

3.2 Synthesis of Benzo[b]carbazoles and Heteroaryl $[b]$ carbazoles 41, 44, 45-51

.225

4. Synthesis of 1-Indol-3-ylcarbazoles and $\alpha$-Indol-3-yl- $\alpha$-alkenylacetophenones

240

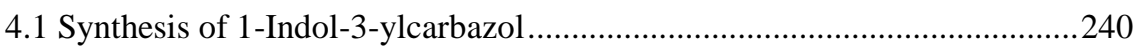

4.1.1. Synthesis of $\alpha, \alpha$-Bis(indol-3-yl) Ketones 52 .....................................240

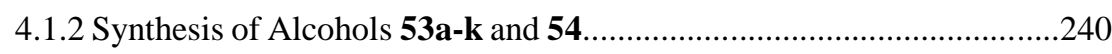

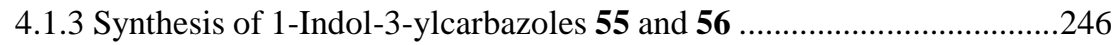

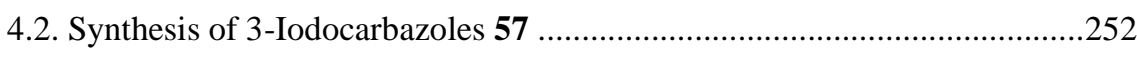

4.3 Synthesis of $\alpha$-Indolil- $\alpha$-alkenylacetophenones ........................................254

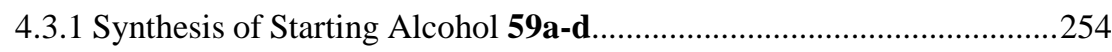

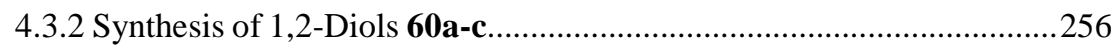

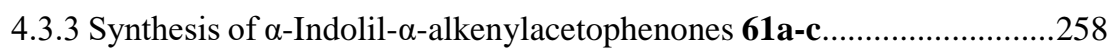

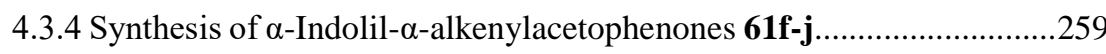




\section{INTRODUCCIÓN}

I. INTRODUCCIÓN

II. ANTECEDENTES

GENERALES

III. DISCUSIÓN DE

RESULTADOS

IV. CONCLUSIONES

V. EXPERIMENTAL SECTION 

El indol, nombre común que recibe el benzo[b]pirrol, es un compuesto aromático que fue aislado en 1869 y cuya estructura fue propuesta por Adolf von Baeyer. Desde entonces el indol se ha convertido en una "estructura privilegiada" y ha sido objeto de estudio en varios campos entre los que cabe destacar la industria farmacéutica, perfumería y ciencia de materiales, entre otros. La amplia variedad de aplicaciones que presentan los derivados indólicos justifica la acepción "The Lord of the Rings" de los compuestos aromáticos que se ha dado al indol. En la década de los 50, el empleo del alcaloide Reserpina como primera droga en tratamientos de enfermedades del sistema nervioso central, tales como la ansiedad y otros desórdenes mentales, hizo que la química del indol se convirtiera en uno de los grandes campos de investigación para los químicos. Así, en la década de los 60, se descubrieron las propiedades antitumorales de la Vincristina. Posteriormente otros alcaloides con esqueleto indólico han sido empleados como antinflamatorios y en tratamientos de diferentes enfermedades del sistema nervioso central. ${ }^{*}$

Además, derivados indólicos tales como carbazoles y benzocarbazoles también presentan importantes propiedades biológicas y farmacéuticas, así como múltiples aplicaciones en ciencia de materiales derivadas de sus propiedades ópticas y electrónicas. ${ }^{\dagger}$

Por otra parte, el desarrollo de nuevos sistemas catalíticos para la reacción de sustitución nucleofílica directa de alcoholes ha sido un campo de gran interés durante la última década en Síntesis Orgánica. Para este tipo de procesos nuestro grupo ha sido pionero en el empleo como catalizador de un ácido de Brønsted sencillo, barato, y benigno para el medio ambiente tal como el ácido $p$-toluensulfónico (PTSA), que evita el uso de especias metálicas caras y/o tóxicas. Esta metodología podría ser considerada como un proceso ideal ya que en la reacción se libera agua como único subproducto.

Asimismo, la catálisis con complejos de oro ha emergido en los últimos años como una herramienta muy potente para la síntesis de una gran variedad de estructuras difícilmente accesibles por metodologías convencionales. La gran quimioselectividad que presentan estos catalizadores hacia carbonos insaturados los hace compatibles con una amplia variedad de grupos funcionales. En este

\footnotetext{
${ }^{*}$ M. Bandini, A. Eicholzer, Angew. Chem. Int. Ed. 2009, 48, 9608-9644.

† (a) A. W. Schmidt, K. R. Reddy, H.-J. Knölker, Chem. Rev. 2012, 112, 3193-3328. (b) J. Roy, A. K. Jana, D. Mal, Tetrahedron 2012, 68, 6099-6121.

* (a) D. Miguel, Tesis Doctoral, Universidad de Burgos, 2009. (b) A. Martínez, Tesis Doctoral, Universidad de Burgos, 2010.
} 
campo, nuestro grupo ha estudiado en profundidad la reactividad de $o$ (alquinil)estirenos y 3-propargilindoles. ${ }^{\S}$

Los resultados experimentales que se recogen en esta Memoria, y que tienen que ver con ambas líneas de investigación de nuestro grupo, se han organizado en cuatro capítulos. Los tres primeros, se centran en el empleo de PTSA como catalizador en la síntesis de estructuras con esqueleto indólico: compuestos policíclicos fusionados con el indol, $\alpha$-indolilcetonas- $\alpha$ funcionalizadas, y benzo $[b]$ carbazoles. Por su parte, en el capítulo 4 se emplean catalizadores de $\mathrm{Au}$ (III) en la síntesis de 1-indolilcarbazoles a partir de sustratos fácilmente accesibles. Antes de pasar a discutir los resultados obtenidos se ha hecho una revisión de aquellos aspectos de la química del indol más directamente relacionados con nuestros resultados.

§ (a) A. M. Sanjuán, Tesis Doctoral, Universidad de Burgos, 2015. (b) E. Álvarez, Tesis Doctoral, Universidad de Burgos, 2016. 


\section{ANTECEDENTES GENERALES}

I. INTRODUCCIÓN

II. ANTECEDENTES GENERALES

III. DISCUSIÓN DE RESULTADOS

IV. CONCLUSIONES

V. EXPERIMENTAL SECTION 



\section{Indoles 3-funcionalizados: el indol como nucleófilo}

El indol es un heterociclo $\pi$-excedente, característica que determina gran parte de su reactividad. Normalmente se emplea como nucleófilo en reacciones tipo Michael con sustratos $\alpha, \beta$-insaturados, reacciones de adición a aldehídos, cetonas, e iminas, y en reacciones de apertura de epóxidos, entre otras. Esta elevada nucleofilia se debe a que el par de electrones del átomo de nitrógeno se encuentra conjugado con el sistema $\pi$ del anillo aromático, lo que trae como consecuencia que el C-3 del indol reaccione con electrófilos más rápidamente que la mayoría de los derivados del benceno. El C-2 del indol también posee carácter nucleofílico, sin embargo, esta posición sólo interviene cuando la posición C-3 del anillo está bloqueada.

La reactividad del indol como nucleófilo puede ser expresada mediante su parámetro de nucleofilia $N$. En este sentido, Mayr y col. han estudiado la reactividad de varios indoles con diferentes modelos de sustitución frente a diarilcarbocationes. ${ }^{1}$ Parte de las conclusiones a las que se llega en este trabajo se resumen en el Esquema A.1.

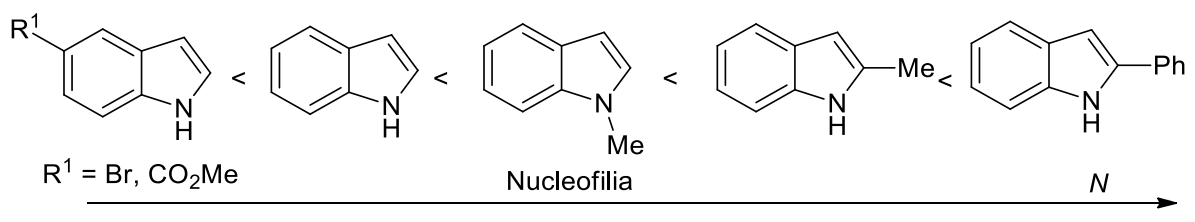

Esquema A.1

En este apartado de Antecedentes Generales se ha hecho una revisión bibliográfica de algunas de las metodologías que emplean el indol como nucleófilo y que permiten su funcionalización por la posición 3. La discusión se ha centrado en tres apartados, por ser los que están más directamente relacionados con el trabajo de investigación que se describirá en esta Memoria:

- Reacciones catalíticas de alquilación Friedel-Crafts (F.-C.) de indoles con alcoholes como agentes alquilantes.

- Reacciones de alquilación F.-C. de indoles empleando aldehídos como agentes alquilantes.

- Reacciones intramoleculares de indoles y alquinos catalizadas por complejos de oro.

\footnotetext{
${ }^{1}$ S. Lakhdar, M. Westermaier, F. Terrier, R. Goumont, T. Boubaker, A.-R. Ofial, H. Mayr, J. Org. Chem. 2006, 71, 9088-9095.
} 


\subsection{Reacciones de indoles con alcoholes}

La funcionalización regiosectiva del anillo indólico en posición C-3 sigue siendo uno de los grandes retos de la Síntesis Orgánica debido a la presencia de este modelo de sustitución en una gran variedad de productos naturales o sintéticos empleados en la industria farmacéutica y que presentan actividad biológica. En este sentido, la reacción de alquilación F.-C. de indoles con alcoholes es una de las metodologías más potentes.

Desde el punto de vista de la Química Verde este proceso puede ser considerado como ideal ya que en principio se genera agua como único subproducto. Además, la alta disponibilidad de los alcoholes, así como la facilidad con la que se preparan, hace de esta reacción una opción especialmente atractiva desde el punto de vista sintético. Sin embargo, la baja capacidad que presenta el grupo hidroxilo como grupo saliente ${ }^{2}$ hacía que fuera necesario el empleo de cantidades estequiométricas ${ }^{3}$ de catalizadores ácidos y/o condiciones drásticas de reacción, además de grandes excesos de aditivos. Afortunadamente, a lo largo de estos últimos años estos problemas han quedado resueltos mediante el uso de alcoholes $\pi$-activados y catalizadores basados en especies metálicas o ácidos de Brønsted. ${ }^{4}$

Los alcoholes $\pi$-activados son aquellos que poseen un sistema $\pi$ en el carbono adyacente al grupo hidroxilo. Este tipo de alcoholes generalmente reaccionan mediante un mecanismo tipo $S_{\mathrm{N} 1}$ a través de un intermedio carbocatiónico estabilizado, generado por la activación directa del grupo hidroxilo por parte del catalizador. Además, estos sustratos no poseen generalmente átomos de hidrógenos en posición $\beta$ al grupo hidroxilo y, por lo tanto, no compiten procesos de eliminación. En los casos en los que se encuentra otro sistema aromático en posición $\alpha$ al grupo hidroxilo $(\mathrm{X}=\mathrm{Ar})$, la reactividad del alcohol se ve incrementada (Esquema A.2).

${ }^{2}$ R. Bohlmann, Comprehensive Organic Synthesis, Vol 6 (Ed: B.-M. Trost, I. Fleming), Pergamon Press, New York, 1991, Cap. 1.7.

${ }^{3}$ (a) K.-M. Nicholas, M. Mulvaney, M. Bayer, J. Am. Chem. Soc. 1980, 102, 2508-2510. (b) K.M. Nicholas, Acc. Chem. Res. 1987, 20, 207-214. (c) A.-J.-M. Caffyn, K.-M. Nicholas, Comprehensive Organic Synthesis II, Vol. 12 (Ed: E.-W. Abel, G. A. Stone, G. Wilkinson), Pergamon Press, New York, 1995, Cap 7.1. (d) T.-J.-J. Müller, Eur. J. Org. Chem. 2001, 2021-2033. (e) B.-J. Teobald, Tetrahedron 2002, 58, 4133-4170.

${ }^{4}$ (a) M. Bandini, M. Tragni, Org. Biomol. Chem. 2009, 7, 1501-1507. (b) E. Emer, R. Sinisi, M. Guiteras-Capdevila, D. Petruzziello, F. De Vincentiis, P. G. Cozzi, Eur. J. Org. Chem. 2011, 647-666. (c) L. Chen, X. Ping-Yin, C. Hong-Wang, J. Zhou, Org. Biomol. Chem. 2014, 12, 6033-6048. (d) M. Dryzhakov, E. Richmond, J. Moran, Synthesis 2016, 48, 935-959. 
<smiles>[R]C#CC([X])O</smiles>

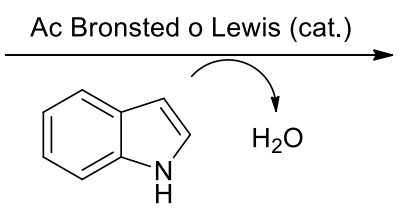<smiles>[X]C(c1cc[R]cc1)c1c[nH]c2ccccc12</smiles><smiles>[R]C=CC([X])c1c[nH]c2ccccc12</smiles><smiles>[R]C#CC([X])c1c[nH]c2ccccc12</smiles>

\section{Esquema A.2}

\subsubsection{Alcoholes bencílicos}

La funcionalización selectiva del C-3 del indol mediante la reacción F.-C. con alcoholes bencílicos se ha llevado a cabo en presencia de catalizadores ácidos, tanto de Brønsted como de Lewis. En los últimos años, los esfuerzos en este campo se han centrado en el desarrollo de catalizadores más eficientes, baratos y benignos para el medio ambiente. En la Tabla A.1 se muestra algunos de los catalizadores y condiciones de reacción descritos en la bibliografía.

\section{Tabla A.1 Reacción de indoles y alcoholes bencílicos catalizada por ácidos}
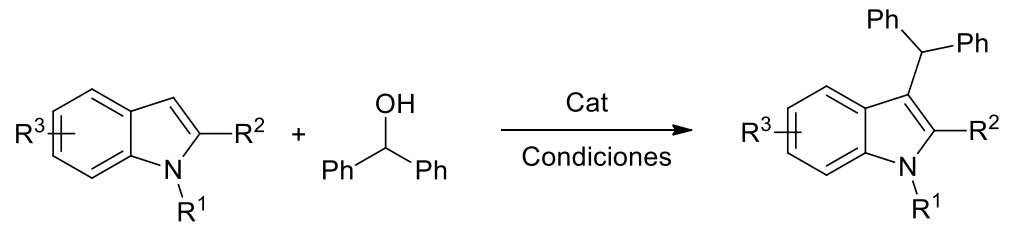

\begin{tabular}{ccccc}
\hline Cat. $(\mathbf{m o l} \%)$ & Disolvente & T $\left({ }^{\circ} \mathbf{C}\right)$ & Rto. $(\%)$ & Ref. \\
\hline H-Mont & $n$-Heptano & 100 & $70-99$ & 5 \\
DBSA (10) & $\mathrm{H}_{2} \mathrm{O}$ & 80 & $75-95$ & 6 \\
$\mathrm{InCl}_{3}$ & Tolueno & $80-100$ & $61-95$ & 7 \\
$\mathrm{NaAuCl}_{4} \cdot 2 \mathrm{H}_{2} \mathrm{O}(2)$ & $\mathrm{H}_{2} \mathrm{O}$ & 80 & $50-95$ & 8 \\
\hline
\end{tabular}

\footnotetext{
${ }^{5}$ K. Motokura, N. Nakagiri, T. Mizugaki, K. Ebitani, K. Kaneda, J. Org. Chem. 2007, 72, 6006-6015.

${ }^{6}$ Y.-L. Liu, L. Liu, Y.-L. Wang, Y.-C. Han, D. Wang, Y.-J. Chen, Org. Lett. 2007, 9, 311-314.

${ }^{7}$ M. Yasuda, T. Somyo, A. Baba, Angew. Chem. Int. Ed. 2006, 45, 793-796.

${ }^{8}$ H. Hikawa, H. Suzuki, I. Azumaya, J. Org. Chem. 2013, 78, 12128-12135.
} 


\subsubsection{Alcoholes alílicos}

El empleo de alcoholes alílicos como agentes alquilantes en la funcionalización regioselectiva de indoles se ha llevado a cabo en presencia de catalizadores ácidos de Lewis tales como $\mathrm{FeCl}_{3}$ ó $\mathrm{AuCl}_{3}$. Posteriormente, avances en este campo se centraron en la búsqueda de catalizadores menos tóxicos y más baratos (Tabla A.2).

\section{Tabla A.2 Reacción de indoles y alcoholes alílicos catalizada por ácidos}

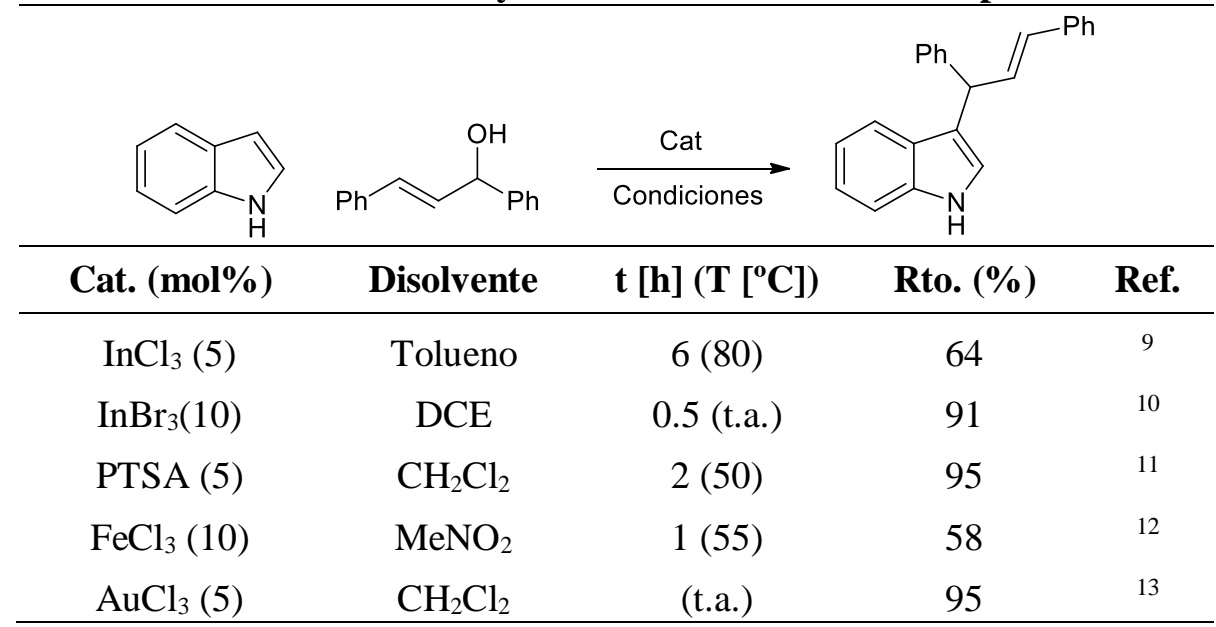

En este campo, nuestro grupo de investigación ha hecho aportaciones significativas. Así, en 2006 se describió por primera vez que una cantidad catalítica de un ácido de Brønsted sencillo y comercial como el ácido $p$ toluensulfónico (PTSA) era capaz de activar alcoholes alílicos secundarios frente a indoles como nucleófilos, generando los correspondientes productos alquilados con muy buenos rendimientos. La reacción transcurre de manera totalmente regioselectiva en el C-3 del indol no habiéndose observado su correspondiente producto de $N$ - ó C-2 sustitución (Esquema A.3). ${ }^{14}$

\footnotetext{
${ }^{9}$ M. Yasuda, T. Somyo, A. Baba, Angew. Chem. Int. Ed. 2006, 118, 807-810.

${ }^{10}$ J.-S. Yadav, B.-V.-S. Reddy, A. Aravind, G.-K Kumar, Tetrahedron Lett. 2007, 48, 6117-6120.

${ }^{11}$ J. Le Bras, J. Muzart, Tetrahedron 2007, 63, 7942-7948.

${ }^{12}$ U. Jana, S. Maiti, S. Biswas, Tetrahedron Lett. 2007, 48, 7160-7163.

${ }^{13}$ W. Rao, P.-W.-H. Chan, Org. Biomol. Chem. 2008, 6, 2426-2433.

${ }^{14}$ (a) R. Sanz, A. Martínez, J.-M. Álvarez-Gutiérrez, F. Rodríguez, Eur. J. Org. Chem. 2006, 1383-1386. (b) R. Sanz, A. Martínez, D. Miguel, J-M. Álvarez, F. Rodríguez, Adv. Synth. Catal. 2006, 348, 1841-1845. (c) R. Sanz, D. Miguel, J.-M. Álvarez, F. Rodríguez, Synlett 2008, 975-978. (d) R. Sanz, M. Gohain, D. Miguel, A. Martínez, F. Rodríguez, Synlett 2009, 1985-1989. (e) R. Sanz, D. Miguel, A. Martínez, M. Gohain, P. García, M.-A. Fernández, E. Álvarez, F. Rodríguez, Eur. J. Org. Chem. 2010, 7027-7039.
} 


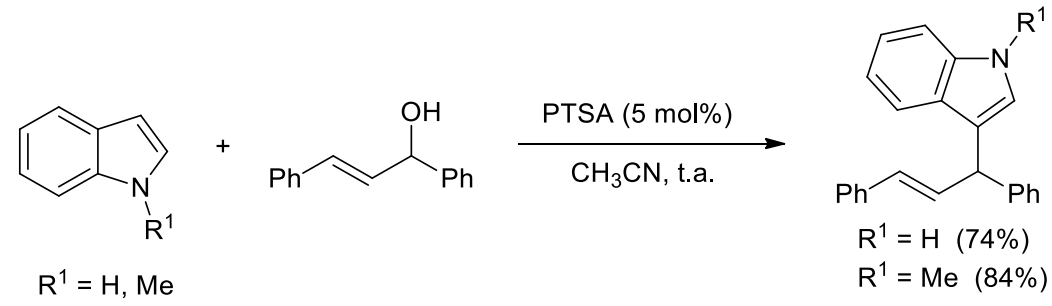

\section{Esquema A.3}

\subsubsection{Alcoholes propargílicos}

La reacción F.-C. de indoles con alcoholes propargílicos es una metodología eficiente para acceder a 3-propargilindoles, estructuras empleadas con frecuencia en la obtención de sustratos más complejos de gran interés sintético. Esta reacción se ha llevado a cabo en presencia de una amplia variedad de ácidos de Lewis (Tabla A.3).

Tabla A.3 Reacciones de indoles y alcoholes propargílicos catalizada por ácidos

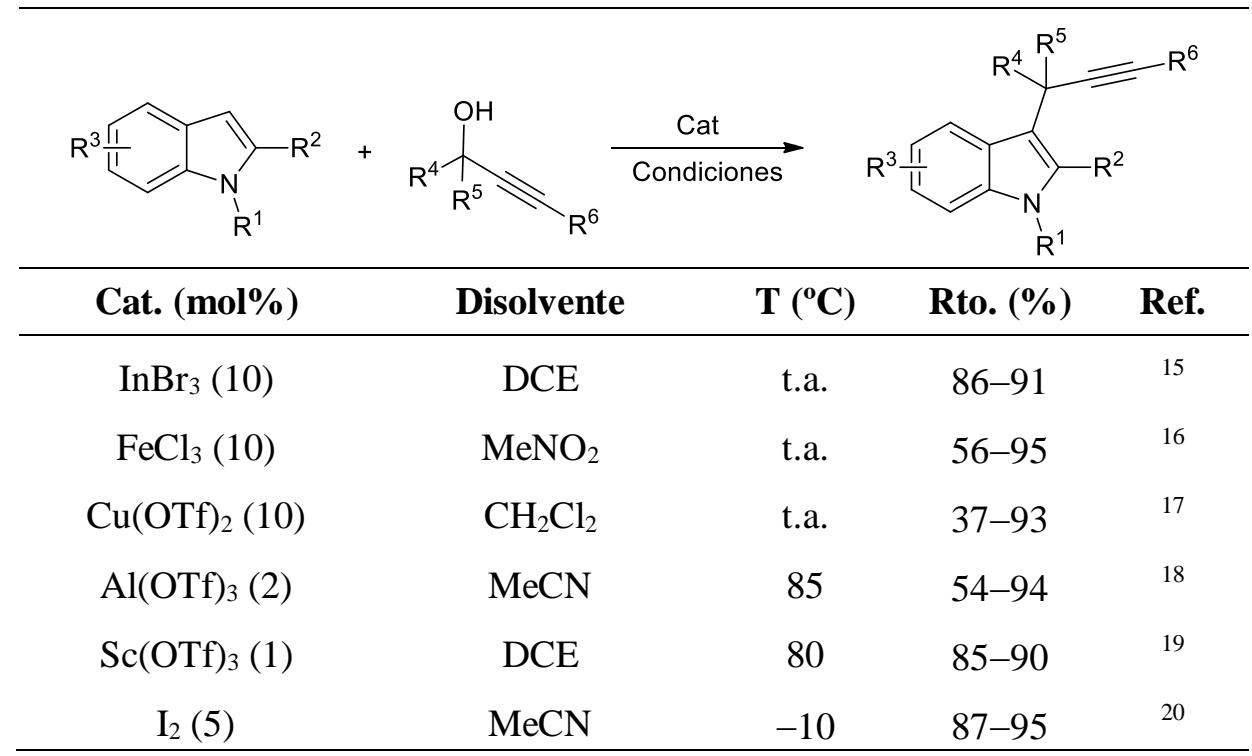

${ }^{15}$ B.-V.-S. Reddy, K.-V.-R. Rao, G.-G.-K.-S. Kumar, J. S. Yadav, Synthesis 2007, 3205-3210.

${ }^{16}$ S. Maiti, S. Biswas, U. Jana, Tetrahedron Lett. 2007, 48, 7160-7163.

${ }^{17}$ L. Zhang, Y. Zhu, G. Yin, P. Lu, Y. Wang, J. Org. Chem. 2012, 77, 9510-9520.

${ }^{18}$ M. Gohain, C. Marais, B.-C.-B. Bezuidenhoudt, Tetrahedron Lett. 2012, 53, 4704-4707.

${ }^{19}$ B.-V.-S. Reddy, T.-S. Rao, K.-V.-R. Rao, G.-G.-K.-S. Kumar, J.-S. Yadav, Tetrahedron Lett. 2007, 48, 5573-5576.

${ }^{20}$ D.-C. Bhunia, P. Sreedhar, S.-S. Mandal, J.-S.-S. Reddy, P. Srihari, Tetrahedron Lett. 2007, 48, 8120-8124. 
Otra estrategia más económica y libre de metales ha sido la descrita por nuestro grupo al emplear un ácido orgánico sencillo (PTSA) como catalizador y $\mathrm{MeCN}$ como disolvente. Esta metodología permitió obtener una gran variedad de indoles C-3 propargilados con rendimientos entre moderados y buenos. ${ }^{14 a, c-e}$

En presencia de ácidos de Brønsted o de Lewis, los alcoholes propargílicos experimentan la eliminación de una molécula de agua dando lugar al intermedio catiónico A que está en resonancia con A’ (Esquema A.4). De este modo, la formación de los productos finales I ó II podría explicarse mediante el ataque del nucleófilo al intermedio A (mecanismo $\mathrm{S}_{\mathrm{N}}$ ), o bien sobre el intermedio $\mathbf{A}^{\prime}$ (mecanismo $S_{N}$ ') dando lugar a alenos. La regioquímica de este proceso $\left(S_{N} v s\right.$ $\mathrm{S}_{\mathrm{N}}$ ') depende de varios factores como los sustituyentes que posee el alcohol propargílico y el tipo de catalizador, así como de la naturaleza del nucleófilo empleado (Esquema A.4).
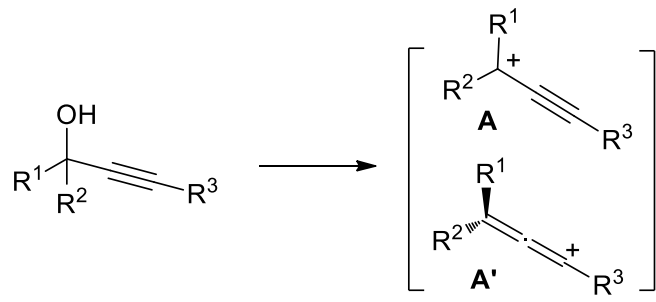

Esquema A.4

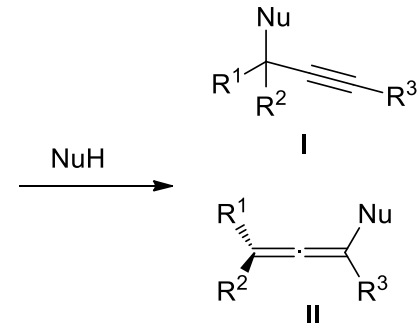

II

\subsection{Reacciones de indoles con aldehídos}

Los aldehídos también pueden ser empleados como agentes alquilantes en la reacción de alquilación F.-C. con indoles. Dado su elevado carácter nucleofílico, los indoles son capaces de reaccionar de manera muy rápida con aldehídos en presencia de una gran variedad de catalizadores ácidos de Lewis o de Brønsted. ${ }^{21}$ En estos casos, una primera reacción F.-C. entre el indol y el aldehído da lugar a un 3-indolilmetanol intermedio III. Este intermedio es inestable en medio ácido y experimenta la eliminación de una molécula de agua conduciendo al intermedio de tipo alquilideniminio B. Posteriormente, una adición tipo Michael de otra molécula de indol sobre B conduciría a la formación del 3,3'-bisindolilmetano (3,3'-BIM) IV (Esquema A.5).

${ }^{21}$ Revisiones: (a) M. Shiri, M. Ali, H. Gerhardous, Z. Tanbakouchian, Chem. Rev. 2010, 110, 2250-2293. (b) P.-J. Praveen, P.-S. Parameswaran, M.-S. Majik, Synthesis 2015, 47, 1827-1837. 


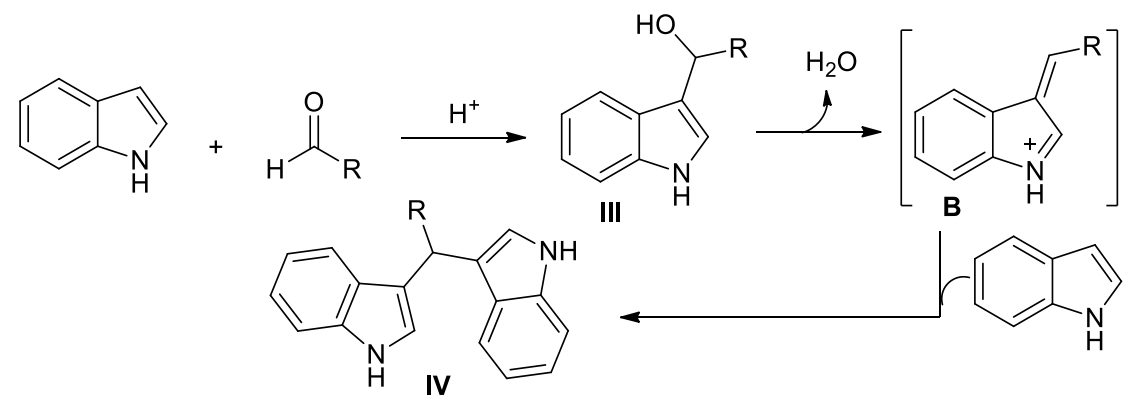

Esquema A.5

El intermedio B del Esquema A.5 es una especie catiónica y muy reactiva que una vez generada reacciona rápidamente con nucleófilos, para dar productos finales análogos a IV. A pesar de esta elevada reactividad, el empleo de ácido tetrafluorobórico en la reacción F.-C. de indoles y aldehídos ha permitido aislar estos intermedios como tetrafluoroboratos (Esquema A.6) ${ }^{22}$ La reacción se puede llevar a cabo en presencia de una gran variedad de aldehídos (hetero)aromáticos con sustituyentes tanto electrón-dadores como atractores y los correspondientes tetrafluoroboratos de alquilideniminio $\mathbf{V}$ se aíslan con muy buenos rendimientos.

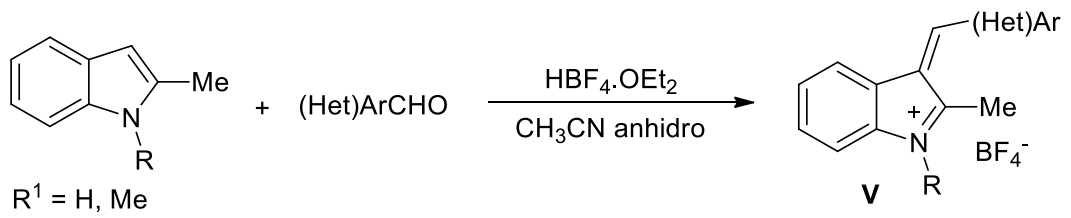

\section{Esquema A.6}

\subsubsection{Síntesis de 3,3'-bisindolilmetanos (3,3'-BIMs)}

Los BIMs son una clase de estructuras presentes en la naturaleza que han sido aisladas generalmente de fuentes terrestres o marinas. ${ }^{23}$ Existe una gran variedad de BIMs con importantes actividades farmacológicas ${ }^{24}$ como por ejemplo la Araundina, que posee actividad carcinogénica, y el Vibrindol A, que posee actividad antibacteriana (Esquema A.7).

\footnotetext{
${ }^{22}$ M. Barbero, R. Buscaino, S. Cadamuro, S. Dughera, A. Gualandi, D. Marabello, P.-G. Cozzi, J. Org. Chem. 2015, 80, 4791-4796.

${ }^{23}$ T.-R. Garbe, M. Kobayashi, N. Shimizu, N. Takesue, M. Ozawa, H. Yukawa, J. Nat. Prod. 2000, 63, 596-598.

${ }^{24}$ P. Diana, A. Carbone, P. Baraja, A. Montalbano, A. Martorana, G. Dattolo, O. Gai, L.-D. Via,

G. Cirrincione, Bioorg. Med. Chem. Lett. 2007, 17, 2342-2346.
} 


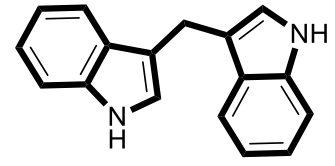

Araundina

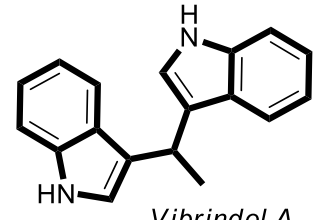

Vibrindol A

Esquema A.7

Como se ha comentado, la reacción de formación de los BIMs puede ser catalizada por una gran variedad de catalizadores ácidos, tanto de Lewis como de Brønsted, y puede ser llevada a cabo en medios de reacción convencionales o alternativos. Como consecuencia del aumento de la demanda de procesos medioambientalmente benignos, a lo largo de los últimos años se ha profundizado en la búsqueda de catalizadores más eficientes. En la Tabla A.4 se muestran algunos de los ejemplos más representativos.

Tabla A.4 Reacción de indoles y aldehídos catalizada por ácidos

\begin{tabular}{|c|c|c|c|c|c|}
\hline Cat. (mol\%) & $\mathbf{R}$ & Disolvente & $\mathbf{t}[\mathbf{h}] \mathbf{T}\left[{ }^{\circ} \mathbf{C}\right]$ & Rto. (\%) & Ref. \\
\hline $\mathrm{CuBr}_{2}(5)$ & $\mathrm{Ph}$ & $\mathrm{CH}_{3} \mathrm{CN}$ & 0,4 (t.a.) & 95 & 25 \\
\hline $\mathrm{H}_{2} \mathrm{SO}_{4}$ & $\mathrm{Ph}$ & $\mathrm{CH}_{3} \mathrm{CN}$ & 12 (t.a.) & 99 & 26 \\
\hline $\mathrm{NaBAr}_{4}{ }_{4}(0,2)$ & $\mathrm{Ph}$ & $\mathrm{H}_{2} \mathrm{O}$ & $5(30)$ & 99 & 27 \\
\hline $\mathrm{H}_{2} \mathrm{NSO}_{3}(50)$ & $\mathrm{Ph}$ & $\mathrm{MeOH}$ & 3 (t.a.) & 90 & 28 \\
\hline $\mathrm{CeCl}_{3} .7 \mathrm{H}_{2} \mathrm{O}-\mathrm{NaI}-\mathrm{SiO}_{2}$ & Alq & - & $2-7$ & $85-97$ & 29 \\
\hline $\mathrm{La}\left(\mathrm{NO}_{3}\right)_{3} \cdot 6 \mathrm{H}_{2} \mathrm{O}$ & $\mathrm{Ar}$ & - & $0,5-1$ & $96-99$ & 30 \\
\hline $\mathrm{Cu}\left(\mathrm{BF}_{4}\right)_{2} \cdot \mathrm{SiO}_{2}$ & $\mathrm{Ar}$ & $\mathrm{CH}_{2} \mathrm{Cl}_{2}$ & $0,5-2(80)$ & $89-99$ & 31 \\
\hline $\mathrm{InCl}_{3}$ & Ar & $\mathrm{CH}_{3} \mathrm{CN}$ & $4-10(\mathrm{ta})$ & $73-96$ & 32 \\
\hline $\mathrm{CuBr}_{2}$ & $\mathrm{Ar}$ & $\mathrm{CH}_{3} \mathrm{CN}$ & $0,5-1$ (t.a.) & $35-95$ & 33 \\
\hline
\end{tabular}

${ }^{25}$ L.-P. Mo, Z.-C. Ma, Z.-H. Zhang, Synth. Commun. 2005, 35, 1997-2004.

${ }^{26}$ B. Ke, Y. Qin, Y. Wang, F. Wang, Synth. Commun. 2005, 35, 1209-1212.

${ }^{27}$ B.-S. Liao, J.-T. Chen, S.T. Liu, Synthesis 2007, 3125-3128.

${ }^{28}$ W.-J. Liu, X.-F. Lin, J. Wang, G.-L. Li, Y.-G. Wang, Synth. Commun. 2005, 35, 2765-2769.

${ }^{29}$ G. Bartoli, M. Bosco, G. Foglia, A. Giuliani, E. Marcantoni, L. Sambri, Synthesis 2004, 895-900.

30 J.-J. Paul-Selvam, M. Srinivasulu, V. Suresh, S. Malla-Reddy, Y. Venkateswarlu, Synth. Commun. 2008, 38, 1760-1767.

${ }^{31}$ G.-A. Meshram, V.-D. Patil, Synth. Commun. 2010, 40, 29-38.

${ }^{32}$ G. Babu, N. Sridhar, P.-T. Perumal, Synth. Commun. 2000, 30, 1609-1614.

${ }^{33}$ L.-P. Mo, Z.-C. Ma, Z.-H. Zhang, Synth. Commun. 2005, 35, 1997-2004. 
Los aldehídos protegidos en forma de acetales también son capaces de reaccionar con indoles en presencia de catalizadores ácidos para dar 3,3'-BIMs, aunque en la bibliografía existen muy pocos ejemplos que describen el uso de acetales como agentes alquilantes de indoles. En este sentido Graham y col. describieron la reacción de indoles y acetales empleando un alumino-silicato como catalizador (Esquema A.8) ${ }^{34}$ La reacción permitió aislar los bisindoles VI con buenos rendimientos cuando se emplearon acetales aromáticos ó alifáticos.

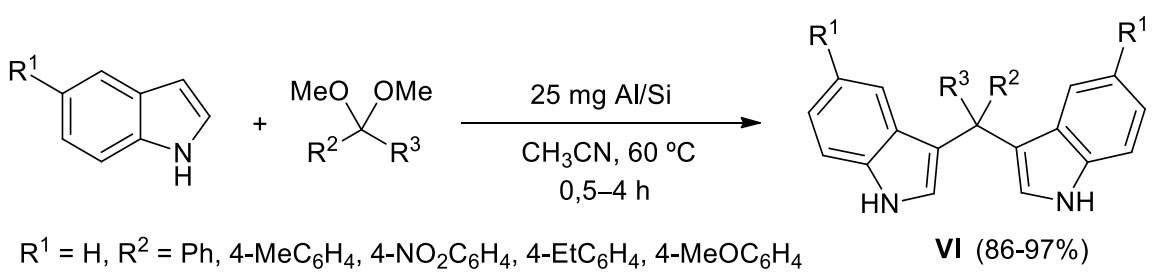

\section{Esquema A.8}

\subsubsection{Síntesis de 3-indolilmetanoles}

Los 3-indolilmetanoles son intermedios muy versátiles para la funcionalización selectiva de indoles en posición C-3. Su elevada reactividad en medio ácido hace que sea difícil aislarlos a partir de la reacción directa de indoles y aldehídos. Sin embargo, bajo condiciones ligeramente básicas ha sido posible obtener los 3-indolilmetanoles VII y VIII con buenos rendimientos (Esquema A.9). ${ }^{35,36}$<smiles>[R]c1cc2cc[nH]c2cc1[R]</smiles>
$\mathrm{R}^{1}=\mathrm{H}, \mathrm{Me} \mathrm{R}^{2}=\mathrm{H}, \mathrm{Me}, \mathrm{Cl}$<smiles>[R]C=O</smiles>
$\mathrm{R}^{1}=\mathrm{H}, \mathrm{Br} \quad \mathrm{R}^{2}=\mathrm{Ar}$, Alq

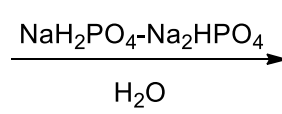

(62-84\%)

1) TMSOTf, i- $\mathrm{Pr}_{2} \mathrm{NEt}, \mathrm{Et}_{2} \mathrm{O},-78^{\circ} \mathrm{C}$ 2) $P y$

3) TBF, THF, t.a. $\mathrm{R}^{3}=\mathrm{H}, \mathrm{Me}, \mathrm{Bn}$, Alilo<smiles>[R]c1cc2[nH]cc(C(O)C(=O)OCC)c2cc1[R]</smiles>

VII<smiles>[Y]n1cc(C(O)[Al])c2cc[R1][14cH]c21</smiles>

\section{Esquema A.9}

\footnotetext{
34 T.-M. Kubczyk, S.-M. Williams, J.-R. Kean, T.-E. Davies, S.-H. Taylor, A.-E. Graham, Green Chem. 2011, 13, 2320-2325.

${ }^{35}$ W. Zhuang, K.-A. Jørgensen, Chem. Commun. 2002, 1336-1337.

${ }^{36}$ C. Wade-Downey, C.-D. Poff, A.-N. Nizinski, J. Org. Chem. 2015, 80, 10364-10369.
} 
Otra alternativa que permite el acceso a 3-indolilmetanoles funcionalizados con un grupo carbonilo adicional, a partir de indoles y aldehídos consiste en hacer reaccionar diferentes indoles con una variedad de arilglioxales en benceno como disolvente. La reacción permite aislar las $\alpha$-indolilaciloínas IX con rendimientos moderados. ${ }^{37}$ Posteriormente, en el contexto de la búsqueda de medios de reacción medioambientalmente benignos y condiciones de reacción más suaves, esta misma reacción fue descrita en agua, dando lugar a las mismas $\alpha$ indolilaciloínas IX con rendimientos excelentes (89-97\%) (Esquema A.10). ${ }^{38}$

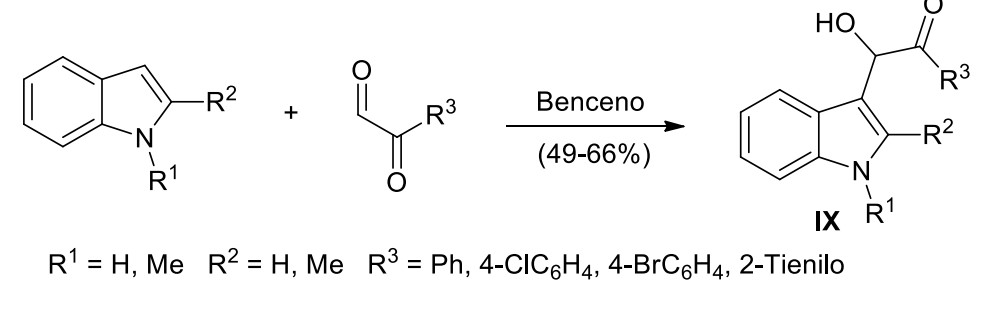

\section{Esquema A.10}

Más recientemente, también ha sido descrita la reacción de una serie de glioxilamidas $N$-sustituídas con varios indoles que, en presencia de ácido acético como catalizador, condujo a la formación de 2-hidroxi-2-(1H-indol-3il)acetamidas $\mathbf{X}$ con rendimientos entre moderados y buenos (Esquema A.11). ${ }^{39}$<smiles>[R][Ga]1C=Cc2cccn21</smiles><smiles>[R]NC(=O)C=O</smiles>

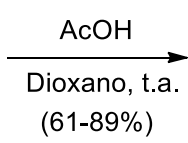<smiles>[R]NC(=O)C(O)c1c[nH]c2cc[R]([R])cc12</smiles>

\section{Esquema A.11}

Los indol-3-il-metanoles intermedios III del Esquema A.5, implicados en la síntesis de los 3,3- BIMs, juegan un papel muy importante en Síntesis Orgánica, ya que a partir de ellos se puede acceder a una gran variedad de indoles C-3 funcionalizados por su tratamiento con nucleófilos externos en medio ácido. ${ }^{40} \mathrm{Sin}$ embargo, si el aldehído de partida posee en su estructura un nucleófilo situado en

\footnotetext{
${ }^{37}$ S.-P. Ivonin, A.-V. Lapandin, A.-A. Anishchenko, V.-G. Shtamburg, Synth. Commun. 2004, 34, 451-661.

${ }^{38}$ M. Anary-Abbasinejad, M. Talebizadeh, J. Iran. Chem. Soc. 2014, 11, 963-968.

${ }^{39}$ Z. Zhan, R. Li, Y. Zheng, Y. Zhou, L. Hai, Y. Wu, Synlett. 2015, 26, 2261-2266.

${ }^{40}$ Revisiones: (a) A. Palmieri, M. Petrini, R.-R. Shaikh, Org. Biomol. Chem. 2010, 8, 1259-1270. (b) L. Chen, X.-P. Yin, C. Wang, H. Zhou, Org. Biomol. Chem. 2014, 12, 6033-6048. (c) L. Wang, Y. Chen, J. Xiao, Asian J. Org. Chem. 2014, 3, 1036-1052.
} 
posición adecuada, en lugar de generarse un 3,3'-BIM al reaccionar con indoles, se puede producir una segunda reacción F.-C. sobre el intermedio $\mathbf{C}$, esta vez intramolecular, que daría lugar a estructuras policíclicas tipo D. Esta estrategia ha permitido la síntesis de compuestos policíclicos de gran interés, a partir de productos de partida muy accesibles como indoles y aldehídos (Esquema A.12).

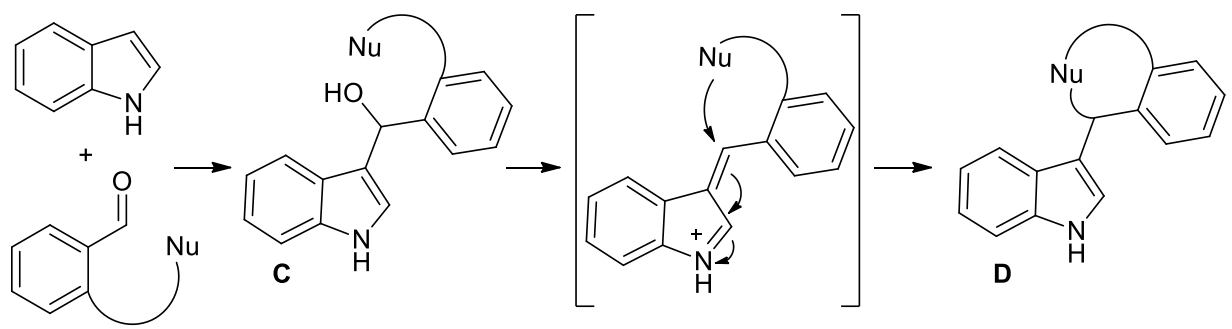

Esquema A.12

En este sentido, You y col. describieron la síntesis enantioselectiva de los fluorenos XI a partir de indoles y 2-formilbifenilos, en presencia de un ácido fosfórico como catalizador quiral (Esquema A.13). ${ }^{41}$ La reacción da buenos resultados cuando se emplean 2-metilindoles con sustituyentes tanto electróndadores como atractores en posición 5 del indol. También fueron evaluados otros indoles 2-sustituidos y 2-formilbifenilos, obteniéndose excelentes ee. Sin embargo, el empleo de $\mathrm{NH}$-indol resultó en una disminución del rendimiento debido a la formación del correspondiente 3,3-BIM, mientras que el empleo de 1,2-dimetilindol provocó una disminución drástica del ee.

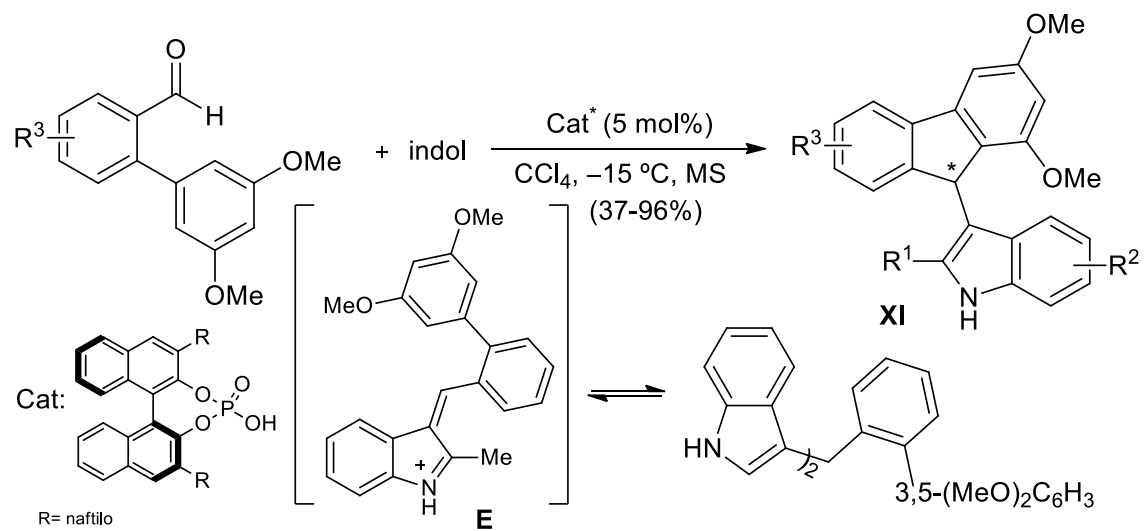

Esquema A.13

${ }^{41}$ F.-L. Sun, M.-Z. Qing, Q. Gu, S.-L. You, Chem. Eur. J. 2009, 15, 8709-8712. 
La reacción tiene lugar a través del catión iminio intermedio $\mathbf{E}$ donde el anión fosfato crea un entorno quiral mediante interacción por puentes de hidrógeno que determina la enantioselectividad de la segunda reacción F.-C., hecho que según los autores justifica el bajo ee obtenido cuando se emplea $N$-metilindol. Posteriormente, una captura intramolecular del intermedio $\mathbf{E}$ por parte del anillo aromático del bifenilo, daría lugar a los fluorenos XI. A partir de E también se podría formar el correspondiente 3,3'-BIM, el cual también es capaz de evolucionar hasta los fluorenos XI (Esquema A.13).

La misma estrategia fue empleada por Li-Liu y col. para acceder a derivados de xantano XIII, a partir de los 2-ariloxibenzaldehídos XII e indoles, en presencia de $\mathrm{FeCl}_{3}$ como catalizador (Esquema A.14). ${ }^{42}$

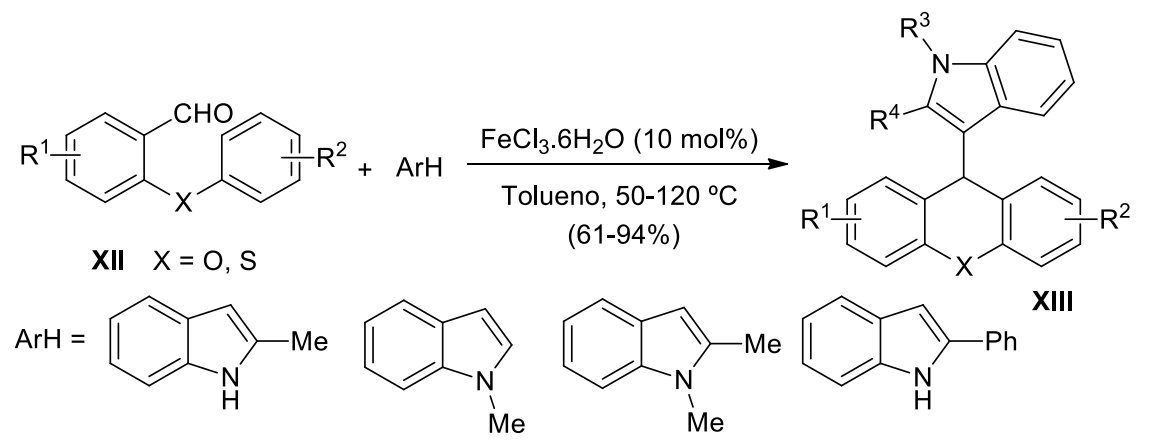

Esquema A.14

\subsection{Reacciones intramoleculares de indoles y alquinos catalizadas por complejos de Au(I) y Au(III)}

En los últimos años la catálisis homogénea con sales y complejos de oro ha experimentado un crecimiento exponencial convirtiéndose en una de las áreas de investigación más activas en Química Orgánica. ${ }^{43}$ Gran parte de la reactividad

\footnotetext{
${ }^{42}$ H. Li, J. Yang, Y. Liu, Y. Li, J. Org. Chem. 2009, 74, 6797-6801.

${ }^{43}$ Revisiones recientes de reacciones catalizadas por oro: (a) J. Miró, C. del Pozo, Chem. Rev. 2016, 116, 11924-11966. (b) M. Rudolph, A. Stephen, K. Hashmi, Chem. Soc. Rev. 2012, 41, 2448-2462. (c) A. Leela, A. Siva. K.-S. Kumara, Org. Biomol. Chem, 14, 6651-6671. (d) A. Fürstner, Chem. Soc. Rev. 2009, 38, 3208-3221. (e) N.-D. Shapiro, F.-D. Toste, Synlett. 2010, 675-691. (f) N. Krause, C. Winter, Chem. Rev. 2011, 111, 1994-2009. (g) M. Bandini, Chem. Soc. Rev. 2011, 40, 1358-1367. (h) A.-S.-K. Hashmi, F.-D. Toste, Modern Gold Catalyzed Synthesis, Wiley-VCH, Weinheim, 2012. (i) A.-S.-K. Hashmi, Acc. Chem. Res. 2014, 47, 864-876. (j) L. Fensternbank, M. Malacria, Acc. Chem. Res. 2014, 47, 953-965. (k) R. Dorel, A.-M. Echavarren, Chem. Rev. 2015, 117, 9028-9072.
} 
que poseen los complejos de oro viene determinada por los efectos relativistas ${ }^{44}$ que les confiere características especiales como su escasa propensión para participar en procesos redox, ${ }^{45}$ que son habituales en otros metales como el $\mathrm{Ru}$, $\mathrm{Rh}, \mathrm{Pd}, \mathrm{Ni}$. Estos efectos también son los responsables de que los complejos de oro puedan actuar como excelentes ácidos de Lewis blandos con una afinidad muy alta por los enlaces múltiples $\mathrm{C}-\mathrm{C}$, lo que hace que estos complejos sean capaces de promover transformaciones complejas imposibles mediante metodologías de síntesis convencionales. En este sentido varios autores han empleado la reactividad de alquinos activados por catalizadores de oro frente a indoles como nucleófilos para acceder a estructuras más complejas basadas en el esqueleto indólico. ${ }^{46}$

El primer ejemplo de reacción intramolecular de indol con alquinos catalizada por complejos de oro fue descrito por Echavarren y col. (Esquema A.15). ${ }^{47}$ Estos autores describieron la síntesis de azepinoindoles $\mathbf{X V}$ e indoloazocinas XVI a partir del mismo precursor, un derivado de la triptamina XIV. La reacción está muy influenciada por el tipo de catalizador de oro empleado. Así, partiendo de un alquino terminal el empleo de un catalizador de $\mathrm{Au}(\mathrm{I})$ con ligandos fosfina favorece la formación de los productos $\mathbf{X V}$ a través de una ciclación 7-exo-dig. Por el contrario, el empleo de $\mathrm{AuCl}$ ó $\mathrm{AuCl}_{3}$ favorece la formación de los aductos XVI en el que está involucrada una ciclación formal 8-endo-dig. Este mismo proceso también tiene lugar con alquinos internos independientemente del catalizador (Esquema A.15).

\footnotetext{
${ }^{44}$ Publicaciones sobre los efectos relativistas: (a) D.-J. Gorin, F.-D. Toste, Nature 2007, 446, 395. (b) A. Fürstner, P.-W. Davies, Angew. Chem. Int. Ed. 2007, 46, 3410. (c) A. Leyva-Pérez, A. Corma, Angew. Chem. Int. Ed. 2012, 51, 614-635. (d) F.-D. Toste, Beilstein J. Org. Chem. 2013, 9, 2040.

${ }^{45}$ La estabilidad química es general para este tipo de complejos. Sin embargo, ha sido descrito que catalizadores de $\mathrm{Au}(\mathrm{I})$ pueden desproporcionar en el medio de reacción a $\mathrm{Au}(0)$ y $\mathrm{Au}(\mathrm{III})$ : (a) E.M. Wansen, J.-C.-W. Folmer, G.-A. Wiegers, J. Less-Common Met. 1974, 38, 71-76. (b) A. Vogler, H. Kunkely, Coord. Chem. Rev. 2001, 209-211, 489-507.

${ }^{46}$ Revisión: P. Michael-Barbour, L.-J. Marholz, L. Chang, W. Xu, X. Wang, Chem. Lett. 2014, 43, $572-578$.

${ }^{47}$ (a) C. Ferrer, A.-M. Echavarren, Angew. Chem. Int. Ed. 2006, 45, 1105-1109. (b) C. Ferrer, A.H.-M. Amijs, A.-M. Echavarren, Chem. Eur. J. 2007, 13, 1358-1373.
} 


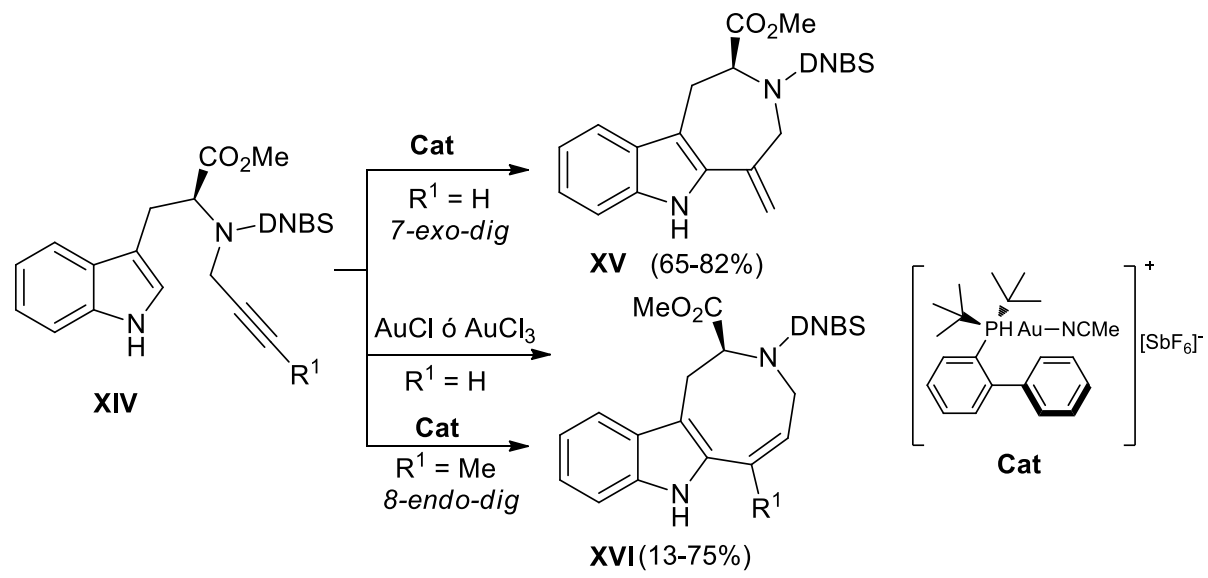

Esquema A.15

Los dos posibles mecanismos propuestos por los autores implican la formación de los intermedios espiránicos $\mathbf{F}$ ó $\mathbf{G}$ a través de una ciclación 6-exodig o 7-endo-dig, respectivamente. Sobre estos intermedios tendría lugar una migración selectiva 1,2 del resto alquenilo para dar lugar a los intermedios catiónicos $\mathbf{H}$ e I. La posterior pérdida de protón y protodesmetalación conduce a los productos finales XV y XVI (Esquema A.16).

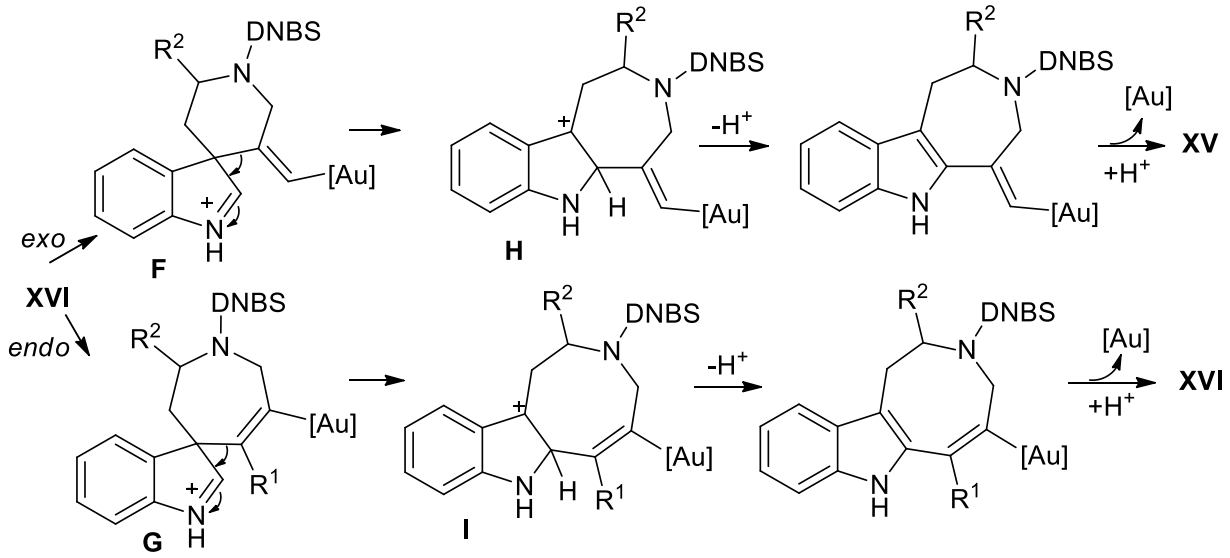

\section{Esquema A.16}

De manera análoga, la reacción intramolecular de las propionamidas XVII catalizada por $\mathrm{Au}(\mathrm{I})$ condujo a la obtención de las indoloazocinas XVIII a través 
de una ciclación 7-endo-dig (Esquema A.17). ${ }^{48}$ La posterior migración 1,2 del resto alquenilo en el intermedio iminio espiránico seguida de protodesmetalación conduce a la formación de las azocinas finales. De nuevo, los sustratos XVII que presentan un alquino terminal reaccionaron preferentemente a través de una ciclación 6-exo-dig, si bien ésta no tuvo lugar de manera selectiva.
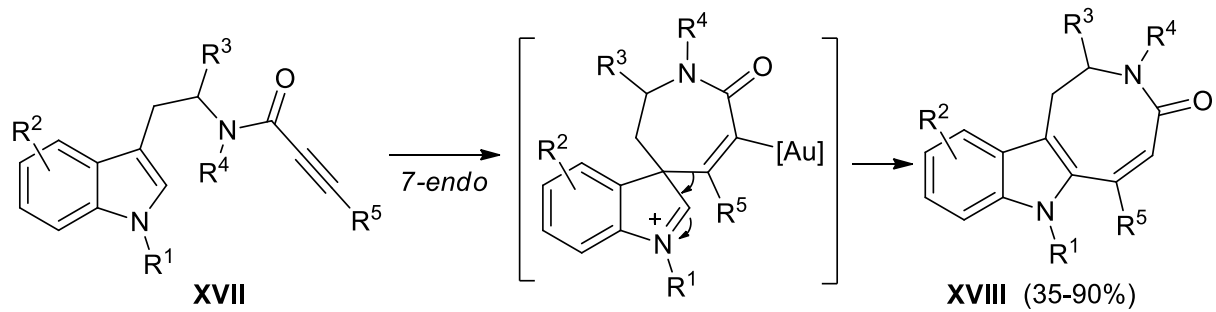

Condiciones: $\mathrm{PPh}_{3} \mathrm{AuOTf}, \mathrm{CHCl}_{3}$, t.a. ó $50^{\circ} \mathrm{C}$

$\mathrm{R}^{1}=\mathrm{H}, \mathrm{Me}, \mathrm{R}^{2}=\mathrm{H}, \mathrm{MeO}, \mathrm{R}^{3}=\mathrm{H}, \mathrm{CO}_{2} \mathrm{Me}, \mathrm{CH}_{2} \mathrm{OTIPS}, \mathrm{R}^{4}=\mathrm{Me}, \mathrm{Bn}, \mathrm{R}^{5}=\mathrm{Me}, i-\mathrm{Pr}, \mathrm{Ph}$

\section{Esquema A.17}

Esta selectividad en la migración 1,2 sobre el intermedio espiránico ha sido también observada en la reacción entre (Z)-eninoles e indoles catalizada por $\mathrm{Au}(\mathrm{I})$ (Esquema A.18). ${ }^{49}$ Esta reacción es un proceso tándem reacción F.-C. I hidroarilación y permite acceder de manera directa a los dihidrociclohepta[ $b]$ indoles $\mathbf{X X}$ con muy buenos rendimientos. En este proceso el catalizador de oro (I) interviene en dos ciclos catalíticos. En primer lugar, es capaz de activar el alcohol para generar un catión alílico que es capturado por el indol para dar lugar al indolilenino XIX. Este producto sufriría una reacción de hidroarilación intramolecular, a través de una ciclación 6-endo-dig, y posterior migración selectiva 1,2 del resto alquenilo para dar el producto final $\mathbf{X X}$ (Esquema A.18).

48 (a) V.-A. Peskov, O.-P. Pershivki, E.-V. Van der Eycken, Adv. Synth. Catal. 2012, 354, 2841-2848. (b) S.-G. Modha, D.-D. Vachhani, J. Jacobs, L. Van Meervelt, E.-V. Van der Eycken, Chem Commun. 2012, 48, 6550-6552.

${ }^{49}$ Y. Lu, X. Du, X. Jia, Y. Liu, Adv. Synth. Catal. 2009, 351, 1517-1522. 


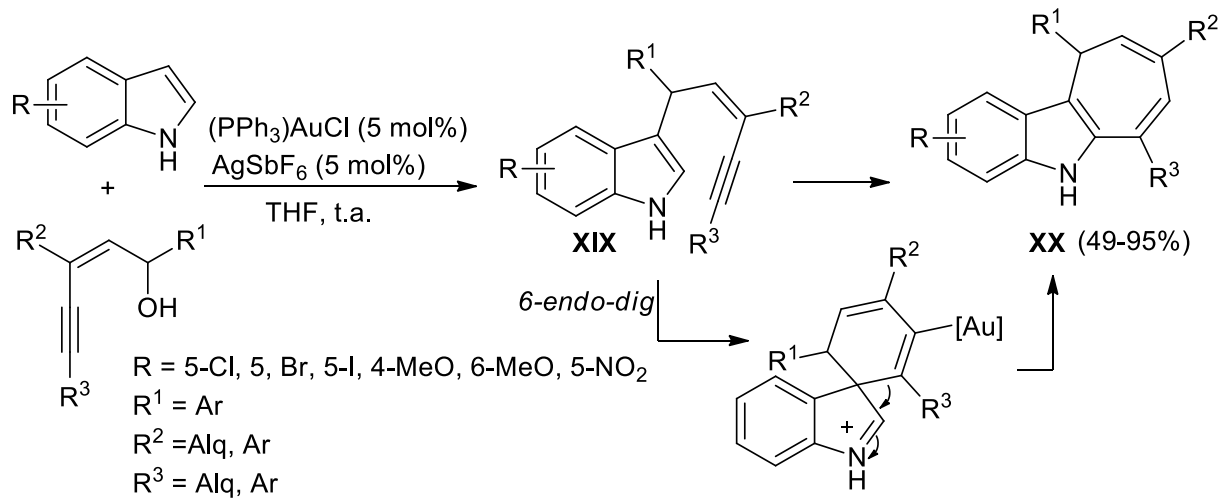

Esquema A.18

Esta misma estrategia fue posteriormente empleada por Carbery y col. en la síntesis de las dihidrociclohepta[b]indol-8(5H)-onas XXII. Estos autores estudiaron la reacción entre indoles y eninonas en presencia de un catalizador de $\mathrm{Au}$ (III) (Esquema A.19). ${ }^{50}$ De manera análoga al ejemplo anterior, la reacción es un proceso tándem F.-C. / hidroarilación, esta vez iniciado por una reacción tipo Michael del indol sobre la eninona para dar lugar a la indolilalquinona intermedia XXI. Una ciclación 6-endo-dig de esta última, iniciada por el ataque del C-3 del indol al alquino activado por el $\mathrm{Au}(\mathrm{III})$, conduce al intermedio espiránico habitual $\mathbf{J}$, donde nuevamente, se produciría la migración selectiva 1,2 del resto alquenilo que conduce a las indolonas finales XXII (Esquema A.19).

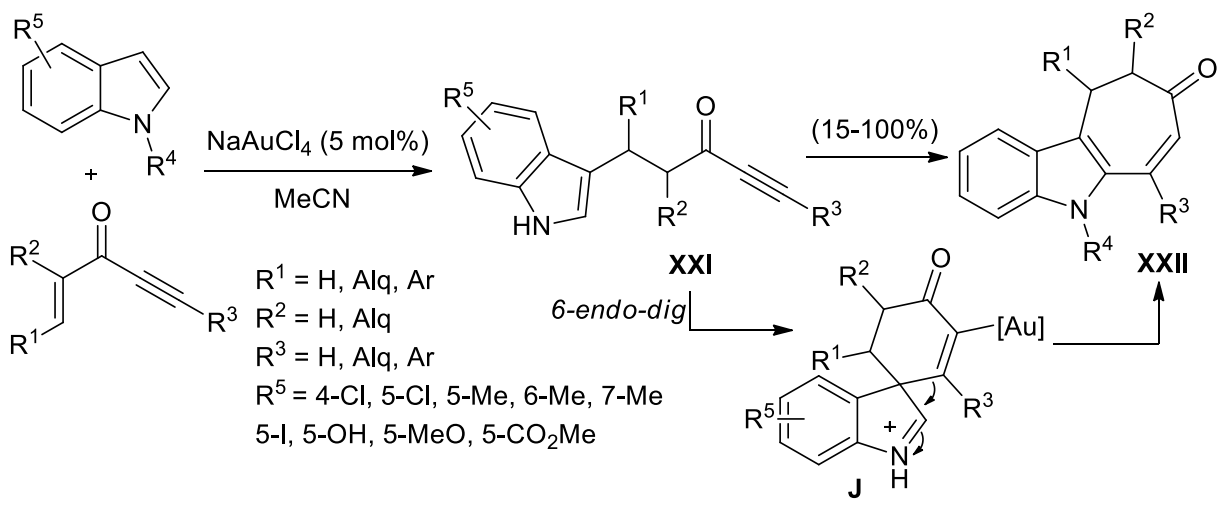

\section{Esquema A.19}

50 S.-J. Heffernan, J.-P. Tellam, M. E. Queru, A.-C. Silvanus, D. Benito, M.-F. Mahon, A.-J. Hennessy, B.-I. Andrews, D.-R. Carbery, Adv. Synth. Catal. 2013, 355, 1149-1159. 
Por otro lado, las reacciones intramoleculares de indoles y triples enlaces también han sido empleadas para sintetizar alenilindoles funcionalizados. En este sentido, Liu y col. describieron la reactividad de los sustratos XXIII frente a $\mathrm{Au}(\mathrm{I})$ (Esquema A.20). ${ }^{51}$ Este proceso consiste en una ciclación / fragmentación heterolítica, cuyo resultado global es la migración formal 1,5 del indol, sin precedentes hasta ese momento. Esta reacción comienza por una ciclación 6endo-dig que da lugar al intermedio espiránico K. Sin embargo, en este caso K no evoluciona mediante la migración 1,2 habitual, sino que se produce una fragmentación heterolítica inducida por el grupo hidroxilo presente en la posición C-3 del indol hasta los alenilindoles finales XXIV (Esquema A.20).
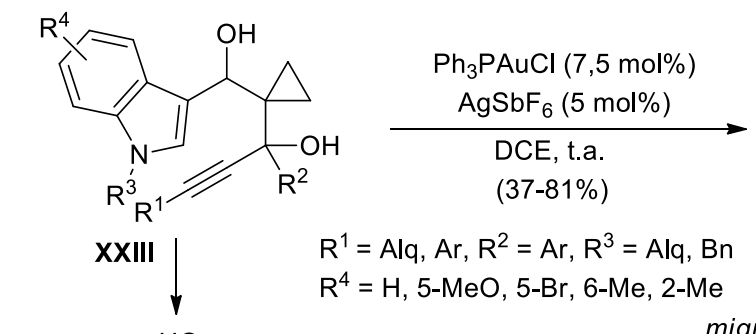

$R^{1}=A l q, A r, R^{2}=A r, R^{3}=A l q, B n$ $\mathrm{R}^{4}=\mathrm{H}, 5-\mathrm{MeO}, 5-\mathrm{Br}, 6-\mathrm{Me}, 2-\mathrm{Me}$

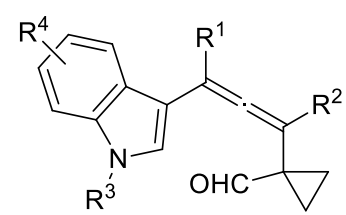

XXIV

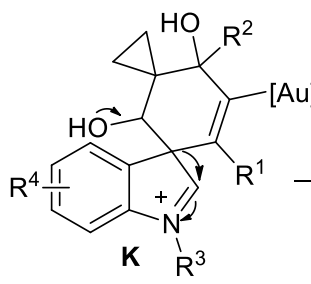

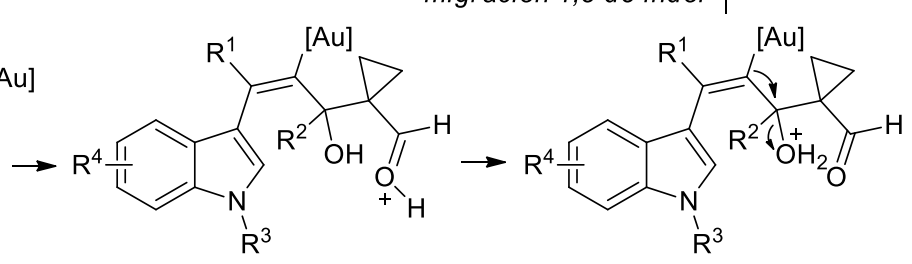

Esquema A.20

Por último, un ejemplo muy interesante de reacción intramolecular de indoles con triples enlaces, con una evolución del intermedio espiránico no habitual, fue descrito por Xu y col. y permitió la síntesis de los bisindoles XXVI a partir de los 1,1-bis(indolil)-5-alquinos terminales XXVI y un catalizador de $\mathrm{Au}(\mathrm{I})$ (Esquema A.21). ${ }^{52}$ En una primera etapa se produce una ciclación 6-exo-dig que genera el intermedio L, de manera análoga a lo descrito por el grupo de Echavarren (ver Esquema A.16). Sin embargo, en este caso este intermedio espiránico $\mathbf{L}$ no evoluciona a través de la migración 1,2 habitual del resto alquenilo o del alquilo sino que, en su lugar y asistida por el otro núcleo indólico presente en la molécula, se produce la apertura del espirano dando lugar al

${ }^{51}$ G. Li, Y. Liu, J. Org. Chem. 2010, 75, 3526-3528.

${ }^{52}$ L. Huang, H.-B. Yang, D.-H. Zhang, Z. Zhang, X.-Y. Tang, Q. Xu, M. Shi, Angew. Chem. Int. Ed. 2013, 52, 6767-6771. 
intermedio viniloro M. Por último, una reacción tipo Michael en M, y posterior protodemetalación, permite la obtención de los cicloaductos XXVI con buenos rendimientos (Esquema A.21).

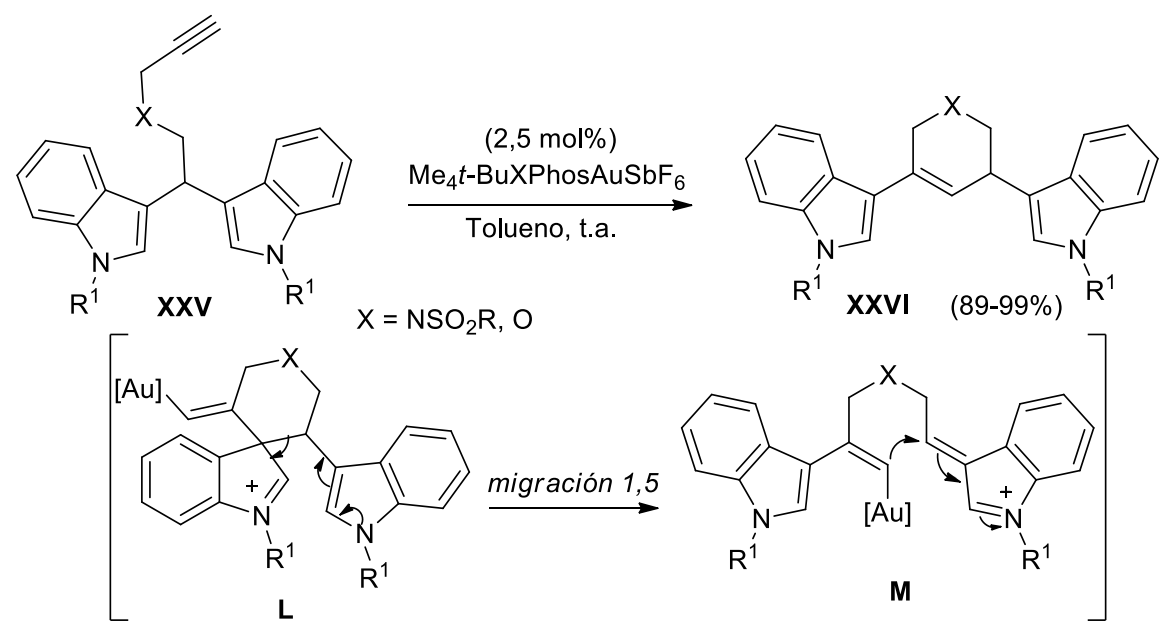

Esquema A.21

\subsubsection{Reactividad de 2 y 3-(but-3-inil)-1H-indoles: Síntesis de carbazoles}

El empleo de catalizadores de oro en la activación de triples enlaces $\mathrm{C}-\mathrm{C}$ ha jugado también un papel fundamental en la síntesis de carbazoles ya que ha permitido, mediante el diseño adecuado de los sustratos de partida, acceder a estos sistemas heterocíclicos con variados modelos de sustitución. En este campo, en 2011 Perumal y col. describieron la síntesis de los carbazoles 4,6-disustituídos XXVII a partir de (Z)-2-eninilindoles en presencia de un catalizador de Au(I). La reacción transcurriría a través de una ciclación 6-endo-dig seguida de una etapa de protodesmetalación (Esquema A.22). ${ }^{53}$

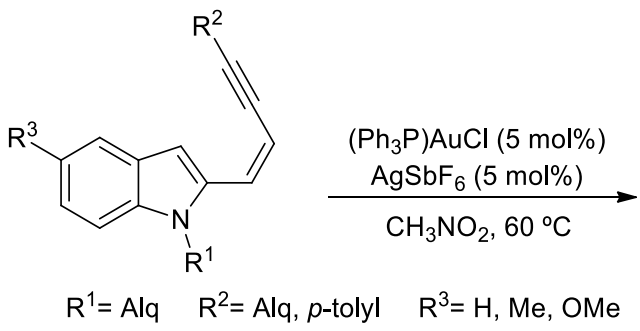

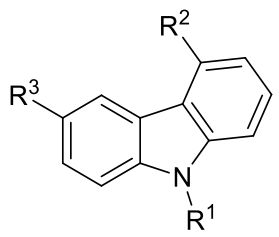

XXVII (50-80\%)

Esquema A.22

${ }^{53}$ C. Praveen, P.-T. Pemural, Synlett 2011, 521-524. 
Otra estrategia para obtener carbazoles fue la descrita por Ma y col. en 2012, y consiste en hacer reaccionar los 1-(indol-2-il)-3-alquin-1-oles XXVIII en presencia de $\mathrm{AuCl}_{3}$ como catalizador (Esquema A.23). ${ }^{54} \mathrm{Al}$ igual que en el caso anterior la reacción transcurre a través de una ciclación 6-endo-dig, seguida de un proceso de protodesmetalación y eliminación de una molécula de agua para recuperar la aromaticidad. Esta metodología permitió acceder a carbazoles 2,4,6y 2,4,7-trisustituídos XXIX con rendimientos entre moderados y buenos.

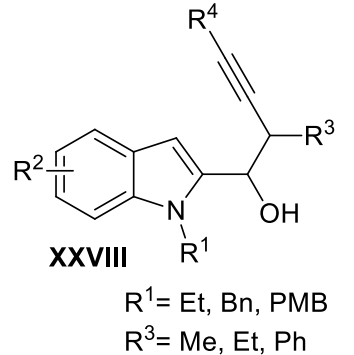

$\mathrm{R}^{3}=\mathrm{Me}, \mathrm{Et}, \mathrm{Ph}$

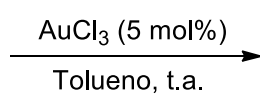

Tolueno, t.a.

$$
\begin{aligned}
& \mathrm{R}^{2}=\mathrm{H}, 5-\mathrm{Me}, 5-\mathrm{Me}, 5-\mathrm{Br}, 4-\mathrm{Me}, 7-\mathrm{Me} \\
& \mathrm{R}^{4}=\mathrm{Ph}, \mathrm{Et}, n-\mathrm{Bu}
\end{aligned}
$$

\section{Esquema A.23}

Carbazoles con un modelo de sustitución íntimamente relacionado con los anteriores fueron obtenidos a partir de los (3-yodoindol-2-il)butinoles XXX en presencia de catalizadores de $\mathrm{Au}(\mathrm{I})$ (Esquema A.24) ${ }^{55}$ La reacción trascurre a través de una ciclación 6-endo-dig hasta el intermedio N. A continuación, una migración 1,3 de yodo y eliminación de agua condujo a los yodocarbazoles finales. La presencia de un átomo de yodo en la posición 3 del carbazol permite su posterior funcionalización a través de reacciones de acoplamiento catalizadas por complejos de Pd. La reacción con alquinos terminales también permitió obtener carbazoles XXXI sin sustitución en posición 4 del esqueleto carbazólico.

\footnotetext{
${ }^{54}$ Y. Qiu, W. Kong, C. Fu, S. Ma, Org. Lett. 2012, 14, 6198-6201.

${ }^{55}$ B. Alcaide, P. Almendros, J.-M. Alonso, E. Busto, I. Fernández, M.-P. Ruiz, G. Xiaokaiti, ACS Catal. 2015, 5, 3417-3421.
} 


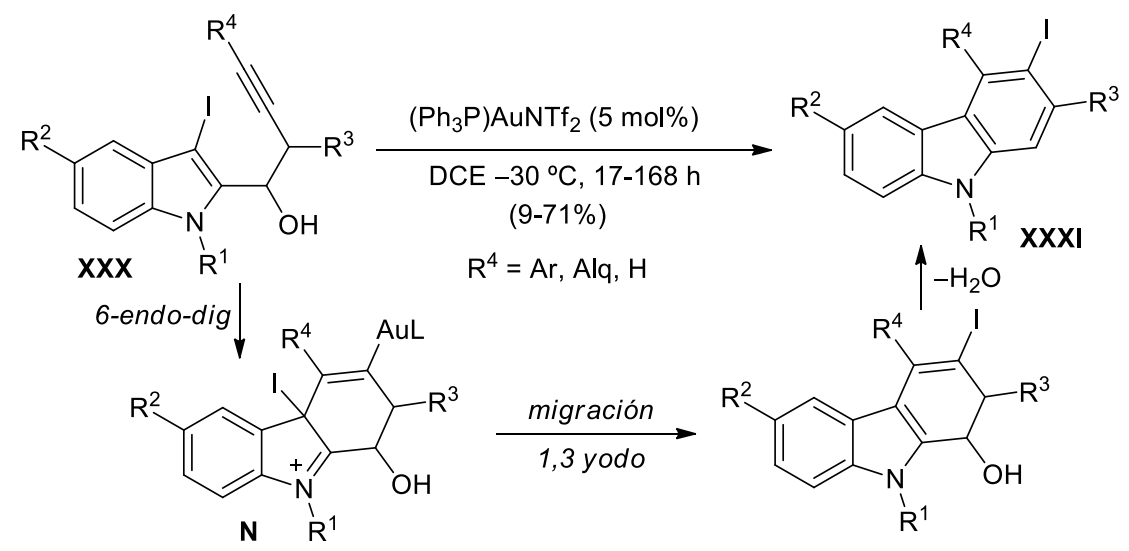

Esquema A.24

En este mismo campo, Liu y col. estudiaron la cicloisomerización de los 3acilindoles XXXII en presencia de catalizadores de $\mathrm{Au}(\mathrm{I})$ que conduce a carbazoles con diferentes modelos de sustitución (Esquema A.25). ${ }^{56}$ La reacción transcurre a través de una ciclación 6-endo-dig para dar lugar al intermedio $\mathbf{O}$, el cual experimenta una fragmentación heterolítica inducida por el grupo acetilo del C-3 del indol que libera el catión acilo. Finalmente, procesos de protodesmetalación y deshidratación conducirían a la formación de los carbazoles 4,6-disustituídos XXXIII.

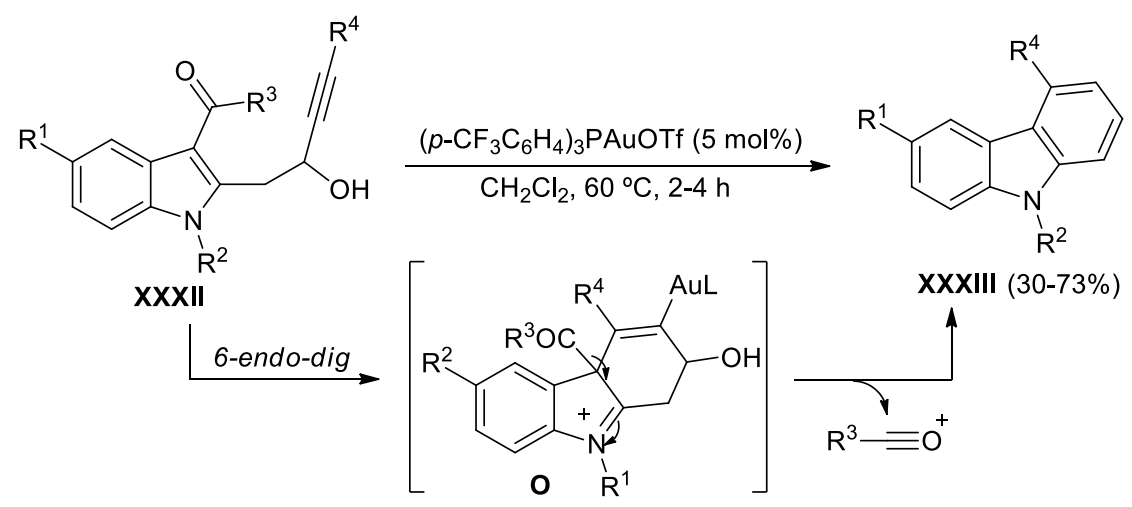

\section{Esquema A.25}

Siguiendo esta estrategia estos mismos autores diseñaron las inonas XXXIV como sustratos de partida eficaces para acceder a 2-hidroxicarbazoles (Esquema A.26). ${ }^{56}$ La reacción transcurre de manera análoga al caso anterior, a través de

${ }^{56}$ L. Wang, G. Li, Y. Liu, Org. Lett. 2011, 13, 3786-3789. 
una ciclación inicial 6-endo-dig en presencia de un catalizador de $\mathrm{Au}(\mathrm{I})$ y 5 eq de $\mathrm{H}_{2} \mathrm{O}$, seguido de una fragmentación heterolítica que da lugar a los 2hidroxicarbazoles-4-6-disustituidos con buenos rendimientos. La presencia de agua en la reacción es esencial en el trascurso de la misma ya que, en su ausencia los carbazoles XXXV se obtienen con muy bajo rendimiento.<smiles>[R]C#CC(=O)Cc1c(C([R])=O)c2cc([R])ccc2n1[R2]</smiles>

\section{Esquema A.26}

Por su parte, Hashmi y col. demostraron que tanto los 1-(indol-2-il)-3-alquin1-oles XXXVI como los 1-(indol-3-il)-3-alquin-1-oles XXXVII reaccionaban intramolecularmente para dar lugar a los mismos carbazoles 4-arilsustituidos XXXVIII (Esquema A.27). ${ }^{57}$ Los sustratos en los que el alquino se encuentra en la cadena lateral del C-2 del indol reaccionan mediante una ciclación 6-endo-dig que genera directamente los carbazoles XXXVIII.
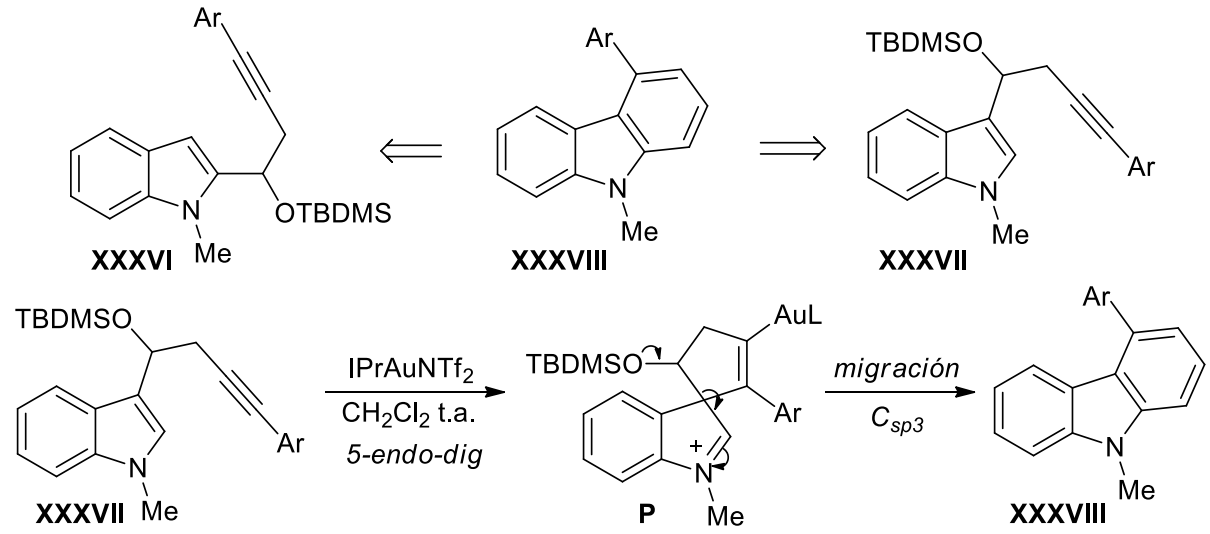

\section{Esquema A.27}

Sin embargo, para aquellos sustratos en los que el triple enlace se encuentra en la cadena lateral del C-3 del indol se produciría una ciclación 5-endo-dig para dar lugar al intermedio espiránico P. En este caso, este intermedio no evoluciona

${ }^{57}$ A. S. K. Hashmi, W. Yang, F. Rominger, Chem. Eur. J. 2012, 18, 6576-6580. 
de la manera habitual anteriormente descrita (migración 1,2 de alquenilo), sino que se produce la migración 1,2 del resto hidroxialquilo $\left(\mathrm{Csp}^{3}\right)$ que conduce tras protodesmetalación y pérdida de agua al carbazol XXXVIII final (Esquema A.27). Cabe destacar que en la bibliografía los ejemplos en los que migra de manera selectiva un resto alquilo $\left(\mathrm{Csp}^{3}\right)$ frente un resto alquenilo son bastante escasos, y los existentes se encuentran limitados a sustratos en los que siempre hay presente un oxígeno en el carbono que migra, es decir, se trata de restos hidroxialquílicos en los que el átomo de oxígeno aumenta la capacidad migratoria del sustituyente hidroxialquilo.

Y así, Shi y col. también observaron esta selectividad en la migración 1,2 sobre el intermedio espiránico cuando estudiaron la ciclación de 1-(indol-3-il)-3alquin-1-oles sustituídos IXL y XLI. Estos autores obtuvieron carbazoles a partir de moléculas sencillas. Así, la reacción de los sustratos IXL en presencia de un catalizador de oro(I) condujo a la formación de los carbazoles XL con rendimientos entre moderados y buenos. Por su parte, la formación de los 2alcoxietilcarbazoles XLII fue observada cuando se emplearon alcoholes como disolvente (Esquema A.28). ${ }^{58}$

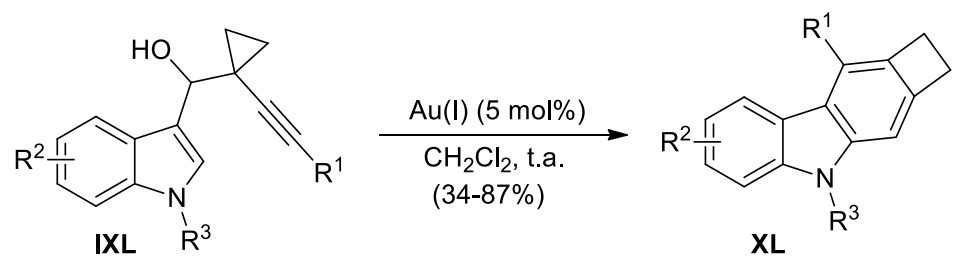

$\mathrm{R}^{1}=\mathrm{Ph}, 4-\mathrm{MeC}_{6} \mathrm{H}_{4}, 4-\mathrm{MeOC}_{6} \mathrm{H}_{4}$, Alq $\mathrm{R}^{2}=4-\mathrm{Br}, 5-\mathrm{Br}, 5-\mathrm{MeO}, 6-\mathrm{F}, 7-\mathrm{Me} \mathrm{R}^{3}=\mathrm{Me}, \mathrm{Bn}$

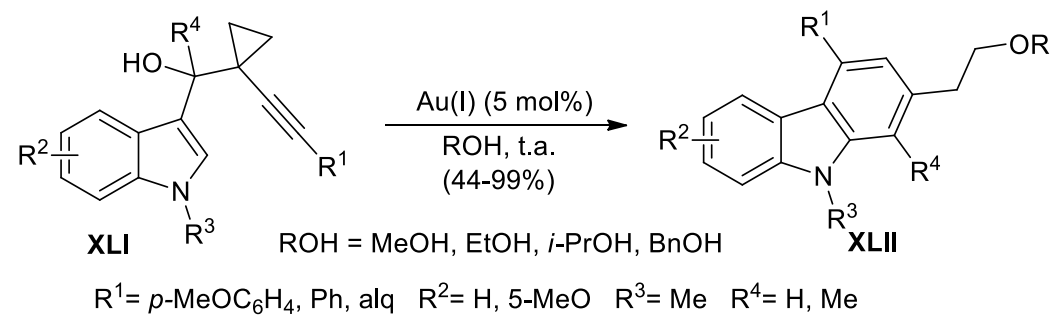

Esquema A.28

\subsubsection{Reactividad de 3-propargilindoles}

Nuestro grupo de investigación ha descrito ampliamente la reactividad de los 3-propargilindoles XLIII catalizada por $\mathrm{Au}(\mathrm{I})$ dando lugar a los 2-indenilindoles

${ }^{58}$ Z. Zhang, X. Tang, Q. Xu, M. Shi, Chem. Eur. J. 2013, 19, 10625-10631. 
XLIV. Su formación implica una migración 1,2 de indol, sin precedentes hasta ese momento, siendo éste el primer ejemplo descrito en la bibliografía de migración 1,2 de un resto carbonado sobre un sustrato propargílico (Esquema A.29) ${ }^{59}$ La reactividad de los 3-propargilindoles y, por lo tanto el producto final obtenido, viene determinada por la naturaleza de los sustituyentes sobre las posiciones tanto propargílicas como terminal del triple enlace. De esta manera cuando el sustituyente sobre la posición propargílica es aromático, el producto observado es el indenilindol XLIV (Esquema A.29). La reacción trascurre a través de un intermedio ciclopropil viniloro $\mathbf{Q}$ que evoluciona hasta un intermedio carbenoide de oro $\alpha, \beta$-insaturado $\mathbf{R}$ por apertura del anillo de ciclopropano. Esta etapa de reacción implicaría la migración 1,2 del núcleo indólico. Posteriormente, la adición del anillo aromático al carbeno de oro conduce al producto final. Este proceso viene mejor descrito como una ciclación aura-iso-Nazarov como demostraron cálculos teóricos llevados a cabo posteriormente. $^{60}$

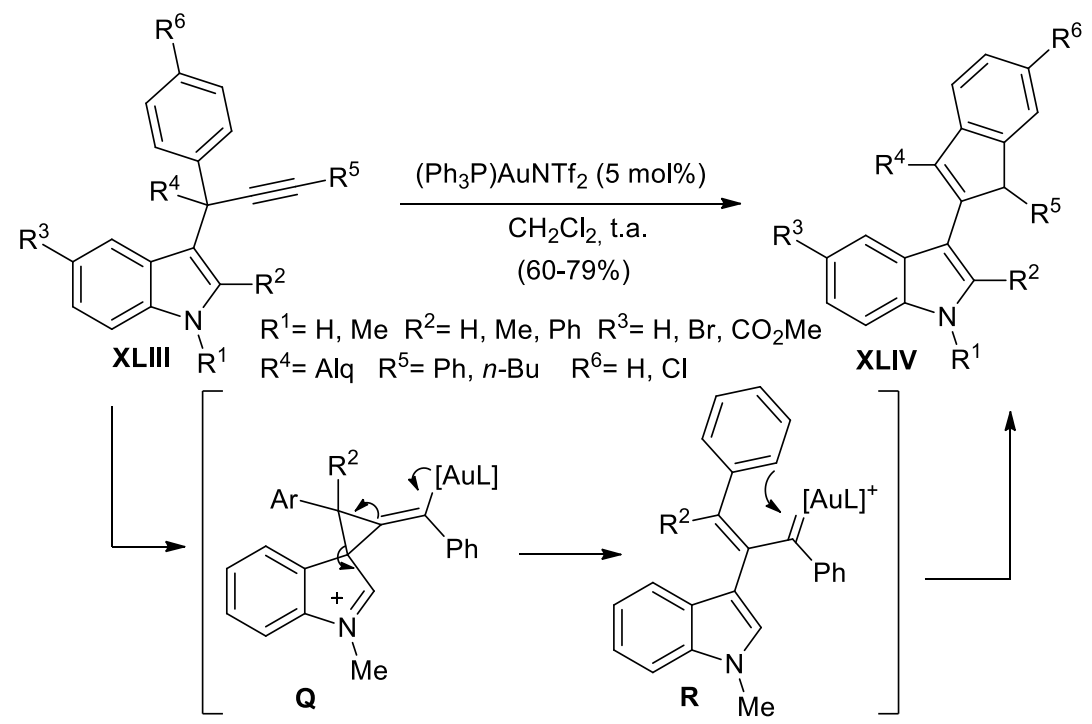

Esquema A.29

Sin embargo, la reacción con los sustratos $\mathbf{X L V}$ que no poseen grupos arilo sobre la posición propargílica, en presencia del mismo catalizador de oro(I), condujo a los nuevos indenilindoles XLVI, en los que el grupo fenilo que

\footnotetext{
${ }^{59}$ R. Sanz, D. Miguel, F. Rodriguez, Angew. Chem. Int. Ed. 2008, 47, 7354-7357.

${ }^{60}$ R. Sanz, D. Miguel, M. Gohain, P. García-García, M.-A. Fernández-Rodríguez, A. GonzalezPérez, O. Nieto-Faza, A.-R. de Lera, F. Rodríguez, Chem. Eur. J. 2010, 16, 9818-9828.
} 
participa en la formación del indeno es el que se encuentra en la posición terminal del triple enlace. En este caso, una vez formado el intermedio carbenoide de oro éste experimenta una ciclación aura-Nazarov en la que interviene el anillo aromático de la posición terminal y que conduce a los indenilindoles XLVI (Esquema A.30).

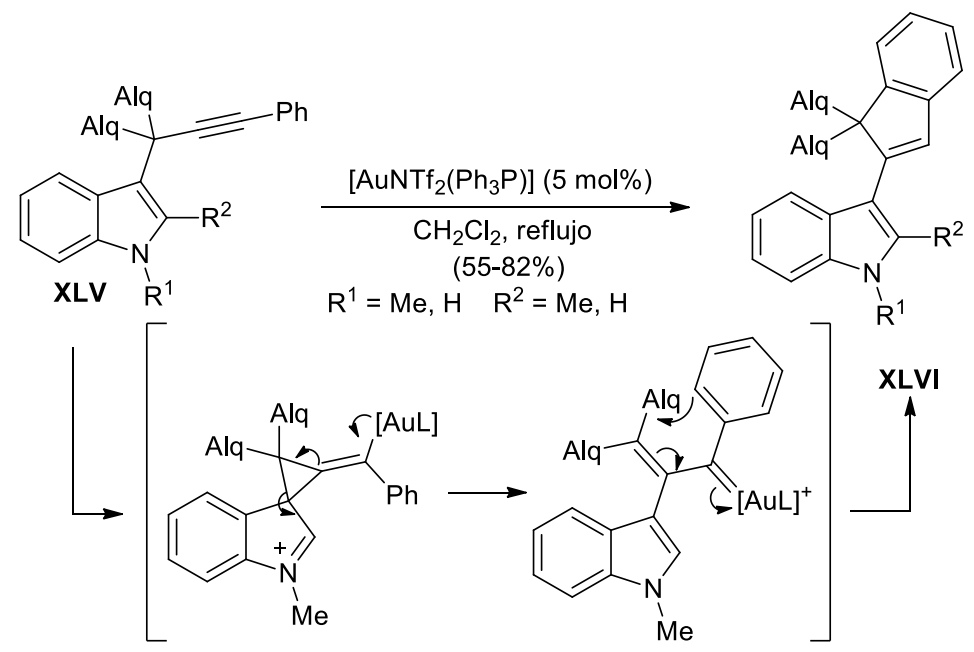

Esquema A.30

En el caso de sustratos con restos con restos aromáticos tanto en la posición propargílica como en la terminal se forman los aductos XLIV. Sin embargo, fue posible invertir esta selectividad en favor del producto Nazarov, aunque no de manera completa (Esquema A.31). El empleo de tolueno como disolvente parece ser clave en el cambio de selectividad del proceso. Esta estrategia fue extendida a una serie de propargilindoles XLIII con restos arilo con sustituyentes tanto electron-dadores como electron-atractores, obteniéndose los 2-indenilindoles XLVI como productos mayoritarios, que pudieron ser aislados con buenos rendimientos. ${ }^{61}$

${ }^{61}$ E. Álvarez, D. Miguel, P. García-García, M. A. Fernández-Rodríguez, F. Rodríguez, R. Sanz, Beilstein J. Org. Chem. 2011, 7, 786-793. 


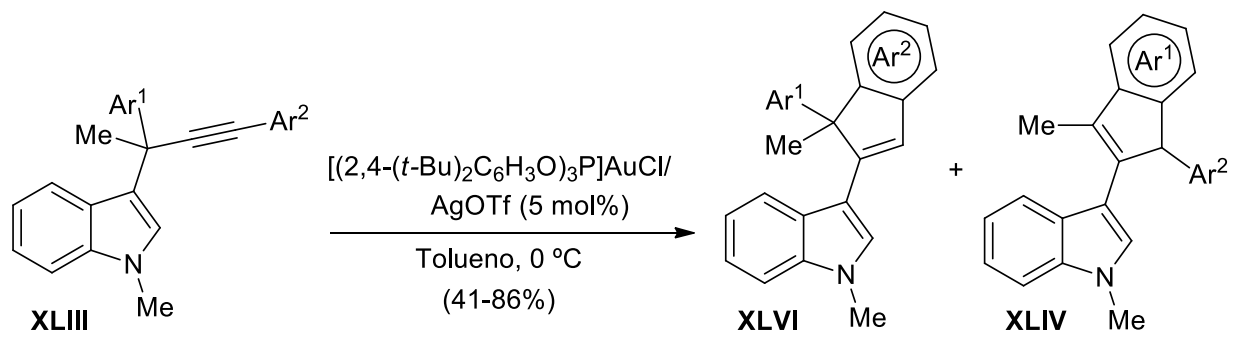

\section{Esquema A.31}

\section{Indoles 3-funcionalizados: cationes indoleniminio}

En el apartado anterior se ha descrito cómo se puede llevar a cabo la funcionalización selectiva de indoles en posición 3 mediante reacciones F.-C. de indoles con agentes alquilantes tales como alcoholes y aldehídos. Otras alternativas implican la reacción F.-C. de indoles con olefinas con sustituyentes electrón atractores como electrófilos, en presencia de catalizadores ácidos de Lewis, o reacciones de acoplamiento carbono-carbono de 3-haloindoles. Sin embargo, en los últimos años, el empleo de intermedios alquilidenindoleniminio se ha convertido en una alternativa muy atractiva para la fucionalización selectiva de indoles en posición 3. Estos intermedios se generan habitualmente por tratamiento en medio ácido o básico de los precursores apropiados: 3indolilmetanoles, indolilsulfonas y graminas (Esquema A. 32).<smiles></smiles>
$\mathrm{GS}=\mathrm{SO}_{2} \mathrm{Ar}, \mathrm{OH}, \mathrm{NR}_{2}$

\section{Esquema A.32}

La reactividad de los cationes alquilideniminio como electrófilos puede ser expresada con su parámetro de electrofilia E. Recientemente, Mayr y col. estudiaron el carácter electrofílico de una serie de alquilideniminios sustituídos llegando a las conclusiones que se representan en el Esquema A.33. ${ }^{62}$

${ }^{62}$ E. Follet, G. Berionni, P. Mayer, H. Mayr, J. Org. Chem. 2015, 80, 8643-8656. 


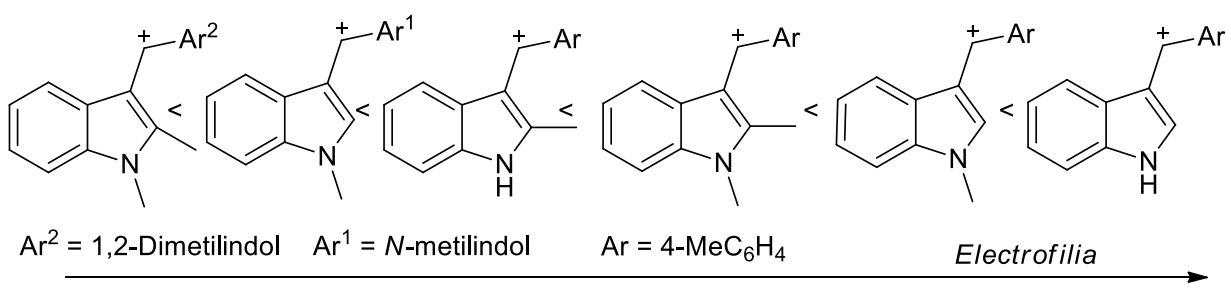

\section{Esquema A.33}

En este apartado de la Tesis se ha hecho una breve reseña sobre algunas metodologías que implican la funcionalización selectiva de indoles en posición 3 a través de intermedios indoleniminio.

\subsection{Reacciones de indol-3-il metanoles}

La formación del catión indoleniminio puede tener lugar a partir de un 3indolilmetanol. Los 3,3'-BIMs asimétricos se encuentran presentes en una gran variedad de productos naturales con actividad biológica. Y así, Ji y col. describieron una ruta de acceso a bisindolilmetanos asimétricos a partir de 3indolilmetanoles y diferentes indoles como nucleófilos, en presencia de CAN como catalizador. La reacción tiene lugar a través de un catión iminio y da lugar a los productos finales con excelentes rendimientos (Esquema A.34). ${ }^{63}$

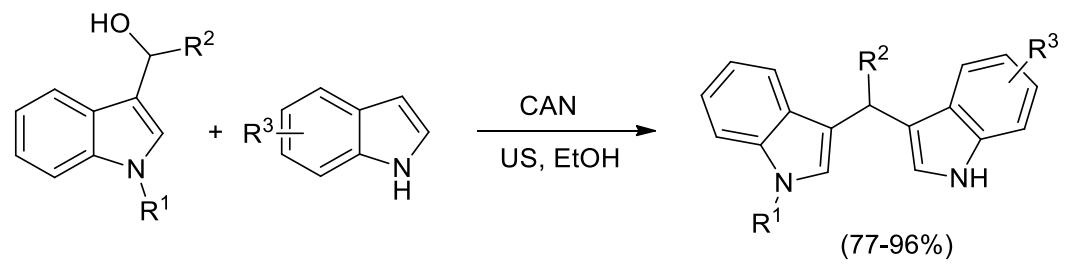

\section{Esquema A.34}

Posteriormente la misma metodología fue empleada por estos autores para preparar 3,3-bis(indolil)indolin-2-onas, tanto simétricas como asimétricas, también con muy buenos rendimientos (Esquema A.35). ${ }^{64}$

\footnotetext{
${ }^{63}$ X.-F. Zeng, S.-J. Ji, S.-Y. Wang, Tetrahedron 2005, 61, 10235-10241.

${ }^{64}$ S.-Y. Wang, S.-J. Ji, Tetrahedron 2006, 62, 1527-1535.
} 
<smiles>[R]c1ccc2c(c1)NC(=O)C2(O)c1cn([R])c2ccccc12</smiles><smiles>[R7]n1ccc2cc[R1]cc21</smiles>

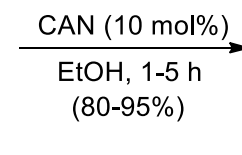<smiles>[R]c1ccc2c(c1)NC(=O)C2(c1cn([R])c2ccccc12)c1cn([R])c2ccccc12</smiles>

\section{Esquema A.35}

Durante el desarrollo de nuestro trabajo de investigación, Shao-Xiao y col. han descrito una ruta de acceso a 3,3'-BIMs asimétricos empleando trifluoroetanol (TFE) como disolvente y en ausencia de catalizador. Esta reacción, que transcurre en condiciones muy suaves, condujo a la formación de los 3,3'-BIMs con rendimientos excelentes. Además de indoles se emplearon otros nucleofilos carbonados y heteronucleófilos dando lugar a indoles C-3 funcionalizados con buenos rendimientos (Esquema A.36). ${ }^{65} \mathrm{Al}$ poco tiempo estas mismas reacciones de $S_{N}$ con indolil alcoholes fueron descritas en agua como disolvente. ${ }^{66}$

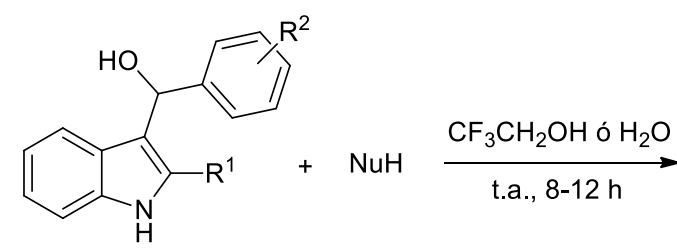<smiles>[R]c1ccc(C([N])c2c([R])[nH]c3ccccc23)cc1</smiles><smiles>[R]C(=O)CC([R7])=O</smiles>

\section{Esquema A.36}

\subsection{Reacciones de 3-sulfonilindoles}

Los 3-sulfonilindoles se han convertido en los últimos años en los competidores más importantes de los indol-3-il metanoles para la funcionalización de indoles con reactivos nucleofílicos, gracias a la excelente

\footnotetext{
${ }^{65}$ H. Wen, L. Wang, L. Xu, Z. Hao, C.-L. Shao, C.-Y. Wang, J. Xiao, Adv. Synth. Catal. 2015, 357, 4023-4030.

${ }^{66}$ J. Xiao, H. Wen, L. Wang, L. Xu, Z. Hao, C.-L. Shao, C.-Y. Wang, Green Chem. 2016, 18, 1032-1037.
} 
capacidad del anión arilsulfinilo como grupo saliente ${ }^{67}$ Petrini y col. han sido pioneros en este campo y en 2007 describieron un método general para la síntesis de 3-sulfonilindoles mediante una reacción multicomponente entre indoles, compuestos carbonilos y ácidos sulfínicos, en presencia de PTSA. La reacción funciona bien con aldehídos, tanto aromáticos como alifáticos, pero no con cetonas ni con aldehídos $\alpha, \beta$-insaturados (Esquema A.37). ${ }^{68 a}$ Alternativamente, se han podido preparar sulfonil indoles con diferentes grupos funcionales por alquilación en $\alpha$ del 3-(sulfonilmetil)indol, preparado a su vez a partir del 3-metil$N$-Boc indol (Esquema A.37). ${ }^{68 \mathrm{~b}}$

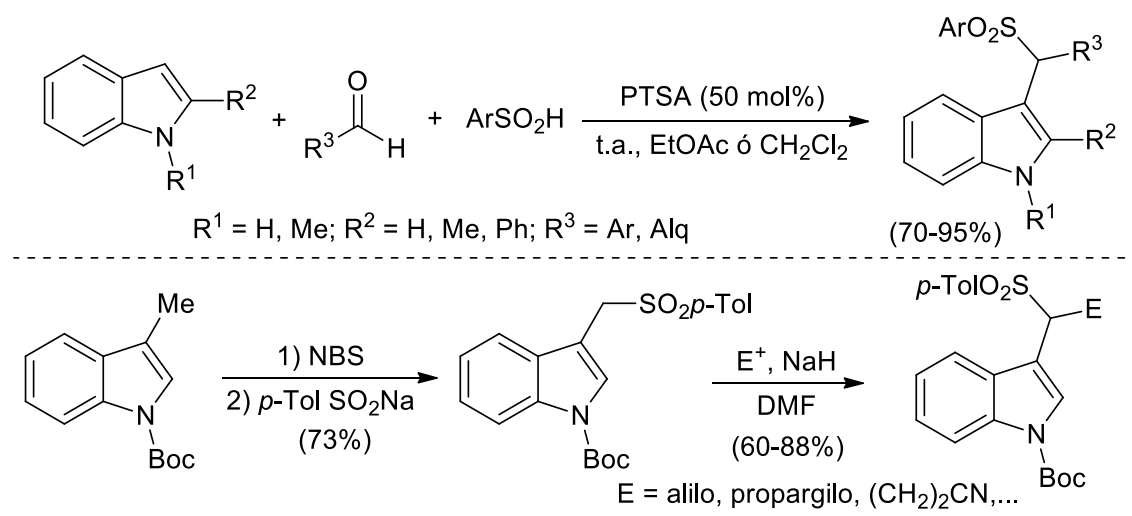

Esquema A.37

Algunas aplicaciones sintéticas de estos sulfonilindoles se muestran en el Esquema A.38 e incluyen sus reacciones con reactivos organometálicos, tales como magnesianos, ácidos borónicos (en presencia de $\mathrm{Rh}$ ), o $\alpha$-halocarbonilos en presencia de $\mathrm{Zn}$. ${ }^{68 \mathrm{a}}$ Todos ellos actúan a la vez como bases, para eliminar el ácido sulfínico y generar el intermedio indoleniminio, y como nucleófilos. ${ }^{69}$

${ }^{67}$ Revisiones: (a) A. Palmieri, M. Petrini, R. R. Shaikh, Org. Biomol. Chem. 2010, 8, 1259-1270. (b) F. Martinelli, A. Palmieri, M. Petrini, Phos. Sulf. Sil. 2011, 186, 1032-1045. (c) A. Palmieri, M. Petrini, Chem. Rec. 2016, 16, 1353-1379.

68 (a) A. Palmieri, M. Petrini, J. Org. Chem. 2007, 72, 1863-1866. (b) A. Palmieri, M. Petrini, R. R. Shaikh, Synlett 2008, 1845-1851.

${ }^{69}$ (a) R. Ballini, A. Palmieri, M. Petrini, E. Torregiani, Org. Lett. 2006, 8, 4093-4096. (b) L.-L. Cao, Z.-S. Ye, G.-F. Jiang, Y.-G. Zhou, Adv. Synth. Catal. 2011, 353, 3352-3356. 


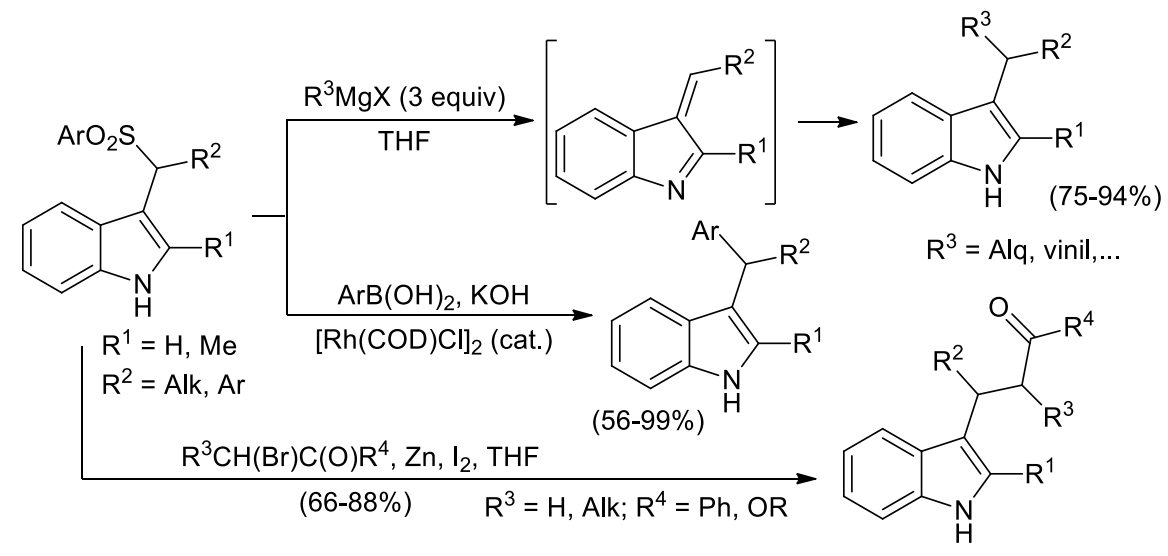

\section{Esquema A.38}

Además, en los últimos años se han seguido desarrollando numerosas reacciones en este campo, incluyendo procesos enantioselectivos de adición de diferentes tipos de enolatos a estos intermedios indoleniminio generados a partir de sulfonilindoles. ${ }^{70}$

${ }^{70}$ (a) R. R. Shaikh, A. Mazzanti, M. Petrini, G. Bartoli, P. Melchiorre, Angew. Chem. Int. Ed. 2008, 47, 8707-8710. (b) M. C. Dobish, J. N. Johnston, Org. Lett. 2010, 12, 5744-5747. 



\section{DISCUSIÓN DE RESULTADOS}

I. INTRODUCCIÓN

II. ANTECEDENTES GENERALES

III. DISCUSIÓN DE RESULTADOS

IV. CONCLUSIONES

V. EXPERIMENTAL SECTION 



\section{CAPÍTULO 1 Reacciones de alquilación intramolecular de indoles con alcoholes catalizadas por ácidos de Brønsted}

\subsection{ANTECEDENTES: REACCIONES INTRAMOLECULARES DE SUSTITUCIÓN NUCLEOFÍLICA DIRECTA DE ALCOHOLES}

El uso de ácidos de Brønsted o de Lewis para promover la ciclación F.-C. de alcoholes secundarios o terciarios sobre anillos aromáticos continúa siendo un reto sintético de interés para el que se han propuesto diferentes aproximaciones, aunque no existe ningún método general que proporcione elevados rendimientos en todos los casos. Y así, a continuación, se describirán los ejemplos más significativos que han ido apareciendo en la bibliografía durante los últimos años.

En 2006, Rueping describió que $1 \mathrm{~mol} \%$ de $\mathrm{Bi}(\mathrm{OTf})_{3}$ era capaz de catalizar la reacción intramolecular F.-C. del derivado de bifenilo I para dar lugar a los fluorenos sustituídos II. La reacción transcurre en condiciones suave y con muy buenos rendimientos cuando se emplean alcoholes terciarios (Esquema 1.1). ${ }^{71}$
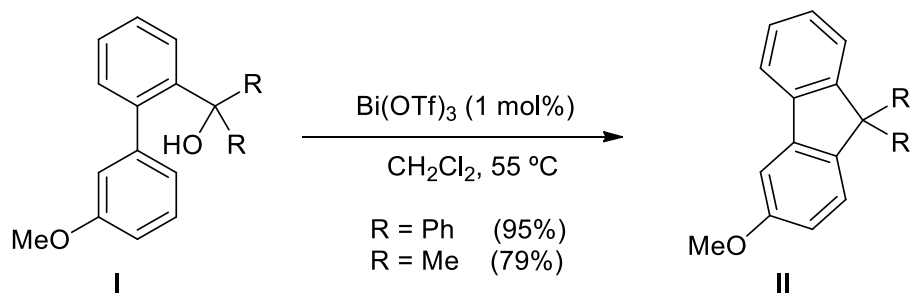

Esquema 1.1

Este mismo catalizador fue empleado posteriormente por Bunce y col. para acceder a derivados de tetrahidronaftaleno y tetrahidroisoquinolina, mediante la ciclación intramolecular de los alcoholes bencílicos terciarios III. La reacción conduce a una gran variedad de carbociclos y heterociclos tales como IV con rendimientos entre moderados y muy buenos (Esquema 1.2). ${ }^{72}$

\footnotetext{
${ }^{71}$ M. Rueping, B.-J. Natchsheim, N. Ieawsuwan, Adv. Synth. Catal. 2006, 348, 1033-1037.

${ }^{72}$ B. Nammalwar, R.-A. Bunce, Tetrahedron Lett. 2013, 54, 4330-4332.
} 


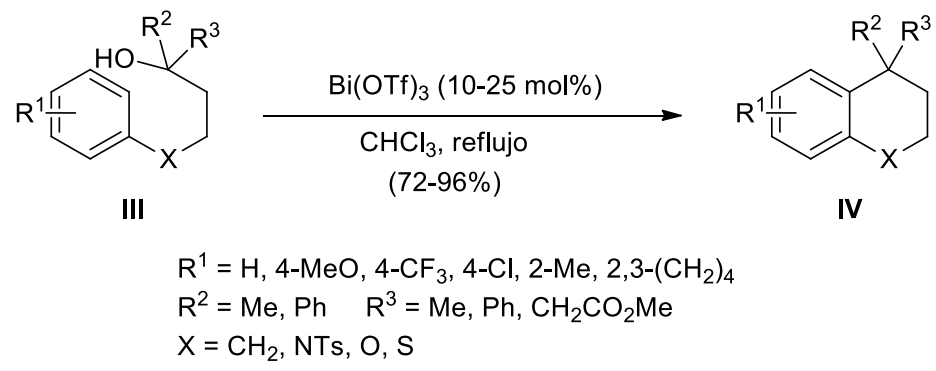

\section{Esquema 1.2}

También empleando como catalizador sales de bismuto(III), se describió la ciclación intramolecular de los furilalcoholes $\mathbf{V}$, que permite acceder a compuestos que presentan el esqueleto de furano en su estructura (Esquema 1.3).$^{73}$ Estas reacciones transcurren a través de un carbocatión generado tras la activación del alcohol por el catalizador que, posteriormente, es capturado por un nucleófilo interno oxigenado o nitrogenado. Mediante esta metodología se han sintetizado una gran variedad de benzofuranos VI con rendimientos entre moderados y muy buenos.
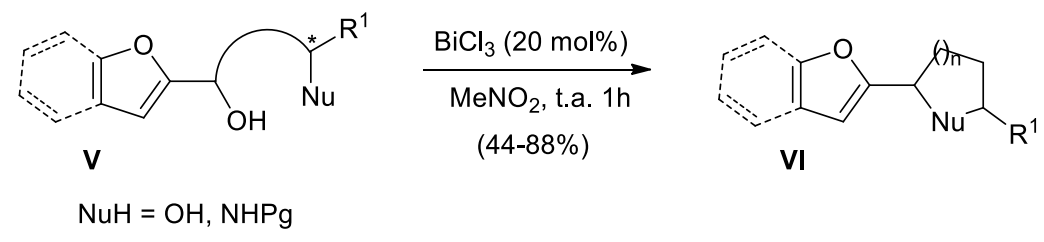

\section{Esquema 1.3}

La ciclación intramolecular de alcoholes bencílicos secundarios, empleando $\mathrm{FeCl}_{3}$ como catalizador, ha sido descrita por Panda y col. como una metodología muy eficiente para acceder a 9-arilxantanos (Esquema 1.4) ${ }^{74}$ Estos autores estudiaron la ciclación de los diarilcarbinoles VII que poseen un grupo ariloxi en posición orto y diferente capacidad de estabilización del carbocatión intermedio, obteniéndose los xantanos VIII con muy buenos rendimientos.

\footnotetext{
${ }^{73}$ S. Dhiman, S.-V. Ramasastry, Org. Biomol. Chem. 2013, 11, 4299-4303.

${ }^{74}$ S.-K. Das, R. Singh, G. Panda, Eur. J. Org. Chem. 2009, 4757-4761.
} 


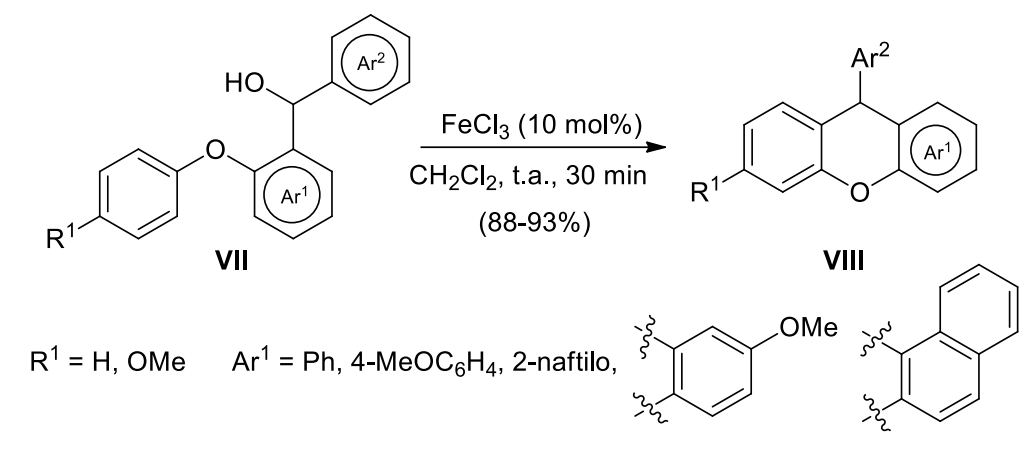

$\mathrm{Ar}^{2}=\mathrm{Ph}, 2-\mathrm{MeOC}_{6} \mathrm{H}_{4}, 3-\mathrm{MeOC}_{6} \mathrm{H}_{4}, 4-\mathrm{MeOC}_{6} \mathrm{H}_{4}$, 2-Tienilo, 9-fenantril, 2-MeSC $6 \mathrm{H}_{4}$

\section{Esquema 1.4}

Por su parte, Zhou y col. describieron la primera ciclación de alcoholes propargílicos bencilamino sustituídos, tales como IX, catalizada por hierro (III). La reacción consiste en un proceso de alenilación / ciclación a través del ataque $\mathrm{S}_{\mathrm{N}}$, del anillo aromático al alcohol propargílico generando los alenos $\mathbf{X}$. Dependiendo de los sustituyentes estos alenos se isomerizan hasta los derivados de isoquinolina XI con rendimientos entre buenos y muy buenos (Esquema $1.5) .^{75}$

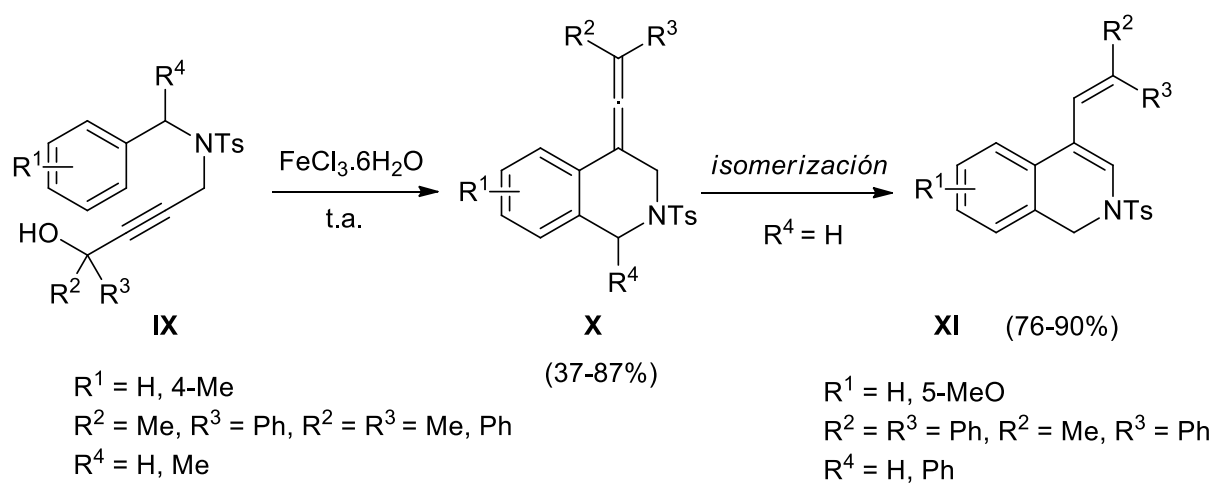

Esquema 1.5

Poco después, estos mismos autores también pusieron a punto la síntesis de dihidro y tetrahidronaftalenos XIII y XIV a partir de los alcoholes propargílicos XII, empleando de nuevo $\mathrm{FeCl}_{3}$ como catalizador (Esquema 1.6). ${ }^{76}$

\footnotetext{
${ }^{75}$ W. Huang, P. Zheng, Z. Zhang, R. Liu, Z. Chen, X. Zhou, J. Org. Chem. 2008, 73, 6845-6848.
}

76 W. Huang, L. Hong, P. Zhen, R. Liu, X. Zhou, Tetrahedron 2009, 65, 3603-3610. 


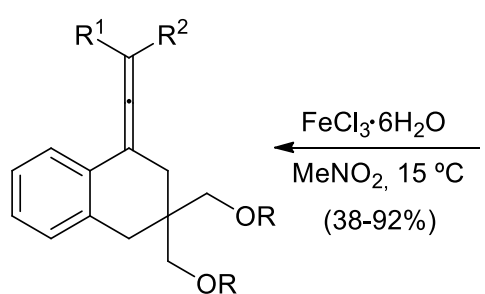

XIII

$\mathrm{R}=\mathrm{Me}, \mathrm{Et} \quad \mathrm{R}^{1}=\mathrm{R}^{2}=\mathrm{Ar}$<smiles>[R]OCC(CC#CC([R])([R])O)(CO[R])Cc1ccccc1</smiles>

XII<smiles>[R]CC1(CO)C=C(C=C([R])[R])c2ccccc2C1</smiles>

XIV

\section{Esquema 1.6}

También empleando $\mathrm{FeCl}_{3}$ como catalizador, aunque anhidro en este caso, Jana y col. describieron la reacción de ciclación intramolecular de los biarilalcoholes $\mathbf{X V}$, como una metodología eficiente para acceder a los fluorenos XVI con rendimientos entre buenos y excelentes (Esquema 1.7). ${ }^{77}$

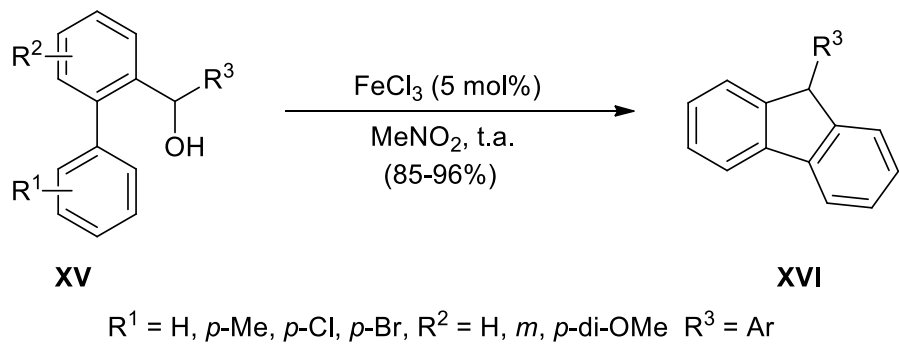

\section{Esquema 1.7}

En este campo, el empleo de alcoholes no activados como electrófilos en reacciones de alquilación F.-C. continúa siendo un reto sin resolver completamente. En este contexto, Cook y col. pusieron a punto la reacción de alquilación intramolecular de los alcoholes alifáticos XVII en presencia de hierro (III) como catalizador, lo que permite obtener los productos XVIII (Esquema 1.8). ${ }^{78} \mathrm{El}$ empleo de $\mathrm{AgSbF}_{6}$ es determinante en el resultado de la reacción ya que en ausencia de esta sal de plata la reacción no tiene lugar. El proceso transcurre de manera más rápida y con mejores rendimientos cuando el areno que actúa como nucleófilo posee sustituyentes electrón-dadores que cuando se trata de arenos con sustituyentes electrón deficientes.

\footnotetext{
77 S. Sarkar, S. Maiti, K. Bera, S. Jalal, U. Jana, Tetrahedron Lett. 2012, 53, 5544-5547.

${ }^{78}$ R. Latisha, S.-P. Cook, Org. Lett. 2014, 16, 2026-2029.
} 


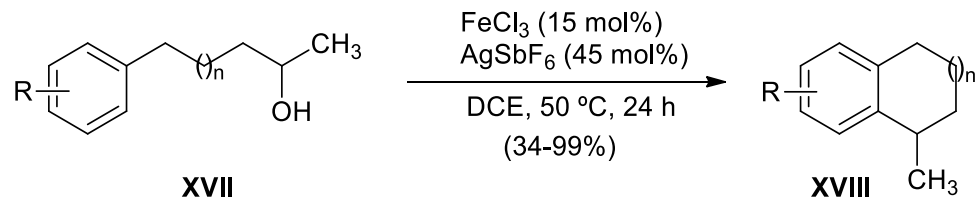

\section{Esquema 1.8}

La reacción F.-C. empleando alcoholes alílicos como electrófilos también ha sido ampliamente estudiada. En este sentido, Bandini y col. describieron que tanto el empleo de AgOTf, o de $\left(\mathrm{Ph}_{3} \mathrm{P}\right) \mathrm{AuCl} / \mathrm{AgOTf}$, como catalizadores permitía llevar a cabo la reacción de alquilación F.-C. de arenos electrónicamente ricos empleando los alcoholes bencílicos XIX como electrófilos (Esquema 1.9, Ec 1). ${ }^{79}$ La estereoquímica de la olefina de partida puede ser tanto $Z$ como $E$, dando lugar a los 1-vinil-1,2,3,4-tetrahidronaftalenos $\mathbf{X X}$ con rendimientos entre moderados y buenos. El mecanismo de reacción que proponen estos autores implicaría, bien la coordinación del catalizador al doble enlace de la olefina y posterior ataque nucleofílico del areno, o bien la coordinación del metal al grupo hidroxilo para generar un catión alílico que, posteriormente, sería atrapado por el areno rico en densidad electrónica.
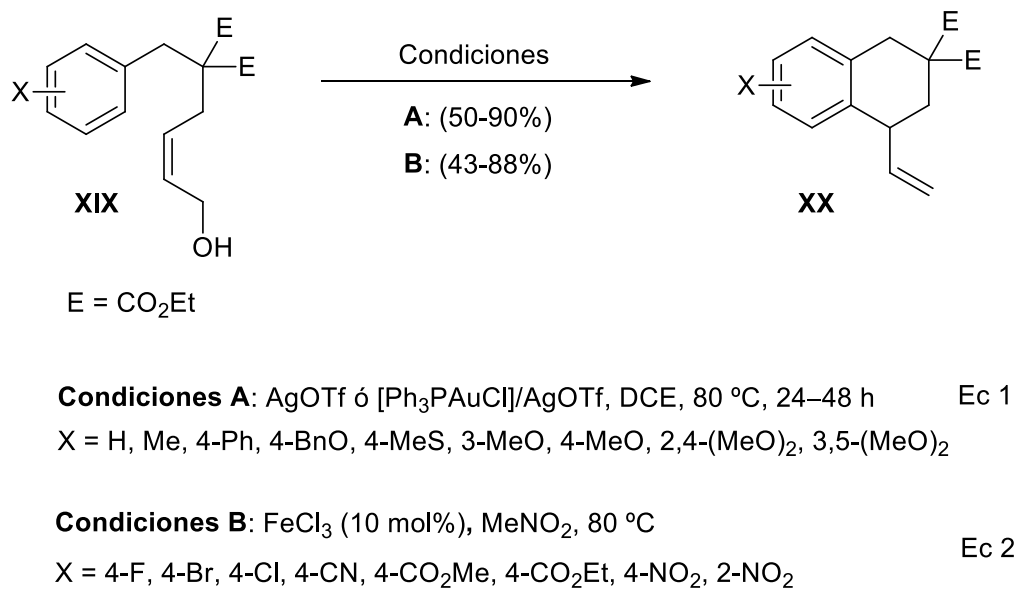

\section{Esquema 1.9}

${ }^{79}$ M. Bandini, A. Eichholzer, P. Kotrusz, M. Tragni, S. Troisi, A-U. Ronchi, Adv. Synth. Catal. 2009, 351, 319-324. 
Poco después, este mismo grupo de investigación describió la primera reacción de alquilación F.-C. de arenos electrón deficientes con alcoholes alílicos en presencia de un catalizador de hierro (III), lo que permitió obtener los productos XX funcionalizados con grupos electrón atractores con rendimientos entre moderados y buenos (Esquema 1.9, Ec 2). ${ }^{80}$

También empleando alcoholes alílicos como sustratos de partida, Chan y col. describieron la reacción intramolecular de los 2-tosilaminofenilprop-1-en3-oles XXI, en presencia del sistema catalítico $\mathrm{AuCl}_{3} / \mathrm{AgSbF}_{6}$, para acceder a las 1,2-dihidroquinolinas XXII (Esquema 1.10). ${ }^{81}$

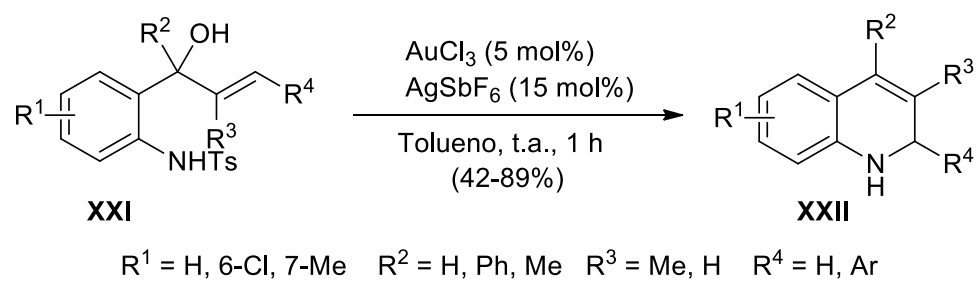

\section{Esquema 1.10}

Por otra parte, los compuestos policíclicos basados en el esqueleto indólico son estructuras de gran importancia en Síntesis Orgánica debido a su presencia en innumerables productos naturales. En este sentido, la ciclación intramolecular de indoles con alcoholes alílicos podría ser considerada como una estrategia muy directa para acceder a este tipo de estructuras. Sin embargo, mientras que en la bibliografía existen descritos numerosos ejemplos de ciclación intramolecular de indoles con acetatos alílicos, las metodologías descritas a partir de los correspondientes alcoholes alílicos son bastante más escasas.

Por lo que hace referencia a ciclaciones intramoleculares de indoles hidroxifuncionalizados, en 2008 Nishizawa y col. describieron la reacción F.-C. intramolecular de indoles y alcoholes alílicos a partir de XXIII, en presencia de sales de $\mathrm{Hg}(\mathrm{II})$ (Esquema 1.11). ${ }^{82}$ Los autores proponen que la reacción transcurre mediante la coordinación del catalizador de mercurio al doble enlace para dar un complejo A. Posteriormente, se produciría el ataque nucleofílico del

\footnotetext{
${ }^{80}$ M. Bandini, M. Tragni, U-A. Ronchi, Adv. Synth. Catal. 2009, 351, 2521-2524.

${ }^{81}$ P. Kothandaraman, S.-J. Foo, P.-W. Chan, J. Org. Chem. 2009, 74, 5947-5952.

${ }^{82}$ K. Namba, H. Yamamoto, I. Jasaki, K. Mori, H. Imagawa, M. Nishizawa, Org. Lett. 2008, 10, 1767-1770.
} 
indol al doble enlace activado y pérdida de un protón para dar lugar al intermedio organomercúrico B. La protonación del grupo hidroxilo por el ácido tríflico, generado in-situ, conduce al catión oxonio $\mathbf{C}$ que, tras un proceso de desmercuración, conduce al $N$-tosil-4-viniltetrahidrocarbazol XXIV, el cual fue aislado de manera prácticamente cuantitativa.

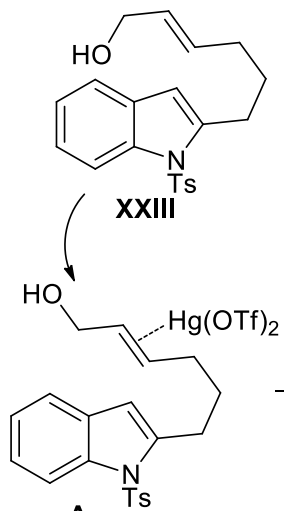

A

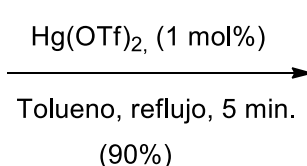

$(90 \%)$

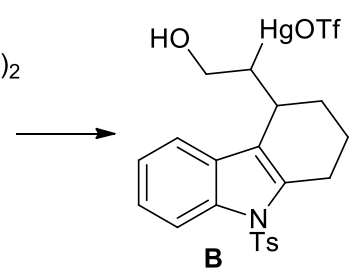

B
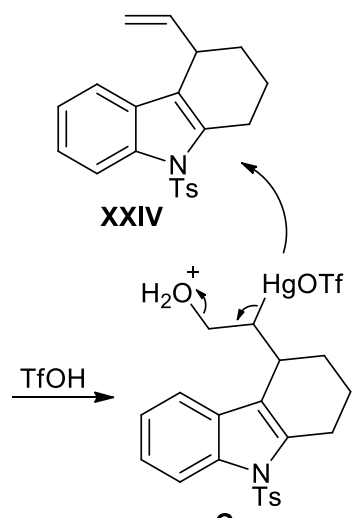

C

\section{Esquema 1.11}

También en este campo Bandini describió la reacción de ciclación enantioselectiva de los alcoholes alílicos XXV en presencia de catalizadores de $\mathrm{Au}(\mathrm{I})$ quirales no racémicos para acceder a las estructuras policíclicas XXVI de forma enantioselectiva (Esquema 1.12). ${ }^{83}$

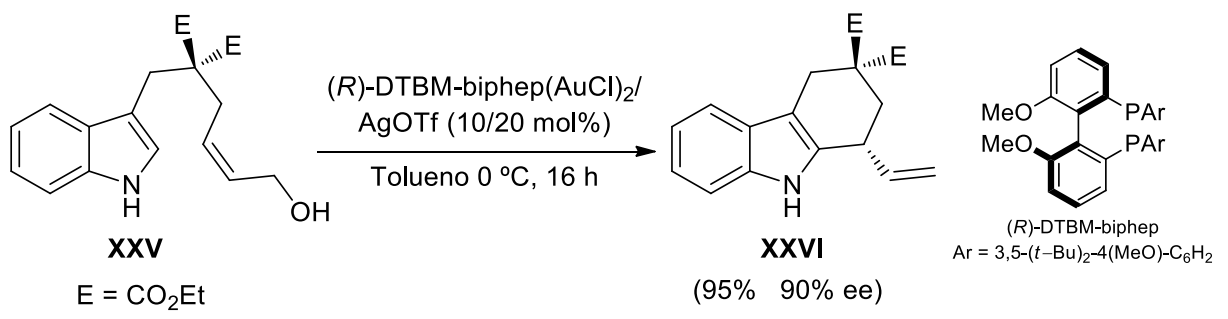

\section{Esquema 1.12}

Por otro lado, es conocido que los alcoholes alílicos, en presencia de ácidos borónicos como catalizadores, experimentan una transposición 1,3 del grupo hidroxilo. ${ }^{84}$ Sin embargo, Hall y col. describieron que la presencia de un

${ }^{83}$ M. Bandini, A. Eicholzer, Angew. Chem. Int. Ed. 2009, 48, 9533-9537.

${ }^{84}$ H. Zheng, M. Lejkowski, D.-G. Hall, Chem. Sci. 2011, 2, 1305-1310. 
nucleófilo externo en la cadena lateral del alcohol alílico inhibe la transposición dando lugar a los productos de alquilación F.-C. de una manera suave y con rendimientos entre moderados y buenos (Esquema 1.13). ${ }^{85}$ La optimización del proceso permitió concluir que los ácidos pentafluorofenil, hexafluoronaftil, y $\mathrm{N}$ metil-2,3-difluoropiridinio borónicos son los que ofrecen mejores resultados en términos de rendimientos y tiempos de reacción, permitiendo aislar los productos XXVIII a partir de los alcoholes de partida XXVII.<smiles>[X]c1ccccc1CC=CC([R])(O)c1ccccc1</smiles>

XXVII

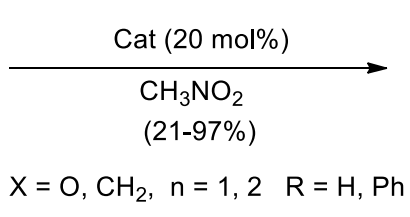

$X=O, \mathrm{CH}_{2}, \mathrm{n}=1,2 \mathrm{R}=\mathrm{H}, \mathrm{Ph}$<smiles>[Z]C(O)(/C=C/CC[R19]Nc1ccccc1)c1ccccc1</smiles>

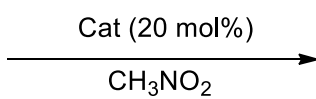

(62-95\%)<smiles>[R]/C(=C/C1CCCCC1)C(=O)c1ccccc1[X]</smiles>

XXVIII<smiles>[R]/C(=C\C1CCCN1)c1ccccc1</smiles>

XXIX $\mathrm{NuH}=\mathrm{OH}, \mathrm{NHTs}, \mathrm{n}=1,2,3 \quad \mathrm{R}^{1}=\mathrm{H}, \mathrm{Ph}$

Cat:<smiles>Oc1c(F)c(F)c(F)c(F)c1Br</smiles><smiles>Oc1cc(F)c(F)c2c(F)c(F)c(F)c(F)c12</smiles><smiles>COc1c(Br)cc[n+](C)c1F</smiles>

\section{Esquema 1.13}

Además, la reacción no está limitada a nucleófilos carbonados. Así, se pueden obtener heterociclos tales como tetrahidrofuranos, piranos, pirrolidinas, y piperidinas XXXIX con buenos rendimientos mediante el empleo de hidroxilos o aminas como nucleófilos internos. En cuanto a la naturaleza del alcohol de partida se comprobó que estos ácidos son capaces de catalizar la reacción $\mathrm{S}_{\mathrm{N}}$ intramolecular de alcoholes bencílicos tanto secundarios como terciarios y alcoholes no bencílicos terciarios (Esquema 1.13). Más recientemente, Qu y col. llevaron a cabo esta misma reacción en ausencia de catalizador y empleando agua como disolvente. ${ }^{86}$

${ }^{85}$ H. Zheng, S. Ghanbari, S. Nakamura, D.-G. Hall, Angew. Chem. Int. Ed. 2012, 51, 6187-6190.

${ }^{86}$ F.-Z. Zhang, Y. Tian, G.-X. Li, J. Qu, J. Org. Chem. 2015, 80, 1107-1115. 
Por último, hay que reseñar que los ácidos de Brønsted también se han empleado en la $\mathrm{S}_{\mathrm{N}}$ directa de alcoholes. En este sentido, Lautens y col. describieron la síntesis de una serie de indenos 2-aril sustituídos a partir de los alcoholes alílicos XXX en presencia de un exceso de ácido fosfórico (Esquema 1.14) ${ }^{87}$ Esta reacción transcurre mediante una $\mathrm{S}_{\mathrm{N}}$ directa del areno al grupo hidroxilo, y permite aislar los indenos XXXI con rendimientos entre buenos y excelentes.<smiles>[Y17]/C(=C/[Al])C([R])O</smiles>

$\mathbf{x x X}$

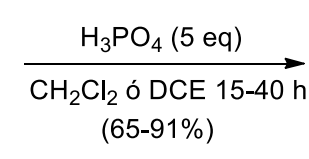

$\mathrm{R}^{1}=\mathrm{H}, \mathrm{Me} \quad \mathrm{Ar}^{1}=\mathrm{Ph}, 2,4-(\mathrm{Me})_{2} \mathrm{C}_{6} \mathrm{H}_{3}, 2,4-(\mathrm{MeO})_{2}\left(\mathrm{C}_{6} \mathrm{H}_{3}\right)$, 2-Tienilo, 5- $\mathrm{MeOC}_{6} \mathrm{H}_{4}, 3-\mathrm{MeOC}_{6} \mathrm{H}_{4}$ $\mathrm{Ar}^{2}=\mathrm{Ph}, 4-\mathrm{TBSOC}_{6} \mathrm{H}_{4}, 2-\mathrm{Tienilo}, 3,4-(\mathrm{MeO})_{2} \mathrm{C}_{6} \mathrm{H}_{3}, 4-\mathrm{ClC}_{6} \mathrm{H}_{4}, 2-\mathrm{MeC}_{6} \mathrm{H}_{4}, 3-\mathrm{NO}_{2} \mathrm{C}_{6} \mathrm{H}_{4}$

\section{Esquema 1.14}

\subsection{OBJETIVO}

Como ya se ha comentado en el apartado de Antecedentes Generales de esta memoria, el empleo de alcoholes como electrófilos en la reacción F.-C. presenta múltiples ventajas desde el punto de vista de la economía atómica. $\mathrm{Si}$, además, el catalizador empleado es una molécula sencilla de naturaleza orgánica la reacción es prácticamente ideal ya que únicamente genera agua como subproducto, no implicando el uso de metales en el proceso.

Por otra parte, los compuestos policíclicos que contienen indol en su estructura son de gran relevancia sintética debido a que dicho heterociclo se encuentra presente en un gran número de productos con actividad biológica. A la vista de los antecedentes cabe mencionar que, a pesar de que en la bibliografía existen varios ejemplos de ciclación intramolecular de alcoholes alílicos con arenos, únicamente existían dos ejemplos en los que se empleaba indol como nucleófilo (Ver Esquemas 1.11 y 1.12). Además, en uno de ellos se utiliza como catalizador un compuesto de mercurio (II), con las implicaciones medioambientales que trae como consecuencia el empleo de sales de este metal.

${ }^{87}$ J. Panteleev, R.-Y. Huang, E.-K. Lui, M. Lautens, Org. Lett. 2011, 13, 5314-5317. 
Por lo tanto, y como continuación al trabajo que se llevaba realizando en el grupo relativo al empleo de ácidos de Brønsted en la reacción de alquilación directa de indoles con alcoholes $\pi$-activados, nos propusimos como objetivo estudiar su versión intramolecular, con el aliciente añadido de poder acceder a estructuras policíclicas basadas en el esqueleto indólico (Esquema 1.15). Esta metodología podría ser muy versátil ya que, mediante el diseño apropiado de los sustratos de partida, se podría acceder a una amplia variedad de productos policíclicos con estructura de indol.

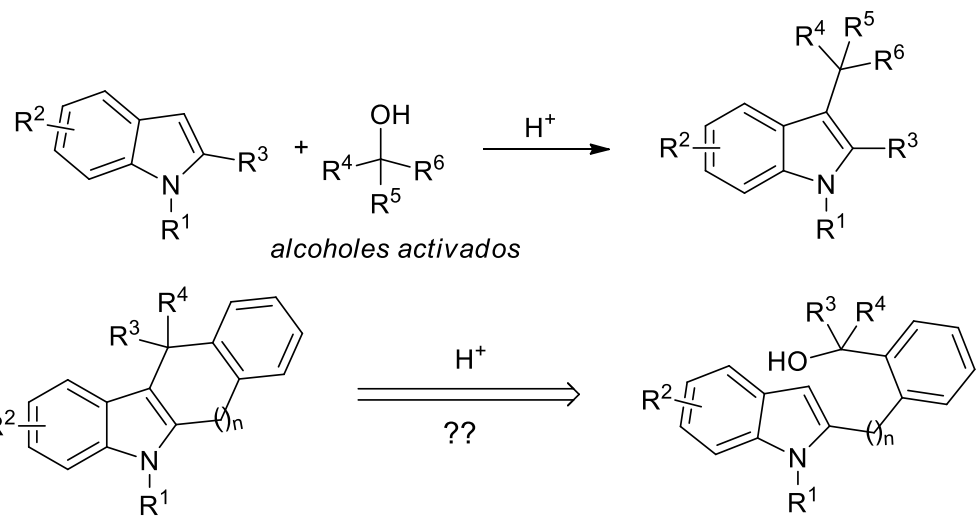

Esquema 1.15

\subsection{DISCUSIÓN DE RESULTADOS}

\subsubsection{Síntesis de los indoles hidroxifuncionalizados de partida}

Para comenzar el estudio en primer lugar, se llevó a cabo la síntesis de una familia de alcoholes $\pi$-activados que presentan un núcleo indólico en su estructura. En general la preparación de estos alcoholes implicó utilizar como producto de partida un derivado indólico que presenta un átomo de bromo en una posición adecuada sobre la cual se introduce posteriormente un grupo hidroxialquilo.

La obtención de los alcoholes 5 y 6 se llevó a cabo a partir de los bromoindoles 1, 2 y 4, obtenidos a su vez mediante la síntesis de indoles de Fisher, haciendo reaccionar la 2'-bromoacetofenona o el 2-acetil-3- 
bromotiofeno con fenilhidrazina en ácido polifosfórico (PPA) ${ }^{88}$ Posteriormente, el átomo de nitrógeno del indol fue metilado por tratamiento de $\mathbf{1}$ y $\mathbf{3}$ con MeI en medio básico ${ }^{89}$ (Esquema 1.16).

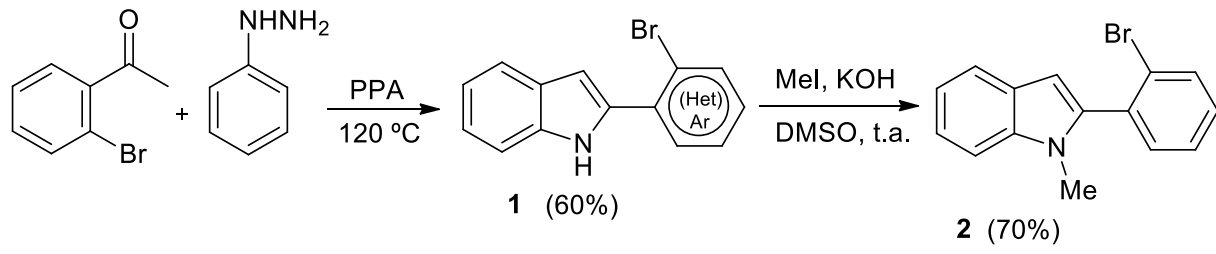

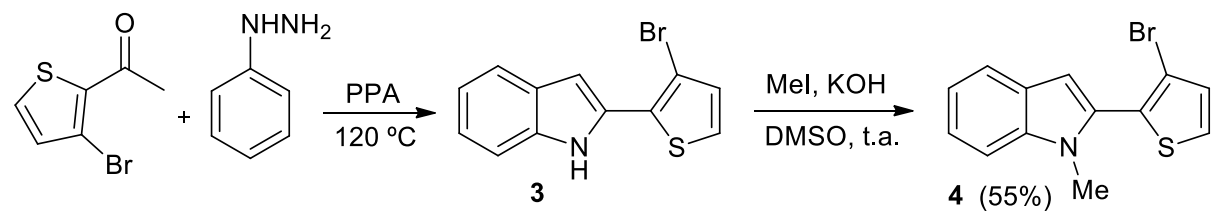

Esquema 1.16

La reacción de $\mathbf{1}, \mathbf{2}$ y $\mathbf{4}$ con $n$-BuLi, en THF y a baja temperatura, seguido de la adición de un compuesto carbonílico condujo a la formación de los alcoholes 5 y 6 con rendimientos moderados (Tabla 1.1). De esta manera se prepararon una serie de alcoholes bencílicos tanto secundarios como terciarios y con sustituyentes tanto electrón dadores como atractores en el arilo procedente del carbonilo (entradas 1-3, 9-14, 17 y 18). Se sintetizaron también alcoholes alílicos (entradas 6 y 15) y propargílicos internos (entradas 7 y 8), además de alcoholes secundarios (entrada 16) y terciarios (entradas 4 y 5) procedentes de aldehídos y cetonas alifáticas, respectivamente. Para el intercambio $\mathrm{Br}-\mathrm{Li}$ se empleó 1 equivalente de $n$-BuLi excepto en el caso del indol 1 para el que se requieren 2 equivalentes debido a la presencia del $N$ - $H$. En algunos casos (entradas 2-5, 8, 9, 11-13 y 17) no se llevó a cabo la purificación cromatográfica de los alcoholes y se emplearon directamente en el siguiente paso.

${ }^{88}$ C. M. So, C. P. Lau, F. Y. Kwong, Angew. Chem. Int. Ed. 2008, 47, 8059-8063.

${ }^{89}$ H. Heany, S. V. Ley, J. Chem. Soc., Perkin Trans. 1 1973, 499-500. 
Tabla 1.1 Síntesis de los alcoholes 5 y 6
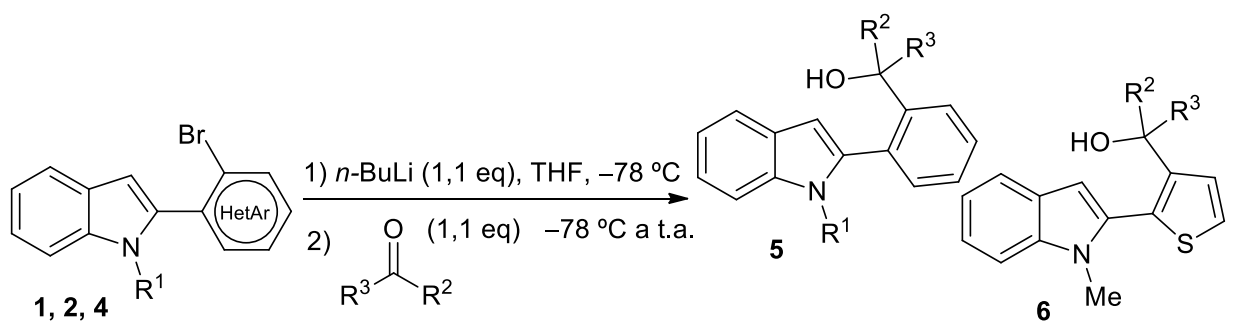

\begin{tabular}{|c|c|c|c|c|c|c|}
\hline Entrada & Indol & $\mathbf{R}^{1}$ & $\mathbf{R}^{2}$ & $\mathbf{R}^{3}$ & Producto & $\operatorname{Rto}(\%)^{\mathbf{a}}$ \\
\hline 1 & 2 & $\mathrm{Me}$ & $\mathrm{Me}$ & $\mathrm{Ph}$ & $5 \mathbf{a}$ & 64 \\
\hline 2 & 2 & $\mathrm{Me}$ & $c-\mathrm{C}_{3} \mathrm{H}_{5}$ & $\mathrm{Ph}$ & $5 \mathbf{b}$ & $-{ }^{\mathrm{b}}$ \\
\hline 3 & 2 & $\mathrm{Me}$ & Et & 2-Th & $5 c$ & $-{ }^{\mathrm{b}}$ \\
\hline 4 & 2 & $\mathrm{Me}$ & $\mathrm{Me}$ & $c-\mathrm{C}_{3} \mathrm{H}_{5}$ & $5 d$ & $-{ }^{\mathrm{b}}$ \\
\hline $5^{c}$ & 1 & $\mathrm{H}$ & $\mathrm{Me}$ & $c-\mathrm{C}_{3} \mathrm{H}_{5}$ & $5 e$ & $-{ }^{\mathrm{b}}$ \\
\hline 6 & 2 & $\mathrm{Me}$ & $\mathrm{Me}$ & $(E)-\mathrm{PhCH}=\mathrm{CH}-$ & $5 f^{c}$ & 62 \\
\hline 7 & 2 & $\mathrm{Me}$ & $\mathrm{Me}$ & $3-\mathrm{ThC} \equiv \mathrm{C}$ & $5 g$ & 59 \\
\hline 8 & 2 & $\mathrm{Me}$ & $c-\mathrm{C}_{3} \mathrm{H}_{5}$ & $\mathrm{PhC} \equiv \mathrm{C}$ & $5 h$ & $--^{\mathrm{b}}$ \\
\hline 9 & 2 & $\mathrm{Me}$ & 4- $\mathrm{MeOC}_{6} \mathrm{H}_{4}$ & $\mathrm{H}$ & $5 \mathbf{i}$ & $-{ }^{\mathrm{b}}$ \\
\hline $10^{\mathrm{c}}$ & 1 & $\mathrm{H}$ & $4-\mathrm{MeOC}_{6} \mathrm{H}_{4}$ & $\mathrm{H}$ & $5 \mathbf{j}$ & 49 \\
\hline 11 & 2 & $\mathrm{Me}$ & $4-\mathrm{ClC}_{6} \mathrm{H}_{4}$ & $\mathrm{H}$ & $5 \mathbf{k}$ & $-{ }^{b}$ \\
\hline $12^{\mathrm{c}}$ & 1 & $\mathrm{H}$ & $4-\mathrm{ClC}_{6} \mathrm{H}_{4}$ & $\mathrm{H}$ & 51 & $--^{\mathrm{b}}$ \\
\hline 13 & 2 & $\mathrm{Me}$ & 5-Me-2-Fur & $\mathrm{H}$ & $5 \mathrm{~m}$ & $-{ }^{\mathrm{b}}$ \\
\hline $14^{\mathrm{c}}$ & 1 & $\mathrm{H}$ & 2-Th & $\mathrm{H}$ & $5 n$ & 51 \\
\hline 15 & 2 & $\mathrm{Me}$ & $(E)-\mathrm{PhCH}=\mathrm{CH}-$ & $\mathrm{H}$ & 50 & 55 \\
\hline 16 & 2 & $\mathrm{Me}$ & $n$-Pr & $\mathrm{H}$ & $5 p$ & 45 \\
\hline 17 & 4 & $\mathrm{Me}$ & $c-\mathrm{C}_{3} \mathrm{H}_{5}$ & $\mathrm{Ph}$ & $6 \mathbf{a}$ & $-{ }^{\mathrm{b}}$ \\
\hline 18 & 4 & $\mathrm{Me}$ & 4- $\mathrm{MeC}_{6} \mathrm{H}_{4}$ & 4- $\mathrm{MeC}_{6} \mathrm{H}_{4}$ & $6 b$ & 50 \\
\hline
\end{tabular}

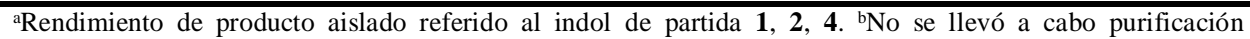
cromatográfica. ${ }^{\mathrm{C}}$ Reacción llevada a cabo empleando 2,1 eq de $n$-BuLi. 2-Th $=2$-Tienilo. 5-Me-2-Th $=5$ Metil-fur-2-ilo. 3-Th = 3-Tienilo.

Por otra parte la preparación de los alcoholes 8, que presentan dos restos indólicos en su estructura, fue llevada a cabo a partir del bisindol 7, preparado 
mediante una metodología desarrollada por Zhang y col. en $2010 .^{90}$ Estos autores, describieron la reacción de homoacoplamiento de indoles catalizada por un complejo de paladio (II), en presencia de $\mathrm{Cu}(\mathrm{OAc})_{2} \cdot \mathrm{H}_{2} \mathrm{O}$ que genera el bisindol 7 con excelente rendimiento. Su tratamiento con $t$-BuLi a $0^{\circ} \mathrm{C}$ durante $30 \mathrm{~min}$, y posterior adición del correspondiente compuesto carbonílico, condujo a la obtención de los alcoholes $\mathbf{8}$ con rendimientos moderados (Esquema 1.17).

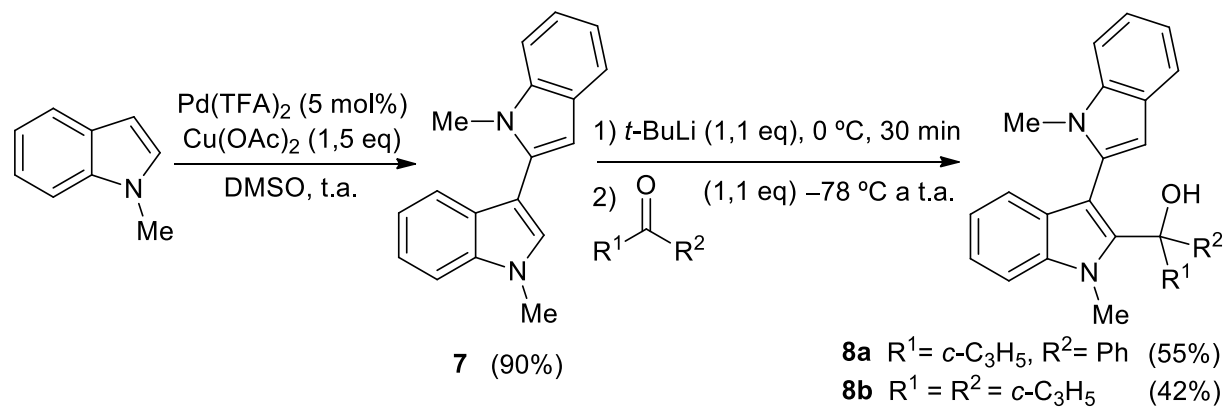

\section{Esquema 1.17}

Por último, decidimos también sintetizar los derivados indólicos 9, en los que la cadena lateral que soporta el átomo de bromo se encuentra sobre el átomo de nitrógeno, y 10, en los que dicha cadena lateral se encuentra sobre el C-2 del indol pero posee un eslabón más que los indoles 1 y 2 (Esquema 1.18). Para ello, en primer lugar, se llevó a cabo la reacción entre el indol o el 3metilindol y el bromuro de 2-bromobencilo en medio básico para dar lugar a 9a y 9b, respectivamente. El tratamiento de 9a a reflujo de PPA condujo a la obtención de 10a a través de un reagrupamiento del resto bencílico de la posición 1 a la 2 del anillo indólico. ${ }^{91}$ Finalmente, la reacción de metilación de 10a permitió preparar 10b con un 60\% de rendimiento (Esquema 1.18)

\footnotetext{
${ }^{90}$ Z. Liang, J. Zhao, Y. Zhang, J. Org. Chem. 2010, 75, 170-177.

${ }^{91}$ P. Wicdenan, S. Blechert, Synth. Commun. 1997, 27, 2033-2039.
} 


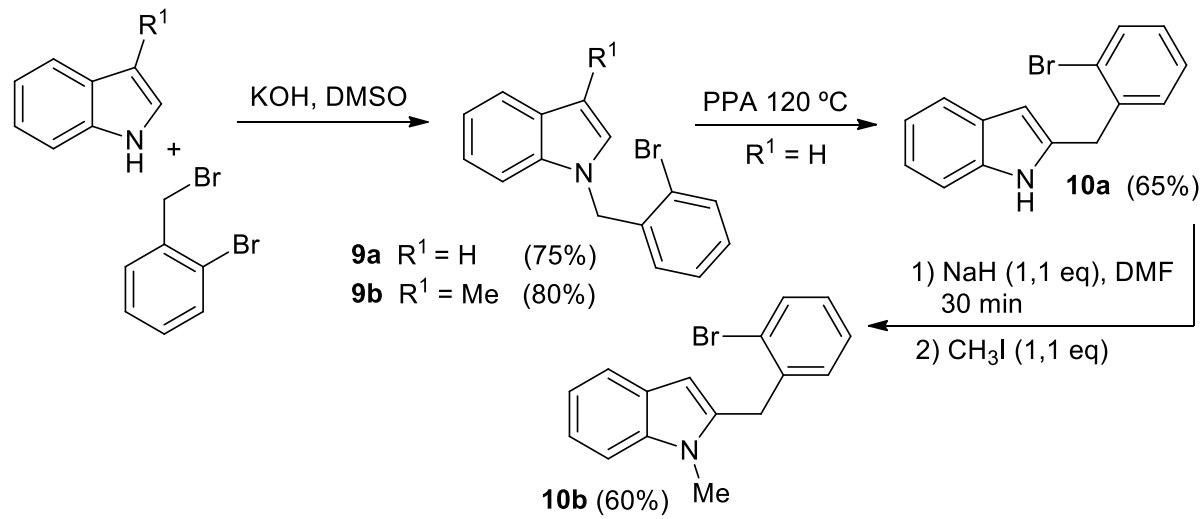

\section{Esquema 1.18}

Una vez sintetizados estos derivados indólicos con átomos de bromo en su estructura se procedió a la síntesis de una variedad de alcoholes secundarios y terciarios, 11 y 12, de manera análoga a los alcoholes 5 y 6 (Tablas 1.2 y 1.3), que fueron obtenidos con rendimientos entre moderados y buenos.

\section{Tabla 1.2 Síntesis de los alcoholes 11a-g}
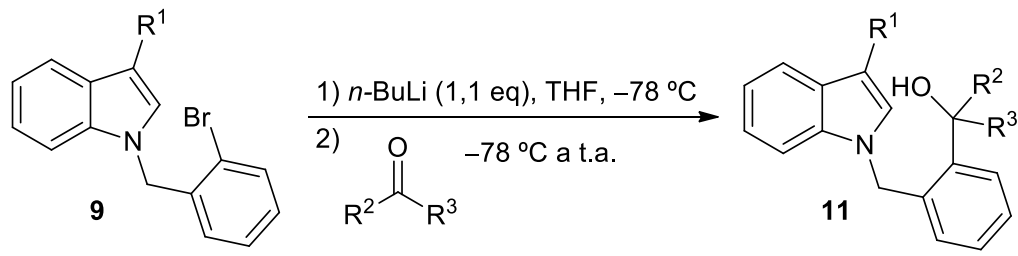

\begin{tabular}{ccccccc}
\hline Entrada & Indol & $\mathbf{R}^{\mathbf{1}}$ & $\mathbf{R}^{\mathbf{2}}$ & $\mathbf{R}^{\mathbf{3}}$ & $\mathbf{1 1}$ & Rto $(\boldsymbol{\%})^{\mathbf{a}}$ \\
\hline 1 & $\mathbf{9 a}$ & $\mathrm{H}$ & $c-\mathrm{C}_{3} \mathrm{H}_{5}$ & $\mathrm{Ph}$ & $\mathbf{1 1 a}$ & 71 \\
2 & $\mathbf{9 a}$ & $\mathrm{H}$ & $\mathrm{Me}$ & $\mathrm{Me}$ & $\mathbf{1 1 b}$ & 40 \\
3 & $\mathbf{9 a}$ & $\mathrm{H}$ & $\mathrm{H}$ & $4-\mathrm{MeOC}_{6} \mathrm{H}_{4}$ & $\mathbf{1 1 c}$ & 50 \\
4 & $\mathbf{9 b}$ & $\mathrm{Me}$ & $\mathrm{H}$ & $4-\mathrm{MeOC}_{6} \mathrm{H}_{4}$ & $\mathbf{1 1 d}$ & 49 \\
5 & $\mathbf{9 b}$ & $\mathrm{Me}$ & $\mathrm{H}$ & $i-\mathrm{Pr}_{1}$ & $\mathbf{1 1 e}$ & 51 \\
6 & $\mathbf{9 b}$ & $\mathrm{Me}$ & $\mathrm{Me}$ & $4-\mathrm{MeOC}_{6} \mathrm{H}_{4}$ & $\mathbf{1 1 f}$ & 73 \\
7 & $9 \mathbf{b}$ & $\mathrm{Me}$ & $4-\mathrm{MeC}_{6} \mathrm{H}_{4}$ & $4-\mathrm{MeC}_{6} \mathrm{H}_{4}$ & $\mathbf{1 1 g}$ & 67
\end{tabular}

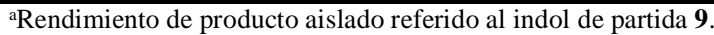




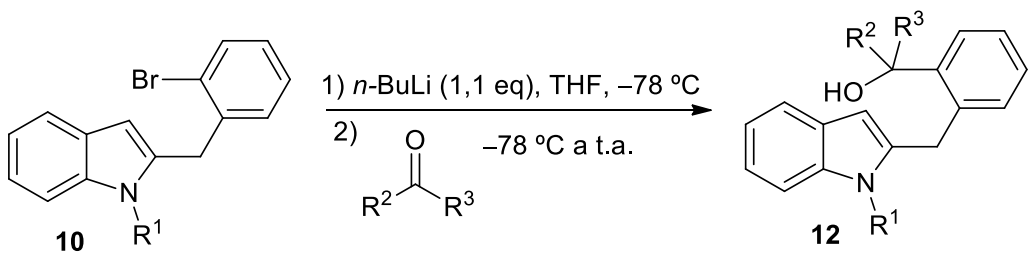

\begin{tabular}{ccccccc}
\hline Entrada & Indol & $\mathbf{R}^{\mathbf{1}}$ & $\mathbf{R}^{\mathbf{2}}$ & $\mathbf{R}^{\mathbf{3}}$ & $\mathbf{1 2}$ & Rto $(\boldsymbol{\%})^{\mathbf{a}}$ \\
\hline $1^{\mathrm{b}}$ & $\mathbf{1 0 a}$ & $\mathrm{H}$ & $4-\mathrm{MeC}_{6} \mathrm{H}_{4}$ & $4-\mathrm{MeC}_{6} \mathrm{H}_{4}$ & $\mathbf{1 2 a}$ & 52 \\
$2^{\mathrm{b}}$ & $\mathbf{1 0 a}$ & $\mathrm{H}$ & $\mathrm{H}$ & $4-\mathrm{MeOC}_{6} \mathrm{H}_{4}$ & $\mathbf{1 2 b}$ & 40 \\
3 & $\mathbf{1 0 b}$ & $\mathrm{Me}$ & $c-\mathrm{C}_{3} \mathrm{H}_{5}$ & $\mathrm{Me}$ & $\mathbf{1 2 c}$ & 62 \\
4 & $\mathbf{1 0 b}$ & $\mathrm{Me}$ & $c-\mathrm{C}_{3} \mathrm{H}_{5}$ & $\mathrm{Ph}$ & $\mathbf{1 2 d}$ & 48 \\
5 & $\mathbf{1 0 b}$ & $\mathrm{Me}$ & $\mathrm{Me}$ & $2-\mathrm{Th}$ & $\mathbf{1 2 e}$ & 60 \\
6 & $\mathbf{1 0 b}$ & $\mathrm{Me}$ & $\mathrm{H}$ & $4-\mathrm{MeOC} \mathrm{H}_{4}$ & $\mathbf{1 2 f}$ & 56 \\
7 & $\mathbf{1 0 b}$ & $\mathrm{Me}$ & $\mathrm{H}$ & $2-\mathrm{Th}$ & $\mathbf{1 2 g}$ & $-{ }^{\mathrm{c}}$ \\
8 & $\mathbf{1 0 b}$ & $\mathrm{Me}$ & $\mathrm{H}$ & $(E)-\mathrm{CH}=\mathrm{CH}-\mathrm{Ph}$ & $\mathbf{1 2 h}$ & 64
\end{tabular}

${ }^{\text {a} R e n d i m i e n t o ~ d e ~ p r o d u c t o ~ a i s l a d o ~ r e f e r i d o ~ a l ~ i n d o l ~ d e ~ p a r t i d a ~ 10 . ~}{ }^{b}$ Reacción llevada a cabo empleando 2,1 eq de $n$-BuLi. 'No se llevó a cabo purificación cromatográfica. 2-Th =2-Tienilo.

\subsubsection{Reacción de ciclación intramolecular de indoles con alcoholes catalizada por ácido de Brønsted}

\subsubsection{Síntesis de 5,10 dihidroindeno[1,2-b]indoles}

El esqueleto de indeno[1,2- $b$ ]indol presenta gran relevancia debido a sus propiedades biológicas y farmacológicas. ${ }^{92}$ Entre estos derivados, es de especial interés el 5,10-dihidroindeno[1,2-b]indol XXXII por ser un intermedio clave en la preparación del reactivo BARAC-Fluor. ${ }^{93}$ Los productos XXXIII y XXXIV, poseen una potente actividad anticancerígena ${ }^{94}$ (Esquema 1.19).

92 (a) S.-E. Lewis, Tetrahedron 2006, 62, 8655-8681. (b) T. Higuchi, T. Kawasaki, Nat. Prod. Rep. 2007, 24, 843-868. (c) P. Rongved, G. Kirsh, Z. Bouaziz, J. José, M. Le Borgne, Eur. J. Med. Chem. 2013, 69, 465-479.

${ }^{93}$ (a) J.-C. Jewett, E.-M. Sletten, C.-R. Bertozzi, J. Am. Chem. Soc. 2010, 132, 3688-3690. (b) J.C. Jewett, C.-R. Bertozzi, Org. Lett. 2011, 13, 5937-5939.

${ }^{94}$ M. Kashyap, S. Kandekar, A.-T. Baviskar, D. Das, R. Preet, P. Mohapatra, S.-R. Satapathy, S. Siddharth, S.-K. Guchhait, C.-N. Kundu, U.-C. Banerjee, Bioorg. Med. Chem. Lett. 2013, 23, 934-938. 


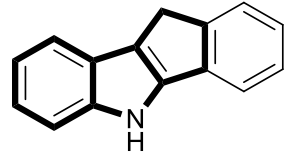

XXXII

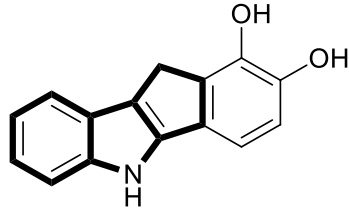

XXXIII

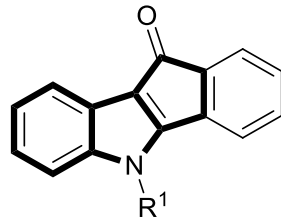

XXXIV

\section{Esquema 1.19}

Sin embargo, a pesar del interés que despiertan estas estructuras por sus posibles aplicaciones, no existen prácticamente metodologías generales que permitan acceder a 5,10-dihidroindeno[1,2-b]indoles con variedad de sustituyentes en la posición 10. En este contexto, recientemente ha sido descrito un proceso "one-pot" que permite acceder a 10-fenil-5,10-dihidroindeno[1,2$b$ ]indoles promovido por ácido tríflico (Esquema 1.20). ${ }^{95}$ El proceso global implica una reacción dominó F.-C. / acilación intramolecular de cinamatos de etilo hasta las correspondientes indanonas $\mathbf{X X X V}$, seguido de una reacción de indolización de Fisher. Esta metodología permitió aislar los dihidroindeno[1,2$b$ ]indoles XXXVI con centros tanto terciarios como cuaternarios en posición 10, si bien el modelo de sustitución en esta posición se encuentra limitado a un sustituyente arilo en el caso de los terciarios, o bien a un grupo Me y otro arilo en el caso de los cuaternarios (Esquema 1.20).

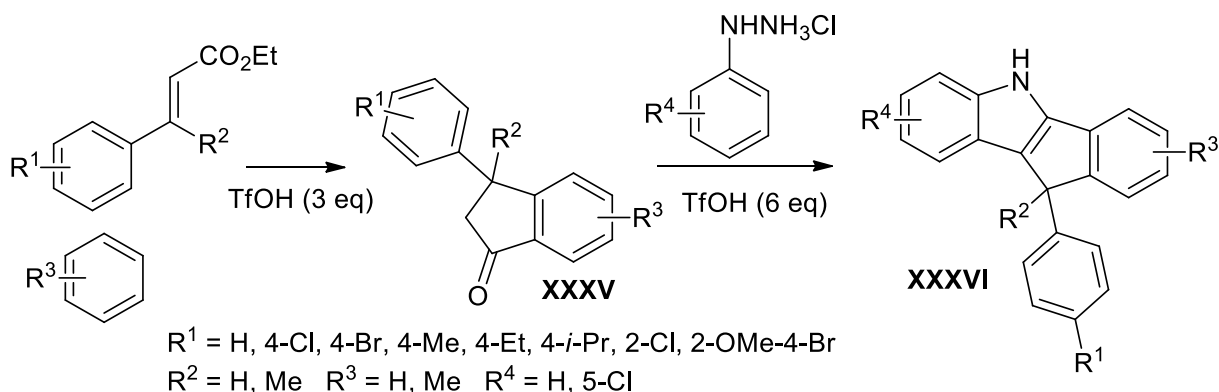

\section{Esquema 1.20}

Por otra parte, la ciclación intramolecular de 2-((2-fenil-1-tosil-1H-indol-3il)metilen)malonatos de dietilo XXXVII catalizada por triflato de escandio, condujo a la formación de los 10-malonato-5,10-dihidroindeno[1,2- $b$ ]indoles XXXVIII con muy buenos rendimientos. Una vez más, la sustitución sobre la

95 A.-G. Reddy, G. Satyanarayana, Synthesis 2015, 47, 1269-1279. 
posición 10 se encuentra limitada por el modelo de sustitución del producto de partida que implica obligatoriamente la presencia de un grupo malonato en el C10 del producto final (Esquema 1.21). ${ }^{96}$

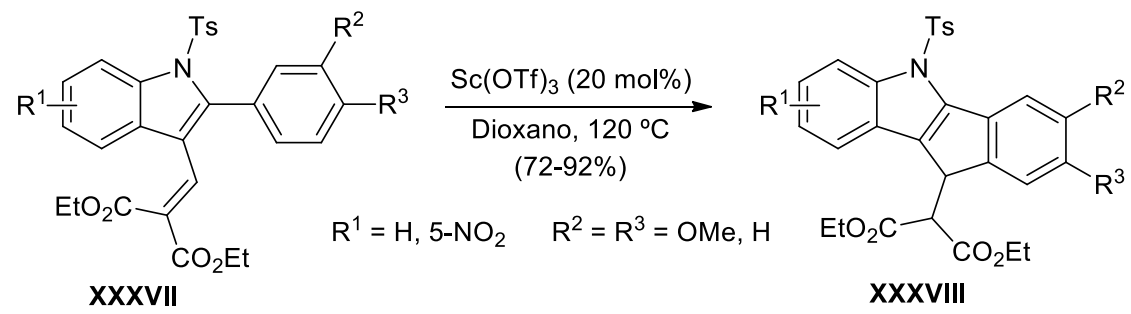

\section{Esquema 1.21}

Más recientemente ha sido descrita una ruta sintética para acceder a los ciclopenta $[b]$ indoles XL mediante una ciclación F.-C. en XXXIX catalizada por ácido tríflico (Esquema 1.22).$^{97} \mathrm{~A}$ su vez, XXXIX se obtuvo mediante una reacción de Michael oxidante entre aductos de Morita-Baylis-Hillman (MBH) e indoles en presencia de IBX. Posteriormente, la reducción del grupo carbonilo generado in-situ conduce al $\beta$-hidroxiéster XXXIX. El proceso global consta de tres pasos y permite obtener los ciclopenta[b]indoles con rendimientos de moderados a buenos, aunque el modelo de sustitución de estos productos se encuentra limitado. En la posición 1 y 2 del ciclopenta[b]indol únicamente pueda haber un grupo metileno y un carboxilato, respectivamente. Además, el sustituyente $\mathrm{R}^{1}$ sobre la posición 3 está limitado a restos arílicos capaces de estabilizar carbocationes, no habiéndose observado reacción cuando este resto es alquílico (Esquema 1.22).<smiles>[R]c1ccc2[nH]ccc2c1</smiles>

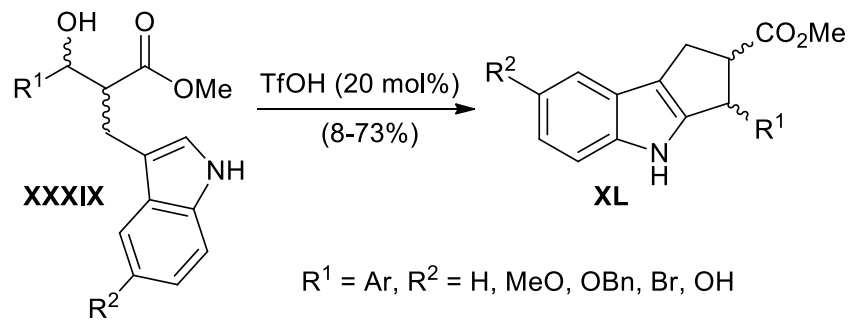

Esquema 1.22

\footnotetext{
${ }^{96}$ C. H Oh, H. S. Park, N. Park, S. Kim, L. Piao, Synlett. 2014, 25, 579-585.

${ }^{97}$ M. Santos, D. Fernández, M. Rodriguez, T. Regiani, A. Andricupolo, A. Lúcia, D. Vendramini, J. de Carvalho, M. Eberlin, F. Coehlo, J. Org.Chem. 2016, 81, 6626-6639.
} 
En este contexto, nosotros pensamos que la reacción de ciclación intramolecular de los alcoholes 5 podría ser una estrategia adecuada para acceder a indeno[1,2- $b$ ]indoles mono y di-sustituídos en posición 10. Para abordar el objetivo propuesto se llevó a cabo la reacción de los alcoholes 5 bajo las condiciones estándar encontradas por nuestro grupo para la $\mathrm{S}_{\mathrm{N}}$ directa de alcoholes $\pi$-activados: PTSA (5 mol\%), acetonitrilo como disolvente y temperatura ambiente. Además, teniendo en mente la importancia que supone en Síntesis Orgánica la construcción de centros cuaternarios con sustituyentes carbonados, en primer lugar, decidimos ensayar la reacción intramolecular de los sustratos 5a-h, para acceder a 5,10-dihidroindeno[1,2-b]indoles con un centro cuaternario en posición 10 (Tabla 1.4).

Tabla 1.4 Síntesis de los 5,10-dihidroindeno[1,2-b]indoles $13 a-\mathrm{h}^{\mathrm{a}}$

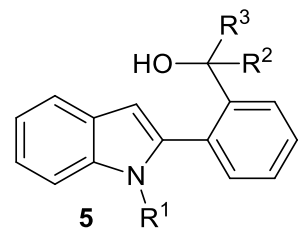

$5 \quad \mathrm{R}^{1}$

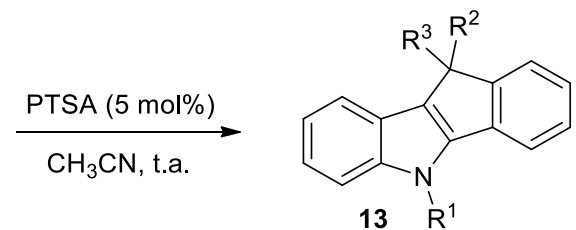

\begin{tabular}{ccccccc}
\hline Entrada & $\mathbf{5}$ & $\mathbf{R}^{\mathbf{1}}$ & $\mathbf{R}^{\mathbf{2}}$ & $\mathbf{R}^{\mathbf{3}}$ & $\mathbf{1 3}$ & $\mathbf{R t o}^{(\%)^{\mathbf{b}}}$ \\
\hline 1 & $\mathbf{5 a}$ & $\mathrm{Me}$ & $\mathrm{Me}$ & $\mathrm{Ph}$ & $\mathbf{1 3 a}$ & 90 \\
$2^{\mathrm{c}}$ & $\mathbf{5 b}$ & $\mathrm{Me}$ & $c-\mathrm{C}_{3} \mathrm{H}_{5}$ & $\mathrm{Ph}$ & $\mathbf{1 3 b}$ & 85 \\
$3^{\mathrm{c}}$ & $\mathbf{5 c}$ & $\mathrm{Me}$ & $\mathrm{Et}$ & $2-\mathrm{Th}$ & $\mathbf{1 3 c}$ & 80 \\
$4^{\mathrm{c}}$ & $\mathbf{5 d}$ & $\mathrm{Me}$ & $\mathrm{Me}$ & $c-\mathrm{C}_{3} \mathrm{H}_{5}$ & $\mathbf{1 3 d}$ & 63 \\
$5^{\mathrm{c}}$ & $\mathbf{5 e}$ & $\mathrm{H}$ & $\mathrm{Me}$ & $c-\mathrm{C}_{3} \mathrm{H}_{5}$ & $\mathbf{1 3 e}$ & 73 \\
6 & $\mathbf{5 f}$ & $\mathrm{Me}$ & $\mathrm{Me}$ & $(E)-\mathrm{PhCH}=\mathrm{CH}$ & $\mathbf{1 3 f}$ & 80 \\
7 & $\mathbf{5 g}$ & $\mathrm{Me}$ & $\mathrm{Me}$ & $3-\mathrm{ThC} \equiv \mathrm{C}$ & $\mathbf{1 3 g}$ & 80 \\
$8^{c}$ & $\mathbf{5 h}$ & $\mathrm{Me}$ & $c-\mathrm{C}_{3} \mathrm{H}_{5}$ & $\mathrm{PhC} \equiv \mathrm{C}$ & $\mathbf{1 3 h}$ & 88
\end{tabular}

${ }^{\mathrm{a} C}$ Condiciones de reacción: 5 (0,5 mmol), PTSA $(5 \mathrm{mg}), \mathrm{MeCN}(1 \mathrm{ml}) .{ }^{\mathrm{b}}$ Rendimiento de producto aislado referido al indol de partida. ${ }^{c}$ Llevada a cabo con el crudo de los alcoholes correspondientes. 2 -Th $=2$-Tienilo.

En general la reacción transcurrió de manera muy limpia para todos los alcoholes ensayados tanto alílicos, como bencílicos y propargílicos, además de para los alifáticos, en tiempos cortos y con la generación de agua como único subproducto, permitiendo aislar los 5,10-dihidroindeno[1,2-b]indoles 13a-h disustituídos en el C-10 con rendimientos entre buenos y excelentes (Tabla 1.4). Además, cabe resaltar que tal y como se muestra en las entradas 6-8, sobre la 
posición 10 se puede encontrar tanto un sustituyente alquenilo (entrada 6) como uno alquinilo (entradas 7 y 8), hecho que podría ser muy interesante de cara a posibles funcionalizaciones posteriores del indenoindol. El núcleo indólico empleado como nucleófilo para la reacción intramolecular puede presentar tanto un $\mathrm{N}$-metilo como un $\mathrm{N}$-H, dando buenos resultados en ambos casos. Cabe destacar que para ninguno de los alcoholes ensayados se observó la formación de productos procedentes de reacciones de eliminación.

Tabla 1.5 Síntesis de 5,10-dihidroindeno[1,2-b]indoles 13i-p ${ }^{\mathrm{a}}$
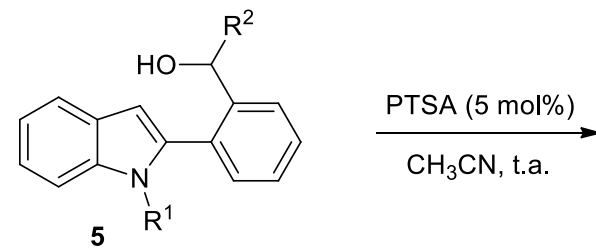

5

\begin{tabular}{cccccc}
\hline Entrada & $\mathbf{5}$ & $\mathbf{R}^{\mathbf{1}}$ & $\mathbf{R}^{\mathbf{2}}$ & $\mathbf{1 3}$ & $\left.\mathbf{R t o}^{(\%)}\right)^{\mathbf{b}}$ \\
\hline $1^{\mathrm{c}}$ & $\mathbf{5 i}$ & $\mathrm{Me}$ & $4-\mathrm{MeOC}_{6} \mathrm{H}_{4}$ & $\mathbf{1 3 i}$ & 97 \\
2 & $\mathbf{5 j}$ & $\mathrm{H}$ & $4-\mathrm{MeOC}_{6} \mathrm{H}_{4}$ & $\mathbf{1 3 j}$ & 80 \\
$3^{\mathrm{c}}$ & $\mathbf{5 k}$ & $\mathrm{Me}$ & $4-\mathrm{ClC}_{6} \mathrm{H}_{4}$ & $\mathbf{1 3 k}$ & 82 \\
$4^{\mathrm{c}}$ & $\mathbf{5 l}$ & $\mathrm{H}$ & $4-\mathrm{ClC}_{6} \mathrm{H}_{4}$ & $\mathbf{1 3 l}$ & 65 \\
$5^{\mathrm{c}}$ & $\mathbf{5 m}$ & $\mathrm{Me}$ & $2-\mathrm{Fur}$ & $\mathbf{1 3 m}$ & 55 \\
6 & $\mathbf{5 n}$ & $\mathrm{H}$ & $2-\mathrm{Th}$ & $\mathbf{1 3 n}$ & 80 \\
7 & $\mathbf{5 o}$ & $\mathrm{Me}$ & $(E)-\mathrm{PhCH}=\mathrm{CH}$ & $\mathbf{1 3 o}$ & 79 \\
$8^{\mathrm{c}, \mathrm{d}}$ & $\mathbf{5 p}$ & $\mathrm{Me}$ & $n-\mathrm{Pr}$ & $\mathbf{1 3 p}$ & 69 \\
\hline
\end{tabular}

${ }^{\mathrm{a} C}$ Condiciones de reacción: $5(0,5 \mathrm{mmol})$, PTSA $(5 \mathrm{mg}), \mathrm{MeCN}(1 \mathrm{ml})$. ${ }^{\mathrm{b}}$ Rendimiento de producto aislado referido al indol de partida. 'Llevada a cabo con el crudo de los alcoholes correspondientes. ${ }^{\mathrm{d}}$ Reacción realizada a $50{ }^{\circ} \mathrm{C}$ en DCE, en presencia de $\mathrm{FeCl}_{3}(15 \mathrm{~mol} \%)$ y $\mathrm{AgSbF}_{6}(45 \mathrm{~mol} \%)$. 2-Th $=2$-Tienilo. 3-Th $=3-$ Tienilo. 2-Fur $=2$-Furilo.

Alcoholes bencílicos secundarios (Tabla 1.5), menos activados que los terciarios para la reacción F.-.C intramolecular, también condujeron a buenos resultados cuando en el anillo aromático de la posición bencílica se encuentran tanto sustituyentes electrón-dadores (entradas 1 y 2), como electrón-atractores (entradas 3 y 4), o heteroaromáticos (entradas 5 y 6). De igual manera, también fue posible el empleo de sustratos alílicos (entrada 7), lo que permitió aislar el indenoindol 130 con un centro terciario que soporta un sustituyente alquenilo. Por el contrario, el sustrato 5p, alcohol secundario con un sustituyente alifático, 
únicamente condujo, bajo nuestras condiciones de reacción, a productos de descomposición. Sin embargo, mediante el empleo de las condiciones descritas recientemente por Cook y col. para la reacción de $\mathrm{S}_{\mathrm{N}}$ directa de alcoholes no activados, basadas en el empleo del sistema catalítico $\mathrm{FeCl}_{3} / \mathrm{AgSbF}_{6}{ }^{78}$ también fue posible aislar el indenoindol 13p con buen rendimiento (entrada 8).

Por otra parte, la sustitución del anillo de fenilo en posición 2 del indol de partida 5 por otro anillo heterocíclico, tal como tiofeno u otra molécula de indol, no tuvo efecto negativo sobre el transcurso de la reacción (Esquema 1.23). De esta manera, la reacción de los sustratos de partida 6 y 7, en presencia de PTSA, condujo a un resultado análogo a lo descrito para los sustratos anteriores. Esta reacción permitió la obtención de los dihidrociclopenta[1,2-b]indoles que presentan un anillo de tiofeno 14a,b o de indol 15a,b fusionado, y un centro cuaternario en posición 10. Además, cabe destacar que este tipo de compuestos no tenía precedentes en la bibliografía y han sido sintetizados por primera vez en esta memoria con rendimientos entre buenos y excelentes.
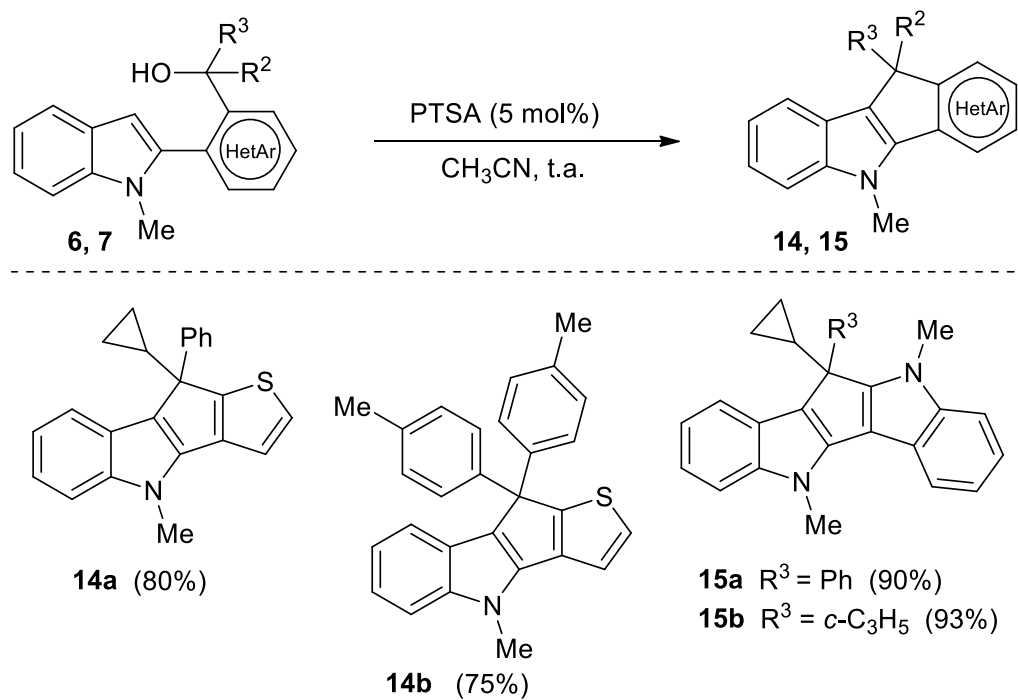

15a $\mathrm{R}^{3}=\mathrm{Ph}(90 \%)$

15b $\mathrm{R}^{3}=c-\mathrm{C}_{3} \mathrm{H}_{5}(93 \%)$

\section{Esquema 1.23}

\subsubsection{Síntesis de 6,11-dihidro-5H-benzo[b]carbazoles}

Los 6,11-dihidro-5H-benzo[ $b]$ carbazoles presentan interés como productos para acceder a benzo $[b]$ carbazoles, estructuras privilegiadas por su gran número de aplicaciones, y cuya síntesis se discutirá con más detalle en el Capítulo 3. A pesar de ello, las rutas para acceder a 6,11-dihidro-5H-benzo[b]carbazoles con diferentes modelos de sustitución en posición 11 son bastante escasas. 
Siendo conscientes de la versatilidad de esta nueva metodología para la construcción de sistemas policíclicos con indol condensados, y considerando el interés por desarrollar una nueva ruta para acceder a 6,11-dihidro-5Hbenzo[ $b]$ carbazoles, se diseñaron los sustratos de partida 12, en los que se ha alargado un eslabón la cadena lateral en la que se encuentra el grupo hidroxilo, y se estudiaron sus reacciones de alquilación intramolecular en presencia de PTSA como catalizador (Esquema 1.24). Bajo las condiciones de reacción ensayadas, los alcoholes 12 tanto terciarios (12a-d) como secundarios (12e-h) se comportaron de manera análoga a lo descrito en el apartado anterior conduciendo, en este caso, a la formación de los 6,11-dihidro-5Hbenzo[ $b]$ carbazoles 16 sustituídos en posición 11 por restos alquílicos (16a), arílicos (16b,d-f), heteroarílicos (16c,h), y alquenilo (16g) con muy buenos rendimientos. Cabe señalar que en el caso de los dihidrocarbazoles 16e-h, en los que la posición 11 es un centro terciario, no se observó en ningún caso su oxidación a los correspondientes benzo[b]carbazoles.

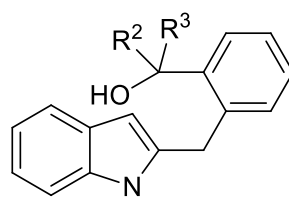

$12 R^{1}$

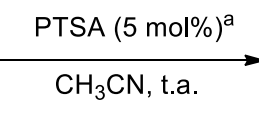

$\mathrm{CH}_{3} \mathrm{CN}$, t.a.

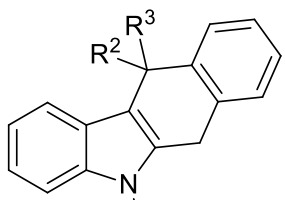

$16 \mathrm{R}^{1}$
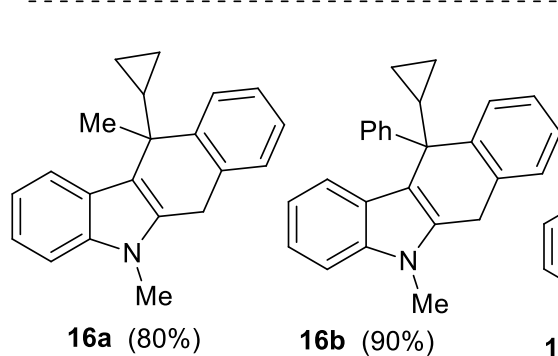

16b $(90 \%)$

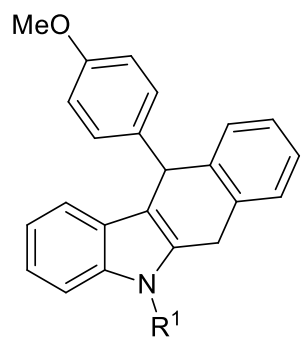

16e $R^{1}=M e \quad(84 \%)$

$16 f R^{1}=H \quad(98 \%)$

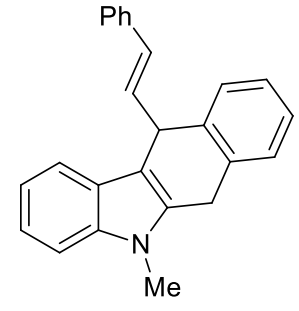

$16 \mathrm{~g}(85 \%)$

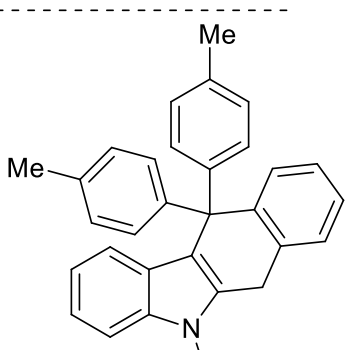

16d $(95 \%) \mathrm{Me}$

Esquema 1.24 


\subsubsection{Síntesis de 6,11-dihidroindolo[1,2-b]isoquinolinas}

Finalmente, nos planteamos la posibilidad de extender la ciclación intramolecular de indoles con alcoholes a la construcción de anillos de seis miembros basados en el esqueleto modelo de isoquinolina (Esquema 1.25). Esta estrategia implicaría que la reacción F.-C. intramolecular del indol con alcoholes como electrófilos tendría lugar por la posición 2 del mismo, menos nucleofílica que la posición 3.
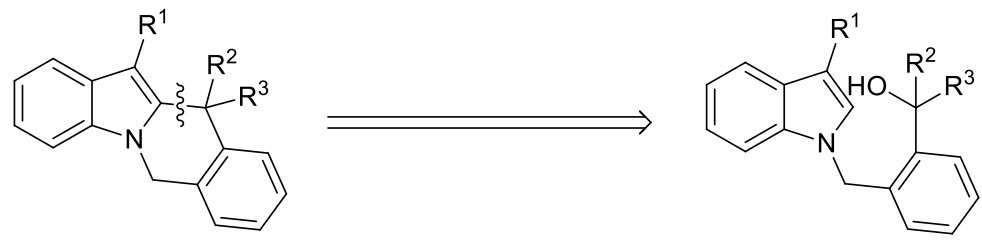

\section{Esquema 1.25}

Para abordar este último objetivo se eligió como sustrato modelo el alcohol 11a, que no posee sustituyente en el C-3 del indol. Su reacción en presencia de cantidades catalíticas de PTSA condujo a la formación de la 6,11dihidroindolo[1,2- $b$ ] isoquinolina 17a con un rendimiento moderado (Esquema 1.26). Posteriormente, estudiamos el alcance de la reacción para una serie de alcoholes 11b-g sintetizados anteriormente. En general, y como cabría esperar, la reacción transcurre de manera más lenta que para los sustratos previamente estudiados, probablemente debido a la menor nucleofilia del C-2 del indol, siendo los rendimientos consistentemente inferiores en estos casos. Aún así, ha sido posible sintetizar una variedad de dihidroindolo[1,2-b]isoquinolilnas 17a-g con centros tanto terciarios como cuaternarios en posición 11, aunque con rendimientos moderados. En el caso de emplear alcoholes secundarios con un resto alquílico (11c) o terciarios con dos restos alquílicos (11f) la ciclación se tuvo que realizar de nuevo con el sistema catalítico $\mathrm{FeCl}_{3} / \mathrm{AgSbF}_{6}$ (Esquema 1.26). 

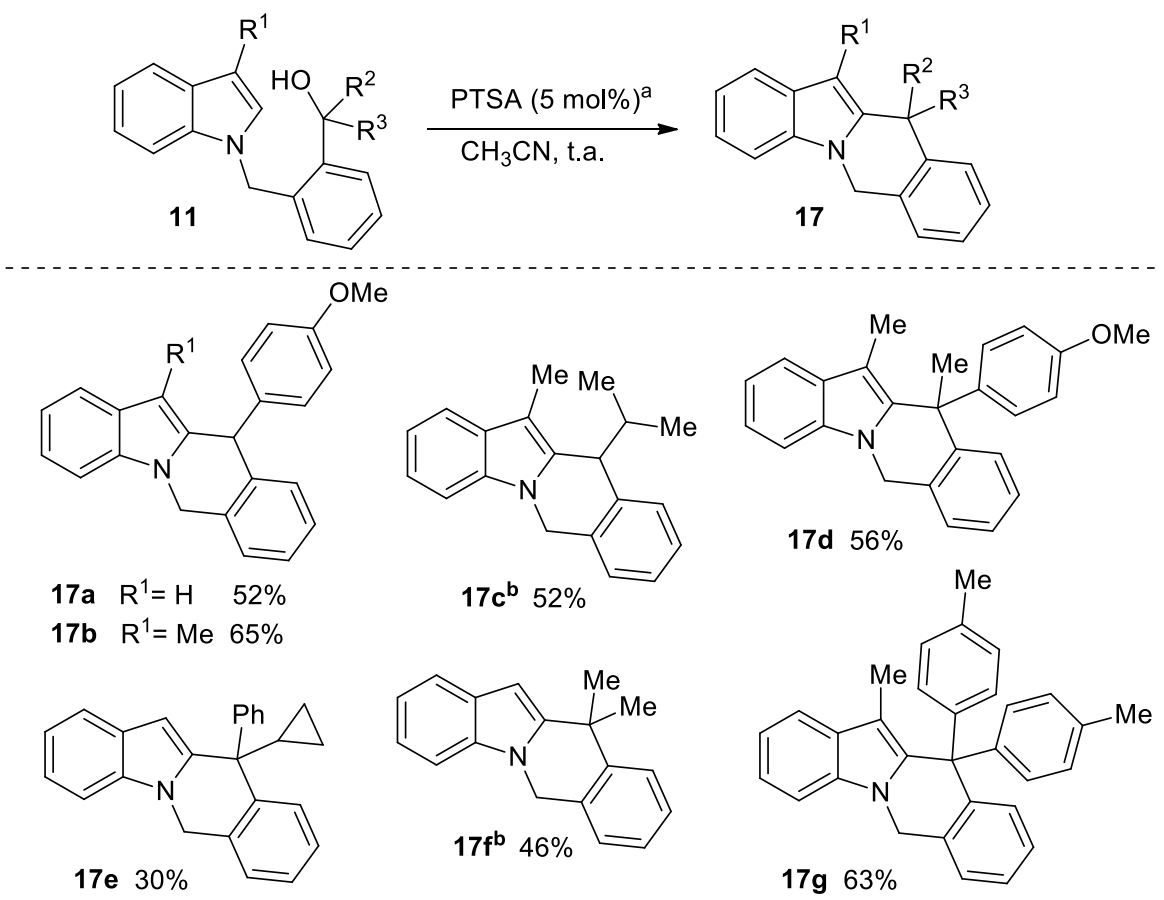

aCondiciones de reacción: $11(0,5 \mathrm{mmol})$, PTSA $(5 \mathrm{mg}), \mathrm{MeCN}(1 \mathrm{ml})$. Rendimiento de producto aislado referido al indol de partida. ${ }^{b}$ Reacción llevada a cabo a $50{ }^{\circ} \mathrm{C}$ en DCE, en presencia de $\mathrm{FeCl}_{3}(15 \mathrm{~mol} \%)$, $\mathrm{AgSbF}_{6}(45 \mathrm{~mol} \%)$.

\section{Esquema 1.26}

\subsection{CONCLUSIONES}

En este primer capítulo de la Tesis se ha estudiado la reacción de ciclación intramolecular de alcoholes con indoles en presencia de PTSA como catalizador. Esta metodología es una extensión de la versión intermolecular previamente estudiada por nuestro grupo, y ha permitido el acceso a valiosas estructuras policíclicas. La reacción de alcoholes e indoles, bajo las condiciones descritas, presenta importantes ventajas como la economía atómica y la generación de agua como único subproducto de reacción.

La metodología desarrollada es muy versátil ya que, mediante el diseño adecuado de los indoles de partida, ha sido posible acceder a una gran variedad de estructuras basadas en el esqueleto indólico tales como benzociclopenta[ $b]$ indoles, dihidro-5 $H$-benzo[ $b]$ carbazoles y dihidroindolo[ $[1,2-$ $b$ ]isoquinolinas, con buenos rendimientos y de una manera sencilla. Los productos así sintetizados presentan diferentes modelos de sustitución. Además, 
aquellos alcoholes menos activados, que no reaccionan bajo las condiciones descritas por el grupo, fueron ciclados con buenos resultados empleando el sistema catalítico $\mathrm{FeCl}_{3} / \mathrm{AgSbF}_{6}$, lo que permitió ampliar el rango de sustituyentes presentes en determinadas posiciones de los sistemas heterocíclicos preparados. 


\section{CAPÍTULO 2 Síntesis de $\alpha$-indolilcetonas funcionalizadas por sustitución nucleofílica de $\alpha$ - indolilaciloínas}

\subsection{ANTECEDENTES}

Las $\alpha$-indolilcetonas son sustratos de partida muy interesantes para la síntesis de moléculas con potencial actividad biológica entre las que cabe destacar el Hepaindol Q, el Fisherindol U, $\beta$-carbolinas, así como derivados de la serotonina y el triptofol (Esquema 2.1). ${ }^{98}$<smiles>C=C[C@]1(C)CC[C@@H](C(C)=O)[C@H](c2c[nH]c3ccccc23)[C@H]1C(C)C</smiles>

Hepaindol Q

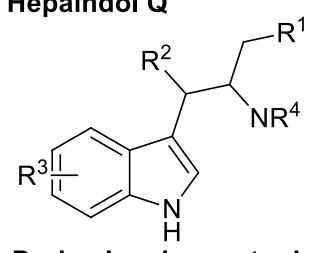<smiles>C=C[C@]1(C)CC[C@H]2[C@@H](c3c([nH]c4ccccc34)C2(C)C)[C@H]1C#N</smiles>

Fisherindol U<smiles>[R]Cc1nc([R4])c2[nH]c3c(c2c1[R])C=C[R1]C=C3</smiles>

$\beta$-Carbolinas

Derivados de serotonina<smiles>[R]CC(O)C([R])c1c[nH]c2c1C=C[R1]C=C2</smiles>

Derivados de triptofol

Esquema 2.1

Tradicionalmente, la síntesis de $\alpha$-indolilcetonas se ha llevado a cabo en varios pasos, como por ejemplo: apertura de epóxidos con cloruro de indolilmagnesio seguido de la oxidación del alcohol, ${ }^{99}$ por reacción de amidas de Weinreb con reactivos de Grignard, o mediante reacciones de condensación de cetonas con indoles protegidos, seguidas de un proceso de hidroxilación y oxidación.

98 (a) A.-J. Kochanowska, M.-T. Hamann, Chem. Rev. 2010, 110, 4489-4497. (b) H.-J. Knölker, K. Reddy, Chem. Rev. 2002, 102, 4303-4427. (c) E. Duval, D. Cuny, Tetrahedron Lett. 2004, 45, 5411-5413. (d) S. Garden, R. Da Silva, A. Pinto, Tetrahedron 2002, 58, 8399-8412. (e) P.S. Baran, J.-M, Richter, J. Am. Chem. Soc. 2005, 127, 15394-15396.

${ }^{99}$ A. Ghosh, W. Wang, J.-P. Freeman, J. Althaust, P.-F. Von Voigtlander, T. Scahill, S. Mizsak, J. Szmuszkovicz, Tetrahedron 1991, 47, 8653-8662. 
Metodologías más directas para la síntesis de $\alpha$-indolilcetonas implican la reacción directa de indoles con compuestos carbonílicos. En este contexto, en 2004 Baran y col. describieron la reacción de acoplamiento de indoles $\mathrm{NH}$ y enolatos generados in situ, en presencia de LHMDS como base y $\mathrm{Cu}$ (II) como agente oxidante (Esquema 2.2). ${ }^{100}$ Esta metodología fue aplicada a la síntesis de productos naturales como el Fisherindol o el Hepaindol Q entre otros.

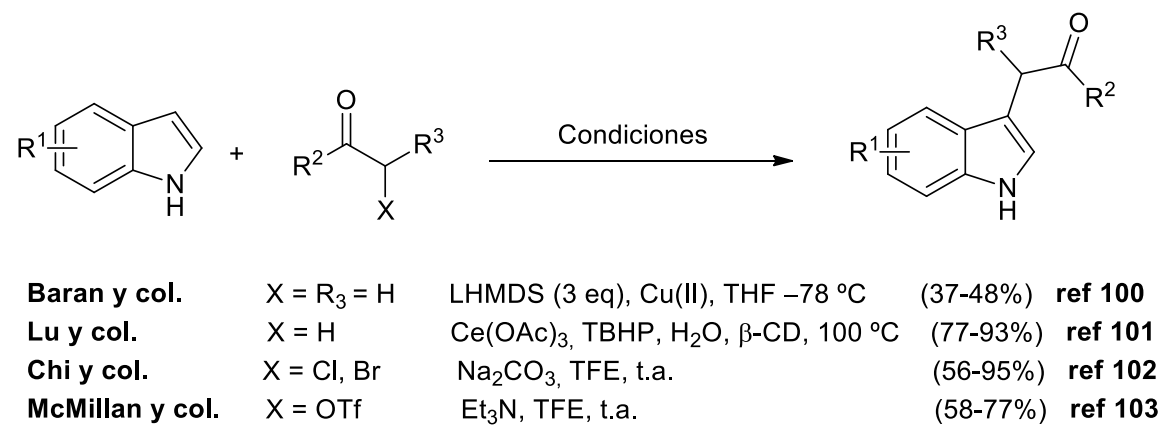

Esquema 2.2

Una metodología muy eficiente y benigna con el medio ambiente fue descrita posteriormente por $\mathrm{Hu}-\mathrm{Lu}$ y col. (Esquema 2.2). ${ }^{101}$ Estos autores llevaron a cabo el acoplamiento oxidante de indoles y cetonas en presencia de $\mathrm{Ce}(\mathrm{OAc})_{3}$ como catalizador e hidroperóxido de $t$-butilo como agente oxidante. La reacción se realiza en presencia de $\beta$-ciclodextrina como catalizador de transferencia de fase y da lugar a las $\alpha$-indolilcetonas con muy buenos rendimientos.

Por otra parte, los cationes oxialílicos, generados in situ a partir de $\alpha$ halocetonas en medio básico, pueden reaccionar con nucleófilos. Esta estrategia ha sido empleada por Chi y col. para acceder a $\alpha$-indolilcetonas partiendo de $\alpha$ halocetonas e indoles, y empleando $\mathrm{Na}_{2} \mathrm{CO}_{3}$ como base. ${ }^{102}$ La reacción está muy influenciada por el tipo de base empleada y, así, en presencia de $\mathrm{NaHCO}_{3}$ la reacción no tiene lugar mientras que el empleo de $\mathrm{NaOH}$ condujo a una mezcla de productos debido a la formación de aductos derivados del reagrupamiento de Favorskii. Sin embargo, el empleo de bases orgánicas como la $\mathrm{Et}_{3} \mathrm{~N}$ o la pirrolidina permitieron obtener la $\alpha$-indolilcetonas, aunque con menor rendimiento y tiempos más prolongados de reacción. Poco después McMillan y

\footnotetext{
100 P.-S. Baran, J.-M. Richter, J. Am. Chem. Soc. 2004, 126, 7450-7451.

101 Y. Hu, H. Jiang, M. Lu, Green Chem. 2011, 13, 3079-3087.

102 Q. Tang, X. Chen, B. Tiwari, Y.-R. Chi, Org. Lett. 2012, 14, 1922-1925.
} 
col. ${ }^{103}$ emplearon esta misma estrategia para la obtención de $\alpha$-indolilcetonas de manera enantioselectiva empleando un aminoalcohol como catalizador quiral. Cabe mencionar que las metodologías descritas en el Esquema 2.2 únicamente permiten acceder a indolilcetonas en las que en la posición $\alpha$ al grupo carbonilo se encuentran sustituyentes arílicos o alquílicos.

Por lo que respecta a la síntesis de indolilcetonas sin sustituyentes en posición $\alpha$, una estrategia descrita consiste en construir el anillo indólico mediante la ciclación intramolecular de 1-fenil-4-(fenilamino)but-2-in-1-onas I en presencia de triflato de escandio como catalizador. De esta manera fue posible acceder a una gran variedad de $\alpha$-indolilcetonas II sin sustituyentes en la posición $\alpha$ al carbonilo con buenos rendimientos (Esquema 2.3). ${ }^{104}$
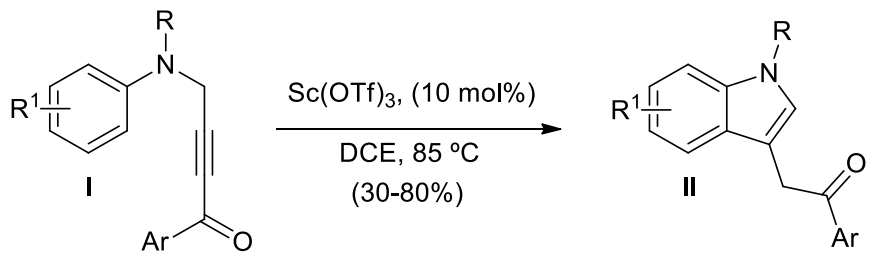

\section{Esquema 2.3}

Por otra parte, las $\alpha$-indolilsulfonas son reactivos de partida muy versátiles y ampliamente empleados en la funcionalización selectiva del C-3 del indol, ya que mediante su tratamiento en medio básico generan indoleniminas que pueden ser capturadas por una amplia variedad de nucleófilos. ${ }^{67 a, c}$ En este campo, You y col. describieron la síntesis de la $\alpha$-indolilcetona IV a través de la reacción de Stetter entre los arilsulfonilindoles III y aldehídos, en presencia de base y de una sal de tiazolio como catalizador. ${ }^{105}$ La reacción es un proceso umpolung y transcurriría por adición del intermedio de Breslow $\mathbf{B}$, generado in situ por adición del carbeno al aldehído, a la indolenimina intermedio A para dar lugar a los compuestos finales IV con buenos rendimientos. De igual manera que las metodologías descritas hasta el momento, las indolilcetonas que pueden prepararse con esta estrategia únicamente presentan sustituyentes arílicos o alquílicos en posición $\alpha$ al grupo carbonilo (Esquema 2.4).

${ }^{103}$ C. Liu, E.-Z. Oblak, M.-N. Van Der Wal, A. Dilger, D. Almstead, D. MacMillan, J. Am. Chem. Soc. 2016, 138, 2134-2137.

104 F. Yang, K.-G. Ji, S. Ali, Y. Liang, J. Org. Chem. 2011, 76, 8329-8355.

105 Y. Li, F. Shi, Q. He, S. You, Org. Lett. 2009, 11, 3182-3185. 


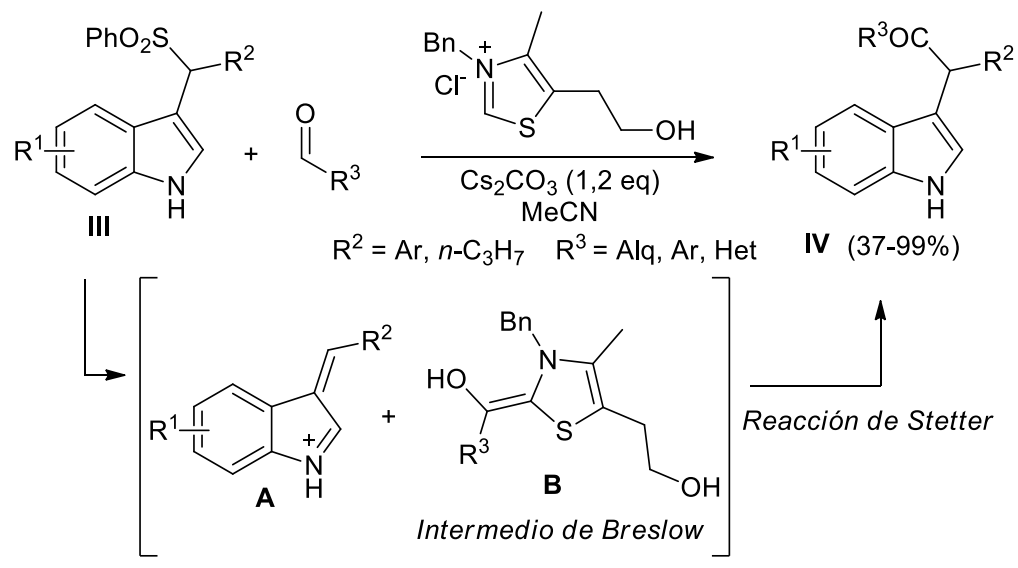

Esquema 2.4

Otra aproximación interesante que también emplea indolilsulfonas como productos de partida fue introducida posteriormente por Petrini y col. Estos autores hicieron reaccionar una serie de cetosulfonilindoles $\mathbf{V}$ con varios nucleófilos carbonados en presencia de cantidades estequiométricas de $\mathrm{AlEtCl}_{2}$ (Esquema 2.5). ${ }^{106}$ Por su parte, los sulfonilindoles de partida $\mathbf{V}$ se prepararon mediante una reacción multicomponente entre indoles, arilglioxales y ácido $p$ toluensulfínico en presencia de PTSA como catalizador. A diferencia de las metodologías comentadas hasta el momento, en este caso, la reacción consiste en una funcionalización de la posición $\alpha$ del esqueleto de $\alpha$-indolilcetona que ya se encuentra funcionalizada en el producto de partida. En principio, el modelo de sustitución que puede resultar en la posición $\alpha$ al grupo carbonilo es tan variado como nucleófilos son capaces de participar en la reacción. Sin embargo, este proceso únicamente resultó compatible con nucleófilos carbonados tales como aliltributilestannano, trimetilsililenol éteres y derivados de furano, lo que limita el rango de la funcionalización en posición $\alpha$ de la $\alpha$-indolilcetona VI (Esquema 2.5).

106 A. Palmieri, M. Petrini, Org. Biomol. Chem. 2012, 10, 3486-3493. 


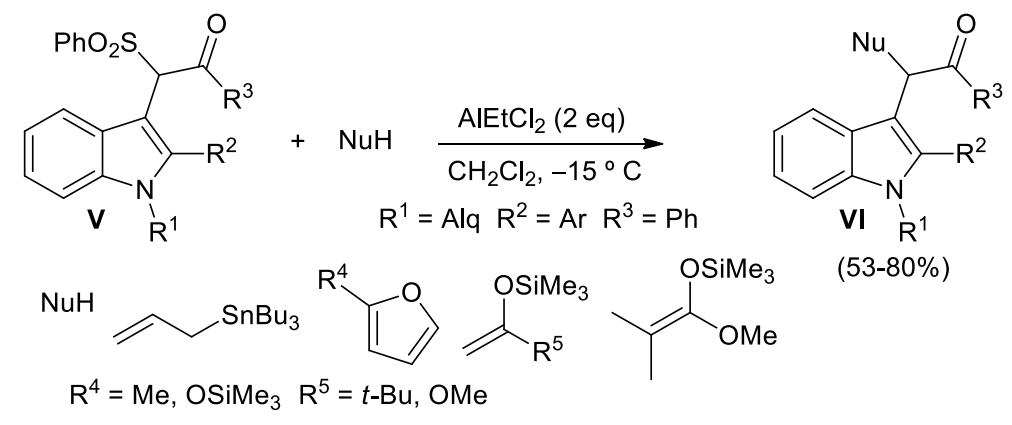

Esquema 2.5

Por otra parte, es conocido que los 1,2-dioles, en presencia de ácidos de Brønsted, son capaces de evolucionar hasta aldehídos o cetonas en una reacción denominada transposición pinacolínica. En este contexto, Antilla y col. accedieron de manera enantioselectiva a una gran variedad de $\alpha$-indolilcetonas VIII a partir de los 1,2-dioles indolil sustituídos VII en presencia de un ácido fosfórico quiral como catalizador. ${ }^{107} \mathrm{La}$ reacción transcurre de manera totalmente regioselectiva a través de un intermedio de tipo indoleniminio $\mathbf{C}$, generado tras la activación del alcohol por el catalizador. Finalmente, una migración 1,2 de uno de los sustituyentes $\mathrm{R}^{3}$ conduce a las indolilcetonas con excelentes rendimientos y excesos enantioméricos (Esquema 2.6).

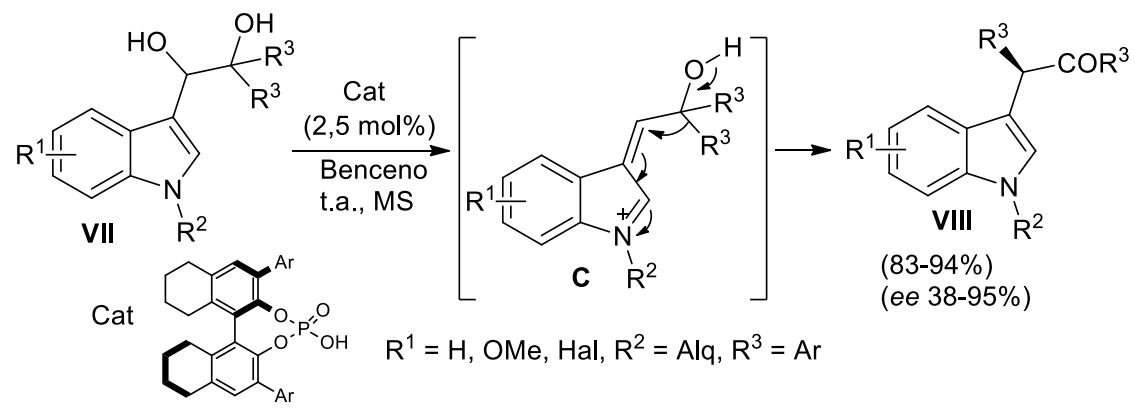

\section{Esquema 2.6}

Como ya se comentó en el apartado de Antecedentes Generales, la reacción F.-C. de indoles con alcoholes es una herramienta muy potente para la funcionalización selectiva de indoles en posición C-3. En este contexto, Zhou y col. han descrito la reacción de las aciloínas terciarias IX con indoles en

${ }^{107}$ T. Liang, Z. Zhang, J.-C. Antilla, Angew. Chem. Int. Ed. 2010, 49, 9734-9736. 
presencia de ácido perclórico como catalizador. ${ }^{108}$ Esta metodología permite acceder a una gran variedad de $\alpha$-indolilcetonas $\mathbf{X}$ con un centro cuaternario dió tri-aril sustituído en posición $\alpha$ al grupo carbonilo, con rendimientos entre moderados y buenos (Esquema 2.7).

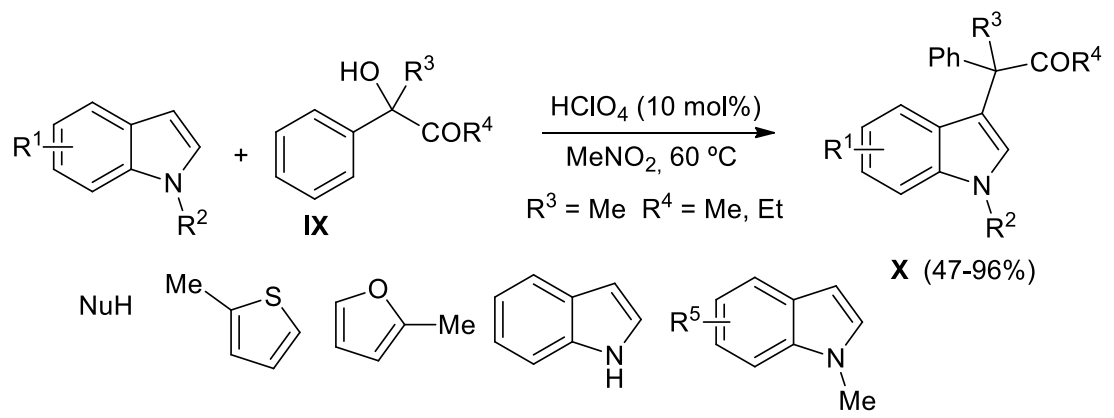

Esquema 2.7

Posteriormente, y durante el desarrollo de este trabajo de investigación, Liang, Gao y col. describieron que la reacción de las aciloínas secundarias XI con indoles, en presencia de bromo como catalizador, conducía a la obtención de las indolilcetonas XII con rendimientos entre moderados y buenos (Esquema 2.8). ${ }^{109}$ Según los autores, la reacción transcurriría a través de un proceso $S_{N} 1$ con la generación de un carbocatión bencílico secundario, favorecida por la formación de enlaces por puentes de hidrógeno entre el bromo y el grupo hidroxilo de la aciloína de partida. De nuevo, esta estrategia únicamente permite acceder a $\alpha$-indolilcetonas con sustituyentes arílicos en posición $\alpha$.<smiles></smiles><smiles>[R]C(=O)C([R])O</smiles>

XI

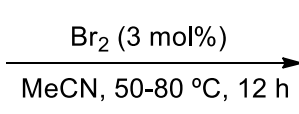

$(36-94 \%)$<smiles>[R]C([R])C([R])c1cn([R])c2c1=CC#[R1]=CC=2</smiles>

XII

$\mathrm{R}^{1}=\mathrm{H}$, Alq $\mathrm{R}^{3}=\mathrm{Ph}, \mathrm{Me}, 4-\mathrm{MeOC}_{6} \mathrm{H}_{4}, 4-\mathrm{MeC}_{6} \mathrm{H}_{4}, 4-\mathrm{ClC}_{6} \mathrm{H}_{4}, 4-\mathrm{BrC}_{6} \mathrm{H}_{4}, 2-\mathrm{C}_{6} \mathrm{H}_{4} 2-\mathrm{Fur}$ $\mathrm{R}^{4}=\mathrm{Ar}, \mathrm{Me}$

\section{Esquema 2.8}

${ }^{108}$ L. Chen, J. Zhou, Chem. Asian J. 2012, 7, 2510-2515.

${ }^{109}$ D. Liang, X. Li, Y. Li, Y. Yang, S. Gao, P. Cheng, RSC Adv. 2016, 6, 29020-29025. 


\subsection{OBJETIVO}

A la vista de estos antecedentes cabe mencionar que, a pesar de que en la literatura existe una variedad de rutas para la síntesis de $\alpha$-indolilcetonas, los modelos de sustitución en la posición $\alpha$ están limitados a grupos arilo, alquilo, alilo, y furilo.

Por lo tanto, y teniendo en cuenta la relevancia de las $\alpha$-indolilcetonas, el objetivo del presente proyecto se centró en el estudio de la reactividad de $\alpha$ indolilaciloínas frente a nucleófilos, como una nueva estrategia más versátil para acceder a indolilcetonas que presentan una mayor variedad de modelos de sustitución en posición $\alpha$, a los que no es posible acceder mediante las metodologías descritas hasta el momento (Esquema 2.9).

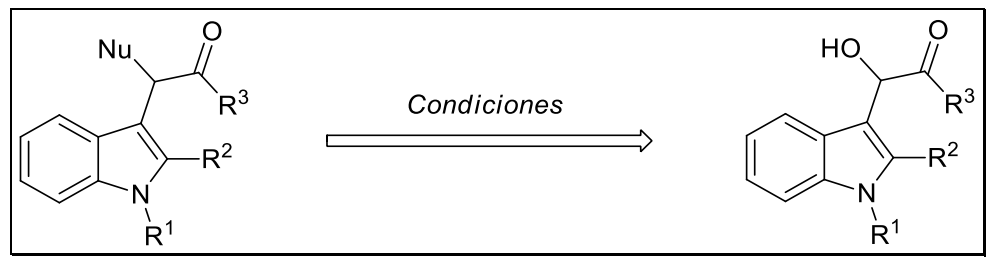

Esquema 2.9

\subsection{DISCUSIÓN DE RESULTADOS}

\subsubsection{Síntesis de las $\alpha$-indolilaciloínas 18}

En primer lugar, se llevó a cabo la síntesis de las aciloínas de partida $\mathbf{1 8}$ siguiendo un protocolo previamente descrito y que implica la reacción de indoles con arilglioxales (Tabla 2.1). ${ }^{37}$ Para ello, se hicieron reaccionar los correspondientes indoles 19a-d con los glioxales 20a-b, todos ellos comercialmente asequibles, en benceno como disolvente y en ausencia de catalizador. La temperatura de la reacción depende de la naturaleza del indol de partida empleado. Así, las aciloínas 18b-d se obtuvieron a temperatura ambiente, mientras que para la formación de $\mathbf{1 8 a}$ es necesario calentar a reflujo durante $2 \mathrm{~h}$. De esta manera se sintetizaron una serie de $\alpha$-indolilaciloínas 18a-d con rendimientos entre moderados y buenos que se aíslan por simple filtración no siendo necesaria posterior purificación cromatográfica. 
Tabla 2.1 Síntesis de las aciloínas 18

\begin{tabular}{|c|c|c|c|c|c|c|c|}
\hline & 19a-d & & 0 & & & $\mathrm{R}^{1}$ & \\
\hline Entrada & Indol & Glioxal & Aciloína & $\mathbf{R}^{1}$ & $\mathbf{R}^{2}$ & $\mathbf{R}^{3}$ & Rto $(\%)^{b}$ \\
\hline $1^{\mathrm{c}}$ & $19 a$ & $20 a$ & $18 a$ & $\overline{\mathrm{H}}$ & $\mathrm{H}$ & $\mathrm{Ph}$ & 70 \\
\hline 2 & 19b & $20 a$ & $18 b$ & $\mathrm{H}$ & $\mathrm{Me}$ & $\mathrm{Ph}$ & 85 \\
\hline 3 & $19 c$ & $20 a$ & $18 c$ & $\mathrm{Me}$ & $\mathrm{H}$ & $\mathrm{Ph}$ & 62 \\
\hline 4 & 19d & $20 a$ & 18d & $\mathrm{Me}$ & $\mathrm{Me}$ & $\mathrm{Ph}$ & 81 \\
\hline 5 & 19c & $20 \mathrm{~b}$ & $18 \mathrm{e}$ & $\mathrm{Me}$ & $\mathrm{H}$ & $\mathrm{Me}$ & 42 \\
\hline
\end{tabular}

a Condiciones de reacción: $19(10 \mathrm{mmol}), \mathbf{2 0}(10 \mathrm{mmol})$ en benceno $(20 \mathrm{ml})$. ${ }^{\mathrm{b}}$ Rendimiento de producto aislado referido al indol 19 de partida. ${ }^{c}$ Llevada a cabo a reflujo.

La aciloína 18e, descrita por primera vez en esta memoria, fue obtenida de manera análoga a las anteriores, pero empleando aldehído pirúvico en lugar de fenilglioxal. Hay que destacar que este 2-oxoaldehído está disponible comercialmente como una disolución acuosa al 40\%. Sin embargo, en este caso fue necesaria una purificación por cromatografía en columna para aislar el producto final, hecho que justifica un rendimiento más moderado.

\subsubsection{Reacción de $\mathrm{S}_{\mathrm{N}}$ directa de las aciloínas 18 catalizada por ácidos}

Una de las líneas de investigación en la que se ha centrado el trabajo del grupo en los últimos años ha sido el empleo de ácidos de Brønsted en la sustitución nucleofílica directa de alcoholes $\pi$-activados, con numerosas contribuciones en este campo. ${ }^{14}$ En este sentido, nosotros pensamos que las $\alpha$ indolilaciloínas podrían poseer una reactividad análoga a los 3-indolilmetanoles, descritos en los Antecedentes Generales. Estas especies en presencia de catalizadores ácidos reaccionan con nucleófilos a través de un intermedio iminio. Sin embargo, también hay que tener en cuenta que en este caso la formación del indoleniminio podría estar desfavorecida por la presencia del grupo carbonilo (Esquema 2.10). Teniendo en cuenta nuestra experiencia previa, consideramos el empleo de PTSA (5 mol\%) como catalizador, acetonitrilo como disolvente, y temperatura ambiente como condiciones iniciales para comenzar el estudio. Como ya se ha comentado en el Capítulo anterior, estas condiciones, en las que el agua es el único subproducto generado 
en la reacción, habían sido ya aplicadas anteriormente por el grupo en procesos de $S_{N}$ directa de alcoholes $\pi$-activados.

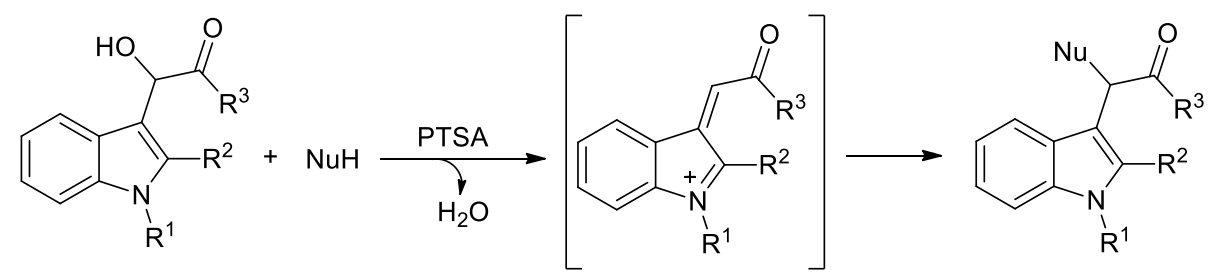

Esquema 2.10

\subsubsection{Reacción de $S_{N}$ directa de 18 con nucleófilos carbonados}

\subsection{Indoles como nucleófilos: Síntesis de 2,2-bis(indol-3-il)-1- ariletanonas asimétricas 21}

Los 3,3-BIMs son estructuras presentes en una gran variedad de productos naturales o sintéticos con potencial actividad biológica. ${ }^{21 \mathrm{~b}}$ En este contexto, las 2,2-bis(indol-3-il)-1-ariletanonas XIII han sido preparadas por reacción de arilmetilcetonas, ${ }^{110}$ o estirenos, ${ }^{111}$ con indoles bajo condiciones oxidantes que se resumen en el Esquema 2.11.

2<smiles>[R]n1ccc2ccccc21</smiles>

$$
X=O, R^{3}=M e
$$<smiles></smiles>

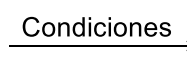$$
\mathrm{X}=\mathrm{CH}_{2}, \mathrm{R}^{3}=\mathrm{H}
$$

$$
\begin{aligned}
& \mathrm{I}_{2} \text {, DMSO, } 95^{\circ} \mathrm{C} \\
& \mathrm{SeO}_{2}, 1,4-\text { Dioxano, } 80^{\circ} \mathrm{C}
\end{aligned}
$$$$
\text { IBX, I } I_{2} \text { DMSO }
$$

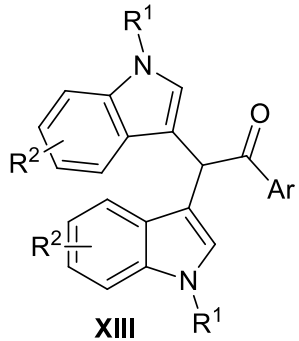

$(58-75 \%)$ ref 111

\section{Esquema 2.11}

En este campo, y de forma paralela a este trabajo, nuestro grupo ha puesto a punto una nueva ruta para acceder a las 2,2-bis(indol-3-il)-1-etanonas XIV, que implica la reacción de indoles y 2-oxoaldehídos catalizada por PTSA (Esquema

110 (a) Y. Zhu, M. Lku, F. Jia, J. Yuan, Q. Gao, M. Lian, A. Wu, Org. Lett. 2012, 14, 3392-3395.

(b) P. Naidu, S. Majumder, P. Bhuyan, Mol. Divers. 2015, 19, 685-693.

${ }^{111}$ F. Jia, Y. Zhu, M. Liu, M. Lian, Q. Gao, Q. Cai, A. Wu, Tetrahedron 2013, 69, 7038-7044. 
12). ${ }^{112}$ Además de la simplicidad procedimental y de los excelentes rendimientos que proporciona esta reacción, hay que destacar que $\mathrm{R}^{3}$ puede ser tanto arilo como alquilo, siendo ésta la primera estrategia que permite preparar 2,2-bis(indol-3-il)-1-alquiletanonas $\left(\mathrm{R}^{3}=\right.$ alquilo).

2<smiles>[R]c1cc2ccccc2n1[R]</smiles>

$\mathrm{R}^{1}=\mathrm{H}, \mathrm{Me} \quad \mathrm{R}^{2}=\mathrm{H}, \mathrm{Me}$<smiles>[R]C(=O)C=O</smiles>

$\mathrm{R}^{3}=\mathrm{Alq}, \mathrm{Ar}$

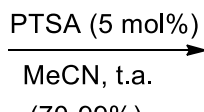

$(70-99 \%)$

\section{Esquema 2.12}

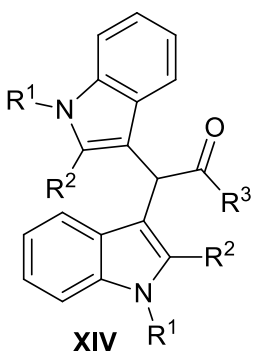

XIV $\mathrm{R}^{1}$

Sin embargo, ninguna de los procedimientos comentados permite acceder a sustratos asimétricos, con dos restos indólicos diferentes. Teniendo en cuenta el elevado carácter nucleofílico que poseen los indoles, nos propusimos como primer objetivo evaluar su comportamiento como nucleófilos en la reacción de $\mathrm{S}_{\mathrm{N}}$ directa de las aciloínas 18 en presencia de PTSA como catalizador.

Para abordar el objetivo planteado, se eligió la aciloína 18a como sustrato modelo y se le hizo reaccionar con el $N$-metilindol 19c en presencia de PTSA. Estas condiciones permitieron aislar el bisindolilmetano 21ac por simple filtración y con excelente rendimiento (Tabla 2.2 entrada 1). Animados por este resultado, se decidió estudiar el alcance de la reacción para las aciloínas anteriormente preparadas 18 e indoles 19 (Tabla 2.2). Así, bajo las condiciones de reacción ensayadas, las aciloínas 18a-e reaccionaron con una variedad de indoles 19 dando lugar a los correspondientes productos 21 con rendimientos entre buenos y excelentes, en condiciones de reacción suaves, tiempos cortos, y con la formación de agua como único subproducto.

Respecto del nucleófilo empleado, la reacción es compatible con indoles con el átomo de nitrógeno tanto libre como protegido, indoles 2-sustituídos (entrada 2, 6, 7, 9 y 10) e incluso indoles con sustituyentes electrón-atractores en posición 5 (entradas 4, 5, 8 y 11). Cabe destacar que los productos 21 se aíslan del medio de reacción por simple filtración no siendo necesario su

112 (a) F. Martínez, Trabajo Fin de Máster, Universidad de Burgos, 2016. (b) A. Suárez, F. Martínez, S. Suárez-Pantiga, R. Sanz, ChemSelect. 2017, 2, 787-790. 
posterior purificación por cromatografía de columna, lo que supone una gran ventaja desde el punto de vista experimental.

Tabla 2.2 Síntesis de los bisindoles asimétricos $21^{\mathrm{a}}$
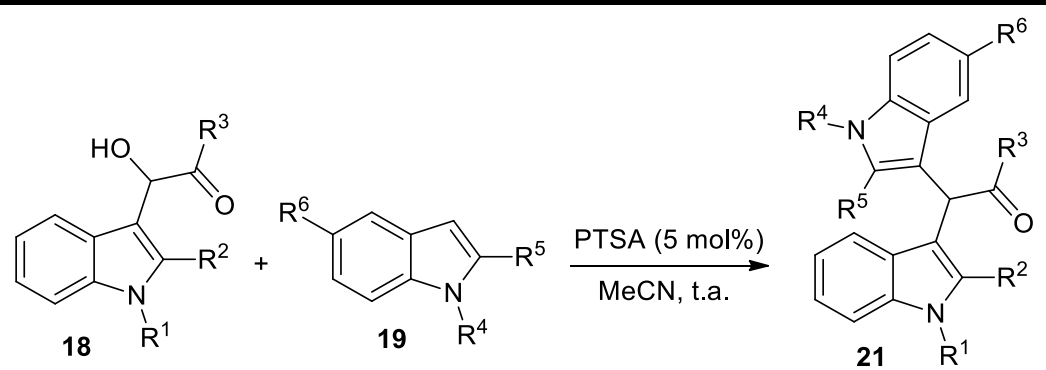

\begin{tabular}{ccccccccccc}
\hline Entrada & $\mathbf{1 8}$ & $\mathbf{R}^{\mathbf{1}}$ & $\mathbf{R}^{\mathbf{2}}$ & $\mathbf{R}^{\mathbf{3}}$ & $\mathbf{1 9}$ & $\mathbf{R}^{\mathbf{4}}$ & $\mathbf{R}^{\mathbf{5}}$ & $\mathbf{R}^{\mathbf{6}}$ & Producto Rto (\%) \\
\hline 1 & $\mathbf{1 8 a}$ & $\mathrm{H}$ & $\mathrm{H}$ & $\mathrm{Ph}$ & $\mathbf{1 9 c}$ & $\mathrm{Me}$ & $\mathrm{H}$ & $\mathrm{H}$ & $\mathbf{2 1 a c}$ & 92 \\
2 & $\mathbf{1 8 a}$ & $\mathrm{H}$ & $\mathrm{H}$ & $\mathrm{Ph}$ & $\mathbf{1 9 d}$ & $\mathrm{Me}$ & $\mathrm{Me}$ & $\mathrm{H}$ & $\mathbf{2 1 a d}$ & 86 \\
3 & $\mathbf{1 8 b}$ & $\mathrm{H}$ & $\mathrm{Me}$ & $\mathrm{Ph}$ & $\mathbf{1 9 a}$ & $\mathrm{H}$ & $\mathrm{H}$ & $\mathrm{H}$ & $\mathbf{2 1 b a}$ & 99 \\
4 & $\mathbf{1 8 b}$ & $\mathrm{H}$ & $\mathrm{Me}$ & $\mathrm{Ph}$ & $\mathbf{1 9 e}$ & $\mathrm{H}$ & $\mathrm{H}$ & $\mathrm{Br}$ & $\mathbf{2 1 b e}$ & 93 \\
5 & $\mathbf{1 8 b}$ & $\mathrm{H}$ & $\mathrm{Me}$ & $\mathrm{Ph}$ & $\mathbf{1 9 f}$ & $\mathrm{H}$ & $\mathrm{H}$ & $\mathrm{NO}_{2}$ & $\mathbf{2 1 b f}$ & 91 \\
6 & $\mathbf{1 8 c}$ & $\mathrm{Me}$ & $\mathrm{H}$ & $\mathrm{Ph}$ & $\mathbf{1 9 b}$ & $\mathrm{H}$ & $\mathrm{Me}$ & $\mathrm{H}$ & $\mathbf{2 1 c b}$ & 90 \\
7 & $\mathbf{1 8 c}$ & $\mathrm{Me}$ & $\mathrm{H}$ & $\mathrm{Ph}$ & $\mathbf{1 9 d}$ & $\mathrm{Me}$ & $\mathrm{Me}$ & $\mathrm{H}$ & $\mathbf{2 1 c d}$ & 98 \\
8 & $\mathbf{1 8 c}$ & $\mathrm{Me}$ & $\mathrm{H}$ & $\mathrm{Ph}$ & $\mathbf{1 9 f}$ & $\mathrm{H}$ & $\mathrm{H}$ & $\mathrm{NO}$ & $\mathbf{2 1 c f}$ & 90 \\
9 & $\mathbf{1 8 c}$ & $\mathrm{Me}$ & $\mathrm{H}$ & $\mathrm{Ph}$ & $\mathbf{1 9 g}$ & $\mathrm{H}$ & $\mathrm{Ph}$ & $\mathrm{H}$ & $\mathbf{2 1 c g}$ & 95 \\
10 & $\mathbf{1 8 d}$ & $\mathrm{Me}$ & $\mathrm{Me}$ & $\mathrm{Ph}$ & $\mathbf{1 9 b}$ & $\mathrm{H}$ & $\mathrm{Me}$ & $\mathrm{H}$ & $\mathbf{2 1 d b}$ & 89 \\
11 & $\mathbf{1 8 d}$ & $\mathrm{Me}$ & $\mathrm{Me}$ & $\mathrm{Ph}$ & $\mathbf{1 9 e}$ & $\mathrm{H}$ & $\mathrm{H}$ & $\mathrm{Br}$ & $\mathbf{2 1 d e}$ & 85 \\
12 & $\mathbf{1 8 e}$ & $\mathrm{Me}$ & $\mathrm{H}$ & $\mathrm{Me}$ & $\mathbf{1 9 a}$ & $\mathrm{H}$ & $\mathrm{H}$ & $\mathrm{H}$ & $\mathbf{2 1 e a}$ & 70 \\
\hline
\end{tabular}

aCondiciones de reacción: 18 (1 mmol), 19 (1mmol), PTSA $(9,5 \mathrm{mg}, 0,05 \mathrm{mmol})$, en $\mathrm{CH}_{3} \mathrm{CN}(2 \mathrm{ml})$. bRendimiento de producto aislado referido a la aciloína de partida $\mathbf{1 8 .}$

Además, de cara a la utilización de esta reacción para la preparación de estos productos como sustratos de partida para posteriores transformaciones, nos pareció interesante estudiar su eficacia en procesos a mayor escala. Con este fin se ensayó una reacción multigramo en la que se empleó la aciloína 18a $(1,26$ g, $5 \mathrm{mmol})$, 1,2-dimetilindol 19d (0,73 g, $5 \mathrm{mmol})$ y PTSA (48 mg, 0,25 mmol), dando como resultado el bisindolilmetano 21ad que se aisló con muy buen rendimiento $(1,61 \mathrm{~g}, 85 \%)$. 


\subsection{Otros heteroarenos como nucleófilos}

Una vez puesta a punto la metodología para acceder a los bisindoles $\mathbf{2 1}$, nos propusimos evaluar otros heterociclos $\pi$-excedentes tales como furanos, pirroles y tiofenos, como potenciales nucleófilos en la reacción de $S_{\mathrm{N}}$ de las aciloínas $\mathbf{1 8}$ en presencia de un ácido de Brønsted.

Para abordar este segundo objetivo, en primer lugar, se llevó a cabo la reacción entre la aciloína modelo 18a y el 2-metilfurano 22a en presencia de cantidades catalíticas de PTSA, lo que condujo al producto 23a con buen rendimiento (Tabla 2.3, entrada 1). Cuando se hicieron reaccionar las aciloínas 18b-d con este mismo nucleófilo, y bajo las mismas condiciones de reacción ensayadas hasta el momento, se obtuvieron las $\alpha$-indolilcetonas- $\alpha$-furil funcionalizadas $\mathbf{2 3 b - d}$ con buenos rendimientos tras tiempos cortos de reacción (Tabla 2.3, entradas 2-4). Sin embargo, a diferencia de lo que ocurría con los bisindoles 21, en estos casos los compuestos $\mathbf{2 3}$ no precipitan en el medio de reacción, por lo que su purificación se lleva a cabo por cromatografía en columna, lo que justifica que los rendimientos sean algo más bajos que en el caso de los bisindoles 21.

Tabla 2.3 Reacción de las aciloínas 18 con los compuestos heteroaromáticos $22^{\mathrm{a}}$

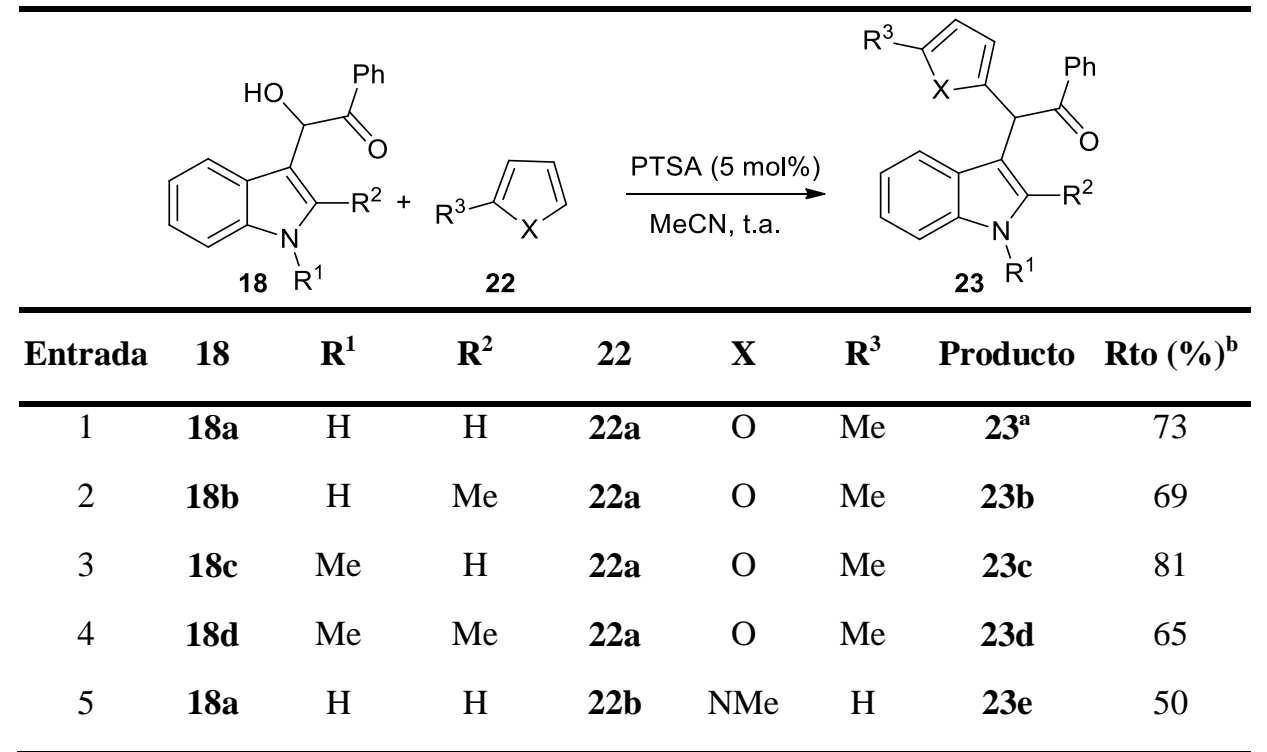

aCondiciones de reacción: 18 (1 mmol), heteroareno $22(1 \mathrm{mmol})$, PTSA $(9,5 \mathrm{mg}, 0,05 \mathrm{mmol})$ en $\mathrm{CH}_{3} \mathrm{CN}(2$

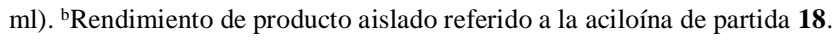


Sin embargo, cuando el $N$-metilpirrol 22b fue evaluado como nucleófilo en la reacción $S_{N}$ del sustrato modelo 18a, bajo las mismas condiciones, la indolilcetona 23e funcionalizada con un resto pirrol-2-ilo fue obtenida con un rendimiento moderado, debido a la formación de subproductos que no pudieron ser identificados (Tabla 2.3, entrada 5).

\subsection{Acetilacetona como nucleófilo}

Los compuestos 1,3-dicarbonílicos se han empleado como nucleófilos en reacciones de $S_{N}$ directa de alcoholes para la formación de nuevos enlaces C-C. ${ }^{113}$ Por ello, nuestro siguiente objetivo consistió en evaluar la reactividad de una serie de compuestos 1,3-dicarbonílicos frente a las aciloínas 18 bajo catálisis ácida. Con este objetivo en mente se hizo reaccionar la aciloína modelo 18a con la acetilacetona $\mathbf{2 4 a}$ en presencia de cantidades catalíticas de PTSA, temperatura ambiente y acetonitrilo como disolvente. Sin embargo, bajo estas condiciones de reacción únicamente se observó la descomposición de los reactivos de partida (Esquema 2.13).

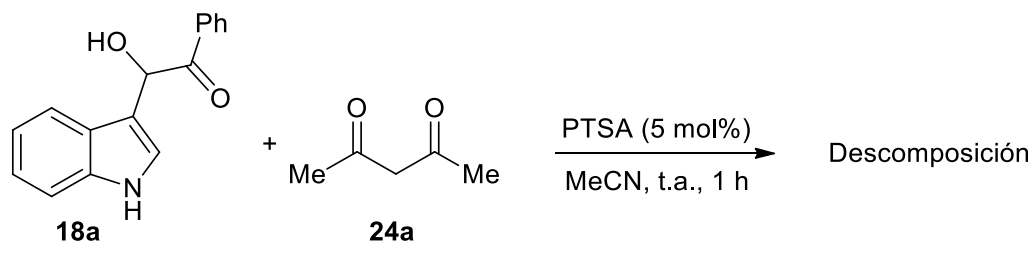

Esquema 2.13

A pesar de este resultado inicial, decidimos ensayar la reacción de la aciloína 18a con la acetilacetona 24 a en presencia de una serie de catalizadores ácidos, tanto de Brønsted como de Lewis, en tolueno como disolvente y a temperatura ambiente (Tabla 2.4). El empleo de ácidos de Brønsted, tales como PTSA y difenilfosfato, únicamente condujo a productos de descomposición (entradas 1 y 2 ).

113 (a) R. Sanz, D. Miguel, A. Martínez, J.-M. Álvarez-Gutiérrez, F. Rodríguez, Org. Lett. 2007, 9, 727-730. (b) R. Sanz, D. Miguel, A. Martínez, J.-M. Álvarez-Gutiérrez, F. Rodríguez, Org. Lett. 2007, 9, 2027-2030. 
Tabla 2.4 Optimización de las condiciones de reacción entre la aciloína 18 a y la acetilacetona $24 a^{a}$

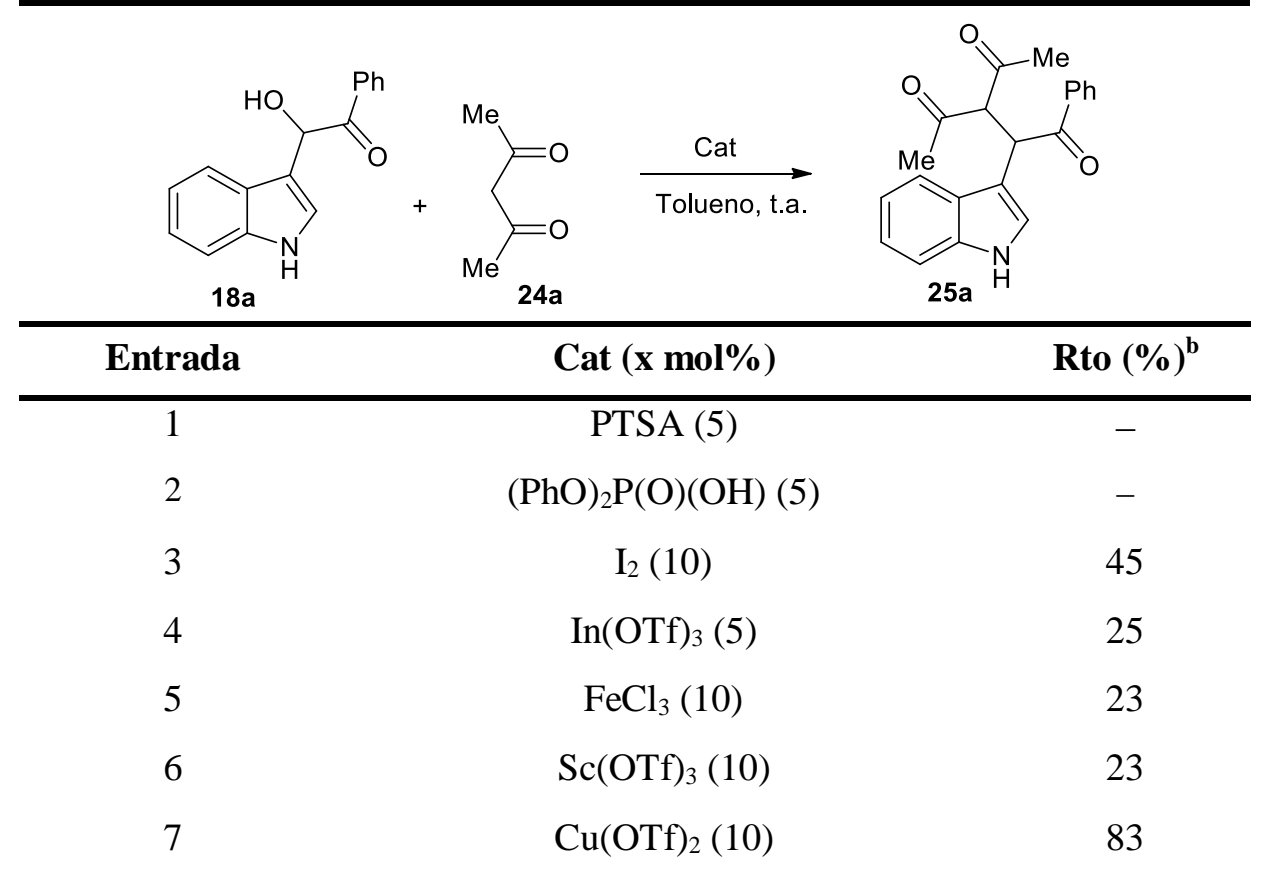

aCondiciones de reacción: 18a $(0,1 \mathrm{mmol})$, acetilacetona 24a $(0,1 \mathrm{mmol})$, tolueno $(0,2 \mathrm{ml})$ t.a., $2 \mathrm{~h}$. bRendimientos calculados por $\mathrm{RMN}$ empleando $\mathrm{CH}_{2} \mathrm{Br}_{2}$ como patrón interno.

Sin embargo, al emplear yodo como catalizador se observó la formación del producto tricarbonílico deseado 25 a con un $45 \%$ de rendimiento (entrada 3). En presencia de otros ácidos de Lewis tales como $\mathrm{In}(\mathrm{OTf})_{3}, \mathrm{FeCl}_{3}, \mathrm{Sc}(\mathrm{OTf})_{3}$, no se produjo una mejora significativa en la reacción, obteniéndose el producto $\mathbf{2 5 a}$ con bajos rendimientos (23-25\%) (entradas 4-6). Gratamente, el empleo de $\mathrm{Cu}(\mathrm{OTf})_{2}$ como catalizador, bajo estas condiciones de reacción, permitió obtener 25a con un $83 \%$ de rendimiento (entrada 7).

\subsection{Otros compuestos 1,3-dicarbonílicos como nucleófilos}

Tras este estudio sobre las condiciones del proceso, se estableció el empleo de un $10 \mathrm{~mol} \%$ de $\mathrm{Cu}(\mathrm{OTf})_{2}$, tolueno como disolvente y temperatura ambiente como condiciones óptimas de reacción por ser las que permiten obtener el producto 25a con un mejor rendimiento. Bajo dichas condiciones, y con el objetivo de estudiar el alcance de la reacción, se trató la aciloína modelo 18a con una selección de compuestos $\beta$-dicarbonílicos $\mathbf{2 4}$ tanto simétricos como asimétricos (Tabla 2.5). 
Tabla 2.5 Reacción de las aciloínas 18 con los compuestos $\beta$-dicarbonílicos 24. Síntesis de los compuestos tricarbonilícos $25^{\mathrm{a}}$

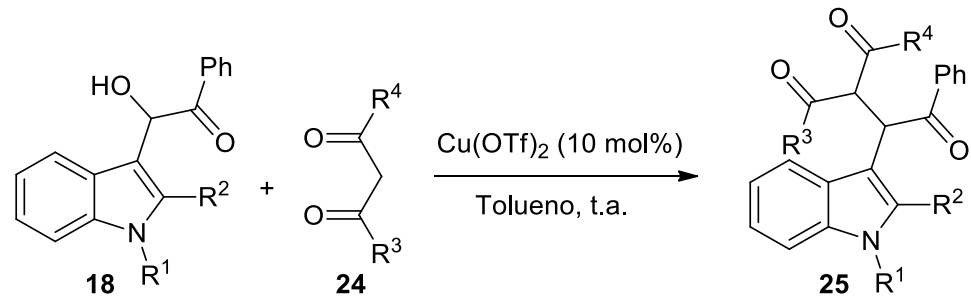

\begin{tabular}{ccccccccc}
\hline Entrada & Aciloína & $\mathbf{R}^{\mathbf{1}}$ & $\mathbf{R}^{\mathbf{2}}$ & $\mathbf{2 4}$ & $\mathbf{R}^{\mathbf{3}}$ & $\mathbf{R}^{\mathbf{4}}$ & Producto $^{\text {Rto }(\boldsymbol{\%})^{\mathbf{b}}}$ \\
\hline 1 & $\mathbf{1 8 a}$ & $\mathrm{H}$ & $\mathrm{H}$ & $\mathbf{2 4 a}$ & $\mathrm{Me}$ & $\mathrm{Me}$ & $\mathbf{2 5 a}$ & 90 \\
2 & $\mathbf{1 8 a}$ & $\mathrm{H}$ & $\mathrm{H}$ & $\mathbf{2 4 b}$ & $\mathrm{Ph}$ & $\mathrm{Ph}$ & $\mathbf{2 5 b}$ & 80 \\
3 & $\mathbf{1 8 a}$ & $\mathrm{H}$ & $\mathrm{H}$ & $\mathbf{2 4 c}$ & $\mathrm{Ph}$ & $\mathrm{Me}$ & $\mathbf{2 5 c}$ & $79^{\mathrm{c}}$ \\
4 & $\mathbf{1 8 a}$ & $\mathrm{H}$ & $\mathrm{H}$ & $\mathbf{2 4 d}$ & $\mathrm{Me}$ & $\mathrm{OEt}$ & $\mathbf{2 5 d}$ & $68^{\mathrm{c}}$ \\
5 & $\mathbf{1 8 a}$ & $\mathrm{H}$ & $\mathrm{H}$ & $\mathbf{2 4 e}$ & $\mathrm{Ph}$ & $\mathrm{OEt}$ & $\mathbf{2 5 e}$ & $80^{\mathrm{d}}$ \\
6 & $\mathbf{1 8 b}$ & $\mathrm{H}$ & $\mathrm{Me}$ & $\mathbf{2 4 a}$ & $\mathrm{Me}$ & $\mathrm{Me}$ & $\mathbf{2 5 f}$ & 99 \\
7 & $\mathbf{1 8 d}$ & $\mathrm{Me}$ & $\mathrm{Me}$ & $\mathbf{2 4 a}$ & $\mathrm{Me}$ & $\mathrm{Me}$ & $\mathbf{2 5 g}$ & 76 \\
\hline
\end{tabular}

${ }^{a}$ Condiciones de reacción: $18(1 \mathrm{mmol}), 24(1 \mathrm{mmol}), \mathrm{Cu}(\mathrm{OTf})_{2}(10 \mathrm{~mol} \%)$, tolueno $(2 \mathrm{ml})$. ${ }^{\mathrm{b}}$ Rendimiento de producto aislado referido a la aciloína de partida 18. 'Obtenido como mezcla 2:1 de diasteroisómeros. dObtenido como mezcla 1:1 de diasteroisómeros.

La reacción transcurrió con muy buenos rendimientos cuando se emplearon como nucleófilos tanto la dibenzoilacetona $\mathbf{2 4 b}$, como la benzoilacetona $\mathbf{2 4 c}$ (entradas 2 y 3). Sin embargo, se observó una gran diferencia en cuanto a los tiempos de reacción y así, mientras que $\mathbf{2 4 b}$ reaccionaba en apenas 2 h, para $\mathbf{2 4 c}$ fue necesario aumentar el tiempo de reacción de hasta $16 \mathrm{~h}$.

Por su parte, los $\beta$-cetoésteres también fueron nucleófilos apropiados para la reacción de $S_{\mathrm{N}}$ de las aciloínas 18. Empleando estos sustratos y la aciloína 18a se pudieron aislar los productos $25 \mathbf{d}$ y $25 \mathbf{e}$ con buenos rendimientos (entradas 4 y 5). Sin embargo, el empleo de malonato de dietilo como nucleófilo, bajo las condiciones óptimas, únicamente condujo a productos de descomposición. Cuando se emplearon compuestos $\beta$-dicarbonílicos asimétricos, que dan lugar a la formación de productos con dos centros estereogénicos adyacentes (entradas 3-5), los productos finales 25 c-e fueron obtenidos como mezcla de diasteroisómeros.

Respecto a las aciloínas de partida también se demostró que tanto $\mathbf{1 8 b}$ como 18d presentan un comportamiento análogo al sustrato modelo 18a, siendo 
capaces de reaccionar con la acetilacetona $24 \mathbf{a}$ en presencia de cantidades catalíticas de $\mathrm{Cu}(\mathrm{OTf})_{2}$, para dar lugar a los productos 25f y 25g con rendimientos entre buenos y excelentes (entradas 6 y 7).

Sin embargo, las $\beta$-dicetonas sustituídas en posición $\alpha$ no se comportaron de manera análoga a las anteriores en la reacción frente a las aciloínas 18. Así, cuando se llevó a cabo la reacción entre la aciloína 18a y la 2acetilciclohexanona 24f, bajo las condiciones previamente descritas, se obtuvo el producto $\mathbf{2 5 h}$, aunque tan solo con un $10 \%$ de rendimiento y aislado como mezcla 5:1 de diasteroisómeros (Esquema 2.14). Asimismo, el empleo de 2metil-1,3-ciclopentadiona condujo a productos de descomposición.<smiles>CC(=O)C1CCCCC1=O</smiles><smiles>CC(C)CC(C)CCCCO</smiles>

Tolueno, t.a.

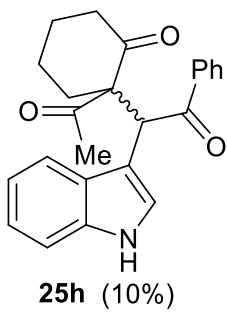

Esquema 2.14

Sorprendentemente, cuando se enfrentó la 3-metil-2,4-pentanodiona $\mathbf{2 4 g}$ con la aciloína 18a, en presencia de cantidades catalíticas de $\mathrm{Cu}(\mathrm{OTf})_{2}$, la reacción condujo a la formación de una mezcla del compuesto tricarbonílico esperado $25 \mathbf{i}$ y un nuevo producto 26i, que no presentaba grupo carbonilo en su estructura, y que resultó ser un 3-(furan-3-il)indol (Esquema 2.15). Ambos productos se obtuvieron con bajo rendimiento en las condiciones ensayadas.<smiles>CC(C)(C)c1ccccc1C(O)C(=O)c1ccccc1</smiles>

$18 a$<smiles>CC(=O)C(C)C(C)=O</smiles>

$\mathrm{Cu}(\mathrm{OTf})_{2}$ $\stackrel{(10 \mathrm{~mol} \%)}{\longrightarrow}$

$24 i$<smiles>CC(=O)C(C(C)=O)(C(C)=O)C(C(=O)c1ccccc1)c1c[nH]c2ccccc12</smiles>

25i $(6 \%)$<smiles>Cc1oc(-c2ccccc2)c(-c2c[nH]c3ccccc23)c1C</smiles>

\section{Esquema 2.15}

Mientras que las aciloínas $\mathbf{1 8 a}, \mathbf{b}, \mathbf{d}$ reaccionan eficientemente con la acetilacetona 24a (Tabla 2.5 entrada 1,6, y 7), cuando se llevó a cabo la reacción entre la aciloína $\mathbf{1 8 c}$ y la acetilacetona $\mathbf{2 4 a}$, en presencia de $\mathrm{Cu}(\mathrm{OTf})_{2}$ y 
durante 3 h, se observó la formación, además del producto esperado $\mathbf{2 5} \mathbf{j}$, otro compuesto con estructura de bis(indol-3-il)acetofenona en una proporción 1,4:1 (Esquema 2.16).
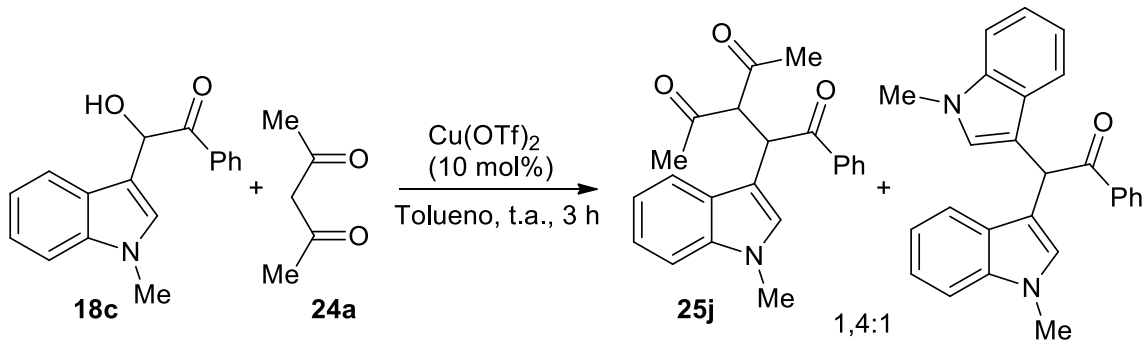

\section{Esquema 2.16}

Este resultado podría explicarse considerando que, en presencia del catalizador de cobre (II), la aciloína 18c podría expulsar una molécula de $\mathrm{N}$ metilindol que, bajo las condiciones de reacción y en presencia de otra molécula de aciloína conduciría a la formación de la bis(indolil)acetofenona, tal y como se propone en el Esquema 2.17.<smiles>Cn1cc(C(O)C(=O)c2ccccc2)c2ccccc21</smiles><smiles>Cn1cc(C(C(=O)c2ccccc2)c2cn(C)c3ccccc23)c2ccccc21</smiles>

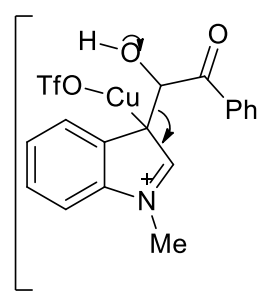<smiles>CCPC1CCCCC1</smiles><smiles>Cn1cc(C(Cl)(Cl)Cl)c2ccccc21</smiles><smiles>CPC</smiles><smiles>Cn1ccc2ccccc21</smiles>

\section{Esquema 2.17}

Para comprobar esta hipótesis se llevó a cabo una prueba cualitativa en la que se hizo reaccionar la aciloína $\mathbf{1 8 c}$ bajo las condiciones óptimas de reacción: $\mathrm{Cu}$ (OTf $)_{2}(10 \mathrm{~mol} \%)$, tolueno, y temperatura ambiente, pero en ausencia de nucleófilo externo. Tras cuatro horas de reacción se comprobó la formación de la misma bis(indolil)acetofenona (Esquema 2.17). 


\subsection{Otros nucleofilos carbonados}

Nuestro siguiente objetivo consistió en explorar si otros nucleófilos carbonados también eran capaces de participar en la reacción de $S_{N}$ de las aciloínas 18 bajo alguna de las dos condiciones estándar que se habían empleado hasta el momento: condiciones A [PTSA (5 mol\%), $\mathrm{CH}_{3} \mathrm{CN}$, t.a.] ó condiciones $\mathbf{B}\left[\mathrm{Cu}(\mathrm{OTf})_{2}(10 \mathrm{~mol} \%)\right.$, tolueno, t.a.]. Inicialmente, se eligió como nucleófilo el 1,3,5-trimetoxibenceno y se le hizo reaccionar con la aciloína $\mathbf{1 8 b}$ en presencia de cantidades catalíticas de PTSA. Bajo estas condiciones se obtuvo la correspondiente $\alpha$-indolilcetona $\alpha$-trimetoxifenil-funcionalizada $27 \mathbf{a}$ con un $60 \%$ de rendimiento (Esquema 2.18).<smiles>Cc1[nH]c2ccccc2c1C(O)C(=O)c1ccccc1</smiles>

$18 b$<smiles>COc1cc(OC)cc(OC)c1</smiles>

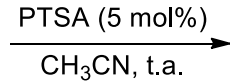
$\mathrm{CH}_{3} \mathrm{CN}$, t.a.

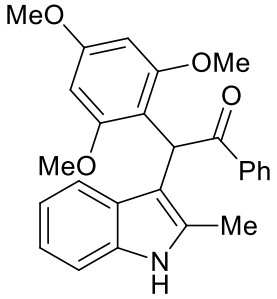

27a $(60 \%)$

\section{Esquema 2.18}

Por el contrario, cuando se evaluaron otros nucleófilos tales como fenol, $p$ cresol, aliltrimetilsilano, 1,2,3-trimetoxibenceno, bajo catálisis con PTSA o $\mathrm{Cu}(\mathrm{OTf})_{2}$, en todos los casos ensayados se obtuvieron únicamente productos de descomposición.

\subsubsection{Reacción de $S_{N}$ de aciloínas 18 con nucleófilos heteroatómicos}

Una vez estudiado el comportamiento de una amplia variedad de nucleófilos carbonados en la $\mathrm{S}_{\mathrm{N}}$ de las $\alpha$-indolilaciloínas 18, el siguiente objetivo fue ensayar la reacción de estas aciloínas con nucleófilos heteroatómicos. De esta manera se podrían formar enlaces $\mathrm{C}-\mathrm{O}, \mathrm{C}-\mathrm{S}$ y $\mathrm{C}-\mathrm{N}$, procesos también fundamentales en Síntesis Orgánica.

\subsection{Alcoholes como nucleófilos}

Basados en la experiencia del grupo en el empleo de etanol como nucleófilo en reacciones catalíticas de $\mathrm{S}_{\mathrm{N}}$ directa de alcoholes propargílicos, decidimos 
iniciar el estudio de la reactividad de las aciloínas $\mathbf{1 8}$ frente a nucleófilos heteroatómicos empleando dicho alcohol. Sin embargo, cuando se hizo reaccionar la aciloína modelo 18a con un exceso de etanol (5 eq) en presencia de cantidades catalíticas de PTSA, acetonitrilo como disolvente y a temperatura ambiente, no se observó la formación del éter, sino que únicamente se obtuvieron productos de descomposición.

Teniendo en cuenta que, desde un punto de vista sintético, la incorporación de etanol en la indolilcetona, comparada con la propia aciloína de partida, presenta un interés menor, decidimos no insistir más en esta reacción y explorar otros nucleofilos heteroatómicos.

\subsection{Tiofenoles como nucleófilos}

Los compuestos que contienen sustituyentes azufrados en la posición C-3 del indol son muy interesantes por su potencial actividad biológica y farmacológica. ${ }^{114}$ A pesar de ello, las rutas sintéticas para acceder a estas estructuras son bastante escasas. ${ }^{115}$

Considerando el carácter nucleofílico que poseen los tioles, así como su uso como nucleófilos en reacciones de $S_{N}$ directa de alcoholes $\pi$-activados, ${ }^{116}$ decidimos estudiar su comportamiento en las reaciones de $S_{N}$ de las aciloínas $\mathbf{1 8}$ catalizadas por ácidos de Brønsted. En primer lugar, se llevó a cabo la reacción entre la aciloína modelo 18a y el 4-metiltiofenol, en presencia de cantidades catalíticas de PTSA, lo que condujo a la correspondiente $\alpha$-indolil $\alpha$-tioaril cetona 28a con muy buen rendimiento (Tabla 2.6, entrada 1).

114 (a) T-M. Williams, y col. J. Med. Chem. 1993, 36, 1291-1294. (b) R. Vardanyan, V. Hruby, Synthesis of Essential Drugs (Elsevier, Amsterdam, 2006).

115 (a) S. Shirakawa, S. Kobayashi, Org. Lett. 2006, 8, 4939-4942. (b) S. Gao, C. Tseng, B. Raju, C. Tsai, C. Yao, Synlett 2009, 3201-3205. (c) A. Khorshidi, S. Shariati, RSC Adv. 2014, 4, 41469-41475. (d) A. Dar, S. Ali, A. Khan, Tetrahedron Lett. 2014, 55, 486-489.

116 (a) M. Roggen, E. Carreira, Angew. Chem. Int. Ed. 2012, 51, 8652-8655. (b) S. Webster, P. C. Young, G. Barker, G. M. Rosair, A.-L. Lee, J. Org. Chem. 2015, 80, 1703-1718. 
Tabla 2.6 Reacción de las aciloínas 18 con tiofenoles. Síntesis de $28^{\mathrm{a}}$

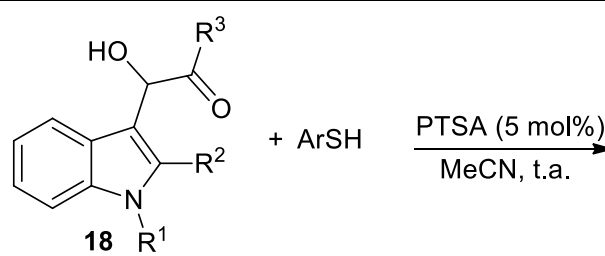

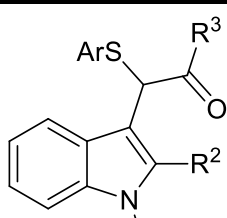

$28 \mathrm{R}^{1}$

\begin{tabular}{cccccccc}
\hline Entrada Aciloína & $\mathbf{R}^{\mathbf{1}}$ & $\mathbf{R}^{\mathbf{2}}$ & $\mathbf{R}^{\mathbf{3}}$ & $\mathbf{A r}$ & $\mathbf{2 8}$ & Rto (\%) \\
\hline 1 & $\mathbf{1 8 a}$ & $\mathrm{H}$ & $\mathrm{H}$ & $\mathrm{Ph}$ & $4-\mathrm{MeC}_{6} \mathrm{H}_{4}$ & $\mathbf{2 8 a}$ & 87 \\
2 & $\mathbf{1 8 a}$ & $\mathrm{H}$ & $\mathrm{H}$ & $\mathrm{Ph}$ & $4-\mathrm{MeOC}_{6} \mathrm{H}_{4}$ & $\mathbf{2 8 b}$ & 83 \\
3 & $\mathbf{1 8 a}$ & $\mathrm{H}$ & $\mathrm{H}$ & $\mathrm{Ph}$ & $2,5-(\mathrm{MeO})_{2} \mathrm{C}_{6} \mathrm{H}_{3}$ & $\mathbf{2 8 c}$ & 76 \\
4 & $\mathbf{1 8 a}$ & $\mathrm{H}$ & $\mathrm{H}$ & $\mathrm{Ph}$ & $3,4-(\mathrm{MeO})_{2} \mathrm{C}_{6} \mathrm{H}_{3}$ & $\mathbf{2 8 d}$ & 75 \\
5 & $\mathbf{1 8 b}$ & $\mathrm{H}$ & $\mathrm{Me}$ & $\mathrm{Ph}$ & $2-\mathrm{BrC}_{6} \mathrm{H}_{4}$ & $\mathbf{2 8 e}$ & 78 \\
6 & $\mathbf{1 8 c}$ & $\mathrm{Me}$ & $\mathrm{H}$ & $\mathrm{Ph}$ & $2-\mathrm{BrC}_{6} \mathrm{H}_{4}$ & $\mathbf{2 8 f}$ & 86 \\
7 & $\mathbf{1 8 c}$ & $\mathrm{Me}$ & $\mathrm{H}$ & $\mathrm{Ph}$ & $4-\mathrm{ClC}_{6} \mathrm{H}_{4}$ & $\mathbf{2 8 g}$ & 89 \\
8 & $\mathbf{1 8 c}$ & $\mathrm{Me}$ & $\mathrm{H}$ & $\mathrm{Ph}$ & $4-\mathrm{MeOC}_{6} \mathrm{H}_{4}$ & $\mathbf{2 8 h}$ & 87 \\
9 & $\mathbf{1 8 e}$ & $\mathrm{Me}$ & $\mathrm{H}$ & $\mathrm{Me}$ & $4-\mathrm{MeC}_{6} \mathrm{H}_{4}$ & $\mathbf{2 8 i}$ & 73 \\
\hline
\end{tabular}

aCondiciones de reacción: 18 (1 mmol), tiofenol $(1 \mathrm{mmol})$, PTSA $(9,5 \mathrm{mg}, 0,05 \mathrm{mmol})$, en $\mathrm{CH}_{3} \mathrm{CN}(2 \mathrm{ml})$.

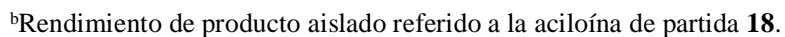

Teniendo en cuenta este resultado positivo se decidió comprobar la generalidad del proceso para las distintas aciloínas 18a-e empleando diferentes tiofenoles. Respecto a la aciloína de partida $\mathbf{1 8}$ se observó el mismo comportamiento que cuando se emplearon nucleófilos heteroaromáticos, siendo la reacción compatible con la presencia tanto de indoles con el átomo de nitrógeno libre (entradas 1-5), como protegido (entradas 6-9). Con respecto al tiofenol se observó que la reacción se puede llevar a cabo con tiofenoles que presentan sustituyentes tanto electrón-atractores (entradas 5-7), como electróndadores (1-4 y 8,9) en el anillo aromático. La reacción transcurre, en general, de manera muy limpia, en tiempos cortos y permite aislar los productos $\mathbf{2 8}$ con muy buenos rendimientos.

\subsection{Aminas como nucleófilos}

Nuestro siguiente objetivo consistió en extender esta reacción a otros nucleófilos heteroatómicos. Teniendo en cuenta la importancia de la formación 
de enlaces $\mathrm{C}-\mathrm{N}$ en Síntesis Orgánica decidimos evaluar nucleófilos tales como aminas aromáticas y sulfonamidas, que también participan en diferentes procesos de $\mathrm{S}_{\mathrm{N}}$ directa catalizados por ácidos. ${ }^{117}$

En primer lugar, se hizo reaccionar la aciloína modelo 18a con la $p$ nitroanilina, bajo catálisis con PTSA, obteniéndose la $\alpha$-indolil $\alpha$-aminocetona 29a con buen rendimiento (Tabla 2.7, entrada 1). A continuación, se procedió a comprobar la generalidad de la reacción. Así, con respecto a la aciloína de partida se observó que 18b y 18e también eran capaces de reaccionar con la $p$ nitroanilina dando lugar a las correspondientes aminocetonas 29b y 29c con buenos rendimientos (entradas 2 y 4). Por el contrario, el empleo de la aciloína 18c, bajo estas mismas condiciones de reacción, condujo a la descomposición de los productos de partida (entrada 3). Sin embargo, todos los intentos llevados a cabo empleando 3-cloroanilina, p-cianoanilina, 2-nitroanilina y bencenosulfonamida como nucleófilos, en presencia de PTSA, condujeron únicamente a productos de descomposición, por lo que el alcance de este procedimiento con respecto a nucleófilos nitrogenados parece muy limitado.

Tabla 2.7 Reacción de las aciloínas 18 con la 4-nitroanilina ${ }^{\text {a }}$

\begin{tabular}{|c|c|c|c|c|c|c|}
\hline & ${ }^{\mathrm{HO}}$ & & & $5 \mathrm{~mol} /$ & $=$ & \\
\hline Entrada & Aciloína & $\mathbf{R}^{1}$ & $\mathbf{R}^{2}$ & $\mathbf{R}^{3}$ & Producto & Rto $(\%)^{b}$ \\
\hline 1 & $18 \mathrm{a}$ & $\mathrm{H}$ & $\mathrm{H}$ & $\mathrm{Ph}$ & $29 a$ & 65 \\
\hline 2 & $18 b$ & $\mathrm{H}$ & $\mathrm{Me}$ & $\mathrm{Ph}$ & 29b & 88 \\
\hline 3 & $18 \mathrm{c}$ & $\mathrm{Me}$ & $\mathrm{H}$ & $\mathrm{Ph}$ & - & $-^{\mathrm{c}}$ \\
\hline 4 & $18 \mathrm{e}$ & $\mathrm{Me}$ & $\mathrm{H}$ & $\mathrm{Me}$ & $29 c$ & 67 \\
\hline
\end{tabular}

aCondiciones de reacción: 18 (1 mmol), $p$-nitroanilina (1,1 mmol), PTSA (9,5 mg, 0,05 mmol), en $\mathrm{CH}_{3} \mathrm{CN}(2$

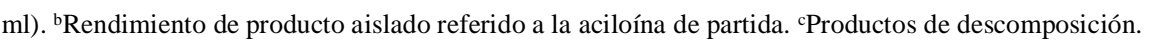

117 (a) O. Debleds, C. Dal Zotto, E. Vrancken, J.-M. Campagne, P. Retailleau, Adv. Synth. Catal. 2009, 351, 1991-1998. (b) Y. Masuyama, M: Hayashi, N. Suzuki, Eur. J. Org. Chem. 2013, 2914-2921. (c) N. Thies, M. Gerlach, E. Haak, Eur. J. Org. Chem. 2013, 7354-7365. (d) K. Huang, H. Wang, L. Liu, W. Chang, J. Li, Chem. Eur. J. 2016, 22, 6458-6465. 


\subsubsection{Aplicaciones sintéticas de las $\alpha$-indolilcetonas preparadas}

Como ya se comentó en el apartado de Antecedentes de este Capítulo, las $\alpha$ indolilcetonas son productos muy interesantes desde el punto de vista sintético por sus potenciales aplicaciones como reactivos de partida para acceder a otros sustratos que contienen el núcleo indólico en su estructura. Con esta idea en mente nos propusimos como siguiente objetivo la síntesis de nuevos derivados indólicos a partir de las $\alpha$-indolilcetonas funcionalizadas previamente sintetizadas.

\subsubsection{Síntesis de derivados del triptofol}

Los triptofoles son otra clase de derivados indólicos de gran interés debido a su potencial actividad biológica (Esquema 2.1). ${ }^{21 b, 118}$ Una de las metodologías más directas para acceder a derivados de triptofol implica la alquilación directa de indoles con arilepóxidos en presencia de un catalizador ácido. Bajo estas condiciones el ataque del indol se produce preferentemente sobre la posición bencílica dando lugar a alcoholes primarios (Esquema 2.19, ec 1). ${ }^{119}$

Considerando el interés por el desarrollo de nuevas aproximaciones para la síntesis de derivados de triptofoles nos propusimos como siguiente objetivo acceder a estos compuestos mediante la reducción del grupo carbonilo de las indolilcetonas previamente sintetizadas. Esta estrategia presentaría en principio, algunas ventajas respecto de la alquilación de arilepóxidos. Por una parte, la reacción no presenta problemas en cuanto al control de la selectividad, dado que solo hay un centro electrofílico. Por otra parte, esta metodología permitiría obtener triptofoles funcionalizados ya que, a priori, en la posición $\alpha$ al grupo hidroxilo puede haber tantos sustituyentes como nucleófilos hayan sido capaces de reaccionar con las aciloínas 18. Además, también se pueden controlar las posiciones $\mathrm{R}^{1}, \mathrm{R}^{2}, \mathrm{y} \mathrm{R}^{3}$ (Esquema 2.19 , Ec 2)

\footnotetext{
${ }^{118}$ T. Shen, Y. Zhang, Y.-F. Liang, N. Jiao, J. Am. Chem. Soc. 2016, 138, 13147-13150.
}

${ }^{119}$ Y. Liu, Q. Liu, Z. Zhang, Tetrahedron Lett. 2009, 50, 916-921. 
<smiles>[R]c1cc2ccccc2n1[R1]</smiles><smiles>[R]C(=O)C(C#N)c1c([R])n([R])c2ccccc12</smiles>

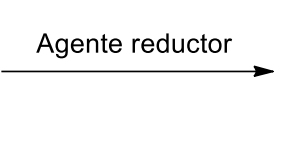<smiles>[R]c1c([C@H](C#N)[C@@H]([R])O)c2ccccc2n1[R]</smiles>
Ec 2 $R^{1}=H, M e R^{2}=H, M e, R^{3}=P h, M e$

Esquema 2.19

Para abordar el objetivo propuesto en primer lugar se eligió la cetona 28a (ver Tabla 2.6) y se le hizo reaccionar con $\mathrm{NaBH}_{4}(1,1 \mathrm{eq})$, en metanol y a temperatura ambiente, obteniéndose tras $1 \mathrm{~h}$ de reacción el correspondiente alcohol secundario 30a como mezcla 2:1 de diasteroisómeros, el cual fue aislado con un $78 \%$ de rendimiento. De la misma manera se hicieron reaccionar las indolilcetonas funcionalizadas 22a y 29b, lo que dio lugar a los correspondientes triptofoles 30b y 30c como mezclas 4:1 y 2:1 de diasteroisómeros y con rendimientos del 80 y $81 \%$, respectivamente (Esquema 2.20). En algún caso el diastereoisómero mayoritario pudo ser aislado tras la purificación por cromatografía de columna.

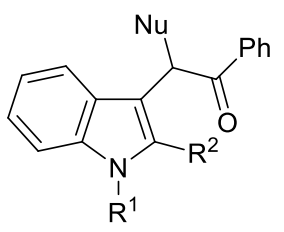

$22,28,29$<smiles>Cc1ccc(SC(c2c[nH]c3ccccc23)[C@H](O)c2ccccc2)cc1</smiles>

$30 \mathbf{a}(d r=2: 1,78 \%)$
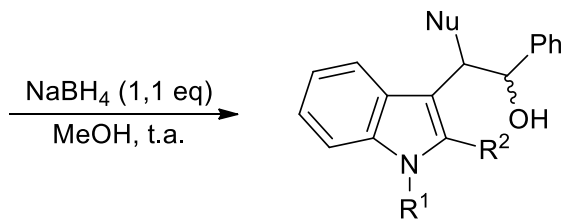

30

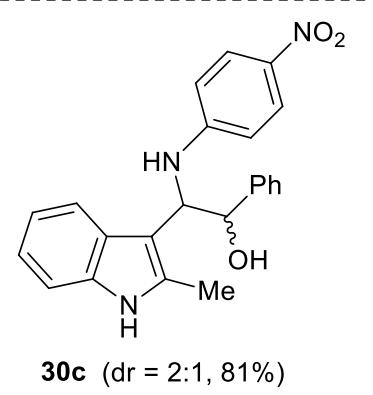

Esquema 2.20 


\subsubsection{Síntesis de furanilindoles}

Los indoles sustituídos en C-3 por otro anillo heterocíclico son compuestos que poseen interesantes propiedades biológicas y farmacológicas. ${ }^{120}$ A pesar de ello, acceder a este tipo de compuestos no siempre es fácil y una de las rutas implica una heteroarilación directa de indoles ${ }^{121}$ que, sin embargo, posee varios inconvenientes como pueden ser la falta de regioselectividad, que depende en gran medida de la sustitución del nitrógeno, y reacciones de homoacoplamiento, entre otros. Por ello, los procedimientos más habituales consisten en la construcción del anillo de furilo sobre un precursor indólico funcionalizado. ${ }^{122}$

Considerando que los compuestos 1,4-dicarbonílicos han sido ampliamente empleados en la síntesis de furanos de Paal-Knorr, nos propusimos como siguiente objetivo acceder a 3-furanilindoles a partir de los derivados tricarbonílicos 25 sintetizados previamente (Esquema 2.21).

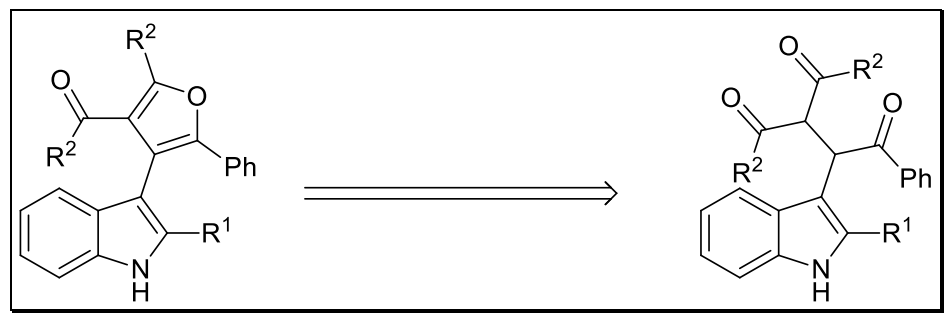

Esquema 2.21

Con este objetivo en mente, se eligió como sustrato modelo el compuesto tricarbonílico 25a y se le hizo reaccionar con PTSA (1,1 eq), en tolueno y bajo diferentes condiciones de temperatura y tiempos de reacción (Tabla 2.8). A temperatura ambiente y durante $16 \mathrm{~h}$ la ciclación no fue completa, sino que se obtuvo una mezcla 3:1 de los productos 25a:26a. Para conseguir alcanzar conversión completa, se llevó a cabo la reacción a reflujo de tolueno durante 2 h, lo que permitió aislar el furanilindol $\mathbf{2 6 a}$ con un $50 \%$ de rendimiento. Por último, y con el objetivo de minimizar la descomposición observada en el crudo cuando se llevó a cabo la reacción a reflujo, decidimos disminuir la temperatura

${ }^{120}$ (a) P. Diana, A. Carbone, P. Barraja, A. Montalbano, B. Parrino, A. Lopergolo, M. Pennati, N. Zaffaroni, G. Cirrincione, Chem. Med. Chem 2011, 6, 1300-1309. (b) M. Zhang, Q. Chen, G. Yang, Eur. J. Med. Chem. 2015, 89, 421-441.

121 (a) Z. Wang, F. Song, Y. Zhao, Y. Huang, L. Lang, D. Zhao, J. Lan, J. You, Chem. Eur. J. 2012, 18, 16616-16620. (b) X. Qin, H. Liu, D. Qin, Q. Wu, J. You, D. Zhao, Q. Guo, X. Huang, J. Lan, J. Chem. Sci. 2013, 4, 1964-1969. (c) D. Alberico, M. Scott, M. Lautens, M. Chem. Rev. 2007, 107, 174-238.

${ }^{122}$ G. Blay, I. Fernández, A. Monleón, J. R. Pedro, C. Vila, Tetrahedron 2009, 65, 9264-9270. 
de la reacción hasta $50{ }^{\circ} \mathrm{C}$. Bajo estas condiciones, y tras $2 \mathrm{~h}$ de reacción, fue posible aislar el indolilfurano $\mathbf{2 6 a}$ con un $85 \%$ de rendimiento.

Tabla 2.8 Optimización en la síntesis del furanilindol $26 \mathrm{a}^{\mathrm{a}}$

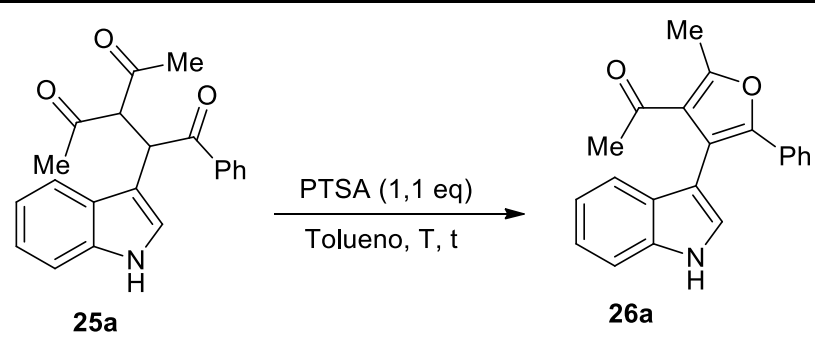

\begin{tabular}{cccc}
\hline $\mathbf{T ~}\left({ }^{\mathbf{o}} \mathbf{C}\right)$ & $\mathbf{t}(\mathbf{h})$ & $(\mathbf{2 5 a} \mathbf{2 6} \mathbf{a})^{\mathbf{b}}$ & $\left.\mathbf{R t o}^{\mathbf{\%}}\right)^{\mathbf{c}}$ \\
\hline t.a. & 16 & $3: 1$ & - \\
reflujo & 2 & $0: 1$ & 50 \\
50 & 2 & $0: 1$ & 85
\end{tabular}

aCondiciones de reacción: 25a $(0,5 \mathrm{mmol})$, PTSA $(0,55 \mathrm{mmol})$, tolueno $(1 \mathrm{ml})$. ${ }^{\mathrm{b}}$ Relación determinada mediante análisis de ${ }^{1} \mathrm{H}-\mathrm{RMN}$. ${ }^{\mathrm{R}}$ Rendimiento aislado referido a $\mathbf{2 5 a}$.

Considerando el empleo de tolueno como disolvente, tanto para la obtención de los productos $\mathbf{2 5}$ como para 26, nos planteamos la posibilidad de acceder a los 3-furilindoles $\mathbf{2 6}$ de manera directa a partir de 18, sin que fuera necesario aislar los compuestos tricarbonílicos 25 intermedios (Esquema 2.22).

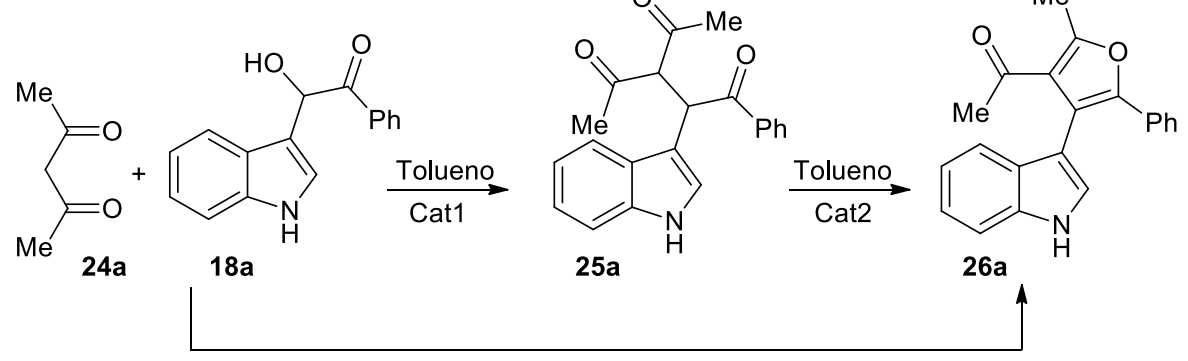

Esquema 2.22

Para abordar este nuevo reto, se eligió nuevamente la aciloína 18a como sustrato modelo y se le hizo reaccionar con la acetilacetona $\mathbf{2 4 a}$ en presencia de cantidades catalíticas de $\mathrm{Cu}(\mathrm{OTf})_{2}$, en tolueno y a temperatura ambiente. Después de $2 \mathrm{~h}$ de reacción el producto 25a fue detectado tanto por 
cromatografía en capa fina (TLC), como por cromatografía de gases (CG). Una vez detectada su formación, y la desaparición de la aciloína de partida, se añadió al mismo matraz 1,1 eq de PTSA y se llevó la mezcla a $50{ }^{\circ} \mathrm{C}$. Tras $2 \mathrm{~h}$ de reacción se confirmó la formación $\mathbf{2 6 a}$ como único producto, el cual fue aislado con un $80 \%$ de rendimiento (Esquema 2.23).

Una vez conseguido el objetivo de llevar a cabo la reacción en un proceso "one pot" sin necesidad de aislar los productos 25, decidimos evaluar su alcance. Las aciloínas de partida $\mathbf{1 8 b}$ y $\mathbf{1 8 d}$ se comportaron de manera análoga a la aciloína 18a, permitiendo aislar los furanilindoles 26b,c con diferentes modelos de sustitución en el anillo de indol y con rendimientos excelentes (Esquema 2.23). Con respecto al compuesto $\beta$-dicarbonílico la reacción también dio buenos resultados cuando se emplearon $\beta$-cetoésteres, obteniéndose el producto $\mathbf{2 6 d}$ con un $67 \%$ de rendimiento.

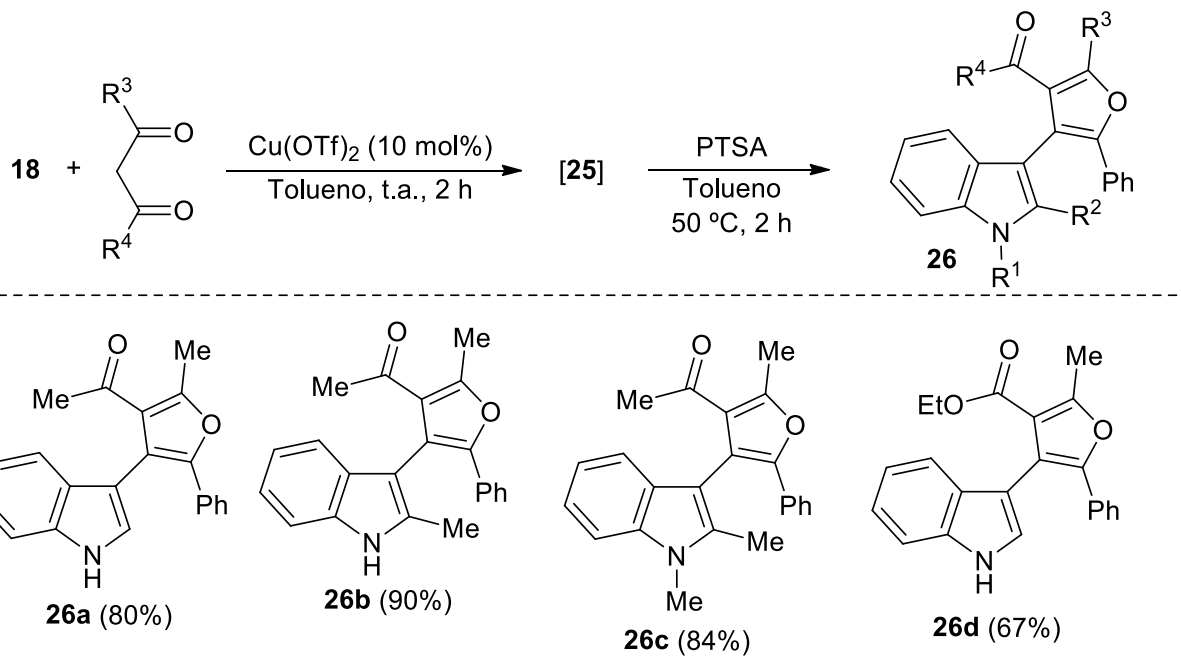

Esquema 2.23

Además, bajo las condiciones puestas a punto para este proceso se pudo dirigir la reacción de la aciloína $\mathbf{1 8 a}$ y la 2-metil-1,4-pentanodiona $\mathbf{2 4 g}$ hacia la formación selectiva del furano 26i, el cual fue aislado con un rendimiento del $58 \%$ (Esquema 2.24). En cuanto al mecanismo que explica la formación del nuevo furanilindol 26i, proponemos que inicialmente se forma el producto de $\mathrm{S}_{\mathrm{N}}$ directa $25 \mathbf{i}$, el cual a través de su tautómero $25^{\prime} \mathbf{i}$ cicla en el medio ácido para generar el intermedio A. Éste podría eliminar fácilmente una molécula de agua conduciendo al metilendihidrofurano B. El ataque de una molécula de $\mathrm{H}_{2} \mathrm{O}$ al grupo carbonilo, activado por el ácido, generaría un nuevo intermedio $\mathbf{C}$, el cual podría eliminar ácido acético generando el producto final $\mathbf{2 6 \mathbf { i }}$. 


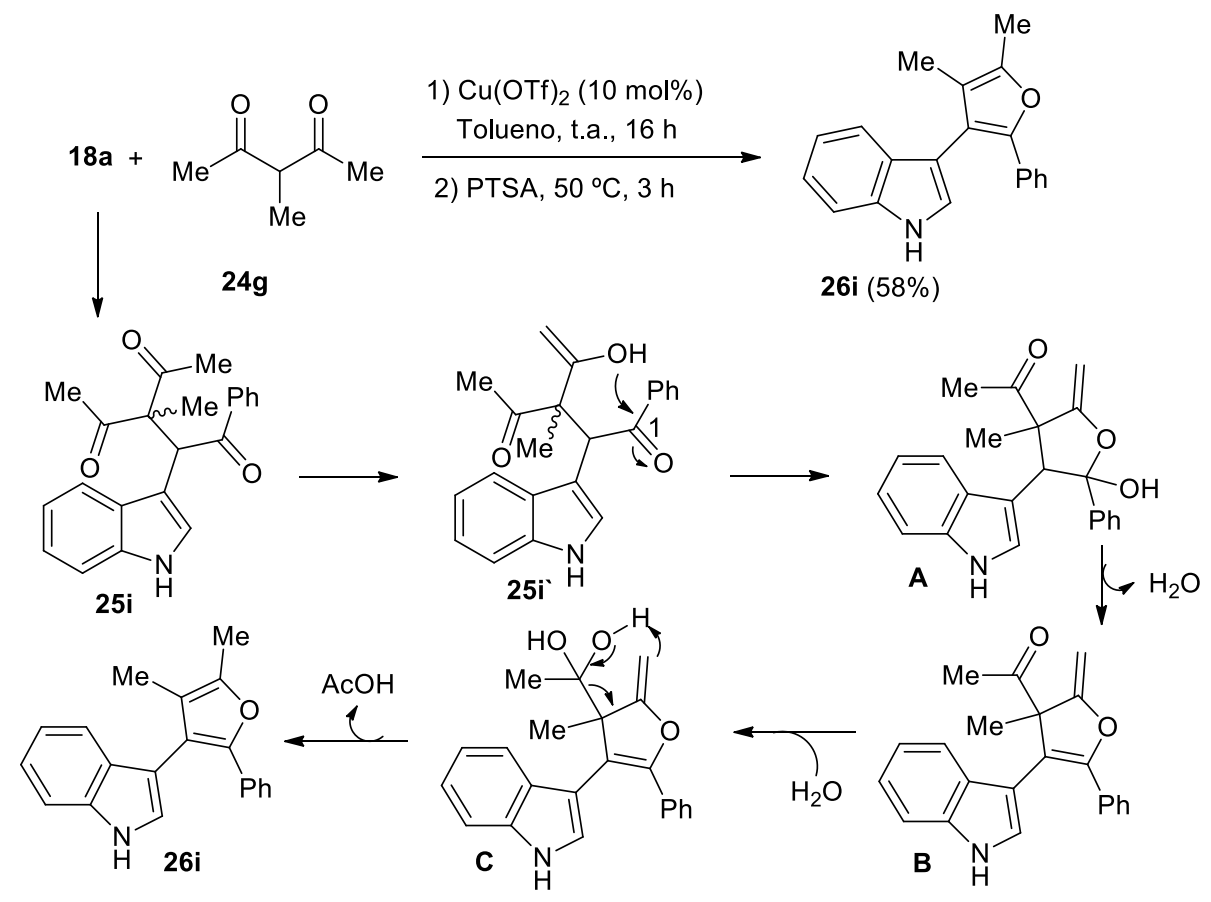

Esquema 2.24

\subsection{CONCLUSIONES}

En este capítulo se ha puesto a punto un nuevo método para la síntesis de una amplia variedad de $\alpha$-indolilcetonas funcionalizadas adicionalmente en posición $\alpha$ con una gran variedad de sustituyentes, que incluyen tanto grupos carbonados (arilos, heteroarilos y compuestos 1,3-dicarbonílicos), como heteroatómicos (tioles, anilinas). Las reacciones transcurren mediante una $S_{N}$ directa sobre $\alpha$-indolilaciloínas, las cuales se han empleado por primera vez como agentes alquilantes en este tipo de procesos. Esta estrategia permite obtener las $\alpha$-indolilcetonas $\alpha$-funcionalizadas con buenos rendimientos $y$, además, las reacciones se llevan a cabo en condiciones suaves y con la generación de agua como único subproducto.

Además, hemos demostrado la utilidad sintética de algunas de las $\alpha$ indolilcetonas obtenidas empleándolas como productos de partida o intermedios en la preparación de otros derivados indólicos con potencial actividad biológica como son los triptofoles y los furanilindoles. 



\section{CAPÍTULO 3 Síntesis de benzo[b]carbazoles por reacción de indoles con acetales de benzaldehído o- hidroxialquil funcionalizados}

\subsection{ANTECEDENTES}

Los carbazoles aril- y heteroaril-condensados presentan gran interés debido al amplio espectro de actividades biológicas que presentan ${ }^{123}$. Entre los carbazoles $[b]$-anulados destacan la elipticina y sus derivados con interestantes propiedades farmacológicas. ${ }^{124}$ Por ello y por sus aplicaciones en ciencia de materiales, ${ }^{125}$ el desarrollo de métodos eficientes para la preparación de benzo[b]carbazoles ha sido objeto de estudio por parte de la comunidad sintética. Y así, en la bibliografía, existe una amplia variedad de aproximaciones para acceder a este heterociclo. Generalmente, estas metodologías implican la construcción del anillo $\mathbf{B}$ ó $\mathbf{C}$ del benzocarbazol, o bien la construcción de ambos a la vez (Esquema 3.1). De entre el gran número de métodos empleados cabría destacar la reacción de indolización de Fisher con tosilhidrazonas, ${ }^{126}$ a partir de derivados de naftalenos ${ }^{127}$ incluyendo la ciclación reductora de compuestos nitroaromáticos, ${ }^{127 \mathrm{c}}$ y mediante la reacción Diels-Alder de piranoindolonas, ${ }^{128}$ furoindoles, ${ }^{129}$ y 2,4-dihidropirroloindoles ${ }^{130}$ con arinos (Esquema 3.1).

${ }^{123}$ Revisiones: (a) T. Janosik, N. Wahlström, J. Bergman, Tetrahedron 2008, 64, 9159-9180. (b) A. W. Schmidt, K. R. Reddy, H.-J. Knölker, Chem. Rev. 2012, 112, 3193-3328.

124 (a) J. M. Pedersen, W. R. Bowman, M. R. J. Elsegood, A. J. Fletcher, P. J. Lovell, J. Org. Chem. 2005, 70, 10615-10618. (b) P.-L. Kuo, Y.-L. Hsu, C.-H. Chang, C.-C. Lin, Cancer Lett. 2005, 223, 293-301.

125 (a) M. T. Levick, S. C. Coote, I. Grace, C. Lambert, M. L. Turner, D. J. Procter, Org. Lett. 2012, 14, 5744-5747. (b) J.-Y. Balandier, N. Henry, J.-B. Arlin, L. Sanguinet, V. Lemaur, C. Niebel, B. Chattopadhyay, A. R. Kennedy, P. Leriche, P. Blanchard, J. Cornil, Y. H. Geerts, Org. Lett. 2013, 15, 302-305.

${ }^{126}$ L. Martarello, D. Joseph, G. Kirsh, Heterocycles 1996, 43, 367-379.

127 (a) V.-R. Huisgen, G. Sorge, Justus Liebbigs Ann. Chem. 1950, 566, 162-184. (b) M.-E. Budén, V.-A. Vaillard, S.-E. Martin, R.-A. Rossi, J. Org. Chem. 2009, 74, 4490-4498. (c) P. Appukkuttan, E.-V. Der Eycken, W. Dehaen, Synlett 2005, 127-133.

${ }^{128}$ C.-J. Moody, J. Chem. Soc. Perkin Trans. 1985, 2505-2508.

${ }^{129}$ G.-W. Gribble, D.-J. Keavy, D.-A. Davis, M.-G. Saulnier, B. Pelcman, T.-C. Barden, M.-P. Sibi, E.-R. Olson, J.-J. BelBruno, J. Org. Chem. 1992, 57, 5878-5891.

${ }^{130}$ C.-K. Sha, K.-S. Chuang, S.-J. Wey, J. Chem. Soc. Perkin Trans. 1987, 977-980. 


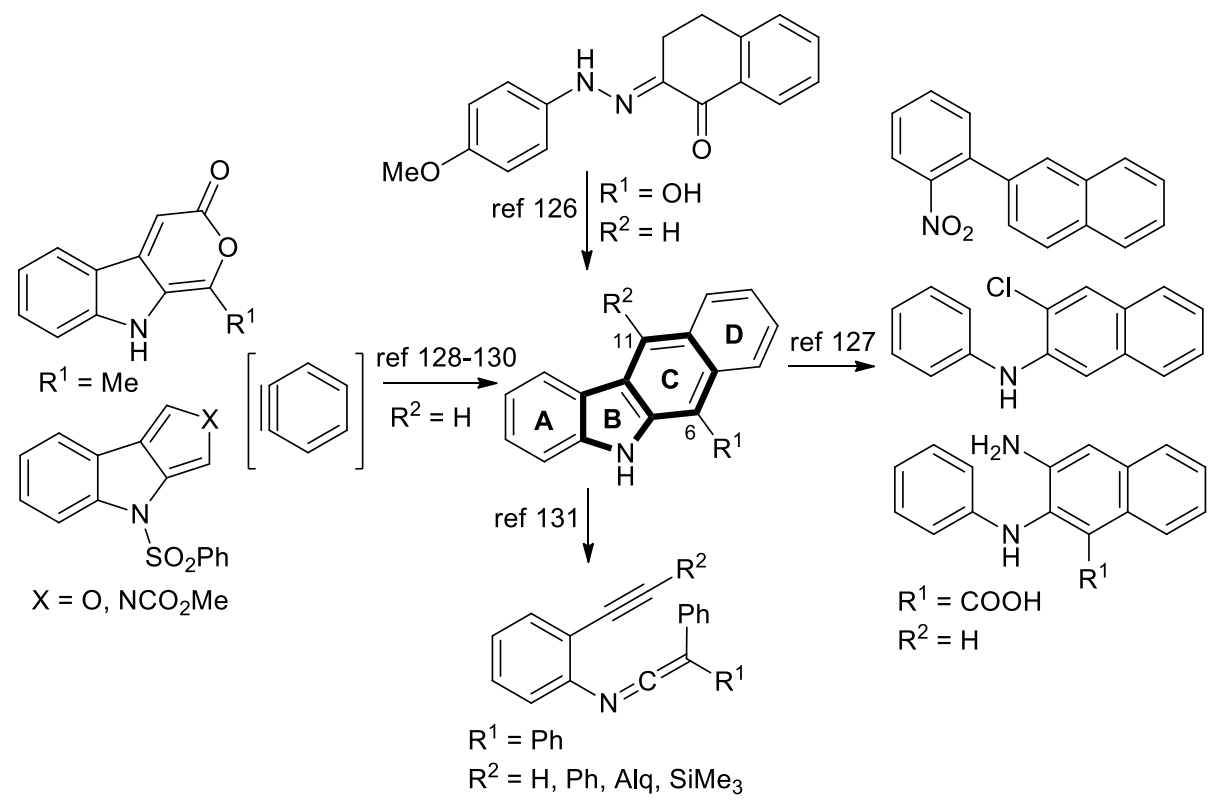

Esquema 3.1

Por otra parte, los derivados de ceteniminas, generadas in situ a partir de fosforanos, también han sido utilizados para la construcción de benzocarbazoles. ${ }^{131}$ Dentro de esta última estrategia, y a modo de ejemplo, se muestra la ciclación de la cetenimina $\mathbf{V}$ que dio lugar a la formación de los benzocarbazoles III con rendimientos entre moderados y muy buenos (Esquema 3.2). ${ }^{132}$ Esta metodología permite la construcción tanto del anillo $\mathbf{B}$ como $\mathbf{C}$ del heterociclo en un único paso de reacción. En cuanto al modelo de sustitución del anillo central, éste puede presentar en la posición 6 un sustituyente fenilo, un resto carbonílico o un hidrógeno, mientras que la posición 11 puede estar ocupada por un resto alquílico o aromático. Por su parte, la cetenimina de partida se genera in situ mediante una reacción aza-Wittig del fosforano I y la cetena IV, esta última obtenida por un reagrupamiento de Wolf de la $\alpha$-diazocetona II. Asimismo, el fosforano I se generó mediante una reacción de Staudinger sobre una $o$-alquinil azida (Esquema 3.2).

${ }^{131}$ C. Shi, K.-K. Wang, J. Org. Chem. 1998, 63, 3517-3520.

${ }^{132}$ Y. Xing, B. Hu, Q. Yao, P. Lu, Y. Wang, Chem. Eur. J. 2013, 19, 12788-12793. 
<smiles>[R]C#Cc1cc[R17]cc1N=P</smiles><smiles>[R]C(=[W])C(=O)c1ccc([R])cc1</smiles>
II

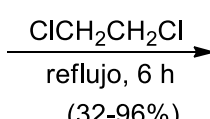

$(32-96 \%)$<smiles></smiles>

III

$\mathrm{R}^{1}=\mathrm{C}_{6} \mathrm{H}_{5}, p-\mathrm{MeC}_{6} \mathrm{H}_{4}, p-\mathrm{MeOC}_{6} \mathrm{H}_{4}, p-\mathrm{ClC}_{6} \mathrm{H}_{4}, n-\mathrm{C}_{5} \mathrm{H}_{11} \quad \mathrm{R}^{2}=\mathrm{H}, \mathrm{Me}, \mathrm{Cl}$ $\mathrm{R}^{3}=\mathrm{H}, \mathrm{Me}, \mathrm{OMe}, \mathrm{F}, \mathrm{Br} \mathrm{R}^{4}=\mathrm{H}, \mathrm{Ph}, \mathrm{CH}_{3} \mathrm{CO}$<smiles>[R]C#Cc1ccccc1N</smiles><smiles>[R]C#Cc1c(N=C=O)cccc1N=Pc1ccccc1</smiles>

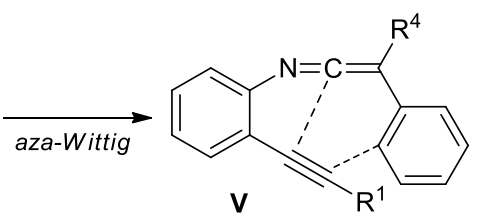

\section{Esquema 3.2}

Otra metodología empleada para la construcción de benzo[b]carbazoles consiste en la reacción dehidro-Diels-Alder (DIDA) de las inamidas VI (Esquema 3.3). ${ }^{133}$ El proceso tiene lugar en tolueno empleando altas temperaturas y permite la construcción tanto de arilbenzo[b]carbazoles VII como de heteroarilbenzo $[b]$ carbazoles IX, de manera directa y con buenos rendimientos. Sin embargo, el modelo de sustitución del anillo $\mathbf{C}$ se encuentra limitado a la presencia de hidrógeno, fenilo, o trimetilsililo. Cabe mencionar que el empleo de la reacción Diels-Alder y similares posee numerosas ventajas en términos de economía atómica, reducción de subproductos, y el no empleo de catalizadores metálicos. Sin embargo, en este caso la preparación de las inamidas de partida VI implica una secuencia de reacción de tres pasos a partir de la $o$-yodoanilina: una reacción de Sonogashira y $N$-tosilación, que dan lugar al producto VIII y, finalmente, una $N$-etinilación empleando una sal de (trimetilsilil)etinilyodonio (Esquema 3.3).

133 (a) M.-F. Martínez, D. Rodriguez, L. Castedo, C. Saá, Org. Lett. 2005, 7, 2213-2216. (b) M.-F. Martínez, D. Rodriguez, L. Castedo, C. Saá, Tetrahedron 2008, 64, 3674-3686. 

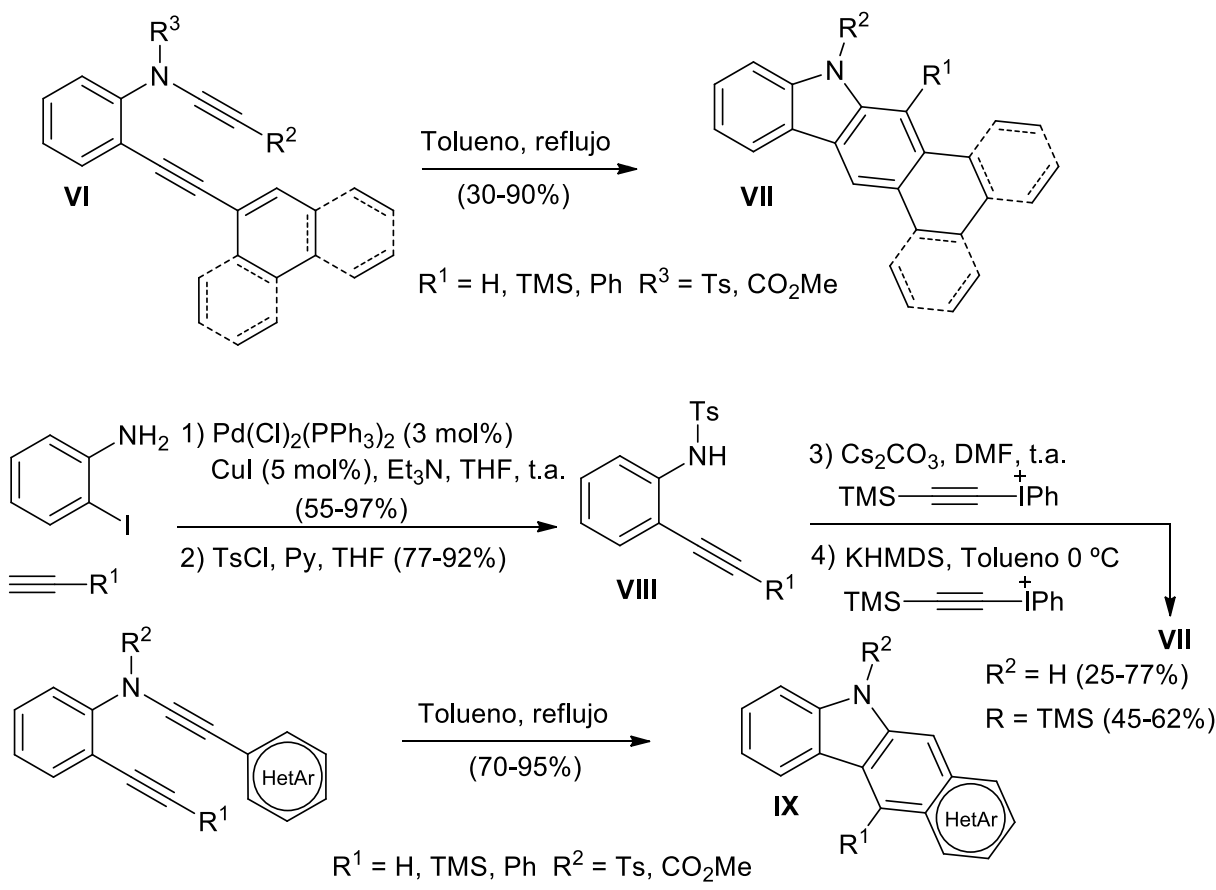

Esquema 3.3

Otra aproximación sintética para la obtención del esqueleto de benzo[b]carbazol consiste en la construcción del anillo $\mathbf{C}$ mediante procesos de benzanulación de indoles. Generalmente esta estrategia requiere la prefuncionalización del esqueleto indólico implicando secuencias de reacción multipaso. En este contexto, Kano y col. describieron la síntesis del 6metilbenzocarbazol XII, con un $26 \%$ de rendimiento, por tratamiento térmico del indol 2,3-disustituído XI. A su vez XI fue obtenido mediante una reacción de Wittig del 2-benzoilindol X. Por su parte, la introducción del grupo benzoilo en posición 2 del indol se llevó a cabo por tratamiento del 3-metil- $N$-sulfonilindol con LDA y anhídrido benzoico (Esquema 3.4). ${ }^{134}$

${ }^{134}$ S. Kano, E. Sugino, S. Shibuya, S. Hibino, J. Org. Chem. 1981, 46, 2979-2981. 


\section{Aproximación de Kano}

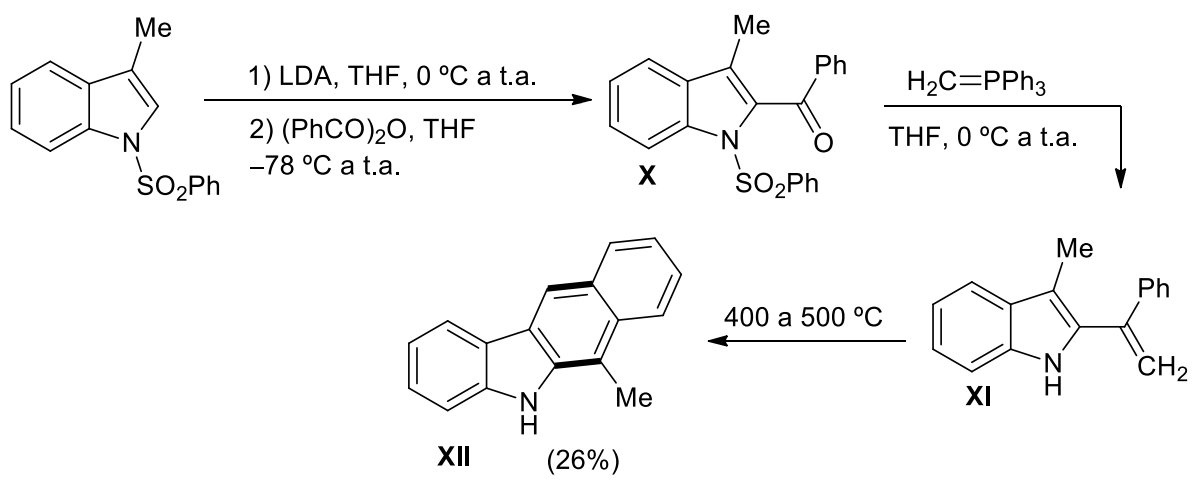

Esquema 3.4

Otras posibilidades para acceder al esqueleto de benzocarbazol, que además permiten la doble sustitución en el anillo central, se describen en el Esquema 3.5. Así, Koomen y col. construyeron el esqueleto de benzocarbazol 6,11-diona XIII a partir de indoles y anhídrido ftálico. ${ }^{135}$ La adición de metillitio sobre XIII, y posterior deshidratación, dio lugar al benzocarbazol XIV con buen rendimiento. Sin embargo, con esta ruta los sustituyentes sobre las posiciones 6 y 11 tienen que ser necesariamente iguales.

Esta limitación fue resuelta posteriormente por Gribble y col. Estos autores emplearon una estrategia sintética similar a la anteriormente descrita, pero a partir de la indolo[1,2- $b$ ]isoquinolina-6,11-diona XV. Aprovechando la diferente electrofilia que poseen ambos grupos carbonilo en $\mathbf{X V}$ pudieron obtener benzocarbazoles con sustituyentes diferentes en posiciones 6 y 11 (Esquema 3.5). ${ }^{136} \mathrm{Y}$ así, la adición de MeLi a XV seguido de tratamiento con $n$-BuLi condujo a la formación de XVI con un $61 \%$ de rendimiento, mientras que el regioisómero XVII fue aislado como producto minoritario. La inversión en el orden de adición de los organolíticos dio lugar a XVII, aislado en este caso como producto mayoritario con un $72 \%$ de rendimiento. El esquema también recoge la retrosíntesis de XV que implica una secuencia de 4 pasos partiendo de indol y anhídrido ftálico (Esquema 3.5)

\footnotetext{
${ }^{135}$ A.-T. Boogaard, U.-K, Pandit, G.-J. Koomen, Tetrahedron 1994, 50, 4811-4824.

${ }^{136}$ H.-L. Fraser, G.-W, Gribble, Can. J. Chem. 2001, 79, 1515-1521.
} 


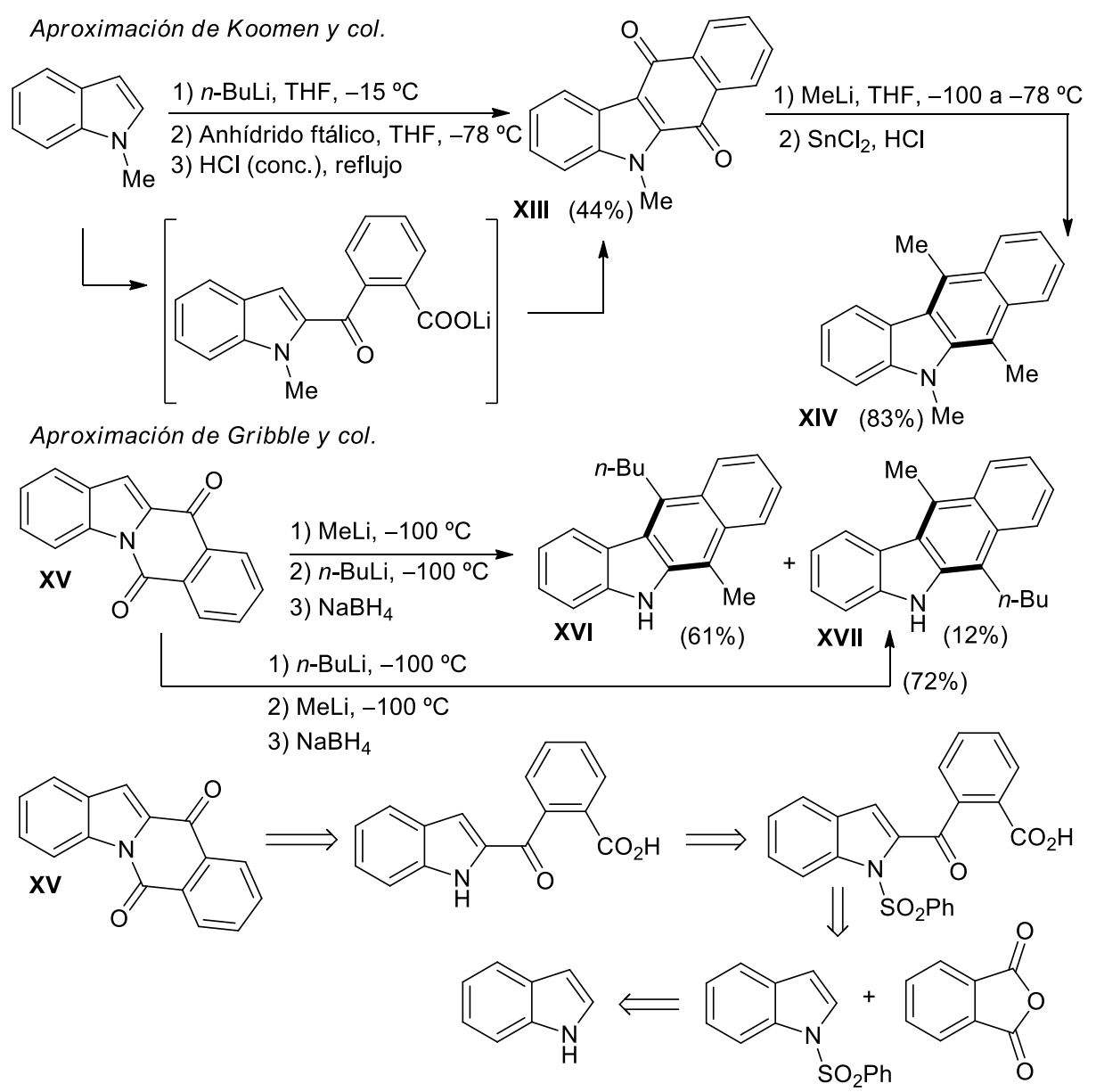

Esquema 3.5

Las metodologías comentadas hasta el momento para acceder a benzo[ $b]$ carbazoles poseen innumerables inconvenientes. Por una parte, cabría mencionar el empleo de condiciones drásticas de reacción (altas temperaturas, empleo de medios fuertemente ácidos), el uso de catalizadores metálicos, y la preparación de los productos de partida que, en muchas ocasiones requiere secuencias de varios pasos de reacción. Por otra parte, el empleo de reactivos organolíticos en cantidades estequiométricas limita el alcance de la reacción debido a la incompatibilidad con otros grupos funcionales. Muchas de estas metodologías también requieren uso de atmósfera inerte y bajas temperaturas, lo que podría ser una desventaja desde el punto de vista operacional. Además, su falta de flexibilidad conduce a carbazoles con modelos de sustitución limitados debido a la naturaleza de los materiales de partida. 
Teniendo en cuenta todo lo anterior se concluye que el desarrollo de nuevas rutas para preparar benzo[b]carbazoles que empleen indoles 2,3 no funcionalizados resulta muy interesante ya que son aproximaciones más directas que reducen el número de pasos de reacción. En este sentido, Black y col. describieron la síntesis de benzo[b]carbazoles a partir de indoles y ftaldialdehído en presencia de $\mathrm{POCl}_{3}$, lo que condujo a los 11-indolilbenzo[ $b$ ]carbazoles XVIII con buenos rendimientos (Esquema 3.6). ${ }^{137}$

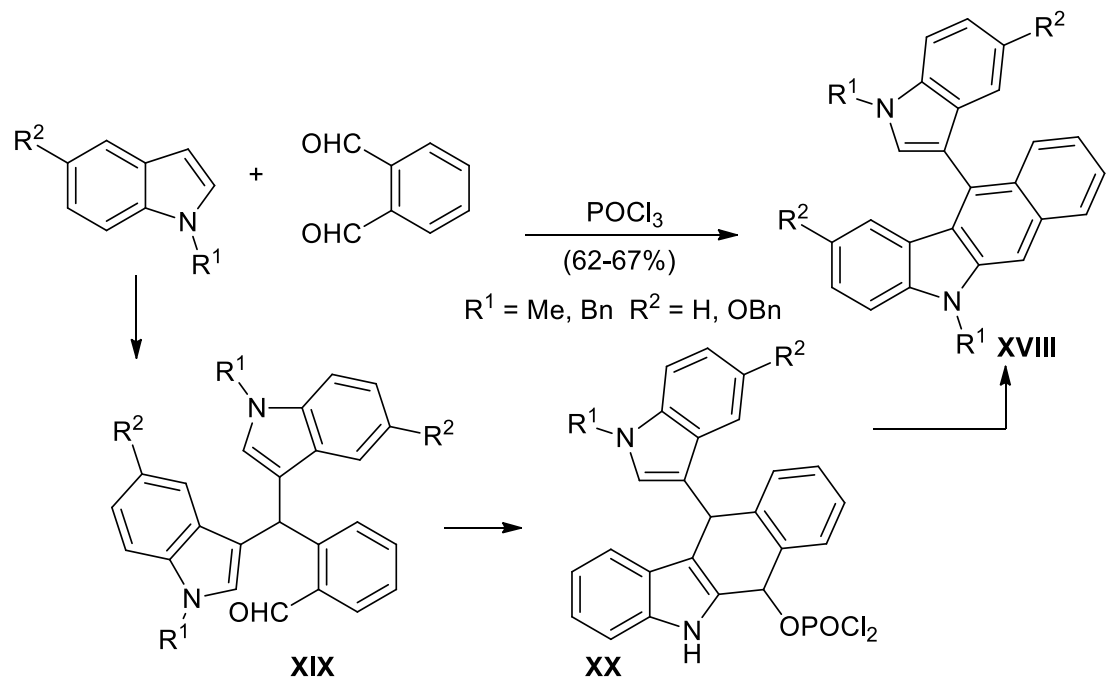

Esquema 3.6

Sin embargo, el mismo proceso, pero bajo catálisis con PTSA y metanol como disolvente, dio lugar al 6-indolilbenzo[b]carbazol XXI (Esquema 3.7). Los autores justifican este cambio en la selectividad del proceso por las diferencias que presenta la velocidad de la reacción bajo ambas condiciones. Así, en el primer caso la reacción es más rápida y tiene lugar a través del bisindol XIX que, posteriormente, ciclaría a través del C-2 del indol para dar lugar a $\mathbf{X X}$ que, tras una reacción de eliminación, conduce al 11-indolilbenzo[b]carbazol XXI de forma selectiva. Sin embargo, al emplear como catalizador un ácido más débil en metanol, se produce una disminución de la velocidad de la reacción lo que permite la existencia del diol XXII como intermedio. A partir de este diol una nueva ciclación a través del C-2 del indol conduciría, tras deshidratación, al 6indolilbenzo[ $b]$ carbazol final XXI.

${ }^{137}$ D. Black, D.-C. Craig, M. Santoso, Tetrahedron Lett. 1999, 40, 6653-6656. 
2

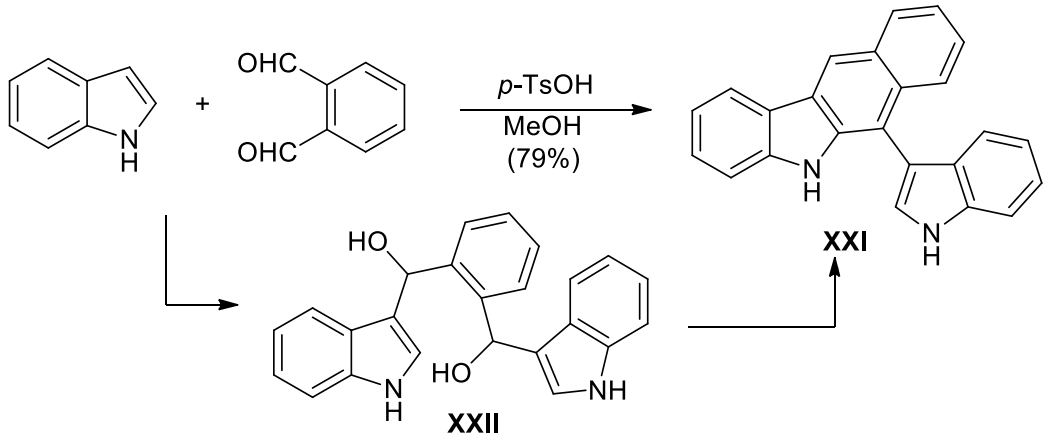

Esquema 3.7

Una ruta sintética más reciente, basada en la capacidad que poseen los metales de transición para activar enlaces múltiples $\mathrm{C}-\mathrm{C}$, consiste en la reacción de $o$-(alquinil)benzaldehídos XXIII e indoles 2,3 no sustituídos catalizada por $\mathrm{Pd}(\mathrm{II})$ (Esquema 3.8). ${ }^{138} \mathrm{El}$ proceso conduce a la formación de los benzo $[b]$ carbazoles XXIV con buenos rendimientos mediante una ciclación electrocíclica del intermedio A. La reacción proporciona una metodología muy directa para acceder a benzo $[b]$ carbazoles sin necesidad de prefuncionalización en el indol. Sin embargo, esta metodología es poco flexible ya que los carbazoles a los que se accede presentan siempre el mismo patrón de sustitución sobre C-6 y C-11, grupo carbonilo e hidrógeno, respectivamente.<smiles>[R]C#Cc1ccccc1C=O</smiles>

XXIII

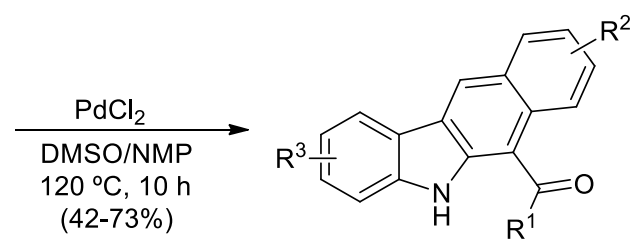

$(42-73 \%)$

$\mathrm{R}^{1}=\mathrm{Ph}, 4-\mathrm{MeC}_{6} \mathrm{H}_{4}, 4-\mathrm{MeOC}_{6} \mathrm{H}_{4}, 4-\mathrm{MeCOC}_{6} \mathrm{H}_{4}, n-\mathrm{Hex} \mathrm{R}^{2}=\mathrm{F}, \mathrm{Me} \quad$ XXIV $\mathrm{R}^{3}=5-\mathrm{Br}, 7-\mathrm{NO}_{2}, 7-\mathrm{Et}$

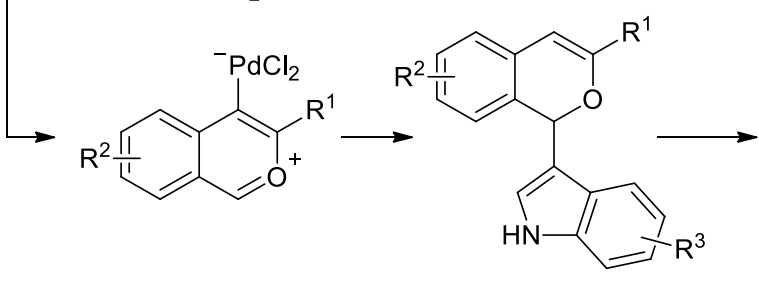

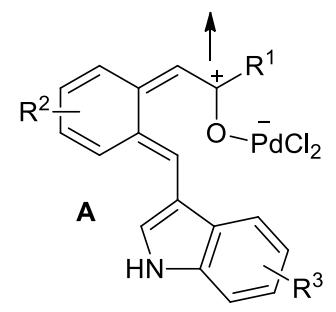

\section{Esquema 3.8}

${ }^{138}$ R.-Y. Tang, J.-H. Li, Chem. Eur. J. 2010, 16, 4733-4738. 


\subsection{OBJETIVO}

A la vista de estos antecedentes cabe mencionar que a pesar de que en la bibliografía se han descrito una gran variedad de metodologías para acceder a benzo $[b]$ carbazoles, todos ellas presentan en mayor o menor medida numerosos inconvenientes entre los que cabe destacar las condiciones drásticas de reacción, la prefuncionalización de los materiales de partida, así como los limitados modelos de sustitución que se obtienen en muchos casos.

Teniendo esto en mente, y siendo conscientes de la necesidad de poner a punto nuevas aproximaciones sintéticas para la preparación de benzocarbazoles de manera más directa, pensamos que una posible desconexión retrosintética hacia este heterociclo podría implicar un indol 2,3-no sustituído como equivalente sintético de un sintón doblemente negativo mientras que, un acetal de benzaldehído $o$-hidroxialquil-funcionalizado podría emplearse como equivalente sintético de un sintón doblemente positivo (Esquema 3.9). Además, basándonos en nuestra experiencia en el empleo de PTSA como catalizador en reacciones de alquilación de indoles con alcoholes, nos propusimos llevar a cabo la reacción bajo las condiciones estándar descritas por el grupo. De funcionar esta estrategia sería una alternativa muy útil para la síntesis de benzocarbazoles, complementaria a las ya existentes, y que además podría tener lugar de manera más directa y en condiciones más suaves de reacción.

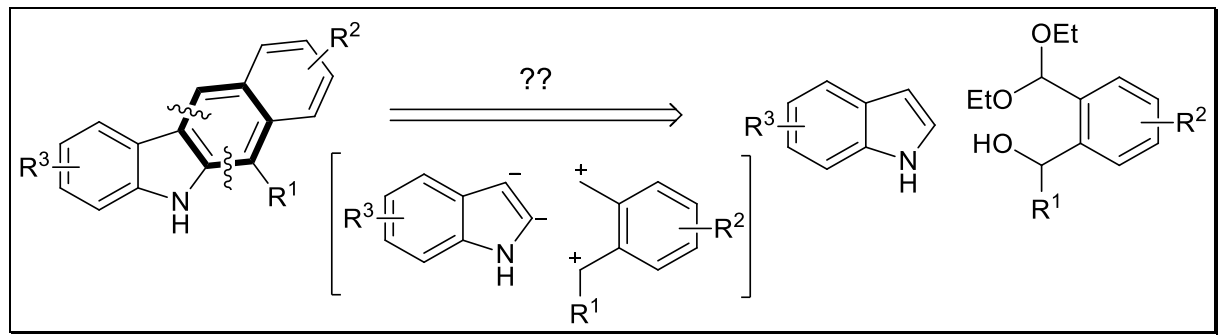

Esquema 3.9

\subsection{DISCUSIÓN DE RESULTADOS}

\subsubsection{Síntesis de los hidroxiacetales de partida 32}

Para abordar el objetivo planteado en este Capítulo nos propusimos sintetizar una serie de acetales de benzaldehído $o$-hidroxialquil sustituídos 32 (Tabla 3.1). Su preparación se llevó a cabo por reacción de intercambio halógeno-metal entre el dietil acetal del 2-bromobenzaldehído 31a, producto comercialmente 
asequible, seguida de una adición nucleofílica del organolítico resultante al correspondiente compuesto carbonílico.

Tabla 3.1 Síntesis de los hidroxiacetales de partida 32

\begin{tabular}{|c|c|c|c|c|}
\hline Entrada & $\mathbf{R}^{1}$ & $\mathbf{R}^{2}$ & Producto & $\operatorname{Rto}(\%)^{\mathbf{a}}$ \\
\hline 1 & $\mathrm{H}$ & $\mathrm{Ph}$ & $32 \mathbf{a}$ & 66 \\
\hline 2 & $\mathrm{H}$ & $4-\mathrm{ClC}_{6} \mathrm{H}_{4}$ & $32 \mathbf{b}$ & $77^{\mathrm{b}}$ \\
\hline 3 & $\mathrm{H}$ & 4- $\mathrm{BrC}_{6} \mathrm{H}_{4}$ & $32 \mathrm{c}$ & $81^{\mathrm{b}}$ \\
\hline 4 & $\mathrm{H}$ & $4-\mathrm{MeOC}_{6} \mathrm{H}_{4}$ & 32d & 85 \\
\hline 5 & $\mathrm{H}$ & $2,3,4-(\mathrm{MeO})_{3} \mathrm{C}_{6} \mathrm{H}_{2}$ & $32 \mathrm{e}$ & 67 \\
\hline 6 & $\mathrm{H}$ & 2-Naftil & $32 f$ & 69 \\
\hline 7 & $\mathrm{H}$ & 2-Th & $32 \mathrm{~g}$ & 88 \\
\hline 8 & $\mathrm{H}$ & 3-Me-2-Th & 32h & $69^{\mathrm{b}}$ \\
\hline 9 & $\mathrm{H}$ & 5-Me-2-Fur & $32 \mathrm{i}$ & 78 \\
\hline 10 & $\mathrm{H}$ & $\mathrm{PhC} \equiv \mathrm{C}$ & $32 \mathbf{j}$ & 60 \\
\hline 11 & $\mathrm{H}$ & $c-\mathrm{C}_{3} \mathrm{H}_{5}$ & $32 \mathrm{k}$ & 75 \\
\hline 12 & $\mathrm{H}$ & $n-\mathrm{Bu}$ & 321 & 81 \\
\hline 13 & $\mathrm{Me}$ & $4-\mathrm{MeOC}_{6} \mathrm{H}_{4}$ & $32 \mathrm{~m}$ & $82^{b}$ \\
\hline 14 & $\mathrm{Me}$ & 2-Th & $32 n$ & $83^{b}$ \\
\hline 15 & $\mathrm{Me}$ & $\mathrm{PhC} \equiv \mathrm{C}$ & 320 & $79^{b}$ \\
\hline 16 & $\mathrm{Me}$ & $c-\mathrm{C}_{3} \mathrm{H}_{5}$ & $32 p$ & $80^{\mathrm{b}}$ \\
\hline 17 & $\mathrm{Me}$ & (E) $-\mathrm{PhCH}=\mathrm{CH}$ & $32 q$ & 91 \\
\hline 18 & $\mathrm{Ph}$ & (E) $-\mathrm{PhCH}=\mathrm{CH}$ & $32 r$ & 68 \\
\hline 19 & $4-\mathrm{ClC}_{6} \mathrm{H}_{4}$ & $4-\mathrm{ClC}_{6} \mathrm{H}_{4}$ & $32 \mathrm{~s}$ & $90^{\mathrm{b}}$ \\
\hline 20 & 4- $\mathrm{MeOC}_{6} \mathrm{H}_{4}$ & 4- $\mathrm{MeOC}_{6} \mathrm{H}_{4}$ & $32 t$ & $80^{\mathrm{b}}$ \\
\hline
\end{tabular}

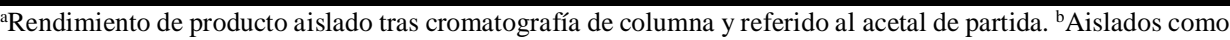
mezclas de diastereoisómeros de los correspondientes acetales cíclicos 32'. 2-Th $=2$ - tienilo. 3-Me-2-Th $=3$ metil-2-tienilo. 5-Me-2-Fur = 5-metil-2-furilo. 
Con esta sencilla metodología se han preparado una serie de alcoholes de partida cuyos rendimientos se muestran en la Tabla 3.1. Hay que destacar que estos acetales hidroxifuncionalizados $\mathbf{3 2}$ se pueden encontrar en equilibrio con los correspondientes acetales cíclicos 32', hecho que se observa en diferente medida para cada sustrato y dependiendo también del disolvente deuterado empleado para su caracterización (Esquema 3.10).<smiles>[R]C([R])(O)c1ccccc1C(OCC)OCC</smiles>

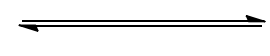

Esquema 3.10<smiles>[R]C1([R])O[C@@H](OCC)c2ccccc21</smiles>

\section{.}


La misma estrategia fue extendida también a la preparación de acetales $o$ hidroxialquil funcionalizados derivados de los aldehídos heterocíclicos 34 y 36ad, permitiendo acceder a los hidroxiacetales 35 y $\mathbf{3 7 - 4 0}$ con rendimientos entre moderados y buenos (Esquemas 3.11 y 3.12).<smiles>CCOC(OCC)c1sc2ccccc2c1Br</smiles>

34
1) $n$-BuLi (1 eq), THF, $-78^{\circ} \mathrm{C}$

2) (1 eq) $\stackrel{O}{\|} \mathrm{THF},-78^{\circ} \mathrm{C}$ a t.a.

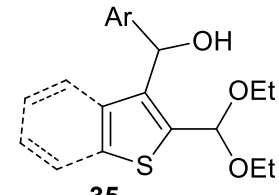

35

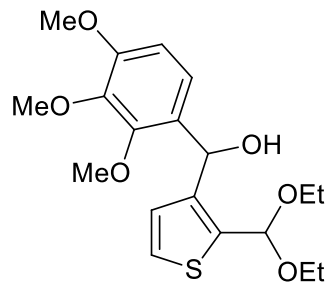

$35 a(70 \%)$

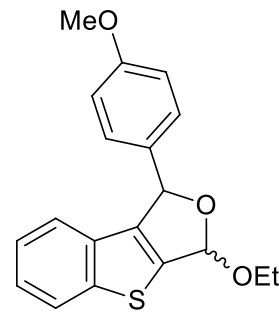

35b r.d. 1,7:1 (40\%)

\section{Esquema 3.11}
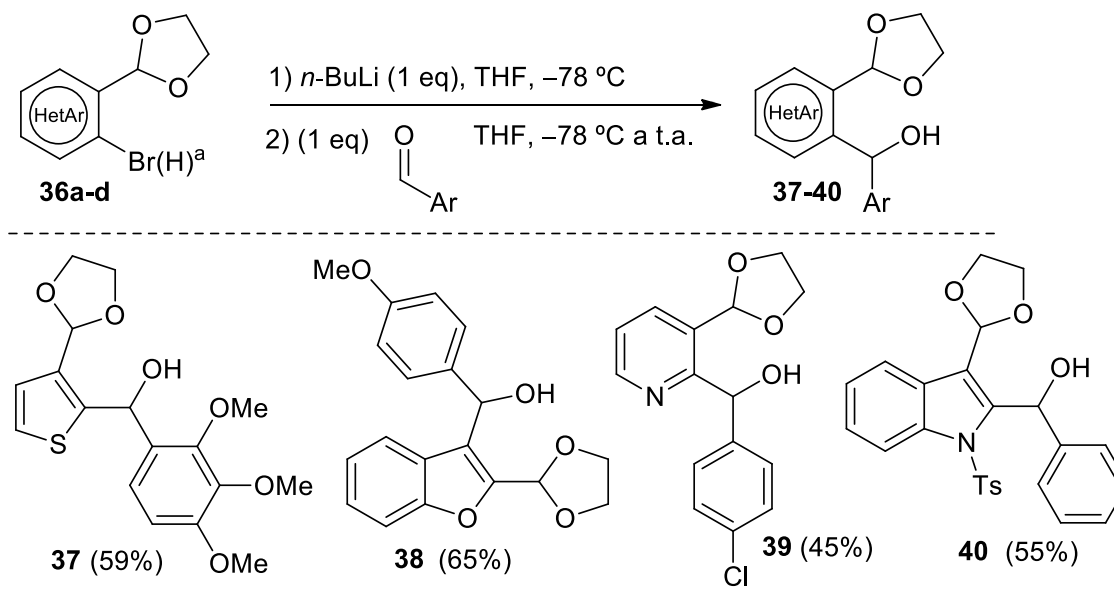

${ }^{a}$ Reacción llevada a cabo empleando $n$-BuLi (1,2 eq), aldehído (1,2 eq).

\section{Esquema 3.12}




\subsubsection{Estudio de la reactividad de los acetales hidroxialquil funcionalizados con indoles}

\subsubsection{Pruebas preliminares}

Inicialmente nos planteamos llevar a cabo la reacción entre el $N$-metilindol 19c y el acetal 32b empleando PTSA como catalizador. Esta reacción, a temperatura ambiente durante $24 \mathrm{~h}$, condujo a la obtención, tras purificación cromatográfica, de un producto con estructura de benzocarbazol, 41b, que se aisló como producto mayoritario con un $40 \%$ de rendimiento. Posteriormente, y con el objetivo de identificar posibles intermedios de reacción, repetimos el mismo proceso, pero a tiempos más cortos. En este caso el resultado obtenido fue completamente diferente. Y así, tras purificación cromatográfica se aislaron un producto con estructura de isobenzofurano, $\mathbf{4 2 b}$, que se obtuvo con un $38 \%$ de rendimiento, y el bisindolilmetano $\mathbf{4 3 b}$ con un $32 \%$ de rendimiento (Esquema 3.13). Estos resultados nos llevaron a pensar que el mecanismo implicado en la formación de los benzocarbazoles $\mathbf{4 1}$ no es directo, sino que podrían estar involucrados los productos $\mathbf{4 2}$ y $\mathbf{4 3}$ como intermedios.
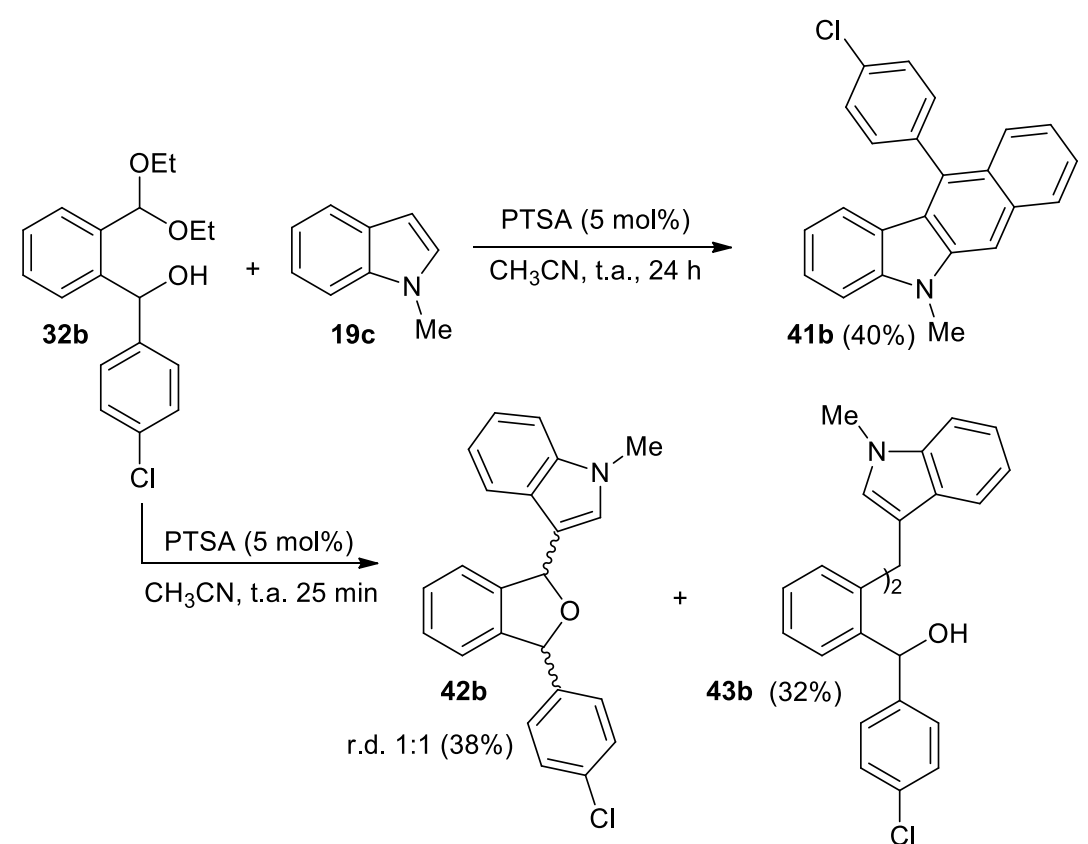

Esquema 3.13 
Teniendo en cuenta que únicamente se observó la formación del isobenzofurano $\mathbf{4 2 b}$ y del bisindolilmetano 43 b cuando la reacción se llevó a cabo a temperatura ambiente y tiempos cortos, nos planteamos la posibilidad de que estas especies fueran intermedios en la obtención del benzocarbazol 41b. Para comprobar esta suposición se llevaron a cabo dos pruebas cualitativas. Por una parte, la evolución a temperatura ambiente del isobenzofurano 42b durante $24 \mathrm{~h}$ en presencia de PTSA condujo a una mezcla de 42b:41b (4:1). Por otra parte, la reacción del 3,3'-BIM 43b con PTSA durante 24 h dio lugar al benzocarbazol 41b y a la liberación de una molécula de $N$-metilindol 19c (Esquema 3.14). Por lo tanto, ambos experimentos apoyan que tanto el isobenzofurano $\mathbf{4 2}$ como el 3,3’-BIM 43 sean intermedios en la formación del benzocarbazol 41.

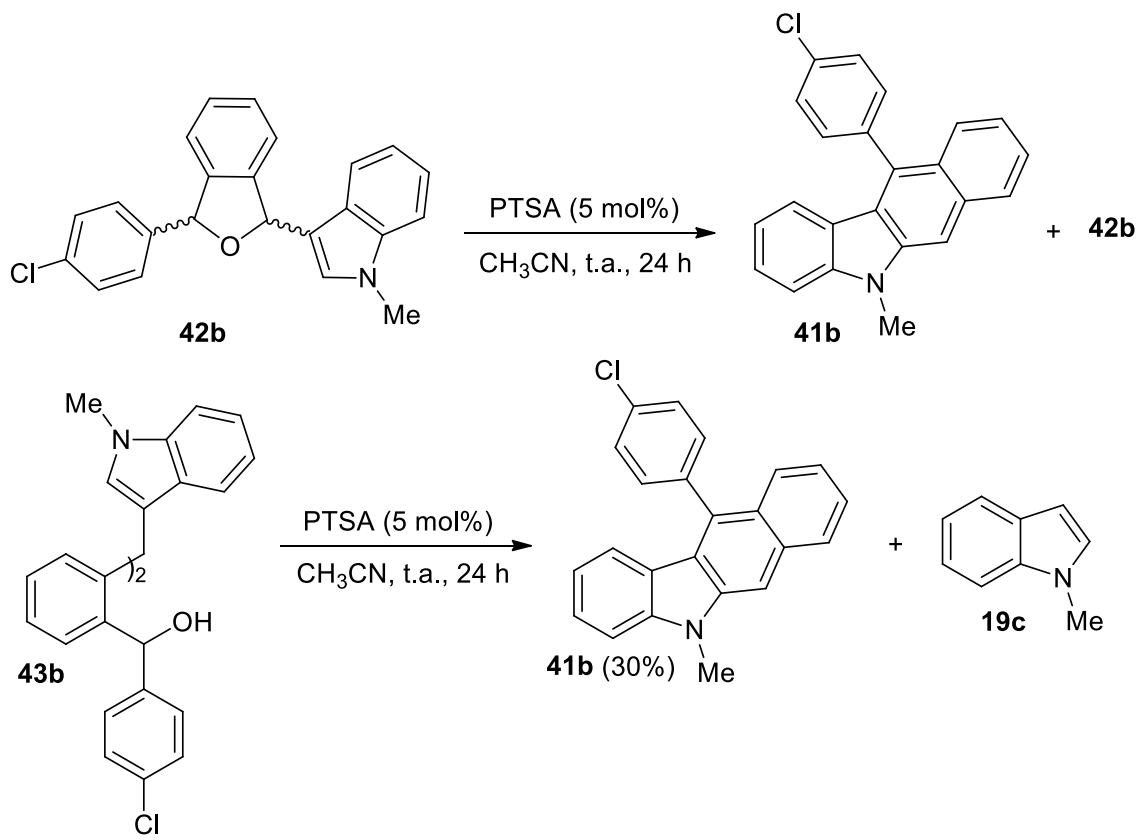

\section{Esquema 3.14}

\subsubsection{Mecanismo de formación del carbazol 41, el isobenzofurano 42 y el 3,3'- BIM 43}

Apoyándonos en las observaciones experimentales hemos propuesto el mecanismo que se representa en los Esquemas 3.14 y 3.15. En primer lugar, el ácido de Brønsted activaría un grupo etoxilo en 32, lo que provocaría la eliminación de una molécula de etanol dando lugar así al catión oxonio A que estaría en equilibrio con el acetal $\mathbf{3 2}^{\prime}$ con pérdida de un protón. Una activación 
del segundo grupo etoxilo por parte del catalizador ácido provocaría una segunda eliminación de etanol generando el catión oxonio cíclico B. Este intermedio es muy electrofílico y en presencia de un nucleófilo, tal como el $N$-metilindol 19c, sufriría una reacción F.-C. generándose el intermedio iminio $\mathbf{C}$ que, tras la eliminación de un protón, conduciría a la formación del isobenzofurano 42 (Esquema 3.15).<smiles>CCOC(O)c1ccccc1C(Br)Br</smiles><smiles>CCOC(=O)c1ccccc1C(O)C(Br)Br</smiles><smiles>[CH+]/C=C/c1ccc2c(c1)[C@@H](OCC)OC2Br</smiles>

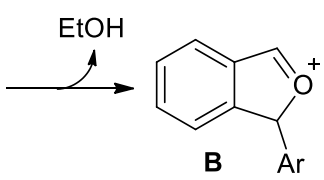<smiles>CO[Y]n1cc([C@H]2OC([Al])c3ccccc32)c2ccccc21</smiles><smiles>Cc1ccccc1C1OC(Br)c2ccccc21</smiles><smiles>Cn1ccc2ccccc21</smiles>

Esquema 3.15

Este isobenzofurano $\mathbf{4 2}$, como se ha demostrado en las pruebas cualitativas descritas en el Esquema 3.14, ha de ser un intermedio en la formación del benzocarbazol 41. Esto se justifica si tenemos en cuenta que en presencia del catalizador ácido el isobenzofurano podría protonarse evolucionando bien hasta el intermedio D, o bien hasta el intermedio espiránico $\mathbf{E}$ mediante el ataque intramolecular del indol isobenzofurano protonado (Esquema 3.16). A partir de D el ataque de una segunda molécula de indol conduciría a la formación del 3,3'BIM 43. Nosotros postulamos que la transformación de 42 a 43 es un equilibrio, de modo que a partir del 3,3'-BIM la eliminación de una molécula de indol conduciría nuevamente al isobenzofurano 42. Sin embargo, el intermedio $\mathbf{E}$ podría evolucionar mediante una migración 1,2 bien del resto hidroxialquilo, o bien del resto alquílico terciario. Esta migración provocaría la expansión del anillo, de forma tal que, si la reacción tiene lugar a través de la via a (migración de hidroxialquilo) se obtendría el nuevo carbocatión $\mathbf{F}$ que, tras la pérdida de un protón para recuperar la aromaticidad, conduciría a la formación del alcohol $\mathbf{G}$ en el que la eliminación de una molécula de agua daría lugar a 41. Un camino alternativo implicaría la via $b$ (migración del resto bencílico) a través de la cual se obtendría, tras la eliminación de un protón en $\mathbf{F}$ ', el alcohol secundario $\mathbf{G}$ ' 
regioisómero de G. A partir de este alcohol una protonación seguida de la eliminación de una molécula de agua conduciría al catión indoleniminio $\mathbf{H}$ en el que una migración 1,4 del resto arilo desde la posición 6 a la 11, seguido de la pérdida de un protón, daría lugar también a 41 (Esquema 3.16).<smiles>Cn1cc(C2OC(Br)c3ccccc32)c2ccccc21</smiles><smiles>C=C[O+]1[C](c2cn(C)c3ccccc23)c2ccccc2C1Br</smiles><smiles>C[N+]1=C/C(=C\c2ccccc2C(O)C2CCCCC2)c2ccccc21</smiles><smiles>CC(C)c1ccccc1Cc1cn(C)c2ccccc12</smiles>

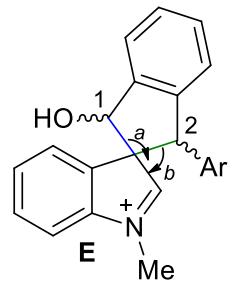<smiles>[13CH]</smiles><smiles>CN1c2ccccc2[C@H]2C(Br)c3ccccc3[C@@H](O)[C@@H]21</smiles><smiles>[CH+]C(C)C</smiles><smiles>Cn1c2c(c3ccccc31)C(Br)c1ccccc1[C@@H]2O</smiles><smiles>C[14CH]([14CH3])O</smiles><smiles>CN1c2ccccc2[C@@H]2C1C(Br)c1ccccc1[C@@H]2O</smiles>

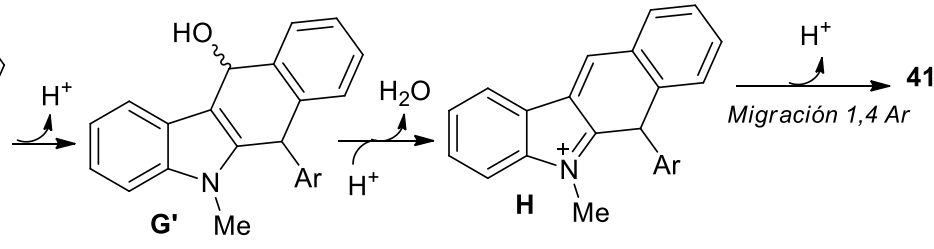

Esquema 3.16

Cabe mencionar que la migración 1,2 que se produce sobre el intermedio indoleniminio $\mathbf{E}$ es un reagrupamiento conocido como Ciamician-Plancher y ha sido ampliamente estudiado. ${ }^{139}$ Estudios preliminares habían demostrado que la selectividad en el resto que migra depende de su capacidad migratoria. Así se ha encontrado que el orden de migración para estos grupos es: $\mathrm{Me}<\mathrm{Et}<i$ - $\mathrm{Pr}<$ alilo $<\mathrm{CH}_{2} \mathrm{Ph}$, lo que está en concordancia con otras migraciones 1,2 como la transposición pinacolínica, o la de Wagner-Meerwein. Además, en el capítulo de Antecedentes Generales de esta Tesis se han revisado algunas metodologías que implican migraciones 1,2 sobre intermedios análogos a E. Para todos esos ejemplos se describió cómo, en general, se producía la migración selectiva de un

139 (a) A.-H. Jackson, P.-P. Lynch, J. Chem. Soc., Perkin Trans. II, 1987, 1215-1219. (b) Y. Kanaoka, K. Miyashita, O. Yonemitsu, Chem. Commun. 1969, 1365. 
grupo alquenilo $\left(\mathrm{Csp}^{2}\right)$ con preferencia a un resto alquílico $\left(\mathrm{Csp}^{3}\right)$. Sin embargo, también era conocido que la presencia de un resto hidroxialquilo era capaz de invertir la selectividad observada hacia la migración del resto alquílico con preferencia al alquenilo (ver págs. 20-22). En base a estos antecedentes, lo más probable es que en nuestro caso la reacción tenga lugar a través de la via a en la que se propone la migración selectiva de un resto hidroxialquilo frente a uno bencílico (Esquema 3.16).

\subsubsection{Optimización de las condiciones de reacción}

Dado el potencial de esta nueva reacción y la interesante estructura del benzocarbazol 41 nos propusimos mejorar el rendimiento del proceso que conduce a su formación. Para ello elegimos como sustrato modelo el alcohol 32a y se le hizo reaccionar con $N$-metilindol 19c bajo diferentes condiciones de reacción (Tabla 3.3). En primer lugar, evaluamos el efecto que produciría sobre la reacción un cambio del tipo de catalizador. Para ello se emplearon varios catalizadores ácidos tanto de Lewis como de Brønsted, llevando a cabo todas las reacciones a temperatura ambiente. De los resultados obtenidos, y mostrados en la Tabla 3.4, se desprende que todos los ácidos de Lewis ensayados conducían mayoritariamente a la formación del isobenzofurano 42a (entradas 1-4). Sin embargo, cuando la reacción se lleva a cabo en presencia de ácidos de Brønsted se empezaba a observar la formación del benzocarbazol 41a (entradas 5-6). Un aumento en la carga de PTSA condujo a la formación del carbazol final 41a con muy buen rendimiento (entrada 7). Además, se comprobó que el empleo de $\mathrm{CH}_{2} \mathrm{Cl}_{2}$ como disolvente conducía a resultados similares en cuanto al rendimiento de la reacción (entrada 8). Sin embargo, el empleo de $\mathrm{CH}_{3} \mathrm{NO}_{2}$ no mejoró el proceso, sino que únicamente condujo a la formación de productos de descomposición. Por lo tanto, tras este pequeño estudio se puede concluir que las mejores condiciones para favorecer la formación del benzocarbazol es el empleo de $20 \mathrm{~mol} \%$ de PTSA en acetonitrilo. 
Tabla 3.3 Optimización de las condiciones de reacción entre el $N$-metilindol 19 c y el hidroxiacetal $32 \mathbf{a}^{a}$

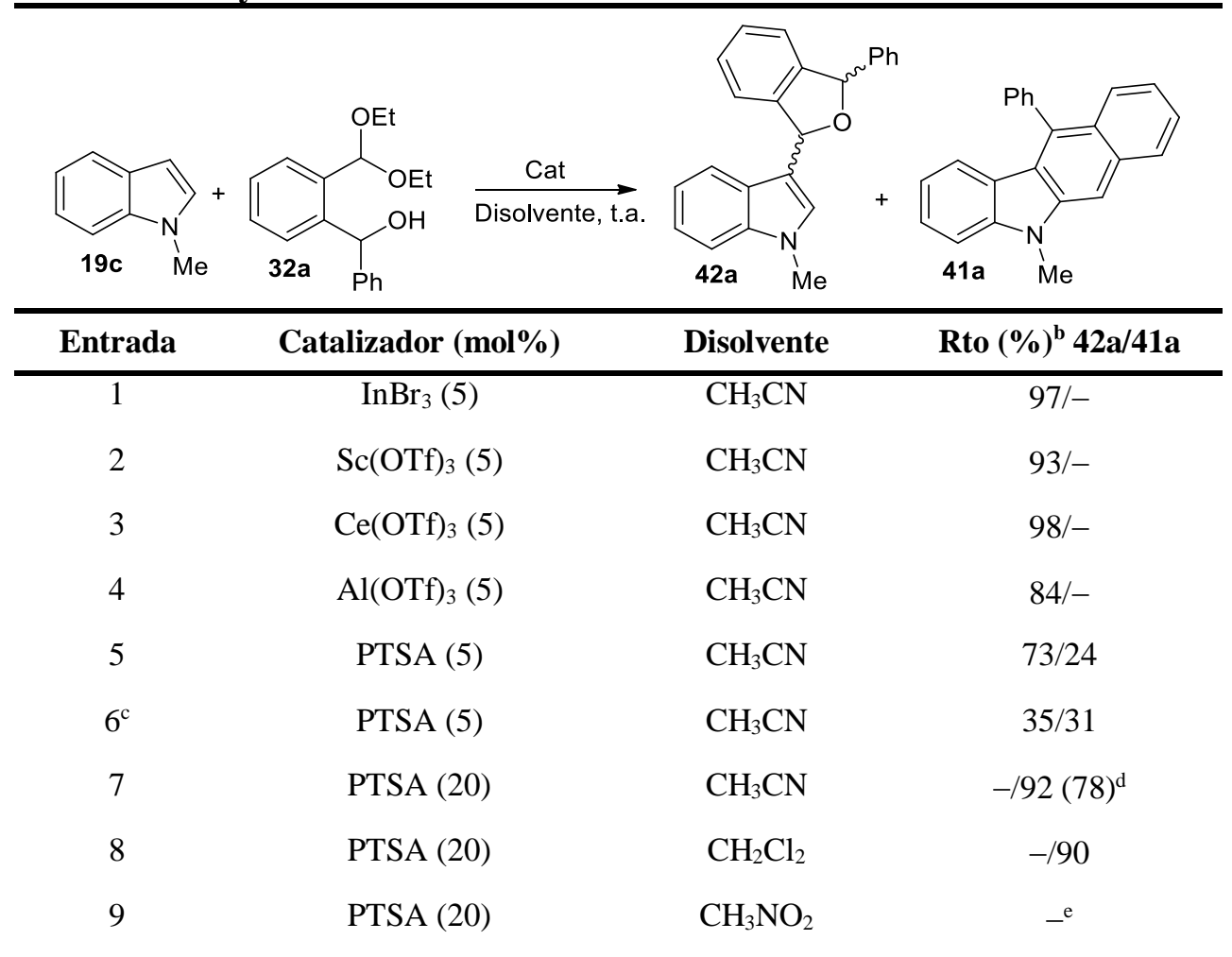

${ }^{a}$ Condiciones de reacción: el catalizador se añade a una disolución de $19 c(0,20 \mathrm{mmol})$ y 32a $(0,20 \mathrm{mmol})$ en $0,5 \mathrm{ml}$ de disolvente $(16 \mathrm{~h})$. ${ }^{\text {b}} \mathrm{Rendimiento} \mathrm{calculado} \mathrm{por}{ }^{1} \mathrm{H}-\mathrm{RMN}$ empleando $\mathrm{CH}_{2} \mathrm{Br}_{2}$ como patrón interno.

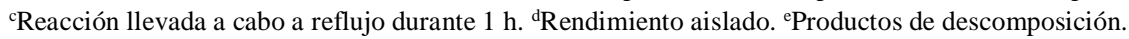

\subsubsection{Alcance de la reacción: Síntesis de los benzo[b]carbazoles 41}

Una vez establecido el empleo de PTSA (20 mol\%) como el mejor catalizador decidimos evaluar el alcance de esta reacción estudiando la posible influencia de la sustitución en $\alpha$ al grupo hidroxilo (Tabla 3.4). En primer lugar, estudiamos la reactividad de los hidroxiacetales secundarios 32a-i que poseen un sustituyente arílico en la posición $\alpha$ al grupo hidroxilo. De manera general la reacción de estos alcoholes, bajo las condiciones descritas, transcurre de manera suave cuando se emplea como nucleófilo tanto el $N$-metilindol 19c (entradas 1-9) como el $\mathrm{NH}$-indol 19a (entradas 10-18), e indoles sustituídos en posición 5 por grupos electrón atractores (entradas 15-18). En la mayoría de los casos la reacción dio lugar a los correspondientes benzocarbazoles $\mathbf{4 1}$ con rendimientos elevados. Además, los compuestos se aíslan en ocasiones por simple filtración lo que supone una gran ventaja experimental. 


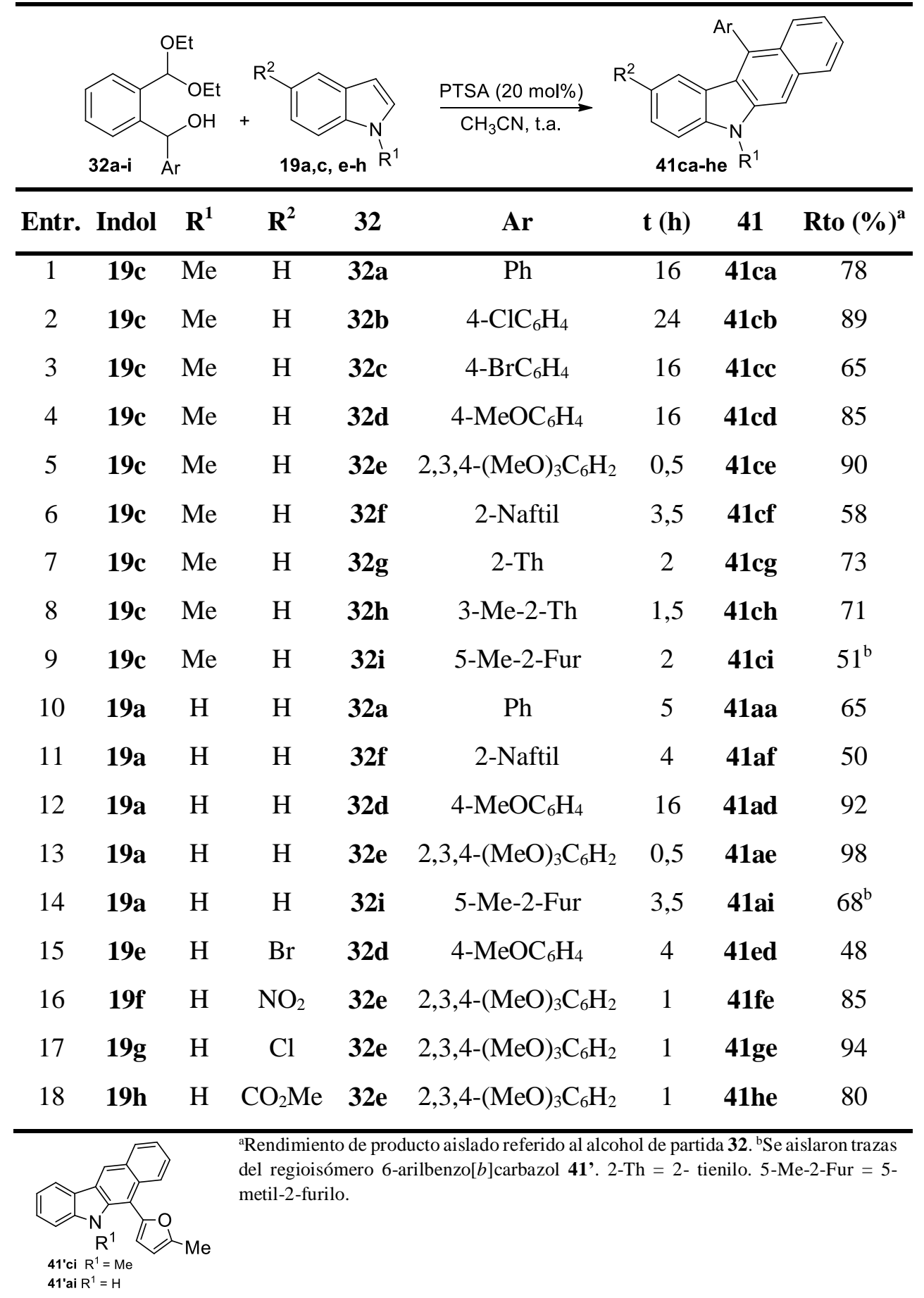


En la práctica totalidad de los ejemplos estudiados la reacción es completamente regioselectiva hacia la formación del 11-arilbenzo[b]carbazol tanto cuando el resto arílico no presenta sustituyentes (entradas 1, 6 y 10-11), como cuando está sustituído por grupos electrón atractores (entradas 2 y 3), electrón dadores (entradas 4-5, 12-13 y 15-18), o heteroaromáticos (entradas 7 y 8). Sin embargo, cuando el alcohol de partida presenta un sustituyente 5-metil2-furilo en posición $\alpha$ al grupo hidroxilo (entradas 9 y 14) se observó la formación competitiva del carbazol regioisómero 41' en el que el arilo se encuentra en posición 6. Aun así, en este caso fue posible aislar el correspondiente 11arilbenzo[b]carbazol mayoritario $\mathbf{4 1}$ con buen rendimiento. La formación del benzocarbazol 41', que posee el resto arílico en posición 6 , fue muy reveladora ya que nos hizo pensar en la posibilidad de que en el proceso pudieran estar operando otros mecanismos. La formación de 41'ci y 41'ai podría justificarse según el mecanismo de reacción que se recoge en el Esquema 3.17., a partir del intermedio espiránico I. Si éste evoluciona a través del camino de reacción $a$ se obtendría el alcohol $\mathbf{J}$, donde la eliminación de agua y una migración 1,4 del arilo conduciría a 41. Alternativamente, a través del camino $b$, que implica una migración 1,2 del resto bencílico, una posterior eliminación de agua conduciría también a 41' (Esquema 3.16).

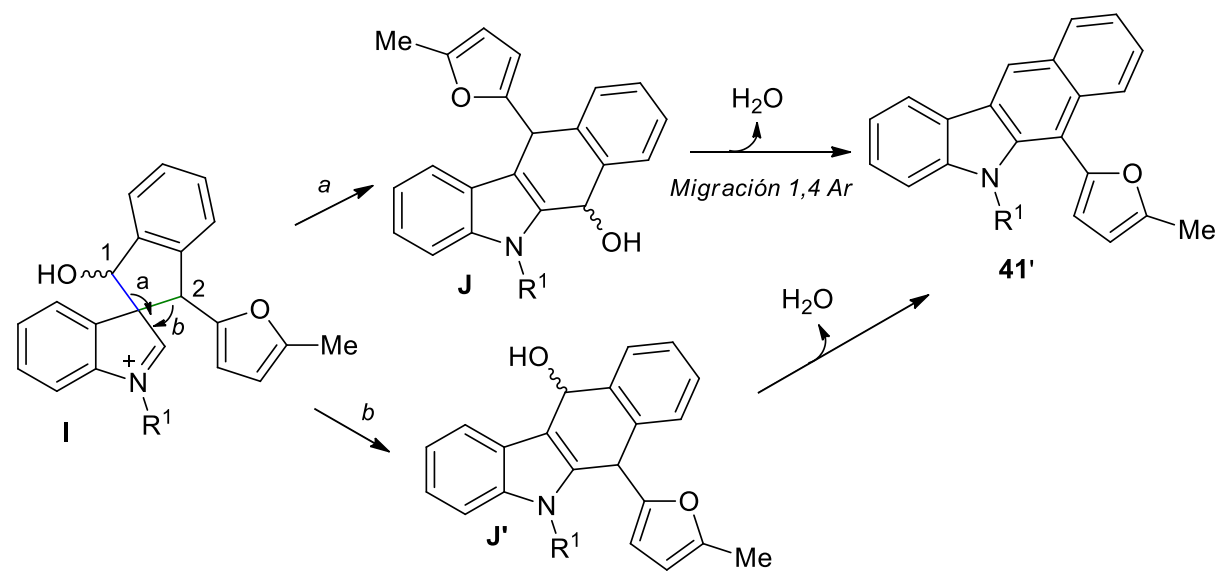

Esquema 3.17

Racionalizar la influencia de la naturaleza del grupo arilo sobre la selectividad resulta difícil en este punto. Sin embargo, parece razonable pensar que a medida que aumenta la capacidad para estabilizar una carga positiva sobre el carbono 2 del intermedio espiránico I la formación del 6-aril carbazol 41' se vea favorecida a través de la via $b$. 
Además, la densidad electrónica sobre C-2 (posición bencílica) tiene un efecto directo en los tiempos de reacción. Así, cuando el anillo aromático no posee sustitución o se encuentra sustituído por grupos electrón atractores e incluso por un grupo metoxilo en posición 4 del anillo, la reacción tarda casi 24 horas en completarse. Por el contrario, a medida que aumenta la densidad electrónica sobre el anillo aromático se observa una disminución de los tiempos de reacción llegando a ser de $30 \mathrm{~min}$ en el caso de anillos aromáticos trimetoxisustituídos (entradas 5 y 13). Además, la influencia que ejercen los sustituyentes del alcohol de partida sobre el trascurso de la reacción se puso aún más de manifiesto cuando se ensayaron los alcoholes secundarios 32j-l (Tabla 3.1) que no poseen sustituyentes arílicos. En estos casos, bajo las condiciones ensayadas hasta el momento, estos sustratos condujeron únicamente a productos de descomposición.

\subsubsection{Reactividad de los acetales de 5-metoxibenzaldehído 2-hidroxialquil funcionalizados 33 con indoles}

Intrigados por la formación de los productos 41', y con el objetivo de establecer las prioridades en la migración 1,2 sobre el intermedio espiránico $\mathbf{K}$ (Esquema 3.18), decidimos estudiar la reactividad de los hidroxiacetales 33 que presentan un grupo metoxilo en posición 5 del anillo aromático que soporta el acetal. De esta manera, la posición del metoxilo en el benzo[b]carbazol final ayudaría a revelar qué resto migra en el intermedio espiránico $\mathbf{K}$ (via $a$ ó $b$ ).

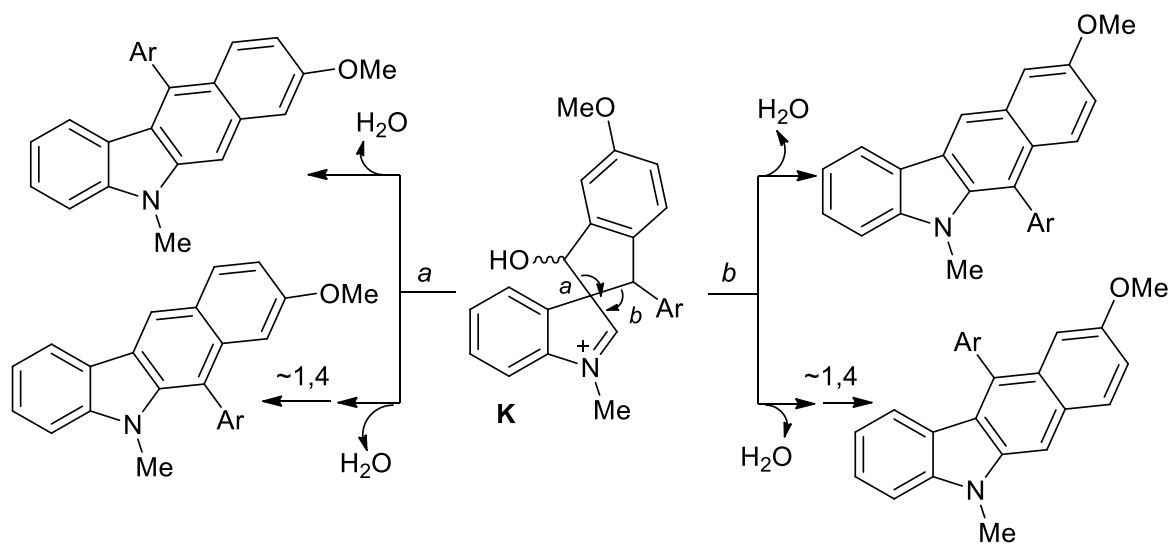

Esquema 3.18

Por su parte, la posición del sustituyente arílico en C-6 ó C-11 del benzocarbazol final nos indicará si se ha producido o no una migración 1,4 del 
mismo, propuesta como camino de reacción alternativo $b$ en el Esquema 3.16 y como vía $a$ en el Esquema 3.17.

Así, la reacción de los hidroxialquilacetales 33a-e y $N$-metilindol 19c, bajo las condiciones estándar de reacción, permitió aislar los 11arilbenzo[ $b]$ carbazoles 44a-e con buenos rendimientos (Tabla 3.5). Estos experimentos revelaron que la reacción de los sustratos 33a-c, en los que el resto aromático de la posición $\alpha$ del alcohol de partida no posee sustituyentes o estos son electrón atractores o dadores moderados, condujo a la formación de los 11arilcarbazoles 44 de manera prácticamente selectiva, observándose únicamente la formación de otros regioisómeros a nivel de trazas (entradas 1-3). Sin embargo, la reacción de los hidroxiacetales 33d,e que poseen grupos arilos con mayor densidad electrónica dio lugar a un incremento de la formación del carbazol regioisómero 45, llegando incluso a ser mayoritario cuando el resto aromático es trimetoxifenilo. Este benzocarbazol presenta el resto metoxilo en una posición diferente respecto al compuesto de partida $33 \mathbf{d}$.

Tabla 3.5 Estudio de la reactividad de los dietilacetales de 2-(hidroxialquil)5-metoxibenzaldehído 33

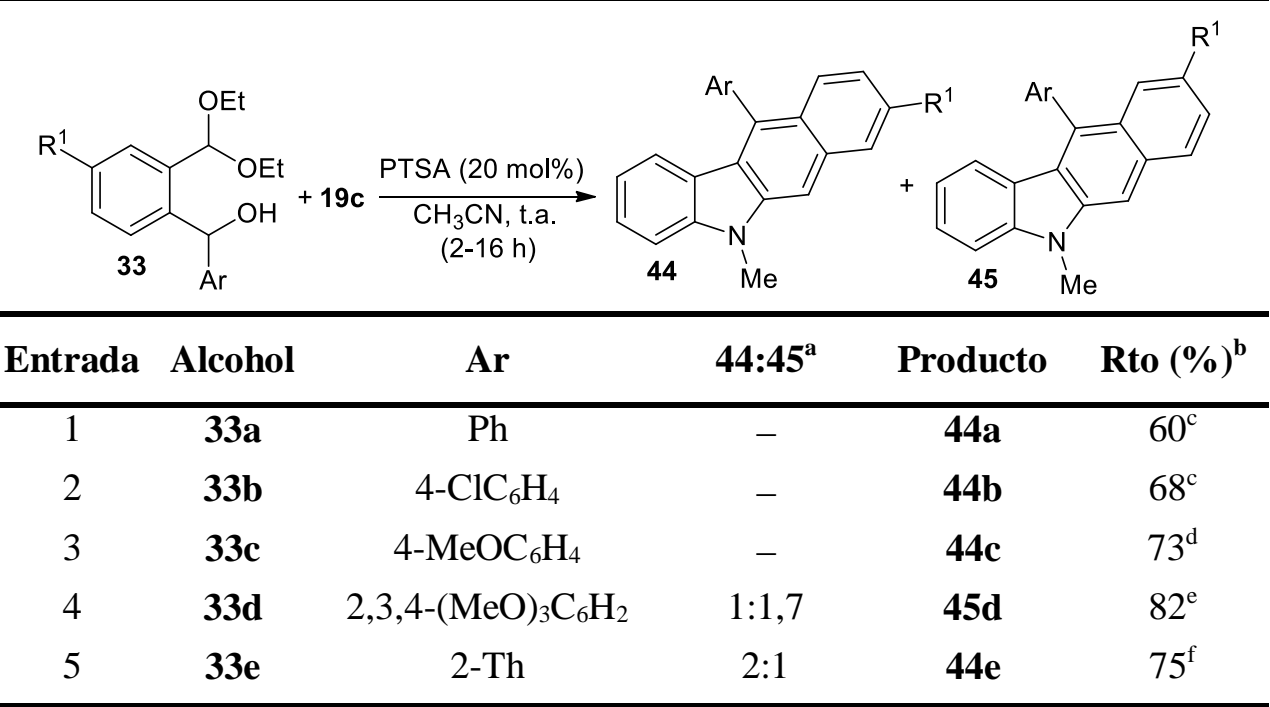

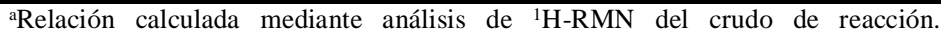

${ }^{\mathrm{b}}$ Rendimiento aislado referido al producto de partida 33. ${ }^{\mathrm{c} S e}$ observó la formación de $\sim 5 \%$ de los regioisómeros 44'a y 44'b. 'Se observaron trazas 45c y 45'c.

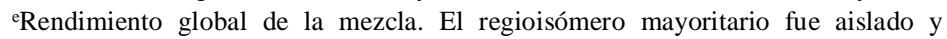

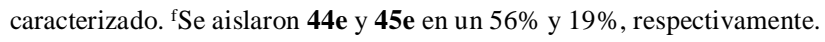

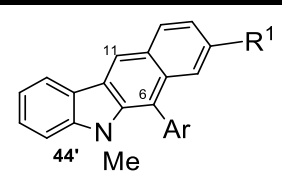


Un mecanismo simplificado que da explicación a los productos formados es el que se representa en el Esquema 3.19. A partir del intermedio espiránico $\mathbf{K}$ la formación del regioisómero mayoritario en casi todos los casos, 44, tendría lugar a través del camino de reacción $a$, el cual implicaría la migración del grupo hidroxialquilo para dar lugar a los alcoholes intermedios L. A partir de ellos la eliminación de una molécula de agua conduciría a la formación de 44. Como ya se adelantó anteriormente, el intermedio espiránico $\mathbf{K}$ también podría evolucionar mediante el camino $b$, en el que el resto que migra fuera el bencílico dando lugar al alcohol L', en el que la eliminación de una molécula de agua y la pérdida de un protón conduciría a los productos 44', los cuales han sido observado únicamente a nivel de trazas. A medida que aumenta la densidad electrónica del anillo aromático la migración del resto bencílico (camino $b$ ) se ve favorecida llegando incluso a invertirse la selectividad del proceso con un resto trimetoxifenilo (entrada 4). Esta misma riqueza electrónica del anillo aromático también puede ser la responsable de que a partir del intermedio L', y tras formación del intermedio indoleniminio $\mathbf{M}$ por protonación y pérdida de $\mathrm{H}_{2} \mathrm{O}$, se produzca una migración 1,4 del resto arilo que daría lugar a los benzocarbazoles 45. Cabe mencionar que cuando los sustratos de partida no poseen el grupo metoxilo adicional en el acetal de partida, los regioisómeros 44 y 45 son indistinguibles, por lo que para la formación de los productos $\mathbf{4 1}$ podrían estar operando ambos caminos de reacción cuando se emplean alcoholes que poseen sustituyentes aromáticos muy ricos en posición $\alpha$.

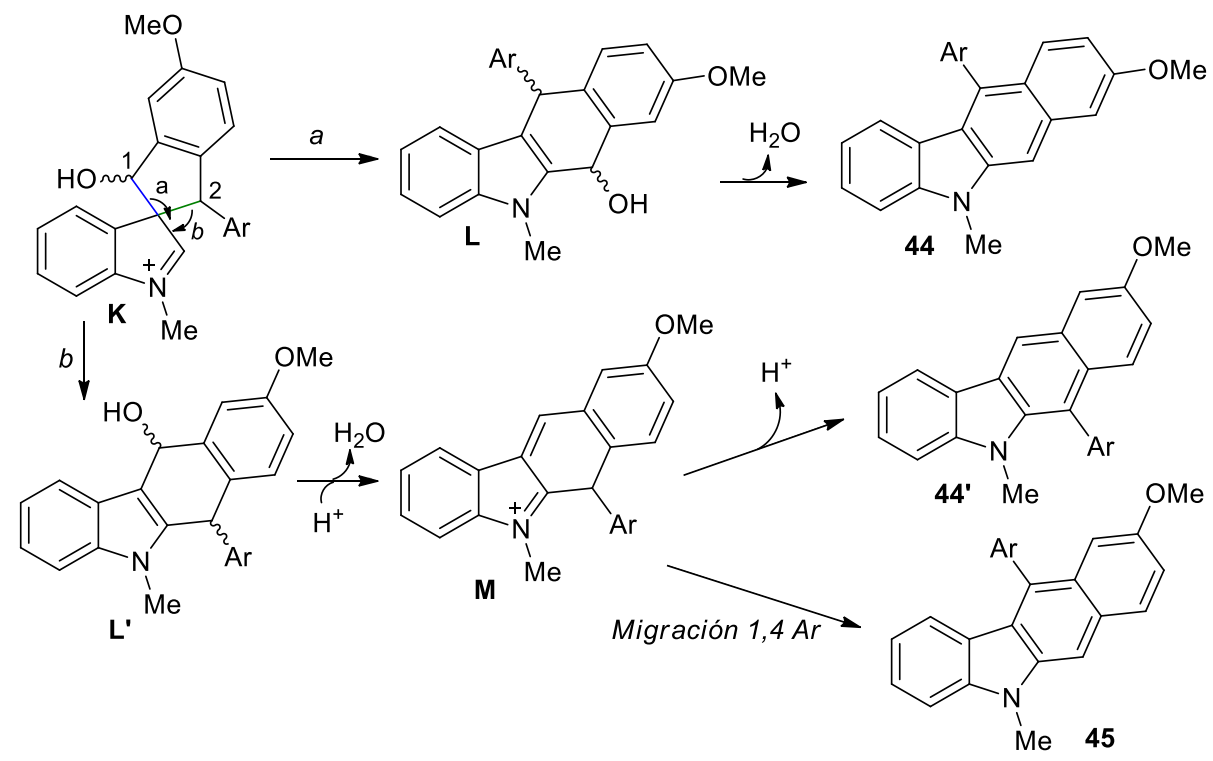

Esquema 3.19 


\subsubsection{Reacciones de los dietilacetales de o-(hidroxialquil)benzaldehído con grupos hidroxilo terciarios $32 m-t$}

A continuación, y teniendo en mente que en el proceso de obtención de los 11 -arilbenzo[ $b]$ carbazoles descritos anteriormente pueden estar implicadas migraciones 1,4 de uno de los sustituyentes (ver Esquema 3.18), nos planteamos la posibilidad de sintetizar benzocarbazoles 6,11-disustituídos partiendo de hidroxiacetales terciarios, ya que los correspondientes intermedios $\mathbf{N}$ o $\mathbf{N}$ ' podrían también evolucionar por una migración 1,4 (Esquema 3.20).

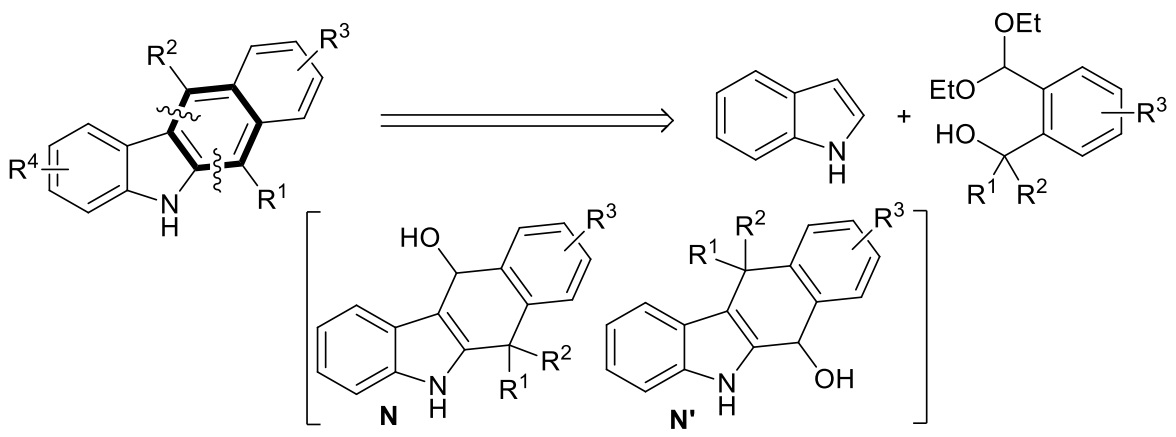

Esquema 3.20

Para ello ensayamos una serie de alcoholes terciarios de partida 32m,o. Y así su reacción con $N$-metilindol 19c, bajo las mismas condiciones empleadas hasta el momento, permitió aislar los benzo[b]carbazoles 6,11-disustituídos 46a,b con buenos rendimientos (Esquema 3.21, Ec 1). A diferencia de lo descrito anteriormente para sus homólogos secundarios, la reactividad de estos alcoholes terciarios no está limitada a aquellos que presentan un sustituyente arílico en la posición bencílica del alcohol de partida, sino que también pueden tener un sustituyente alquinilo en lugar del arilo, como así se demostró con la formación de 46b en el que está presente un resto alquinilo en posición 11 del benzocarbazol, hecho muy interesante de cara a posteriores transformaciones. Asimismo, la reacción también funciona eficientemente con el hidroxiacetal $\mathbf{3 2 m}$ que presentan un resto metilo y otro 4-metoxifenilo, generando el correspondiente benzocarbazol 46a. Sin embargo, en este punto el alcance de la reacción parece más limitado ya que el tratamiento de otros hidroxiacetales 32q,r,t que presentan diferentes sustituyentes, con $N$-metilindol 19c condujo únicamente a productos de descomposición (Esquema 3.21, Ec 2). 
<smiles>[R]C(C)(O)c1ccccc1C(OCC)OCC</smiles>

$32 \mathrm{~m}, 0$<smiles>Cn1ccc2ccccc21</smiles>

19c
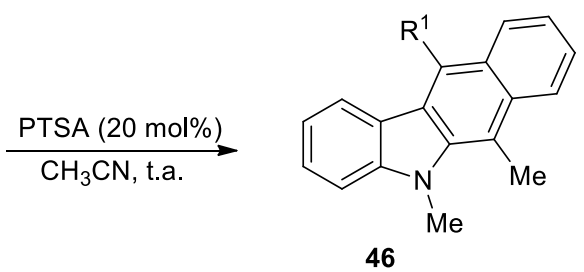

46 46a $(65 \%)$
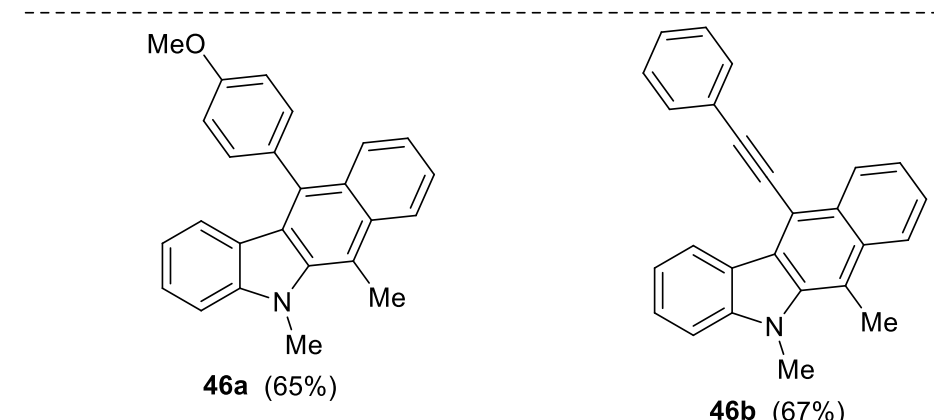

46b $(67 \%)$<smiles>CCOC(OCC)c1ccccc1C(C)(O)/C=C/c1ccccc1</smiles>

$32 q$<smiles>CCOC(OCC)c1ccccc1C(O)(/C=C/c1ccccc1)c1ccccc1</smiles>

$32 r$

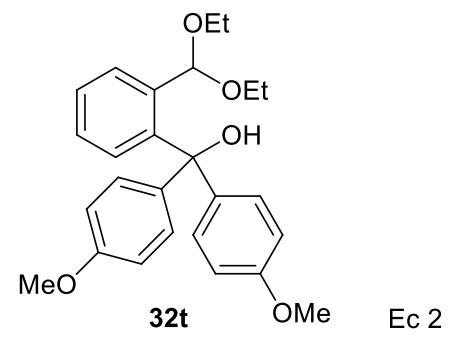

\section{Esquema 3.21}

Por otra parte, los impedimentos estéricos que ejercen los sustituyentes del alcohol terciario también parecen jugar un papel determinante en el proceso. Así, la reacción de los alcoholes 32p y 32s con $N$-metilindol 19c dio lugar a los correspondientes derivados de isobenzofurano 42p y 42s que fueron aislados con buenos rendimientos (Esquema 3.22). En estos casos no fue posible dirigir la reacción hacia la obtención de los correspondientes benzo[b]carbazoles ni mediante un aumento de la temperatura, ni incrementando los tiempos de reacción. 


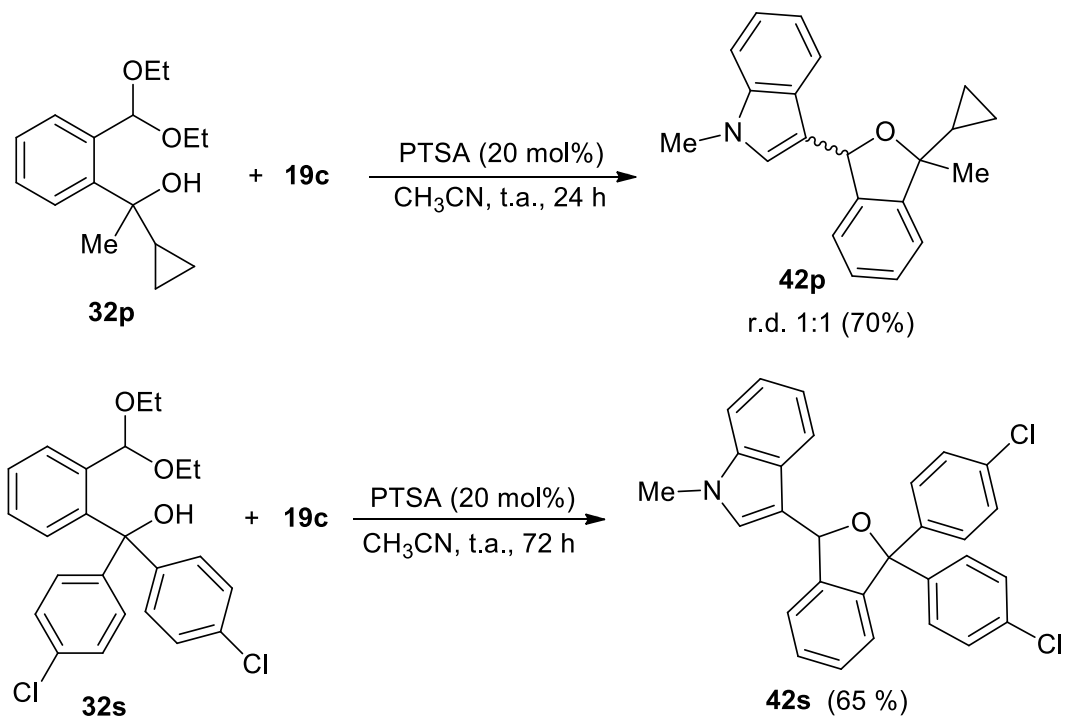

Esquema 3.22

Si comparamos todos estos resultados, y considerando lo explicado anteriormente para los sustratos secundarios, podemos llegar a la conclusión que, aunque es difícil racionalizar todos los factores que podrían estar interviniendo en la formación de los benzo[ $b]$ carbazoles $41, \mathbf{4 5}, \mathrm{y} \mathrm{46}$, parece que el ataque intramolecular del indol en los isobenzofuranos $\mathbf{4 2}$ para generar los correspondientes intermedios espiránicos (ver Esquemas 3.16 y 3.19) podría estar gobernado por factores tanto electrónicos como estéricos.

Por otra parte, en cuanto a la selectividad de la migración 1,2 sobre el intermedio espiránico, para estos alcoholes terciarios se produjo una inversión con respecto a lo que sucedía para los hidroxiacetales secundarios como se demuestra con el alcohol terciario $\mathbf{3 3 f}$ que posee un sustituyente metoxilo en la posición 5 del anillo aromático del acetal. Su reacción con $N$-metilindol 19c, bajo catálisis con PTSA, condujo al benzocarbazol 47, en el que el sutituyente metoxilo se encuentra en posición 9, de manera totalmente regioselectiva (Esquema 3.23). Si comparamos este resultado con lo descrito anteriormente para el alcohol secundario 33c (Tabla 3.5, entrada 3), se observa que a medida que aumenta la densidad electrónica en la posición bencílica del alcohol de partida (terciario $v s$ secundario) se produce un incremento de la capacidad migratoria de dicha posición, lo que trae como consecuencia una inversión de la selectividad de la migración [intermedio $\mathbf{O}$ (Esquema 3.23) vs intermedio K (Esquema 3.19)]. Esta migración selectiva conduce, tras protonación y pérdida de agua, al intermedio indoleniminio $\mathbf{P}$, a partir del cual una migración 1,4 del sustituyente 
arílico seguida de la pérdida de un protón, conduciría al benzo[b]carbazol 6,9,11trisustituído 47. Su estructura de fue confirmada mediante experimentos de RMN bidimensionales y por Rayos-X. ${ }^{140}$<smiles>CCOC(OCC)c1ccc(OC)cc1C(C)(O)Br</smiles><smiles>Cn1ccc2ccccc21</smiles>

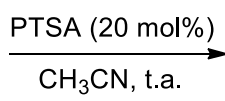<smiles>COc1ccc2c(C)c3c(c(Br)c2c1)c1ccccc1n3C</smiles>

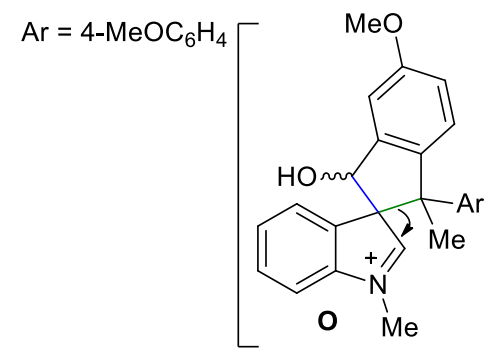<smiles>COC1=CC2C=C3C(=[N+](C)c4ccccc43)C(C)([Al])C2C=C1</smiles>

Esquema 3.23

Asimismo, hay que destacar que en la formación del benzo[b]carbazol $\mathbf{4 6 b}$ que posee un alquino en posición 11 del anillo aromático central ha tenido lugar una migración 1,4 involucrando un resto alquinilo. Cabe mencionar que los alquinos poseen baja capacidad migratoria en migraciones 1,2 relacionadas tales como la transposición pinacolínica, semipinacolínica, o el reagrupamiento dienona-fenol. A pesar de ello en la bibliografía existe algún ejemplo aislado de migración 1,2 de grupos alquinilo, proceso que representa formalmente una sustitución electrofílica intramolecular sobre un $\mathrm{C}_{\mathrm{sp}} .{ }^{141}$ Sin embargo, hasta el momento no se había descrito ningún ejemplo en el que se produjera una migración 1,4 de un resto alquinilo.

\subsubsection{Síntesis de heteroaril[b]carbazoles}

Por último, decidimos evaluar el alcance sintético de esta metodología con objeto de acceder a heteroarilcarbazoles. Así, haciendo reaccionar los

\footnotetext{
${ }^{140}$ Los parámetros estructurales de $\mathbf{4 7}$ están depositados en "The Cambridge Crystaliographic Data Center" bajo el código CCDC 959146.

141 (a) G. E. Salnikov, A. M. Genaev, V. A. Bushmelev, V. G. Shubin, Org. Biomol. Chem. 2013, 11, 1458-1501. (b) T. Wao, L. Huang, S. Shi, M. Rudolph, A.M. Hashmi. Chem. Eur. J. 2014, $20,14868-14871$.
} 
hidroxiacetales heterocíclicos 36 y $N$-metilindol 19c, bajo las mismas condiciones de reacción, fue posible obtener los 10-aril-5H-tieno[3,2$b$ carbazoles 48a,b de manera totalmente selectiva y con rendimientos de moderados a excelentes (Esquema 3.23). Además, partiendo del alcohol 35a, regioisómero de los anteriores, se obtuvo también de manera exclusiva el tieno[2,3-b]carbazol 49 (Esquema 3.23).

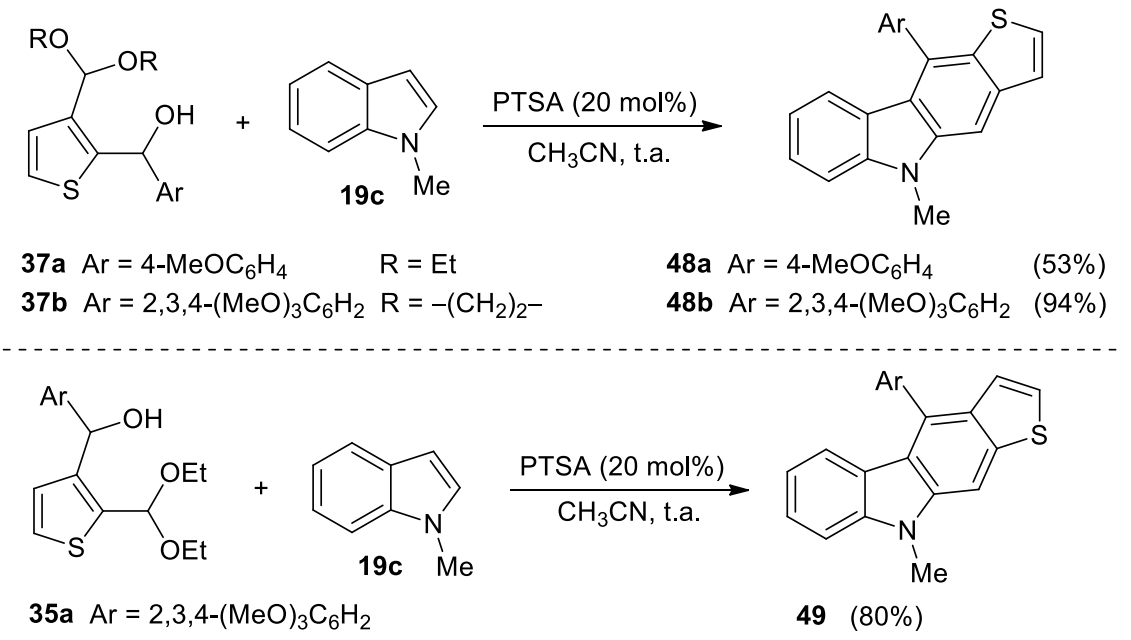

Esquema 3.23

Esta estrategia también pudo ser extendida a la síntesis del benzo[4,5]tieno[2,3- $b$ ]carbazol 50 partiendo del $N$-metilindol 19c y del hidroxicetal con esqueleto de benzo[b]tiofeno 35b (Esquema 3.24). Por otra parte, el empleo de un hidroxicetal con estructura de benzo[ $b]$ furano 36c dio lugar a una mezcla de los benzofuro[2,3- $b$ ] carbazoles 51 y 51' (Esquema 3.24). Por el contrario, los hidroxiacetales 39 y $\mathbf{4 0}$ derivados de $N$-heterociclos, tales como piridina e indol, únicamente condujeron a productos de descomposición.

En todos los casos la formación de los productos mayoritarios de la reacción puede ser entendida de la misma manera que los productos 44, implicando la migración selectiva del resto hidroxialquilo (camino $a$, Esquema 3.18). Además, la formación de estos productos es completamente selectiva a excepción de 51' cuya formación podría explicarse a través del camino $b$ del Esquema 3.18, probablemente favorecido en este caso por un aumento de la capacidad migratoria del resto bencílico, debido a la influencia del átomo de oxígeno del benzofurano. 


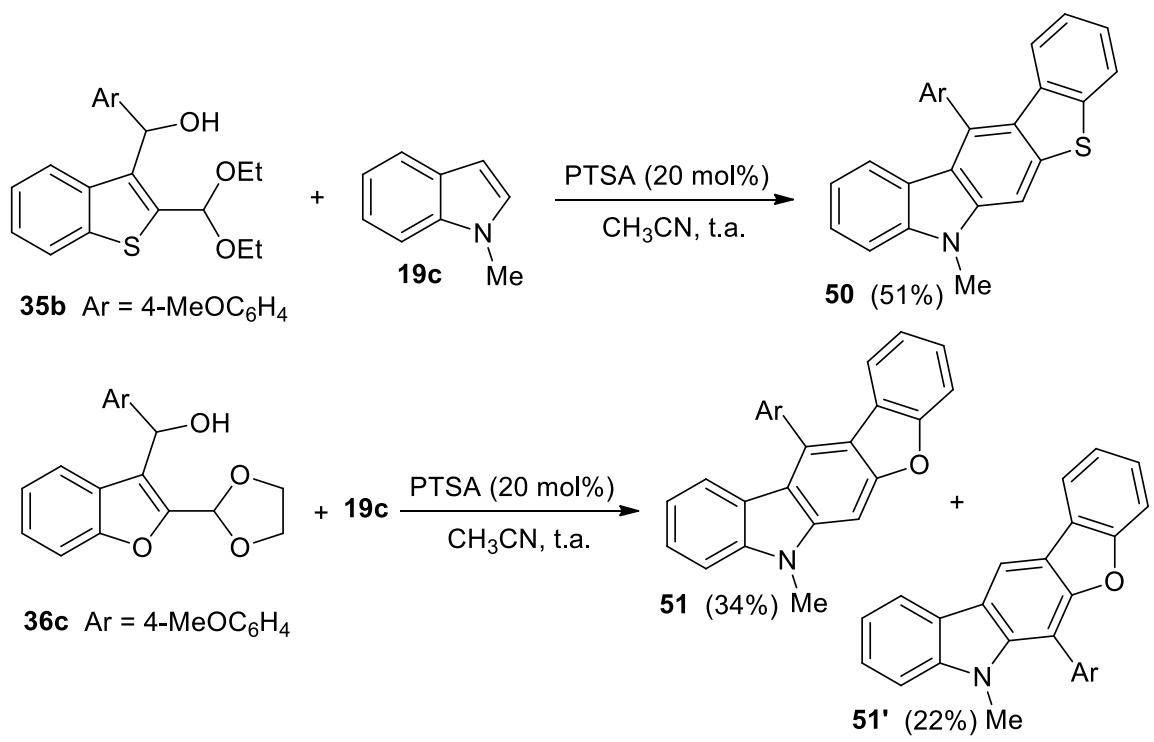

Esquema 3.24

\subsection{CONCLUSIONES}

Se puede concluir que hemos puesto a punto una nueva metodología para la obtención de 11-arilbenzo[ $b]$ carbazoles y benzo[ $b]$ carbazoles 6,11-disustituídos, mediante una reacción catalizada por un ácido de Brønsted sencillo, a partir de sustratos fácilmente accesibles como son indoles 2,3-no sustituídos, comercialmente asequibles, y acetales de benzaldehído o-hidroxialquil funcionalizados. El proceso trascurre de manera suave a temperatura ambiente, generalmente con muy buenos rendimientos, y con la generación de agua y etanol como únicos subproductos de la reacción.

La transformación implica una reacción tándem iniciada por la reacción del indol con los acetales de partida para generar isobenzofuranos. A continuación, el ataque intramolecular del indol genera un intermedio espiránico de tipo indoleniminio que puede evolucionar mediante una cascada de reacciones que se inician con una migración 1,2. La evolución observada para estos intermedios espiránicos depende de la naturaleza electrónica de los hidroxiacetales de partida, observándose una selectividad en la migración opuesta para los alcoholes secundarios frente a los terciarios. 



\section{CAPÍTULO 4 Reacciones de alquinoles $\alpha$-indolilmetil funcionalizados catalizadas por complejos de Au(III)}

\section{INTRODUCCIÓN}

La síntesis de moléculas complejas de manera selectiva y eficiente, es uno de los grandes retos de la Síntesis Orgánica moderna. En los últimos años se han desarrollado una gran variedad de reacciones tándem, las cuales permiten numerosas transformaciones en un único paso de reacción dando lugar a moléculas de relativa complejidad a partir de precursores simples.

En este contexto, los alcoholes propargílicos y sus derivados se han convertido en reactivos de partida muy atractivos por su variada y rica reactividad en presencia de catalizadores metálicos, de ácidos de Brønsted, Lewis,o de reactivos halogenantes (Esquema 4.1). ${ }^{142}$

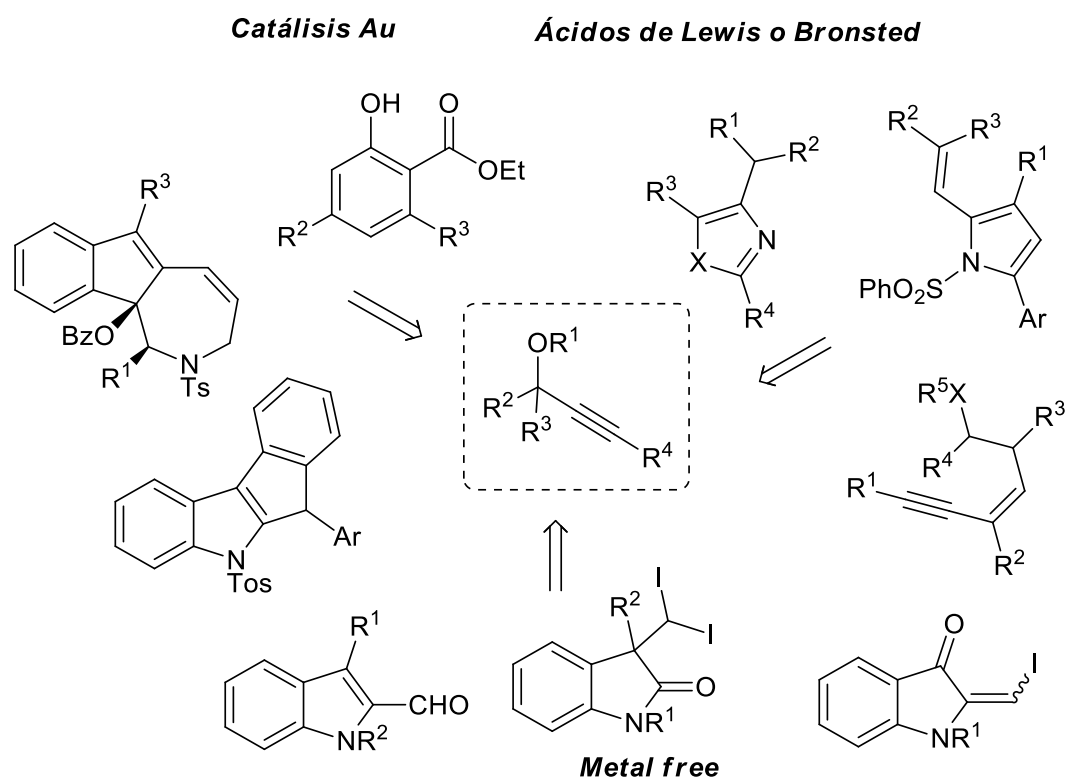

Esquema 4.1

Así, empleando alquinoles como sustratos de partida en presencia de catalizadores oxófilos se produce la activación del grupo hidroxilo permitiendo

142 (a) E. B. Bauer, Synthesis 2012, 44, 1131-1151. (b) Y. Zhu, L. Sun, P. Lu, Y. Wang, ACS Catal. 2014, 4, 1911-1925. (c) B. J. Ayers, P. W. H. Chan, Synlett 2015, 26, 1305-1339. (d) E. Gayon, H. Gerard, E. Vrancken, J.-M. Campagne, Synlett 2015, 26, 2336-2350. (e) R. K. Kumar, X. Bi, Chem. Commun. 2016, 52, 853-868. 
su posterior reacción con nucleófilos (Esquema 4.2, Ec 1). Por otra parte, catalizadores $\pi$-ácidos, como por ejemplo catalizadores de oro, pueden activar el triple enlace permitiendo otras transformaciones posteriores que involucran ataques nucleofílicos sobre el alquino (Esquema 4.2, Ec 2). ${ }^{143}$ En ocasiones, estos dos procesos (activación de hidroxilo-activación de alquino) tienen lugar de manera consecutiva, dando lugar a estructuras más complejas en el mismo paso de reacción (Esquema 4.2, Ec 3). ${ }^{144}$

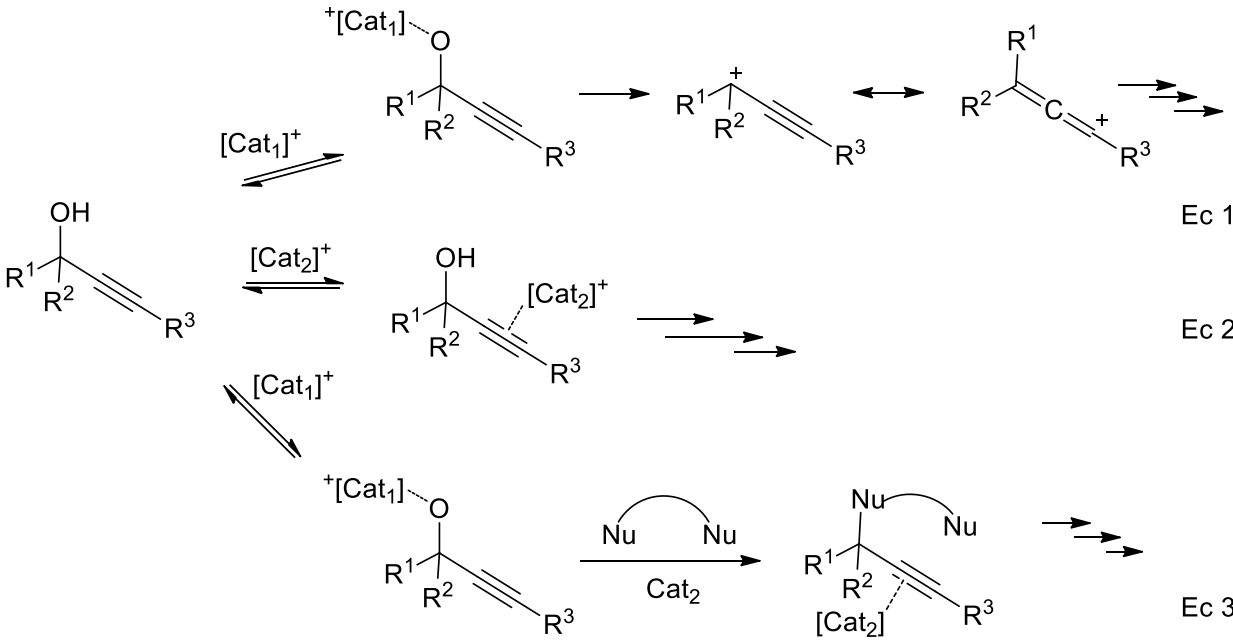

\section{Esquema 4.2}

Este Capítulo de la Tesis se ha centrado en el estudio de la reactividad de alquinoles propargílicos funcionalizados en posición $\alpha$ con grupos indol-3ilalquilo, y se encuentra dividido en tres partes. En primer lugar, se ha llevado a cabo el estudio de alquinoles $\alpha$-bisindolilmetil sustituídos en presencia de catalizadores de $\mathrm{Au}(\mathrm{III})$. En segundo lugar, se ha estudiado la ciclación electrofílica de estos mismos sustratos con cationes yodonio. Por último, también ha sido evaluada la reactividad de alquinoles $\alpha$-indolilmetil- $\alpha$-tiometil sustituídos frente a catalizadores de $\mathrm{Au}(\mathrm{III})$.

${ }^{143}$ Ver, por ejemplo: S. Cacchi, G. Fabrizi, A. Goggiamani, A. Iazzetti, Org. Lett. 2016, 18, 3511-3513.

${ }^{144}$ (a) M. Egi, Y. Yamaguchi, N. Fujiwara, S. Akai, Org. Lett. 2008, 10, 1867-1869. (b) L. Ye, L. Zhang, Org. Lett. 2009, 11, 3646-3649. 


\subsection{ESTUDIO DE LA REACTIVIDAD DE ALQUINOLES $\alpha$ - BISINDOLILMETIL SUSTITUÍDOS EN PRESENCIA DE CATALIZADORES DE Au(III)}

En el apartado de Antecedentes Generales ya se describió con detalle el papel que juegan los catalizadores de oro en la activación de triples enlaces $\mathrm{C}-\mathrm{C}$ como paso clave para la síntesis de carbazoles a partir de indoles alquinil funcionalizados (ver págs 24-28 Antecedentes generales).

\subsubsection{Objetivo}

Teniendo en cuenta las posibilidades sintéticas que ofrece el empleo de alcoholes propargílicos como sustratos de partida, nos propusimos como objetivo estudiar la reactividad de los alquinoles propargílicos $\mathbf{5 3}$ que presentan un sustituyente 3,3'-bisindolilmetilo en posición $\alpha$, frente a catalizadores $\pi$-ácidos. En principio sería esperable que estos sustratos reaccionaren a través de una ciclación 5-endo-dig para dar lugar a un intermedio espiránico tal como A (Esquema 4.3).

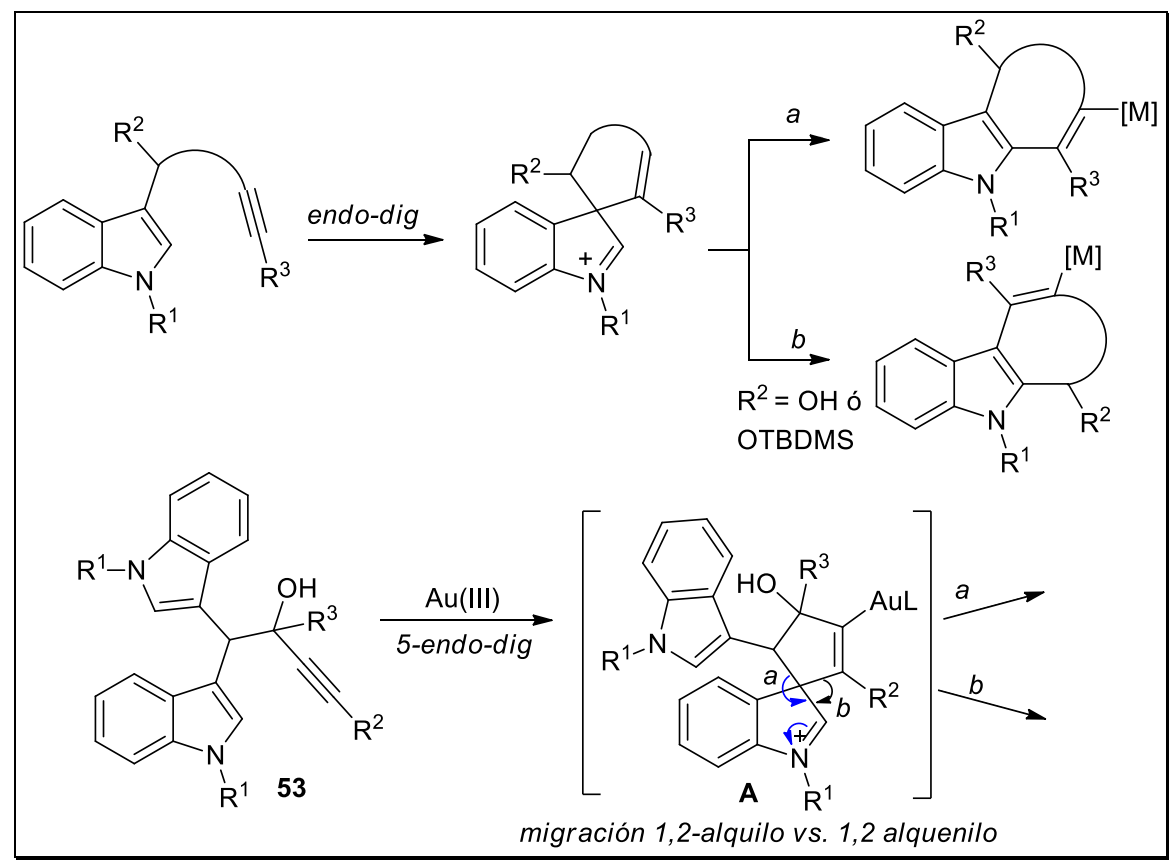

Esquema 4.3 
En el apartado de Antecedentes Generales de esta Memoria ya se discutió la evolución de este tipo de intermedios espiránicos donde lo habitual es que un resto alquenilo experimente la migración 1,2 con preferencia a un resto alquilo, proceso que sólo ha sido descrito en el caso de sustituyentes hidroxialquilo (ver págs 27-28 Antecedentes Generales). En este contexto, nos pareció interesante estudiar cuál de las dos posibles migraciones estaría más favorecida sobre el intermedio $\mathbf{A}$, ya que se trata de la competencia entre un resto alquenilo, a priori más favorable, frente a un resto alquilo que, en este caso, estaría activado por la presencia de un sustituyente indol-3-ilo (Esquema 4.3).

\subsubsection{Discusión de Resultados}

\subsubsection{Síntesis de los alcoholes propargílicos $\alpha$-bisindol-3-il-metil sustituídos 53}

En primer lugar, se describirá la síntesis de los alcoholes propargílicos 53, tanto internos como terminales. La obtención de los alquinoles internos 53a-j se llevó a cabo por reacción de las bisindoliletanonas $\mathbf{5 2}$, cuya síntesis ha sido puesta a punto por nuestro grupo tal y como se comentó en el Capítulo $2,{ }^{112}$ con acetiluros de litio, los cuales fueron generados por desprotonación de los correspondientes alquinos terminales con $n$-BuLi en THF a baja temperatura (Tabla 4.1).

De esta manera se sintetizaron diferentes alquinoles propargílicos $\alpha$ bisindolilmetil sustituídos con muy buenos rendimientos (Tabla 4.1). Estos alquinoles pueden presentar en la posición propargílica tanto un resto aromático (entrada 1-9), como un sustituyente alquílico (entrada 10). En cuanto a la posición terminal del triple enlace, ésta puede estar ocupada por sustituyentes (ciclo)alquílicos (entradas 1-3), alquenilo (entradas 7 y 9), arílicos (4-5, 8 y 10), ó heteroarílicos (entrada 6). Por su parte, la otra posición $\alpha$ al alcohol propargílico está ocupada por un sustituyente bisindolilmetilo que puede presentar como restos indólicos un $N$-metilindol (entradas 1-7) o un $N$ - $H$ indol (entradas 8-10). 
Tabla 4.1 Síntesis de los alquinoles 53a-j

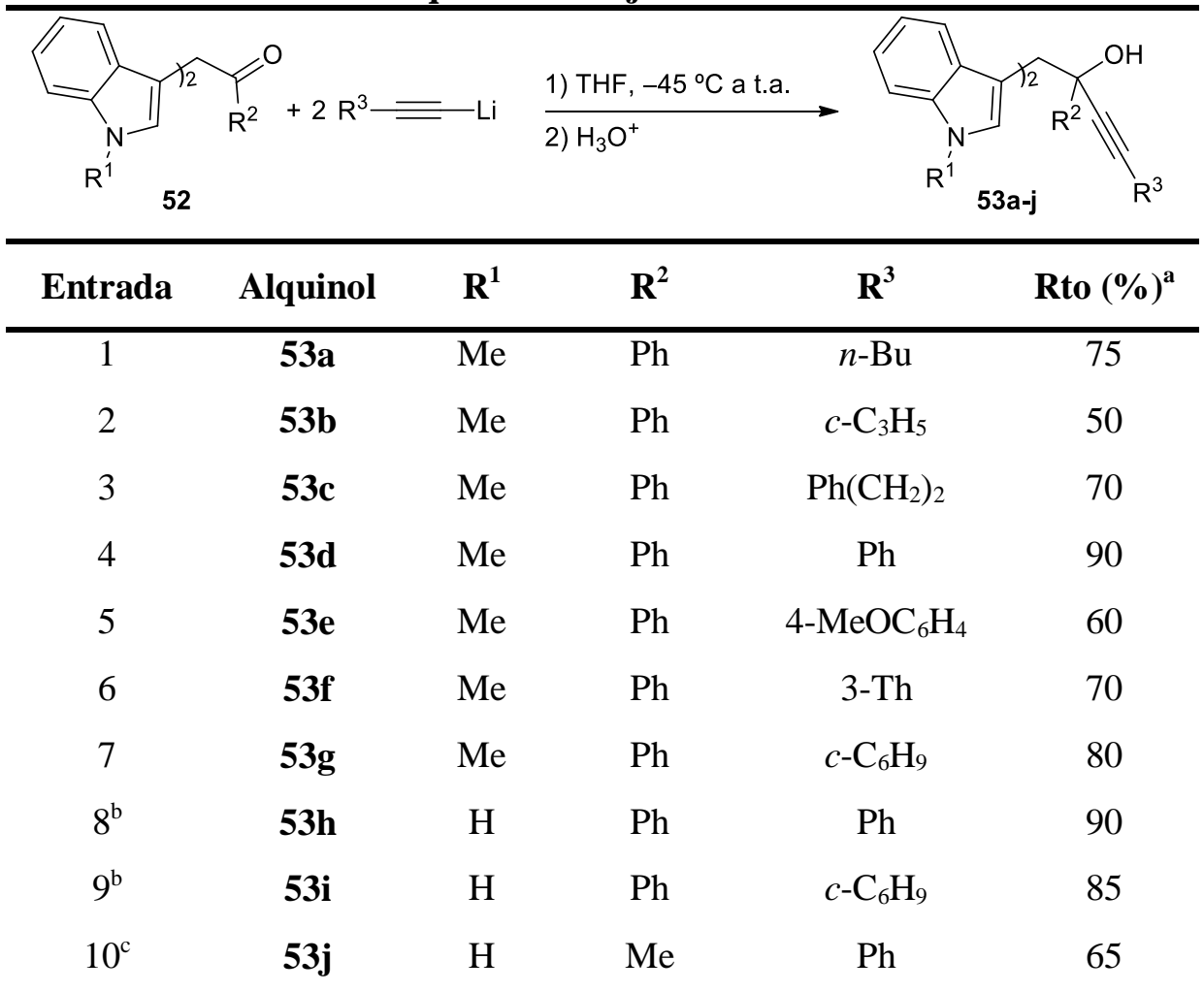

aRendimiento del producto aislado referido a la cetona de partida 52. ${ }^{b}$ Reacción llevada a cabo empleando 4 equivalentes de acetiluro de litio. 'Reacción llevada a cabo empleando 5 equivalentes de acetiluro de litio. $c$ $\mathrm{C}_{6} \mathrm{H}_{9}=$ ciclohexen-1-ilo. 3-Th = 3-tienilo.

Por otra parte, los alquinoles terminales 53k-m se prepararon con buenos rendimientos por reacción de un exceso de bromuro de etinilmagnesio con las correspondientes bisindoliletanonas 52 (Tabla 4.2).

Tabla 4.2 Síntesis de los alquinoles terminales 53k-m

\begin{tabular}{cccccc}
\hline \\
Entrada & Alquinol & $\mathbf{x}$ & $\mathbf{R}^{1}$ & $\mathbf{R}^{2}$ & Rto $(\%)^{\mathbf{a}}$ \\
\hline 1 & $\mathbf{5 3 k}$ & 2 & $\mathrm{Me}$ & $\mathrm{Ph}$ & 60 \\
2 & $\mathbf{5 3 1}$ & 4 & $\mathrm{H}$ & $\mathrm{Ph}$ & 80 \\
3 & $\mathbf{5 3 m}$ & 5 & $\mathrm{H}$ & $\mathrm{Me}$ & 60 \\
\hline
\end{tabular}

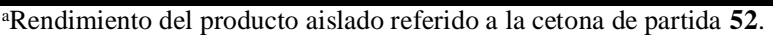


Además, empleando la misma metodología descrita en la Tabla 4.1 se sintetizaron una serie de alquinoles internos 54a-c, que poseen dos restos indólicos diferentes en el sustituyente bisindolilmetilo de la posición $\alpha$, los cuales se obtuvieron con rendimientos moderados, empleando fenilacetiluro de litio en todos los casos. Estos alquinoles fueron obtenidos como mezclas $\sim 1: 1$ de diasteroisómeros en todos los casos (Tabla 4.3).

Tabla 4.3 Síntesis de los alquinoles 54a-c

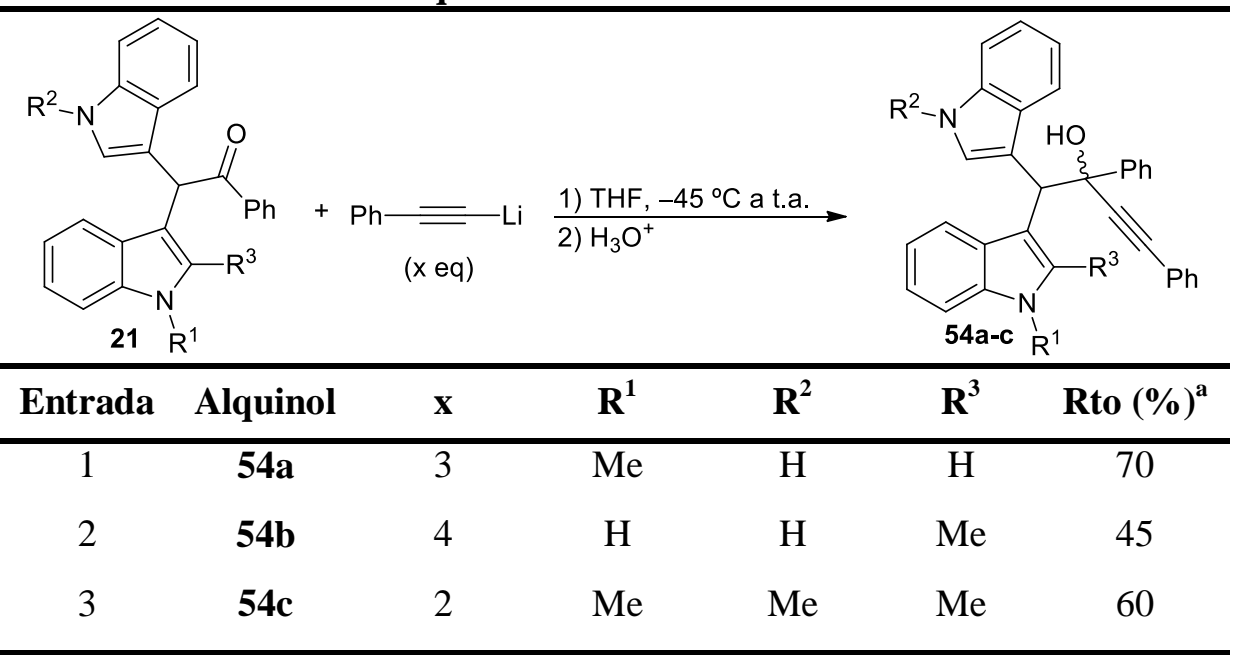

${ }^{\text {aRendimiento del producto aislado referido a la cetona de partida } \mathbf{2 1}}$.

\subsubsection{Reacciones de los alquinoles propargílicos $\alpha$-bisindolilmetil sustituídos 53 frente a complejos de $\mathrm{Au}(\mathrm{III})$}

\subsection{Pruebas preliminares y optimización}

Para abordar el objetivo propuesto en esta parte de la Tesis, dedicado al estudio de la reactividad de los alquinoles 53 en presencia de catalizadores $\pi$ ácidos, en primer lugar, se evaluó la reacción del alquinol 53d en presencia de cantidades catalíticas de $\mathrm{Ph}_{3} \mathrm{AuNTf}_{2}, \mathrm{CH}_{2} \mathrm{Cl}_{2}$ como disolvente y temperatura ambiente (Esquema 4.4). Bajo estas condiciones de reacción se pudo aislar un nuevo producto $\mathbf{5 5 d}$, con esqueleto de carbazol y un $25 \%$ de rendimiento. $\mathrm{Su}$ estructura fue confirmada mediante experimentos de RMN bidimensionales a partir de los cuales se pudo determinar que el sustituyente indol-3-ilo se encontraba sobre la posición 1 del carbazol. Un análisis inicial de la estructura del producto obtenido parece indicar que en la reacción hay implicada una migración de un resto indólico. 

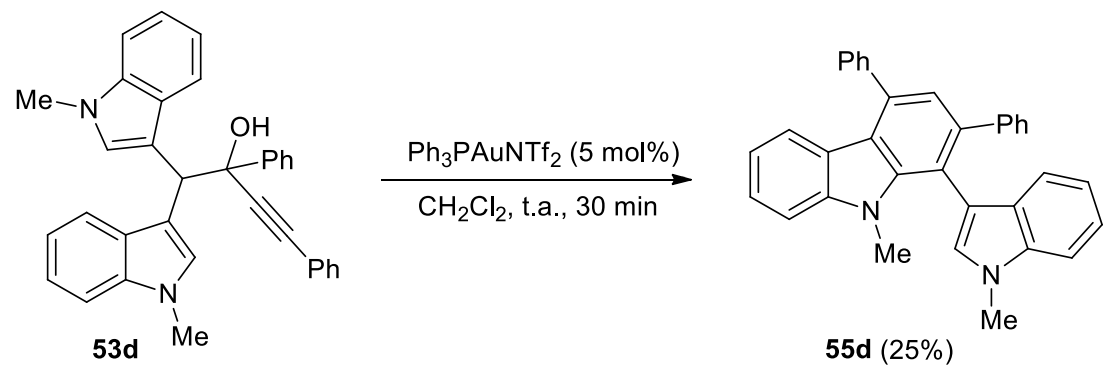

\section{Esquema 4.4}

Es importante destacar que la estructura de 1-indolilcarbazol se encuentra presente en productos naturales. En concreto, el alcaloide $\mathbf{I}$ ha sido aislado a partir de organismos marinos, presentando una moderada citotoxicidad frente a células tumorales humanas HL-60 y Hela (Esquema 4.5). ${ }^{145}$ Por otra parte el Pitiriazol II ha sido sintetizado por Knölker y col. en un proceso de seis pasos de reacción y con un rendimiento global 35\%. ${ }^{146}$ Las etapas clave de su síntesis son tres acoplamientos catalizados por complejos de Pd. La construcción del esqueleto de 1-indolilcarbazol se llevó a cabo mediante un acoplamiento de Suzuki entre la 1yodomukonidina III y el ácido borónico IV. A su vez, III se preparó por ciclación de la diarilamina $\mathbf{V}$, a través de una doble activación $\mathrm{C}-\mathrm{H}$ en presencia de $\mathrm{Pd}(\mathrm{II})$, seguido de la halogenación del carbazol en posición 1. Por su parte, la amina $\mathbf{V}$ fue sintetizada por un acoplamiento de Buchwald-Hartwing a partir de yodobenceno y la anilina VI, ambos comercialmente asequibles (Esquema 4.5).

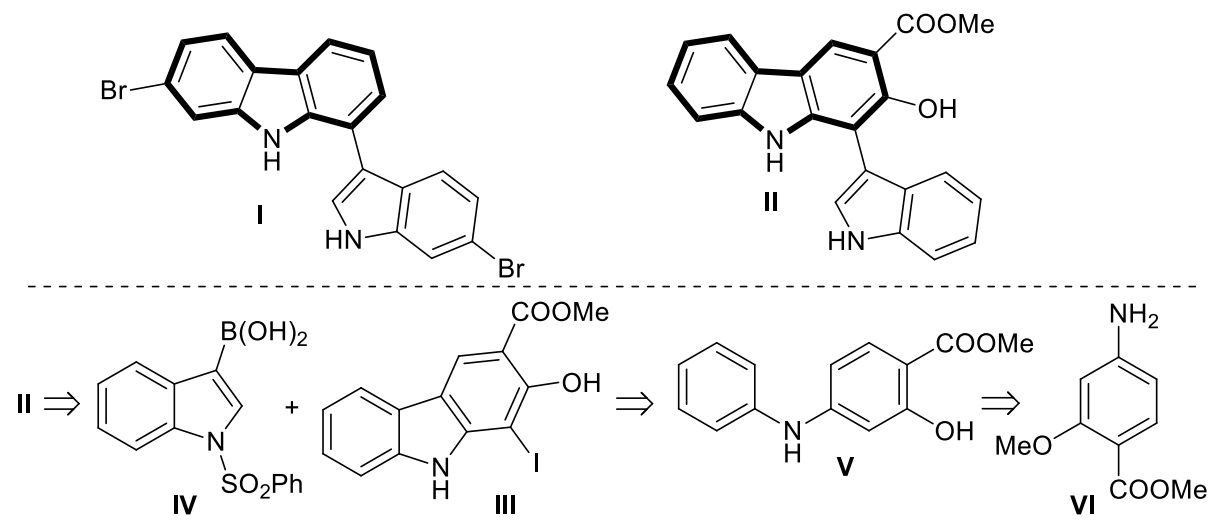

Esquema 4.5

\footnotetext{
${ }^{145}$ E.-G. Lyakhova, S.-A. Kolesnikova, A.-I. Kalinovsky, S.-S. Afiyatullov, A.- S. Dyshlovoy, V.-

B. Krasokhin, C.-V. Minh, V.-A. Stonik, Tetrahedron Lett. 2012, 53, 6119-6122.

${ }^{146}$ R. Forke, A. Jäger, H.-J. Knölker, Org. Biomol. Chem 2008, 6, 2481-2483.
} 
Muy recientemente se ha descrito la síntesis de 2-indol-3-ilcarbazoles por reacción entre 3-vinilindoles y arilglioxales catalizada por un ácido de Brønsted. El proceso implica una reacción tándem iniciada por una adición nucleofílica intermolecular del vinilindol sobre el glioxal, en ausencia de ácido, seguido de la $\mathrm{S}_{\mathrm{N}}$ sobre la $\alpha$-aciloina intermedia por un indol externo y una ciclación final intramolecular, ambos procesos catalizados por el ácido fosfórico (Esquema 4.6). ${ }^{147}$

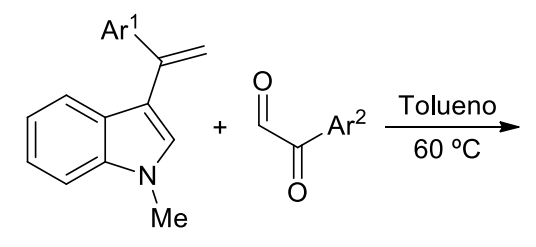

$\mathrm{Ar}^{1}=\mathrm{Ph}, 4-\mathrm{XC}_{6} \mathrm{H}_{4}, 4-\mathrm{MeOC}_{6} \mathrm{H}_{4}, \cdots$

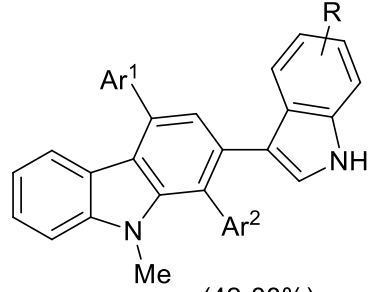

$(42-88 \%)$ $\mathrm{Ar}^{2}=\mathrm{Ph}, 4-\mathrm{XC}_{6} \mathrm{H}_{4}, 4-\mathrm{MeOC}_{6} \mathrm{H}_{4}, 2-\mathrm{CF}_{3} \mathrm{C}_{6} \mathrm{H}_{4}, \ldots \quad \mathrm{R}=\mathrm{H}, 5-\mathrm{Hal}, 6-\mathrm{Hal}, 5-\mathrm{MeO}, \ldots$

\section{Esquema 4.6}

Animados por el resultado preliminar del Esquema 4.4, y siendo conscientes de la necesidad de diseñar nuevas estrategias que accedan a 1-indolilcarbazoles de manera más directa, decidimos estudiar la influencia del catalizador y las condiciones de reacción sobre el proceso, con el fin de mejorar su rendimiento.

Para ello, se eligió como sustrato modelo el alquinol 53a, que posee un sustituyente fenilo sobre la posición propargílica y un resto butilo sobre la terminal, y se estudió su reactividad frente a una serie de catalizadores $\pi$-ácidos (Tabla 4.4). De nuevo, cuando se llevó a cabo la reacción en presencia de cantidades catalíticas de $\mathrm{Ph}_{3} \mathrm{PAuNTf}_{2}$ se observó la formación del carbazol 55a, aunque con bajo rendimiento. Mientras que en presencia de $\mathrm{PtCl}_{4}$ y $\mathrm{AgSbF}_{6}$ no hubo ninguna reacción (entradas 2 y 3), el empleo de $\mathrm{Cu}(\mathrm{OTf})_{2}$ únicamente provocó la descomposición de la mezcla de reacción (entrada 4). Sin embargo, en presencia de $\mathrm{PtCl}_{2}$ como catalizador y a reflujo de tolueno, se formó el mismo producto 55a aunque todavía con un rendimiento moderado (entrada 5). Finalmente, el empleo de catalizadores de oro (III) condujo a la formación del 1indolilcarbazol 55a con buenos rendimientos (entradas 6-8), encontrándose el empleo de $\mathrm{NaAuCl}_{4}$ en $\mathrm{CH}_{2} \mathrm{Cl}_{2}$ como condiciones óptimas, ya que permiten aislar el carbazol final 55a con un excelente rendimiento (entrada 8).

${ }^{147}$ Y.-W. Huang, X.-Y. Li, L.-N. Fu, Q.-X. Guo, Org. Lett. 2016, 18, 6200-6203. 
Tabla 4.4 Optimización de las condiciones de reacción para la obtención del 1-indolilcarbazol 55a
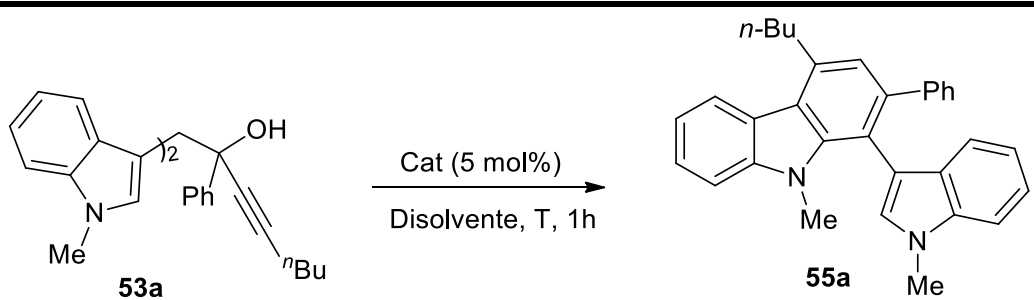

\begin{tabular}{ccccc}
\hline Entrada & Catalizador & Disolvente & T $\left({ }^{\mathbf{o}}\right)$ & Rto $(\%)^{\mathbf{a}}$ \\
\hline 1 & $\mathrm{Ph}_{3} \mathrm{PAuNTf}_{2}$ & $\mathrm{DCM}$ & ta & 32 \\
2 & $\mathrm{AgSbF}_{6}$ & $\mathrm{DCM}$ & ta & $-{ }^{\mathrm{b}}$ \\
3 & $\mathrm{PtCl}_{4}$ & Tolueno & 110 & $-{ }^{\mathrm{b}}$ \\
4 & $\mathrm{Cu}(\mathrm{OTf})_{2}$ & MeCN & 80 & $-{ }^{\mathrm{c}}$ \\
5 & $\mathrm{PtCl}_{2}$ & Tolueno & 110 & 60 \\
6 & $\mathrm{AuCl}_{3}$ & DCM & ta & 71 \\
7 & $\mathrm{HAuCl}_{4} \cdot 3 \mathrm{H}_{2} \mathrm{O}$ & DCM & ta & 81 \\
8 & $\mathrm{NaAuCl}_{4}$ & DCM & ta & 93
\end{tabular}

aRendimientos determinados por ${ }^{1} \mathrm{H}-\mathrm{RMN}$ empleando $\mathrm{CH}_{2} \mathrm{Br}_{2}$ como patrón interno. ${ }^{\text {bPoducto de partida. }}$ 'Productos de descomposición.

\subsection{Propuesta mecanística}

El mecanismo de reacción que se propone para esta transformación es el que se recoge en el Esquema 4.7. En primer lugar, se produciría la coordinación del catalizador de oro al triple enlace promoviendo el ataque intramolecular de uno de los indoles al alquino activado para dar lugar al intermedio espiránico B. A continuación, la apertura de este intermedio espiránico conduciría al indoleniminio $\mathbf{C}$. Ambos intermedios $\mathbf{B}$ y $\mathbf{C}$ podrían encontrarse en equilibrio ya que un ataque del resto indólico por su C-3 sobre el catión indoleniminio en el intermedio $\mathbf{C}$ recupera $\mathbf{B}$. Sin embargo, si el ataque nucleofílico se produce por el C-2 del indol se generaría un nuevo intermedio catiónico D. La eliminación de un protón conduciría al dihidrocarbazol intermedio $\mathbf{E}$, el cual por protodesmetalación y eliminación de agua daría lugar al carbazol final $\mathbf{5 5}$ (Esquema 4.7). 
<smiles>[R]C#CC(O)(C(c1cn([R1])c2ccccc12)c1cn([R1])c2ccccc12)C([R])(O)CC[M]</smiles>

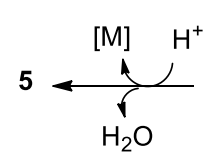<smiles>[R]C1=C([N+]#[C-])C([R])(O)C(c2cn([R])c3ccccc23)c2c1c1ccccc1n2[R]</smiles><smiles></smiles>

\section{Esquema 4.7}

\subsection{Evaluación del alcance de la reacción}

Una vez establecido el empleo de $\mathrm{NaAuCl}_{4}$ (5 mol\%), en $\mathrm{CH}_{2} \mathrm{Cl}_{2}$ y temperatura ambiente, como condiciones óptimas de reacción, pasamos a evaluar su alcance (Esquema 4.8). En primer lugar, estudiamos la influencia del sustituyente sobre la posición terminal del alquinol de partida. Para ello, se llevó a cabo la reacción de los alquinoles de partida $\alpha$-bisindolilmetil sustituídos 53a-l (que presentan ambos indoles sobre la posición $\alpha$ al alquinol de partida idénticos, y un sustituyente fenilo o metilo sobre la posición propargílica) bajo las condiciones previamente descritas. En general la reacción transcurre de manera muy limpia, con muy buenos rendimientos y en tiempos cortos $(\sim 1 \mathrm{~h})$. Asimismo, se demostró que la sustitución sobre la posición terminal del alquinol de partida no tiene ningún efecto sobre la selectividad del proceso ya que para todos los casos se observó la formación de los carbazoles 55a-l de manera totalmente regioselectiva, no habiéndose detectado la presencia del otro posible regioisómero (un 4-indolilcarbazol) en ningún caso. El triple enlace del alquinol de partida puede ser tanto interno, generando los carbazoles $\mathbf{5 5 a - j}$, como terminal, dando lugar al carbazol 55k, lo que permite la obtención de 1indolilcarbazoles con una gran variedad de sustituyentes en posición 4 incluyendo restos (ciclo)alquílicos (55a-c), alquenilo (55g,i), arílicos (55d,e,h,j), heteroarílico (55f), e hidrógeno (55k) (Esquema 4.8). 
Respecto de los restos indólicos, fue posible obtener los correspondientes carbazoles $\mathbf{5 5}$ con sustituyentes tanto metilo como hidrógeno sobre el átomo de nitrógeno (Esquema 4.8).

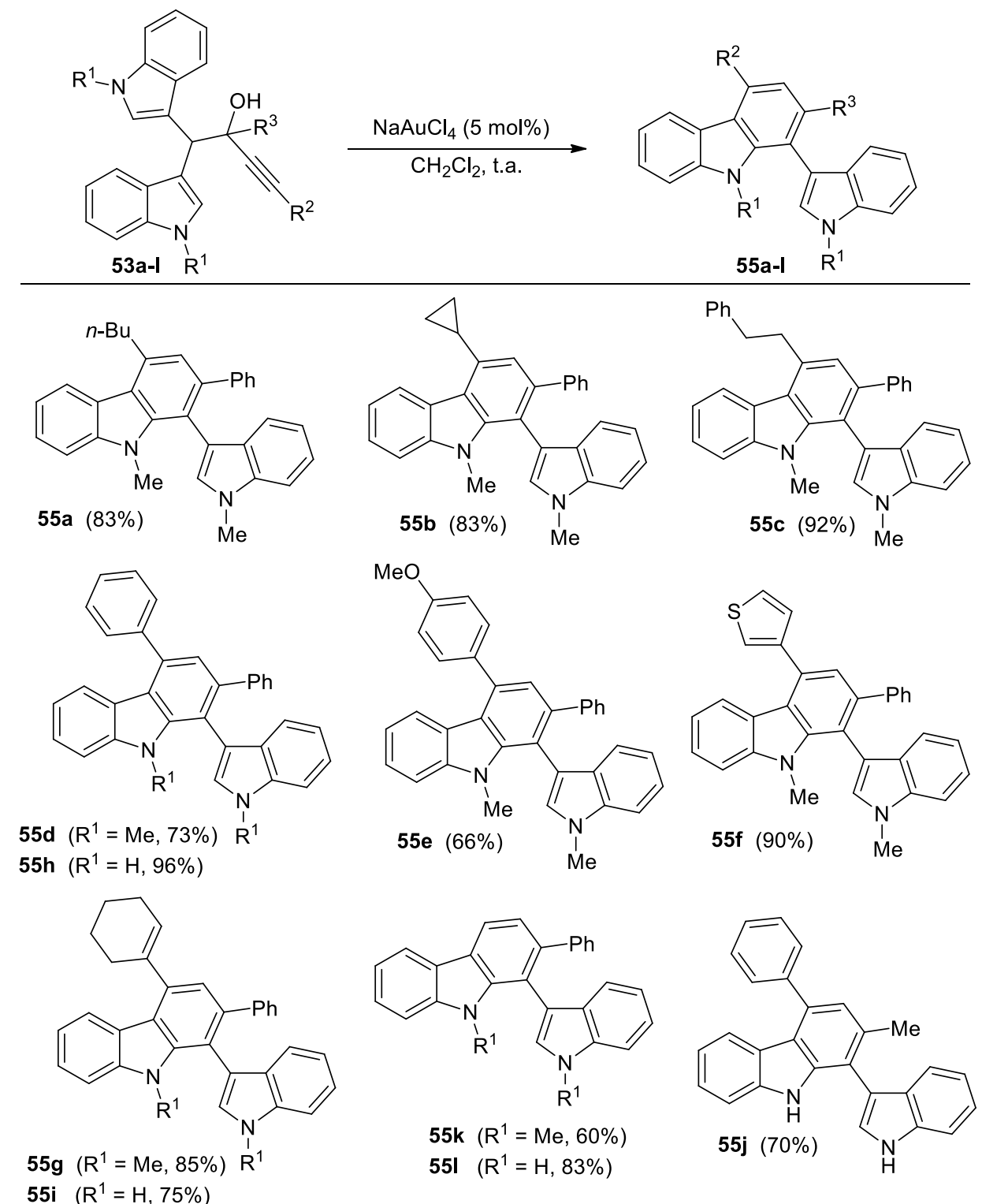

\section{Esquema 4.8}

Por otra parte, la sustitución del fenilo, presente en la posición propargílica, por un metilo no afecta a la reactividad de los alquinoles propargílicos. Y así, el 
sustrato 53j también condujo al carbazol 55j con un rendimiento elevado y de manera totalmente regioselectiva (Esquema 4.8).

Después de estudiar el alcance de la reacción respecto de la sustitución sobre la posición terminal y la propargílica en el alquinol de partida empleando sustratos $\alpha$-bisindolilmetil sustituídos con dos restos indólicos iguales, nos planteamos la posibilidad de acceder a 1-indolilcarbazoles que procedieran de sustratos con dos sustituyentes indólicos diferentes. Para ello se eligió el alquinol 54a, en el que uno de los indoles en la posición adyacente al alcohol propargílico presenta un $N-H$ mientras que el otro posee un $N$-Me (Esquema 4.9). Su evolución, bajo las mismas condiciones de reacción, condujo a una mezcla de los carbazoles 56a y 56'a en una proporción 3:1, que no pudieron ser separados por cromatografía de columna (Esquema 4.9).

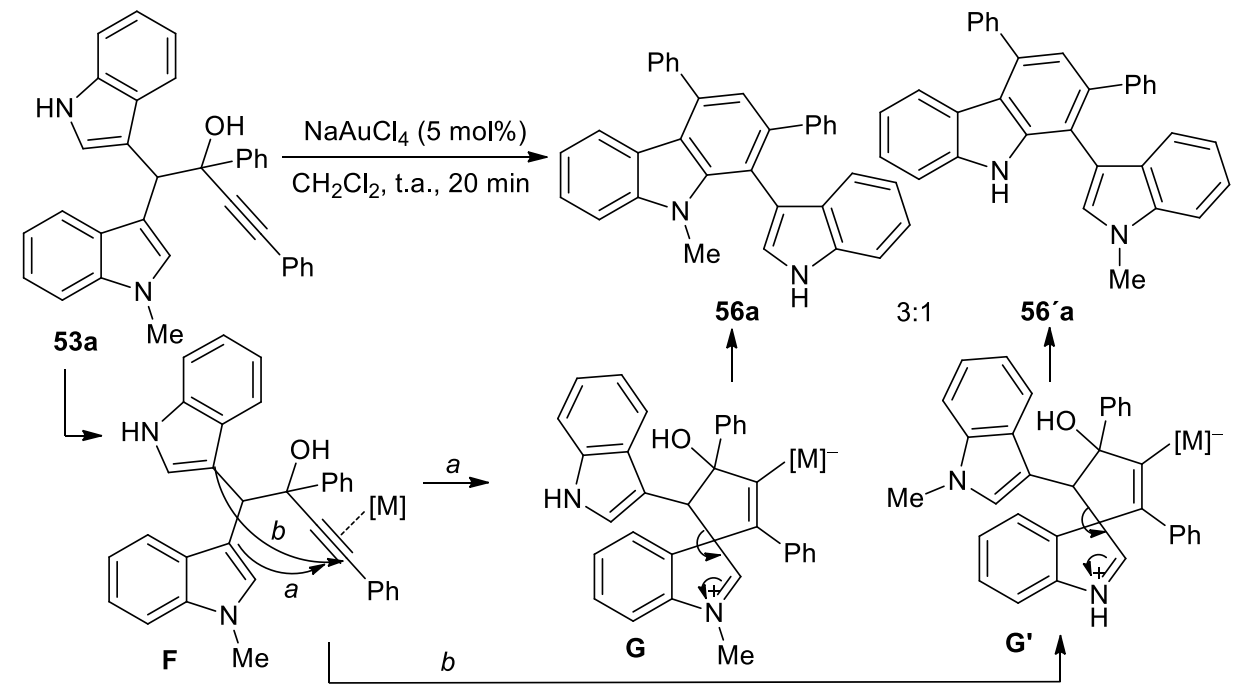

\section{Esquema 4.9}

Las estructuras de estos carbazoles fueron confirmadas mediante experimentos NOE de mezclas enriquecidas en cada uno de los productos. $\mathrm{Su}$ formación pone de manifiesto que cuando los indoles presentes en la posición adyacente al grupo hidroxilo del alquinol de partida poseen diferente naturaleza electrónica se produce una competencia entre los dos núcleos indólicos para el ataque inicial sobre el alquino activado $\mathbf{F}$ y la consiguiente formación de los intermedios espiránicos G ó G'. Así, el producto mayoritario 56a procede del ataque nucleofílico inicial del C-3 del $\mathrm{N}$-metilindol (más nucleofílico que el $\mathrm{N}-\mathrm{H}$ indol) via a al alquino activado por el oro, mientras que el carbazol minoritario 
56'a procede de la ciclación inicial 5-endo cuando es el indol $\mathrm{N}$ - $\mathrm{H}$ el que ataca al alquinol de partida via $b$ (Esquema 4.9).

Esta competencia en el ataque nucleofílico del indol al alquinol de partida se puso aún más de manifiesto cuando se estudió la reactividad de alquinoles en los que el C-2 de uno de los indoles se encuentra sustituído. Así, el alquinol 54b, con un metilo en el C-2 de uno de los indoles, condujo a $\mathbf{5 6 b}$ únicamente con un $14 \%$ de rendimiento, debido a la presencia de varios subproductos que no pudieron ser aislados. De igual manera, a partir de $\mathbf{5 4 c}$ se obtuvo el carbazol 56c, aunque sólo con un $12 \%$ de rendimiento (Esquema 4.10).
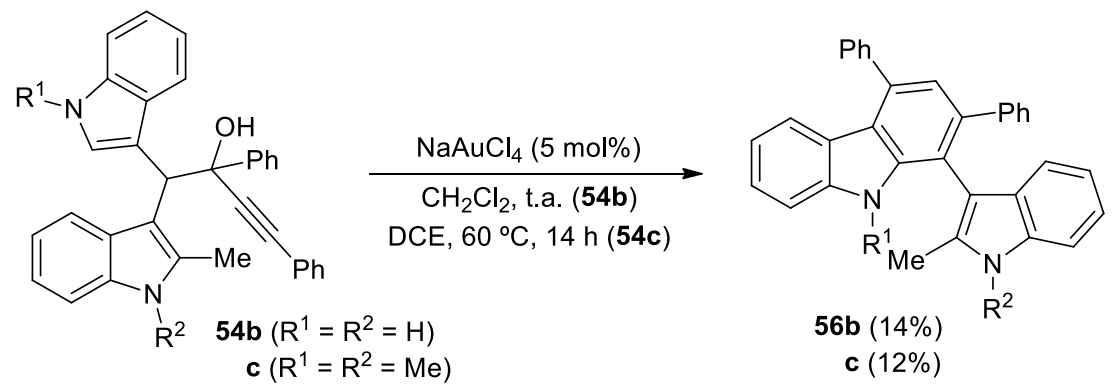

\section{Esquema 4.10}

El bajo rendimiento obtenido para $\mathbf{5 6 b}$ y $\mathbf{5 6 c}$ se podría justificar en base a la diferente nucleofilia de ambos restos indólicos. Teniendo en cuenta el mecanismo de la reacción, anteriormente expuesto en el Esquema 4.6, a priori parecería razonable pensar que si la posición C-2 de uno de los indoles se encuentra bloqueada la reacción de ciclación/migración transcurriría de manera tal que se podrían obtener los carbazoles 56b y 56c de manera totalmente selectiva y con buen rendimiento. Sin embargo, y de manera análoga a lo comentado en el Esquema 4.9, en este caso la reacción se iniciaría con una competencia de ambos indoles por el ataque nucleofílico al alquino activado para conducir a los intermedios I e I'. Debido a que los indoles C-2 sustituídos con grupos alquilo poseen mayor carácter nucleofílico que los indoles que no presentan sustitución en esta posición, la ciclación hasta el intermedio I' se encontrará favorecida frente a la formación de I. Ahora bien, al comparar estos dos intermedios se observa que mientras que $\mathbf{I}$ puede evolucionar a través del camino de reacción anteriormente explicado hasta el intermedio $\mathbf{J}$, donde una nueva ciclación por el carbono C-2 del indol conduciría a los productos 56, esta opción no es posible para I', ya que $\mathbf{J}$ ' posee un resto metilo en el C-2 del indol que impediría el modelo de ciclación planteado. Probablemente, el intermedio I' formado 
mayoritariamente evolucione hacia productos de descomposición, lo que justificaría los bajos rendimientos obtenidos para 56b,c (Esquema 4.11).

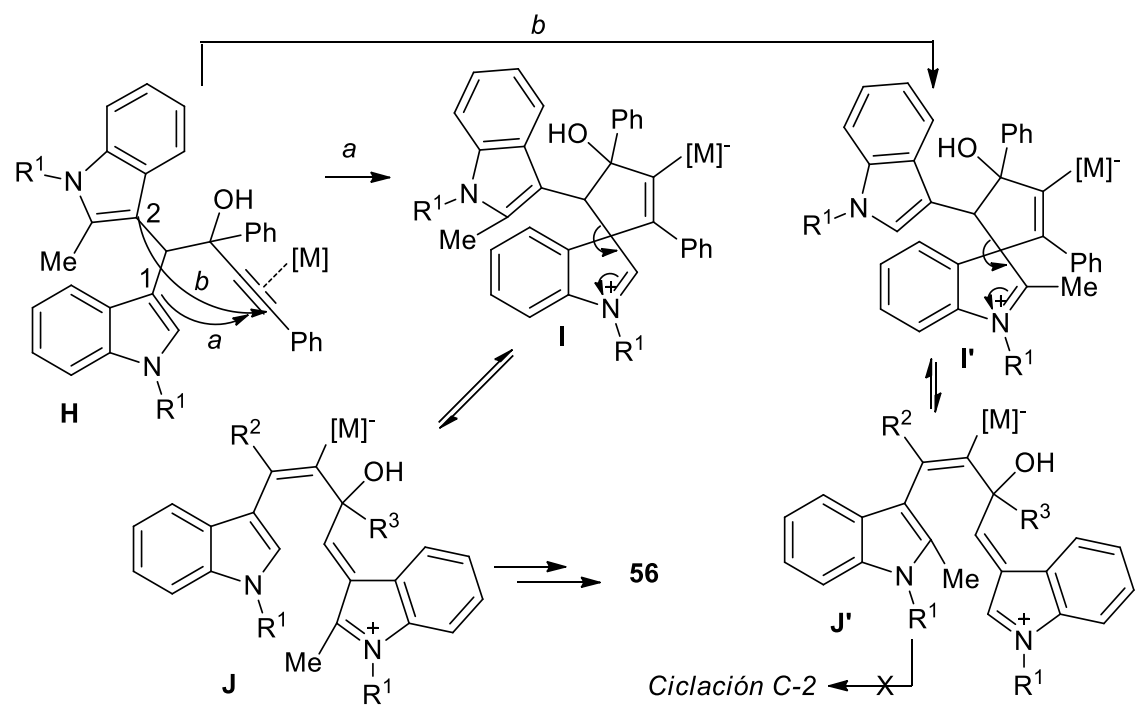

Esquema 4.11

\subsection{Cálculos teóricos}

En el apartado anterior hemos observado que, cuando en el intermedio espiránico hay un indol sobre el resto alquilo, la migración preferida es la de este último frente a la del resto alquenilo. Intrigados por esta inversión de la selectividad habitual de estas migraciones (generalmente tiene preferencia la migración de alquenilo vs. alquilo), decidimos llevar a cabo un estudio computacional de este proceso con el objetivo de aclarar el origen de este fenómeno. Este estudio teórico ha sido realizado en colaboración con el grupo de la Dra. Nieto Faza de la Universidad de Vigo.

Para ello hemos utilizado la teoría del funcional de la densidad (DFT) para caracterizar los puntos estacionarios en la superficie de energía potencial correspondiente a las dos migraciones posibles a partir del intermedio espiránico I (ver Esquema 4.12). La optimización geométrica, el cálculo de frecuencias y de estabilidad de la función de onda, han sido realizados con el funcional híbrido 
B3LYP. ${ }^{148}$ Para los átomos C, H, N y O se han empleado las bases de Pople 6$31 \mathrm{G}^{*}{ }^{149}$ mientras que para el oro, se han utilizado el pseudopotencial de Los Alamos LANL2DZ ${ }^{150}$ para los electrones del core y la base correspondiente para los electrones de valencia. Como B3LYP no describe bien las interacciones de dispersión, hacemos un refinamiento de la energía utilizando el funcional B2PLYP-D ${ }^{151}$ con una base triple zeta de Ahlrichs con polarización extra (tzvpp). ${ }^{152}$ De este modo conseguimos recuperar un mayor porcentaje de correlación electrónica (este funcional doble híbrido aplica teoría de perturbaciones sobre el resultado DFT) e incorporamos la corrección de Grimme para dispersión. Todos los cálculos se han realizado usando un método del continuo (IEFPCM) ${ }^{153}$ para describir el disolvente (diclorometano). Todos los puntos estacionarios han sido caracterizados como mínimos o estados de transición mediante análisis armónico y las frecuencias (sin escalar) han sido utilizadas para calcular parámetros termodinámicos como energías libres. En algunos casos se realizaron cálculos IRC (coordenada intrínseca de reacción) ${ }^{154}$ para conectar sin ambigüedad reactivos, estado de transición y productos.

En una primera aproximación (Esquema 4.12), utilizamos un sistema modelo más sencillo en el que no está presente el segundo indol (I-A). En este sistema encontramos que tanto la migración del resto alquenilo como la del alquilo transcurren en una única etapa, a través de un estado de transición concertado en el que se rompe el enlace $\mathrm{C}-\mathrm{C}$ sobre el $\mathrm{C}$ espiránico y se forma el nuevo enlace $\mathrm{C}-\mathrm{C}$ con el $\mathrm{C}$ más rico en electrones del indol. La barrera correspondiente a la migración de la rama alquenílica, de $13.8 \mathrm{kcal} / \mathrm{mol}$, es $4.6 \mathrm{kcal} / \mathrm{mol}$ menor que la correspondiente a la migración de la rama alquílica, con lo que se mantiene la selectividad esperada. Sin embargo, cuando se estudiaron las dos migraciones alternativas para uno de los $\alpha$-bis(indolil)metil alquinoles empleados en el

148 (a) C. Lee, W. Yang, R. G. Parr, Phys. Rev. B 1988, 37, 785-89. (b) B. Miehlich, A. Savin, H. Stoll, H. Preuss, Chem. Phys. Lett. 1989, 157, 200-206. (c) S. H. Vosko, L. Wilk, M. Nusair, Can. J. Phys. 1980, 58, 1200-1211.

149 (a) R. Ditchfield, W. J. Hehre, J. A. Pople, J. Chem. Phys. 1971, 54, 724. (b) W. J. Hehre, R. Ditchfield, J. A. Pople, J. Chem. Phys. 1972, 56, 2257. (c) P. C. Hariharan, J. A. Pople, Theor. Chem. Acc. 1973, 28, 213-22.

${ }^{150}$ P. J. Hay, W. R. Wadt, J. Chem. Phys. 1985, 82, 299-310.

${ }^{151}$ S. Grimme, J. Comp. Chem. 2006, 27, 1787-1799.

152 (a) F. Weigend, R. Ahlrichs, Phys. Chem. Chem. Phys. 2005, 7, 3297-3305. (b) F. Weigend, Phys. Chem. Chem. Phys. 2006, 8, 1057-1065.

153 (a) J. Tomasi, B. Mennucci, E. Cancès, J. Mol. Struct. (Theochem) 1999, 464, 211-226. (b) M. Cossi, G. Scalmani, N. Rega, V. Barone, J. Chem. Phys.2002, 117, 43-54. (c) B. Mennucci, E. Cancès, J. Tomasi, J. Phys. Chem. B, 1997, 101, 10506-10517.

${ }^{154}$ K. Fukui, Acc. Chem. Res. 1981, 14, 363-368. 
estudio previo experimental (I-B), se encontró que la presencia del segundo indol en posición $\alpha$ al $\mathrm{C}$ espiránico favorece mucho la migración del resto alquílico y, en general, la formación del producto tricíclico. Mientras que la barrera de activación calculada para la migración del resto alquenilo apenas cambia respecto al sistema anterior (1 kcal/mol más alta), encontramos que la barrera para la migración del resto indolilmetilo $(5.2 \mathrm{kcal} / \mathrm{mol})$ baja más de $13 \mathrm{kcal} / \mathrm{mol}$. La explicación de este fenómeno es la estabilización por parte de ese segundo indol de la carga positiva que se genera en el estado de transición en cuanto el enlace $\mathrm{C}-\mathrm{C}$ empieza a romperse, estabilización que llega a ser tan alta que permite la localización de un intermedio carbocatiónico (int-B) como un mínimo en la superficie de potencial. Este intermedio evoluciona después rápidamente hacia el producto a través de la formación de un nuevo enlace $\mathrm{C}-\mathrm{C}$, asociada a una barrera de activación muy baja $(2.9 \mathrm{kcal} / \mathrm{mol})$. Como resultado, el camino preferido por I-B es la migración del resto alquilo frente al alquenilo a través de un mecanismo por etapas, en lugar de concertado como en los otros ejemplos. Esta preferencia "anómala" se justifica por la estabilización de carga positiva en $\alpha$ que origina la presencia de este segundo núcleo indólico, la cual también contribuye a reducir notablemente la barrera de activación del proceso (5.2 vs. $13.8 \mathrm{kcal} / \mathrm{mol}$ en el modelo sin indol).
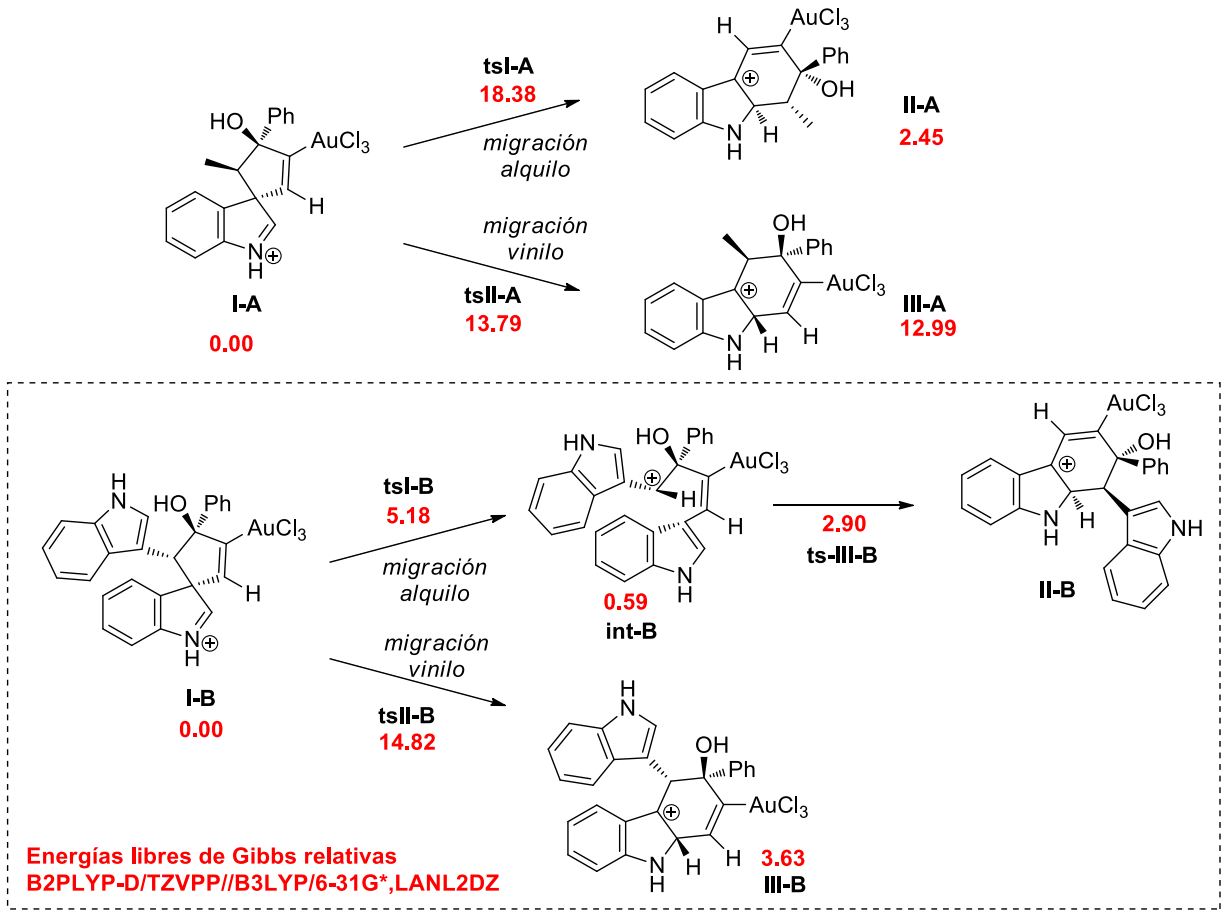

Esquema 4.12 


\subsection{REACCIONES DE YODOCICLACIÓN DE ALQUINOLES $\alpha$ - BISINDOLILMETIL SUSTITUÍDOS}

La halociclación de alquinos es una reacción de ciclación electrofílica en la que un triple enlace es activado por un electrófilo externo, generalmente, $\mathrm{I}^{+}, \mathrm{Br}^{+}$, ó $\mathrm{Cl}^{+}$, favoreciendo una posterior adición de un nucleófilo interno. ${ }^{155}$ Este proceso da lugar a estructuras carbocíclicas o heterocíclicas según se emplee un nucleófilo carbonado o uno heteroatómico.

Generalmente, el triple enlace se encuentra unido a una cadena lateral donde se encuentra el nucleófilo interno (Esquema 4.13). Se propone que los mecanismos por los que trascurren las ciclaciones electrofílicas se inician por reacción del sistema $\pi$ con el electrófilo $\mathrm{E}^{+}$para generar un intermedio activado A que presenta dos posiciones electrofílicas.

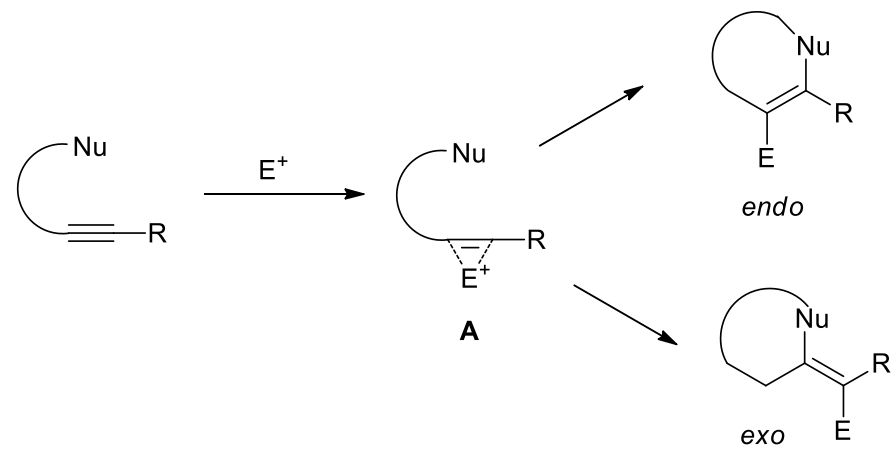

Esquema 4.13

En principio, las ciclaciones tienen lugar como predicen las reglas de Baldwin, si bien la regioquímica está muy influenciada por la sustitución en el triple enlace, que ejerce influencia mediante efectos electrónicos y/o estéricos. Así, en los procesos exo se encuentran favorecidos los ciclos de entre 3 y 7 eslabones. Por el contrario, en los procesos endo no están favorecidos los ciclos de 3 a 5 eslabones, mientras que si lo están los ciclos de 6 y 7 miembros. En cuanto a la estereoselectividad del proceso, la mayoría de estas reacciones tienen lugar mediante una adición estereoespecífica anti al enlace $\pi$.

155 (a) T. Aggarwal, S. Kumar, A. K. Verma, Org. Biomol. Chem. 2016, 14, 7639-7653. (b) S. Singh, S. S. Chimni, Synthesis 2015, 47, 1961-1989. (c) A. Palisse, S. F. Kirsch, Org. Biomol. Chem. 2012, 10, 8041-8047. (d) B. Godoi, R. F. Schumacher, G. Zeni, Chem. Rev. 2011, 111, 2937-2980. (e) F. Rodríguez and F. J. Fañanás, in Handbook of Cyclization Reactions, Ed. S. Ma, Wiley-VCH, Weinheim, Germany, 2010, vol. 2, p. 951. 
En este apartado de la Tesis se ha realizado una breve revisión de diferentes reacciones de yodociclación. Debido a la extensión de la bibliografía en este campo, nos hemos centrado únicamente en reseñar metodologías en las que el nucleófilo interno es carbonado (aromático o alqueno).

\subsubsection{Antecedentes}

Barluenga y col. fueron pioneros en este campo describiendo la ciclación electrofílica del 1,4-difenil-1-butino I mediada por $\mathrm{I}(\mathrm{py}){ }_{2} \mathrm{BF}_{4}$, que da lugar a los 1,2-dihidronaftalenos II mediante una ciclación 6-endo-dig (Esquema 4.14, Ec 1). ${ }^{156}$ Esta metodología ha permitido, además, la síntesis de heterociclos IV con anillos de benceno fusionados a partir de los alquinos III (Esquema 4.14, Ec 2). ${ }^{157}$ Posteriormente, Swanger y col. aplicaron esta estrategia a la síntesis de estructuras policíclicas aromáticas condensadas. ${ }^{158}$

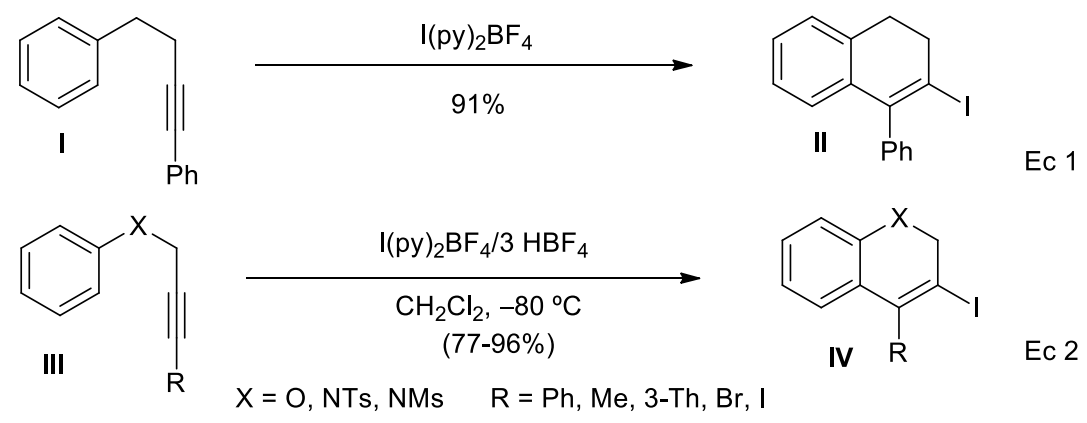

\section{Esquema 4.14}

Por su parte, Larock describió la reacción de ciclación electrofílica de los bifenilos $o$-alquinilsustituídos $\mathbf{V}$, en presencia de ICl como fuente de iodonio, para dar lugar a los compuestos policíclicos yodados VI. Los autores proponen que la reacción tiene lugar a través de una ciclación 6-endo-dig mediante el ataque nucleofílico del anillo aromático al catión iodonio intermedio. Es reseñable que la reacción trascurra de manera selectiva, a través de una ciclación 6-endo, incluso para aquellos productos $\mathbf{V}$ en los que $\mathrm{R}^{2}$ es un grupo fuertemente

\footnotetext{
156 J. Barluenga, J.-M. González, P.-J. Campos, G. Asensio, Angew. Chem., Int. Ed. 1988, 27, 1546-1547

${ }^{157}$ J. Barluenga, M. Trincado, M.-M. Arias, A. Ballesteros, E. Rubio, J.-M. González, Chem. Commun. 2005, 2008-2010.

${ }^{158}$ M. Golfinger, K. Crawford, T. Swanger, J. Am. Chem. Soc. 1997, 119, 4578-4593.
} 
electrón atractor, no habiéndose observado el producto de ciclación 5-exo-dig en ningún caso (Esquema 4.15). ${ }^{159}$<smiles>[R]Cc1ccc(-c2ccccc2C#Cc2ccc([R])cc2)cc1</smiles>

$\mathrm{R}^{1}=\mathrm{H}, \mathrm{CHO}, \mathrm{NO}_{2}$

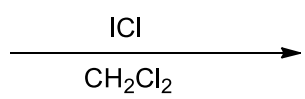

(55-99\%)

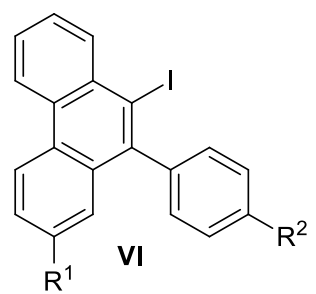

$\mathrm{R}^{2}=\mathrm{H}, \mathrm{OMe}, \mathrm{Me}, \mathrm{H}, \mathrm{CO}_{2} \mathrm{Et}, \mathrm{NO}_{2}$

\section{Esquema 4.15}

Posteriormente, este mismo grupo describió la reactividad de los alquinoles VII y las alquinonas IX frente a cationes yodonio lo que permite acceder a los correspondientes 2-yodonaftalenos VIII y 2-yodo-3-hidroxinaftalenos $\mathbf{X}$ con rendimientos entre moderados y buenos (Esquema 4.16). ${ }^{160}$<smiles>[R]C#CC([R])(O)C([R])c1ccccc1</smiles><smiles>[R]C#CC(=O)Cc1ccccc1</smiles>
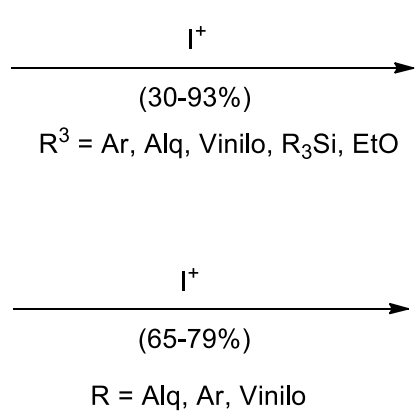<smiles>[R]c1c(I)c([R])c2ccccc2c1[R]</smiles><smiles>[X]c1c(I)c(O)cc2ccccc12</smiles>

\section{Esquema 4.16}

Por otra parte, el empleo de olefinas como nucleófilos en reacciones de ciclación electrofílica no ha sido descrito hasta muy recientemente cuando Kirsch y col. emplearon los 1,5-eninos XI como productos de partida para generar los 1yodobencenos sustituídos XII (Esquema 4.17). ${ }^{161}$ La ciclación tiene lugar de manera análoga a lo descrito para los sustratos anteriores a través de una ciclación 6-endo-dig iniciada mediante el ataque de la olefina al triple enlace activado por el yodonio hasta el intermedio B. Finalmente, una aromatización oxidante

159 T. Yao, M.-A. Campo, R.-C. Larock, Org. Lett. 2004, 6, 2677-2680.

${ }^{160}$ X. Zhang, S. Sarkar, R.-C. Larock, J. Org. Chem. 2006, 71, 236-243.

${ }^{161}$ B. Crone, S.-F. Kirsch, K.-D. Umland, Angew. Chem. Int. Ed. 2010, 49, 4661-4664. 
conduce a los yodobencenos XII. El sustituyente $\mathrm{R}^{4}$ sobre el carbono interno de la olefina es determinante en el trascurso de la reacción ya que contribuye a estabilizar el carbocatión intermedio. Y así, cuando sobre esta posición no hay sustituyentes la reacción no tiene lugar.

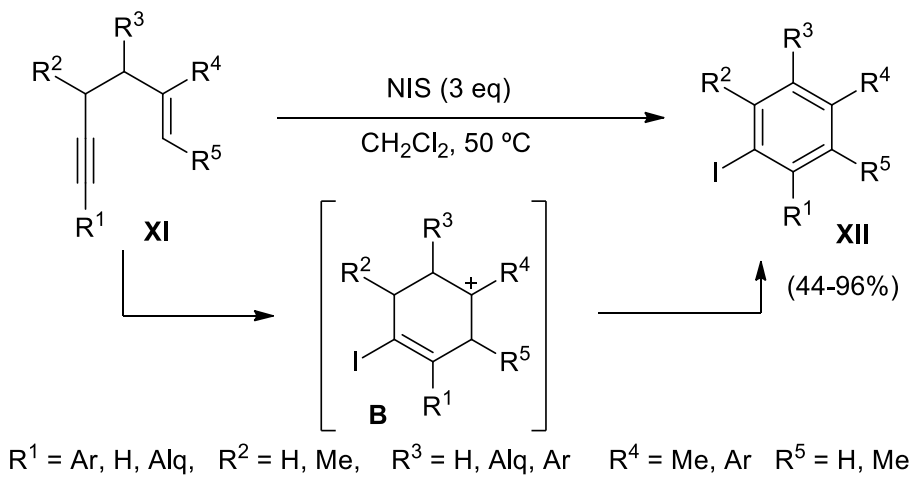

\section{Esquema 4.17}

En este contexto, una de las líneas de nuestro grupo de investigación consiste en el estudio de la reactividad de $o$-alquinilestirenos ${ }^{162}$ en procesos de cicloisomerización con numerosas contribuciones en este campo. ${ }^{163} \mathrm{Y}$ así, nuestro grupo describió cómo la ciclación de los $o$-alquinilestirenos XIII en presencia de NIS da lugar a los 3-yodoindenos XIV a través de una ciclación 5endo-dig, modelo de halociclación que no tenía precedentes en ese momento (Esquema 4.18). ${ }^{164}$ El cambio en la regioquímica del ataque nucleofílico de la olefina, respecto de la reacción descrita por Kirsch, se justifica por la mayor estabilización que aportan los dos grupos metilo al carbocatión intermedio $\mathbf{C}$. Más recientemente, esta yodociclación ha sido extendida también a $o$ alquinilestirenos $\beta, \beta$-diaril susituídos. ${ }^{16 \mathrm{~b}}$

${ }^{162}$ A. Martínez, Tesis Doctoral, Universidad de Burgos, 2010.

163 (a) A. Martínez, P. García-García, M.-A. Fernández-Rodríguez, F. Rodríguez, R. Sanz, Angew. Chem. Int. Ed. 2010, 122, 4737-4741. (b) P. García-García, A. Martínez, A.-M. Sanjuán, M.A. Fernández-Rodríguez, R. Sanz, Org. Lett. 2011, 13, 4970-4973. (c) P. García-García, M.A. Rashid, A.-M. Sanjúan, M.-A. Fernández-Rodríguez, R. Sanz, Org. Lett. 2012, 14, 4778-4781. (d) A.-M. Sanjuán, P. García-García, M.-A. Fernández-Rodríguez, R. Sanz, Adv. Synth. Catal. 2013, 355, 1955-1962. (e) A.-M. Sanjuán, M.-A. Rashid, P. García-García, A. Martínez-Cuezva, M.-A. Fernández-Rodríguez, F. Rodríguez, R. Sanz, Chem. Eur. J. 2015, 21, 3042-3052. (f) A.-M. Sanjuán, C. Virumbrales, P. García-García, M.-A. Fernández-Rodríguez, R. Sanz, Org. Lett. 2016, 18, 1072-1075.

164 (a) R. Sanz, A. Martínez, P. García, M.-A. Fernández, M.-A. Rashid, F. Rodríguez, Chem. Commun. 2010, 46, 7427-7429. (b) P. García-García, A.-M. Sanjuán, A. Martínez-Cuezva, M.A. Rashid, M.-A. Fernández-Rodríguez, F. Rodríguez, R. Sanz, J. Org. Chem. 2017, 82, 1155. 


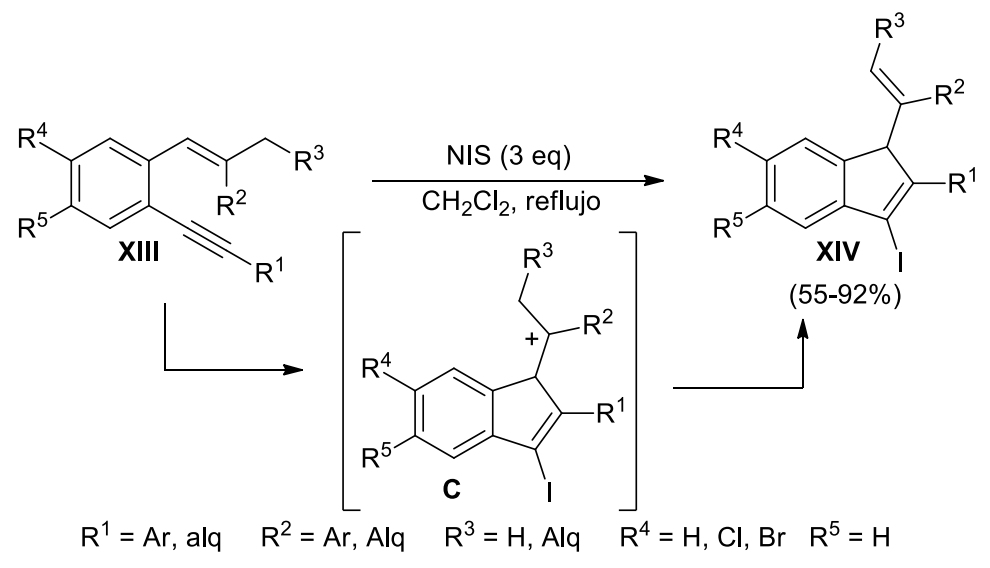

\section{Esquema 4.18}

Por otra parte, la yodociclación de 3-(but-3-inil)-1H-indoles también había sido estudiada como un ejemplo particular de los alquinoles VII (Esquema 4.16), para acceder a yodocarbazoles. Estos alquinoles, en presencia de una fuente de $\mathrm{I}^{+}$, presentan una reactividad análoga a la descrita cuando se emplean catalizadores de oro (ver Esquema A.23, Antecedentes Generales). Un ejemplo de ello se describe en el Esquema 4.19. La reacción del alquinol XV en presencia de ICl trascurre mediante una ciclación 5-endo-dig a través del intermedio espiránico D cuya evolución, mediante una migración 1,2 del resto vinílico, conduce a $\mathbf{E}$ que, por pérdida de un protón y posterior deshidratación, conduce al 2-yodocarbazol XVI (Esquema 4.19). ${ }^{12}$

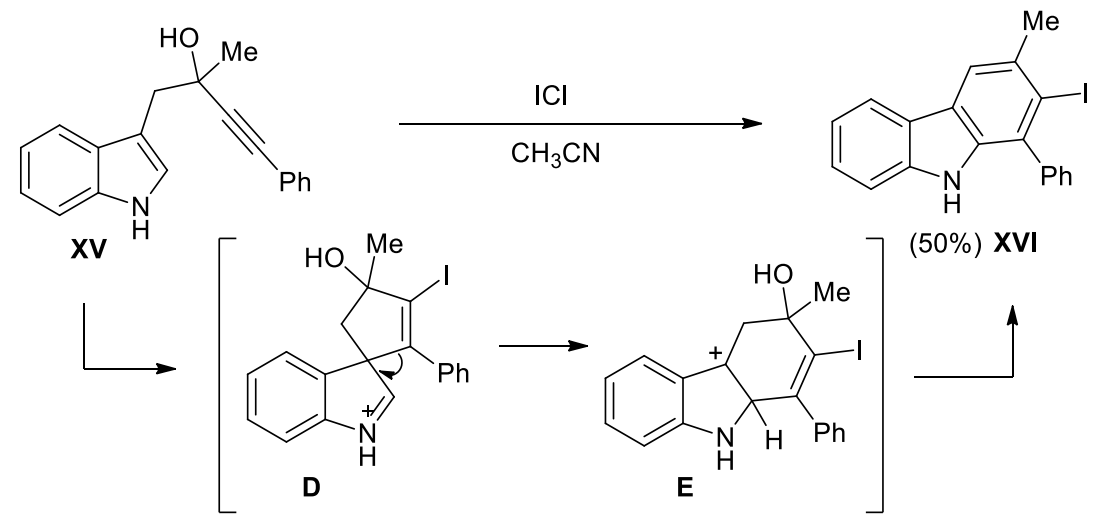

\section{Esquema 4.19}

Sin embargo, cuando en el sustrato de partida se introduce un grupo hidroxilo en posición $\alpha$ al anillo de indol la selectividad de la migración 1,2 sobre el 
intermedio espiránico se ve modificada favoreciéndose la migración del carbono $\mathrm{sp}^{3}$ (Esquema 4.20). ${ }^{165}$ De esta manera ha sido posible acceder a los 3yodocarbazoles XVIII mediante la ciclación electrofílica de los indolilmetanoles alquinil funcionalizados XVII. La reacción transcurre a través de una ciclación 5-endo-dig hasta el intermedio $\mathbf{F}$. En este caso, una migración 1,2 del resto hidroxialquilo da lugar al intermedio $\mathbf{G}$ que evoluciona hasta el producto final por pérdida de un protón y posterior deshidratación. Este cambio en la selectividad de la migración 1,2 se podría justificar considerando la capacidad estabilizante del grupo hidroxilo sobre el $\mathrm{Csp}^{3}$ que migra, ya que ahora la competencia se establece entre un grupo hidroximetilo y uno alquenilo (Esquema 4.20).

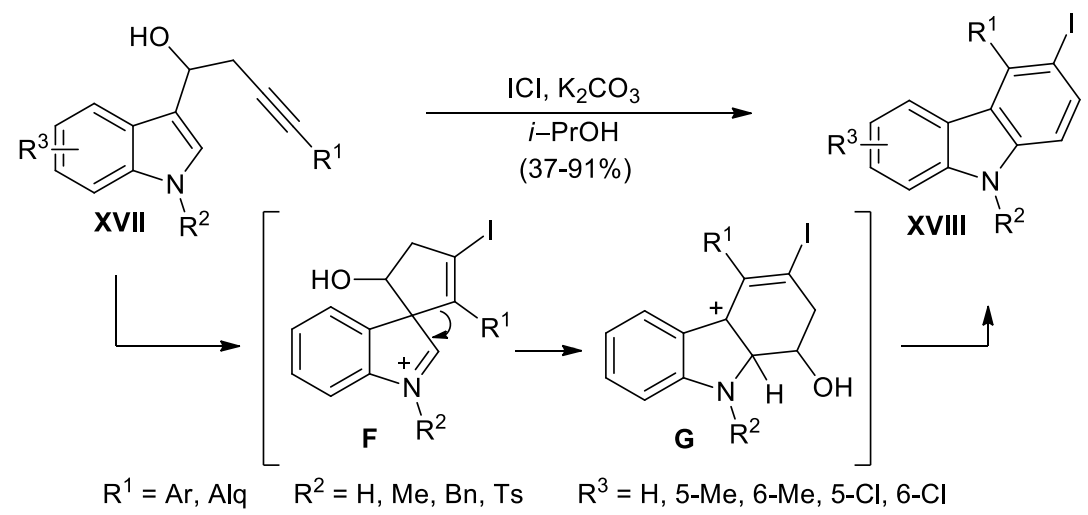

\section{Esquema 4.20}

Por otra parte, la reacción de 2-alquinilbenzaldehídos e indoles en presencia de una fuente de yodonio conduce a la formación de los derivados de haloindoloazulenos XIX. La reacción es un proceso en cascada que implica la formación inicial de un $o$-bisindolilmetilarilalquino $\mathbf{X X}$, el cual sufre una ciclación 6-endo-dig hasta el intermedio $\mathbf{H}$. Una posterior migración 1,2 del resto alquenilo conduce a la formación de los derivados de indoloazulenos XIX (Esquema 4.21) ${ }^{166}$ Cabe destacar que, en este caso, la presencia de otra molécula de indol en $\alpha$ al carbono espiránico del intermedio $\mathbf{H}$ no modifica la selectividad de la migración 1,2, de manera contraria a lo descrito en esta Memoria para la

165 J. Wang, H.-T Zhu, Y.-F Qiu, Y. Niu, S. Chen, Y.-X. Li, X.-Y. Liu, Y.-M. Liang, Org. Lett. 2015, 17, 3186-3189.

${ }^{166}$ S.-D. Gawande, V. Kavala, M. Zanwar, C.-W. Kuo, H.-N. Huang, C.-H. He, T.-S. Kuo, C.-F. Yao, Adv. Synth. Catal. 2013, 355, 3022-3036. 
reactividad de los $\alpha$-bisindolilmetil alquinoles $\mathbf{5 3}$ en presencia de oro (III) (ver Esquema 4.7).<smiles>[X]CCCCCCCCC#Cc1ccccc1C#Cc1c[nH]c2ccccc12</smiles>

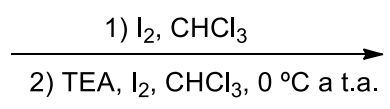<smiles>IC1=C(c2ccccc2)c2[nH]c3ccccc3c2C(c2c[nH]c3ccccc23)c2ccccc21</smiles>

6-endo-dig<smiles>CCCC1(c2ccccc2)C(I)=C(I)c2ccccc2C1c1c[nH]c2ccccc12</smiles>

XIX

Esquema 4.21

\subsubsection{Objetivo}

A la vista de estos antecedentes, y teniendo en cuenta las analogías que presentan algunas reacciones de activación de alquinos con cationes yodonio y con complejos catiónicos de oro, ${ }^{167}$ nos propusimos como objetivo estudiar la reactividad de los $\alpha$-bisindolilmetilalquinoles $\mathbf{5 3}$ frente a fuentes de yodonio, con el fin de comprobar si el $\mathrm{I}^{+}$es capaz de emular la reactividad de estos sustratos frente a catalizadores de $\mathrm{Au}(\mathrm{III})$ (Esquema 4.22).

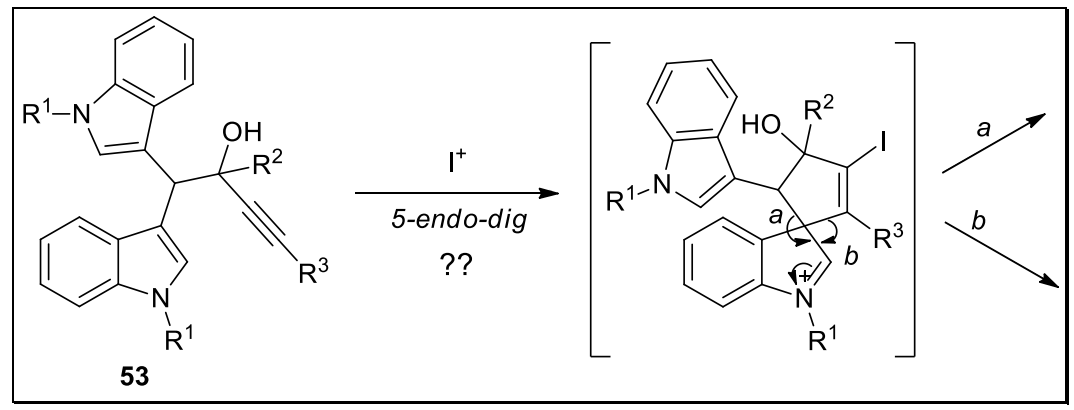

Esquema 4.22

167 (a) S. Hummel, S.-F. Kirsch, Beilstein J. Org. Chem. 2011, 7, 847-859. (b) Y. Yamamoto, I.D. Gridnev, N.-T. Patil, T. Jin, Chem. Commun. 2009, 5075-5087. 


\subsubsection{Síntesis de 1-indolil-3-yodocarbazoles}

\subsubsection{Pruebas preliminares y evaluación inicial del alcance de la reacción}

En una prueba preliminar, en la que se hizo reaccionar al alquinol 53e en presencia de yodo e hidrógeno carbonato sódico, en acetonitrilo como disolvente, se observó la formación del yodocarbazol 57e con un $35 \%$ de rendimiento (Esquema 4.23). La estructura de este producto fue determinada mediante diferentes experimentos de RMN y confirmó la presencia del indol en la posición 1 del carbazol.
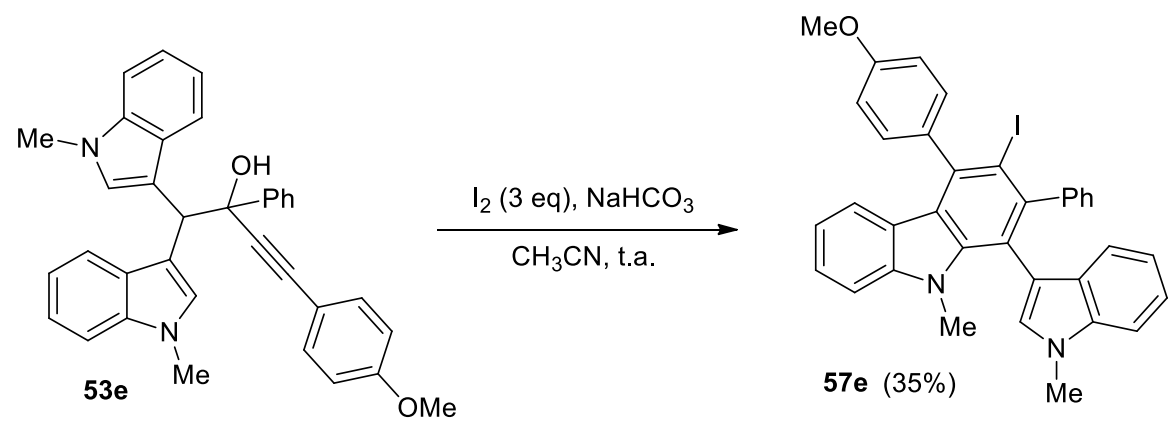

\section{Esquema 4.23}

Por otra parte, también comprobamos que cuando se hizo reaccionar este mismo alquinol 53e con NIS (1,1 eq) se obtuvo una mezcla 8:1 del alcohol 58e, como mezcla $\sim 1: 1$ de diasteroisómeros, y el carbazol 57e con un rendimiento global del $45 \%$ (Esquema 4.24).

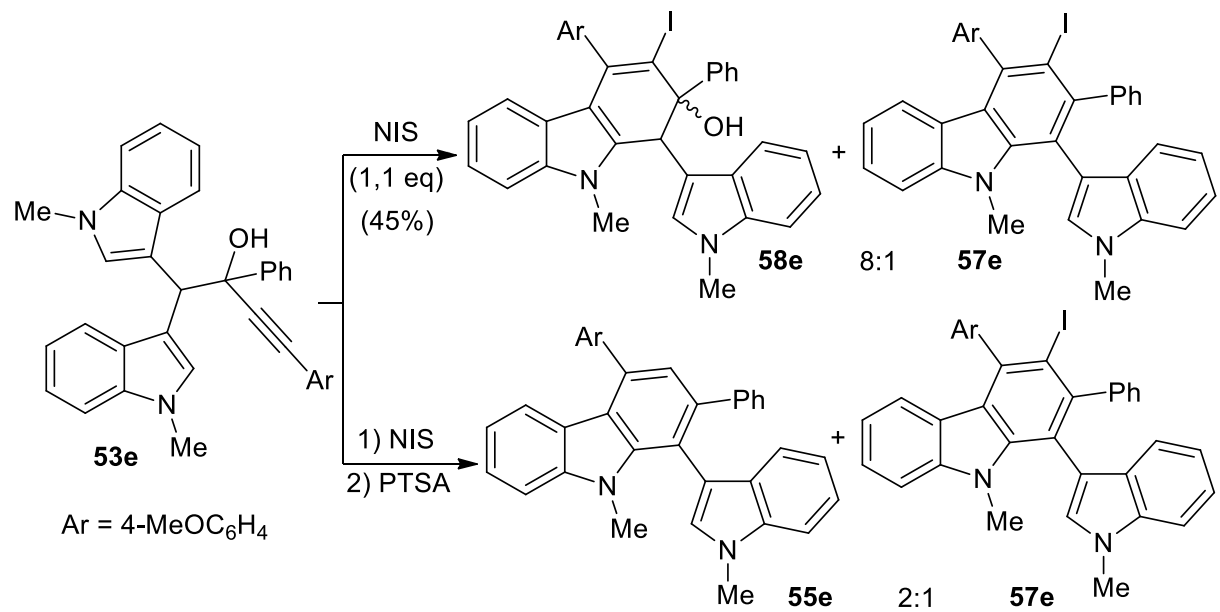

Esquema 4.24 
Teniendo en cuenta la presencia del alcohol $\mathbf{5 8}$ pensamos que añadir una cantidad de PTSA a la reacción favorecería la eliminación de agua en este alcohol intermedio lo que podría conducir, así, a la formación selectiva del carbazol 58e. Sin embargo, esta prueba condujo únicamente a la formación de los carbazoles 55e:57e en una proporción 2:1 (Esquema 4.24). Tras estas pruebas preliminares, y teniendo en cuenta lo descrito en los antecedentes de este tipo de reacciones, decidimos continuar con el empleo de NIS (1,1 eq) y $\mathrm{CH}_{2} \mathrm{Cl}_{2}$ como disolvente como condiciones para los procesos de yodociclación. A continuación, se estudió el alcance de la reacción para una serie de alquinoles 53. Desafortunadamente, bajo las condiciones de reacción elegidas, los alquinoles $\mathbf{5 3 b}, \mathbf{f}, \mathbf{h}$ no condujeron a la formación de los correspondientes yodocarbazoles 57 , sino que únicamente se detectó la formación de productos de descomposición. Por el contrario, la reacción de los alquinoles $\mathbf{5 3 h}$ y $\mathbf{5 3 i}$, en los que el bisindolilmetano de la estructura presenta restos indólicos $\mathrm{N}-\mathrm{H}$, bajo las mismas condiciones, dio lugar a los 1-indolil-3-yodocarbazoles $\mathbf{5 7 h}$ y $\mathbf{5 7 i}$ de manera selectiva y con buenos rendimientos (Esquema 4.25). Estos resultados preliminares parecen indicar que la reacción de yodociclación con los alquinoles $\mathbf{5 3}$ funciona bien con los sustratos que presentan restos indólicos $N-H$. Por el contrario, en el caso de la catálisis con $\mathrm{Au}(\mathrm{III})$ las reacciones transcurrían eficientemente independientemente del modelo de sustitución de los restos indólicos de los productos de partida.

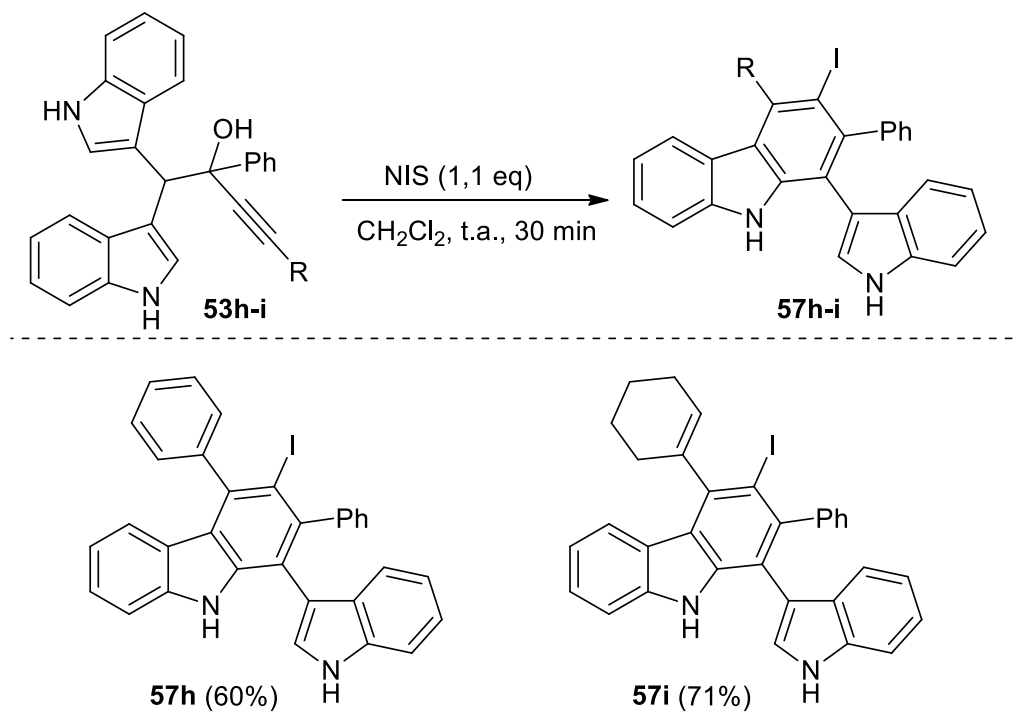

Esquema 4.25 


\subsubsection{Propuesta mecanística}

El mecanismo propuesto para explicar la reacción promovida por los cationes yodonio se recoge en el Esquema 4.26. En primer lugar, se produciría la activación del triple enlace por parte del catión yodonio para dar lugar al intermedio A. A continuación, una ciclación 5-endo-dig a través del C-3 del indol sobre el alquino activado daría lugar al intermedio espiránico B. Posteriormente, y de manera análoga a lo descrito para los procesos catalizados por $\mathrm{Au}$ (III) sobre los mismos sustratos, la apertura del intermedio espiránico generaría el intermedio $\mathbf{C}$. Una ciclación de $\mathbf{C}$ a través del C-2 del indol conduciría a $\mathbf{D}$ el cual, tras perder un protón origina el alcohol 58. Finalmente, la eliminación de una molécula de agua en $\mathbf{5 8}$ genera el 1-indolil-3-yodo carbazol 57. Sin embargo, el mecanismo propuesto no justifica, al menos inicialmente, el que las reacciones de yodociclación funcionen eficientemente sólo con sustratos de partida con los átomos de nitrógeno sin sutituyentes.

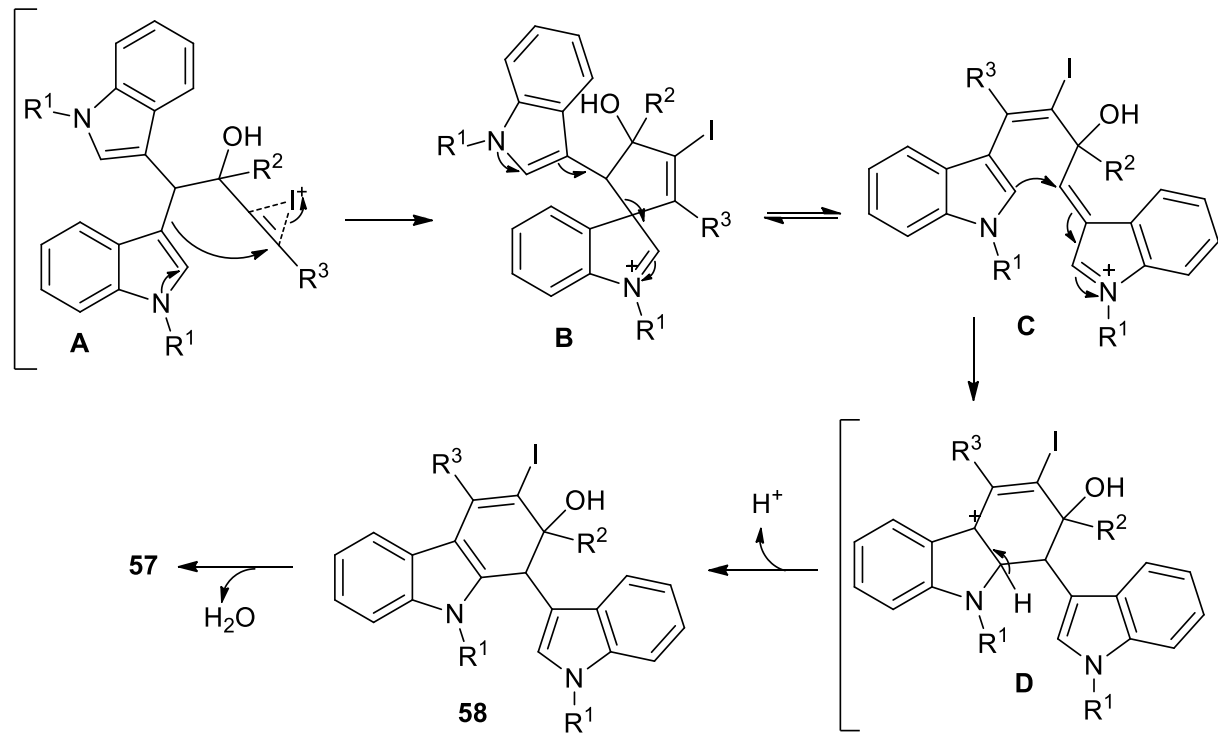

Esquema 4.26 


\subsection{REACTIVIDAD DE ALQUINOLES $\alpha$-TIOALQUIL FUNCIONALIZADOS FRENTE A CATALIZADORES DE Au(III)}

\subsubsection{Antecedentes}

Los sustratos que poseen átomos de azufre en su estructura presentan gran afinidad por los metales de transición. Quizás por ello no son tan abundantes los ejemplos descritos en los que se emplean compuestos azufrados como nucleófilos en reacciones con alquinos catalizadas por complejos metálicos.

La primera reacción de formación de un enlace $\mathrm{C}-\mathrm{S}$ catalizada por complejos de oro consistió en la cicloisomerización de los $\alpha$-tioalenos I a los 2,5dihidrotiofenos II catalizada por $\mathrm{Au}(\mathrm{I})$ (Esquema 4.27). ${ }^{168}$ La reacción se iniciaría mediante la coordinación del catalizador al doble enlace del aleno lo que genera el intermedio A que podría estar en equilibrio con A'. El ataque nucleofílico del átomo de azufre al doble enlace activado genera el intermedio zwiteriónico $\mathbf{B}$ que, por posterior protodesmetalación, conduce a los dihidrotiofenos II.
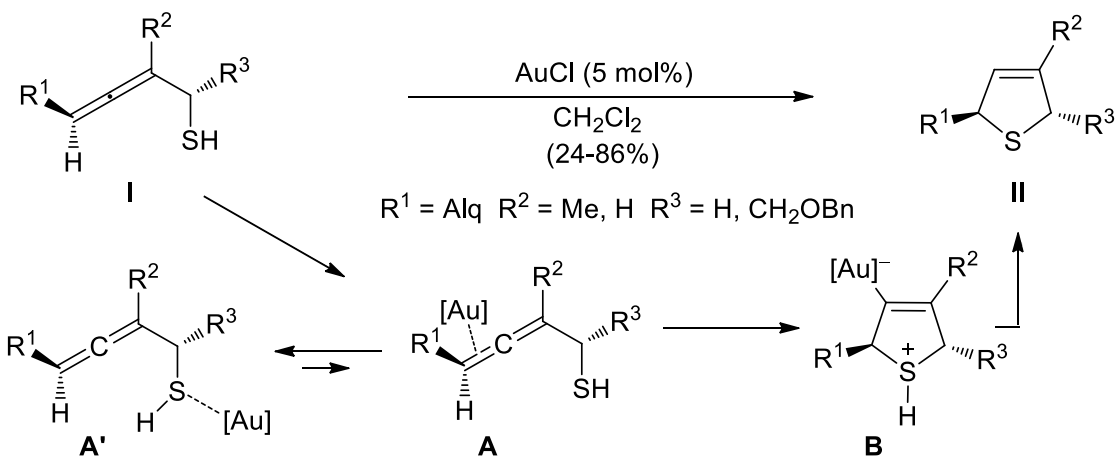

\section{Esquema 4.27}

Los alquinos también han sido empleados como electrófilos en reacciones de carbotiolación catalizadas por Au(I). Y así, la ciclación de los $\alpha$-(alcoxialquil) $o$ (alquinil)-fenil sulfuros III en presencia de $\mathrm{AuCl}$ dio lugar a los benzotiofenos IV (Esquema 4.28). ${ }^{169}$ El proceso transcurre a través del intermedio $\mathbf{C}$, generado por el ataque nucleofílico del tioéter al triple enlace activado. La migración del resto $\alpha$-alcoxialquilo a la posición 3 del benzotiofeno da lugar al intermedio $\mathbf{D}$, el cual conduce a IV por protodesmetalación.

\footnotetext{
${ }^{168}$ N. Morita, N. Krause, Angew. Chem. Int. Ed. 2006, 45, 1897-1899.

169 (a) I. Nakamura, T. Sato, Y. Yamamoto, Angew. Chem. Int. Ed. 2006, 45, 4473-4475. (b) I. Nakamura, T. Sato, M. Tereda, Y. Yamamoto, Org. Lett. 2007, 9, 4081-4083.
} 
<smiles>[R]C#Cc1ccccc1SC([R])O[R]</smiles>

III

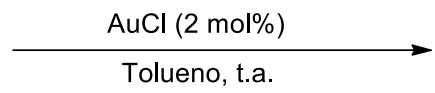

$(92-99 \%)$<smiles>[R]c1sc2ccccc2c1C([R])[R]</smiles>

IV

$\left|\begin{array}{cc}\mathrm{R}^{1}=\text { Alq, Ar } & \mathrm{R}^{2}=\mathrm{Me} \text {, Et, TBS, MPM, TMSE, }\left(\mathrm{CH}_{2}\right)_{4} \mathrm{R}^{3}=\mathrm{H}, \mathrm{Me} \\ \mathrm{R}^{3}\end{array}\right|$

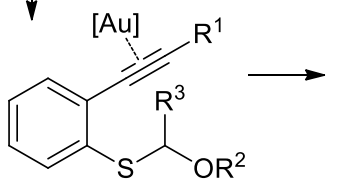<smiles>[R]c1c([Al])c2ccccc2[s+]1C([R])[R]</smiles><smiles>[R]C([R])C1([R])Sc2ccccc2C1([Y])C([R])O</smiles>

D

\section{Esquema 4.28}

Por otra parte, tioéteres y ditianos propargílicos reaccionan, en presencia de catalizadores de oro, de manera análoga a lo descrito para acetatos propargílicos. ${ }^{170}$ Estas reacciones se inician con el ataque del azufre al alquino activado por la especie metálica, E y E', para dar lugar a los intermedios ciclopropano catiónicos $\mathbf{F}$ y $\mathbf{F}$ ', que generan los carbenoides metálicos $\mathbf{G}$ y $\mathbf{G}$ '. La evolución de estos últimos depende de la naturaleza de los sustratos de partida empleados en cada caso (Esquema 4.29). Es destacable que los procesos globales implican la migración 1,2 de un resto alquil o ariltio.
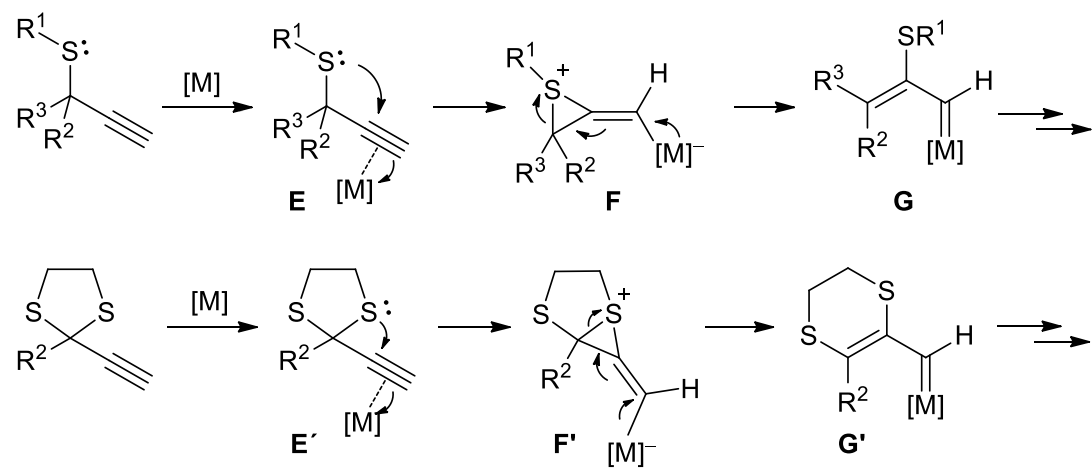

\section{Esquema 4.29}

${ }^{170}$ (a) V. Mamane, T. Gress, H. Krause, A. Fürstner, J. Am. Chem. Soc. 2004, 126, 8654-8655. (b) X. Shi, D. J. Gorin, F. D. Toste, J. Am. Chem. Soc. 2005, 127, 5802-5803. (c) C. H. M. Amijs, V. López-Carrillo, A. M. Echavarren, Org. Lett. 2007, 9, 4021-4024. (d) G. Li, G. Zhang, L. Zhang, J. Am. Chem. Soc. 2008, 130, 3740-3741. 
Así, la reacción de los tioéteres propargílicos $\mathbf{V}$, catalizada por complejos tanto de $\mathrm{Au}(\mathrm{I})$ como de $\mathrm{Au}(\mathrm{III})$, ha sido estudiada por Wang y col. dando lugar a una mezcla de los productos VI y VI' (Esquema 4.30). ${ }^{171}$ La selectividad de la reacción no parece estar influenciada por el tipo de catalizador metálico ni por su estado de oxidación. Para aquellos sustratos en los que los sustituyentes $R^{3}=R^{4}$ la reacción transcurre de manera totalmente selectiva hacia la formación de un único producto $(\mathbf{V I}=\mathbf{V I}$ '), aunque con rendimientos moderados. Como se ha explicado de manera general en el Esquema 4.29, la reacción se iniciaría con el ataque del azufre al alquino previamente activado hasta el intermedio zwiteriónico H. Posteriormente, la apertura del intermedio de tres centros provoca la migración 1,2 del grupo ariltio que conduce al carbenoide $\mathbf{I}$ en equilibrio con I'. A partir de este intermedio una reacción F.-C., que también puede entenderse como una inserción formal $\mathrm{C}-\mathrm{H}$, conduciría al nuevo intermedio catiónico $\mathbf{J}$ que por protodesmetalación da lugar a la mezcla de indenos VI y VI'.

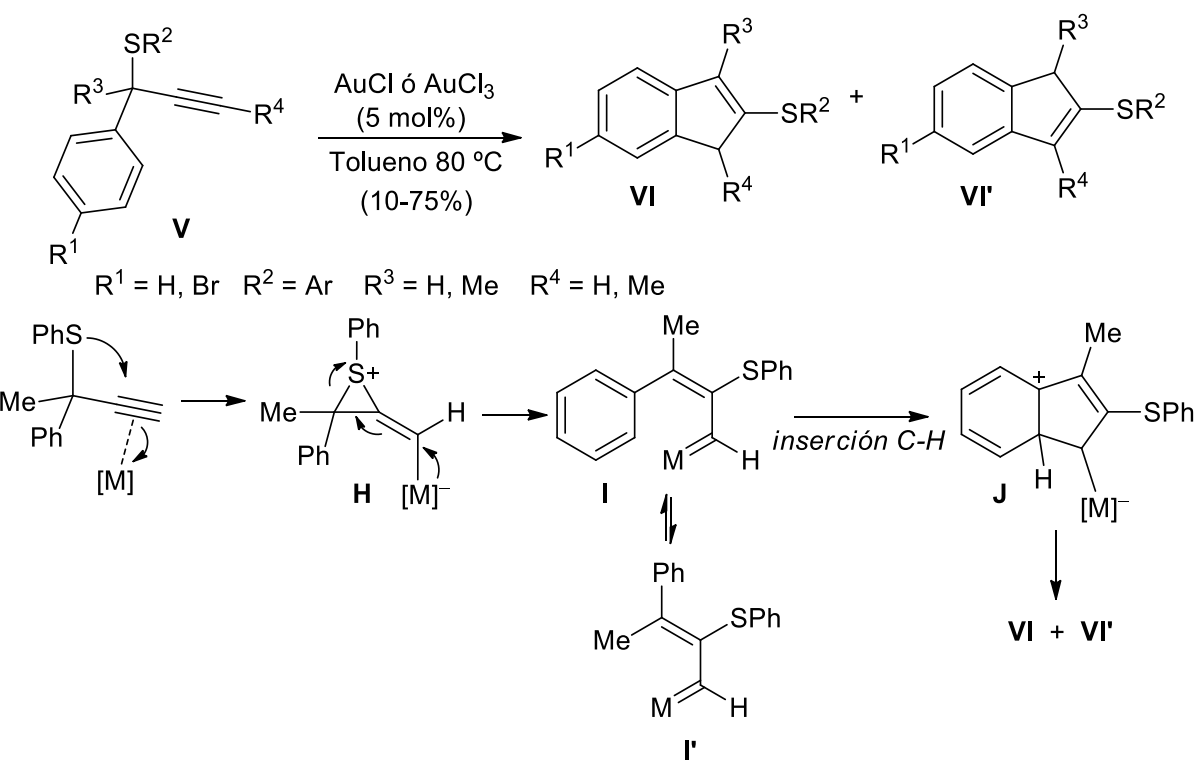

\section{Esquema 4.30}

Estos mismos autores describieron posteriormente la reactividad de los 1,2 y 1,3-ditianos VII catalizada por especies de $\mathrm{Au}(\mathrm{I})$ (Esquema 4.31). ${ }^{172} \mathrm{La}$

${ }^{171}$ L. Peng, X. Zhang, S. Zhang, J. Wang, J. Org. Chem. 2007, 72, 1192-1197.

${ }^{172}$ X. Zhao, Z. Zhong, L. Peng, W. Zhang, J. Wang, Chem. Commun. 2009, 2535-2537. 
formación de los productos VIII, a partir de 1,2-ditianos, puede ser explicada mediante el mecanismo anteriormente comentado. Sin embargo, cuando se parte de 1,3-ditianos $(\mathrm{n}=2)$, se observó la formación de los alenos cíclicos IX. Los autores proponen dos posibles caminos de reacción para su formación. En primer lugar, se generaría una especie de tipo carbenoide $\mathbf{K}$, de manera análoga al mecanismo propuesto para el reagrupamiento de tioéteres propargílicos descrito en el esquema anterior (ruta $a$ ). Sobre este intermedio una segunda migración 1,2 de azufre conduciría a los productos IX a través del intermedio $\mathbf{L}$. Otra alternativa que proponen los autores implicaría una migración inicial 1,3 del azufre para dar lugar a un intermedio $\sigma$-alílico $\mathbf{M}$ que también podría conducir a IX por desmetalación (ruta $b$ ).

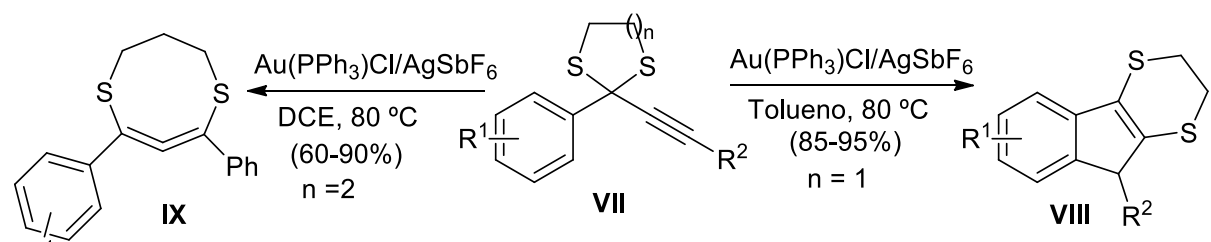

$\mathrm{R}^{1}=4-\mathrm{Br}, 3-\mathrm{Br}, 4-\mathrm{Cl}, 4-\mathrm{MeO}, 3-\mathrm{MeO}$

$\mathrm{R}^{1}=\mathrm{Br}, \mathrm{F}, \mathrm{C}_{6} \mathrm{H}_{5}$

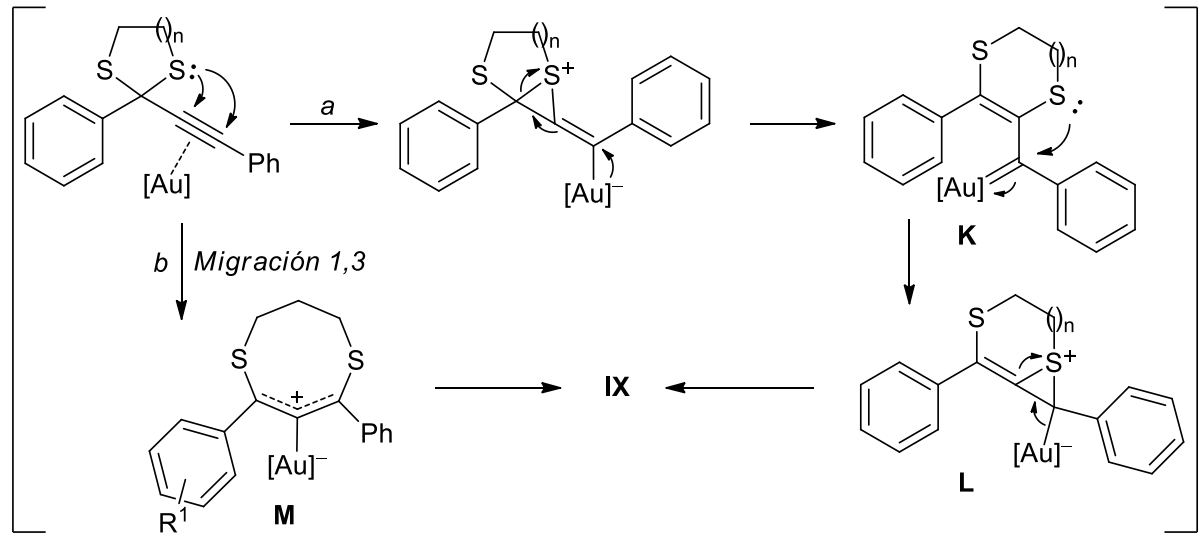

Esquema 4.31

Por otra parte, si el sustrato de partida posee un alquino adicional en posición orto, tal como el diino $\mathbf{X}$, la reacción trascurriría de manera análoga a lo descrito anteriormente hasta la formación del intermedio $\mathbf{N}$ (Esquema 4.32). ${ }^{173}$ A partir de éste una reacción con el segundo alquino de la molécula da lugar a un nuevo carbenoide de oro $\mathbf{P}$, probablemente a través del intermedio ciclopropeno $\mathbf{O}$. Finalmente, la inserción C-H en el carbenoide $\mathbf{P}$ conduciría a los fluorenos XI.

${ }^{173}$ W. Xu, M. Chen, N. Sung, Y. Liu, Chem. Commun. 2016, 52, 11000-11003. 


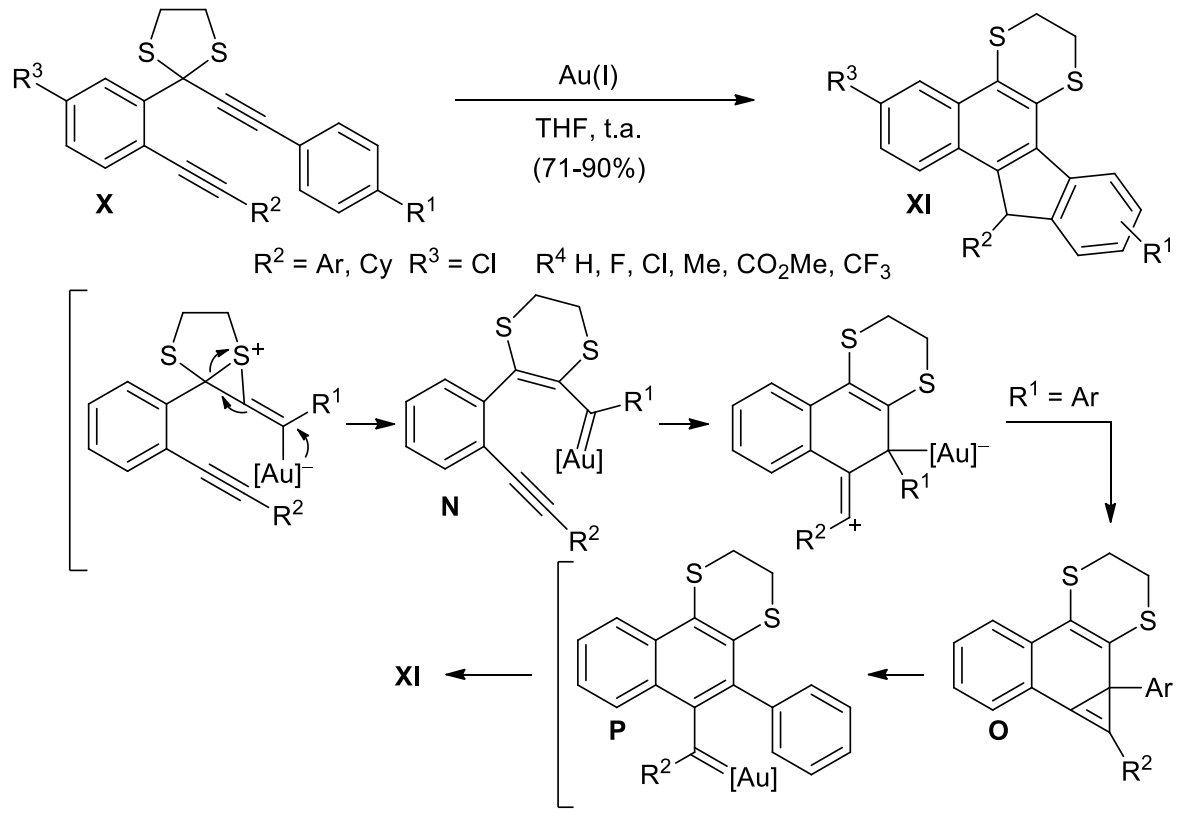

Esquema 4.32

Por otra parte, Liu y col. describieron la síntesis de las estructuras policíclicas condensadas XIII a partir de los sustratos XII (Esquema 4.33). La reacción implicaría la migración totalmente selectiva del átomo de azufre, no habiéndose observado productos procedentes de la migración 1,2 de hidruro o del resto $-\mathrm{NCO}_{2} \mathrm{Me}$. Además, cuando la reacción se llevó a cabo en presencia de $N$-óxidos de piridina, fue posible obtener las cetonas XIV. ${ }^{174}$
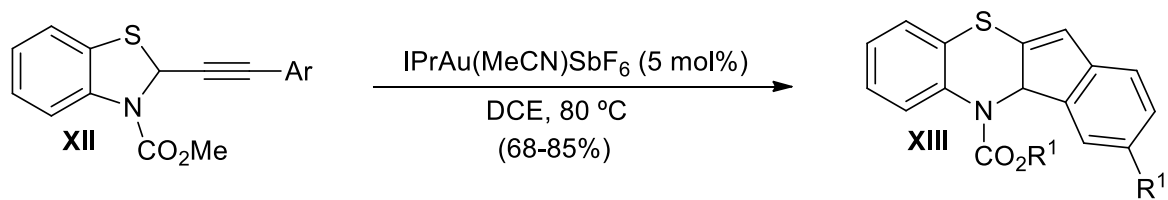

$$
\mathrm{R}^{1}=\mathrm{H}, \mathrm{F}, \mathrm{Cl}, \mathrm{CO}_{2} \mathrm{Me}, \mathrm{CF}_{3}, \mathrm{Me}
$$

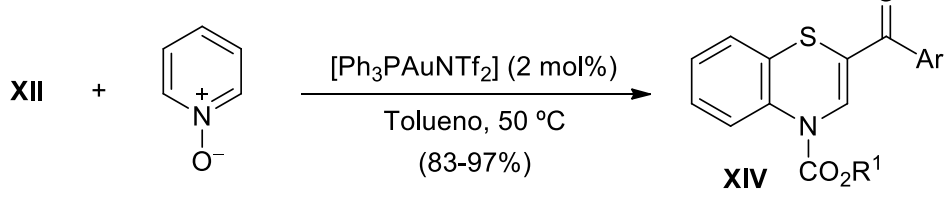

$\mathrm{R}^{1}=\mathrm{Me}, i-\mathrm{Pr}, \mathrm{Bn} \quad \mathrm{R}^{2}=\mathrm{Ph}, 4-\mathrm{FC}_{6} \mathrm{H}_{5}, 4-\mathrm{ClC}_{6} \mathrm{H}_{5}, 4-\mathrm{CO}_{2} \mathrm{MeC}_{6} \mathrm{H}_{5}, 4-\mathrm{NO}_{2} \mathrm{C}_{6} \mathrm{H}_{5}, 2-\mathrm{Th}, \mathrm{Cy}, c-\mathrm{C}_{6} \mathrm{H}_{9}$

\section{Esquema 4.33}

${ }^{174}$ M. Chen, N. Sun, W. Xu, J. Zhao, G. Wang, Y. Liu, Chem. Eur. J. 2015, 21, 18571-18575. 
Los autores proponen que la formación de los productos XIII y XIV podría tener lugar a través de los mecanismos que se recogen el Esquema 4.34. Las vías $a$ y $b$ explican la formación de XIV e implicarían el ataque inicial del $N$-óxido al alquino de manera regioselectiva en posición $\beta$ para dar lugar al intermedio vinílico de oro $\mathbf{Q}$. El ataque nucleofílico del átomo de azufre conduciría al intermedio de tres centros $\mathbf{R}$ que, por apertura del anillo, daría lugar a XIV. Alternativamente, a partir de $\mathbf{Q}$ se podría plantear la generación del $\alpha$ oxocarbenoide $\mathbf{S}$ (vía $b$ ), el cual podría experimentar una expansión del anillo hasta T, el cual por desmetalación conduciría también a XIV. Por su parte, si tiene lugar la migración antes que la oxidación, el camino $c$ implicaría la oxidación del intermedio carbénico $\mathbf{V}$ generado a partir del intermedio de tres centros U. Por otro lado, en ausencia de oxidante externo el intermedio $\mathbf{V}$ que posee un sustituyente arílico $\left(\mathrm{R}^{2}=\mathrm{Ar}\right)$, experimentaría una ciclación tipo Nazarov conduciendo a los productos XIII a través de W (Esquema 4.34).

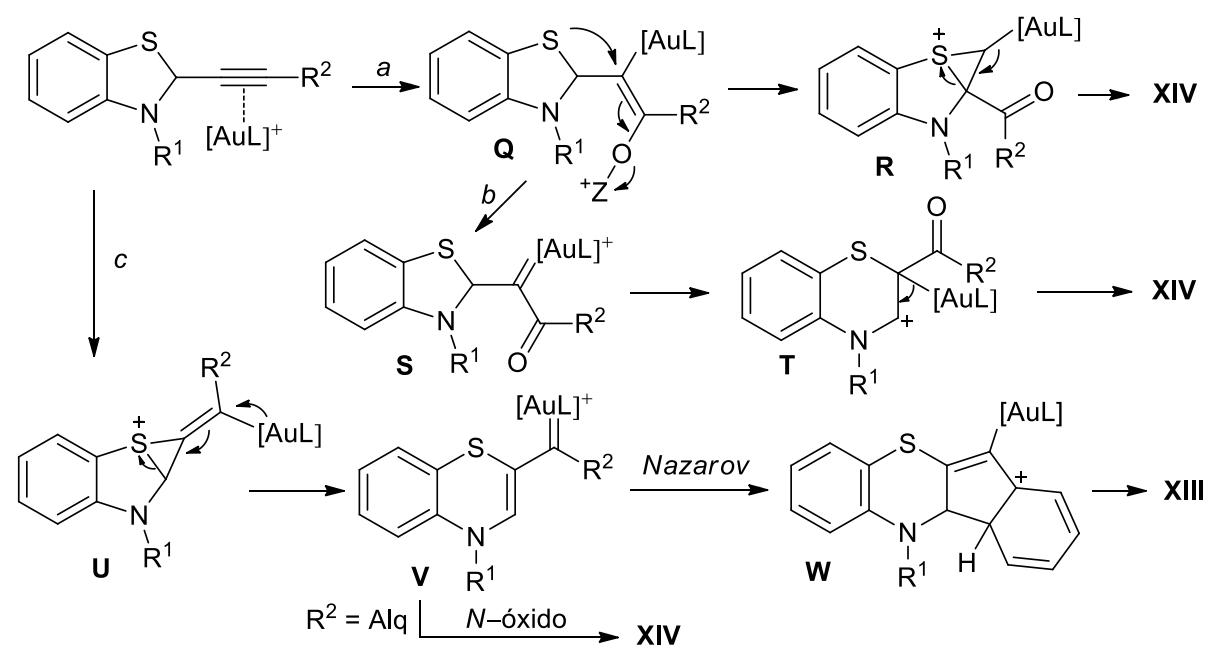

\section{Esquema 4.34}

\subsubsection{Objetivo}

En este último apartado de la Tesis nos propusimos como objetivo estudiar la reactividad de los alquinoles $\mathbf{5 9}$ frente a catalizadores de oro. El estudio de estos sustratos presenta interés ya que, en principio y dados los precedentes bibliográficos, tanto el resto indólico como el tioéter podrían evolucionar mediante una ciclación 5-endo-dig hasta los intermedios $\mathbf{X}$ ó $\mathbf{Y}$, respectivamente, a partir de los cuales se podrían desencadenar distintas transformaciones en cascada (Esquema 4.35). 


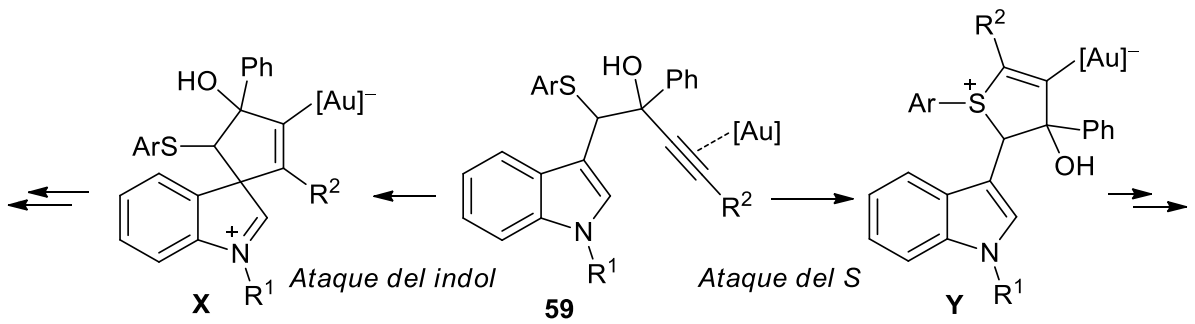

Esquema 4.35

\subsubsection{Discusión de Resultados}

\subsubsection{Síntesis de alquinoles propargílicos $\alpha$-ariltioalquilfuncionalizados 59}

Los alquinoles $\alpha$-ariltioalquilfuncionalizados $\mathbf{5 9}$ se prepararon de manera análoga a los alquinoles bisindolilmetil funcionalizados 53, es decir, por reacción de la correspondiente $\alpha$-indolilcetona $\mathbf{2 8}$ con bromuro de etinil magnesio, o diferentes acetiluros de litio, a baja temperatura (Tabla 4.5). De esta manera se sintetizaron los alquinoles terminales e internos 59a-e con un resto de $N$ metilindol (entradas 1 y 4) o 1,2-dimetilindol (entradas 2, 3 y 5) en su estructura, con rendimientos moderados. Estos alquinoles fueron obtenidos en todos los casos como mezclas $\sim 1: 1$ de diateroisómeros.

Tabla 4.5 Síntesis de los alquinoles terminales $\alpha$-indolil- $\alpha$ ariltioalquilfuncionalizados $59^{\mathrm{a}}$

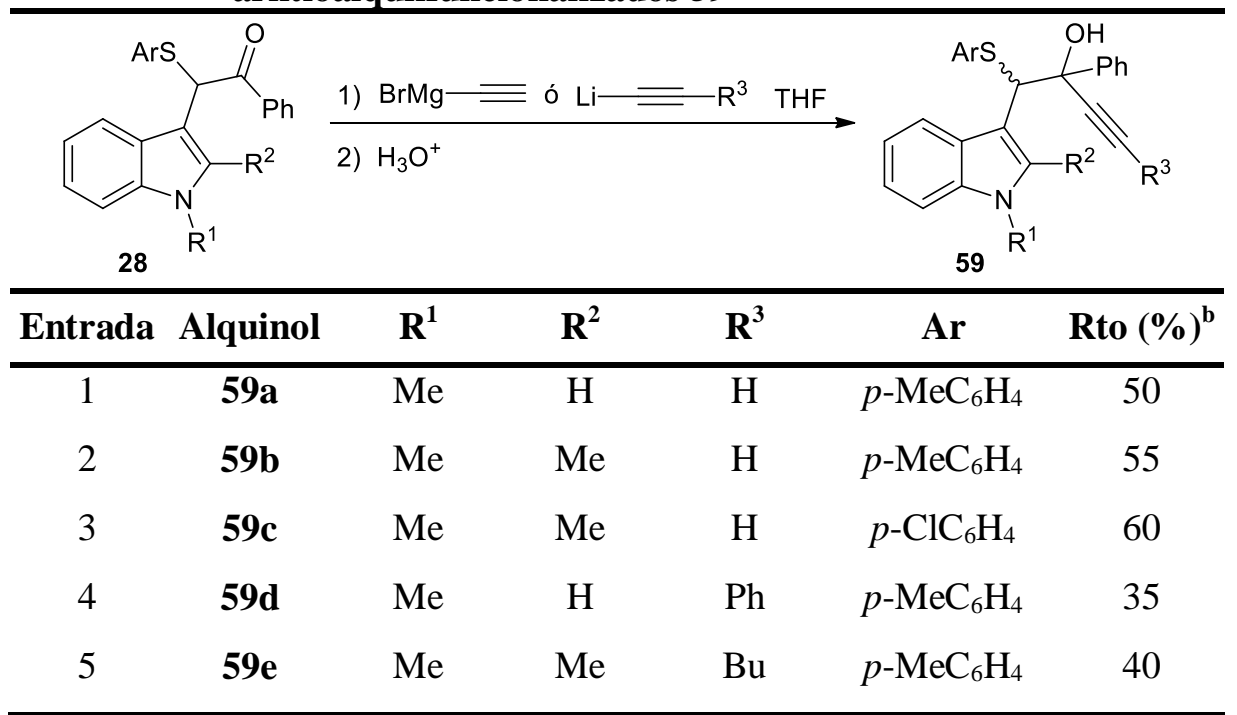

aCondiciones de reacción: $\mathbf{2 8}$ (1 eq), bromuro de etinilmagnesio o acetiluro de litio $\left(1,1\right.$ eq), THF, $-45^{\circ} \mathrm{C}$ a t.a.

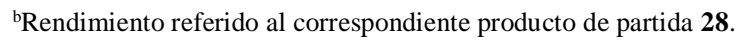




\subsubsection{Síntesis de los indol-3-il-1,2-dioles 60}

Por otra parte, la síntesis de los 1,2-dioles 60 se llevó a cabo por reacción de las correspondientes aciloínas $\mathbf{1 8}$ con bromuro de etinilmagnesio a baja temperatura y en presencia de LiBr. De esta manera se sintetizaron los dioles 60a,b (Esquema 4.36). La síntesis del diol 60c se realizó por tratamiento de la aciloína 18c con cuatro equivalentes de trimetilsilil acetiluro de litio, en presencia de LiBr. A continuación, la desprotección del grupo trimetilsililo con carbonato sódico y metanol permitió la obtención del diol con triple enlace terminal 60c con un $60 \%$ de rendimiento referido a la aciloína de partida (Esquema 4.36).
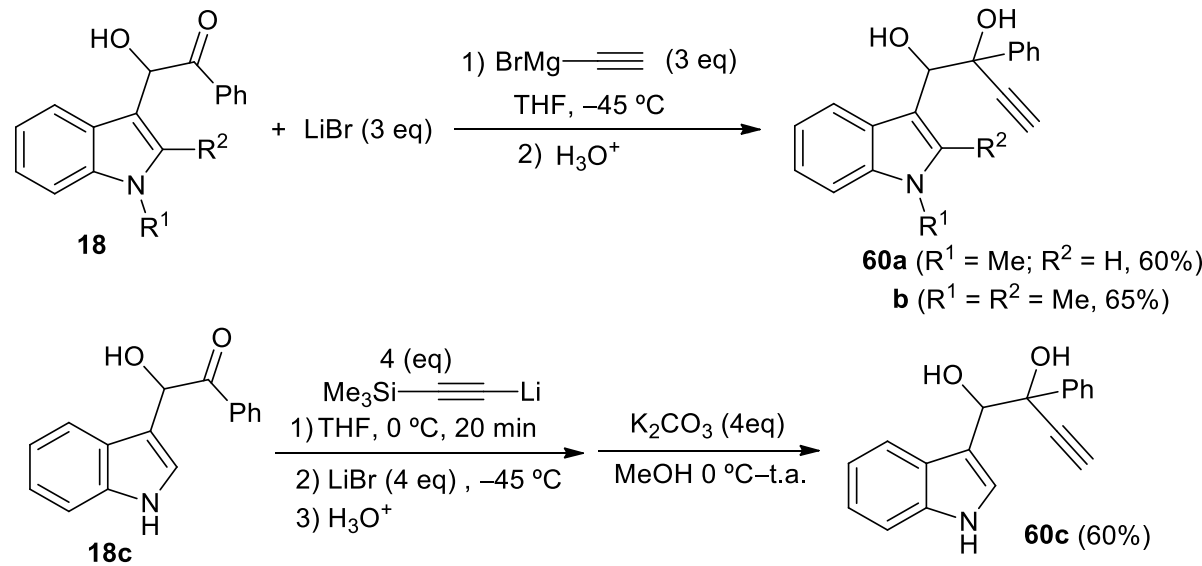

\section{Esquema 4.36}

\subsubsection{Estudio de la reactividad de los alquinoles propargílicos $\alpha$-tioalquil funcionalizados 59}

Para abordar el objetivo propuesto se comenzó evaluando la reactividad del alquinol 59d, que posee un sustituyente fenilo en la posición terminal del triple enlace, en presencia de $\mathrm{NaAuCl}_{4}$ como catalizador y $\mathrm{CH}_{2} \mathrm{Cl}_{2}$ como disolvente. Bajo dichas condiciones se observó la formación de una mezcla de productos que no pudieron ser identificados. Asimismo, en la reacción del alquinol 59e que presenta un sustituyente alquilo en la posición terminal del alquino, bajo las mismas condiciones, no se observó evolución alguna del producto de partida.

A continuación, se decidió evaluar la reactividad de los correspondientes alquinoles terminales, para lo que se eligió como modelo el alquinol 59a. Sorprendentemente, su reacción en presencia del catalizador de $\mathrm{Au}(\mathrm{III})$ condujo 
selectivamente a la formación de un nuevo producto 61a como único isómero geométrico $(Z)$ que no poseía estructura de carbazol, y que fue aislado con un 77\% de rendimiento (Esquema 4.37).

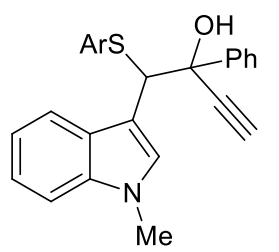

59a $\quad \mathrm{Ar}=p-\mathrm{MeC}_{6} \mathrm{H}_{4}$

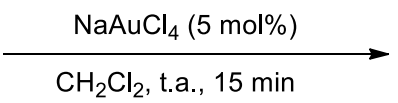

Esquema 4.37

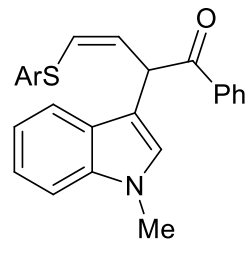

61a $(77 \%)$

Además, los sustratos 59b y 59c, en los que el esqueleto indólico presenta sustituyentes metilo en las posiciones 1 y 2 , y el sustituyente en posición para del resto ariltio es un metilo o un átomo de cloro, dieron lugar a los productos $61 \mathrm{~b}$ y 61c, análogos a 61a, con un $65 \%$ y un $70 \%$ de rendimiento, respectivamente (Esquema 4.38). Hay que destacar que los productos obtenidos, 61a-c, presentan un doble enlace en su estructura con estereoquímica $(Z)$, que fue determinada por análisis por ${ }^{1} \mathrm{H}-\mathrm{RMN}$.

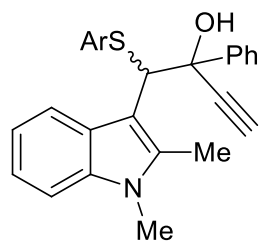

59b $\mathrm{Ar}=p-\mathrm{MeC}_{6} \mathrm{H}_{4}$

59c $\mathrm{Ar}=p-\mathrm{ClC}_{6} \mathrm{H}_{4}$

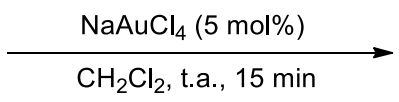

Esquema 4.38

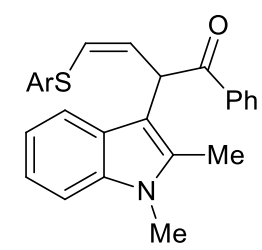

61b $\mathrm{Ar}=p-\mathrm{MeC}_{6} \mathrm{H}_{4} \quad(65 \%)$

61c $\mathrm{Ar}=p-\mathrm{ClC}_{6} \mathrm{H}_{4} \quad(70 \%)$

Animados por estos resultados previos decidimos ensayar el efecto que tendría el empleo de otros catalizadores en esta nueva transformación. Sin embargo, la reacción de un único diasteroisómero del alquinol terminal 59c, en presencia de diferentes catalizadores (5 mol\%), tales como $\mathrm{Ph}_{3} \mathrm{PhAuNTf}_{2}$, $\mathrm{Cu}(\mathrm{OTf})_{2}, \mathrm{I}_{2}$ o DNBSA, condujo únicamente a mezclas $(\sim 1,3-1,5 / 1)$ de los dos diasteroisómeros del producto de partida 59c, sin que tuviera lugar ninguna transformación adicional. Estos resultados parecen indicar el papel determinante que juega el complejo metálico de oro(III) en el transcurso de la reacción. 


\subsubsection{Propuesta mecanística}

El mecanismo de reacción que da explicación a esta nueva transformación se propone en el Esquema 4.39. En primer lugar, se produciría una ciclación 5-endodig iniciada por el ataque nucleofílico del tioéter al alquino $\mathbf{A}$, previamente activado por el catalizador de oro. A continuación, en el intermedio $\mathbf{B}$ así generado, se produciría la apertura del anillo de cinco eslabones asistida por el núcleo indólico hasta el intermedio indoleniminio C. La existencia de intermedios análogos a $\mathbf{C}$ había sido previamente propuesta por Antilla y col. en estudios sobre la transposición pinacolínica de 1,2-indolildioles para acceder a indolilcetonas (pág. 69, Capítulo 2). ${ }^{107}$ Posteriormente, y de manera análoga a lo propuesto por estos autores, se produciría una migración 1,2 del resto alquenilo al C-4 del catión iminio intermedio para generar $\mathbf{D}$. Una protodesmetalación final conduciría a las olefinas 61 con estereoquímica $Z$. Cabe señalar que esta migración se produce de manera totalmente selectiva, no habiéndose observado productos de una posible migración competitiva del resto arílico o del hidruro. La transformación global puede entenderse como una inserción formal de acetileno en el enlace $\mathrm{C}-\mathrm{S}$ de las $\alpha$-indolilcetonas $\mathbf{2 8}$ cuya síntesis fue descrita en el Capítulo 2 de esta Memoria (Esquema 4.39).
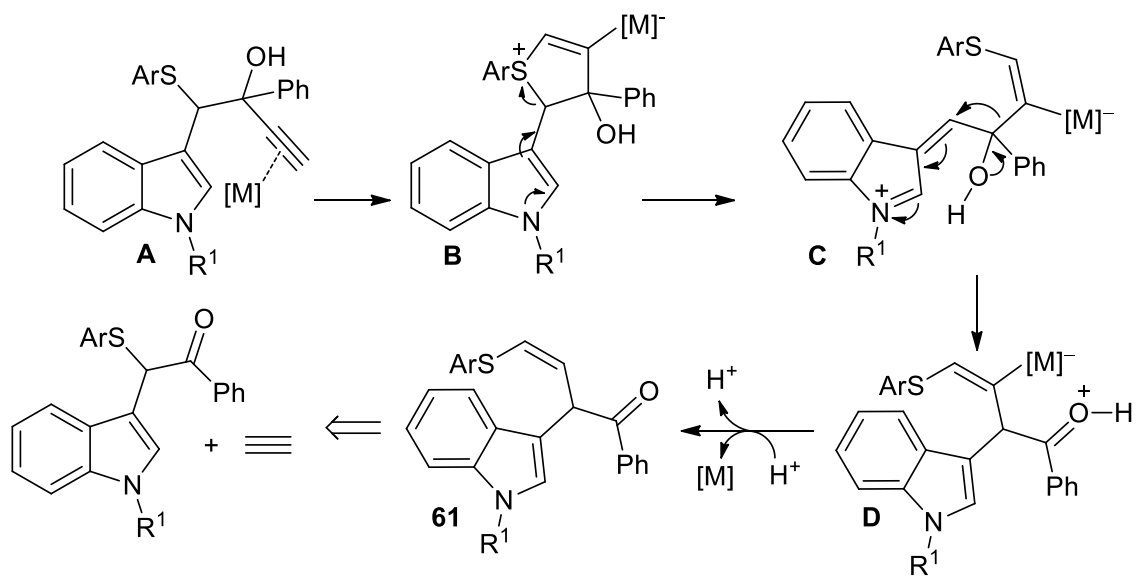

Esquema 4.39

\subsubsection{Reacción de los 1,2-dioles propargílicos 60 y tiofenoles catalizada por complejos de $\mathrm{Au}(\mathrm{III})$}

Basándonos en nuestra experiencia en el estudio de las indol-3-il $\alpha$-aciloínas (Capítulo 2) pensamos que los dioles 60, cuyas posiciones 1 y 2 están 
diferentemente activadas frente al ataque de nucleófilos, podrían comportarse como sustratos de partida adecuados para llevar a cabo la transformación descrita en el apartado anterior manera más directa. Si primero tuviera lugar una reacción de $S_{\mathrm{N}}$ directa del tiofenol sobre la posición 1 del diol, activada por el anillo indólico, se podrían generar los mismos alquinoles 59 descritos anteriormente. Una posterior activación del triple enlace por el catalizador de oro podría desencadenar la reacción en cascada que conduce a la formación de las cetonas 61 (Esquema 4.40).

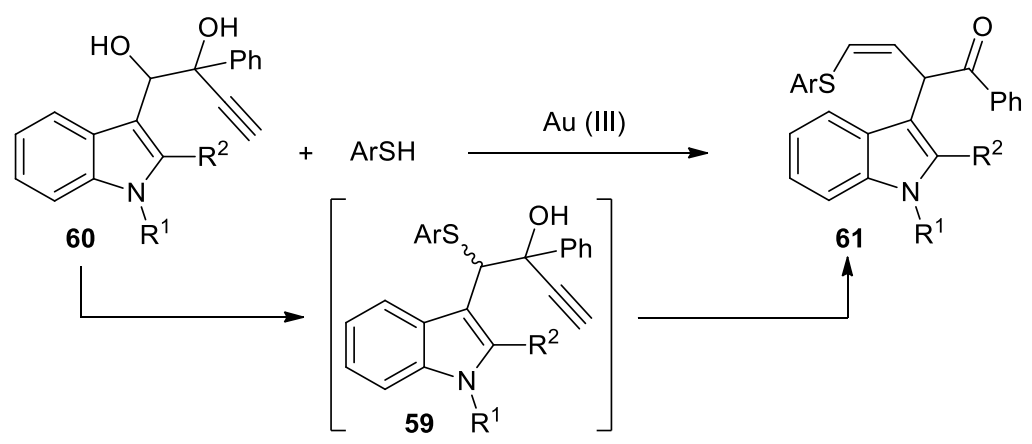

\section{Esquema 4.40}

A pesar de ser conocido que los 1,2-dioles dan lugar a reacciones de transposición en medio ácido (tranposición pinacolínica), y que recientemente Antilla y col describieron esta reacción para 1,2-indolildioles (pág. 69, Capítulo 2), ${ }^{107}$ nosotros pensamos que estos dioles $\mathbf{6 0}$ en presencia de un nucleófilo externo podrían evolucionar de manera diferente, inhibiéndose la transposición. Con esta idea en mente, en primer lugar, evaluamos la reactividad del 1,2-diol 60a en medio ácido. Así, su evolución en presencia de PTSA, diclorometano como disolvente y ausencia de nucleófilo externo, únicamente condujo a la descomposición del producto de partida. Un resultado análogo se observó cuando la reacción se llevó a cabo en presencia de $\mathrm{NaAuCl}_{4}$ como catalizador (Esquema 4.41).
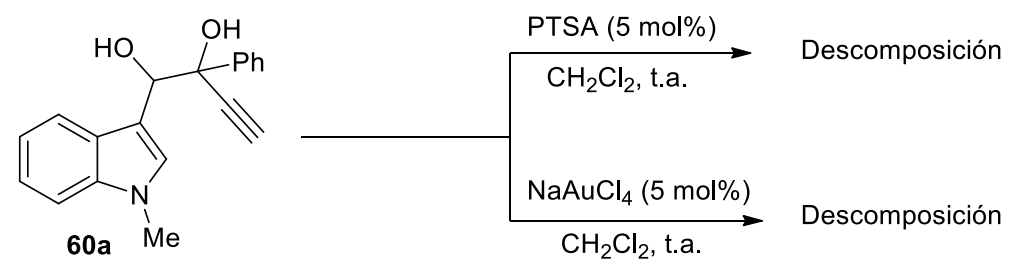

Esquema 4.41 
A continuación, decidimos enfrentar 60a con p-clorotiofenol (Esquema 4.42). Esta reacción, bajo catálisis con $\mathrm{NaAuCl}_{4}$, en $\mathrm{CH}_{2} \mathrm{Cl}_{2}$ y tiempos cortos (10 min), condujo a una mezcla 2:1 de 59f:61f, lo que parece indicar que el primer paso de la reacción es la $\mathrm{S}_{\mathrm{N}}$ directa del hidroxilo activado por el indol. La misma reacción, tras $50 \mathrm{~min}$, condujo al producto $61 \mathrm{f}$ con buen rendimiento, observándose únicamente la formación del isómero $Z$ en el crudo de reacción. Sin embargo, los intentos para llevar a cabo su purificación cromatográfica condujeron a la isomerización parcial del doble enlace permitiendo aislar $61 \mathbf{f}$ como una mezcla $\sim$ 7:1 de isómeros $Z / E$.
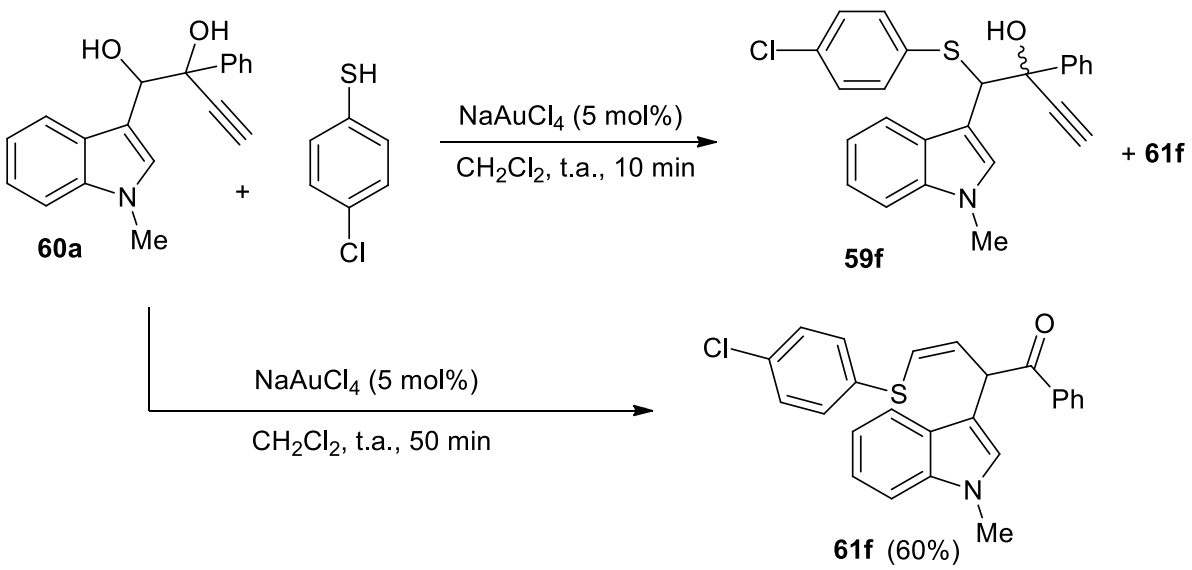

Esquema 4.42

Después pasamos a estudiar el alcance de la reacción respecto del tiofenol empleado como nucleófilo (Esquema 4.43). Para ello se hizo reaccionar el diol 60a, bajo las condiciones de reacción empleadas hasta el momento, con una variedad de tiofenoles comerciales. En general se observó que la reacción conduce a buenos resultados cuando se emplean tiofenoles que poseen sustituyentes tanto electrón-dadores como atractores en posición para del anillo aromático dando lugar a las $\alpha$-indolil- $\alpha$-alquenilacetofenonas $\mathbf{6 1}$ con buenos rendimientos. De igual manera se demostró que el impedimento estérico de tiofenoles orto-sustituídos con sustituyentes tanto electrón-dadores como atractores no juega un papel determinante en la reacción. Sin embargo, los efectos electrónicos sobre esta posición parecen ser más relevantes. Y así, para obtener la $\alpha$-indolil- $\alpha$-alquenilcetona $\mathbf{6 1 h}$ fueron necesarias $16 \mathrm{~h}$ de reacción. Por el contrario, cuando se evaluaron el 2-mercaptobenzotiazol, el ácido tiosalicílico, o el triisopropilsilanotiol, únicamente se observó descomposición de la mezcla de reacción. 


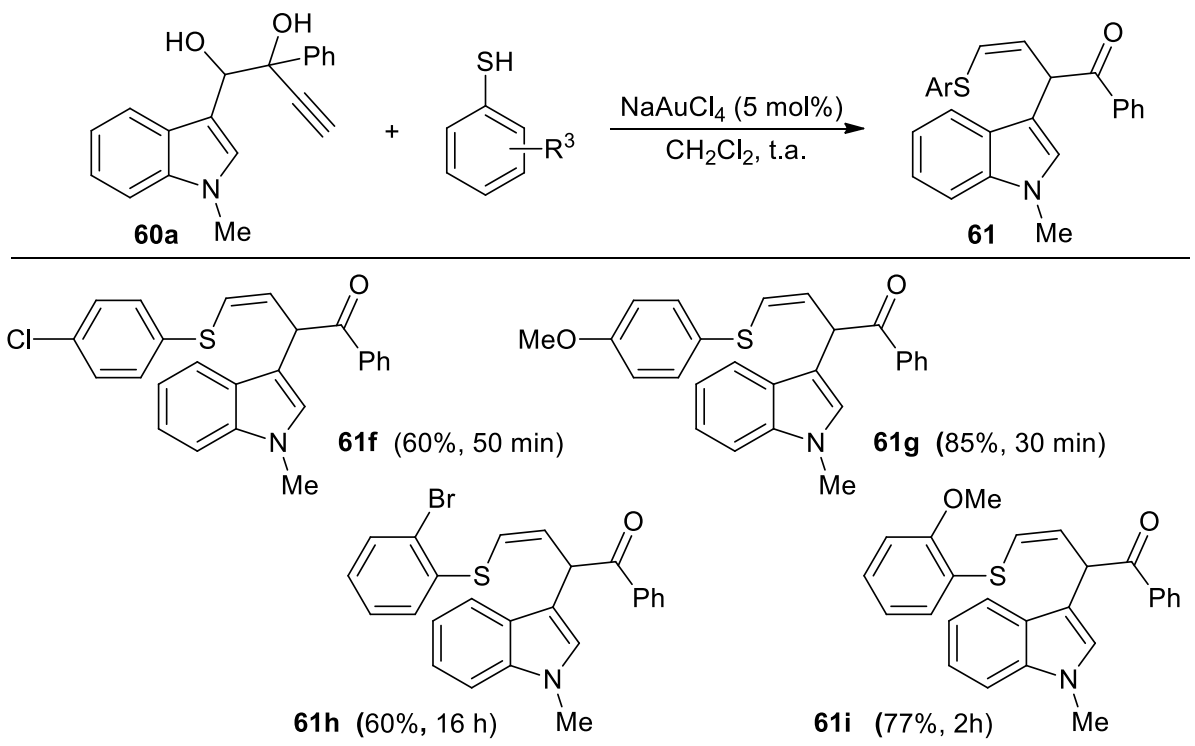

Esquema 4.43

La reacción también conduce a buenos resultados cuando el diol posee en su estructura un $\mathrm{NH}$-indol. De esta manera, la reacción de 60c con 4-metiltiofenol, en presencia del catalizador de oro, permitió aislar el producto $\mathbf{6 1} \mathbf{j}$ de manera selectiva y con muy buen rendimiento (Esquema 4.44).

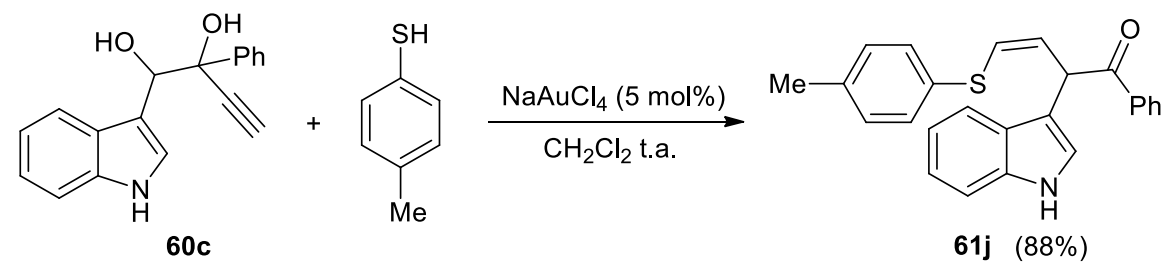

Esquema 4.44

\subsubsection{Propuesta mecanística}

El mecanismo propuesto para este proceso implica la existencia de dos ciclos catalíticos (Esquema 4.45). Como bien anticipamos, primero tendría lugar una reacción de $\mathrm{S}_{\mathrm{N}}$ directa que se iniciaría por la coordinación del catalizador de oro al grupo hidroxilo más activado del diol $\mathbf{E}$, para dar lugar al catión indoleniminio F. El ataque nuclofílico del tiofenol a este intermedio daría lugar al alquinol $\alpha$ tiometilfuncionalizado 59, a partir del cual la reacción trascurriría de manera análoga a lo explicado en el Esquema 4.39. Una ciclación 5-endo-dig conduciría 
a $\mathbf{B}$, que por apertura del ciclo de cinco asistida por el indol daría lugar al intermedio indoleniminio $\mathbf{C}$ donde una migración selectiva 1,2 del resto vinílico daría lugar a los productos $\mathbf{6 1}$ tras protodesmetalación final.
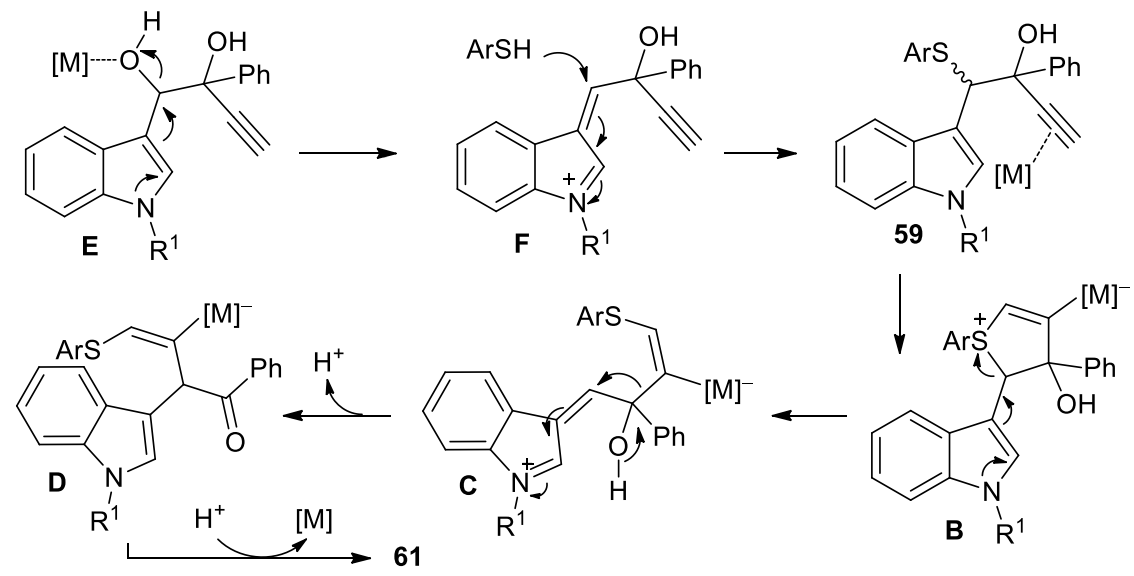

Esquema 4.45

\subsection{Conclusiones}

Para finalizar este último capítulo de la Memoria se puede concluir que, por una parte, se ha puesto a punto una nueva metodología para la obtención de 1indolilcarbazoles a partir de alquinoles $\alpha$-bisindolilmetil sustituídos catalizada por complejos de $\mathrm{Au}(\mathrm{III})$. La transformación se inicia mediante una ciclación 5 endo que conduce a un intermedio espiránico sobre el que tiene lugar, de manera totalmente selectiva, la migración del resto indolilmetilo con preferencia al resto alquenilo. Por otra parte, resultados preliminares indican que la correspondiente ciclación electrofílica mediada por cationes yodonio sobre algunos de los alquinoles anteriores da lugar a 1-indolil-3-yodocarbazoles, demostrándose la similitud de algunos procesos mediados por $\mathrm{I}^{+}$comparados con los mismos procesos catalizados por complejos de $\mathrm{Au}$.

Por último, al tratar alquinoles propargílicos $\alpha$-ariltiometil funcionalizados en presencia de complejos de $\mathrm{Au}$ (III) se ha encontrado una nueva reactividad que ha permitido aislar $\alpha$-indolil- $\alpha$-alquenil cetonas. La reacción se inicia por ataque del átomo de $\mathrm{S}$ sobre el triple enlace activado e implica una transposición pinacolínica sobre el intermedio resultante de la apertura, inducida por el núcleo indólico, del dihidrotiofeno resultante de la ciclación 5-endo inicial. Además, se ha demostrado que se puede acceder a los mismos productos por reacción directa de $\alpha$-indolil glicoles y tiofenoles, por concatenación de dos procesos catalíticos catalizados por $\mathrm{Au}(\mathrm{III})$. 


\section{CONCLUSIONES}

I. INTRODUCCIÓN

II. ANTECEDENTES

GENERALES

III. DISCUSIÓN DE

RESULTADOS

IV. CONCLUSIONES

V. EXPERIMENTAL SECTION 

- Se ha estudiado la reacción de sustitución nucleofílica directa de alcoholes con indoles en su versión intramolecular, en presencia de PTSA como catalizador. Esta metodología ha permitido acceder a una amplia variedad de estructuras policíclicas fusionadas basadas en el esqueleto indólico, tales como benzociclopenta $[b]$ indoles, dihidro- $5 H$-benzo $[b]$ carbazoles y dihidroindolo[1,2$b$ ]isoquinolinas, con buenos rendimientos y de una manera sencilla. Algunos de estos compuestos han mostrado una actividad biológica prometedora en ensayos realizados por la farmacéutica Lilly en el marco del programa OIDD.

- Se ha puesto a punto un nuevo método para la síntesis de una amplia variedad de $\alpha$-indolilcetonas funcionalizadas adicionalmente en posición $\alpha$ con una gran variedad de sustituyentes que incluyen tanto grupos carbonados (arilos, heteroarilos y compuestos 1,3-dicarbonílicos), como heteroatómicos. Esta estrategia, que ha demostrado por primera vez el potencial de las $\alpha$-indolil aciloínas como agentes alquilantes en procesos de $S_{N}$ directa, ha permitido obtener las $\alpha$-indolilcetonas $\alpha$-funcionalizadas con buenos rendimientos y en condiciones suaves de reacción. Se ha demostrado también la utilidad sintética de algunas de los compuestos obtenidos empleándolos como productos de partida en la preparación de otros derivados indólicos con potencial actividad biológica como son triptofoles y furanilindoles.

- Se ha desarrollado una nueva metodología para la obtención de 11arilbenzo $[b]$ carbazoles y benzo[b]carbazoles 6,11-disustituídos, mediante la reacción de indoles 2,3-no sustituídos con acetales de benzaldehído ohidroxialquil funcionalizados, catalizada por un ácido de Brønsted. Los sustratos de partida son comerciales o fácilmente accesibles y, además, esta estrategia también fue extendida a la síntesis de heteroarilbenzo[ $b]$ carbazoles. El proceso, que trascurre de manera suave a temperatura ambiente, con buenos rendimientos, y con la generación de agua y etanol como únicos subproductos de la reacción, implica formalmente dos reacciones de tipo Friedel-Crafts consecutivas y selectivas entre los C-2 y C-3 del indol con un bis(electrófilo) que posee un alcohol y un acetal como grupos aceptores.

- Se ha estudiado la reactividad alquinoles $\alpha$-bis(indolil)metil sustituídos en presencia de complejos de oro(III). En este contexto hemos puesto a punto una nueva metodología que permite la obtención de 1-indolilcarbazoles, derivados carbazólicos sin precedentes en la literatura, de manera totalmente 
regioselectiva y con buenos rendimientos. Los alquinoles de partida se preparan fácil y eficientemente haciendo uso de una ruta sintética que hemos descrito en el capítulo 2, en el contexto de la síntesis de las $\alpha$-indolilcetonas. Además, se ha ensayado la ciclación electrofílica de dichos sustratos en presencia de cationes yodonio. Los resultados preliminares de este estudio permiten afirmar que existen algunas similitudes entre la yodociclación y la ciclación catalizada por oro(III). Se han podido aislar algunos 1-indolil-3-yodocarbazoles, los cuales presentan la potencialidad de una posterior funcionalización a través del átomo de yodo.

- Por último, se ha ensayado la reactividad de alquinoles propargílicos $\alpha$ ariltiometil funcionalizados frente a complejos de $\mathrm{Au}(\mathrm{III})$. Esta novedosa reacción, que conduce a la formación de $\alpha$-indolil- $\alpha$-alquenil cetonas, se iniciaría por ataque del átomo de azufre sobre el triple enlace activado en lugar de por un ataque del resto indólico. Además, el proceso también implica una transposición pinacolínica selectiva y, aún más interesante, también se ha demostrado que se puede acceder a los mismos productos por reacción directa de $\alpha$-indolil glicoles y tiofenoles, por concatenación de dos procesos catalizados por el mismo complejo de $\mathrm{Au}(\mathrm{III})$. 


\section{EXPERIMENTAL SECTION}

I. INTRODUCCIÓN

II. ANTECEDENTES GENERALES

III. DISCUSIÓN DE RESULTADOS

IV. CONCLUSIONES

V. EXPERIMENTAL SECTION 



\section{O. GENERAL INFORMATION}

\section{STARTING REAGENTS}

All common reagents were obtained from commercial suppliers and used without any further purification.

\section{SOLVENTS}

Solvents were obtained from commercial suppliers and dried by standard methods. Hexane and ethyl acetate were purchased as extra-pure-grade reagents and used as received.

\section{CHROMATOGRAPHY}

TLC was performed on aluminum-backed plates coated with silica gel 60 with F254 indicator; the chromatograms were visualized under ultraviolet light and/or by staining with a Ce/Mo reagent and subsequent heating. $R_{f}$ values are reported on silica gel. Flash column chromatography was carried out on silica gel 60, 230-240 mesh. Deactivated silica gel was obtained by stirring with an aqueous $\mathrm{K}_{2} \mathrm{HPO}_{4}$ solution for $3 \mathrm{~h}$ and subsequent filtration and drying at $140{ }^{\circ} \mathrm{C}$ for 3 days.

\section{INSTRUMENTAL TECHNIQUES}

Nuclear Magnetic Resonance: NMR spectra were measured on Varian Mercury-Plus $300 \mathrm{MHz}$ and Varian Inova-400 $\mathrm{MHz}$ spectrometers. ${ }^{1} \mathrm{H}$ NMR: splitting pattern abbreviations are: s, singlet; bs, broad singlet; d, doublet; ad, apparent doublet; t, triplet; at, apparent triplet; dd, double doublet; ddd, double doublet of doublets; dt, doublet of triplets; ddt, double doublet of triplet; td, triple doublet; tt, tiple triplet; m, multiplet; the chemical shifts are reported in ppm using residual solvent peak as reference. ${ }^{13} \mathrm{C}$ NMR spectra were recorded at $75.4 \mathrm{MHz}$ or $100.6 \mathrm{MHz}$ using broadband proton decoupling and chemical shifts are reported in ppm using residual solvent peaks as reference $\left(\mathrm{CDCl}_{3}\right.$, $\delta 77.16$ ) and the multiplicities were determined by DEPT experiments.

Mass spectrometry: High resolution mass spectra (HRMS) were recorded on a Micromass Autospec spectrometer using EI at 70eV. GC-MS and low resolution mass spectra (LRMS) measurements were recorded on an Agilent 6890N/5973 Network GC System, equipped with a HP-5MS column.

X Ray Diffraction: Single Crystal X Ray Drifractometer Bruker

Melting points: Measured on Gallenkamp apparatus using open capillary tubes and are uncorrected. 



\section{SYNTHESIS OF FUSED POLYCYCLIC INDOLES}

\subsection{Preparation of Starting Materials}

\subsubsection{Synthesis of Indole Derivatives 1-4}

Indoles $\mathbf{1}$ and $\mathbf{3}$ were prepared by Fisher indolization. ${ }^{88}$ Indoles $\mathbf{2}$ and $\mathbf{4}$ were prepared by $N$-methylation of indoles $\mathbf{1}$ and $\mathbf{3}{ }^{89}$

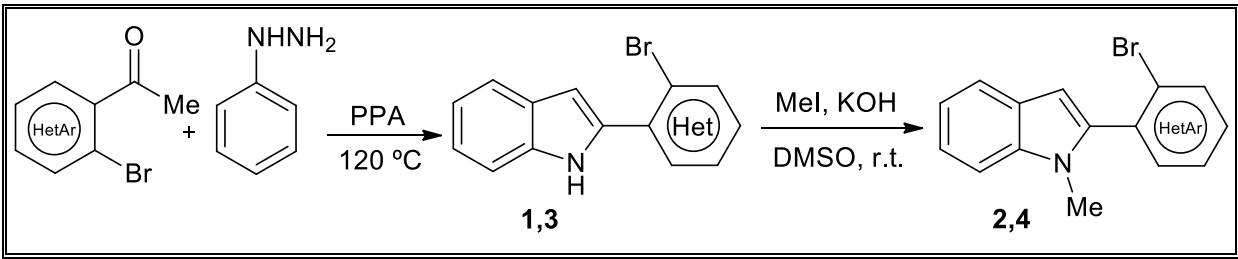

\subsubsection{Synthesis of Indole Derivatives 7, 9, 10}

1,1'-Dimethyl-1 $H, 1^{\prime} H$-2, $3^{\prime}$-biindole 7 was prepared by oxidative homocoupling of $N$-methylindole. ${ }^{90}$ 2-Bromobenzylindoles $9 \mathbf{a}$ y $9 \mathbf{b}$ were prepared by $N$-benzylation, ${ }^{89}$ followed by benzyl migration ${ }^{91}$ for $\mathbf{9 a}$ (and a subsequent $N$-methylation for 10a). Data of $\mathbf{1}, \mathbf{2}, \mathbf{3}, \mathbf{7}, \mathbf{9} \mathbf{a}$, and $\mathbf{1 0}$ are in agreement with those previously reported. ${ }^{88-91}$
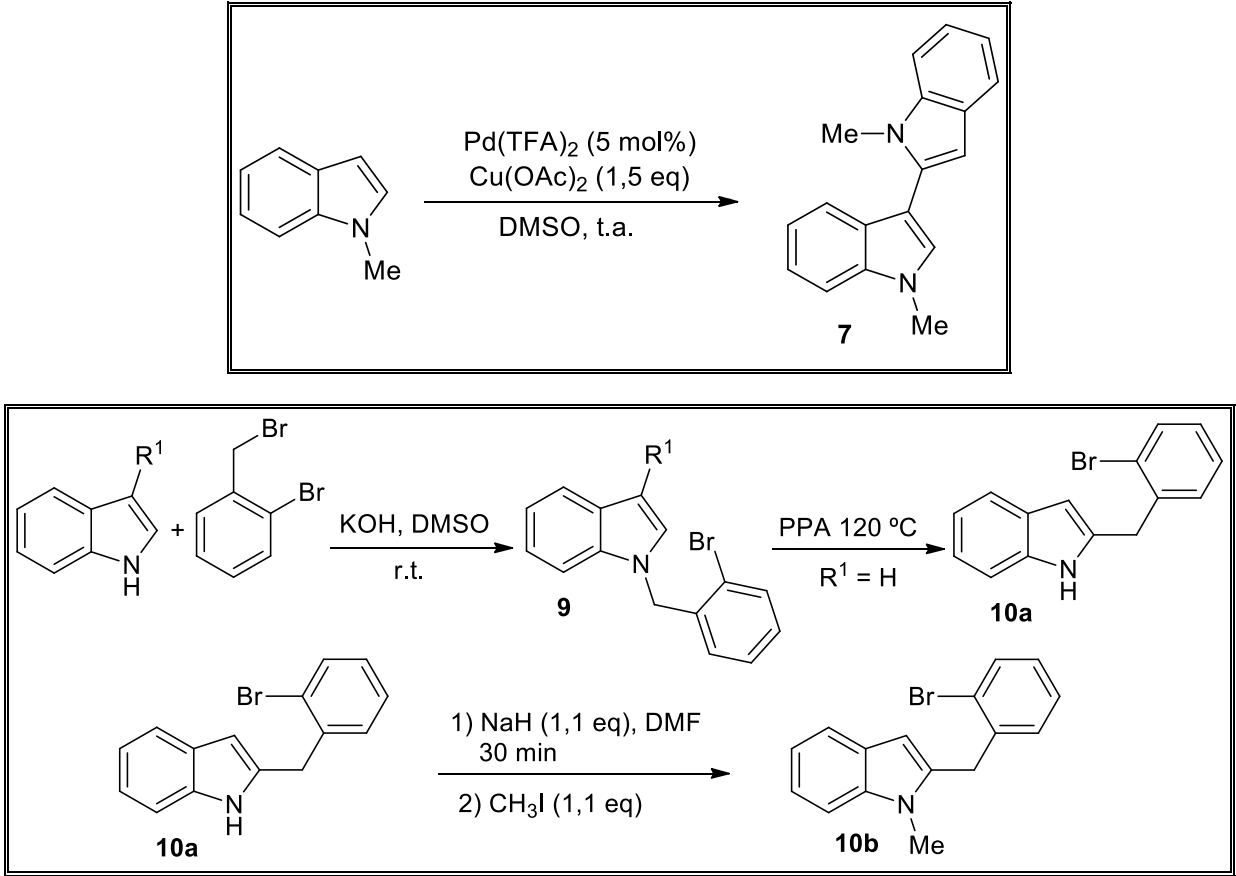
Data for $4,9 \mathrm{~b}$ and $\mathbf{1 0 b}$ are shown below.

2-(3-Bromothiophen-2-yl)-1-methyl-1H-indole (4).

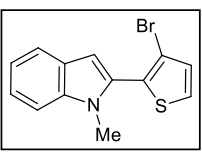

Yellow foam; yield $=55 \% ; R_{f}=0.23$ (hexane/EtOAc, 30:1).

${ }^{1} \mathbf{H}$ NMR $\left(300 \mathrm{MHz}, \mathrm{CDCl}_{3}\right) \delta(\mathrm{ppm})=3.75(\mathrm{~s}, 3 \mathrm{H}), 6.77(\mathrm{~s}, 1 \mathrm{H})$, 7.16-7.26 (m, 2H), 7.33-7.45 (m, 3H), $7.73(\mathrm{dd}, J=7.9,0.9 \mathrm{~Hz}, 1 \mathrm{H})$.

${ }^{13} \mathrm{C}$ NMR $\left(75.4 \mathrm{MHz}, \mathrm{CDCl}_{3}\right) \delta(\mathrm{ppm})=31.1\left(\mathrm{CH}_{3}\right), 105.2(\mathrm{CH}), 109.8(\mathrm{CH})$, 112.4 (C), $120.1(\mathrm{CH}), 121.0(\mathrm{CH}), 122.5(\mathrm{CH}), 127.5(\mathrm{CH}), 129.4(\mathrm{C}), 130.8(\mathrm{C}), 130.9(\mathrm{CH}), 138.1(\mathrm{C})$.

LRMS (70 eV, EI) $m / z(\%) 293\left[(\mathrm{M}+2)^{+}, 98\right], 291\left(\mathrm{M}^{+}, 100\right)$.

HRMS $\left(\mathrm{EI}^{+}\right)$calcd for $\mathrm{C}_{13} \mathrm{H}_{10} \mathrm{BrNS}, 290.9717$; found 290.9719 .

\section{1-(2-Bromobenzyl)-3-methyl-1H-indole (9b).}

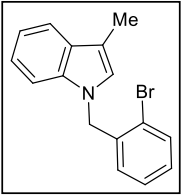

White solid; yield $=80 \%$; m.p. $56-58^{\circ} \mathrm{C}$.

${ }^{1} \mathbf{H}$ NMR $\left(300 \mathrm{MHz}, \mathrm{CDCl}_{3}\right) \delta(\mathrm{ppm})=2.39(\mathrm{~s}, 3 \mathrm{H}), 5.34(\mathrm{~s}, 2 \mathrm{H}), 6.56$ (dd, $J=5.6,3.8 \mathrm{~Hz}, 1 \mathrm{H}), 6.91(\mathrm{~s}, 1 \mathrm{H}), 7.11-7.22(\mathrm{~m}, 5 \mathrm{H}), 7.59-7.65(\mathrm{~m}, 2 \mathrm{H})$.

${ }^{13} \mathbf{C ~ N M R}\left(75.4 \mathrm{MHz}, \mathrm{CDCl}_{3}\right) \delta(\mathrm{ppm})=9.8\left(\mathrm{CH}_{3}\right), 50.0\left(\mathrm{CH}_{2}\right), 109.6$ $(\mathrm{CH}), 111.4(\mathrm{C}), 119.1(\mathrm{CH}), 119.2(\mathrm{CH}), 122.0(\mathrm{CH}), 122.2(\mathrm{C}), 126.0(\mathrm{CH}), 127.9(\mathrm{CH})$, $128.2(\mathrm{CH}), 129.02(\mathrm{C}), 129.04(\mathrm{CH}), 132.8(\mathrm{CH}), 136.7(\mathrm{C}), 137.1(\mathrm{C})$.

HRMS $\left(\mathrm{EI}^{+}\right)$calcd for $\mathrm{C}_{16} \mathrm{H}_{14} \mathrm{BrN}, 299.0310$; found 299.0312 .

2-(2-Bromobenzyl)-1-methyl-1H-indole (10b).

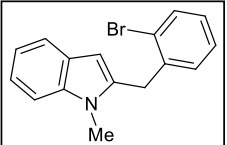

Brown solid; yield $=60 \%$; m.p. $110-112^{\circ} \mathrm{C}$

${ }^{1} \mathbf{H}$ NMR $\left(300 \mathrm{MHz}, \mathrm{CDCl}_{3}\right) \delta(\mathrm{ppm})=3.61(\mathrm{~s}, 3 \mathrm{H}), 4.27(\mathrm{~s}, 2 \mathrm{H}), 6.29$ (s, 1H), $7.01(\mathrm{dd}, J=7.4,1.5 \mathrm{~Hz}, 1 \mathrm{H}), 7.12-7.17(\mathrm{~m}, 2 \mathrm{H}), 7.20-7.26$ $(\mathrm{m}, 2 \mathrm{H}), 7.33(\mathrm{~d}, J=8.0 \mathrm{~Hz}, 1 \mathrm{H}), 7.61(\mathrm{~d}, J=7.8 \mathrm{~Hz}, 1 \mathrm{H}), 7.65(\mathrm{dd}, J=7.8,1.3 \mathrm{~Hz}, 1 \mathrm{H})$. ${ }^{13} \mathbf{C ~ N M R}\left(75.4 \mathrm{MHz}, \mathrm{CDCl}_{3}\right) \delta(\mathrm{ppm})=29.8\left(\mathrm{CH}_{3}\right), 33.6\left(\mathrm{CH}_{2}\right), 101.7(\mathrm{CH}), 109.1(\mathrm{CH})$, $119.5(\mathrm{CH}), 120.2(\mathrm{CH}), 121.1(\mathrm{CH}), 124.5(\mathrm{C}), 127.8(\mathrm{CH}), 127.9(\mathrm{C}), 128.3(\mathrm{CH}), 130.4$ $(\mathrm{CH}), 132.8(\mathrm{CH}), 137.7(\mathrm{C}), 137.9(\mathrm{C}), 138.1(\mathrm{C})$.

LRMS (70 eV, EI) $\mathrm{m} / z(\%) 301\left[(\mathrm{M}+2)^{+}, 99\right], 299\left(\mathrm{M}^{+}, 100\right)$.

HRMS $\left(\mathrm{EI}^{+}\right)$calcd for $\mathrm{C}_{16} \mathrm{H}_{14} \mathrm{BrN}$, 299.0310; found 299.0309 . 


\subsubsection{Syntesis of Alcohol Derivatives 5, 6, 11, and 12}

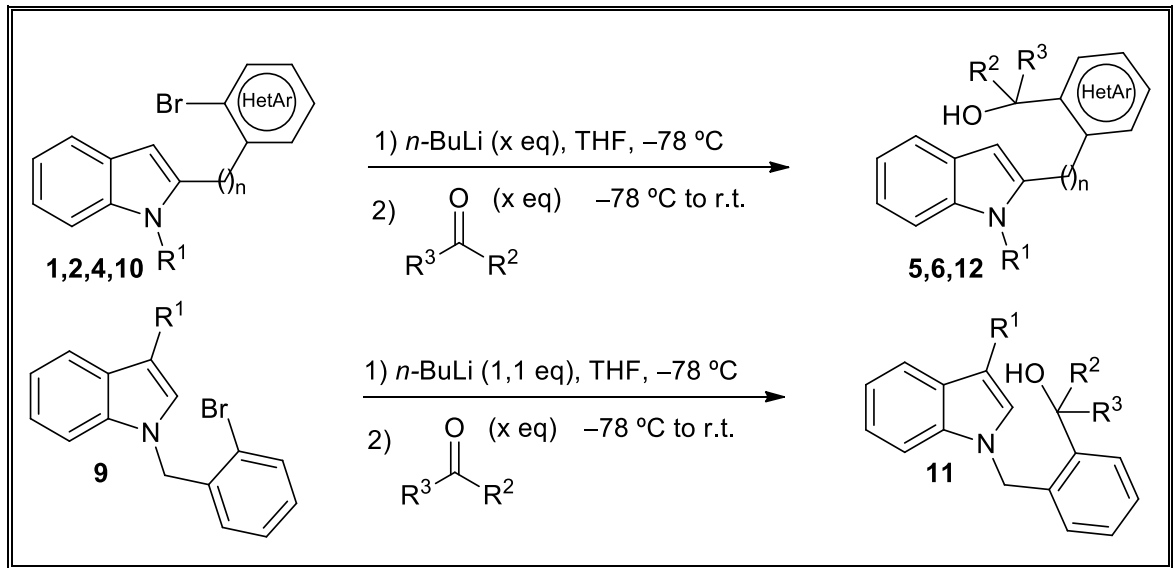

General Procedure: To a solution of the corresponding starting indole 1, 2, 4, 9, 10 $(1 \mathrm{mmol})$ in THF $(2 \mathrm{ml})$ at $-78^{\circ} \mathrm{C}$, was added $n$-BuLi [for $\mathbf{2}, \mathbf{4}, \mathbf{9}$ and $\mathbf{1 0}$ : $(0.68 \mathrm{ml}, 1.1$ mmol, 1.6 $\mathrm{M}$ in hexanes); for $\mathbf{1}$ and $\mathbf{1 0 a}$ : (1.36 ml, $2.2 \mathrm{mmol} 1.6 \mathrm{M}$ in hexanes). The solution was stirred at $-78{ }^{\circ} \mathrm{C}$ for $20 \mathrm{~min}$ and subsequently the appropriate aldehyde or ketone was added. The resulting mixture was warmed to room temperature and stirred until the corresponding indole was consumed as determined by TLC or GC-MS. The reaction was quenched with a saturated $\mathrm{NH}_{4} \mathrm{Cl}$ aqueous solution and extracted with $\mathrm{Et}_{2} \mathrm{O}$ $(3 \times 10 \mathrm{ml})$. The combined organic layers were dried over anhydrous $\mathrm{Na}_{2} \mathrm{SO}_{4}$ and concentrated at reduced pressure. The residue was purified by flash silica gel column chromatography using mixtures of hexane and EtOAc as eluents to obtain the corresponding alcohols 5, 6, 11, and 12. In some cases, the synthesized alcohols were not characterized due to the presence of impurities after the column chromatography. So, in these cases the products obtained after the column chromatography were directly used in the cyclization step.

\subsubsection{Synthesis of Alcohol Derivatives 8}

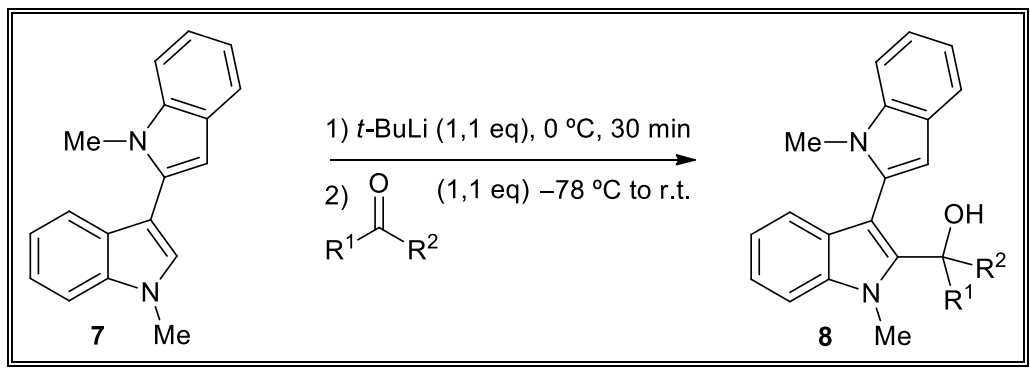


General Procedure: To a solution of the corresponding starting indole 7 (260,1 mg, $1 \mathrm{mmol})$ in THF $(5 \mathrm{ml})$ at $-78^{\circ} \mathrm{C}$, was added $t$ - $\mathrm{BuLi}(0.65 \mathrm{ml}, 1.1 \mathrm{mmol}, 1.7 \mathrm{M}$ in pentane $)$. The solution was stirred at $0{ }^{\circ} \mathrm{C}$ for $30 \mathrm{~min}$. Then the appropriate ketone was added at -78 ${ }^{\circ} \mathrm{C}$. The resulting mixture was warmed to room temperature and stirred until the corresponding indole was consumed as determined by TLC or GC-MS. The reaction was quenched with a saturated $\mathrm{NH}_{4} \mathrm{Cl}$ aqueous solution and extracted with $\mathrm{Et}_{2} \mathrm{O}(3 \times 10 \mathrm{ml})$. The combined organic layers were dried over anhydrous $\mathrm{Na}_{2} \mathrm{SO}_{4}$ and concentrated at reduced pressure. The residue was purified by flash silica gel column chromatography using mixtures of hexane and EtOAc as eluents to obtain the corresponding alcohols $\mathbf{8}$.

\section{Data for 5, 6, 8, 11 and 12}

\section{1-(2-(1-Methyl-1H-indol-2-yl)phenyl)-1-phenylethanol (5a).}

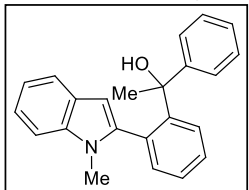

White foam; yield $=64 \% ;{ }^{1} \mathrm{H}$ and ${ }^{13} \mathrm{C}$ NMR were consistent with the formation of rotamers in a $\sim 2: 1$ ratio, designed as $\mathrm{M}$ (major rotamer) and $\mathrm{m}$ (minor rotamer).

${ }^{1} \mathbf{H}$ NMR $\left(300 \mathrm{MHz}, \mathrm{CDCl}_{3}\right) \delta(\mathrm{ppm})=1,89(\mathrm{~s}, 3 \mathrm{H}, \mathrm{M}), 1.95$ (s, 3H, m), $2.54(\mathrm{~s}, 3 \mathrm{H}, \mathrm{M}), 2.65(\mathrm{~s}, 1 \mathrm{H}, \mathrm{m}), 3.32(\mathrm{~s}, 3 \mathrm{H}, \mathrm{m}), 4.11(\mathrm{~s}, 1 \mathrm{H}, \mathrm{M}), 5.63(\mathrm{~s}, 1 \mathrm{H}, \mathrm{m})$, $6.49(\mathrm{~s}, 1 \mathrm{H}, \mathrm{M}), 6.87-6.93(\mathrm{~m}, 3 \mathrm{H}), 7.07-7.31(\mathrm{~m}, 14 \mathrm{H}), 7.35-7.58(\mathrm{~m}, 6 \mathrm{H}), 7.66(\mathrm{~d}, J=$ $7.7 \mathrm{~Hz}, 1 \mathrm{H}, \mathrm{M}), 7.84-7.87$ (m, 2H, M + m).

${ }^{13} \mathrm{C} \mathrm{NMR}\left(75.4 \mathrm{MHz}, \mathrm{CDCl}_{3}\right) \delta(\mathrm{ppm})=29.4\left(\mathrm{CH}_{3}, \mathrm{M}\right), 30.5\left(\mathrm{CH}_{3}, \mathrm{~m}\right), 31.2\left(\mathrm{CH}_{3}, \mathrm{M}\right)$, $31.9\left(\mathrm{CH}_{3}, \mathrm{~m}\right), 77.1(\mathrm{C}, \mathrm{M}), 77.3(\mathrm{C}, \mathrm{m}), 101.7(\mathrm{CH}, \mathrm{M}), 103.0(\mathrm{CH}, \mathrm{m}), 109.6(2 \times \mathrm{CH}$, $\mathrm{M}+\mathrm{m}), 119.7(\mathrm{CH}, \mathrm{m}), 120.0(\mathrm{CH}, \mathrm{M}), 120.5(\mathrm{CH}, \mathrm{M}), 120.6(\mathrm{CH}, \mathrm{m}), 121.7(\mathrm{CH}, \mathrm{m})$, $121.9(\mathrm{CH}, \mathrm{M}), 124.9(2 \times \mathrm{CH}, \mathrm{M}), 125.4(2 \times \mathrm{CH}, \mathrm{m}), 126.27(\mathrm{CH}, \mathrm{M}), 126.32(\mathrm{CH}, \mathrm{M})$, $126.82(\mathrm{CH}, \mathrm{m}), 126.84(\mathrm{CH}, \mathrm{m}), 127.0(\mathrm{CH}, \mathrm{M}), 127.2(2 \times \mathrm{C}, \mathrm{M}+\mathrm{m}), 127.4(\mathrm{CH}, \mathrm{m})$, $127.9(2 \times \mathrm{CH}, \mathrm{M}), 128.0(2 \times \mathrm{CH}, \mathrm{m}), 128.5(\mathrm{CH}, \mathrm{m}), 129.0(\mathrm{CH}, \mathrm{M}), 130.7(\mathrm{C}, \mathrm{m})$, $131.3(\mathrm{C}, \mathrm{M}), 133.4(2 \times \mathrm{C}, \mathrm{M}+\mathrm{m}), 136.6(\mathrm{C}, \mathrm{M}), 136.9$ (C, m), 139.4 (C, m), 139.6 (C, M), 147.5 (C, m), 147.7 (C, M), 148.5 (C. M), 149.8 (C, m).

LRMS (70 eV, EI) $\mathrm{m} / z$ (\%) $327\left(\mathrm{M}^{+}, 100\right)$.

HRMS $\left(\mathrm{EI}^{+}\right)$calcd for $\mathrm{C}_{23} \mathrm{H}_{21} \mathrm{NO}, 327.1623$; found 327.1626.

\section{(E)-2-(2-(1-Methyl-1H-indol-2-yl)phenyl)-4-phenylbut-3-en-2-ol (5f).}

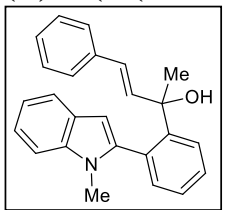

Yellow foam; yield $=62 \% ; R_{f}=0.20($ hexane/EtOAc, $7: 1) ;{ }^{1} \mathrm{H}$ and ${ }^{13} \mathrm{C}$ NMR were consistent with the formation of rotamers in a $\sim 1: 1$ ratio. ${ }^{1} \mathbf{H}$ NMR $\left(300 \mathrm{MHz}, \mathrm{CDCl}_{3}\right) \delta(\mathrm{ppm})=1.75(\mathrm{~s}, 3 \mathrm{H}), 1.81(\mathrm{~s}, 3 \mathrm{H}), 2.43$ $(\mathrm{s}, 1 \mathrm{H}), 3.27(\mathrm{~s}, 3 \mathrm{H}), 3.35(\mathrm{~s}, 1 \mathrm{H}), 3.38(\mathrm{~s}, 3 \mathrm{H}), 6.03-6.11(\mathrm{~m}, 1 \mathrm{H}), 6.27-6.37$ (m, 3H), 6.48-6.58 (m, 2H), 6.75-6.81 (m, 1H), 7.03-7.14 (m, 4H), 7.18-7.29 (m, 11H), 7.35-7.60 (m, 6H), 7.66-7.71 (m, 2H), 7.76-7.79 (m, 1H), 7.88-7.90 (m, 1H).

${ }^{13}$ C NMR $\left(75.4 \mathrm{MHz}, \mathrm{CDCl}_{3}\right) \delta(\mathrm{ppm})=28.9\left(\mathrm{CH}_{3}\right), 30.6\left(2 \times \mathrm{CH}_{3}\right), 31.3\left(\mathrm{CH}_{3}\right), 75.4$ (C), $75.6(\mathrm{C}), 101.7(\mathrm{CH}), 102.4(\mathrm{CH}), 109.7(\mathrm{CH}), 109.8(\mathrm{CH}), 119.8(\mathrm{CH}), 120.1(\mathrm{CH})$, $120.4(\mathrm{CH}), 120.5(\mathrm{CH}), 121.75(\mathrm{CH}), 121.82(\mathrm{CH}), 126.2(\mathrm{CH}), 126.47(4 \times \mathrm{CH}), 126.51$ $(\mathrm{CH}), 126.6(\mathrm{CH}), 126.9(\mathrm{CH}), 127.41(\mathrm{CH}), 127.46(\mathrm{C}), 127.50(\mathrm{CH}), 127.56(\mathrm{C}), 127.7$ 
$(\mathrm{CH}), 128.35(\mathrm{CH}), 128.45(2 \times \mathrm{CH}), 128.52(2 \times \mathrm{CH}), 129.1(\mathrm{CH}), 129.2(\mathrm{CH}), 130.2(\mathrm{C})$, $131.0(\mathrm{C}), 132.9(\mathrm{CH}), 133.2(\mathrm{CH}), 136.2(\mathrm{CH}), 136.6(2 \times \mathrm{C}), 136.9(\mathrm{CH}), 137.0(\mathrm{C}), 137.1(\mathrm{C})$, 140.3 (C), 140.5 (C), 146.6 (C), $147.3(\mathrm{C})$.

LRMS (70 eV, EI) $\mathrm{m} / \mathrm{z}(\%) 353\left(\mathrm{M}^{+}, 34\right), 218$ (100).

HRMS $\left(\mathrm{EI}^{+}\right)$calcd for $\mathrm{C}_{25} \mathrm{H}_{23} \mathrm{NO}, 353.1780$; found 353.1781 .

2-(2-(1-Methyl-1H-indol-2-yl)phenyl)-4-(thiophen-3-yl)but-3-yn-2-ol (5g).

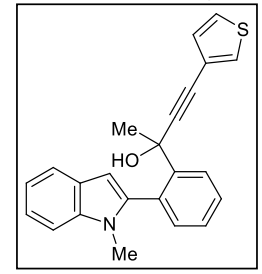

White foam; yield $=59 \% ;{ }^{1} \mathrm{H}$ and ${ }^{13} \mathrm{C}$ NMR were consistent with the formation of rotamers in a $\sim 1: 1$ ratio.

${ }^{1} \mathbf{H}$ NMR $\left(300 \mathrm{MHz}, \mathrm{CDCl}_{3}\right) \delta(\mathrm{ppm})=1.99(\mathrm{~s}, 3 \mathrm{H}), 2.00(\mathrm{~s}, 3 \mathrm{H})$, $2.83(\mathrm{~s}, 1 \mathrm{H}), 3.38(\mathrm{~s}, 1 \mathrm{H}), 3.45(\mathrm{~s}, 3 \mathrm{H}), 3.46(\mathrm{~s}, 3 \mathrm{H}), 6.58(\mathrm{~d}, J=5.0$ $\mathrm{Hz}, 1 \mathrm{H}), 6.62-6.65(\mathrm{~m}, 2 \mathrm{H}), 6.74(\mathrm{~d}, J=2.9 \mathrm{~Hz}, 1 \mathrm{H}), 6.80(\mathrm{~d}, J=5.0$ $\mathrm{Hz}, 1 \mathrm{H}), 7.02-7.13(\mathrm{~m}, 2 \mathrm{H}), 7.14-7.35(\mathrm{~m}, 9 \mathrm{H}), 7.36-7.47(\mathrm{~m}, 2 \mathrm{H})$,

7.48-7.58 (m, 2H), 7.68-7.72 (m, 2H), $7.84(\mathrm{~d}, J=7.9 \mathrm{~Hz}, 1 \mathrm{H}), 7.98(\mathrm{~d}, J=7.9 \mathrm{~Hz}, 1 \mathrm{H})$. ${ }^{13} \mathbf{C ~ N M R}\left(75.4 \mathrm{MHz}, \mathrm{CDCl}_{3}\right) \delta(\mathrm{ppm})=30.7\left(\mathrm{CH}_{3}\right), 30.8\left(\mathrm{CH}_{3}\right), 31.0\left(\mathrm{CH}_{3}\right), 34.0\left(\mathrm{CH}_{3}\right)$, $69.4(\mathrm{C}), 69.8(\mathrm{C}), 79.4(\mathrm{C}), 80.0(\mathrm{C}), 91.4(\mathrm{C}), 92.2(\mathrm{C}), 102.2(\mathrm{CH}), 103.1(\mathrm{CH}), 109.6$ $(\mathrm{CH}), 109.7(\mathrm{CH}), 119.7(\mathrm{CH}), 120.0(\mathrm{CH}), 120.5(\mathrm{CH}), 120.6(\mathrm{CH}), 121.3(\mathrm{C}), 121.5$ $(\mathrm{C}), 121.7(\mathrm{CH}), 121.9(\mathrm{CH}), 124.9(\mathrm{CH}), 125.2(\mathrm{CH}), 125.7(\mathrm{CH}), 125.8(\mathrm{CH}), 127.1$ $(\mathrm{CH}), 127.4(\mathrm{CH}), 127.7(2 \times \mathrm{C}), 128.7(\mathrm{CH}), 128.9(\mathrm{CH}), 129.1(\mathrm{CH}), 129.2(\mathrm{CH}), 129.7$ $(\mathrm{CH}), 129.8(\mathrm{CH}), 130.1(\mathrm{C}), 131.2(\mathrm{C}), 132.8(\mathrm{CH}), 133.2(\mathrm{CH}), 137.2(2 \times \mathrm{C}), 139.4(\mathrm{C})$, 140.0 (C), $144.4(\mathrm{C}), 145.5(\mathrm{C})$.

LRMS (70 eV, EI) $\mathrm{m} / \mathrm{z}$ (\%) $357\left(\mathrm{M}^{+}, 11\right), 339$ (100).

HRMS $\left(\mathrm{EI}^{+}\right)$calcd for $\mathrm{C}_{23} \mathrm{H}_{19} \mathrm{NOS}$, 357.1187; found 357.1188.

(2-(1H-Indol-2-yl)phenyl)-(4-methoxyphenyl)methanol (5j).

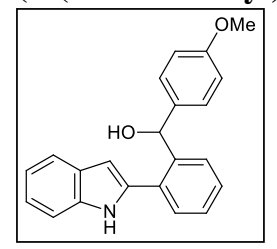

Yellow foam; yield $=49 \% ; R_{f}=0.25$ (hexane/EtOAc, 4:1).

${ }^{1} \mathbf{H}$ NMR $\left(300 \mathrm{MHz}, \mathrm{CDCl}_{3}\right) \delta(\mathrm{ppm})=2.69(\mathrm{~d}, J=5.1 \mathrm{~Hz}, 1 \mathrm{H}), 3.80$ $(\mathrm{s}, 3 \mathrm{H}), 6.05(\mathrm{~d}, J=5.0 \mathrm{~Hz}, 1 \mathrm{H}), 6.62-6.65(\mathrm{~m}, 1 \mathrm{H}), 6.84-6.91(\mathrm{~m}$, 2H), 7.11-7.25 (m, 4H), 7.28-7.42 (m, 4H), $7.61(\mathrm{dd}, J=6.5,1.0$ $\mathrm{Hz}, 1 \mathrm{H}), 7.64-7.70(\mathrm{~m}, 1 \mathrm{H}), 9.30(\mathrm{~s}, 1 \mathrm{H})$.

${ }^{13} \mathrm{C}$ NMR $\left(75.4 \mathrm{MHz}, \mathrm{CDCl}_{3}\right) \delta(\mathrm{ppm})=55.4\left(\mathrm{CH}_{3}\right), 73.3(\mathrm{CH}), 102.7(\mathrm{CH}), 111.2(\mathrm{CH})$, $114.0(2 \times \mathrm{CH}), 120.1(\mathrm{CH}), 120.6(\mathrm{CH}), 122.1(\mathrm{CH}), 128.0(2 \times \mathrm{CH}), 128.29(\mathrm{CH})$, $128.32(\mathrm{CH}), 128.5(\mathrm{CH}), 128.6(\mathrm{C}), 130.6(\mathrm{CH}), 133.3(\mathrm{C}), 134.8(\mathrm{C}), 136.5(\mathrm{C}), 137.4$ (C), 140.4 (C), 159.1 (C).

LRMS (70 eV, EI) $m / z$ (\%) $329\left(\mathbf{M}^{+}, 15\right), 311$ (100).

HRMS $\left(\mathrm{EI}^{+}\right)$calcd for $\mathrm{C}_{22} \mathrm{H}_{19} \mathrm{NO}_{2}, 329.1416$; found 329.1413. 


\section{(2-(1H-Indol-2-yl)phenyl)(thiophen-2-yl)methanol (5n).}

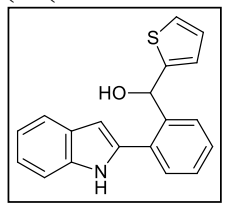

Yellow foam; yield $=51 \% ; R_{f}=0.25$ (hexane/EtOAc, 4:1).

${ }^{1} \mathbf{H}$ NMR $\left(300 \mathrm{MHz}, \mathrm{CDCl}_{3}\right) \delta(\mathrm{ppm})=2.90(\mathrm{~s}, 1 \mathrm{H}), 6.27(\mathrm{~s}, 1 \mathrm{H})$, 6.54-6.64 (m, 1H), 6.76-6.87 (m, 1H), 6.93-7.01 (m, 1H), 7.12-7.44 $(\mathrm{m}, 6 \mathrm{H}), 7.53-7.62(\mathrm{~m}, 2 \mathrm{H}), 7.66(\mathrm{~d}, J=7.7 \mathrm{~Hz}, 1 \mathrm{H}), 8.87(\mathrm{bs}, 1 \mathrm{H})$.

${ }^{13} \mathrm{C} \mathrm{NMR}\left(75.4 \mathrm{MHz}, \mathrm{CDCl}_{3}\right) \delta(\mathrm{ppm})=70.1(\mathrm{CH}), 103.1(\mathrm{CH}), 111.2(\mathrm{CH}), 120.2(\mathrm{CH})$, $120.7(\mathrm{CH}), 122.3(\mathrm{CH}), 125.4(\mathrm{CH}), 125.7(\mathrm{CH}), 127.0(\mathrm{CH}), 127.9(\mathrm{CH}), 128.56(\mathrm{CH})$, $128.60(\mathrm{CH}+\mathrm{C}), 130.4(\mathrm{CH}), 132.5(\mathrm{C}), 136.5(\mathrm{C}), 136.7(\mathrm{C}), 140.2(\mathrm{C}), 147.4(\mathrm{C})$.

LRMS (70 eV, EI) $m / z$ (\%) $305\left(\mathrm{M}^{+}, 4\right), 287$ (100).

HRMS $\left(\mathrm{EI}^{+}\right)$calcd for $\mathrm{C}_{19} \mathrm{H}_{15} \mathrm{NOS}, 305.0877$; found 305.0876 .

(E)-1-(2-(1-Methyl-1H-indol-2-yl)phenyl)-3-phenylprop-2-en-1-ol (5o).

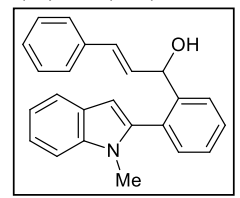

White foam; yield $=55 \% ; R_{f}=0.25$ (hexane/EtOAc, $4: 1$ ).

${ }^{1} \mathbf{H}$ NMR $\left(400 \mathrm{MHz}, \mathrm{CDCl}_{3}, 50{ }^{\circ} \mathrm{C}\right) \delta(\mathrm{ppm})=2.00(\mathrm{bs}, 1 \mathrm{H}), 3.45(\mathrm{~s}$, $3 \mathrm{H}), 5.44(\mathrm{bs}, 1 \mathrm{H}), 6.25(\mathrm{~m}, 2 \mathrm{H}), 6.52(\mathrm{~s}, 1 \mathrm{H}), 7.16-7.32(\mathrm{~m}, 9 \mathrm{H}), 7.39$ $(\mathrm{t}, J=7.5 \mathrm{~Hz}, 1 \mathrm{H}), 7.52(\mathrm{t}, J=7.6 \mathrm{~Hz}, 1 \mathrm{H}), 7.66(\mathrm{~d}, J=7.9 \mathrm{~Hz}, 1 \mathrm{H})$,

$7.75(\mathrm{~d}, J=7.8 \mathrm{~Hz}, 1 \mathrm{H})$.

${ }^{13} \mathbf{C ~ N M R}\left(75.4 \mathrm{MHz}, \mathrm{CDCl}_{3}\right) \delta(\mathrm{ppm})=30.7\left(\mathrm{CH}_{3}\right), 72.1(\mathrm{CH}), 102.0(\mathrm{CH}), 109.7(\mathrm{CH})$, $119.9(\mathrm{CH}), 120.6(\mathrm{CH}), 121.7(\mathrm{CH}), 126.6(2 \times \mathrm{CH}), 127.4(\mathrm{CH}), 127.8(\mathrm{CH}), 127.9(\mathrm{C})$, $128.6(2 \times \mathrm{CH}), 129.5(\mathrm{CH}), 130.5(\mathrm{CH}), 131.2(\mathrm{C}), 131.4(\mathrm{CH}), 136.5(\mathrm{C}), 137.3(\mathrm{C})$, $138.7(\mathrm{C}), 142.8(\mathrm{C})$, two aromatic $\mathrm{CH}$ peaks were not observed.

LRS (70 eV, EI) $m / z$ (\%) $339\left(\mathbf{M}^{+}, 19\right), 248$ (100).

HRMS $\left(\mathrm{EI}^{+}\right)$calcd for $\mathrm{C}_{24} \mathrm{H}_{21} \mathrm{NO}, 339.1623$; found 339.1624.

1-(2-(1-Methyl-1H-indol-2-yl)phenyl)butan-1-ol (5p).

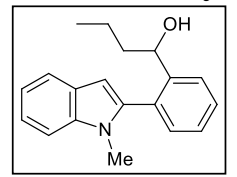

White foam; yield $=45 \% ; R_{f}=0.25$ (hexane/EtOAc, 6:1).

${ }^{1} \mathbf{H}$ NMR $\left(300 \mathrm{MHz}, \mathrm{CDCl}_{3}\right) \delta(\mathrm{ppm})=0.80(\mathrm{t}, J=7.3 \mathrm{~Hz}, 3 \mathrm{H}), 1.10$ $1.42(\mathrm{~m}, 3 \mathrm{H}), 1.52-1.77$ (m, 3H), 1.85 (bs, 1H), 3.54 (s, 3H), 4.71 (bs, $1 \mathrm{H}), 6.47(\mathrm{~s}, 1 \mathrm{H}), 7.19(\mathrm{t}, J=7.4 \mathrm{~Hz}, 1 \mathrm{H}), 7.24-7.32(\mathrm{~m}, 2 \mathrm{H}), 7.33-$ $7.43(\mathrm{~m}, 2 \mathrm{H}), 7.51(\mathrm{t}, J=7.5 \mathrm{~Hz}, 1 \mathrm{H}), 7.63-7.71(\mathrm{~m}, 2 \mathrm{H})$.

${ }^{13} \mathbf{C ~ N M R}\left(75.4 \mathrm{MHz}, \mathrm{CDCl}_{3}\right) \delta(\mathrm{ppm})=14.0\left(\mathrm{CH}_{3}\right), 19.1\left(\mathrm{CH}_{2}\right), 30.7\left(\mathrm{CH}_{3}\right), 70.9(\mathrm{CH})$, $102.6(\mathrm{CH}), 109.6(\mathrm{CH}), 119.9(\mathrm{CH}), 120.5(\mathrm{CH}), 121.6(\mathrm{CH}), 126.1(\mathrm{CH}), 127.1(\mathrm{CH})$, $128.0(\mathrm{C}), 129.4(\mathrm{CH}), 131.0(\mathrm{C}), 131.4(\mathrm{CH}), 137.4(\mathrm{C}), 139.0(\mathrm{C}), 144.8(\mathrm{C})$, two aliphatic $\mathrm{CH}_{2}$ peaks were not observed.

LRMS (70 eV, EI) $m / z$ (\%) $279\left(\mathbf{M}^{+}, 100\right), 218$ (61).

HRMS $\left(\mathrm{EI}^{+}\right)$calcd for $\mathrm{C}_{19} \mathrm{H}_{21} \mathrm{NO}, 279.1623$; found 279.1623 . 
Dicyclopropyl-(1,1'-dimethyl-1H,1'H-[2,3'-biindol]-2'-yl)methanol (8b).

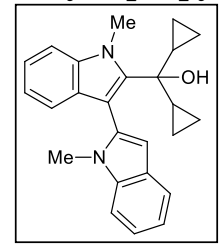

Yellow foam; yield $=42 \%$.

${ }^{1} \mathbf{H}$ NMR $\left(300 \mathrm{MHz}, \mathrm{CDCl}_{3}\right) \delta(\mathrm{ppm})=0.25-0.68(\mathrm{~m}, 7 \mathrm{H}), 0.76-0.85$ (m, 1H), 1.35-1.49 (m, 1H), 1.50-1.64 (m, 1H), $2.09(\mathrm{~s}, 1 \mathrm{H}), 3.59$ (s, $3 \mathrm{H}), 4.19(\mathrm{~s}, 3 \mathrm{H}), 6.61(\mathrm{~s}, 1 \mathrm{H}), 7.10-7.19(\mathrm{~m}, 2 \mathrm{H}), 7.19-7.23(\mathrm{~m}, 1 \mathrm{H})$, $7.31(\mathrm{~d}, J=7.3 \mathrm{~Hz}, 1 \mathrm{H}), 7.36(\mathrm{~d}, J=7.4 \mathrm{~Hz}, 1 \mathrm{H}), 7.41-7.49(\mathrm{~m}, 2 \mathrm{H})$,

$7.71(\mathrm{~d}, J=7.8 \mathrm{~Hz}, 1 \mathrm{H})$.

${ }^{13} \mathbf{C ~ N M R}\left(\mathrm{CDCl}_{3}, 75.4 \mathrm{MHz}\right) \delta(\mathrm{ppm})=1.1\left(\mathrm{CH}_{2}\right), 1.8\left(\mathrm{CH}_{2}\right), 1.9\left(\mathrm{CH}_{2}\right), 3.3\left(\mathrm{CH}_{2}\right), 19.9$ $(\mathrm{CH}), 21.1(\mathrm{CH}), 30.4\left(\mathrm{CH}_{3}\right), 33.3\left(\mathrm{CH}_{3}\right), 73.7(\mathrm{C}), 103.3(\mathrm{CH}), 104.4(\mathrm{C}), 109.2(\mathrm{CH})$, $109.5(\mathrm{CH}), 119.4(2 \times \mathrm{CH}), 120.2(\mathrm{CH}), 120.3(\mathrm{CH}), 121.2(\mathrm{CH}), 122.3(\mathrm{CH}), 128.1(\mathrm{C})$, $129.2(\mathrm{C}), 135.6(\mathrm{C}), 137.3(\mathrm{C}), 137.4(\mathrm{C}), 143.6(\mathrm{C})$.

LRMS (70 eV, EI) $m / z$ (\%) $352\left(\mathrm{M}^{+}, 100\right), 323$ (27).

HRMS $\left(\mathrm{EI}^{+}\right)$calcd for $\mathrm{C}_{25} \mathrm{H}_{24} \mathrm{~N}_{2}, 352.1939$; found 352.1940 .

(2-(1-Methyl-1H-indol-2-yl)thiophen-3-yl)di-p-tolylmethanol (6b).

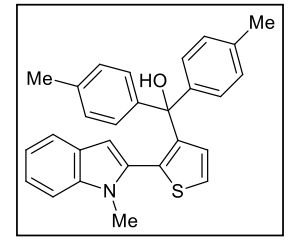

Yellow foam; yield $=50 \% ; R_{f}=0.25$ (hexane/EtOAc, 15:1).

${ }^{1} \mathbf{H}$ NMR $\left(300 \mathrm{MHz}, \mathrm{CDCl}_{3}\right) \delta(\mathrm{ppm})=2.37(\mathrm{~s}, 6 \mathrm{H}), 3.23(\mathrm{~s}, 1 \mathrm{H})$, $3.52(\mathrm{~s}, 3 \mathrm{H}), 6.29(\mathrm{~d}, J=2.5 \mathrm{~Hz}, 1 \mathrm{H}), 6.66(\mathrm{dd}, J=5.3,3.0 \mathrm{~Hz}, 1 \mathrm{H})$, 7.05-7.18 (m, 8H), 7.22-7.36 (m, 3H), $7.53(\mathrm{~d}, J=7.9 \mathrm{~Hz}, 1 \mathrm{H})$.

${ }^{13} \mathbf{C ~ N M R}\left(75.4 \mathrm{MHz}, \mathrm{CDCl}_{3}\right) \delta(\mathrm{ppm})=21.2\left(2 \times \mathrm{CH}_{3}\right), 30.8$ $\left(\mathrm{CH}_{3}\right), 81.0(\mathrm{C}), 104.9(\mathrm{CH}), 109.7(\mathrm{CH}), 120.0(\mathrm{CH}), 120.8(\mathrm{CH}), 122.4(\mathrm{CH}), 125.4$ $(\mathrm{CH}), 126.0(\mathrm{CH}), 127.4(\mathrm{C}), 127.6(2 \times \mathrm{CH}), 128.0(\mathrm{C}), 128.6(2 \times \mathrm{CH}), 128.9(\mathrm{CH})$, $130.5(\mathrm{CH}), 132.0(\mathrm{C}), 137.1(2 \times \mathrm{C}), 137.7(\mathrm{C}), 144.5(2 \times \mathrm{C}), 148.6(\mathrm{C})$.

LRMS (70 eV, EI) $m / z(\%) 423\left(\mathbf{M}^{+}, 100\right)$.

HRMS $\left(\mathrm{EI}^{+}\right)$calcd for $\mathrm{C}_{28} \mathrm{H}_{25} \mathrm{NOS}, 423.1657$; found 423.1655 .

(2-((1H-Indol-1-yl)methyl)phenyl)(cyclopropyl)(phenyl)methanol (11a).

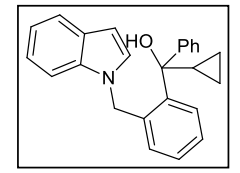

Yellow oil; yield $=71 \% ; R_{f}=0.26($ hexane/EtOAc, 5:1).

${ }^{1} \mathbf{H}$ NMR $\left(400 \mathrm{MHz}, \mathrm{CDCl}_{3}\right) \delta(\mathrm{ppm})=0.32-0.45(\mathrm{~m}, 1 \mathrm{H}), 0.52-0.62$ (m, 1H), 0.64-0.7 (m, 2H), $1.75(\mathrm{tt}, J=8.2,5.5 \mathrm{~Hz}, 1 \mathrm{H}), 2.26(\mathrm{~s}, 1 \mathrm{H})$, $4.85(\mathrm{~d}, J=17.5 \mathrm{~Hz}, 1 \mathrm{H}), 5.44(\mathrm{~d}, J=17.5 \mathrm{~Hz}, 1 \mathrm{H}), 6.44-6.53(\mathrm{~m}, 2 \mathrm{H})$, 6.57-6.63 (m, 1H), $6.85(\mathrm{~d}, J=3.1 \mathrm{~Hz}, 1 \mathrm{H}), 6.99-6.05(\mathrm{~m}, 1 \mathrm{H}), 7.06-7.11(\mathrm{~m}, 1 \mathrm{H}), 7.14$ (dd, $J=7.6,1.2 \mathrm{~Hz}, 1 \mathrm{H}), 7.29-7.45(\mathrm{~m}, 6 \mathrm{H}), 7.59-7.65(\mathrm{~m}, 1 \mathrm{H}), 8.12(\mathrm{dd}, J=7.8,1.2 \mathrm{~Hz}, 1 \mathrm{H})$. ${ }^{13} \mathrm{C}$ NMR $\left(75.4 \mathrm{MHz}, \mathrm{CDCl}_{3}\right) \delta(\mathrm{ppm})=1.5\left(\mathrm{CH}_{2}\right), 2.9\left(\mathrm{CH}_{2}\right), 23.4(\mathrm{CH}), 47.9\left(\mathrm{CH}_{2}\right)$, $78.7(\mathrm{C}), 101.3(\mathrm{CH}), 109.9(\mathrm{CH}), 119.3(\mathrm{CH}), 120.7(\mathrm{CH}), 121.4(\mathrm{CH}), 126.6(\mathrm{CH})$, $126.7(2 \times \mathrm{CH}), 127.1(\mathrm{CH}), 127.3(\mathrm{CH}), 127.5(\mathrm{CH}), 128.0(2 \times \mathrm{CH}), 128.4(\mathrm{CH}), 128.5$ (C), $128.9(\mathrm{CH}), 136.3(\mathrm{C}), 138.0(\mathrm{C}), 143.5(\mathrm{C}), 144.1(\mathrm{C})$.

LRMS (70 eV, EI) $m / z$ (\%) $353\left(\mathbf{M}^{+}, 100\right)$.

HRMS $\left(\mathrm{EI}^{+}\right)$calcd for $\mathrm{C}_{25} \mathrm{H}_{23} \mathrm{NO}$, 353.1780; found 353.1777. 
2-(2-((1H-Indol-1-yl)methyl)phenyl)propan-2-ol (11b).

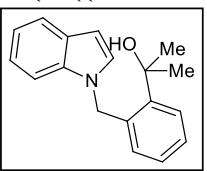

Yellow oil; yield $=40 \% ; R_{f}=0.17$ (hexane/EtOAc, 4:1).

${ }^{1} \mathbf{H}$ NMR $\left(400 \mathrm{MHz}, \mathrm{CDCl}_{3}\right) \delta(\mathrm{ppm})=1.79(\mathrm{~s}, 6 \mathrm{H}), 5.84(\mathrm{~s}, 2 \mathrm{H}), 6.63-$ $6.74(\mathrm{~m}, 2 \mathrm{H}), 7.07-7.30(\mathrm{~m}, 6 \mathrm{H}), 7.32-7.42(\mathrm{~m}, 1 \mathrm{H}), 7.45(\mathrm{~d}, J=7.7$ $\mathrm{Hz}, 1 \mathrm{H}), 7.69-7.81(\mathrm{~m}, 1 \mathrm{H})$.

${ }^{13} \mathrm{C}$ NMR $\left(75.4 \mathrm{MHz}, \mathrm{CDCl}_{3}\right) \delta(\mathrm{ppm})=31.9\left(2 \times \mathrm{CH}_{3}\right), 48.8\left(\mathrm{CH}_{2}\right), 74.2(\mathrm{C}), 101.5$ $(\mathrm{CH}), 110.0(\mathrm{CH}), 119.5(\mathrm{CH}), 121.0(\mathrm{CH}), 121.7(\mathrm{CH}), 125.7(\mathrm{CH}), 127.2(\mathrm{CH}), 127.7$ $(\mathrm{CH}), 128.5(\mathrm{CH}), 128.70(\mathrm{C}), 128.73(\mathrm{CH}), 136.1(\mathrm{C}), 136.6(\mathrm{C}), 144.6(\mathrm{C})$.

LRMS (70 eV, EI) $\mathrm{m} / z$ (\%) $265\left(\mathrm{M}^{+}, 80\right), 232$ (100).

HRMS $\left(\mathrm{EI}^{+}\right)$calcd for $\mathrm{C}_{18} \mathrm{H}_{19} \mathrm{NO}, 265.1467$; found 265.1467.

(2-((1H-Indol-1-yl)methyl)phenyl)-(4-methoxyphenyl)methanol (11c).

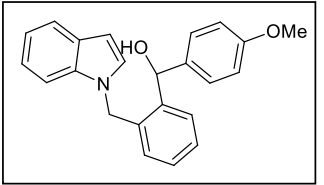

White foam; yield $=50 \% ; R_{f}=0.13$ (hexane/EtOAc, 5:1).

${ }^{1} \mathbf{H}$ NMR $\left(300 \mathrm{MHz}, \mathrm{CDCl}_{3}\right) \delta(\mathrm{ppm})=2.57(\mathrm{bs}, 1 \mathrm{H}), 3.83(\mathrm{~s}$, $3 \mathrm{H}), 5.16(\mathrm{~d}, J=16.4 \mathrm{~Hz}, 1 \mathrm{H}), 5.27(\mathrm{~d}, J=16.4 \mathrm{~Hz}, 1 \mathrm{H}), 5.94$ $(\mathrm{s}, 1 \mathrm{H}), 6.56(\mathrm{~d}, J=3.1 \mathrm{~Hz}, 1 \mathrm{H}), 6.66(\mathrm{~d}, J=7.7 \mathrm{~Hz}, 1 \mathrm{H})$, 6.88-6.94 (m, 2H), $6.97(\mathrm{~d}, J=3.1 \mathrm{~Hz}, 1 \mathrm{H}), 6.98-7.04(\mathrm{~m}, 1 \mathrm{H}), 7.12-7.20(\mathrm{~m}, 3 \mathrm{H})$, $7.22-7.29(\mathrm{~m}, 2 \mathrm{H}), 7.34(\mathrm{t}, J=7.6 \mathrm{~Hz}, 1 \mathrm{H}), 7.61(\mathrm{~d}, J=7.6 \mathrm{~Hz}, 1 \mathrm{H}), 7.66-7.70(\mathrm{~m}, 1 \mathrm{H})$. ${ }^{13} \mathbf{C ~ N M R}\left(75.4 \mathrm{MHz}, \mathrm{CDCl}_{3}\right) \delta(\mathrm{ppm})=47.2\left(\mathrm{CH}_{2}\right), 55.4\left(\mathrm{CH}_{3}\right), 73.1(\mathrm{CH}), 101.7(\mathrm{CH})$, $109.7(\mathrm{CH}), 114.1(2 \times \mathrm{CH}), 119.6(\mathrm{CH}), 121.0(\mathrm{CH}), 121.7(\mathrm{CH}), 127.0(\mathrm{CH}), 127.4$ $(\mathrm{CH}), 127.7(\mathrm{CH}), 128.2(\mathrm{CH}), 128.4(\mathrm{CH}), 128.5(2 \times \mathrm{CH}), 128.6(\mathrm{C}), 134.5(\mathrm{C}), 134.9$ (C), 136.3 (C), 140.5 (C), 159.3 (C).

LRMS (70 eV, EI) $m / z$ (\%) $343\left(\mathbf{M}^{+}, 100\right)$.

HRMS $\left(\mathrm{EI}^{+}\right)$calcd for $\mathrm{C}_{23} \mathrm{H}_{21} \mathrm{NO}_{2}, 343.1572$; found 343.1574 .

(4-Methoxyphenyl)-(2-((3-methyl-1H-indol-1-yl)methyl)phenyl)methanol (11d).

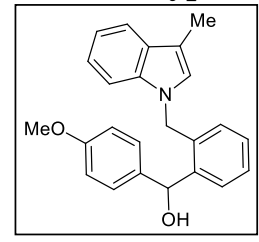

Yellow oil; yield $=49 \% ; R_{f}=0.20$ (hexane/EtOAc, $\left.2: 1\right)$.

${ }^{1} \mathbf{H}$ NMR $\left(300 \mathrm{MHz}, \mathrm{CDCl}_{3}\right) \delta(\mathrm{ppm})=2.22(\mathrm{~d}, J=3.6 \mathrm{~Hz}, 1 \mathrm{H}), 2.30$ (s, 3H), $3.82(\mathrm{~s}, 3 \mathrm{H}), 5.09$ (d, $J=16.3 \mathrm{~Hz}, 1 \mathrm{H}), 5.21(\mathrm{~d}, J=16.3 \mathrm{~Hz}$, $1 \mathrm{H}), 5.97(\mathrm{~d}, J=3.6 \mathrm{~Hz}, 1 \mathrm{H}), 6.66-6.73(\mathrm{~m}, 2 \mathrm{H}), 6.89(\mathrm{dd}, J=9.1$, $2.7 \mathrm{~Hz}, 2 \mathrm{H}), 6.93-7.02(\mathrm{~m}, 1 \mathrm{H}), 7.08-7.13(\mathrm{~m}, 2 \mathrm{H}), 7.13-7.20(\mathrm{~m}$,

$1 \mathrm{H}), 7.21-7.27(\mathrm{~m}, 2 \mathrm{H}), 7.33(\mathrm{t}, J=7.6 \mathrm{~Hz}, 1 \mathrm{H}), 7.54-7.64(\mathrm{~m}, 2 \mathrm{H})$.

${ }^{13} \mathrm{C} \mathrm{NMR}\left(75.4 \mathrm{MHz}, \mathrm{CDCl}_{3}\right) \delta(\mathrm{ppm})=9.7\left(\mathrm{CH}_{3}\right), 46.9\left(\mathrm{CH}_{2}\right), 55.4\left(\mathrm{CH}_{3}\right), 73.0(\mathrm{CH})$, $109.5(\mathrm{CH}), 110.9(\mathrm{CH}), 114.1(2 \times \mathrm{CH}), 118.9(\mathrm{CH}), 119.0(\mathrm{CH}), 121.6(\mathrm{CH}), 125.9$ $(\mathrm{CH}), 126.9(\mathrm{CH}), 127.60(\mathrm{CH}), 127.63(\mathrm{CH}), 128.1(\mathrm{C}), 128.5(2 \times \mathrm{CH}), 128.9(\mathrm{C}), 134.6$ (C), 135.1 (C), 136.7 (C), $140.6(\mathrm{C}), 159.3(\mathrm{C})$.

LRMS (70 eV, EI) $\mathrm{m} / \mathrm{z}$ (\%) $357\left(\mathrm{M}^{+}, 16\right), 132$ (100).

HRMS $\left(\mathrm{EI}^{+}\right)$calcd for $\mathrm{C}_{24} \mathrm{H}_{23} \mathrm{NO}_{2}, 357.1729$; found 357.1728 . 


\section{2-Methyl-1-(2-((3-methyl-1H-indol-1-yl)methyl)phenyl)propan-1-ol (11e).}

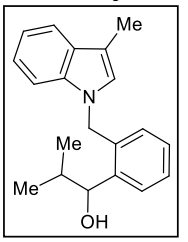

Yellow oil; yield $=51 \% ; R_{f}=0.20($ hexane/EtOAc, $8: 1)$.

${ }^{1} \mathbf{H}$ NMR $\left(300 \mathrm{MHz}, \mathrm{CDCl}_{3}\right) \delta(\mathrm{ppm})=0.87(\mathrm{~d}, J=6.7 \mathrm{~Hz}, 3 \mathrm{H}), 1.11(\mathrm{~d}$, $J=6.5 \mathrm{~Hz}, 3 \mathrm{H}), 1.96(\mathrm{bs}, 1 \mathrm{H}), 1.99-2.10(\mathrm{~m}, 1 \mathrm{H}), 2.38(\mathrm{~s}, 3 \mathrm{H}), 4.64(\mathrm{dd}$, $J=7.1,2.7 \mathrm{~Hz}, 1 \mathrm{H}), 5.32(\mathrm{~d}, J=16.0 \mathrm{~Hz}, 1 \mathrm{H}), 5.41(\mathrm{~d}, J=16.0 \mathrm{~Hz}, 1 \mathrm{H})$, 6.72-6.90 (m, 2H), 7.10-7.31 (m, 4H), $7.34(\mathrm{t}, J=7.4 \mathrm{~Hz}, 1 \mathrm{H}), 7.52(\mathrm{~d}, J$ $=7.5 \mathrm{~Hz}, 1 \mathrm{H}), 7.66(\mathrm{~d}, J=7.4 \mathrm{~Hz}, 1 \mathrm{H})$.

${ }^{13} \mathrm{C} \mathrm{NMR}\left(75.4 \mathrm{MHz}, \mathrm{CDCl}_{3}\right) \delta(\mathrm{ppm})=9.8\left(\mathrm{CH}_{3}\right), 18.3\left(\mathrm{CH}_{3}\right), 19.6\left(\mathrm{CH}_{3}\right), 34.8(\mathrm{CH})$, $47.1\left(\mathrm{CH}_{2}\right), 76.0(\mathrm{CH}), 109.4(\mathrm{CH}), 111.1(\mathrm{C}), 119.0(\mathrm{CH}), 119.2(\mathrm{CH}), 121.8(\mathrm{CH}), 125.7$ $(\mathrm{CH}), 127.0(\mathrm{CH}), 127.8(\mathrm{CH}), 127.9(2 \times \mathrm{CH}), 129.0(\mathrm{C}), 134.8(\mathrm{C}), 136.8(\mathrm{C}), 141.4(\mathrm{C})$. LRMS (70 eV, EI) $m / z$ (\%) $293\left(\mathbf{M}^{+}, 100\right)$.

HRMS (EI ${ }^{+}$) calcd for $\mathrm{C}_{20} \mathrm{H}_{23} \mathrm{NO}, 293.1780$; found 293.1778.

1-(4-Methoxyphenyl)-1-(2-((3-methyl-1H-indol-1-yl)methyl)phenyl)ethanol (11f).

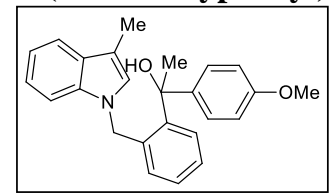

Yellow oil; yield $=73 \% ; R_{f}=0.21$ (hexane/EtOAc, 4:1).

${ }^{1} \mathbf{H}$ NMR $\left(300 \mathrm{MHz}, \mathrm{CDCl}_{3}\right) \delta(\mathrm{ppm})=2.03(\mathrm{~s}, 3 \mathrm{H}), 2.35(\mathrm{~s}$, $3 \mathrm{H}), 2.40$ (bs, 1H), 3.85 (s, 3H), 4.92 (d, $J=17.4 \mathrm{~Hz}, 1 \mathrm{H}), 5.38$ $(\mathrm{d}, J=17.4 \mathrm{~Hz}, 1 \mathrm{H}), 6.56(\mathrm{~d}, J=7.7 \mathrm{~Hz}, 1 \mathrm{H}), 6.65(\mathrm{~s}, 1 \mathrm{H}), 6.71$

(dd, $J=6.3,2.1 \mathrm{~Hz}, 1 \mathrm{H}), 6.87-6.99(\mathrm{~m}, 2 \mathrm{H}), 7.01-7.19(\mathrm{~m}, 3 \mathrm{H}), 7.23-7.41(\mathrm{~m}, 3 \mathrm{H}), 7.59$ (dd, $J=6.2,2.4 \mathrm{~Hz}, 1 \mathrm{H}), 7.70(\mathrm{~d}, J=7.8 \mathrm{~Hz}, 1 \mathrm{H})$.

${ }^{13} \mathbf{C ~ N M R}\left(75.4 \mathrm{MHz}, \mathrm{CDCl}_{3}\right) \delta(\mathrm{ppm})=9.7\left(\mathrm{CH}_{3}\right), 33.7\left(\mathrm{CH}_{3}\right), 47.7\left(\mathrm{CH}_{2}\right), 55.4\left(\mathrm{CH}_{3}\right)$, $76.7(\mathrm{C}), 109.8(\mathrm{CH}), 110.5(\mathrm{CH}), 113.8(2 \times \mathrm{CH}), 118.6(\mathrm{CH}), 118.8(\mathrm{CH}), 121.4(\mathrm{CH})$, $126.0(\mathrm{CH}), 126.5(\mathrm{CH}), 126.57(2 \times \mathrm{CH}), 126.64(\mathrm{CH}), 127.8(\mathrm{CH}), 128.3(\mathrm{C}), 128.7$ (C), 136.7 (C), 138.0 (C), 139.8 (C), 143.4 (C), 158.7 (C).

LRMS (70 eV, EI) $\mathrm{m} / z$ (\%) $371\left(\mathrm{M}^{+}, 100\right), 338$ (72).

HRMS $\left(\mathrm{EI}^{+}\right)$calcd for $\mathrm{C}_{25} \mathrm{H}_{25} \mathrm{NO}_{2}, 371.1885$; found 371.1884.

\section{(2-((3-Methyl-1H-indol-1-yl)methyl)phenyl)di-p-tolylmethanol (11g).}

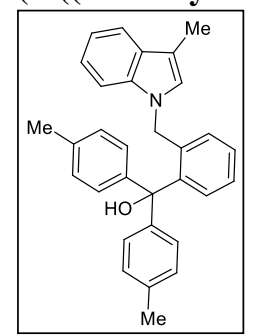

Yellow oil; yield $=67 \% ; R_{f}=0.21$ (hexane/EtOAc, 10:1).

${ }^{1} \mathbf{H}$ NMR $\left(300 \mathrm{MHz}, \mathrm{CDCl}_{3}\right) \delta(\mathrm{ppm})=2.37(\mathrm{~d}, J=1.0 \mathrm{~Hz}, 3 \mathrm{H}), 2.47$ (s, 6H), $3.10(\mathrm{~s}, 1 \mathrm{H}), 5.37$ (s, 2H), 6.55-6.62 (m, 1H), 6.69-6.83 (m, 3H), 7.02-7.13 (m, 4H), 7.18-7.29 (m, 8H), 7.56-7.63 (m, 1H).

${ }^{13} \mathrm{C} \mathrm{NMR}\left(75.4 \mathrm{MHz}, \mathrm{CDCl}_{3}\right) \delta(\mathrm{ppm})=9.8\left(\mathrm{CH}_{3}\right), 21.2\left(2 \times \mathrm{CH}_{3}\right)$, $48.3\left(\mathrm{CH}_{2}\right), 83.3(\mathrm{C}), 109.8(\mathrm{CH}), 110.4(\mathrm{CH}), 118.5(\mathrm{CH}), 118.8$ $(\mathrm{CH}), 121.3(\mathrm{CH}), 125.9(\mathrm{CH}), 126.6(\mathrm{CH}), 127.5(\mathrm{CH}), 127.8$ $(4 \times \mathrm{CH}), 128.2(\mathrm{CH}), 128.7(\mathrm{C}), 129.0(4 \times \mathrm{CH}), 129.6(\mathrm{C}), 136.8(\mathrm{C}), 137.4(2 \times \mathrm{C}), 138.8$ (C), $143.5(\mathrm{C}), 143.6(2 \times \mathrm{C})$.

LRMS (70 eV, EI) $m / z$ (\%) 431 (58), 322 (100).

HRMS $\left(\mathrm{EI}^{+}\right)$calcd for $\mathrm{C}_{31} \mathrm{H}_{29} \mathrm{NO}, 431.2249$; found 431.2248. 
(2-((1H-Indol-2-yl)methyl)phenyl)di-p-tolylmethanol (12a).

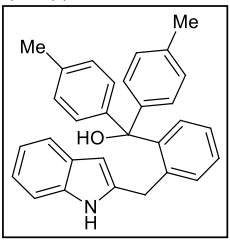

Yellow foam; yield $=52 \% ; R_{f}=0.30$ (hexane/EtOAc, 5:1).

${ }^{1} \mathbf{H}$ NMR $\left(300 \mathrm{MHz}, \mathrm{CDCl}_{3}\right) \delta(\mathrm{ppm})=2.40(\mathrm{~s}, 6 \mathrm{H}), 3.26(\mathrm{~s}, 1 \mathrm{H}), 4.04$ (s, 2H), 6.24-6.30 (m, 1H), $6.73(\mathrm{dd}, J=7.9,1.3 \mathrm{~Hz}, 1 \mathrm{H}), 6.99-7.10$ (m, 3H), 7.12-7.23 (m, 10H), 7.32 (dd, $J=7.6,1.4 \mathrm{~Hz}, 1 \mathrm{H}), 7.48-7.55$ $(\mathrm{m}, 1 \mathrm{H}), 8.01(\mathrm{bs}, 1 \mathrm{H})$.

${ }^{13} \mathrm{C}$ NMR $\left(75.4 \mathrm{MHz}, \mathrm{CDCl}_{3}\right) \delta(\mathrm{ppm})=21.2\left(2 \times \mathrm{CH}_{3}\right), 32.8\left(\mathrm{CH}_{2}\right), 83.5(\mathrm{C}), 100.2$ $(\mathrm{CH}), 110.5(\mathrm{CH}), 119.3(\mathrm{CH}), 119.9(\mathrm{CH}), 120.9(\mathrm{CH}), 125.5(\mathrm{CH}), 127.9(4 \times \mathrm{CH})$, $128.2(\mathrm{CH}), 128.6(\mathrm{C}), 129.0(4 \times \mathrm{CH}), 129.9(\mathrm{CH}), 132.7(\mathrm{CH}), 136.3(\mathrm{C}), 137.4(2 \times$ C), 139.3 (C), $139.8(\mathrm{C}), 144.1(\mathrm{C}), 144.3(2 \times \mathrm{C})$.

LRMS $(70 \mathrm{eV}, \mathrm{EI}) \mathrm{m} / z(\%) 399\left[\left(\mathrm{M}-\mathrm{H}_{2} \mathrm{O}\right)^{+}, 45\right), 308$ (100).

HRMS $\left(\mathrm{EI}^{+}\right)$calcd for $\mathrm{C}_{30} \mathrm{H}_{25} \mathrm{~N}\left(\mathrm{M}-\mathrm{H}_{2} \mathrm{O}\right)^{+}, 399.1887$; found 399.1885 .

\section{(2-((1H-Indol-2-yl)methyl)phenyl)-(4-methoxyphenyl)methanol (12b).}

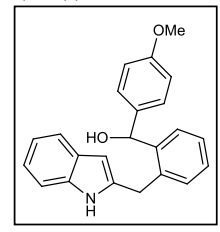

Yellow foam; yield $=40 \% ; R_{f}=0.25$ (hexane/EtOAc, 3:1).

${ }^{1} \mathbf{H}$ NMR $\left(300 \mathrm{MHz}, \mathrm{CDCl}_{3}\right) \delta(\mathrm{ppm})=2.56(\mathrm{bs}, 1 \mathrm{H}), 3.79(\mathrm{~s}, 3 \mathrm{H}), 3.98$ $(\mathrm{d}, J=15.9 \mathrm{~Hz}, 1 \mathrm{H}), 4.09(\mathrm{~d}, J=15.9 \mathrm{~Hz}, 1 \mathrm{H}), 6.00(\mathrm{~d}, J=3.3 \mathrm{~Hz}, 1 \mathrm{H})$, $6.27(\mathrm{~d}, J=1.9 \mathrm{~Hz}, 1 \mathrm{H}), 6.87(\mathrm{~d}, J=8.8 \mathrm{~Hz}, 2 \mathrm{H}), 7.03-7.12(\mathrm{~m}, 3 \mathrm{H})$, 7.19-7.30 (m, 5H), 7.45-7.55 (m, 2H), $7.88(\mathrm{bs}, 1 \mathrm{H})$.

${ }^{13} \mathrm{C}$ NMR $\left(100.6 \mathrm{MHz}, \mathrm{CDCl}_{3}\right) \delta(\mathrm{ppm})=31.5\left(\mathrm{CH}_{2}\right), 55.4\left(\mathrm{CH}_{3}\right), 73.0(\mathrm{CH}), 100.6(\mathrm{CH})$, $110.6(\mathrm{CH}), 114.0(2 \times \mathrm{CH}), 119.6(\mathrm{CH}), 119.9(\mathrm{CH}), 121.2(\mathrm{CH}), 127.1(\mathrm{CH}), 127.5$ $(\mathrm{CH}), 128.1(\mathrm{CH}), 128.4(2 \times \mathrm{CH}), 128.6(\mathrm{C}), 130.8(\mathrm{CH}), 135.1(\mathrm{C}), 136.3(\mathrm{C}), 136.5$ (C), 137.9 (C), $141.3(\mathrm{C}), 159.2(\mathrm{C})$.

LRMS (70 eV, EI) $m / z(\%) 325\left[\left(\mathrm{M}-\mathrm{H}_{2} \mathrm{O}\right)^{+}, 62\right], 217(100)$.

HRMS $\left(\mathrm{EI}^{+}\right)$calcd for $\mathrm{C}_{23} \mathrm{H}_{19} \mathrm{NO}\left(\mathrm{M}-\mathrm{H}_{2} \mathrm{O}\right)^{+} 325.1572$; found 325.1571 .

1-Cyclopropyl-1-(2-((1-methyl-1H-indol-2-yl)methyl)phenyl)ethanol (12c).

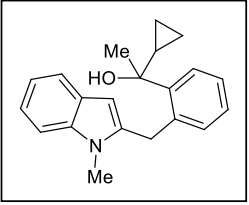

Yellow oil; yield $=62 \% ; R_{f}=0.23($ hexane/EtOAc, 5:1).

${ }^{1} \mathbf{H}$ NMR $\left(400 \mathrm{MHz}, \mathrm{CDCl}_{3}\right) \delta(\mathrm{ppm})=0.46-0.54(\mathrm{~m}, 1 \mathrm{H}), 0.58-$ $0.74(\mathrm{~m}, 3 \mathrm{H}), 1.48-1.58(\mathrm{~m}, 1 \mathrm{H}), 1.56(\mathrm{~s}, 3 \mathrm{H}), 1.85(\mathrm{~s}, 1 \mathrm{H}), 3.73(\mathrm{~s}$, $3 \mathrm{H}), 4.55-4.70(\mathrm{~m}, 2 \mathrm{H}), 6.02(\mathrm{~s}, 1 \mathrm{H}), 7.14-7.40(\mathrm{~m}, 6 \mathrm{H}), 7.59(\mathrm{t}, J=$

$7.2 \mathrm{~Hz}, 1 \mathrm{H}), 7.74-7.81(\mathrm{~m}, 1 \mathrm{H})$

${ }^{13} \mathrm{C} \mathrm{NMR}\left(100.6 \mathrm{MHz}, \mathrm{CDCl}_{3}\right) \delta(\mathrm{ppm})=1.7\left(\mathrm{CH}_{2}\right), 3.3\left(\mathrm{CH}_{2}\right), 23.0(\mathrm{CH}), 27.9\left(\mathrm{CH}_{3}\right)$, $29.7\left(\mathrm{CH}_{3}\right), 32.5\left(\mathrm{CH}_{2}\right), 75.0(\mathrm{C}), 100.8(\mathrm{CH}), 108.8(\mathrm{CH}), 119.3(\mathrm{CH}), 119.9(\mathrm{CH}), 120.7(\mathrm{CH}), 126.5$ $(\mathrm{CH}), 126.9(\mathrm{CH}), 127.2(\mathrm{CH}), 127.9(\mathrm{C}), 132.2(\mathrm{CH}), 136.4(\mathrm{C}), 137.6(\mathrm{C}), 142.1(\mathrm{C}), 145.5(\mathrm{C})$.

LRMS (70 eV, EI) m/z (\%) $305\left(\mathrm{M}^{+}, 30\right), 110$ (100)

HRMS $\left(\mathrm{EI}^{+}\right)$calcd for $\mathrm{C}_{21} \mathrm{H}_{23} \mathrm{NO}, 305.1780$; found 305.1779 . 
Cyclopropyl-(2-((1-methyl-1H-indol-2-yl)methyl)phenyl)(phenyl)methanol (12d).

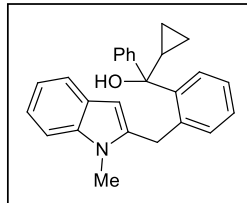

Yellow foam; yield $=48 \% ; R_{f}=0.30$ (hexane/EtOAc, 5:1).

${ }^{1} \mathbf{H}$ NMR $\left(300 \mathrm{MHz}, \mathrm{CDCl}_{3}\right) \delta(\mathrm{ppm})=0.33-0.44(\mathrm{~m}, 1 \mathrm{H})$, $0.52-0.72(\mathrm{~m}, 3 \mathrm{H}), 1.66(\mathrm{ddd}, J=16.3,8.0,5.7 \mathrm{~Hz}, 1 \mathrm{H}), 2.08(\mathrm{~s}$, $1 \mathrm{H}), 3.13(\mathrm{~s}, 3 \mathrm{H}), 3.61(\mathrm{~d}, J=17.2 \mathrm{~Hz}, 1 \mathrm{H}), 4.13(\mathrm{~d}, J=17.2 \mathrm{~Hz}$, $1 \mathrm{H}), 6.03(\mathrm{~d}, J=0.7 \mathrm{~Hz}, 1 \mathrm{H}), 6.96(\mathrm{dd}, J=7.6,1.2 \mathrm{~Hz}, 1 \mathrm{H})$, $7.02-7.09(\mathrm{~m}, 1 \mathrm{H}), 7.13(\mathrm{dd}, J=8.1,1.3 \mathrm{~Hz}, 1 \mathrm{H}), 7.16-7.20(\mathrm{~m}, 1 \mathrm{H}), 7.21-7.34(\mathrm{~m}, 6 \mathrm{H})$, $7.38(\mathrm{dd}, J=7.5,1.4 \mathrm{~Hz}, 1 \mathrm{H}), 7.46-7.52(\mathrm{~m}, 1 \mathrm{H}), 8.15(\mathrm{dd}, J=7.8,1.4 \mathrm{~Hz}, 1 \mathrm{H})$.

${ }^{13} \mathrm{C}$ NMR $\left(75.4 \mathrm{MHz}, \mathrm{CDCl}_{3}\right) \delta(\mathrm{ppm})=2.0\left(\mathrm{CH}_{2}\right), 2.4\left(\mathrm{CH}_{2}\right), 23.5(\mathrm{CH}), 29.4\left(\mathrm{CH}_{3}\right)$, $31.4\left(\mathrm{CH}_{2}\right), 78.0(\mathrm{C}), 101.2(\mathrm{CH}), 108.9(\mathrm{CH}), 119.3(\mathrm{CH}), 119.9(\mathrm{CH}), 120.7(\mathrm{CH}), 126.1$ $(\mathrm{CH}), 126.3(2 \times \mathrm{CH}), 126.8(\mathrm{CH}), 127.7(\mathrm{CH}), 127.9(2 \times \mathrm{CH}), 128.1(\mathrm{CH}), 131.3(\mathrm{CH})$, $137.6(\mathrm{C}), 138.0(\mathrm{C}), 140.4(\mathrm{C}), 144.5(\mathrm{C}), 145.6(\mathrm{C})$, one aromatic carbon peak was misssing due to overlapping.

LRMS (70 eV, EI) $m / z(\%) 349\left[\left(\mathrm{M}-\mathrm{H}_{2} \mathrm{O}\right)^{+}, 57\right), 308(100)$.

HRMS $\left(\mathrm{EI}^{+}\right)$calcd for $\mathrm{C}_{26} \mathrm{H}_{23} \mathrm{~N}\left(\mathrm{M}-\mathrm{H}_{2} \mathrm{O}\right)^{+}, 349.1830$; found 349.1832 .

\section{1-(2-((1-Methyl-1H-indol-2-yl)methyl)phenyl)-1-(thiophen-2-yl)ethanol (12e).}

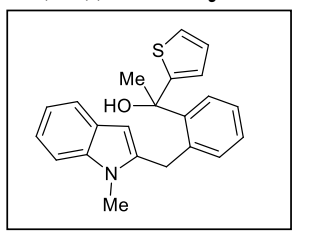

Yellow foam; yield $=60 \% ; R_{f}=0.25$ (hexane/EtOAc, 6:1).

${ }^{1} \mathbf{H}$ NMR $\left(300 \mathrm{MHz}, \mathrm{CDCl}_{3}\right) \delta(\mathrm{ppm})=2.07(\mathrm{~s}, 3 \mathrm{H}), 2.50(\mathrm{bs}, 1 \mathrm{H})$, $3.35(\mathrm{~s}, 3 \mathrm{H}), 3.95(\mathrm{~d}, J=17.0 \mathrm{~Hz}, 1 \mathrm{H}), 4.23(\mathrm{~d}, J=17.1 \mathrm{~Hz}, 1 \mathrm{H})$, $6.05(\mathrm{~d}, J=0.7 \mathrm{~Hz}, 1 \mathrm{H}), 6.76(\mathrm{dd}, J=3.5,1.2 \mathrm{~Hz}, 1 \mathrm{H}), 6.91(\mathrm{dd}$, $J=5.1,3.6 \mathrm{~Hz}, 1 \mathrm{H}), 7.00-7.05(\mathrm{~m}, 1 \mathrm{H}), 7.08(\mathrm{dd}, J=7.8,1.1 \mathrm{~Hz}$, $1 \mathrm{H}), 7.12-7.20(\mathrm{~m}, 1 \mathrm{H}), 7.21-7.35(\mathrm{~m}, 4 \mathrm{H}), 7.50(\mathrm{~d}, J=7.8 \mathrm{~Hz}, 1 \mathrm{H}), 7.72(\mathrm{dd}, J=7.7,1.2 \mathrm{~Hz}, 1 \mathrm{H})$. ${ }^{13} \mathrm{C}$ NMR $\left(75.4 \mathrm{MHz}, \mathrm{CDCl}_{3}\right) \delta(\mathrm{ppm})=29.5\left(\mathrm{CH}_{3}\right), 31.6\left(\mathrm{CH}_{2}\right), 33.3\left(\mathrm{CH}_{3}\right), 75.6(\mathrm{C})$, $101.3(\mathrm{CH}), 108.9(\mathrm{CH}), 119.3(\mathrm{CH}), 120.0(\mathrm{CH}), 120.8(\mathrm{CH}), 123.8(\mathrm{CH}), 124.5(\mathrm{CH})$, $126.2(\mathrm{CH}), 126.4(\mathrm{CH}), 126.7(\mathrm{CH}), 127.8(\mathrm{C}), 128.3(\mathrm{CH}), 131.5(\mathrm{CH}), 137.3(\mathrm{C}), 137.7$ (C), $140.4(\mathrm{C}), 143.9(\mathrm{C}), 153.5(\mathrm{C})$.

LRMS (70 eV, EI) $m / z$ (\%) $347\left(\mathrm{M}^{+}, 77\right), 110$ (100).

HRMS $\left(\mathrm{EI}^{+}\right)$calcd for $\mathrm{C}_{22} \mathrm{H}_{21} \mathrm{NOS}, 347.1344$; found 347.1345.

(4-Methoxyphenyl)-(2-((1-methyl-1H-indol-2-yl)methyl)phenyl)methanol (12f).

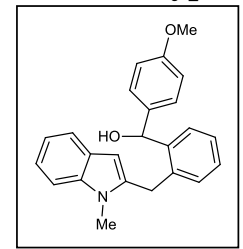

Yellow foam; yield $=56 \% ; R_{f}=0.19$ (hexane/EtOAc, 5:1).

${ }^{1} \mathbf{H}$ NMR $\left(\mathrm{CDCl}_{3}, 300 \mathrm{MHz}\right) \delta(\mathrm{ppm})=2.29-2.48(\mathrm{~m}, 1 \mathrm{H}), 3.40(\mathrm{~s}$, $3 \mathrm{H}), 3.79$ (s, 3H), $3.98(\mathrm{~d}, J=16.9 \mathrm{~Hz}, 1 \mathrm{H}), 4.08(\mathrm{~d}, J=16.9 \mathrm{~Hz}, 1 \mathrm{H})$, $6.01(\mathrm{~s}, 1 \mathrm{H}), 6.13(\mathrm{~d}, J=3.9 \mathrm{~Hz}, 1 \mathrm{H}), 6.84-6.90(\mathrm{~m}, 2 \mathrm{H}), 6.99(\mathrm{~d}, J=$ $7.6 \mathrm{~Hz}, 1 \mathrm{H}), 7.07-7.15(\mathrm{~m}, 1 \mathrm{H}), 7.18-7.31(\mathrm{~m}, 5 \mathrm{H}), 7.35(\mathrm{t}, J=7.5 \mathrm{~Hz}$,

$1 \mathrm{H}), 7.51-7.58(\mathrm{~m}, 1 \mathrm{H}), 7.64(\mathrm{~d}, J=7.7 \mathrm{~Hz}, 1 \mathrm{H})$.

${ }^{13} \mathbf{C ~ N M R}\left(100.6 \mathrm{MHz}, \mathrm{CDCl}_{3}\right) \delta(\mathrm{ppm})=29.5\left(\mathrm{CH}_{3}\right), 30.2\left(\mathrm{CH}_{2}\right), 55.3\left(\mathrm{CH}_{3}\right), 73.0$ $(\mathrm{CH}), 101.4(\mathrm{CH}), 108.9(\mathrm{CH}), 113.9(2 \times \mathrm{CH}), 119.4(\mathrm{CH}), 120.1(\mathrm{CH}), 120.9(\mathrm{CH})$, $126.9(\mathrm{CH}), 127.0(\mathrm{CH}), 127.8(\mathrm{C}), 127.9(\mathrm{CH}), 128.5(2 \times \mathrm{CH}), 129.7(\mathrm{CH}), 135.0(\mathrm{C})$, 135.7 (C), 137.7 (C), 138.9 (C), 141.4 (C), 159.2 (C).

LRMS (70 eV, EI) $m / z(\%) 357\left(\mathrm{M}^{+}, 100\right), 355$ (5).

HRMS $\left(\mathrm{EI}^{+}\right)$calcd for $\mathrm{C}_{24} \mathrm{H}_{23} \mathrm{NO}_{2}, 357.1729$; found 357.1728. 
(E)-1-(2-((1-Methyl-1H-indol-2-yl)methyl)phenyl)-3-phenylprop-2-en-1-ol (12h).

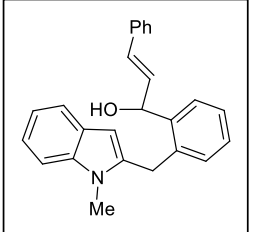

Yellow foam; yield $=64 \% ; R_{f}=0.10$ (hexane/EtOAc, 3:1).

${ }^{1} \mathbf{H}$ NMR $\left(300 \mathrm{MHz}, \mathrm{CDCl}_{3}\right) \delta(\mathrm{ppm})=2.16(\mathrm{bs}, 1 \mathrm{H}), 3.60(\mathrm{~s}, 3 \mathrm{H})$, $4.25-4.30(\mathrm{~m}, 2 \mathrm{H}), 5.64(\mathrm{~d}, J=5.9 \mathrm{~Hz}, 1 \mathrm{H}), 6.11(\mathrm{~d}, J=0.6 \mathrm{~Hz}, 1 \mathrm{H})$, $6.40(\mathrm{dd}, J=15.9,5.9 \mathrm{~Hz}, 1 \mathrm{H}), 6.64(\mathrm{dd}, J=15.9,1.2 \mathrm{~Hz}, 1 \mathrm{H}), 7.08$ $(\mathrm{dd}, J=7.6,1.1 \mathrm{~Hz}, 1 \mathrm{H}), 7.12(\mathrm{dd}, J=7.8,1.0 \mathrm{~Hz}, 1 \mathrm{H}), 7.20(\mathrm{dd}, J=$ 8.2, 1.2 Hz, 1H), 7.23-7.34 (m, 7H), 7.37 (dd, $J=7.4,1.4 \mathrm{~Hz}, 1 \mathrm{H}), 7.54$ (d, $J=7.8 \mathrm{~Hz}$, $1 \mathrm{H}), 7.63(\mathrm{dd}, J=7.6,1.4 \mathrm{~Hz}, 1 \mathrm{H})$.

${ }^{13} \mathbf{C ~ N M R}\left(75.4 \mathrm{MHz}, \mathrm{CDCl}_{3}\right) \delta(\mathrm{ppm})=29.8\left(\mathrm{CH}_{3}\right), 30.5\left(\mathrm{CH}_{2}\right), 71.9(\mathrm{CH}), 101.4(\mathrm{CH})$, $109.0(\mathrm{CH}), 119.5(\mathrm{CH}), 120.1(\mathrm{CH}), 121.1(\mathrm{CH}), 126.7(2 \times \mathrm{CH}), 127.0(\mathrm{CH}), 127.4$ $(\mathrm{CH}), 127.86(\mathrm{C}), 127.92(\mathrm{CH}), 128.3(\mathrm{CH}), 128.7(2 \times \mathrm{CH}), 130.2(\mathrm{CH}), 130.7(\mathrm{CH})$, $130.9(\mathrm{CH}), 135.8(\mathrm{C}), 136.5(\mathrm{C}), 137.8(\mathrm{C}), 139.3(\mathrm{C}), 140.6(\mathrm{C})$.

LRMS $(70 \mathrm{eV}, \mathrm{EI}) \mathrm{m} / \mathrm{z}(\%) 353\left(\mathrm{M}^{+}, 100\right)$.

HRMS $\left(\mathrm{EI}^{+}\right)$calcd for $\mathrm{C}_{25} \mathrm{H}_{23} \mathrm{NO}, 353.1780$; found 353.1780.

\subsection{Synthesis of Polycyclic Adducts 13-17}

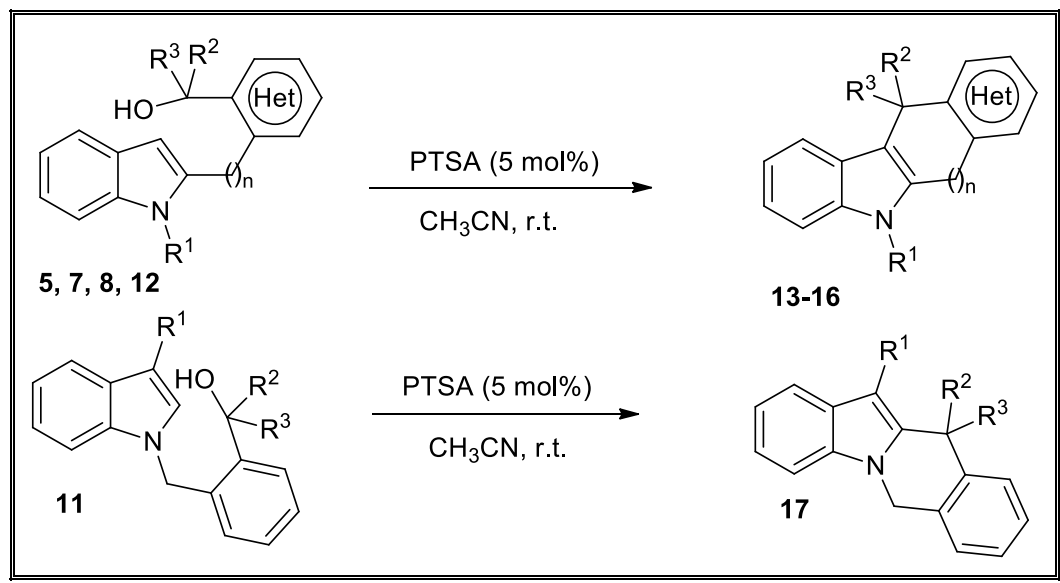

General Procedure: Acid-catalyzed procedure: PTSA (5 mg, $5 \mathrm{~mol} \%$ ) was added to a solution of the corresponding alcohol derivative 5, 8, 11, $12(0.5 \mathrm{mmol})$ in $\mathrm{MeCN}$ (1 $\mathrm{ml}$ ) and the resulting reaction mixture was stirred at $\mathrm{rt}$ until the alcohol was consumed as determined by TLC $(0.5-24 \mathrm{~h})$. The crude mixture was quenched with aqueous $\mathrm{NaOH}$ $(0.5 \mathrm{M})$ and extracted with EtOAc $(3 \times 10 \mathrm{ml})$, and the combined organic layers were dried over anhydrous $\mathrm{Na}_{2} \mathrm{SO}_{4}$ and concentrated at reduced pressure. The residue was purified by flash chromatography using mixtures of hexane and EtOAc as eluents to obtain the corresponding cycloadducts 13-17. In some cases, the final product precipitates from the reaction mixture and could be isolated by simple filtration in pure form. 


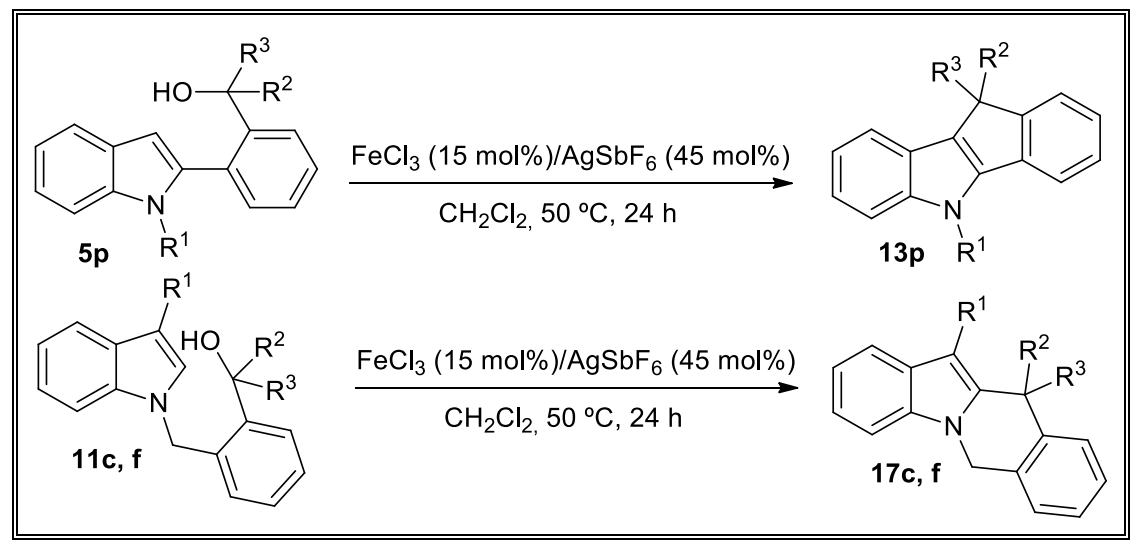

General Procedure: Fe-catalyzed procedure (for the preparation of $13 p$, and $17 \boldsymbol{c}, \boldsymbol{f}):^{78}$ To an oven dried vial containing $\mathrm{FeCl}_{3}(12 \mathrm{mg}, 0.075 \mathrm{mmol})$ was added a solution of the alcohol $\mathbf{5 p}$, or $\mathbf{1 1 c}, \mathbf{f}(0.5 \mathrm{mmol})$ in DCE $(3 \mathrm{ml})$, and allowed to stir until $\mathrm{FeCl}_{3}$ was completely dissolved (10-15min). Then $\mathrm{AgSbF}_{6}(77 \mathrm{mg}, 0.225 \mathrm{mmol}$ ) was added and the resulting reaction mixture was stirred at $50{ }^{\circ} \mathrm{C}$ for $24 \mathrm{~h}$. The reaction was quenched with aqueous $\mathrm{HCl}(1 \mathrm{M})$, extracted with $\mathrm{CH}_{2} \mathrm{Cl}_{2}(3 \times 10 \mathrm{ml})$, and the water layer was basified with aqueous $\mathrm{NaOH}(1 \mathrm{M})$, and extracted with $\mathrm{CH}_{2} \mathrm{Cl}_{2}(2 \times 5 \mathrm{ml})$. The organic extracts combined and dried, filtered and concentrated to give the residue. The residue was purified by silica flash chromatography using mixtures of hexane and EtOAc as eluents to obtain the corresponding cycloadducts $13 \mathbf{p}$, and $\mathbf{1 7} \mathbf{c}, \mathbf{f}$.

\section{5,10-Dimethyl-10-phenyl-5,10-dihydroindeno[1,2-b]indole (13a).}

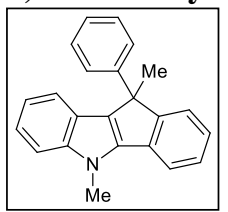

White solid; yield $=90 \%$; m.p. $178-180^{\circ} \mathrm{C}$.

${ }^{1} \mathbf{H}$ NMR $\left(300 \mathrm{MHz}, \mathrm{CDCl}_{3}\right) \delta(\mathrm{ppm})=2.06(\mathrm{~s}, 3 \mathrm{H}), 4.13(\mathrm{~s}, 3 \mathrm{H}), 7.12-7.20$ (m, 1H), 7.22-7.40 (m, 6H), 7.42-7.52 (m, 5H), 7.70 (dd, J=7.5, 0.6 Hz, 1H)

${ }^{13} \mathbf{C ~ N M R}\left(75.4 \mathrm{MHz}, \mathrm{CDCl}_{3}\right) \delta(\mathrm{ppm})=24.8\left(\mathrm{CH}_{3}\right), 31.3\left(\mathrm{CH}_{3}\right), 50.3$ $(\mathrm{C}), 110.0(\mathrm{CH}), 118.0(\mathrm{CH}), 119.0(\mathrm{CH}), 119.8(\mathrm{CH}), 121.4(\mathrm{CH}), 123.0(\mathrm{C}), 124.4(\mathrm{CH})$, $125.7(\mathrm{CH}), 126.41(2 \times \mathrm{CH}), 126.43(\mathrm{CH}), 126.9(\mathrm{CH}), 128.4(2 \times \mathrm{CH}), 130.0(\mathrm{C}), 133.7$ (C), $142.1(\mathrm{C}), 142.4(\mathrm{C}), 144.5(\mathrm{C}), 159.0(\mathrm{C})$.

LRMS (70 eV, EI) $\mathrm{m} / z(\%) 309\left(\mathrm{M}^{+}, 80\right), 294$ (100).

HRMS $\left(\mathrm{EI}^{+}\right)$calcd for $\mathrm{C}_{23} \mathrm{H}_{19} \mathrm{~N}, 309.1517$; found 309.1518 .

10-Cyclopropyl-5-methyl-10-phenyl-5,10-dihydroindeno[1,2-b]indole (13b).

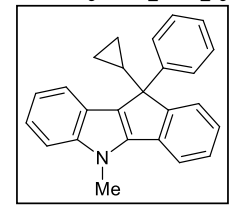

White solid; yield $=85 \%$; m.p. $174-176^{\circ} \mathrm{C}$.

${ }^{1} \mathbf{H}$ NMR $\left(300 \mathrm{MHz}, \mathrm{CDCl}_{3}\right) \delta(\mathrm{ppm})=0.01-0.05(\mathrm{~m}, 1 \mathrm{H}), 0.39-0.46$ (m, 1H), 0.63-0.82 (m, 2H), 2.00-2.12 (m, 1H), 4.09 (s, 3H), 7.08-7.15 $(\mathrm{m}, 1 \mathrm{H}), 7.20-7.49(\mathrm{~m}, 9 \mathrm{H}), 7.56-7.63(\mathrm{~m}, 2 \mathrm{H}), 7.69(\mathrm{~d}, J=7.3 \mathrm{~Hz}, 1 \mathrm{H})$.

${ }^{13} \mathrm{C} \mathrm{NMR}\left(75.4 \mathrm{MHz}, \mathrm{CDCl}_{3}\right) \delta(\mathrm{ppm})=1.6\left(\mathrm{CH}_{2}\right), 4.1\left(\mathrm{CH}_{2}\right), 18.4(\mathrm{CH}), 31.2\left(\mathrm{CH}_{3}\right)$, $56.0(\mathrm{C}), 109.9(\mathrm{CH}), 117.9(\mathrm{CH}), 119.4(\mathrm{CH}), 119.9(\mathrm{CH}), 121.2(\mathrm{CH}), 124.0(\mathrm{C}), 124.9$ 
$(\mathrm{CH}), 125.6(\mathrm{CH}), 125.9(\mathrm{C}), 126.4(\mathrm{CH}), 126.9(\mathrm{CH}), 127.4(2 \times \mathrm{CH}), 128.3(2 \times \mathrm{CH})$, 134.3 (C), 141.9 (C), 143.7 (C), 144.8 (C), 157.6 (C).

LRMS (70 eV, EI) $\mathrm{m} / \mathrm{z}$ (\%) $335\left(\mathrm{M}^{+}, 43\right), 307$ (100).

HRMS $\left(\mathrm{EI}^{+}\right)$calcd for $\mathrm{C}_{25} \mathrm{H}_{21} \mathrm{~N}, 335.1674$; found 335.1677.

10-Ethyl-5-methyl-10-(thiophen-2-yl)-5,10-dihydroindeno[1,2-b]indole (13c).

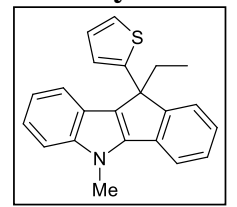

White solid; yield $=80 \%$; m.p. $136-138^{\circ} \mathrm{C}$.

${ }^{1} \mathbf{H}$ NMR $\left(300 \mathrm{MHz}, \mathrm{CDCl}_{3}\right) \delta(\mathrm{ppm})=0.70(\mathrm{t}, J=7.3 \mathrm{~Hz}, 3 \mathrm{H}), 2.38$ $(\mathrm{dq}, J=14.5,7.3 \mathrm{~Hz}, 1 \mathrm{H}), 2.71(\mathrm{dq}, J=14.5,7.3 \mathrm{~Hz}, 1 \mathrm{H}), 4.09$ (s, 3H), $6.90(\mathrm{dd}, J=5.1,3.6 \mathrm{~Hz}, 1 \mathrm{H}), 6.97(\mathrm{dd}, J=3.6,1.2 \mathrm{~Hz}, 1 \mathrm{H}), 7.09-7.38$ (m, 5H), $7.44(\mathrm{~d}, J=8.2 \mathrm{~Hz}, 1 \mathrm{H}), 7.53-7.70(\mathrm{~m}, 3 \mathrm{H})$.

${ }^{13} \mathrm{C} \mathrm{NMR}\left(\mathrm{CDCl}_{3}, 75.4 \mathrm{MHz}\right) \delta(\mathrm{ppm})=9.9\left(\mathrm{CH}_{3}\right), 31.3\left(\mathrm{CH}_{3}\right), 33.8\left(\mathrm{CH}_{2}\right), 53.6(\mathrm{C})$, $110.0(\mathrm{CH}), 118.1(\mathrm{CH}), 119.88(\mathrm{CH}), 119.93(\mathrm{CH}), 121.4(\mathrm{CH}), 123.3(\mathrm{CH}), 123.7(\mathrm{CH})$, $123.8(\mathrm{C}), 124.4(\mathrm{CH}), 125.7(\mathrm{CH}), 126.1(\mathrm{C}), 126.6(\mathrm{CH}), 127.2(\mathrm{CH}), 133.8(\mathrm{C}), 142.1$ (C), 143.5 (C), 149.3 (C), 155.8 (C).

LRMS (70 eV, EI) $m / z$ (\%) $330\left[(\mathrm{M}+1)^{+}, 6\right], 329\left(\mathrm{M}^{+}, 24\right), 300$ (100).

HRMS $\left(\mathrm{EI}^{+}\right)$calcd for $\mathrm{C}_{22} \mathrm{H}_{19} \mathrm{NS}, 329.1238$; found 329.1237 .

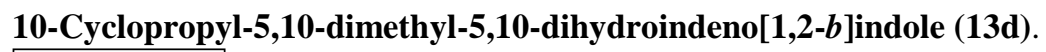

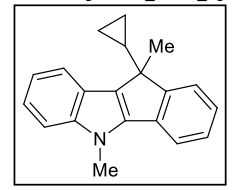

White solid; yield $=63 \%$; m.p. $135-137^{\circ} \mathrm{C}$.

${ }^{1} \mathbf{H}$ NMR (400 MHz, $\left.\mathrm{CDCl}_{3}\right): \delta(\mathrm{ppm})=0.10(\mathrm{bs}, 1 \mathrm{H}), 0.33(\mathrm{bs}, 1 \mathrm{H})$, 0.54-0.64 (m, 1H), 0.67-0.77 (m, 1H), 1.32-1.45 (m, 1H), $1.66(\mathrm{~s}, 3 \mathrm{H})$, 4.07 (s, 3H), 7.19-7.47 (m, 5H), $7.56(\mathrm{~d}, J=6.2 \mathrm{~Hz}, 1 \mathrm{H}), 7.65(\mathrm{~d}, J=$

$7.3 \mathrm{~Hz}, 1 \mathrm{H}), 7.72-7.76(\mathrm{~m}, 1 \mathrm{H})$.

${ }^{13} \mathbf{C ~ N M R}\left(100.6 \mathrm{MHz}, \mathrm{CDCl}_{3}\right) \delta(\mathrm{ppm})=1.1\left(\mathrm{CH}_{2}\right), 2.7\left(\mathrm{CH}_{2}\right), 19.7\left(\mathrm{CH}_{3}\right), 22.8(\mathrm{CH})$, $31.2\left(\mathrm{CH}_{3}\right), 47.4(\mathrm{C}), 110.0(\mathrm{CH}), 117.9(\mathrm{CH}), 119.4(\mathrm{CH}), 119.7(\mathrm{CH}), 121.1(\mathrm{CH}), 123.3$ $(\mathrm{CH}), 124.0(\mathrm{C}), 125.3(\mathrm{CH}), 126.7(\mathrm{CH}), 127.1(\mathrm{C}), 133.8(\mathrm{C}), 142.0(\mathrm{C}), 142.9(\mathrm{C}), 158.6(\mathrm{C})$.

LRMS (70 eV, EI) $\mathrm{m} / z$ (\%) $273\left(\mathbf{M}^{+}, 100\right), 258$ (53).

HRMS $\left(\mathrm{EI}^{+}\right)$calcd for $\mathrm{C}_{20} \mathrm{H}_{19} \mathrm{~N}, 273.1517$; found 273.1515 .

10-Cyclopropyl-10-methyl-5,10-dihydroindeno[1,2-b]indole (13e).

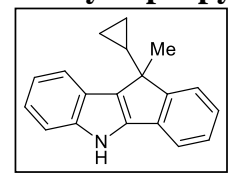

Brown solid; yield $=73 \%$; m.p. $110-112^{\circ} \mathrm{C}$.

${ }^{1} \mathbf{H}$ NMR $\left(400 \mathrm{MHz}, \mathrm{CDCl}_{3}\right) \delta(\mathrm{ppm})=0.02-0.04(\mathrm{~m}, 1 \mathrm{H}), 0.22-0.26$ $(\mathrm{m}, 1 \mathrm{H}), 0.45-0.54(\mathrm{~m}, 1 \mathrm{H}), 0.57-0.63(\mathrm{~m}, 1 \mathrm{H}), 1.24-1.36(\mathrm{~m}, 1 \mathrm{H})$, $1.58(\mathrm{~s}, 3 \mathrm{H}), 7.12-7.19(\mathrm{~m}, 2 \mathrm{H}), 7.20-7.32(\mathrm{~m}, 2 \mathrm{H}), 7.37-7.43(\mathrm{~m}, 2 \mathrm{H})$, $7.47(\mathrm{dd}, J=7.3,0.6 \mathrm{~Hz}, 1 \mathrm{H}), 7.61-7.68(\mathrm{~m}, 1 \mathrm{H}), 8.24(\mathrm{bs}, 1 \mathrm{H})$.

${ }^{13} \mathrm{C} \mathrm{NMR}\left(100.6 \mathrm{MHz}, \mathrm{CDCl}_{3}\right) \delta(\mathrm{ppm})=1.1\left(\mathrm{CH}_{2}\right), 2.2\left(\mathrm{CH}_{2}\right), 19.6\left(\mathrm{CH}_{3}\right), 22.5(\mathrm{CH})$, $47.9(\mathrm{C}), 112.3(\mathrm{CH}), 117.6(\mathrm{CH}), 119.4(\mathrm{CH}), 120.4(\mathrm{CH}), 121.7(\mathrm{CH}), 123.2(\mathrm{CH})$, $124.7(\mathrm{C}), 125.5(\mathrm{CH}), 126.8(\mathrm{CH}), 128.8(\mathrm{C}), 133.4(\mathrm{C}), 140.8(\mathrm{C}), 141.5(\mathrm{C}), 158.2(\mathrm{C})$. LRMS (70 eV, EI) $\mathrm{m} / z$ (\%) $259\left(\mathrm{M}^{+}, 76\right), 231$ (100).

HRMS $\left(\mathrm{EI}^{+}\right)$calcd for $\mathrm{C}_{20} \mathrm{H}_{19} \mathrm{~N}, 259.1361$; found 259.1363 . 
(E)-5,10-Dimethyl-10-styryl-5,10-dihydroindeno[1,2-b]indole (13f).

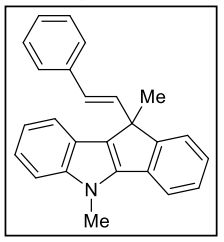

White solid; yield $=80 \%$; m.p. $150-152^{\circ} \mathrm{C}$.

${ }^{1} \mathbf{H}$ NMR $\left(300 \mathrm{MHz}, \mathrm{CDCl}_{3}\right) \delta(\mathrm{ppm})=1.88(\mathrm{~s}, 3 \mathrm{H}), 4.13(\mathrm{~s}, 3 \mathrm{H}), 6.57$ $(\mathrm{d}, J=15.9 \mathrm{~Hz}, 1 \mathrm{H}), 6.77(\mathrm{~d}, J=15.9 \mathrm{~Hz}, 1 \mathrm{H}), 7.21-7.45(\mathrm{~m}, 9 \mathrm{H}), 7.49$ $(\mathrm{d}, J=8.2 \mathrm{~Hz}, 1 \mathrm{H}), 7.54-7.60(\mathrm{~m}, 1 \mathrm{H}), 7.67-7.77(\mathrm{~m}, 2 \mathrm{H})$.

${ }^{13} \mathbf{C ~ N M R}\left(75.4 \mathrm{MHz}, \mathrm{CDCl}_{3}\right) \delta(\mathrm{ppm})=23.8\left(\mathrm{CH}_{3}\right), 31.2\left(\mathrm{CH}_{3}\right), 49.0$ $(\mathrm{C}), 110.0(\mathrm{CH}), 118.1(\mathrm{CH}), 119.0(\mathrm{CH}), 119.9(\mathrm{CH}), 121.4(\mathrm{CH}), 123.6(\mathrm{C}), 124.0(\mathrm{CH})$, 125.6 (CH), $126.4(2 \times \mathrm{CH}), 127.11(\mathrm{CH}), 127.14(\mathrm{CH}), 127.39(\mathrm{CH}), 127.49(\mathrm{C}), 128.5$ $(2 \times \mathrm{CH}), 133.6(\mathrm{C}), 134.3(\mathrm{CH}), 137.6(\mathrm{C}), 142.1(\mathrm{C}), 142.4(\mathrm{C}), 156.7(\mathrm{C})$.

LRMS (70 eV, EI) $m / z$ (\%) $335\left(\mathbf{M}^{+}, 92\right), 320$ (17).

HRMS $\left(\mathrm{EI}^{+}\right)$calcd for $\mathrm{C}_{25} \mathrm{H}_{21} \mathrm{~N}, 335.1674$; found 335.1673 .

\section{5,10-Dimethyl-10-(thiophen-3-ylethynyl)-5,10-dihydroindeno[1,2-b]indole (13g).}

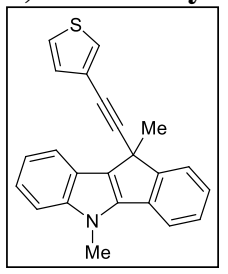

Brown solid; yield $=80 \%$; m.p. $156-158^{\circ} \mathrm{C}$.

${ }^{1} \mathbf{H}$ NMR $\left(300 \mathrm{MHz}, \mathrm{CDCl}_{3}\right) \delta(\mathrm{ppm})=1.94\left(\mathrm{CH}_{3}\right), 4.05\left(\mathrm{CH}_{3}\right)$, 7.05-7.09 (m, 1H), 7.17-7.44 (m, 7H), $7.62(\mathrm{~d}, J=7.2 \mathrm{~Hz}, 1 \mathrm{H})$, 7.68-7.75 (m, 1H), 7.79-7.86 (m, 1H).

${ }^{13} \mathrm{C}$ NMR $\left(75.4 \mathrm{MHz}, \mathrm{CDCl}_{3}\right) \delta(\mathrm{ppm})=27.5\left(\mathrm{CH}_{3}\right), 31.2\left(\mathrm{CH}_{3}\right), 40.3$ (C), $74.5(\mathrm{C}), 91.4(\mathrm{C}), 110.1(\mathrm{CH}), 118.1(\mathrm{CH}), 118.8(\mathrm{CH}), 120.1$ $(\mathrm{CH}), 121.7(\mathrm{CH}), 122.7(\mathrm{C}), 124.2(\mathrm{CH}), 124.9(\mathrm{CH}), 126.1(\mathrm{CH}), 126.3(\mathrm{C}), 127.7(\mathrm{CH})$, $128.2(\mathrm{CH}), 130.3(\mathrm{CH}), 133.3(\mathrm{C}), 142.0(2 \times \mathrm{C}), 155.3(\mathrm{C})$, one aromatic $\mathrm{C}$ peak was missing due to overlapping.

LRMS (70 eV, EI) $m / z$ (\%) $339\left(\mathbf{M}^{+}, 100\right)$.

HRMS $\left(\mathrm{EI}^{+}\right)$calcd for $\mathrm{C}_{23} \mathrm{H}_{17} \mathrm{NS}, 339.1082$; found 339.1083 .

10-Cyclopropyl-5-methyl-10-(phenylethynyl)-5,10-dihydroindeno[1,2-b]indole (13h).

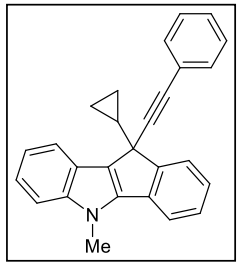

White solid; yield $=88 \%$; m.p. $163-165^{\circ} \mathrm{C}$.

${ }^{1} \mathbf{H}$ NMR $\left(300 \mathrm{MHz}, \mathrm{CDCl}_{3}\right) \delta(\mathrm{ppm})=0.60-0.78(\mathrm{~m}, 2 \mathrm{H}), 0.99-1.15$ (m, 2H), 1.18-1.27 (m, 1H), $4.05(\mathrm{~s}, 3 \mathrm{H}), 7.24-7.47(\mathrm{~m}, 10 \mathrm{H}), 7.64$ (d, $J=7.1 \mathrm{~Hz}, 1 \mathrm{H}), 7.79-7.89(\mathrm{~m}, 2 \mathrm{H})$.

${ }^{13} \mathbf{C ~ N M R}\left(75.4 \mathrm{MHz}, \mathrm{CDCl}_{3}\right) \delta(\mathrm{ppm})=1.7\left(\mathrm{CH}_{2}\right), 2.4\left(\mathrm{CH}_{2}\right), 19.3$ $(\mathrm{CH}), 31.2\left(\mathrm{CH}_{3}\right), 46.4(\mathrm{C}), 81.0(\mathrm{C}), 87.9(\mathrm{C}), 110.1(\mathrm{CH}), 118.1(\mathrm{CH}), 119.6(\mathrm{CH})$, $120.2(\mathrm{CH}), 121.6(\mathrm{CH}), 123.3(\mathrm{C}), 123.6(\mathrm{C}), 124.9(\mathrm{CH}), 125.5(\mathrm{C}), 126.1(\mathrm{CH}), 127.76$ $(\mathrm{CH}), 127.83(\mathrm{CH}), 128.2(2 \times \mathrm{CH}), 131.9(2 \times \mathrm{CH}), 133.4(\mathrm{C}), 142.0(\mathrm{C}), 142.6(\mathrm{C}), 155.0(\mathrm{C})$. LRMS (70 eV, EI) $\mathrm{m} / z(\%) 359\left(\mathrm{M}^{+}, 100\right)$.

HRMS $\left(\mathrm{EI}^{+}\right)$calcd for $\mathrm{C}_{27} \mathrm{H}_{21} \mathrm{~N}, 359.1676$; found 359.1679 . 
10-(4-Methoxyphenyl)-5-methyl-5,10-dihydroindeno[1,2-b]indole (13i).

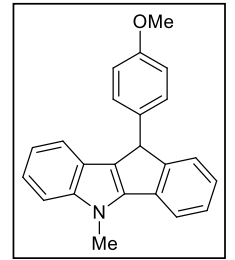

White solid; yield $=97 \%$; m.p. $180-182^{\circ} \mathrm{C}$.

${ }^{1} \mathbf{H}$ NMR $\left(300 \mathrm{MHz}, \mathrm{CDCl}_{3}\right) \delta(\mathrm{ppm})=3.78(\mathrm{~s}, 3 \mathrm{H}), 4.10(\mathrm{~s}, 3 \mathrm{H}), 4.92$ $(\mathrm{s}, 1 \mathrm{H}), 6.83(\mathrm{~d}, J=8.4 \mathrm{~Hz}, 2 \mathrm{H}), 7.08(\mathrm{t}, J=7.5 \mathrm{~Hz}, 1 \mathrm{H}), 7.13-7.28(\mathrm{~m}$, 4H), 7.29-7.46 (m, 4H), $7.66(\mathrm{~d}, J=7.4 \mathrm{~Hz}, 1 \mathrm{H})$.

${ }^{13} \mathrm{C}$ NMR $\left(75.4 \mathrm{MHz}, \mathrm{CDCl}_{3}\right) \delta(\mathrm{ppm})=31.3\left(\mathrm{CH}_{3}\right), 47.8(\mathrm{CH}), 55.3$ $\left(\mathrm{CH}_{3}\right), 109.9(\mathrm{CH}), 114.2(2 \times \mathrm{CH}), 117.8(\mathrm{CH}), 119.1(\mathrm{CH}), 119.8$ $(\mathrm{CH}), 121.4(\mathrm{CH}), 123.9(\mathrm{C}), 124.6(\mathrm{C}), 125.4(\mathrm{CH}), 125.6(\mathrm{CH}), 127.0(\mathrm{CH}), 129.0(2 \times$ $\mathrm{CH}), 132.9$ (C), 134.7 (C), 142.1 (C), 144.2 (C), 153.5 (C), 158.6 (C).

LRMS (70 eV, EI) $m / z$ (\%) $325\left(\mathbf{M}^{+}, 40\right), 324$ (100).

HRMS $\left(\mathrm{EI}^{+}\right)$calcd for $\mathrm{C}_{23} \mathrm{H}_{19} \mathrm{NO}, 325.1467$; found 325.14678 .

10-(4-Methoxyphenyl)-5,10-dihydroindeno[1,2-b]indole (13j).

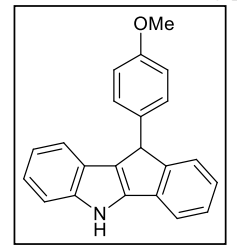

White solid; yield $=80 \%$; m.p. $180-182^{\circ} \mathrm{C}$.

${ }^{1} \mathbf{H}$ NMR $\left(400 \mathrm{MHz}, \mathrm{CDCl}_{3}\right) \delta(\mathrm{ppm})=3.76(\mathrm{~s}, 3 \mathrm{H}), 4.94(\mathrm{~s}, 1 \mathrm{H}), 6.79$ $6.83(\mathrm{~m}, 2 \mathrm{H}), 7.03-7.08(\mathrm{~m}, 1 \mathrm{H}), 7.11-7.19(\mathrm{~m}, 4 \mathrm{H}), 7.28(\mathrm{~d}, J=7.4$ $\mathrm{Hz}, 1 \mathrm{H}), 7.31-7.38$ (m, 2H), 7.44 (t, $J=7.5 \mathrm{~Hz}, 2 \mathrm{H}), 8.40$ (bs, 1H).

${ }^{13} \mathbf{C ~ N M R}\left(100.6 \mathrm{MHz}, \mathrm{CDCl}_{3}\right) \delta(\mathrm{ppm})=48.1(\mathrm{CH}), 55.4\left(\mathrm{CH}_{3}\right), 109.9$ $(\mathrm{CH}), 114.2(2 \times \mathrm{CH}), 117.5(\mathrm{CH}), 119.1(\mathrm{CH}), 120.5(\mathrm{CH}), 122.0(\mathrm{CH}), 124.5(\mathrm{C}), 125.5$ $(\mathrm{CH}), 125.6(\mathrm{CH}), 126.1(\mathrm{C}), 127.0(\mathrm{CH}), 129.0(2 \times \mathrm{CH}), 132.6(\mathrm{C}), 134.3(\mathrm{C}), 140.9$ (C), $142.9(\mathrm{C}), 153.2(\mathrm{C}), 158.6(\mathrm{C})$.

LRMS (70 eV, EI) $\mathrm{m} / z$ (\%) 311 (100).

HRMS $\left(\mathrm{EI}^{+}\right)$calcd for $\mathrm{C}_{22} \mathrm{H}_{19} \mathrm{NO}, 311.1310$; found 311.1307 .

10-(4-Chlorophenyl)-5-methyl-5,10-dihydroindeno[1,2-b]indole (13k).

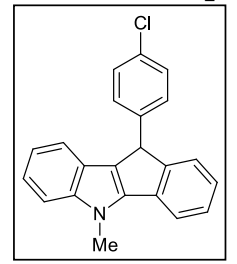

White solid; yield $=82 \%$; m.p. $139-141^{\circ} \mathrm{C}$.

${ }^{1} \mathbf{H}$ NMR $\left(300 \mathrm{MHz}, \mathrm{CDCl}_{3}\right) \delta(\mathrm{ppm})=4.06(\mathrm{~s}, 3 \mathrm{H}), 4.85(\mathrm{~s}, 1 \mathrm{H})$, 7.12-7.22 (m, 3H), 7.24-7.28 (m, 1H), 7.29-7.36 (m, 3H), 7.37-7.47 $(\mathrm{m}, 4 \mathrm{H}), 7.69(\mathrm{~d}, J=7.5 \mathrm{~Hz}, 1 \mathrm{H})$.

${ }^{13} \mathbf{C ~ N M R}\left(75.4 \mathrm{MHz}, \mathrm{CDCl}_{3}\right) \delta(\mathrm{ppm})=31.2\left(\mathrm{CH}_{3}\right), 47.6(\mathrm{CH}), 110.0$ $(\mathrm{CH}), 117.9(\mathrm{CH}), 118.9(\mathrm{CH}), 119.9(\mathrm{CH}), 1121.6(\mathrm{CH}), 123.6(\mathrm{C}), 123.8(\mathrm{C}), 125.48$ $(\mathrm{CH}), 125.54(\mathrm{CH}), 127.2(\mathrm{CH}), 128.9(2 \times \mathrm{CH}), 129.4(2 \times \mathrm{CH}), 132.4(\mathrm{C}), 134.6(\mathrm{C})$, $139.6(\mathrm{C}), 142.0(\mathrm{C}), 144.2(\mathrm{C}), 152.7(\mathrm{C})$.

LRMS (70 eV, EI) $\mathrm{m} / z$ (\%) 331 [(M+2)+, 34], $329\left(\mathrm{M}^{+}, 100\right), 218$ (29).

HRMS $\left(\mathrm{EI}^{+}\right)$calcd for $\mathrm{C}_{22} \mathrm{H}_{16} \mathrm{ClN}, 329.0971$; found 329.0972. 
10-(4-Chlorophenyl)-5,10-dihydroindeno[1,2-b]indole (131).

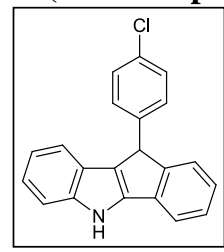

Yellow solid; yield $=65 \%$; m.p. $180-182^{\circ} \mathrm{C}$.

${ }^{1} \mathbf{H}$ NMR $\left(300 \mathrm{MHz}, \mathrm{CDCl}_{3}\right) \delta(\mathrm{ppm})=4.94(\mathrm{~s}, 1 \mathrm{H}), 7.07-7.30(\mathrm{~m}$, 7H), 7.31-7.41 (m, 3H), 7.42-7.53 (m, 2H), 8.37 (bs, 1H).

${ }^{13} \mathrm{C} \mathrm{NMR}\left(\mathrm{CDCl}_{3}, 75.4 \mathrm{MHz}\right) \delta(\mathrm{ppm})=48.0(\mathrm{CH}), 112.3(\mathrm{CH}), 117.7$ $(\mathrm{CH}), 118.9(\mathrm{CH}), 120.6(\mathrm{CH}), 122.1(\mathrm{CH}), 124.2(\mathrm{C}), 125.36(\mathrm{C})$, $125.42(\mathrm{CH}), 125.7(\mathrm{CH}), 127.3(\mathrm{CH}), 128.9(2 \times \mathrm{CH}), 129.4(2 \times \mathrm{CH}), 132.5(\mathrm{C}), 134.2$ (C), 139.3 (C), 140.8 (C), 143.0 (C), 152.4 (C).

LRMS (70 eV, EI) m/z (\%) 317 [(M+2)+, 34], $315\left(\mathrm{M}^{+}, 100\right), 313$ (35).

HRMS $\left(\mathrm{EI}^{+}\right)$calcd for $\mathrm{C}_{21} \mathrm{H}_{14} \mathrm{ClN}, 315.0815$; found 315.0813 .

\section{5-Methyl-10-(5-methylfuran-2-yl)-5,10-dihydroindeno[1,2-b]indole (13m).}

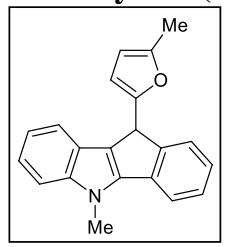

White solid; yield $=55 \%$; m.p. $146-148^{\circ} \mathrm{C}$.

${ }^{1} \mathbf{H}$ NMR $\left(300 \mathrm{MHz}, \mathrm{CDCl}_{3}\right) \delta(\mathrm{ppm})=2.36(\mathrm{~s}, 3 \mathrm{H}), 4.07(\mathrm{~s}, 3 \mathrm{H}), 5.07$ $(\mathrm{s}, 1 \mathrm{H}), 5.86-5.92(\mathrm{~m}, 2 \mathrm{H}), 7.16-7.30(\mathrm{~m}, 3 \mathrm{H}), 7.31-7.43(\mathrm{~m}, 2 \mathrm{H})$, 7.64-7.78 (m, 3H).

${ }^{13} \mathbf{C ~ N M R}\left(75.4 \mathrm{MHz}, \mathrm{CDCl}_{3}\right) \delta(\mathrm{ppm})=13.9\left(\mathrm{CH}_{3}\right), 31.2\left(\mathrm{CH}_{3}\right), 41.8$ $(\mathrm{CH}), 106.06(\mathrm{CH}), 106.14(\mathrm{CH}), 109.9(\mathrm{CH}), 118.0(\mathrm{CH}), 119.6(\mathrm{CH}), 119.9(\mathrm{CH}), 120.9$ $(\mathrm{C}), 121.4(\mathrm{CH}), 124.0(\mathrm{C}), 125.4(\mathrm{CH}), 126.1(\mathrm{CH}), 127.4(\mathrm{CH}), 134.6(\mathrm{C}), 142.0(\mathrm{C})$, 144.2 (C), $149.5(\mathrm{C}), 151.6(\mathrm{C}), 151.9(\mathrm{C})$.

LRMS (70 eV, EI) $\mathrm{m} / z$ (\%) $299\left(\mathbf{M}^{+}, 100\right), 298$ (61).

HRMS $\left(\mathrm{EI}^{+}\right)$calcd for $\mathrm{C}_{21} \mathrm{H}_{17} \mathrm{NO}, 299.1310$; found 299.1310 .

\section{0-(Thiophen-2-yl)-5,10-dihydroindeno[1,2-b]indole (13n).}

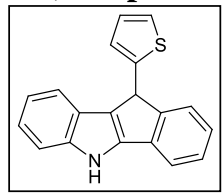

White solid; yield $=80 \%$; m.p. $137-139^{\circ} \mathrm{C}$.

${ }^{1} \mathbf{H}$ NMR $\left(400 \mathrm{MHz}, \mathrm{CDCl}_{3}\right) \delta(\mathrm{ppm})=5.27(\mathrm{~s}, 1 \mathrm{H}), 6.95(\mathrm{dd}, J=4.8$, $3.8 \mathrm{~Hz}, 1 \mathrm{H}), 7.04(\mathrm{dd}, J=3.3,1.0 \mathrm{~Hz}, 1 \mathrm{H}), 7.09-7.15(\mathrm{~m}, 2 \mathrm{H}), 7.17-$ $7.24(\mathrm{~m}, 2 \mathrm{H}), 7.32(\mathrm{t}, J=7.5 \mathrm{~Hz}, 1 \mathrm{H}), 7.42-7.47(\mathrm{~m}, 2 \mathrm{H}), 7.49-7.55$ (m, 2H), 8.35 (s, 1H).

${ }^{13}$ C NMR (100.6 MHz, $\left.\mathrm{CDCl}_{3}\right) \delta(\mathrm{ppm})=43.5(\mathrm{CH}), 112.3(\mathrm{CH}), 117.7(\mathrm{CH}), 119.3$ $(\mathrm{CH}), 120.7(\mathrm{CH}), 122.1(\mathrm{CH}), 123.9(\mathrm{CH}), 124.4(\mathrm{C}), 124.9(\mathrm{CH}), 125.0(\mathrm{C}), 125.6(\mathrm{CH})$, $125.8(\mathrm{CH}), 126.9(\mathrm{CH}), 127.5(\mathrm{CH}), 133.8(\mathrm{C}), 140.8(\mathrm{C}), 142.8(\mathrm{C}), 143.6(\mathrm{C}), 151.6(\mathrm{C})$. LRMS (70 eV, EI) $\mathrm{m} / z(\%) 287\left(\mathbf{M}^{+}, 100\right)$.

HRMS $\left(\mathrm{EI}^{+}\right)$calcd for $\mathrm{C}_{19} \mathrm{H}_{13} \mathrm{NS}, 287.0769$; found 287.0768. 
(E)-5-Methyl-10-styryl-5,10-dihydroindeno[1,2-b]indole (13o).

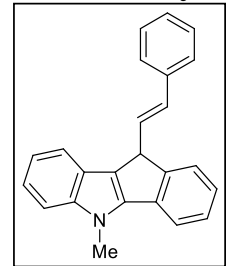

White solid; yield $=79 \%$; m.p. $125-127^{\circ} \mathrm{C}$.

${ }^{1} \mathbf{H}$ NMR $\left(300 \mathrm{MHz}, \mathrm{CDCl}_{3}\right) \delta(\mathrm{ppm})=4.10(\mathrm{~s}, 3 \mathrm{H}), 4.63(\mathrm{~d}, J=8.4$ $\mathrm{Hz}, 1 \mathrm{H}), 6.26(\mathrm{dd}, J=15.6,8.4 \mathrm{~Hz}, 1 \mathrm{H}), 7.00(\mathrm{~d}, J=15.6 \mathrm{~Hz}, 1 \mathrm{H})$, 7.16-7.50 (m, 10H), 7.59 (d, $J=7.4 \mathrm{~Hz}, 1 \mathrm{H}), 7.67-7.75(\mathrm{~m}, 2 \mathrm{H})$.

${ }^{13} \mathbf{C ~ N M R}\left(75.4 \mathrm{MHz}, \mathrm{CDCl}_{3}\right) \delta(\mathrm{ppm})=31.2\left(\mathrm{CH}_{3}\right), 46.4(\mathrm{CH}), 110.0$ $(\mathrm{CH}), 117.8(\mathrm{CH}), 119.1(\mathrm{CH}), 119.9(\mathrm{CH}), 121.5(\mathrm{CH}), 122.9(\mathrm{C})$,

$124.3(\mathrm{C}), 125.3(\mathrm{CH}), 125.8(\mathrm{CH}), 126.4(2 \times \mathrm{CH}), 127.3(2 \times \mathrm{CH}), 128.6(2 \times \mathrm{CH})$, $129.5(\mathrm{CH}), 131.7(\mathrm{CH}), 134.8(\mathrm{C}), 137.5(\mathrm{C}), 142.0(\mathrm{C}), 144.1(\mathrm{C}), 151.3(\mathrm{C})$.

LRMS (70 eV, EI) $\mathrm{m} / z$ (\%) $321\left(\mathbf{M}^{+}, 100\right), 320$ (26).

HRMS $\left(\mathrm{EI}^{+}\right)$calcd for $\mathrm{C}_{24} \mathrm{H}_{19} \mathrm{~N}, 321.1517$; found 321.1520 .

\section{5-Methyl-10-propyl-5,10-dihydroindeno[1,2-b]indole (13p).}

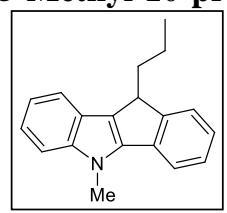

White solid; yield $=69 \%$; m.p. $130-132{ }^{\circ} \mathrm{C}$.

${ }^{1} \mathbf{H}$ NMR $\left(300 \mathrm{MHz}, \mathrm{CDCl}_{3}\right) \delta(\mathrm{ppm})=0.99(\mathrm{t}, J=7.3 \mathrm{~Hz}, 3 \mathrm{H}), 1.48$ $1.58(\mathrm{~m}, 2 \mathrm{H}), 1.17-1.86(\mathrm{~m}, 1 \mathrm{H}), 2.12-2.23(\mathrm{~m}, 1 \mathrm{H}), 3.88-3.99(\mathrm{~m}$, $1 \mathrm{H}), 4.06(\mathrm{~s}, 3 \mathrm{H}), 7.17-7.22(\mathrm{~m}, 1 \mathrm{H}), 7.23-7.29(\mathrm{~m}, 2 \mathrm{H}), 7.35(\mathrm{t}, J=$ $7.4 \mathrm{~Hz}, 1 \mathrm{H}), 7.40(\mathrm{~d}, J=8.2 \mathrm{~Hz}, 1 \mathrm{H}), 7.54(\mathrm{dd}, J=7.4,0.7 \mathrm{~Hz}, 1 \mathrm{H}), 7.65(\mathrm{~d}, J=7.5 \mathrm{~Hz}$, $1 \mathrm{H}), 7.71(\mathrm{dd}, J=7.8,0.6 \mathrm{~Hz}, 1 \mathrm{H})$.

${ }^{13} \mathbf{C ~ N M R}\left(75.4 \mathrm{MHz}, \mathrm{CDCl}_{3}\right) \delta(\mathrm{ppm})=14.6\left(\mathrm{CH}_{3}\right), 20.4\left(\mathrm{CH}_{2}\right), 31.2\left(\mathrm{CH}_{3}\right), 35.7\left(\mathrm{CH}_{2}\right)$, $42.9(\mathrm{CH}), 109.9(\mathrm{CH}), 117.7(\mathrm{CH}), 119.6(\mathrm{CH}), 119.7(\mathrm{CH}), 121.2(\mathrm{CH}), 124.4(\mathrm{C})$, $124.7(\mathrm{CH}), 124.9(\mathrm{CH}), 126.7(\mathrm{CH}), 135.0(\mathrm{C}), 142.0(\mathrm{C}), 144.1(\mathrm{C}), 153.1(2 \times \mathrm{C})$.

LRMS (70 eV, EI) $\mathrm{m} / z$ (\%) $261\left(\mathrm{M}^{+}, 21\right), 218$ (100).

HRMS $\left(\mathrm{EI}^{+}\right)$calcd for $\mathrm{C}_{19} \mathrm{H}_{19} \mathrm{~N}, 261.1517$; found 261.1519 .

\section{4-Cyclopropyl-9-methyl-4-phenyl-4,9-dihydrothieno[3',2':4,5] cyclopenta[1,2-b]indole (14a).}

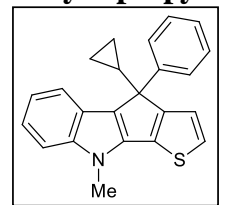

White solid; yield $=80 \%$; m.p. $152-154{ }^{\circ} \mathrm{C}$.

${ }^{1} \mathbf{H}$ NMR $\left(300 \mathrm{MHz}, \mathrm{CDCl}_{3}\right) \delta(\mathrm{ppm})=0.14-0.24(\mathrm{~m}, 1 \mathrm{H}), 0.38-0.62,(\mathrm{~m}$, $3 \mathrm{H}), 1.86-1.96(\mathrm{~m}, 1 \mathrm{H}), 3.95(\mathrm{~s}, 3 \mathrm{H}), 7.09(\mathrm{~d}, J=4.9 \mathrm{~Hz}, 1 \mathrm{H}), 7.11-7.34(\mathrm{~m}$, $6 \mathrm{H}), 7.36(\mathrm{~d}, J=7.8 \mathrm{~Hz}, 1 \mathrm{H}), 7.45(\mathrm{~d}, J=7.6 \mathrm{~Hz}, 1 \mathrm{H}), 7.61(\mathrm{~d}, J=7.9 \mathrm{~Hz}, 2 \mathrm{H})$.

${ }^{13} \mathrm{C}$ NMR $\left(75.4 \mathrm{MHz}, \mathrm{CDCl}_{3}\right) \delta(\mathrm{ppm})=2.4\left(\mathrm{CH}_{2}\right), 3.1\left(\mathrm{CH}_{2}\right), 18.3(\mathrm{CH}), 31.6\left(\mathrm{CH}_{3}\right)$, $56.1(\mathrm{C}), 110.2(\mathrm{CH}), 118.7(\mathrm{CH}), 120.2(\mathrm{CH}), 120.3(\mathrm{CH}), 123.1(\mathrm{CH}), 124.9(\mathrm{CH})$, $126.6(\mathrm{CH}), 127.1(\mathrm{C}), 127.2(2 \times \mathrm{CH}), 128.5(2 \times \mathrm{CH}), 132.1(\mathrm{C}), 140.4(\mathrm{C}), 141.2(\mathrm{C})$, $143.9(\mathrm{C}), 160.0(\mathrm{C})$, one aromatic $\mathrm{C}$ peak was missing due to overlapping.

LRMS (70 eV, EI) $m / z$ (\%) $341\left(\mathbf{M}^{+}, 88\right), 313$ (100).

HRMS $\left(\mathrm{EI}^{+}\right)$calcd for $\mathrm{C}_{23} \mathrm{H}_{19} \mathrm{NS}, 341.1238$; found 341.1238 . 
9-Methyl-4,4-di-p-tolyl-4,9-dihydrothieno[3',2':4,5]cyclopenta[1,2-b]indole (14b).

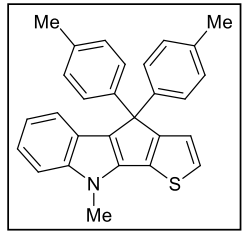

White solid; yield $=75 \%$; m.p. $213-215^{\circ} \mathrm{C}$.

${ }^{1} \mathbf{H}$ NMR $\left(400 \mathrm{MHz}, \mathrm{CDCl}_{3}\right) \delta(\mathrm{ppm})=2.27(\mathrm{~s}, 6 \mathrm{H}), 3.92(\mathrm{~s}, 3 \mathrm{H})$, $7.02(\mathrm{dd}, J=7.9,0.6 \mathrm{~Hz}, 4 \mathrm{H}), 7.06-7.09(\mathrm{~m}, 1 \mathrm{H}), 7.10-7.15(\mathrm{~m}, 1 \mathrm{H})$, 7.16-7.19(m, 1H), 7.20-7.24 (m, 5H), 7.31-7.35 (m, 1H), 7.45-7.47 (m, 1H).

${ }^{13} \mathbf{C ~ N M R}\left(75.4 \mathrm{MHz}, \mathrm{CDCl}_{3}\right) \delta(\mathrm{ppm})=21.1\left(2 \times \mathrm{CH}_{3}\right), 31.6\left(\mathrm{CH}_{3}\right)$, $60.3(\mathrm{C}), 110.2(\mathrm{CH}), 118.6(\mathrm{CH}), 120.4(\mathrm{CH}), 120.5(\mathrm{CH}), 124.0(\mathrm{CH}), 124.6(\mathrm{C}), 125.3$ $(\mathrm{CH}), 128.0(4 \times \mathrm{CH}), 128.6(\mathrm{C}), 129.1(4 \times \mathrm{CH}), 132.2(\mathrm{C}), 136.2(2 \times \mathrm{C}), 140.0(\mathrm{C}), 140.7$ (C), $141.6(2 \times C), 160.5(\mathrm{C})$.

LRMS (70 eV, EI) $m / z(\%) 405\left(\mathrm{M}^{+}, 100\right), 314$ (73).

HRMS $\left(\mathrm{EI}^{+}\right)$calcd for $\mathrm{C}_{28} \mathrm{H}_{23} \mathrm{NS}$, 405.1551; found 405.1551 .

11-Cyclopropyl-5,10-dimethyl-11-phenyl-10,11-dihydro-5 $H$-cyclopenta[1,2-b:3,4- $\left.b^{\prime}\right]$ diindole (15a).

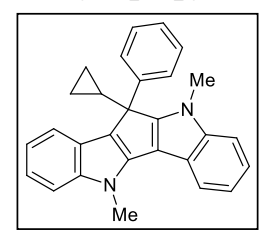
Yellow solid; yield $=90 \%$; m.p. $299-301^{\circ} \mathrm{C}$.

${ }^{1} \mathbf{H}$ NMR $\left(300 \mathrm{MHz}, \mathrm{CDCl}_{3}\right) \delta(\mathrm{ppm})=-0.19-0.11(\mathrm{~m}, 1 \mathrm{H})$, $0.24-0.33(\mathrm{~m}, 1 \mathrm{H}), 0.91-1.00(\mathrm{~m}, 1 \mathrm{H}), 1.05-1.13(\mathrm{~m}, 1 \mathrm{H}), 1.96-2.04$ (m, 1H), 3.70, (s, 3H), $4.20(\mathrm{~s}, 3 \mathrm{H}), 6.96-7.08(\mathrm{~m}, 2 \mathrm{H}), 7.17-7.39(\mathrm{~m}$, 7H), 7.40-7.47 (m, 1H), 7.51-7.62 (m, 2H), 7.85-7.98 (m, 1H).

${ }^{13} \mathrm{C} \mathrm{NMR}\left(\mathrm{CDCl}_{3}, 100.6 \mathrm{MHz}\right) \delta(\mathrm{ppm})=0.3\left(\mathrm{CH}_{2}\right), 5.9\left(\mathrm{CH}_{2}\right), 15.4(\mathrm{CH}), 31.2\left(\mathrm{CH}_{3}\right)$, $32.6\left(\mathrm{CH}_{3}\right), 54.7(\mathrm{C}), 109.6(\mathrm{CH}), 110.5(\mathrm{CH}), 111.1(\mathrm{C}), 116.6(\mathrm{CH}), 118.1(\mathrm{CH}), 118.4$ $(\mathrm{C}), 119.5(\mathrm{CH}), 119.6(\mathrm{C}), 119.9(\mathrm{CH}), 120.5(\mathrm{CH}), 120.7(\mathrm{CH}), 125.6(\mathrm{C}), 126.8(\mathrm{CH})$, $126.9(2 \times \mathrm{CH}), 128.7(2 \times \mathrm{CH}), 139.1(\mathrm{C}), 140.3(\mathrm{C}), 142.8(\mathrm{C}), 143.9(\mathrm{C}), 160.4(\mathrm{C})$.

LRMS (70 eV, EI) $\mathrm{m} / \mathrm{z}(\%) 388\left(\mathrm{M}^{+}, 100\right), 360$ (76).

HRMS $\left(\mathrm{EI}^{+}\right)$calcd for $\mathrm{C}_{28} \mathrm{H}_{26} \mathrm{~N}_{2} \mathrm{O}, 388.1939$; found 388.1938.

11,11-Dicyclopropyl-5,10-dimethyl-10,11-dihydro-5H-cyclopenta[1,2-b:3,4-b']diindole (15b).

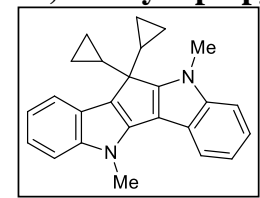

Yellow solid; yield $=93 \%$; m.p. $291-293^{\circ} \mathrm{C}$.

${ }^{1} \mathbf{H}$ NMR $\left(400 \mathrm{MHz}, \mathrm{C}_{6} \mathrm{D}_{6}\right) \delta(\mathrm{ppm})=0.13-0.22(\mathrm{~m}, 2 \mathrm{H}), 0.27-0.32$ $(\mathrm{m}, 2 \mathrm{H}), 0.34-0,41(\mathrm{~m}, 2 \mathrm{H}), 0.87-0.93(\mathrm{~m}, 2 \mathrm{H}), 1.01-1.08(\mathrm{~m}, 2 \mathrm{H})$, $3.38(\mathrm{~s}, 3 \mathrm{H}), 3.41(\mathrm{~s}, 3 \mathrm{H}), 7.05(\mathrm{~d}, J=8.1 \mathrm{~Hz}, 1 \mathrm{H}), 7.08-7.09(\mathrm{~m}, 1 \mathrm{H})$,

$7.13(\mathrm{dd}, J=8.1,1.1 \mathrm{~Hz}, 1 \mathrm{H}), 7.19-7.23(\mathrm{~m}, 1 \mathrm{H}), 7.23-7.29(\mathrm{~m}, 2 \mathrm{H}), 7.69-7.74(\mathrm{~m}, 2 \mathrm{H})$.

${ }^{13} \mathrm{C}$ NMR $\left(100.6 \mathrm{MHz}, \mathrm{C}_{6} \mathrm{D}_{6}\right) \delta(\mathrm{ppm})=0.8\left(2 \times \mathrm{CH}_{2}\right), 4.1\left(2 \times \mathrm{CH}_{2}\right), 14.8(2 \times \mathrm{CH})$, $31.2\left(\mathrm{CH}_{3}\right), 31.9\left(\mathrm{CH}_{3}\right), 52.1(\mathrm{C}), 110.2(\mathrm{CH}), 110.7(\mathrm{CH}), 110.8(\mathrm{C}), 117.0(\mathrm{C}), 118.3$ $(\mathrm{CH}), 118.6(\mathrm{CH}), 119.9(\mathrm{CH}), 120.3(\mathrm{C}), 120.6(\mathrm{CH}), 120.7(\mathrm{CH}), 120.8(\mathrm{CH}), 127.0$ (C), 140.0 (C), $141.0(\mathrm{C}), 144.4(\mathrm{C}), 160.4(\mathrm{C})$.

LRMS (70 eV, EI) $\mathrm{m} / \mathrm{z}$ (\%) $352\left(\mathrm{M}^{+}, 100\right), 323$ (38).

HRMS $\left(\mathrm{EI}^{+}\right)$calcd for $\mathrm{C}_{25} \mathrm{H}_{24} \mathrm{~N}_{2}$, 352.1939; found 352.1937. 
11-Cyclopropyl-5,11-dimethyl-6,11-dihydro-5H-benzo[b]carbazole (16a).

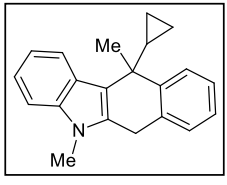

White solid; yield $=80 \%$; m.p. $135-137^{\circ} \mathrm{C}$.

${ }^{1} \mathbf{H}$ NMR $\left(400 \mathrm{MHz}, \mathrm{CDCl}_{3}\right) \delta(\mathrm{ppm})=0.01-0.09(\mathrm{~m}, 1 \mathrm{H}), 0.21-0.36$ $(\mathrm{m}, 3 \mathrm{H}), 1.34-1.42(\mathrm{~m}, 1 \mathrm{H}), 1.99(\mathrm{~s}, 3 \mathrm{H}), 3.72(\mathrm{~s}, 3 \mathrm{H}), 4.06-4.16(\mathrm{~m}$, $2 \mathrm{H}), 7.08-7.13(\mathrm{~m}, 1 \mathrm{H}), 7.18(\mathrm{~d}, J=7.3 \mathrm{~Hz}, 1 \mathrm{H}), 7.22(\mathrm{~d}, J=8.3 \mathrm{~Hz}$,

$1 \mathrm{H}), 7.26-7.36(\mathrm{~m}, 3 \mathrm{H}), 7.67(\mathrm{~d}, J=7.9 \mathrm{~Hz}, 1 \mathrm{H}), 7.89$ (d, $J=7.9 \mathrm{~Hz}, 1 \mathrm{H})$.

${ }^{13} \mathrm{C} \mathrm{NMR}\left(75.4 \mathrm{MHz}, \mathrm{CDCl}_{3}\right) \delta(\mathrm{ppm})=2.9\left(\mathrm{CH}_{2}\right), 3.8\left(\mathrm{CH}_{2}\right), 25.9\left(\mathrm{CH}_{3}\right), 27.3(\mathrm{CH})$, $27.6\left(\mathrm{CH}_{2}\right), 29.3\left(\mathrm{CH}_{3}\right), 40.8(\mathrm{C}), 109.0(\mathrm{CH}), 112.8(\mathrm{C}), 118.7(\mathrm{CH}), 120.6(\mathrm{CH}), 121.1$ $(\mathrm{CH}), 125.8(\mathrm{CH}), 126.5(\mathrm{CH}), 127.5(\mathrm{CH}), 129.0(\mathrm{CH}), 131.6(\mathrm{C}), 133.2(\mathrm{C}), 137.7(\mathrm{C})$, $144.7(\mathrm{C})$, one aromatic carbon peak was missing due to overlapping.

LRMS (70 eV, EI) $m / z$ (\%) $287\left(\mathbf{M}^{+}, 28\right), 246$ (100).

HRMS $\left(\mathrm{EI}^{+}\right)$calcd for $\mathrm{C}_{21} \mathrm{H}_{21} \mathrm{~N}, 287.1674$; found 287.1671 .

\section{1-Cyclopropyl-5-methyl-11-phenyl-6,11-dihydro-5 $H$-benzo[b]carbazole $(16 \mathrm{~b})$.}

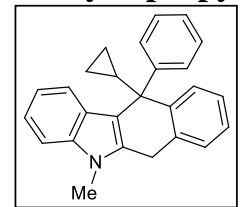

White solid; yield $=90 \%$; m.p. $239-241^{\circ} \mathrm{C}$.

${ }^{1} \mathbf{H}$ NMR $\left(300 \mathrm{MHz}, \mathrm{CDCl}_{3}\right) \delta(\mathrm{ppm})=-0.6-0.11(\mathrm{~m}, 2 \mathrm{H}), 0.34-0.50$ $(\mathrm{m}, 2 \mathrm{H}), 1.82(\mathrm{tt}, J=8.2,5.6 \mathrm{~Hz}, 1 \mathrm{H}), 3.79(\mathrm{~s}, 3 \mathrm{H}), 4.24(\mathrm{~s}, 2 \mathrm{H}), 6.62$ $(\mathrm{d}, J=8.0 \mathrm{~Hz}, 1 \mathrm{H}), 6.80(\mathrm{ddd}, J=8.0,7.0,1.0 \mathrm{~Hz}, 1 \mathrm{H}), 6.94(\mathrm{dd}, J=$ $7.8,1.4 \mathrm{~Hz}, 1 \mathrm{H}), 7.09$ (ddd, $J=8.2,5.3,1.2 \mathrm{~Hz}, 1 \mathrm{H}), 7.14(\mathrm{dd}, J=7.5,1.2 \mathrm{~Hz}, 1 \mathrm{H})$, $7.18-7.38(\mathrm{~m}, 6 \mathrm{H}), 7.63(\mathrm{~d}, J=6.9 \mathrm{~Hz}, 2 \mathrm{H})$.

${ }^{13} \mathbf{C ~ N M R}\left(75.4 \mathrm{MHz}, \mathrm{CDCl}_{3}\right) \delta(\mathrm{ppm})=2.3\left(\mathrm{CH}_{2}\right), 2.9\left(\mathrm{CH}_{2}\right), 23.4(\mathrm{CH}), 27.8\left(\mathrm{CH}_{2}\right)$, $29.5\left(\mathrm{CH}_{3}\right), 50.0(\mathrm{C}), 108.7(\mathrm{CH}), 112.5(\mathrm{C}), 118.8(\mathrm{CH}), 120.1(\mathrm{CH}), 120.6(\mathrm{CH}), 125.7$ $(\mathrm{CH}), 126.0(\mathrm{CH}), 126.2(\mathrm{CH}), 126.6(\mathrm{C}), 127.9(2 \times \mathrm{CH}), 128.6(\mathrm{CH}), 129.6(2 \times \mathrm{CH})$, $130.4(\mathrm{CH}), 132.5(\mathrm{C}), 134.2(\mathrm{C}), 137.5(\mathrm{C}), 144.2(\mathrm{C}), 149.6(\mathrm{C})$.

LRMS (70 eV, EI) $m / z$ (\%) $349\left(\mathbf{M}^{+}, 30\right), 260$ (100).

HRMS $\left(\mathrm{EI}^{+}\right)$calcd for $\mathrm{C}_{26} \mathrm{H}_{23} \mathrm{~N}, 349.1830$; found 349.183 .

5,11-Dimethyl-11-(thiophen-2-yl)-6,11-dihydro-5H-benzo[b]carbazole (16c).

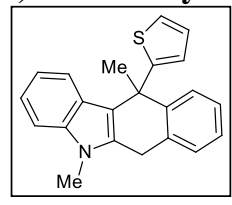

White solid; yield $=80 \%$; m.p. $179-181^{\circ} \mathrm{C}$.

${ }^{1} \mathbf{H}$ NMR $\left(300 \mathrm{MHz}, \mathrm{CDCl}_{3}\right) \delta(\mathrm{ppm})=2.17(\mathrm{~s}, 3 \mathrm{H}), 3.77(\mathrm{~s}, 3 \mathrm{H}), 4.22$ $(\mathrm{d}, J=20.6 \mathrm{~Hz}, 1 \mathrm{H}), 4.31(\mathrm{~d}, J=20.6 \mathrm{~Hz}, 1 \mathrm{H}), 6.96-7.04(\mathrm{~m}, 2 \mathrm{H})$, $7.15-7.29(\mathrm{~m}, 6 \mathrm{H}), 7.31-7.44(\mathrm{~m}, 3 \mathrm{H})$.

${ }^{13} \mathrm{C} \mathrm{NMR}\left(75.4 \mathrm{MHz}, \mathrm{CDCl}_{3}\right) \delta(\mathrm{ppm})=27.2\left(\mathrm{CH}_{2}\right), 29.4\left(\mathrm{CH}_{3}\right), 31.9\left(\mathrm{CH}_{3}\right), 42.9(\mathrm{C})$, $108.8(\mathrm{CH}), 115.4(\mathrm{C}), 119.0(\mathrm{CH}), 119.5(\mathrm{CH}), 121.0(\mathrm{CH}), 124.1(\mathrm{CH}), 124.9(\mathrm{CH})$, $125.5(\mathrm{C}), 125.9(\mathrm{CH}), 126.1(\mathrm{CH}), 127.0(\mathrm{CH}), 128.8(\mathrm{CH}), 129.2(\mathrm{CH}), 130.3(\mathrm{C}), 131.7$ (C), 137.8 (C), 144.7 (C), $156.3(\mathrm{C})$.

LRMS (70 eV, EI) $m / z$ (\%) $329\left(\mathbf{M}^{+}, 30\right), 314$ (100).

HRMS $\left(\mathrm{EI}^{+}\right)$calcd for $\mathrm{C}_{22} \mathrm{H}_{19} \mathrm{NS} 329.1238$; found 329.1241 . 


\section{5-Methyl-11,11-di-p-tolyl-6,11-dihydro-5H-benzo[b]carbazole (16d).}

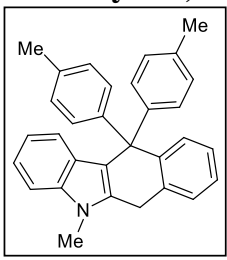

White solid; yield $=95 \%$; m.p. $267-269^{\circ} \mathrm{C}$.

${ }^{1} \mathbf{H}$ NMR (400 MHz, acetone- $\left.\mathrm{d}_{6}\right) \delta(\mathrm{ppm})=2.26(\mathrm{~s}, 6 \mathrm{H}), 4.01(\mathrm{~s}, 2 \mathrm{H})$, $6.50(\mathrm{~d}, J=8.1 \mathrm{~Hz}, 1 \mathrm{H}), 6.73(\mathrm{ddd}, J=8.1,7.2,1.0 \mathrm{~Hz}, 1 \mathrm{H}), 6.94-7.02$ (m, 10H), 7.12-7.17 (m, 1H), $7.20(\mathrm{dd}, J=7.4,1.5 \mathrm{~Hz}, 1 \mathrm{H}), 7.33-7.40$ $(\mathrm{m}, 2 \mathrm{H}), 10.21(\mathrm{bs}, 1 \mathrm{H})$.

${ }^{13}$ C NMR (100.6 MHz, acetone-d 6$) \delta(\mathrm{ppm})=20.8\left(2 \times \mathrm{CH}_{3}\right), 55.8(\mathrm{C}), 111.6(\mathrm{CH})$, $117.7(\mathrm{C}), 119.4(\mathrm{CH}), 120.5(\mathrm{CH}), 121.0(\mathrm{CH}), 126.3(\mathrm{CH}), 126.5(\mathrm{CH}), 127.9(\mathrm{C}), 128.9$ $(4 \times \mathrm{CH}), 129.2(\mathrm{CH}), 130.3(4 \times \mathrm{CH}), 131.1(\mathrm{CH}), 134.9(\mathrm{C}), 135.7(\mathrm{C}), 135.9(2 \times \mathrm{C})$, $137.6(\mathrm{C}), 145.2(2 \times \mathrm{C}), 146.1(\mathrm{C})$, the peak corresponding to the aliphatic $\mathrm{CH}_{2}$ was overlapped by the peak of the deuterated solvent.

LRMS (70 eV, EI) $\mathrm{m} / \mathrm{z}$ (\%) $399\left(\mathrm{M}^{+}, 33\right), 308$ (100).

HRMS $\left(\mathrm{EI}^{+}\right)$calcd for $\mathrm{C}_{30} \mathrm{H}_{25} \mathrm{~N}, 399.1987$; found 399.1989 .

\section{1-(4-Methoxyphenyl)-5-methyl-6,11-dihydro-5H-benzo[b]carbazole (16e).}

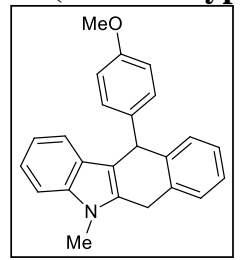

White solid; yield $=84 \%$; m.p. $239-241^{\circ} \mathrm{C}$.

${ }^{1} \mathbf{H}$ NMR $\left(300 \mathrm{MHz}, \mathrm{CDCl}_{3}\right) \delta(\mathrm{ppm})=3.76(\mathrm{~s}, 3 \mathrm{H}), 3.77(\mathrm{~s}, 3 \mathrm{H}), 4.16$ $(\mathrm{dd}, J=20.5,4.0 \mathrm{~Hz}, 1 \mathrm{H}), 4.34(\mathrm{dd}, J=20.5,4.0 \mathrm{~Hz}, 1 \mathrm{H}), 5.42(\mathrm{t}, J=$ $4.0 \mathrm{~Hz}, 1 \mathrm{H}), 6.81(\mathrm{~d}, J=8.5 \mathrm{~Hz}, 2 \mathrm{H}), 7.02(\mathrm{t}, J=7.4 \mathrm{~Hz}, 1 \mathrm{H})$, 7.15-7.29 (m, 7H), $7.33(\mathrm{~d}, J=8.2 \mathrm{~Hz}, 1 \mathrm{H}), 7.36-7.43(\mathrm{~m}, 1 \mathrm{H})$.

${ }^{13}$ C NMR (75.4 MHz, $\left.\mathrm{CDCl}_{3}\right) \delta(\mathrm{ppm})=27.2\left(\mathrm{CH}_{2}\right), 29.4\left(\mathrm{CH}_{3}\right), 44.1(\mathrm{CH}), 55.2\left(\mathrm{CH}_{3}\right)$, 108.6 $(\mathrm{CH}), 111.0(\mathrm{C}), 113.9(2 \times \mathrm{CH}), 118.9(\mathrm{CH}), 119.1(\mathrm{CH}), 121.0(\mathrm{CH}), 126.0(\mathrm{CH})$, $126.3(\mathrm{C}), 126.7(\mathrm{CH}), 129.3(\mathrm{CH}), 129.6(2 \times \mathrm{CH}), 130.5(\mathrm{CH}), 131.7(\mathrm{C}), 132.8(\mathrm{C})$, 137.7 (C), $139.2(\mathrm{C}), 139.7$ (C), $157.9(\mathrm{C})$.

LRMS (70 eV, EI) $\mathrm{m} / \mathrm{z}$ (\%) $339\left(\mathrm{M}^{+}, 25\right), 337$ (100).

HRMS $\left(\mathrm{EI}^{+}\right)$calcd for $\mathrm{C}_{24} \mathrm{H}_{21} \mathrm{NO} 339.1623$; found 339.1622 .

\section{1-(4-Methoxyphenyl)-6,11-dihydro-5H-benzo[b]carbazole (16f).}

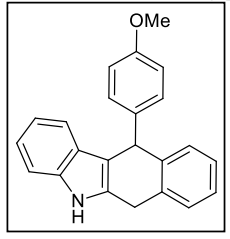

White solid; yield $=98 \%$; m.p. $180-182^{\circ} \mathrm{C}$.

${ }^{1} \mathbf{H}$ NMR $\left(400 \mathrm{MHz}, \mathrm{CDCl}_{3}\right) \delta(\mathrm{ppm})=3.73(\mathrm{~s}, 3 \mathrm{H}), 4.14(\mathrm{dd}, J=20.4$, $4.0 \mathrm{~Hz}, 1 \mathrm{H}), 4.32(\mathrm{dd}, J=20.4,3.8 \mathrm{~Hz}, 1 \mathrm{H}), 5.39$ (at, $J=3.8 \mathrm{~Hz}, 1 \mathrm{H})$, 6.73-6.82 (m, 2H), 6.94-6.99 (m, 1H), 7.08-7.13 (m, 1H), 7.15-7.32 $(\mathrm{m}, 8 \mathrm{H}), 7.85(\mathrm{bs}, 1 \mathrm{H})$.

${ }^{13}$ C NMR (75.4 MHz, $\left.\mathrm{CDCl}_{3}\right) \delta(\mathrm{ppm})=28.1\left(\mathrm{CH}_{2}\right), 44.0(\mathrm{CH}), 55.3\left(\mathrm{CH}_{3}\right), 110.6(\mathrm{CH})$, $112.3(\mathrm{C}), 114.0(2 \times \mathrm{CH}), 119.1(\mathrm{CH}), 119.5(\mathrm{CH}), 121.6(\mathrm{CH}), 126.1(\mathrm{CH}), 126.7(\mathrm{CH})$, $126.9(\mathrm{C}), 129.1(\mathrm{CH}), 129.6(2 \times \mathrm{CH}), 130.6(\mathrm{CH}), 131.3(\mathrm{C}), 131.9(\mathrm{C}), 136.6(\mathrm{C})$, 138.9 (C), $139.6(\mathrm{C}), 158.0(\mathrm{C})$.

LRMS (70 eV, EI) $\mathrm{m} / z$ (\%) $325\left(\mathbf{M}^{+}, 94\right), 218$ (100).

HRMS $\left(\mathrm{EI}^{+}\right.$) calcd for $\mathrm{C}_{23} \mathrm{H}_{19} \mathrm{NO} 325.1467$; found 325.1468 . 
(E)-5-Methyl-11-styryl-6,11-dihydro-5H-benzo[b]carbazole (16g).

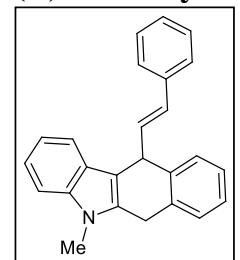

Yellow solid; yield $=85 \%$; m.p. $159-161{ }^{\circ} \mathrm{C}$.

${ }^{1} \mathbf{H}$ NMR $\left(400 \mathrm{MHz}, \mathrm{CDCl}_{3}\right) \delta(\mathrm{ppm})=3.77(\mathrm{~s}, 3 \mathrm{H}), 4.13(\mathrm{dd}, J=20.4$, $3.8 \mathrm{~Hz}, 1 \mathrm{H}), 4.22(\mathrm{dd}, J=20.3,3.7 \mathrm{~Hz}, 1 \mathrm{H}), 5.04-5.10(\mathrm{~m}, 1 \mathrm{H}), 6.24$ $(\mathrm{dd}, J=15.6,9.0 \mathrm{~Hz}, 1 \mathrm{H}), 6.79(\mathrm{~d}, J=15.6 \mathrm{~Hz}, 1 \mathrm{H}), 7.08(\mathrm{t}, J=7.5$ $\mathrm{Hz}, 1 \mathrm{H}), 7.16-7.24(\mathrm{~m}, 2 \mathrm{H}), 7.24-7.31(\mathrm{~m}, 4 \mathrm{H}), 7.32-7.41(\mathrm{~m}, 4 \mathrm{H})$, $7.50-7.57(\mathrm{~m}, 1 \mathrm{H}), 7.69(\mathrm{~d}, J=7.9 \mathrm{~Hz}, 1 \mathrm{H})$.

${ }^{13} \mathrm{C} \mathrm{NMR}\left(100.6 \mathrm{MHz}, \mathrm{CDCl}_{3}\right) \delta(\mathrm{ppm})=27.2\left(\mathrm{CH}_{2}\right), 29.5\left(\mathrm{CH}_{3}\right), 42.9(\mathrm{CH}), 108.4(\mathrm{C})$, $108.8(\mathrm{CH}), 119.17(\mathrm{CH}), 119.19(\mathrm{CH}), 121.2(\mathrm{CH}), 126.5(3 \times \mathrm{CH}), 126.7(\mathrm{CH}), 126.8$ (C), $127.2(\mathrm{CH}), 128.6(2 \times \mathrm{CH}), 129.3(\mathrm{CH}), 129.5(\mathrm{CH}), 130.4(\mathrm{CH}), 132.1(\mathrm{C}), 132.9$ (C), $134.4(\mathrm{CH}), 137.3(\mathrm{C}), 137.6(\mathrm{C}), 137.7(\mathrm{C})$.

LRMS (70 eV, EI) $\mathrm{m} / z$ (\%) $335\left(\mathbf{M}^{+}, 63\right), 333$ (100).

HRMS $\left(\mathrm{EI}^{+}\right)$calcd for $\mathrm{C}_{25} \mathrm{H}_{21} \mathrm{~N}, 335.1674$; found 335.1674 .

5-Methyl-11-(thiophen-2-yl)-6,11-dihydro-5H-benzo[b]carbazole (16h).

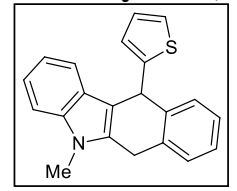

Yellow solid; yield $=75 \%$; m.p. $163-165^{\circ} \mathrm{C}$.

${ }^{1} \mathbf{H}$ NMR $\left(300 \mathrm{MHz}, \mathrm{CDCl}_{3}\right) \delta(\mathrm{ppm})=3.76(\mathrm{~s}, 3 \mathrm{H}), 4.15(\mathrm{dd}, J=20.3$, $3.7 \mathrm{~Hz}, 1 \mathrm{H}), 4.28(\mathrm{dd}, J=20.3,3.7 \mathrm{~Hz}, 1 \mathrm{H}), 5.61(\mathrm{t}, J=3.7 \mathrm{~Hz}, 1 \mathrm{H})$, $6.73(\mathrm{dd}, J=4.9,1.1 \mathrm{~Hz}, 1 \mathrm{H}), 7.03(\mathrm{t}, J=7.5 \mathrm{~Hz}, 2 \mathrm{H}), 7.11(\mathrm{dd}, J=$ 4.9, $2.9 \mathrm{~Hz}, 1 \mathrm{H}), 7.16-7.44(\mathrm{~m}, 8 \mathrm{H})$.

${ }^{13} \mathrm{C} \mathrm{NMR}\left(75.4 \mathrm{MHz}, \mathrm{CDCl}_{3}\right) \delta(\mathrm{ppm})=27.3\left(\mathrm{CH}_{2}\right), 29.5\left(\mathrm{CH}_{3}\right), 40.0(\mathrm{CH}), 108.8(\mathrm{CH})$, $110.3(\mathrm{C}), 118.8(\mathrm{CH}), 119.1(\mathrm{CH}), 120.8(\mathrm{CH}), 121.1(\mathrm{CH}), 125.8(\mathrm{CH}), 126.2(\mathrm{CH})$, $126.4(\mathrm{C}), 126.7(\mathrm{CH}), 127.9(\mathrm{CH}), 129.4(\mathrm{CH}), 130.2(\mathrm{CH}), 132.0(\mathrm{C}), 132.9(\mathrm{C}), 137.7$ (C), $138.6(\mathrm{C}), 147.2(\mathrm{C})$.

LRMS (70 eV, EI) $m / z$ (\%) $315\left(\mathbf{M}^{+}, 100\right), 232$ (97).

HRMS $\left(\mathrm{EI}^{+}\right)$calcd for $\mathrm{C}_{21} \mathrm{H}_{17} \mathrm{NS}, 315.1082$; found 315.1083 .

\section{1-(4-Methoxyphenyl)-6,11-dihydroindolo[1,2-b]isoquinoline (17a).}

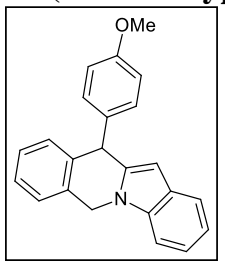

Yellow solid; yield $=52 \%$; m.p. $138-140{ }^{\circ} \mathrm{C}$.

${ }^{1} \mathbf{H}$ NMR $\left(300 \mathrm{MHz}, \mathrm{CDCl}_{3}\right) \delta(\mathrm{ppm})=3.80(\mathrm{~s}, 3 \mathrm{H}), 5.31(\mathrm{~s}, 2 \mathrm{H}), 5.46$ $(\mathrm{s}, 1 \mathrm{H}), 6.28(\mathrm{~d}, J=0.8 \mathrm{~Hz}, 1 \mathrm{H}), 6.86(\mathrm{~d}, J=8.3 \mathrm{~Hz}, 2 \mathrm{H}), 7.10-7.21$ (m, 3H), 7.22-7.36 (m, 4H), 7.37-7.44 (m, 1H), $7.47(\mathrm{~d}, J=8.1 \mathrm{~Hz}$, $1 \mathrm{H}), 7.61(\mathrm{dd}, J=7.8,0.6 \mathrm{~Hz}, 1 \mathrm{H})$.

${ }^{13} \mathrm{C} \mathrm{NMR}\left(75.4 \mathrm{MHz}, \mathrm{CDCl}_{3}\right) \delta(\mathrm{ppm})=44.5\left(\mathrm{CH}_{2}\right), 44.9(\mathrm{CH}), 55.4\left(\mathrm{CH}_{3}\right), 98.4(\mathrm{CH})$, $108.9(\mathrm{CH}), 114.1(2 \times \mathrm{CH}), 119.9(\mathrm{CH}), 120.4(\mathrm{CH}), 120.8(\mathrm{CH}), 126.5(\mathrm{CH}), 126.8$ $(\mathrm{CH}), 127.7(\mathrm{CH}), 128.8(\mathrm{C}), 129.0(\mathrm{CH}), 129.7(2 \times \mathrm{CH}), 131.8(\mathrm{C}), 135.2(\mathrm{C}), 135.7$ (C), $136.9(\mathrm{C}), 139.3(\mathrm{C}), 158.5(\mathrm{C})$.

LRMS (70 eV, EI) $m / z$ (\%) $325\left(\mathrm{M}^{+}, 100\right), 217$ (30).

HRMS $\left(\mathrm{EI}^{+}\right)$calcd for $\mathrm{C}_{23} \mathrm{H}_{19} \mathrm{NO}, 325.1467$; found 325.1466 . 
11-(4-Methoxyphenyl)-11-methyl-6,11-dihydroindolo[1,2-b]isoquinoline (17b).

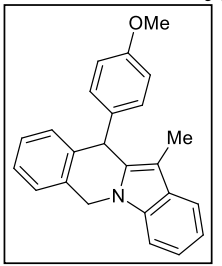

Yellow oil; yield $=65 \% ; R_{f}=0.20($ hexane/EtOAc, $5: 1)$.

${ }^{1} \mathbf{H}$ NMR $\left(300 \mathrm{MHz}, \mathrm{CDCl}_{3}\right) \delta(\mathrm{ppm})=2.11(\mathrm{~s}, 3 \mathrm{H}), 3.76(\mathrm{~s}, 3 \mathrm{H}), 4.83$ $(\mathrm{d}, J=15.2 \mathrm{~Hz}, 1 \mathrm{H}), 5.25(\mathrm{~d}, J=15.2 \mathrm{~Hz}, 1 \mathrm{H}), 6.47(\mathrm{~s}, 1 \mathrm{H}), 6.72-6.76$ $(\mathrm{m}, 2 \mathrm{H}), 6.97-7.00(\mathrm{~m}, 2 \mathrm{H}), 7.14-7.19(\mathrm{~m}, 1 \mathrm{H}), 7.23-7.45(\mathrm{~m}, 5 \mathrm{H})$, $7.55(\mathrm{~d}, J=7.7 \mathrm{~Hz}, 1 \mathrm{H}), 7.67(\mathrm{~d}, J=7.7 \mathrm{~Hz}, 1 \mathrm{H})$.

${ }^{13} \mathbf{C ~ N M R}\left(75.4 \mathrm{MHz}, \mathrm{CDCl}_{3}\right) \delta(\mathrm{ppm})=28.1\left(\mathrm{CH}_{3}\right), 44.97\left(\mathrm{CH}_{2}\right), 45.03$ (C), $55.3\left(\mathrm{CH}_{3}\right), 97.6(\mathrm{CH}), 108.7(\mathrm{CH}), 113.4(2 \times \mathrm{CH}), 119.7(\mathrm{CH}), 120.6(\mathrm{CH}), 120.9$ $(\mathrm{CH}), 126.2(\mathrm{CH}), 126.6(2 \times \mathrm{CH}), 127.7(\mathrm{CH}), 128.5(2 \times \mathrm{CH}), 133.3(\mathrm{C}), 135.8(\mathrm{C})$, $138.6(\mathrm{C}), 142.4(\mathrm{C}), 144.2(\mathrm{C}), 158.0(\mathrm{C})$.

LRMS (70 eV, EI) $m / z$ (\%) $339\left(\mathbf{M}^{+}, 100\right), 324$ (28).

HRMS $\left(\mathrm{EI}^{+}\right)$calcd for $\mathrm{C}_{24} \mathrm{H}_{21} \mathrm{NO}, 339.1623$; found 339.1623 .

11-Isopropyl-12-methyl-6,11-dihydroindolo[1,2-b]isoquinoline (17c).

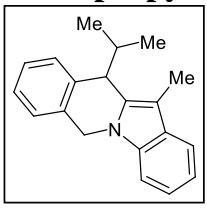

Yellow solid; yield $=60 \%$; m.p. $120-122^{\circ} \mathrm{C}$.

${ }^{1} \mathbf{H}$ NMR $\left(400 \mathrm{MHz}, \mathrm{CDCl}_{3}\right) \delta(\mathrm{ppm})=0.89-1.00(\mathrm{~m}, 6 \mathrm{H}), 2.07-2.17(\mathrm{~m}$, $1 \mathrm{H}), 2.41(\mathrm{~s}, 3 \mathrm{H}), 4.07(\mathrm{dd}, J=6.2,3.5 \mathrm{~Hz}, 1 \mathrm{H}), 5.18(\mathrm{dd}, J=15.5,2.3 \mathrm{~Hz}$, $1 \mathrm{H}), 5.31(\mathrm{dd}, J=15.5,2.5 \mathrm{~Hz}, 1 \mathrm{H}), 7.12-7.46(\mathrm{~m}, 7 \mathrm{H}), 7.59-7.65(\mathrm{~m}, 1 \mathrm{H})$.

${ }^{13} \mathbf{C ~ N M R}\left(75.4 \mathrm{MHz}, \mathrm{CDCl}_{3}\right) \delta(\mathrm{ppm})=9.4\left(\mathrm{CH}_{3}\right), 20.4\left(\mathrm{CH}_{3}\right), 20.8\left(\mathrm{CH}_{3}\right), 37.0\left(\mathrm{CH}_{2}\right)$, $45.5(\mathrm{CH}), 45.7(\mathrm{CH}), 105.3(\mathrm{C}), 108.4(\mathrm{CH}), 118.5(\mathrm{CH}), 118.9(\mathrm{CH}), 120.6(\mathrm{CH}), 126.4(\mathrm{CH})$, $126.5(\mathrm{CH}), 126.9(\mathrm{CH}), 129.3(\mathrm{C}), 129.8(\mathrm{CH}), 133.3(\mathrm{C}), 134.7(\mathrm{C}), 135.4(\mathrm{C}), 136.9(\mathrm{C})$.

LRMS (70 eV, EI) $\mathrm{m} / z$ (\%) $275\left(\mathrm{M}^{+}, 14\right), 232$ (100).

HRMS $\left(\mathrm{EI}^{+}\right)$calcd for $\mathrm{C}_{20} \mathrm{H}_{21} \mathrm{~N}, 275.1674$; found, 275.1675 .

11-(4-Methoxyphenyl)-11,12-dimethyl-6,11-dihydroindolo[1,2-b]isoquinoline (17d).

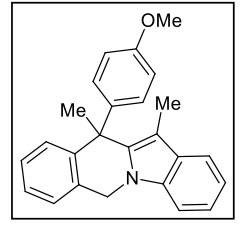

Yellow solid; yield $=56 \%$; m.p. $124-126^{\circ} \mathrm{C}$.

${ }^{1} \mathbf{H}$ NMR $\left(400 \mathrm{MHz}, \mathrm{CDCl}_{3},\right) \delta(\mathrm{ppm})=1.79(\mathrm{~s}, 3 \mathrm{H}), 1.95(\mathrm{~s}, 3 \mathrm{H})$, $3.80(\mathrm{~s}, 3 \mathrm{H}), 5.26(\mathrm{~d}, J=15.7 \mathrm{~Hz}, 1 \mathrm{H}), 5.39(\mathrm{~d}, J=15.7 \mathrm{~Hz}, 1 \mathrm{H}), 6.79$ $6.84(\mathrm{~m}, 2 \mathrm{H}), 7.01(\mathrm{dd}, J=7.7,1.5 \mathrm{~Hz}, 1 \mathrm{H}), 7.12-7.16(\mathrm{~m}, 1 \mathrm{H}), 7.18$ (dd, $J=7.3,1.5 \mathrm{~Hz}, 1 \mathrm{H}), 7.20-7.27(\mathrm{~m}, 4 \mathrm{H}), 7.32-7.35(\mathrm{~m}, 1 \mathrm{H}), 7.44$ (d, $J=8.1 \mathrm{~Hz}, 1 \mathrm{H}), 7.50-7.54(\mathrm{~m}, 1 \mathrm{H})$.

${ }^{13} \mathbf{C ~ N M R}\left(75.4 \mathrm{MHz}, \mathrm{CDCl}_{3}\right) \delta(\mathrm{ppm})=9.2\left(\mathrm{CH}_{3}\right), 29.3\left(\mathrm{CH}_{3}\right), 44.5\left(\mathrm{CH}_{2}\right), 55.2\left(\mathrm{CH}_{3}\right)$, $105.6(\mathrm{C}), 108.7(\mathrm{CH}), 113.4(2 \times \mathrm{CH}), 118.2(\mathrm{CH}), 119.3(\mathrm{CH}), 120.9(\mathrm{CH}), 126.1(\mathrm{CH})$, $126.2(\mathrm{CH}), 127.6(\mathrm{CH}), 128.3(\mathrm{CH}), 129.4(2 \times \mathrm{CH}), 129.7(\mathrm{C}), 129.9(\mathrm{C}), 134.6(\mathrm{C})$, 138.7 (C), 139.7 (C), 143.3 (C), 157.9 (C).

LRMS (70 eV, EI) $\mathrm{m} / z$ (\%) $353\left(\mathrm{M}^{+}, 55\right), 338$ (100).

HRMS $\left(\mathrm{EI}^{+}\right)$calcd for $\mathrm{C}_{25} \mathrm{H}_{23} \mathrm{NO}, 353.1780$; found 353.1782 . 


\section{1-Cyclopropyl-11-phenyl-6,11-dihydroindolo[1,2-b]isoquinoline (17e).}

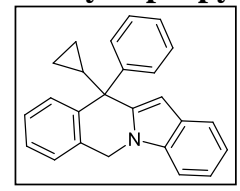

Yellow solid; yield $=30 \%$; m.p. $163-165^{\circ} \mathrm{C}$.

${ }^{1} \mathbf{H}$ NMR $\left(300 \mathrm{MHz}, \mathrm{CDCl}_{3}\right) \delta(\mathrm{ppm})=0.08-0.16(\mathrm{~m}, 1 \mathrm{H}), 0.28-0.36$ (m, 1H), 0.67-0.77 (m, 2H), 1.70-1.79 (m, 1H), $4.86(\mathrm{~d}, J=15.2 \mathrm{~Hz}$, $1 \mathrm{H}), 5.26(\mathrm{~d}, J=15.2 \mathrm{~Hz}, 1 \mathrm{H}), 6.49(\mathrm{~s}, 1 \mathrm{H}), 7.14-7.42(\mathrm{~m}, 10 \mathrm{H}), 7.47$ (d, $J=8.1 \mathrm{~Hz}, 1 \mathrm{H}), 7.61-7.74(\mathrm{~m}, 2 \mathrm{H})$.

${ }^{13}$ C NMR (75.4 MHz, $\left.\mathrm{CDCl}_{3}\right) \delta(\mathrm{ppm})=1.0\left(\mathrm{CH}_{2}\right), 1.9\left(\mathrm{CH}_{2}\right), 20.3(\mathrm{CH}), 45.1(\mathrm{C}), 50.1$ $\left(\mathrm{CH}_{2}\right), 99.9(\mathrm{CH}), 108.8(\mathrm{CH}), 119.7(\mathrm{CH}), 120.6(\mathrm{CH}), 120.9(\mathrm{CH}), 126.4(\mathrm{CH}), 126.6$ $(\mathrm{CH}), 126.7(\mathrm{CH}), 127.4(\mathrm{CH}), 127.5(2 \times \mathrm{CH}), 128.2(\mathrm{CH}), 128.3(\mathrm{C}), 130.0(2 \times \mathrm{CH}), 133.3(\mathrm{C})$, $135.6(\mathrm{C}), 142.2(\mathrm{C}), 142.6(\mathrm{C})$, one aromatic carbon peak was missing due to overlapping.

LRMS (70 eV, EI) $m / z$ (\%) $335\left(\mathbf{M}^{+}, 84\right), 294$ (100).

HRMS $\left(\mathrm{EI}^{+}\right)$calcd for $\mathrm{C}_{25} \mathrm{H}_{21} \mathrm{~N}, 335.1674$; found 335.1677 .

\section{1,11-Dimethyl-6,11-dihydroindolo[1,2-b]isoquinoline (17f).}

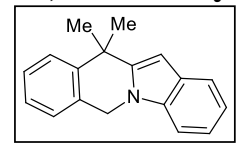

Yellow oil; yield $=46 \% ; R_{f}=0.23$ (hexane/EtOAc, $4: 1$ ).

${ }^{1}$ H NMR $\left(400 \mathrm{MHz}, \mathrm{CDCl}_{3}\right) \delta(\mathrm{ppm})=1.73(\mathrm{~s}, 6 \mathrm{H}), 5.30(\mathrm{~s}, 2 \mathrm{H}), 6.47$

(s, 1H), 7.12-7.20 (m, 1H), 7.21-7.26 (m, 1H), 7.26-7.32 (m, 1H), $7.35(\mathrm{~d}, J=6.8 \mathrm{~Hz}, 1 \mathrm{H}), 7.38(\mathrm{~d}, J=7.1 \mathrm{~Hz}, 1 \mathrm{H}), 7.43(\mathrm{~d}, J=8.1 \mathrm{~Hz}, 1 \mathrm{H}), 7.58(\mathrm{~d}, J=$ $7.8 \mathrm{~Hz}, 1 \mathrm{H}), 7.64(\mathrm{dd}, J=7.8,0.7 \mathrm{~Hz}, 1 \mathrm{H})$.

${ }^{13} \mathbf{C ~ N M R}\left(100.6 \mathrm{MHz}, \mathrm{CDCl}_{3}\right) \delta(\mathrm{ppm})=30.3\left(2 \times \mathrm{CH}_{3}\right), 36.5(\mathrm{C}), 44.8\left(\mathrm{CH}_{2}\right), 95.1$ $(\mathrm{CH}), 108.7(\mathrm{CH}), 119.8(\mathrm{CH}), 120.4(\mathrm{CH}), 120.7(\mathrm{CH}), 124.7(\mathrm{CH}), 126.4(\mathrm{CH}), 126.6$ $(\mathrm{CH}), 128.0(\mathrm{CH}), 128.7(\mathrm{C}), 131.2(\mathrm{C}), 135.8(\mathrm{C}), 142.5(\mathrm{C}), 145.3(\mathrm{C})$.

LRMS (70 eV, EI) $\mathrm{m} / \mathrm{z}$ (\%) $247\left(\mathrm{M}^{+}, 19\right), 232$ (100).

HRMS $\left(\mathrm{EI}^{+}\right)$calcd for $\mathrm{C}_{18} \mathrm{H}_{17} \mathrm{~N}, 247.1361$; found 247.1360 .

12-Methyl-11,11-di-p-tolyl-6,11-dihydroindolo[1,2-b]isoquinoline (17g).

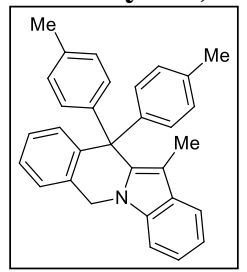

Yellow solid; yield $=63 \%$; m.p. $129-131{ }^{\circ} \mathrm{C}$.

${ }^{1} \mathbf{H}$ NMR $\left(300 \mathrm{MHz}, \mathrm{CDCl}_{3}\right) \delta(\mathrm{ppm})=1.58(\mathrm{~s}, 3 \mathrm{H}), 2.34(\mathrm{~s}, 6 \mathrm{H})$, $4.93(\mathrm{~s}, 2 \mathrm{H}), 6.83-6.89(\mathrm{~m}, 4 \mathrm{H}), 7.01-7.08(\mathrm{~m}, 4 \mathrm{H}), 7.13(\mathrm{ddd}, J=$ 7.9, 7.0, $1.0 \mathrm{~Hz}, 1 \mathrm{H}), 7.19-7.28(\mathrm{~m}, 3 \mathrm{H}), 7.29-7.35(\mathrm{~m}, 1 \mathrm{H}), 7.37-$ $7.42(\mathrm{~m}, 1 \mathrm{H}), 7.56-7.60(\mathrm{~m}, 1 \mathrm{H})$.

${ }^{13} \mathrm{C}$ NMR (75.4 MHz, $\left.\mathrm{CDCl}_{3}\right) \delta(\mathrm{ppm})=9.5\left(\mathrm{CH}_{3}\right), 21.1\left(2 \times \mathrm{CH}_{3}\right)$, $44.7\left(\mathrm{CH}_{2}\right), 56.6(\mathrm{C}), 107.9(\mathrm{C}), 108.4(\mathrm{CH}), 118.7(\mathrm{CH}), 118.9(\mathrm{CH}), 121.1(\mathrm{CH}), 126.2$ $(\mathrm{CH}), 126.5(\mathrm{CH}), 126.9(\mathrm{CH}), 128.8(4 \times \mathrm{CH}), 129.7(\mathrm{CH}), 129.8(\mathrm{C}), 130.2(4 \times \mathrm{CH})$, $133.9(\mathrm{C}), 134.4(\mathrm{C}), 136.3(2 \times \mathrm{C}), 137.6(\mathrm{C}), 141.1(2 \times \mathrm{C}), 143.8(\mathrm{C})$.

LRMS (70 eV, EI) $\mathrm{m} / z$ (\%) 413 (100).

HRMS $\left(\mathrm{EI}^{+}\right)$calcd for $\mathrm{C}_{31} \mathrm{H}_{27} \mathrm{~N}, 413.2143$; found, 413.2142 . 


\section{SYNTHESIS OF $\alpha$-INDOLYLKETONES}

\subsection{Synthesis of $\alpha$-Indolylaciloins 18a-e}

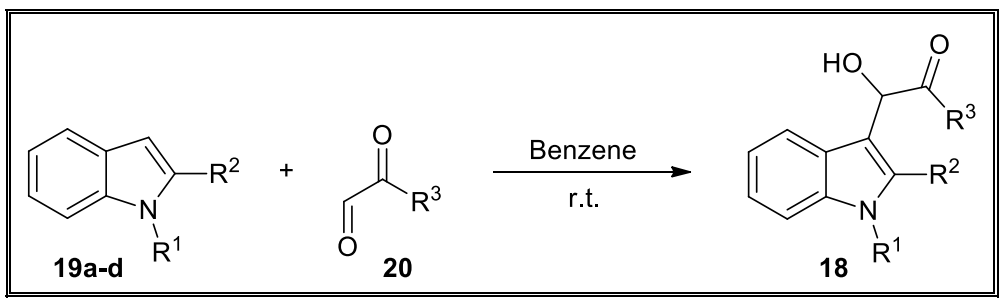

General Procedure: Acyloins 18a-e were prepared by reaction of phenyl glyoxal (760.7 $\mathrm{mg}, 5 \mathrm{mmol}$ ) with the corresponding indole $(5 \mathrm{mmol})$ in benzene following a reported procedure. ${ }^{37}$ Acyloin $18 \mathrm{e}$ was prepared in the same way from pyruvic aldehyde (20b) (1.5 $\mathrm{ml}$ of a $40 \% \mathrm{w} / \mathrm{w}$ aqueous solution, $10 \mathrm{mmol})$ and $N$-methylindole (19c) (1.31 $\mathrm{g}, 10 \mathrm{mmol})$ in benzene $(20 \mathrm{ml})$ at r.t. for $16 \mathrm{~h}$. Characterization data for acyloins $\mathbf{1 8 a}-\mathbf{d}$ have been previously reported. ${ }^{37}$

\section{1-Hydroxy-1-(1-methyl-1H-indol-3-yl)propan-2-one (18e)}

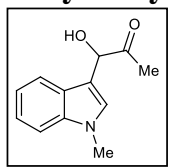

White foam; yield $=42 \% ; R_{f}=0.20$ (hexane/EtOAc, $\left.2: 1\right)$.

${ }^{1} \mathbf{H}$ NMR $\left(300 \mathrm{MHz}, \mathrm{CDCl}_{3}\right) \delta(\mathrm{ppm})=2.10(\mathrm{~s}, 3 \mathrm{H}), 3.72(\mathrm{~s}, 3 \mathrm{H}), 4.29(\mathrm{bs}$, $1 \mathrm{H}), 5.36(\mathrm{~d}, J=3.3 \mathrm{~Hz}, 1 \mathrm{H}), 7.09(\mathrm{~s}, 1 \mathrm{H}), 7.11-7.11(\mathrm{~m}, 1 \mathrm{H}), 7.23-7.36$ $(\mathrm{m}, 2 \mathrm{H}), 7.51-7.57(\mathrm{~m}, 1 \mathrm{H})$.

${ }^{13} \mathbf{C ~ N M R}\left(75.4 \mathrm{MHz}, \mathrm{CDCl}_{3}\right) \delta(\mathrm{ppm})=25.2\left(\mathrm{CH}_{3}\right), 32.7\left(\mathrm{CH}_{3}\right), 73.4(\mathrm{CH}), 109.6(\mathrm{CH})$, $111.1(\mathrm{C}), 119.1(\mathrm{CH}), 119.8(\mathrm{CH}), 122.1(\mathrm{CH}), 125.8(\mathrm{C}), 128.6(\mathrm{CH}), 137.3(\mathrm{C}), 208.2(\mathrm{C})$.

LRMS (70 eV, EI) $\mathrm{m} / z$ (\%) $203\left(\mathrm{M}^{+}, 13\right), 158$ (100).

HRMS $\left(\mathrm{EI}^{+}\right)$calcd for $\mathrm{C}_{12} \mathrm{H}_{13} \mathrm{NO}_{2}, 203.0946$; found, 203.0945.

\subsection{Synthesis of $\alpha$-(Indol-3-yl) Carbonyl Compounds 21}

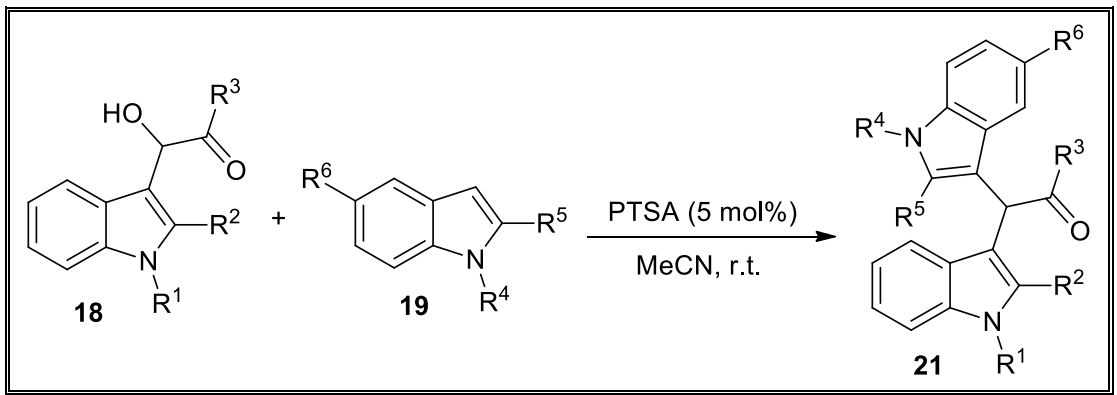

General Procedure: PTSA ( $9 \mathrm{mg}, 5 \mathrm{~mol} \%$ ) was added to a solution of the corresponding $\alpha$-acyloin 18 ( $1 \mathrm{mmol})$ and indole 19a-g $(1 \mathrm{mmol})$ in $\mathrm{MeCN}(2 \mathrm{ml})$. The resulting reaction mixture was stirred at r.t. until the alcohol was consumed as determined 
by TLC. The crude mixture was quenched with aqueous $\mathrm{NaOH}(0.5 \mathrm{M})$ and extracted with $\mathrm{CH}_{2} \mathrm{Cl}_{2}(3 \times 10 \mathrm{ml})$, and the combined organic layers were dried over anhydrous $\mathrm{Na}_{2} \mathrm{SO}_{4}$ and concentrated at reduced pressure. The residue was purified by flash chromatography using mixtures of hexane and EtOAc as eluents to obtain the corresponding $\alpha$-(indol-3-yl) carbonyl compounds derivatives 21 . In some cases the final product precipitates from the reaction mixture and could be isolated by simple filtration in pure form.

\section{2-(1H-Indol-3-yl)-2-(1-methyl-1H-indol-3-yl)-1- phenylethanone (21ac).}

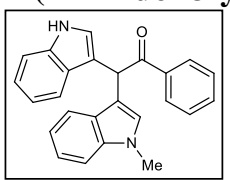

Brown solid; yield $=92 \%$; m.p. $204-206{ }^{\circ} \mathrm{C}$.

${ }^{1} \mathbf{H}$ NMR $\left(400 \mathrm{MHz}, \mathrm{CDCl}_{3}\right) \delta(\mathrm{ppm})=3.71(\mathrm{~s}, 3 \mathrm{H}), 6.57(\mathrm{~s}, 1 \mathrm{H}), 6.89$ (s, 1H), 6.96-7.02 (m, 1H), 7.09-7.17 (m, 2H), 7.19-7.24 (m, 1H), 7.25-7.28 (m, 1H), 7.28-7.33 (m, 1H), 7.34-7.39 (m, 1H), 7.42-7.48 (m, 2H), 7.52-7.57 (m, 1H), 7.59-7.64 (m, 2H), $8.12(\mathrm{~s}, 1 \mathrm{H}), 8.14-8.20(\mathrm{~m}, 2 \mathrm{H})$.

${ }^{13} \mathrm{C} \mathrm{NMR}\left(75.4 \mathrm{MHz}, \mathrm{CDCl}_{3}\right) \delta(\mathrm{ppm})=32.9\left(\mathrm{CH}_{3}\right), 42.0,(\mathrm{CH}), 109.5(\mathrm{CH}), 111.4$ $(\mathrm{CH}), 112.7(\mathrm{C}), 114.6(\mathrm{C}), 119.14(\mathrm{CH}), 119.29(\mathrm{CH}), 119.3(\mathrm{CH}), 119.8(\mathrm{CH}), 121.9$ $(\mathrm{CH}), 122.3(\mathrm{CH}), 124.0(\mathrm{CH}), 126.7(\mathrm{C}), 127.2(\mathrm{C}), 128.7,(2 \times \mathrm{CH}), 128.9(2 \times \mathrm{CH})$, $133.0(\mathrm{CH}), 136.6(\mathrm{C}), 137.1(\mathrm{C}), 137.4(\mathrm{C}), 198.8(\mathrm{C})$, one aromatic carbon peak was misssing due to overlapping.

LRMS (70 eV, EI) $m / z$ (\%) $364\left(\mathrm{M}^{+}, 3\right), 259$ (100).

HRMS $\left(\mathrm{EI}^{+}\right)$: calcd for $\mathrm{C}_{25} \mathrm{H}_{20} \mathrm{~N}_{2} \mathrm{O}, 364.1576$; found, 364.1577 .

\section{2-(1,2-Dimethyl-1H-indol-3-yl)-2-(1H-indol-3-yl)-1-phenylethanone (21ad).}

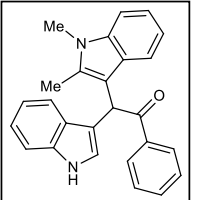

Violet solid; yield $=86 \%$; m.p. $105-107^{\circ} \mathrm{C}$.

${ }^{1} \mathbf{H}$ NMR $\left(300 \mathrm{MHz},\left(\mathrm{CD}_{3}\right)_{2} \mathrm{CO}\right) \delta(\mathrm{ppm})=2.40(\mathrm{~s}, 3 \mathrm{H}), 3.63(\mathrm{~s}, 3 \mathrm{H})$, $6.43(\mathrm{~d}, J=1.1 \mathrm{~Hz}, 1 \mathrm{H}), 6.85(\mathrm{dd}, J=2.5,1.1 \mathrm{~Hz}, 1 \mathrm{H}), 7.00-7.10(\mathrm{~m}$, 2H), 7.12-7.19 (m, 2H), $7.25(\mathrm{~d}, J=8.0 \mathrm{~Hz}, 1 \mathrm{H}), 7.28-7.43(\mathrm{~m}, 4 \mathrm{H})$, 7.44-7.51 (m, 1H), 7.69 (d, J = 7.9 Hz, 1H), $7.97(\mathrm{~s}, 1 \mathrm{H}), 8.04-8.10(\mathrm{~m}, 2 \mathrm{H})$.

${ }^{13} \mathrm{C}$ NMR $\left(75.4 \mathrm{MHz},\left(\mathrm{CD}_{3}\right)_{2} \mathrm{CO}\right) \delta(\mathrm{ppm})=11.0\left(\mathrm{CH}_{3}\right), 29.7\left(\mathrm{CH}_{3}\right), 42.6(\mathrm{CH}), 107.5$ $(\mathrm{C}), 108.8(\mathrm{CH}), 111.4(\mathrm{CH}), 114.8(\mathrm{C}), 119.05(\mathrm{CH}), 119.1(\mathrm{CH}), 119.4(\mathrm{CH}), 119.6$ $(\mathrm{CH}), 120.8(\mathrm{CH}), 122.1(\mathrm{CH}), 127.1(\mathrm{C}), 127.3(\mathrm{C}), 128.6(2 \times \mathrm{CH}), 128.7(2 \times \mathrm{CH})$, $132.7(\mathrm{CH}), 134.6(\mathrm{C}), 136.6(\mathrm{C}), 136.9(\mathrm{C}), 137.4(\mathrm{C}), 198.1(\mathrm{C})$.

LRMS (70 eV, EI) $m / z(\%) 378\left(\mathrm{M}^{+}, 3\right), 273(100)$.

HRMS $\left(\mathrm{EI}^{+}\right)$calcd for $\mathrm{C}_{26} \mathrm{H}_{22} \mathrm{~N}_{2} \mathrm{O}, 378.1732$; found, 378.1730 . 


\section{2-(1H-Indol-3-yl)-2-(2-methyl-1H-indol-3-yl)-1-phenylethanone (21ba).}

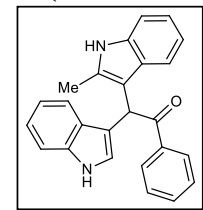

Yellow solid; yield $=99 \%$; m.p. $220-222^{\circ} \mathrm{C}$.

${ }^{1} \mathbf{H}$ NMR $\left(400 \mathrm{MHz}, \mathrm{CDCl}_{3}\right) \delta(\mathrm{ppm})=2.24(\mathrm{~s}, 3 \mathrm{H}), 6.38(\mathrm{~s}, 1 \mathrm{H}), 6.71$ $(\mathrm{s}, 1 \mathrm{H}), 7.02(\mathrm{~d}, J=7.8 \mathrm{~Hz}, 1 \mathrm{H}), 7.05-7.19(\mathrm{~m}, 3 \mathrm{H}), 7.21-7.24(\mathrm{~m}, 1 \mathrm{H})$, 7.33-7.41 (m, 4H), 7.44-7.50 (m, 1H), 7.60-7.65 (m, 1H), $7.83(\mathrm{~s}, 1 \mathrm{H})$, 7.95 (s, 1H), 8.04-8.09 (m, 2H).

${ }^{13} \mathrm{C} \mathrm{NMR}\left(75.4 \mathrm{MHz}, \mathrm{CDCl}_{3}\right) \delta(\mathrm{ppm})=12.4\left(\mathrm{CH}_{3}\right), 42.4(\mathrm{CH}), 108.2(\mathrm{C}), 110.5(\mathrm{CH})$, $111.5(\mathrm{CH}), 114.3(\mathrm{C}), 118.9(\mathrm{CH}), 119.0(\mathrm{CH}), 119.6(\mathrm{CH}), 119.7(\mathrm{CH}), 121.2(\mathrm{C}), 122.1$ $(\mathrm{CH}), 124.3(\mathrm{CH}), 127.0(\mathrm{C}), 128.2(\mathrm{C}), 128.6(2 \times \mathrm{CH}), 128.7(2 \times \mathrm{CH}), 132.8(\mathrm{CH})$, $132.9(\mathrm{CH}), 135.3(\mathrm{C}), 136.6(\mathrm{C}), 137.3(\mathrm{C}), 198.4(\mathrm{C})$.

LRMS (70 eV, EI) $m / z$ (\%) $364\left(\mathrm{M}^{+}, 2\right), 259$ (100).

HRMS $\left(\mathrm{EI}^{+}\right)$calcd for $\mathrm{C}_{25} \mathrm{H}_{20} \mathrm{~N}_{2} \mathrm{O}, 364.1576$; found, 364.1581 .

2-(5-Bromo-1H-indol-3-yl)-2-(2-methyl-1H-indol-3-yl)-1-phenylethanone (21be).

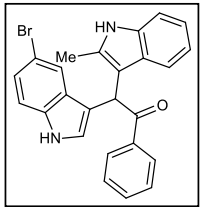

White solid; yield $=93 \%$; m.p. $152-154{ }^{\circ} \mathrm{C}$.

${ }^{1} \mathbf{H}$ NMR $\left(300 \mathrm{MHz}, \mathrm{CDCl}_{3}\right) \delta(\mathrm{ppm})=2.30(\mathrm{~s}, 3 \mathrm{H}), 6.28(\mathrm{~s}, 1 \mathrm{H}), 6.65$ (s, 1H), 7.00-7.12 (m, 3H), 7.14-7.27 (m, 2H), 7.33-7.40 (m, 2H), 7.44-7.52 (m, 2H), $7.57(\mathrm{~d}, J=7.8 \mathrm{~Hz}, 1 \mathrm{H}), 7.91(\mathrm{~s}, 1 \mathrm{H}), 8.02-8.10(\mathrm{~m}, 3 \mathrm{H})$.

${ }^{13}$ C NMR (75.4 MHz, $\left.\mathrm{CDCl}_{3}\right) \delta(\mathrm{ppm})=12.4\left(\mathrm{CH}_{3}\right), 42.3(\mathrm{CH}), 108.0(\mathrm{C}), 110.5(\mathrm{CH})$, $112.9(\mathrm{CH}), 113.0(\mathrm{CH}), 114.0(\mathrm{C}), 118.9(\mathrm{CH}), 119.8(\mathrm{CH}), 121.4(\mathrm{CH}), 121.5(\mathrm{CH})$, $124.9(\mathrm{CH}), 125.7(\mathrm{CH}), 127.9(\mathrm{C}), 128.7(4 \times \mathrm{CH}), 132.7(\mathrm{C}), 133.0(\mathrm{C}), 135.26(\mathrm{C})$, $135.35(\mathrm{C}), 136.9(\mathrm{C}), 198.1(\mathrm{C})$, one aromatic carbon peak was misssing due to overlapping. LRMS (70 eV, EI) $m / z(\%) 444\left[(\mathrm{M}+2)^{+}, 3\right], 442\left(\mathrm{M}^{+}, 2\right) ; 339$ (99) 337 (100).

HRMS $\left(\mathrm{EI}^{+}\right)$calcd for $\mathrm{C}_{25} \mathrm{H}_{19} \mathrm{BrN}_{2} \mathrm{O},\left(\mathrm{M}-\mathrm{C}_{7} \mathrm{H}_{5} \mathrm{O}\right)^{+} 337.0340$; found, 337.0339.

2-(2-Methyl-1H-indol-3-yl)-2-(5-nitro-1H-indol-3-yl)-1-phenylethanone (21bf).

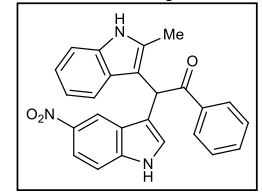
Yellow solid; yield $=91 \%$; m.p. $145-147{ }^{\circ} \mathrm{C}$.

${ }^{1} \mathbf{H}$ NMR $\left(300 \mathrm{MHz},\left(\mathrm{CD}_{3}\right)_{2} \mathrm{SO}\right) \delta(\mathrm{ppm})=2.40(\mathrm{~s}, 3 \mathrm{H}), 6.69(\mathrm{~s}, 1 \mathrm{H})$, 6.85-6.98 (m, 2H), $7.10(\mathrm{~s}, 1 \mathrm{H}), 7.20(\mathrm{~d}, J=7.8 \mathrm{~Hz}, 1 \mathrm{H}), 7.42$ (at, $J$ $=7.4 \mathrm{~Hz}, 2 \mathrm{H}), 7.46-7.56(\mathrm{~m}, 3 \mathrm{H}), 7.97(\mathrm{dd}, J=9.0,1.0 \mathrm{~Hz}, 1 \mathrm{H}), 8.07$ (d, $J=8.1 \mathrm{~Hz}, 2 \mathrm{H}), 8.42(\mathrm{~s}, 1 \mathrm{H}), 10.98(\mathrm{~s}, 1 \mathrm{H}), 11.57$ (s, 1H).

${ }^{13} \mathrm{C}$ NMR $\left(75.4 \mathrm{MHz},\left(\mathrm{CD}_{3}\right)_{2} \mathrm{SO}\right) \delta(\mathrm{ppm})=11.9\left(\mathrm{CH}_{3}\right), 41.5(\mathrm{CH}), 106.8(\mathrm{C}), 110.7$ $(\mathrm{CH}), 112.0(\mathrm{CH}), 116.5(\mathrm{CH}), 116.6(\mathrm{CH}), 116.7(\mathrm{C}), 118.3(\mathrm{CH}), 118.7(\mathrm{CH}), 120.3$ $(\mathrm{CH}), 126.3(\mathrm{C}), 127.3(\mathrm{C}), 128.2(\mathrm{CH}), 128.4(2 \times \mathrm{CH}), 128.6(2 \times \mathrm{CH}), 132.8(\mathrm{CH})$, 133.4 (C), 135.4 (C), 136.8 (C), 139.7 (C), 140.2 (C), 198.0 (C).

LRMS (70 eV, EI) $\mathrm{m} / z$ (\%) $409\left(\mathrm{M}^{+}, 2\right), 304$ (100).

HRMS $\left(\mathrm{EI}^{+}\right)$calcd for $\mathrm{C}_{25} \mathrm{H}_{19} \mathrm{~N}_{3} \mathrm{O}_{3}, 409.1426$; found, 409.1429 . 
2-(1-Methyl-1H-indol-3-yl)-2-(2-methyl-1H-indol-3-yl)-1-phenylethanone (21cb).

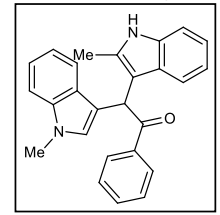

Yellow solid; yield $=90 \%$; m.p. $201-203{ }^{\circ} \mathrm{C}$.

${ }^{1} \mathbf{H}$ NMR $\left(300 \mathrm{MHz}, \mathrm{CDCl}_{3}\right) \delta(\mathrm{ppm})=2.26(\mathrm{~s}, 3 \mathrm{H}), 3.52(\mathrm{~s}, 3 \mathrm{H}), 6.50$ $(\mathrm{s}, 1 \mathrm{H}), 6.80(\mathrm{~s}, 1 \mathrm{H}), 7.09-7.20(\mathrm{~m}, 4 \mathrm{H}), 7.22-7.30(\mathrm{~m}, 2 \mathrm{H}), 7.37-7.47(\mathrm{~m}, 2 \mathrm{H})$, 7.48-7.58 (m, 2H), 7.75-7.79 (m, 1H), 8.05-8.12 (m, 1H), 8.15-8.21 (m, 2H).

${ }^{13} \mathbf{C ~ N M R}\left(75.4 \mathrm{MHz}, \mathrm{CDCl}_{3}\right) \delta(\mathrm{ppm})=12.1\left(\mathrm{CH}_{3}\right), 32.5\left(\mathrm{CH}_{3}\right), 42.3$ $(\mathrm{CH}), 107.8(\mathrm{C}), 109.4(\mathrm{CH}), 110.5(\mathrm{CH}), 112.8(\mathrm{C}), 118.7(\mathrm{CH}), 119.0(\mathrm{CH}), 119.5(\mathrm{CH})$, $121.0(\mathrm{CH}), 121.6(\mathrm{CH}), 127.3(\mathrm{CH}), 127.9(\mathrm{CH}), 128.5(2 \times \mathrm{CH}), 128.6(2 \times \mathrm{CH}), 128.8$ (CH), 132.7 (C), 132.9 (C), 135.2 (C), 137.2 (C), 137.3 (C), 198.5 (C), one aromatic carbon peak was misssing due to overlapping.

LRMS (70 eV, EI) $m / z$ (\%) $378\left(\mathrm{M}^{+}, 4\right), 260$ (100).

HRMS $\left(\mathrm{EI}^{+}\right)$calcd for $\mathrm{C}_{26} \mathrm{H}_{22} \mathrm{~N}_{2} \mathrm{O}, 378.1732$; found, 378.1733 .

2-(1,2-Dimethyl-1H-indol-3-yl)-2-(1-methyl-1H-indol-3-yl)-1-phenylethanone (21cd).

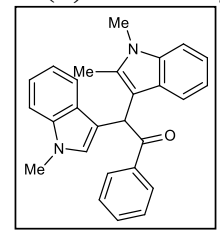

Yellow solid; yield $=98 \%$; m.p. $197-199{ }^{\circ} \mathrm{C}$.

${ }^{1} \mathbf{H}$ NMR $\left(400 \mathrm{MHz}, \mathrm{CDCl}_{3}\right) \delta(\mathrm{ppm})=2.42(\mathrm{~s}, 3 \mathrm{H}), 3.64(\mathrm{~s}, 3 \mathrm{H}), 3.67$ $(\mathrm{s}, 3 \mathrm{H}), 6.43(\mathrm{~s}, 1 \mathrm{H}), 6.77(\mathrm{~s}, 1 \mathrm{H}), 7.01-7.10(\mathrm{~m}, 2 \mathrm{H}), 7.12-7.30(\mathrm{~m}$, $4 \mathrm{H}), 7.34-7.42(\mathrm{~m}, 3 \mathrm{H}), 7.46(\mathrm{t}, J=7.4 \mathrm{~Hz}, 1 \mathrm{H}), 7.69(\mathrm{~d}, J=7.8 \mathrm{~Hz}$, $1 \mathrm{H}), 8.05-8.09(\mathrm{~m}, 2 \mathrm{H})$.

${ }^{13} \mathrm{C} \mathrm{NMR}\left(100.6 \mathrm{MHz}, \mathrm{CDCl}_{3}\right) \delta(\mathrm{ppm})=11.0\left(\mathrm{CH}_{3}\right), 29.7\left(\mathrm{CH}_{3}\right), 32.9\left(\mathrm{CH}_{3}\right), 42.6(\mathrm{CH})$, $107.7(\mathrm{C}), 108.8(\mathrm{CH}), 109.5(\mathrm{CH}), 113.2(\mathrm{C}), 119.07(\mathrm{CH}), 119.09(\mathrm{CH}), 119.2(\mathrm{CH})$, $119.4(\mathrm{CH}), 120.8(\mathrm{CH}), 121.7(\mathrm{CH}), 127.2(\mathrm{C}), 127.5(\mathrm{C}), 128.6(2 \times \mathrm{CH}), 128.7(2 \times$ $\mathrm{CH}), 128.9(\mathrm{CH}), 132.7(\mathrm{CH}), 134.5(\mathrm{C}), 136.9(\mathrm{C}), 137.4(\mathrm{C}), 198.1(\mathrm{C})$, one aromatic carbon peak was misssing due to overlapping.

LRMS (70 eV, EI) $m / z$ (\%) $392\left(\mathrm{M}^{+}, 3\right), 287$ (100).

HRMS $\left(\mathrm{EI}^{+}\right)$calcd for $\mathrm{C}_{27} \mathrm{H}_{24} \mathrm{~N}_{2} \mathrm{O}, 392.1889$; found, 392.1889 .

2-(1-Methyl-1H-indol-3-yl)-2-(5-nitro-1H-indol-3-yl)-1-phenylethanone (21cf).

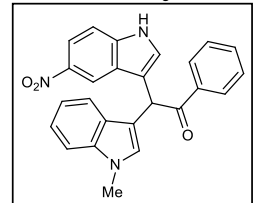

Yellow solid; yield $=90 \%$; m.p. $170-172{ }^{\circ} \mathrm{C}$.

${ }^{1} \mathbf{H}$ NMR $\left(300 \mathrm{MHz},\left(\mathrm{CD}_{3}\right)_{2} \mathrm{SO}\right) \delta(\mathrm{ppm})=3.68(\mathrm{~s}, 3 \mathrm{H}), 6.88(\mathrm{~s}, 1 \mathrm{H})$, 6.96-7.04 (m, 1H), 7.08-7.14 (m, 1H), 7.17 (s, 1H), 7.35 (d, $J=8.2$ $\mathrm{Hz}, 1 \mathrm{H}), 7.44-7.60(\mathrm{~m}, 5 \mathrm{H}), 7.63(\mathrm{~d}, J=7.8 \mathrm{~Hz}, 1 \mathrm{H}), 7.98(\mathrm{dd}, J=$ 9.0, $2.3 \mathrm{~Hz}, 1 \mathrm{H}), 8.18-8.26(\mathrm{~m}, 2 \mathrm{H}), 8.63(\mathrm{~d}, J=2.2 \mathrm{~Hz}, 1 \mathrm{H}), 11.73(\mathrm{~s}, 1 \mathrm{H})$.

${ }^{13} \mathrm{C}$ NMR $\left(75.4 \mathrm{MHz},\left(\mathrm{CD}_{3}\right)_{2} \mathrm{SO}\right) \delta(\mathrm{ppm})=32.4\left(\mathrm{CH}_{3}\right) 41.1(\mathrm{CH}), 109.9(\mathrm{CH}), 111.7$

(C), $112.1(\mathrm{CH}), 116.1(\mathrm{C}), 116.6(2 \times \mathrm{CH}), 118.9(\mathrm{CH}), 119.2(\mathrm{CH}), 121.4(\mathrm{CH}), 125.9$

(C), $126.6(\mathrm{C}), 128.5(\mathrm{CH}), 128.6(\mathrm{CH}), 128.8(2 \times \mathrm{CH}), 133.2(\mathrm{CH}), 136.2(\mathrm{C}), 136.8$

(C), 139.6 (C), $140.4(\mathrm{C}), 197.8$ (C), one aromatic carbon peak was misssing due to overlapping;

LRMS (70 eV, EI) m/z (\%) $409\left(\mathrm{M}^{+}, 3\right), 304$ (100).

HRMS $\left(\mathrm{EI}^{+}\right)$calcd for $\mathrm{C}_{25} \mathrm{H}_{19} \mathrm{~N}_{3} \mathrm{O}_{3}, 409.1426$; found, 409.1428 . 


\section{2-(1-Methyl-1H-indol-3-yl)-1-phenyl-2-(2-phenyl-1H-indol-3-yl)ethanone (21cg).}

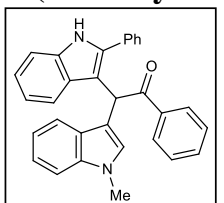

White solid; yield $=95 \%$; m.p. $240-242{ }^{\circ} \mathrm{C}$.

${ }^{1} \mathbf{H}$ NMR $\left(300 \mathrm{MHz},\left(\mathrm{CD}_{3}\right)_{2} \mathrm{SO}\right) \delta(\mathrm{ppm})=3.69(\mathrm{~s}, 3 \mathrm{H}), 6.40(\mathrm{~s}, 1 \mathrm{H})$, $6.86(\mathrm{~s}, 1 \mathrm{H}), 6.89-6.98(\mathrm{~m}, 2 \mathrm{H}), 7.05$ (at, $J=7.5 \mathrm{~Hz}, 1 \mathrm{H}), 7.10-7.18$ $(\mathrm{m}, 2 \mathrm{H}), 7.24(\mathrm{t}, J=7.3 \mathrm{~Hz}, 2 \mathrm{H}), 7.35(\mathrm{~d}, J=8.1 \mathrm{~Hz}, 1 \mathrm{H}), 7.39-7.51$

$(\mathrm{m}, 8 \mathrm{H}), 7.61(\mathrm{ad}, J=7.6 \mathrm{~Hz}, 2 \mathrm{H}), 11.54(\mathrm{~s}, 1 \mathrm{H})$.

${ }^{13} \mathrm{C}$ NMR (75.4 MHz, $\left.\left(\mathrm{CD}_{3}\right)_{2} \mathrm{SO}\right) \delta(\mathrm{ppm})=32.4\left(\mathrm{CH}_{3}\right), 42.6(\mathrm{CH}), 107.7(\mathrm{C}), 109.8$ $(\mathrm{CH}), 111.5(\mathrm{CH}), 112.6(\mathrm{C}), 118.7(2 \times \mathrm{CH}), 119.2(\mathrm{CH}), 120.3(\mathrm{CH}), 121.2(\mathrm{CH}), 121.5$ $(\mathrm{CH}), 126.8(\mathrm{CH}), 127.4(\mathrm{CH}), 127.9(2 \times \mathrm{CH}), 128.2(2 \times \mathrm{CH}), 128.5(2 \times \mathrm{CH}), 129.0$ $(2 \times \mathrm{CH}), 132.3(\mathrm{C}), 132.8(\mathrm{C}), 136.0(\mathrm{C}), 136.2(\mathrm{C}), 136.3(\mathrm{C}), 136.9(\mathrm{C}), 196.8(\mathrm{C})$, two aromatic carbon peaks were misssing due to overlapping.

LRMS (70 eV, EI) $m / z$ (\%) $440\left(\mathrm{M}^{+}, 2\right), 335$ (100).

HRMS $\left(\mathrm{EI}^{+}\right)$calcd for $\mathrm{C}_{31} \mathrm{H}_{24} \mathrm{~N}_{2} \mathrm{O}, 440.1889$; found, 440.1889 .

\section{2-(1,2-Dimethyl-1H-indol-3-yl)-2-(2-methyl-1H -indol-3-yl)-1-phenylethanone (21db).}

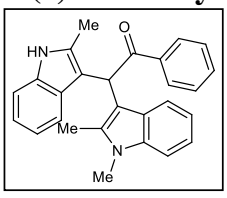

Yellow foam; yield $=89 \% ; R_{f}=0.25$ (hexane/EtOAc, 5:1).

${ }^{1} \mathbf{H}$ NMR $\left(300 \mathrm{MHz}, \mathrm{CDCl}_{3}\right) \delta(\mathrm{ppm})=2.05(\mathrm{~s}, 3 \mathrm{H}), 2.24(\mathrm{~s}, 3 \mathrm{H}), 3.59$ (s, 3H), $6.47(\mathrm{~s}, 1 \mathrm{H}), 6.94-7.04(\mathrm{~m}, 2 \mathrm{H}), 7.07$ (d, $J=6.9 \mathrm{~Hz}, 1 \mathrm{H}), 7.10$ $7.17(\mathrm{~m}, 2 \mathrm{H}), 7.24(\mathrm{~d}, J=8.0 \mathrm{~Hz}, 1 \mathrm{H}), 7.34-7.41(\mathrm{~m}, 4 \mathrm{H}), 7.43-7.52$ (m, 1H), $7.88(\mathrm{~s}, 1 \mathrm{H}), 8.05-8.16(\mathrm{~m}, 2 \mathrm{H})$.

${ }^{13} \mathbf{C ~ N M R}\left(75.4 \mathrm{MHz}, \mathrm{CDCl}_{3}\right) \delta(\mathrm{ppm})=10.9\left(\mathrm{CH}_{3}\right), 12.6\left(\mathrm{CH}_{3}\right), 29.6\left(\mathrm{CH}_{3}\right), 43.3(\mathrm{CH})$, $108.8(\mathrm{CH}), 108.9(\mathrm{C}), 110.4(\mathrm{CH}), 118.5(\mathrm{CH}), 118.6(\mathrm{CH}), 118.7(\mathrm{CH}), 119.2(\mathrm{CH})$, $119.4(\mathrm{CH}), 120.6(\mathrm{CH}), 120.9(\mathrm{CH}), 127.7(\mathrm{C}), 128.6(2 \times \mathrm{CH}), 128.7(2 \times \mathrm{CH}), 132.6$ (C), 132.7 (C), 132.8 (C), 134.4 (C), 135.1 (C), 136.6 (C), 137.2 (C), 199.3 (C).

LRMS (70 eV, EI) $\mathrm{m} / z$ (\%) $392\left(\mathbf{M}^{+}, 3\right), 287$ (100).

HRMS $\left(\mathrm{EI}^{+}\right)$calcd for $\mathrm{C}_{27} \mathrm{H}_{24} \mathrm{~N}_{2} \mathrm{O}, 392.1889$; found, 392.1890 .

\section{2-(5-Bromo-1H-indol-3-yl)-2-(1,2-dimethyl-1H-indol-3-yl)-1-phenylethanone (21de).}

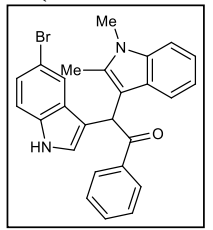

White solid; yield $=85 \%$; m.p. $231-233{ }^{\circ} \mathrm{C}$.

${ }^{1} \mathbf{H}$ NMR $\left(400 \mathrm{MHz},\left(\mathrm{CD}_{3}\right)_{2} \mathrm{SO}\right) \delta(\mathrm{ppm})=2.41(\mathrm{~s}, 3 \mathrm{H}), 3.59(\mathrm{~s}, 3 \mathrm{H})$, $6.55(\mathrm{~s}, 1 \mathrm{H}), 6.89(\mathrm{~s}, 1 \mathrm{H}), 6.92(\mathrm{~d}, J=7.9 \mathrm{~Hz}, 1 \mathrm{H}), 7.00$ (at, $J=7.5 \mathrm{~Hz}$, $1 \mathrm{H}), 7.14(\mathrm{dd}, J=8.6,1.9 \mathrm{~Hz}, 1 \mathrm{H}), 7.30(\mathrm{ad}, J=8.5 \mathrm{~Hz}, 2 \mathrm{H}), 7.39(\mathrm{t}, J$ $=7.6 \mathrm{~Hz}, 2 \mathrm{H}), 7.47-7.54(\mathrm{~m}, 3 \mathrm{H}), 8.02-8.07(\mathrm{~m}, 2 \mathrm{H}), 11.01(\mathrm{~s}, 1 \mathrm{H})$.

${ }^{13} \mathrm{C}$ NMR $\left(100.6 \mathrm{MHz},\left(\mathrm{CD}_{3}\right)_{2} \mathrm{SO}\right) \delta(\mathrm{ppm})=10.4\left(\mathrm{CH}_{3}\right), 29.4\left(\mathrm{CH}_{3}\right), 41.6(\mathrm{CH}), 106.9$ $(\mathrm{C}), 109.2(\mathrm{CH}), 110.9(\mathrm{C}), 113.3(\mathrm{C}), 113.4(\mathrm{CH}), 118.5(\mathrm{CH}), 118.8(\mathrm{CH}), 120.2(\mathrm{CH})$, $121.3(\mathrm{CH}), 123.3(\mathrm{CH}), 126.0(\mathrm{CH}), 126.4(\mathrm{C}), 128.3(2 \times \mathrm{CH}), 128.5(2 \times \mathrm{CH}), 128.7$ (C), $132.7(\mathrm{CH}), 134.8(\mathrm{C}), 135.0(\mathrm{C}), 136.3(\mathrm{C}), 136.9(\mathrm{C}), 197.9(\mathrm{C})$.

LRMS (70 eV, EI) $m / z$ (\%) 458 [(M+2) $\left.{ }^{+}, 5\right], 456\left(\mathrm{M}^{+}, 5\right), 353$ (100), 351 (100).

HRMS $\left(\mathrm{EI}^{+}\right)$calcd for $\mathrm{C}_{26} \mathrm{H}_{21} \mathrm{BrN}_{2} \mathrm{O}, 456.0837$; found, 456.0836 . 
1-(1H-Indol-3-yl)-1-(1-methyl-1H-indol-3-yl)propan-2-one (21ea).

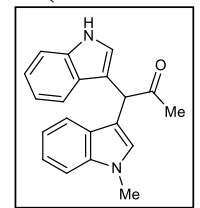

White foam; yield $=70 \% ; R_{f}=0.25$ (hexane/EtOAc, $4: 1$ ).

${ }^{1} \mathbf{H}$ NMR $\left(300 \mathrm{MHz}, \mathrm{CDCl}_{3}\right) \delta(\mathrm{ppm})=2.35(\mathrm{~s}, 3 \mathrm{H}), 3.69(\mathrm{~s}, 3 \mathrm{H}), 5.58(\mathrm{~s}$, $1 \mathrm{H}), 6.93(\mathrm{~s}, 1 \mathrm{H}), 6.97$ (bs, 1H), 7.09-7.17 (m, 2H), 7.20 (dd, $J=8.1,1.2$ $\mathrm{Hz}, 1 \mathrm{H}), 7.23-7.27$ (m, 1H), 7.29-7.35 (m, 2H), $7.58(\mathrm{ad}, J=8.2 \mathrm{~Hz}, 2 \mathrm{H})$, $8.18(\mathrm{~s}, 1 \mathrm{H})$.

${ }^{13} \mathrm{C} \mathrm{NMR}\left(75.4 \mathrm{MHz}, \mathrm{CDCl}_{3}\right) \delta(\mathrm{ppm})=28.8\left(\mathrm{CH}_{3}\right), 32.5\left(\mathrm{CH}_{3}\right), 48.1(\mathrm{CH}), 109.5(\mathrm{CH})$, $111.5(\mathrm{CH}), 111.8(\mathrm{C}), 112.8(\mathrm{C}), 118.9(\mathrm{CH}), 119.2(2 \times \mathrm{CH}), 119.5(\mathrm{CH}), 121.8(\mathrm{CH})$, $122.0(\mathrm{CH}), 123.6(\mathrm{CH}), 126.6(\mathrm{C}), 127.2(\mathrm{C}), 128.2(\mathrm{CH}), 136.4(\mathrm{C}), 137.1(\mathrm{C}), 207.8(\mathrm{C})$. LRMS (70 eV, EI) $m / z$ (\%) $302\left(\mathrm{M}^{+}, 2\right), 259$ (100).

HRMS $\left(\mathrm{EI}^{+}\right)$calcd for $\mathrm{C}_{20} \mathrm{H}_{18} \mathrm{~N}_{2} \mathrm{O}, 302.1419$; found, 302.1412 .

\subsection{Synthesis of $\alpha$-(Indol-3-yl) Carbonyl Compounds 23}

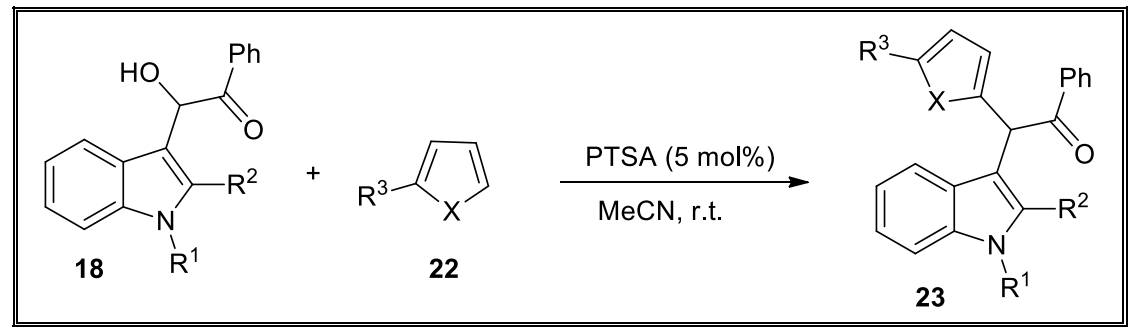

General Procedure: PTSA ( $9 \mathrm{mg}, 5 \mathrm{~mol} \%$ ) was added to a solution of the corresponding $\alpha$-acyloin 18 (1 mmol) and nucleophile $22(1 \mathrm{mmol})$ in $\mathrm{MeCN}(2 \mathrm{ml})$. The resulting reaction mixture was stirred at r.t. until the alcohol was consumed as determined by TLC. The crude mixture was quenched with aqueous $\mathrm{NaOH}(0.5 \mathrm{M})$ and extracted with $\mathrm{CH}_{2} \mathrm{Cl}_{2}(3 \times 10 \mathrm{ml})$, and the combined organic layers were dried over anhydrous $\mathrm{Na}_{2} \mathrm{SO}_{4}$ and concentrated at reduced pressure. The residue was purified by flash chromatography using mixtures of hexane and EtOAc as eluents to obtain the corresponding $\alpha$-(indol-3-yl) carbonyl compounds derivatives $\mathbf{2 3}$.

2-(1H-Indol-3-yl)-2-(5-methylfuran-2-yl)-1-phenylethanone (23a).

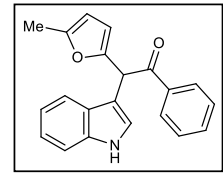

Yellow solid; yield $=73 \%$; m.p. $146-148{ }^{\circ} \mathrm{C}$.

${ }^{1} \mathbf{H}$ NMR $\left(300 \mathrm{MHz}, \mathrm{CDCl}_{3}\right) \delta(\mathrm{ppm})=2.55(\mathrm{~s}, 3 \mathrm{H}), 5.88(\mathrm{dd}, J=2.9$, $0.9 \mathrm{~Hz}, 1 \mathrm{H}), 5.97(\mathrm{~d}, J=3.0 \mathrm{~Hz}, 1 \mathrm{H}), 6.27(\mathrm{~s}, 1 \mathrm{H}), 7.07$ (d, $J=2.5 \mathrm{~Hz}$,

$1 \mathrm{H}), 7.15(\mathrm{ddd}, J=7.6,7.1,1.3 \mathrm{~Hz}, 1 \mathrm{H}), 7.18-7.24(\mathrm{~m}, 1 \mathrm{H}), 7.32-7.44(\mathrm{~m}, 3 \mathrm{H}), 7.48$ $7.54(\mathrm{~m}, 1 \mathrm{H}), 7.64-7.67(\mathrm{~m}, 1 \mathrm{H}), 8.03-8.09(\mathrm{~m}, 2 \mathrm{H}), 8.24(\mathrm{~s}, 1 \mathrm{H})$.

${ }^{13} \mathbf{C ~ N M R}\left(75.4 \mathrm{MHz}, \mathrm{CDCl}_{3}\right) \delta(\mathrm{ppm})=13.8\left(\mathrm{CH}_{3}\right), 44.8(\mathrm{CH}), 106.5(\mathrm{CH}), 109.5(\mathrm{CH})$, $111.3(\mathrm{C}), 111.5(\mathrm{CH}), 118.9(\mathrm{CH}), 120.0(\mathrm{CH}), 122.5(\mathrm{CH}), 124.1(\mathrm{CH}), 126.5(\mathrm{C}), 128.7$ $(2 \times \mathrm{CH}), 129.0(2 \times \mathrm{CH}), 133.1(\mathrm{CH}), 136.4(\mathrm{C}), 150.8(\mathrm{C}), 151.8(\mathrm{C}), 196.4(\mathrm{C})$, one aromatic carbon peak was misssing due to overlapping.

LRMS (70 eV, EI) $m / z$ (\%) $315\left(\mathbf{M}^{+}, 3\right), 210$ (100).

HRMS $\left(\mathrm{EI}^{+}\right)$calcd for $\mathrm{C}_{21} \mathrm{H}_{17} \mathrm{NO}_{2}, 315.1259$; found, 315.1259 . 


\section{2-(2-Methyl-1H-indol-3-yl)-2-(5-methylfuran-2-yl)-1-phenylethanone (23b).}

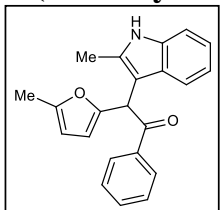

Yellow solid; yield $=69 \%$; m.p. $80-82{ }^{\circ} \mathrm{C}$.

${ }^{1} \mathbf{H}$ NMR $\left(300 \mathrm{MHz}, \mathrm{CDCl}_{3}\right) \delta(\mathrm{ppm})=2.23(\mathrm{~s}, 3 \mathrm{H}), 2.35(\mathrm{~s}, 3 \mathrm{H}), 5.86$ $(\mathrm{d}, J=2.1 \mathrm{~Hz}, 1 \mathrm{H}), 5.93(\mathrm{~d}, J=1.9 \mathrm{~Hz}, 1 \mathrm{H}), 6.14(\mathrm{~s}, 1 \mathrm{H}), 7.05-7.15$ (m, 2H), 7.18-7.24 (m, 1H), 7.33 (at, $J=7.5 \mathrm{~Hz}, 2 \mathrm{H}), 7.44$ (t, $J=7.3$

$\mathrm{Hz}, 1 \mathrm{H}), 7.58-7.66(\mathrm{~m}, 1 \mathrm{H}), 7.94-8.03(\mathrm{~m}, 3 \mathrm{H})$.

${ }^{13}$ C NMR $\left(75.4 \mathrm{MHz}, \mathrm{CDCl}_{3}\right) \delta(\mathrm{ppm})=12.4\left(\mathrm{CH}_{3}\right), 13.7\left(\mathrm{CH}_{3}\right), 45.0(\mathrm{CH}), 106.2(\mathrm{C})$, $106.3(\mathrm{CH}), 109.6(\mathrm{CH}), 110.5(\mathrm{CH}), 118.6(\mathrm{CH}), 119.9(\mathrm{CH}), 121.4(\mathrm{CH}), 127.8(\mathrm{C})$, $128.5(2 \times \mathrm{CH}), 128.6(2 \times \mathrm{CH}), 132.9(\mathrm{CH}), 133.2(\mathrm{C}), 135.3(\mathrm{C}), 136.6(\mathrm{C}), 150.6(\mathrm{C})$, 151.7 (C), $196.4(\mathrm{C})$.

LRMS (70 eV, EI) $m / z(\%) 329\left(\mathrm{M}^{+}, 2\right), 224$ (100).

HRMS $\left(\mathrm{EI}^{+}\right)$calcd for $\mathrm{C}_{22} \mathrm{H}_{19} \mathrm{NO}_{2}, 329.1416$; found, 329.1414 .

2-(1-Methyl-1H-indol-3-yl)-2-(5-methylfuran-2-yl)-1-phenylethanone (23c).

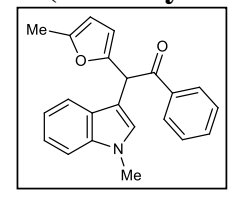

Yellow solid; yield $=81 \%$; m.p. $154-156^{\circ} \mathrm{C}$.

${ }^{1} \mathbf{H}$ NMR $\left(300 \mathrm{MHz}, \mathrm{CDCl}_{3}\right) \delta(\mathrm{ppm})=2.29(\mathrm{~s}, 3 \mathrm{H}), 3.72(\mathrm{~s}, 3 \mathrm{H}), 5.89$ $5.92(\mathrm{~m}, 1 \mathrm{H}), 6.02(\mathrm{~d}, J=2.1 \mathrm{~Hz}, 1 \mathrm{H}), 6.29(\mathrm{~s}, 1 \mathrm{H}), 7.04(\mathrm{~s}, 1 \mathrm{H}), 7.13-$ $7.20(\mathrm{~m}, 1 \mathrm{H}), 7.23-7.34(\mathrm{~m}, 2 \mathrm{H}), 7.41(\mathrm{ddd}, J=8.3,2.3,0.9 \mathrm{~Hz}, 2 \mathrm{H})$, 7.49-7.55 (m, 1H), 7.65-7.70 (m, 1H), 8.06-8.11 (m, 2H).

${ }^{13} \mathbf{C ~ N M R}\left(75.4 \mathrm{MHz}, \mathrm{CDCl}_{3}\right) \delta(\mathrm{ppm})=13.8\left(\mathrm{CH}_{3}\right), 32.9\left(\mathrm{CH}_{3}\right), 44.6(\mathrm{CH}), 106.5(\mathrm{CH})$, $109.4(\mathrm{CH}), 109.5(\mathrm{CH}), 109.7(\mathrm{C}), 119.0(\mathrm{CH}), 119.5(\mathrm{CH}), 122.0(\mathrm{CH}), 126.9(\mathrm{C}), 128.5$ $(\mathrm{CH}), 128.6(2 \times \mathrm{CH}), 128.9(2 \times \mathrm{CH}), 133.1(\mathrm{CH}), 136.4(\mathrm{C}), 137.2(\mathrm{C}), 151.1(\mathrm{C}), 151.7$ (C), $196.2(\mathrm{C})$.

LRMS (70 eV, EI) $m / z(\%) 329\left(\mathrm{M}^{+}, 3\right), 224$ (100).

HRMS $\left(\mathrm{EI}^{+}\right)$calcd for $\mathrm{C}_{22} \mathrm{H}_{19} \mathrm{NO}_{2}, 329.1416$; found, 329.1417 .

2-(1,2-Dimethyl-1H-indol-3-yl)-2-(5-methylfuran-2-yl)-1-phenylethanone (23d).

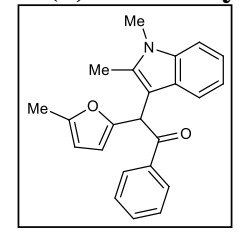

Yellow foam; yield $=65 \%$; m.p. $112-114{ }^{\circ} \mathrm{C}$.

${ }^{1} \mathbf{H}$ NMR $\left(300 \mathrm{MHz}, \mathrm{CDCl}_{3}\right) \delta(\mathrm{ppm})=2.29(\mathrm{~s}, 3 \mathrm{H}), 2.42(\mathrm{~s}, 3 \mathrm{H}), 3.61$ $(\mathrm{s}, 3 \mathrm{H}), 5.89-5.90(\mathrm{~m}, 1 \mathrm{H}), 5.93(\mathrm{~d}, J=2.4 \mathrm{~Hz}, 1 \mathrm{H}), 6.17(\mathrm{~s}, 1 \mathrm{H}), 7.07-$ $7.26(\mathrm{~m}, 3 \mathrm{H}), 7.31-7.35(\mathrm{~m}, 2 \mathrm{H}), 7.41-7.47(\mathrm{~m}, 1 \mathrm{H}), 7.67$ (d, $J=7.4$ $\mathrm{Hz}, 1 \mathrm{H}), 7.95-8.03(\mathrm{~m}, 2 \mathrm{H})$.

${ }^{13} \mathrm{C} \mathrm{NMR}\left(75.4 \mathrm{MHz}, \mathrm{CDCl}_{3}\right) \delta(\mathrm{ppm})=10.9\left(\mathrm{CH}_{3}\right), 13.8\left(\mathrm{CH}_{3}\right), 29.7\left(\mathrm{CH}_{3}\right), 45.2(\mathrm{CH})$, $105.6(\mathrm{C}), 106.3(\mathrm{CH}), 108.8(\mathrm{CH}), 109.6(\mathrm{CH}), 118.7(\mathrm{CH}), 119.6(\mathrm{CH}), 121.0(\mathrm{CH})$, $126.8(\mathrm{C}), 128.5(2 \times \mathrm{CH}), 128.6(2 \times \mathrm{CH}), 132.8(\mathrm{CH}), 134.9(\mathrm{C}), 136.6(\mathrm{C}), 136.8(\mathrm{C})$, $150.9(\mathrm{C}), 151.6(\mathrm{C}), 196.2(\mathrm{C})$.

LRMS (70 eV, EI) $\mathrm{m} / z$ (\%) $343\left(\mathrm{M}^{+}, 2\right), 238$ (100).

HRMS $\left(\mathrm{EI}^{+}\right)$calcd for $\mathrm{C}_{23} \mathrm{H}_{21} \mathrm{NO}_{2}, 343.1572$; found, 343.1568 . 


\section{2-(1H-Indol-3-yl)-2-(1-methyl-1H-pyrrol-2-yl)-1-phenylethanone (23e).}

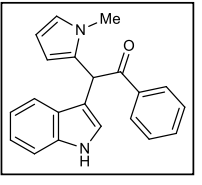

Yellow foam; yield $=50 \%$; m.p. $144-146{ }^{\circ} \mathrm{C}$.

${ }^{1} \mathbf{H}$ NMR $\left(300 \mathrm{MHz}, \mathrm{CDCl}_{3}\right) \delta(\mathrm{ppm})=3.51(\mathrm{~s}, 3 \mathrm{H}), 5.91-5.94(\mathrm{~m}, 1 \mathrm{H})$ $6.07(\mathrm{dd}, J=3.6,2.8 \mathrm{~Hz}, 1 \mathrm{H}), 6.21(\mathrm{~s}, 1 \mathrm{H}), 6.63-6.67(\mathrm{~m}, 1 \mathrm{H}), 6.83(\mathrm{~d}, J=2.1$ $\mathrm{Hz}, 1 \mathrm{H}), 7.10$ (ddd, $J=8.0,7.1,1.1 \mathrm{~Hz}, 1 \mathrm{H}), 7.15-7.22(\mathrm{~m}, 1 \mathrm{H}), 7.32(\mathrm{dd}, J=$ 8.0, 0.9 Hz, 1H), 7.38-7.46 (m, 2H), 7.49-7.57 (m, 2H), 8.01-8.08 (m, 2H), 8.23 (s, 1H).

${ }^{13} \mathrm{C} \mathrm{NMR}\left(75.4 \mathrm{MHz}, \mathrm{CDCl}_{3}\right) \delta(\mathrm{ppm})=34.2\left(\mathrm{CH}_{3}\right), 43.8(\mathrm{CH}), 107.0(\mathrm{CH}), 109.5(\mathrm{CH})$, $111.5(\mathrm{CH}), 112.5(\mathrm{C}), 118.8(\mathrm{CH}), 119.8(\mathrm{CH}), 122.3(\mathrm{CH}), 122.9(\mathrm{CH}), 124.5(\mathrm{CH}), 126.5(\mathrm{C})$, $128.7(2 \times \mathrm{CH}), 128.8(2 \times \mathrm{CH}), 129.7(\mathrm{C}), 133.1(\mathrm{CH}), 136.5(\mathrm{C}), 136.7(\mathrm{C}), 197.2(\mathrm{C})$.

LRMS (70 eV, EI) $\mathrm{m} / z$ (\%) $314\left(\mathrm{M}^{+}, 3\right), 209$ (100).

HRMS $\left(\mathrm{EI}^{+}\right)$calcd for $\mathrm{C}_{21} \mathrm{H}_{18} \mathrm{~N}_{2} \mathrm{O}, 314.1419$; found, 314.1417 .

\subsection{Synthesis of Tricarbonyl Compounds 25}

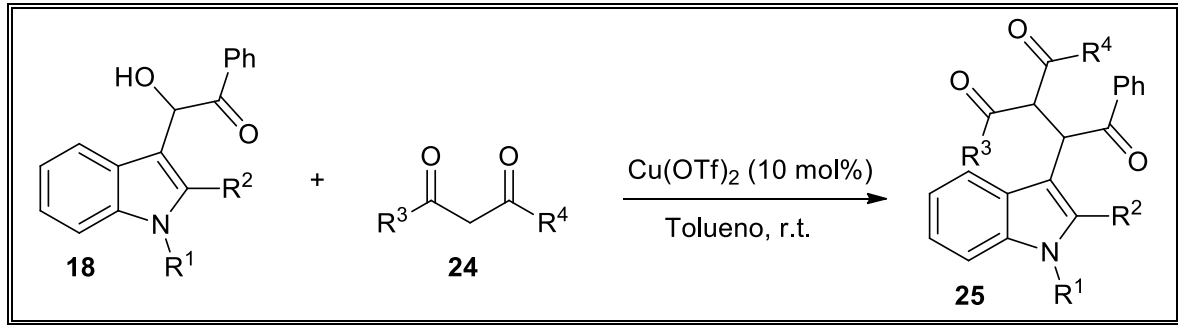

General Procedure: $\mathrm{Cu}(\mathrm{OTf})_{2}(36 \mathrm{mg}, 10 \mathrm{~mol} \%)$ was added to a solution of the corresponding $\alpha$-acyloin 18 (1 mmol) and the corresponding 1,3-dicarbonyl compound $24(1 \mathrm{mmol})$ in toluene $(4 \mathrm{ml})$ at r.t. The resulting mixture was stirred until the alcohol was consumed as determined by TLC. The crude reaction mixture was quenched with aqueous $\mathrm{NaOH}(0.5 \mathrm{M})$ and extracted with EtOAc $(3 \times 10 \mathrm{ml})$, and the combined organic layers were dried over anhydrous $\mathrm{Na}_{2} \mathrm{SO}_{4}$ and concentrated at reduced pressure. The residue was purified by flash chromatography on deactivated silica gel using mixtures of hexane and EtOAc as eluents to obtain the corresponding tricarbonyl compounds $\mathbf{2 5}$. In some cases the final product precipitates from the reaction mixture and could be isolated by simple filtration in pure form.

3-Acetyl-2-(1H-indol-3-yl)-1-phenylpentane-1,4-dione (25a).

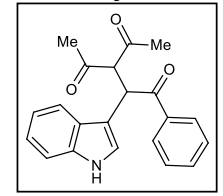

Yellow solid; yield $=90 \%$; m.p. $159-161{ }^{\circ} \mathrm{C}$.

${ }^{1} \mathbf{H}$ NMR $\left(400 \mathrm{MHz}, \mathrm{CDCl}_{3}\right) \delta(\mathrm{ppm})=1.88(\mathrm{~s}, 3 \mathrm{H}), 2.29(\mathrm{~s}, 3 \mathrm{H}), 5.04$ $(\mathrm{d}, J=11.1 \mathrm{~Hz}, 1 \mathrm{H}), 5.67(\mathrm{~d}, J=11.1 \mathrm{~Hz}, 1 \mathrm{H}), 7.04(\mathrm{~d}, J=2.6 \mathrm{~Hz}, 1 \mathrm{H})$, $7.12-7.19(\mathrm{~m}, 2 \mathrm{H}), 7.24-7.32(\mathrm{~m}, 3 \mathrm{H}), 7.39$ (at, $J=7.4 \mathrm{~Hz}, 1 \mathrm{H}), 7.71-$ $7.75(\mathrm{~m}, 1 \mathrm{H}), 7.93-7.96(\mathrm{~m}, 2 \mathrm{H}), 8.28(\mathrm{~s}, 1 \mathrm{H})$ 
${ }^{13} \mathrm{C} \mathrm{NMR}\left(100.6 \mathrm{MHz}, \mathrm{CDCl}_{3}\right) \delta(\mathrm{ppm})=30.4\left(\mathrm{CH}_{3}\right), 31.6\left(\mathrm{CH}_{3}\right), 45.5(\mathrm{CH}), 70.3(\mathrm{CH})$, $109.3(\mathrm{C}), 111.7(\mathrm{CH}), 119.0(\mathrm{CH}), 120.5(\mathrm{CH}), 122.7(\mathrm{CH}), 124.2(\mathrm{C}), 125.8(\mathrm{C}), 128.5$ $(2 \times \mathrm{CH}), 128.8(2 \times \mathrm{CH}), 133.1(\mathrm{CH}), 135.9(\mathrm{CH}), 136.5(\mathrm{C}), 197.8(\mathrm{C}), 202.3(\mathrm{C}), 204.0(\mathrm{C})$.

LRMS (70 eV, EI) $\mathrm{m} / z$ (\%) $333\left(\mathrm{M}^{+}, 6\right), 186$ (100).

HRMS $\left(\mathrm{EI}^{+}\right)$calcd for $\mathrm{C}_{21} \mathrm{H}_{19} \mathrm{NO}_{3}, 333.1365$; found, 333.1360 .

2-Benzoyl-3-(1H-indol-3-yl)-1,4-diphenylbutane-1,4-dione (25b).

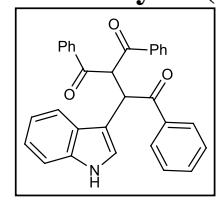

White solid; yield $=80 \%$; m.p. $232-234{ }^{\circ} \mathrm{C} .{ }^{13} \mathrm{C}$ NMR was consistent with the formation of rotamers.

${ }^{1} \mathbf{H}$ NMR $\left(400 \mathrm{MHz},\left(\mathrm{CD}_{3}\right)_{2} \mathrm{SO}\right) \delta(\mathrm{ppm})=5.97(\mathrm{~d}, J=10.6 \mathrm{~Hz}, 1 \mathrm{H})$, $6.68(\mathrm{~d}, J=10.6 \mathrm{~Hz}, 1 \mathrm{H}), 6.97(\mathrm{td}, J=13.6,6.1 \mathrm{~Hz}, 2 \mathrm{H}), 7.20-7.06(\mathrm{~m}$,

$3 \mathrm{H}), 7.26(\mathrm{~d}, J=2.4 \mathrm{~Hz}, 1 \mathrm{H}), 7.45-7.32(\mathrm{~m}, 5 \mathrm{H}), 7.55(\mathrm{t}, J=7.4 \mathrm{~Hz}, 1 \mathrm{H}), 7.67(\mathrm{t}, J=7.7$ $\mathrm{Hz}, 3 \mathrm{H}), 7.94(\mathrm{~d}, J=7.4 \mathrm{~Hz}, 2 \mathrm{H}), 8.02(\mathrm{~d}, J=7.4 \mathrm{~Hz}, 2 \mathrm{H}), 10.82(\mathrm{~s}, 1 \mathrm{H})$.

${ }^{13} \mathrm{C}$ NMR $\left(106.4 \mathrm{MHz},\left(\mathrm{CD}_{3}\right)_{2} \mathrm{SO}, \mathrm{T}=60{ }^{\circ} \mathrm{C}\right) \delta(\mathrm{ppm})=46.2,58.4,107.1,118.1,118.2$, $125.1,125.5,127.1,128.0,128.1,128.5,132.8,135.6,136.0,194.4,195.8,196.9$.

LRMS (70 eV, EI) $m / z$ (\%) $457\left(\mathrm{M}^{+}, 2\right) ; 105$ (100).

HRMS $\left(\mathrm{EI}^{+}\right)$calcd for $\mathrm{C}_{31} \mathrm{H}_{23} \mathrm{NO}_{3}, 457.1678$; found 457.1677.

3-Benzoyl-2-(1H-indol-3-yl)-1-phenylpentane-1,4-dione (25c).

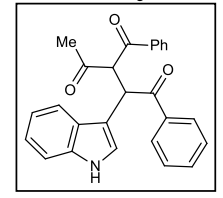

Isolated as a ca. 1.8:1 mixture of diastereoisomers. White foam; yield = $78 \% ; R_{f}=0.25$ (hexane/EtOAc, $3 / 1$ ).

${ }^{1} \mathbf{H}$ NMR $\left(300 \mathrm{MHz}, \mathrm{CDCl}_{3}\right) \delta(\mathrm{ppm})=1.88(\mathrm{~s}, 3 \mathrm{H}$, one diast), $2.22(\mathrm{~s}$, $3 \mathrm{H}$, one diast), $5.84(\mathrm{~d}, J=10.9 \mathrm{~Hz}, 1 \mathrm{H}), 5.95-5.91(\mathrm{~m}, 1 \mathrm{H}), 6.00(\mathrm{dd}, J$ $=11.0,1.1 \mathrm{~Hz}, 1 \mathrm{H}), 6.93(\mathrm{~s}, 1 \mathrm{H}), 7.14-7.00(\mathrm{~m}, 3 \mathrm{H}), 7.22-7.15(\mathrm{~m}, 4 \mathrm{H}), 7.34-7.25(\mathrm{~m}$, $6 \mathrm{H}), 7.44-7.35(\mathrm{~m}, 3 \mathrm{H}), 7.53-7.44(\mathrm{~m}, 3 \mathrm{H}), 7.63-7.54(\mathrm{~m}, 1 \mathrm{H}), 7.67(\mathrm{~d}, J=8.1 \mathrm{~Hz}, 1 \mathrm{H})$, $7.75(\mathrm{~d}, J=7.8 \mathrm{~Hz}, 1 \mathrm{H}), 7.84-7.80(\mathrm{~m}, 1 \mathrm{H}), 7.89(\mathrm{~d}, J=8.2 \mathrm{~Hz}, 1 \mathrm{H}), 8.03-7.97(\mathrm{~m}, 4 \mathrm{H})$, $8.10(\mathrm{ad}, J=8.1 \mathrm{~Hz}, 3 \mathrm{H}), 8.48(\mathrm{~s}, 1 \mathrm{H})$.

${ }^{13} \mathbf{C ~ N M R}\left(75.4 \mathrm{MHz}, \mathrm{CDCl}_{3}\right) \delta(\mathrm{ppm})=30.3\left(\mathrm{CH}_{3}\right), 30.6\left(\mathrm{CH}_{3}\right), 45.9(\mathrm{CH}), 46.1(\mathrm{CH})$, $64.3(\mathrm{CH}), 65.6(\mathrm{CH}), 109.2(\mathrm{C}), 109.3(\mathrm{C}), 111.3(\mathrm{CH}), 111.7(\mathrm{CH}), 111.8(\mathrm{CH}), 118.9$ $(\mathrm{CH}), 119.1(\mathrm{CH}), 120.2(\mathrm{CH}), 120.4(\mathrm{CH}), 122.3(\mathrm{CH}), 122.6(\mathrm{CH}), 122.7(\mathrm{CH}), 124.1$ $(\mathrm{CH}), 124.4(\mathrm{CH}), 125.8(\mathrm{C}), 125.9(\mathrm{C}), 127.1(\mathrm{CH}), 128.4(\mathrm{CH}), 128.5(2 \times \mathrm{CH}), 128.6$ $(\mathrm{CH}), 128.8(2 \times \mathrm{CH}), 128.95(\mathrm{CH}), 129.01(\mathrm{C}), 133.03(\mathrm{CH}), 133.07(\mathrm{CH}), 133.4(\mathrm{CH})$, $133.8(\mathrm{CH}), 135.86(\mathrm{C}), 135.94(\mathrm{C}), 136.3(\mathrm{C}), 136.49(\mathrm{C}), 136.52(\mathrm{C}), 137.0(\mathrm{C}), 195.0$ (C), 196.4 (C), 197.7 (C), 198.3 (C), 202.0 (C), 203.8 (C).

LRMS (70 eV, EI) $\mathrm{m} / z$ (\%) $395\left(\mathrm{M}^{+}, 15\right) ; 105$ (100).

HRMS $\left(\mathrm{EI}^{+}\right)$calcd for $\mathrm{C}_{26} \mathrm{H}_{21} \mathrm{NO}_{3}, 395.1521$; found 395.1528 . 
Ethyl 2-acetyl-3-(1H-indol-3-yl)-4-oxo-4-phenylbutanoate (25d).

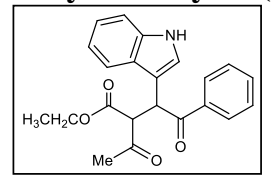

Isolated as a ca. 1.1:1 mixture of diastereoisomers. Yellow foam; yield $=68 \% ; R_{f}=0.25($ hexane/EtOAc, $2: 1)$.

${ }^{1} \mathbf{H}$ NMR $\left(300 \mathrm{MHz}, \mathrm{CDCl}_{3}\right) \delta(\mathrm{ppm})=0.88(\mathrm{t}, J=7.1 \mathrm{~Hz}, 3 \mathrm{H}$, one diast), $1.19(\mathrm{t}, J=7.1 \mathrm{~Hz}, 3 \mathrm{H}), 1.89(\mathrm{~s}, 3 \mathrm{H}$, one diast), 2.37 (s, 3H, one diast), 3.84 (qd, $J=7.1,2.1 \mathrm{~Hz}, 2 \mathrm{H}$, one diast), 4.09-4.20 (m, 2H, one diast), 4.74 (d, $J=11.0 \mathrm{~Hz}, 1 \mathrm{H}$, one diast), $4.87(\mathrm{~d}, J=11.3 \mathrm{~Hz}, 1 \mathrm{H}$, one diast), $5.66(\mathrm{~d}, J=11.4 \mathrm{~Hz}$, $1 \mathrm{H}$, one diast), $5.70(\mathrm{~d}, J=11.1 \mathrm{~Hz}, 1 \mathrm{H}$, one diast), 7.01 (s, 1H, one diast), 7.02 (s, 1H, one diast), 7.10-7.19 (m, 4H, both diast), 7.21-7.32 (m, 6H, both diast), 7.35-7.43 (m, 2H, both diast), 7.73-7.83 (m, 2H), 7.90-8.03 (m, 4H), 8.42-8.58 (m, 2H).

${ }^{13} \mathrm{C} \mathrm{NMR}\left(75.4 \mathrm{MHz}, \mathrm{CDCl}_{3}\right) \delta(\mathrm{ppm})=13.7\left(\mathrm{CH}_{3}\right), 14.0\left(\mathrm{CH}_{3}\right), 29.7\left(\mathrm{CH}_{2}\right), 32.1\left(\mathrm{CH}_{2}\right)$, $44.3(\mathrm{CH}), 44.6(\mathrm{CH}), 61.4(\mathrm{CH}), 61.6\left(\mathrm{CH}_{2}\right), 61.8\left(\mathrm{CH}_{2}\right), 63.7(\mathrm{CH}), 109.0(\mathrm{C}), 109.5$ (C), $111.5(\mathrm{CH}), 111.6(\mathrm{CH}), 119.1(\mathrm{CH}), 119.2(\mathrm{CH}), 120.1(\mathrm{CH}), 120.4(\mathrm{CH}), 122.4$ $(\mathrm{CH}), 122.6(\mathrm{CH}), 124.1(\mathrm{CH}), 124.4(\mathrm{CH}), 125.8(\mathrm{C}), 126.1(\mathrm{C}), 128.47(2 \times \mathrm{CH}), 128.50$ $(2 \times \mathrm{CH}), 128.8(4 \times \mathrm{CH}), 133.0(2 \times \mathrm{CH}), 135.9(\mathrm{C}), 136.37(\mathrm{C}), 136.42(\mathrm{C}), 168.2(\mathrm{C})$, 168.6 (C), 197.7 (C), 197.9 (C), 202.1 (C), 203.8 (C), one aromatic carbon peak was misssing due to overlapping.

LRMS (70 eV, EI) $m / z$ (\%) $363\left(\mathbf{M}^{+}, 10\right), 170$ (100).

HRMS $\left(\mathrm{EI}^{+}\right)$calcd for $\mathrm{C}_{22} \mathrm{H}_{21} \mathrm{NO}_{4}, 363.1471$; found, 363.1470.

Ethyl 2-benzoyl-3-(1H-indol-3-yl)-4-oxo-4-phenylbutanoate (25e).

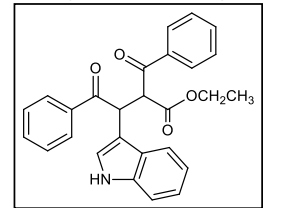

Isolated as a ca. 1:1 mixture of diastereoisomers. White solid; yield $=80 \%$; m.p. $149-151^{\circ} \mathrm{C}$.

${ }^{1} \mathbf{H}$ NMR $\left(300 \mathrm{MHz}, \mathrm{CDCl}_{3}\right) \delta(\mathrm{ppm})=0.76(\mathrm{t}, J=7.1 \mathrm{~Hz}, 3 \mathrm{H}$, one diast), $1.12(\mathrm{t}, J=7.1 \mathrm{~Hz}, 3 \mathrm{H}$, one diast), 3.67-3.80 (m, $2 \mathrm{H}$, one diast), 4.13 (q, $J=7.1 \mathrm{~Hz}, 2 \mathrm{H}$, one diast), 5.48 (d, $J=8.8 \mathrm{~Hz}, 1 \mathrm{H}$, one diast), 5.69 (d, $J=$ $9.1 \mathrm{~Hz}, 1 \mathrm{H}$, one diast), $5.92(\mathrm{~d}, J=11.0 \mathrm{~Hz}, 1 \mathrm{H}$, one diast), $5.99(\mathrm{~d}, J=10.9 \mathrm{~Hz}, 1 \mathrm{H}$, one diast), 6.95 (s, 1H, one diast), 7.07-7.10 (m, 3H), 7.16-7.20 (m, 3H), 7.26-7.33 (m, 5H), 7.38-7.45 (m, 2H), 7.48 (d, $J=7.7 \mathrm{~Hz}, 1 \mathrm{H}), 7.58$ (at, $J=7.3 \mathrm{~Hz}, 2 \mathrm{H}), 7.71$ (d, $J=7.3$ $\mathrm{Hz}, 2 \mathrm{H}), 7.83(\mathrm{t}, J=7.1 \mathrm{~Hz}, 2 \mathrm{H}), 8.01-8.05(\mathrm{~m}, 4 \mathrm{H}), 8.14(\mathrm{~d}, J=7.5 \mathrm{~Hz}, 2 \mathrm{H}), 8.45(\mathrm{~s}, 1 \mathrm{H})$. ${ }^{13} \mathrm{C} \mathrm{NMR}\left(75.4 \mathrm{MHz}, \mathrm{CDCl}_{3}\right) \delta(\mathrm{ppm})=13.6\left(\mathrm{CH}_{3}\right), 14.0\left(\mathrm{CH}_{3}\right), 44.9(\mathrm{CH}), 45.4(\mathrm{CH})$, $56.2(\mathrm{CH}), 59.1(\mathrm{CH}), 61.6\left(\mathrm{CH}_{2}\right), 61.8\left(\mathrm{CH}_{2}\right), 109.4(\mathrm{C}), 109.7(\mathrm{C}), 111.2(\mathrm{CH}), 111.5$ $(\mathrm{CH}), 119.1(\mathrm{CH}), 119.4(\mathrm{CH}), 120.2(\mathrm{CH}), 120.3(\mathrm{CH}), 122.3(\mathrm{CH}), 122.5(\mathrm{CH}), 124.2$ $(\mathrm{CH}), 126.0(\mathrm{C}), 126.3(\mathrm{C}), 128.2(\mathrm{CH}), 128.5(2 \times \mathrm{CH}), 128.7(\mathrm{CH}), 128.8(\mathrm{CH}), 128.9$ $(2 \times \mathrm{CH}), 129.0(2 \times \mathrm{CH}), 133.0(2 \times \mathrm{CH}), 133.2(\mathrm{CH}), 133.8(\mathrm{CH}), 136.0(\mathrm{C}), 136.04$ (C), 136.1 (C), 136.2 (C), 136.5 (C), 136.9 (C), 168.7 (C), 168.9 (C), 193.9 (C), 196.0 (C), 197.7 (C), 198.2 (C).

LRMS (70 eV, EI) $m / z(\%) 425\left(\mathrm{M}^{+}, 13\right), 105$ (100).

HRMS $\left(\mathrm{EI}^{+}\right)$calcd for $\mathrm{C}_{27} \mathrm{H}_{23} \mathrm{NO}_{4}, 425.1627$; found, 425.1626. 


\section{3-Acetyl-2-(2-methyl-1H-indol-3-yl)-1-phenylpentane-1,4-dione (25f).}

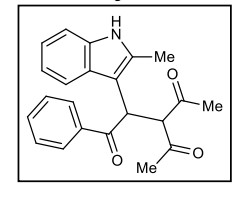

White solid; yield $=93 \%$; m.p. $143-145{ }^{\circ} \mathrm{C} ;{ }^{1} \mathrm{H}$ and ${ }^{13} \mathrm{C}$ NMR were consistent with the formation of rotamers.

${ }^{1} \mathbf{H}$ NMR $\left(400 \mathrm{MHz},\left(\mathrm{CD}_{3}\right)_{2} \mathrm{SO}\right) \delta(\mathrm{ppm})=1.77(\mathrm{~s}, 3 \mathrm{H}), 2.24(\mathrm{~s}, 3 \mathrm{H})$, 2,35 (bs, 3H), 5.13 (bs, 1H), 5.42 (bs, 1H), 6.89-6.96 (m, 2H), 7.08$7.23(\mathrm{~m}, 1 \mathrm{H}), 7.34-747(\mathrm{~m}, 4 \mathrm{H}), 7.85$ (d, $J=7.5 \mathrm{~Hz}, 2 \mathrm{H}), 10.97$ (s, 1H).

${ }^{13} \mathrm{C}$ NMR $\left(100.6 \mathrm{MHz},\left(\mathrm{CD}_{3}\right)_{2} \mathrm{SO}\right) \delta(\mathrm{ppm})=11.1\left(\mathrm{CH}_{3}\right), 29.7\left(\mathrm{CH}_{3}\right), 31.0\left(\mathrm{bs}, \mathrm{CH}_{3}\right)$, 44.1 (bs, CH), 66.0 (bs, CH), $102.1(\mathrm{CH}), 110.4(\mathrm{CH}), 117.4$ (bs, C), $118.7(\mathrm{CH}), 120.1$ $(\mathrm{CH}), 126.0$ (bs, C), $127.6(2 \times \mathrm{CH}), 127.8(\mathrm{C}), 128.2(2 \times \mathrm{CH}), 128.5(\mathrm{C}), 132.5(\mathrm{CH})$, 133.5 (bs, C), 134.9 (bs, C), 135.3 (C), $135.4(\mathrm{CH}), 201.6$ (C), 203.3 (C), one aromatic carbon peak was misssing due to overlapping.

LRMS (70 eV, EI) $\mathrm{m} / z$ (\%) $347\left(\mathrm{M}^{+}, 9\right), 200$ (100).

HRMS $\left(\mathrm{EI}^{+}\right)$calcd for $\mathrm{C}_{22} \mathrm{H}_{21} \mathrm{NO}_{3}, 347.1521$; found, 347.1520 .

\section{3-Acetyl-2-(1,2-dimethyl-1H-indol-3-yl)-1-phenylpentane-1,4-dione (25g).}

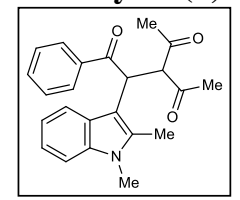

White solid; yield $=76 \%$; m.p. $147-149{ }^{\circ} \mathrm{C} ;{ }^{1} \mathrm{H}$ and ${ }^{13} \mathrm{C}$ NMR were consistent with the formation of rotamers.

${ }^{1} \mathbf{H}$ NMR $\left(300 \mathrm{MHz}, \mathrm{CDCl}_{3}\right): \delta(\mathrm{ppm})=1.82(\mathrm{bs}, 3 \mathrm{H}), 2.33(\mathrm{~s}, 3 \mathrm{H})$, 2.47 (bs, 3H), 3.53 (bs, 3H), 5.29 (bs, 1H), 5.58 (bs, 1H), 7.04-7.17 (m, $3 \mathrm{H}), 7.24-7.32(\mathrm{~m}, 2 \mathrm{H}), 7.35-7.42(\mathrm{~m}, 1 \mathrm{H}), 7.64(\mathrm{bs}, 1 \mathrm{H}), 7.90(\mathrm{ad}, J=6.2 \mathrm{~Hz}, 2 \mathrm{H})$.

${ }^{13} \mathrm{C} \mathrm{NMR}\left(75.4 \mathrm{MHz}, \mathrm{CDCl}_{3}\right) \delta(\mathrm{ppm})=10.7\left(\mathrm{CH}_{3}\right), 29.8\left(\mathrm{CH}_{3}\right), 30.6\left(\mathrm{bs}, \mathrm{CH}_{3}\right), 32.6$ (bs, $\mathrm{CH}_{3}$ ), 46.4 (bs, $\left.\mathrm{CH}\right), 67.2$ (bs, $\left.\mathrm{CH}\right), 103.5(\mathrm{CH}), 109.0(\mathrm{CH}), 118.8$ (bs, C), 119.9 $(\mathrm{CH}), 121.1(\mathrm{CH}), 126.1(\mathrm{bs}, \mathrm{C}), 128.4(2 \times \mathrm{CH}), 128.5(2 \times \mathrm{CH}), 132.8(\mathrm{CH}), 134.9(\mathrm{bs}$, C), 136.3 (bs, C), 136.9 (bs, C), 198.0 (bs, C), 201.4 (C), 203.4 (C).

LRMS (70 eV, EI) $\mathrm{m} / \mathrm{z}$ (\%) $361\left(\mathrm{M}^{+}, 20\right), 214$ (100).

HRMS $\left(\mathrm{EI}^{+}\right)$calcd for $\mathrm{C}_{23} \mathrm{H}_{23} \mathrm{NO}_{3}, 361.1678$; found, 361.1680 .

2-Acetyl-2-(1H-indol-3-yl)cyclohexanone (25h): Isolated as a mixture of

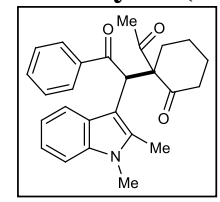
diasteroisomers ca. 5:1. Data for the major one. White foam; yield $=10 \%$. ${ }^{1} \mathbf{H}$ NMR $\left(300 \mathrm{MHz}, \mathrm{CDCl}_{3}\right) \delta(\mathrm{ppm})=1.37-1.57$ (m, 2H both diast), 1.84-2.00 (m, 3H both diast), 2.05 (s, 3H), 2.11-2.25 (m, 2H), 2.33-2.62 (m, 3H both diast), $2.96(\mathrm{td}, J=13.8,3.9 \mathrm{~Hz}, 1 \mathrm{H}), 5.68(\mathrm{~s}, 1 \mathrm{H}), 6.91-6.97$ (m, 1H), 7.09-7.41 (m, 8H), 7.50-7.57 (m, 1H), 7.81-7.91 (m, 2H), $8.35(\mathrm{~s}, 1 \mathrm{H})$.

${ }^{13} \mathbf{C ~ N M R}\left(75.4 \mathrm{MHz}, \mathrm{CDCl}_{3}\right) \delta(\mathrm{ppm})=23.3\left(\mathrm{CH}_{3}\right), 23.5\left(\mathrm{CH}_{2}\right), 27.3\left(\mathrm{CH}_{2}\right), 30.2\left(\mathrm{CH}_{2}\right)$, $42.0\left(\mathrm{CH}_{2}\right), 46.9(\mathrm{CH}), 71.2(\mathrm{C}), 107.5(\mathrm{CH}), 111.7(\mathrm{CH}), 118.3(\mathrm{CH}), 120.5(\mathrm{CH}), 122.6$ $(\mathrm{CH}), 125.2(\mathrm{CH}), 126.9(\mathrm{C}), 128.37(2 \times \mathrm{CH}), 128.41(2 \times \mathrm{CH}), 132.5(\mathrm{C}), 136.2(\mathrm{C})$, 137.4 (C), 198.3 (C), 206.4 (C), 209.2 (C). 


\section{3-Acetyl-2-(1H-indol-3-yl)-3-methyl-1-phenylpentane-1,4-dione (25i).}

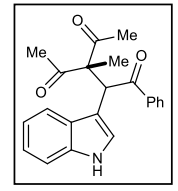

White solid; yield $=6 \%$; m.p. $145-147{ }^{\circ} \mathrm{C}$.

${ }^{1} \mathbf{H}$ NMR $\left(300 \mathrm{MHz}, \mathrm{CDCl}_{3}\right): \delta(\mathrm{ppm})=1.84(\mathrm{~s}, 3 \mathrm{H}), 1.99(\mathrm{~s}, 3 \mathrm{H}), 2.20(\mathrm{~s}$, $3 \mathrm{H}), 6.01(\mathrm{~s}, 1 \mathrm{H}), 7.00(\mathrm{~d}, J=2.6 \mathrm{~Hz}, 1 \mathrm{H}), 7.10-7.21(\mathrm{~m}, 2 \mathrm{H}), 7.22-7.42$ $(\mathrm{m}, 4 \mathrm{H}), 7.61-7.66(\mathrm{~m}, 1 \mathrm{H}), 7.85-7.91(\mathrm{~m}, 2 \mathrm{H}), 8.30(\mathrm{~s}, 1 \mathrm{H})$.

${ }^{13} \mathrm{C} \mathrm{NMR}\left(75.4 \mathrm{MHz}, \mathrm{CDCl}_{3}\right) \delta(\mathrm{ppm})=27.6\left(\mathrm{CH}_{3}\right), 27.7\left(\mathrm{CH}_{3}\right), 48.7(\mathrm{CH}), 70.7(\mathrm{C})$, $111.5(\mathrm{CH}), 119.3(\mathrm{CH}), 120.5(\mathrm{CH}), 122.6(\mathrm{CH}), 125.5(\mathrm{C}), 126.7(\mathrm{C}), 128.46(2 \times \mathrm{CH})$, $128.54(2 \times \mathrm{CH}), 132.7(\mathrm{CH}), 136.3(\mathrm{C}), 136.9(\mathrm{C}), 198.8(\mathrm{C}), 205.9(\mathrm{C}), 207.7(\mathrm{C})$.

\subsection{Synthesis of Furanylindoles 26}

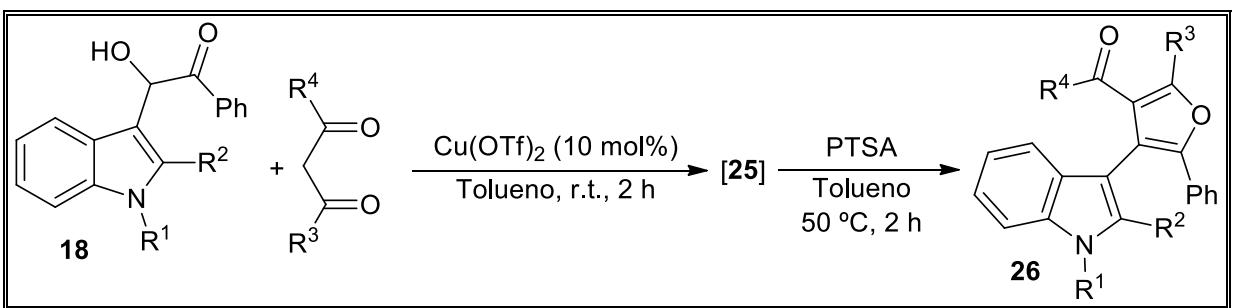

General Procedure: $\mathrm{Cu}(\mathrm{OTf})_{2}(36 \mathrm{mg}, 10 \mathrm{~mol} \%)$ was added to a solution of the corresponding $\alpha$-acyloin 18 ( $1 \mathrm{mmol})$ and dicarbonyl compound (1 mmol) in toluene (4 $\mathrm{ml})$ at r.t. The resulting mixture was stirred for $2 \mathrm{~h}$ at r.t. Then, PTSA ( $9 \mathrm{mg}, 10 \mathrm{~mol} \%$ ) was added and the reaction was heated at $50{ }^{\circ} \mathrm{C}$ until the corresponding intermediate tricarbonyl derivative $\mathbf{2 5}$ was consumed as determined by TLC. The crude reaction mixture was quenched with aqueous $\mathrm{NaOH}(0.5 \mathrm{M})$ and extracted with $\mathrm{CH}_{2} \mathrm{Cl}_{2}(3 \times 15$ $\mathrm{ml}$ ), and the combined organic layers were dried over anhydrous $\mathrm{Na}_{2} \mathrm{SO}_{4}$ and concentrated at reduced pressure. The residue was purified by flash chromatography on deactivated silica gel using mixtures of hexane and EtOAc as eluents to obtain the corresponding furanylindoles 26.

\section{1-(4-(1H-Indol-3-yl)-2-methyl-5-phenylfuran-3-yl)ethanone (26a).}

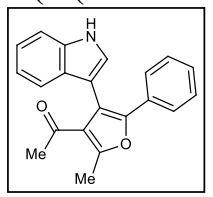

Yellow solid; yield $=80 \%$; m.p. $151-153{ }^{\circ} \mathrm{C}$.

${ }^{1} \mathbf{H}$ NMR $\left(300 \mathrm{MHz}, \mathrm{CDCl}_{3}\right) \delta(\mathrm{ppm})=1.85(\mathrm{~s}, 3 \mathrm{H}), 2.70(\mathrm{~s}, 3 \mathrm{H}), 7.09$ $7.19(\mathrm{~m}, 5 \mathrm{H}), 7.24-7.30(\mathrm{~m}, 1 \mathrm{H}), 7.37-7.47(\mathrm{~m}, 4 \mathrm{H}), 8.43(\mathrm{~s}, 1 \mathrm{H})$.

${ }^{13} \mathrm{C}$ NMR $\left(75.4 \mathrm{MHz}, \mathrm{CDCl}_{3}\right) \delta(\mathrm{ppm})=14.9\left(\mathrm{CH}_{3}\right), 30.1\left(\mathrm{CH}_{3}\right), 108.5$

(C), $111.5(\mathrm{CH}), 113.3(\mathrm{C}), 119.8(\mathrm{CH}), 120.5(\mathrm{CH}), 122.7(\mathrm{CH}), 123.8(\mathrm{CH}), 125.2(2 \times$ $\mathrm{CH}), 125.5(\mathrm{C}), 127.3(\mathrm{CH}), 127.9(\mathrm{C}), 128.3(2 \times \mathrm{CH}), 130.6(\mathrm{C}), 136.3(\mathrm{C}), 148.6(\mathrm{C})$, 157.8 (C), $197.0(\mathrm{C})$.

LRMS (70 eV, EI) $\mathrm{m} / z$ (\%) $315\left(\mathrm{M}^{+}, 100\right)$.

HRMS $\left(\mathrm{EI}^{+}\right)$calcd for $\mathrm{C}_{21} \mathrm{H}_{17} \mathrm{NO}_{2}, 315.1259$, found, 315.1259 . 
1-(2-Methyl-4-(2-methyl-1H-indol-3-yl)-5-phenylfuran-3-yl)ethanone (26b).

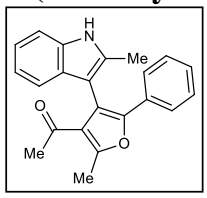

Yellow solid; yield $=90 \%$; m.p. $128-130{ }^{\circ} \mathrm{C}$.

${ }^{1} \mathbf{H}$ NMR $\left(300 \mathrm{MHz},\left(\mathrm{CDCl}_{3}\right) \delta(\mathrm{ppm})=1.84(\mathrm{~s}, 3 \mathrm{H}), 2.20(\mathrm{~s}, 3 \mathrm{H}), 2.72\right.$ (s, 3H), 7.07 (ddd, $J=7.9,7.2,0.9 \mathrm{~Hz}, 1 \mathrm{H}), 7.12-7.23(\mathrm{~m}, 4 \mathrm{H}), 7.31$ (d, $J=7.8 \mathrm{~Hz}, 1 \mathrm{H}), 7.35-7.42(\mathrm{~m}, 3 \mathrm{H}), 8.29(\mathrm{~s}, 1 \mathrm{H})$.

${ }^{13} \mathrm{C} \mathrm{NMR}\left(75.4 \mathrm{MHz}, \mathrm{CDCl}_{3}\right) \delta(\mathrm{ppm})=12.2\left(\mathrm{CH}_{3}\right), 14.9\left(\mathrm{CH}_{3}\right), 29.7\left(\mathrm{CH}_{3}\right), 105.5(\mathrm{C})$, 110.6 (CH), $113.1(\mathrm{C}), 119.1(\mathrm{CH}), 120.4(\mathrm{CH}), 121.9(\mathrm{CH}), 124.8(2 \times \mathrm{CH}), 125.2(\mathrm{C}), 127.2$ $(\mathrm{CH}), 128.5(2 \times \mathrm{CH}), 129.0(\mathrm{C}), 130.8(\mathrm{C}), 133.0(\mathrm{C}), 135.8(\mathrm{C}), 148.5(\mathrm{C}), 158.1(\mathrm{C}), 196.9(\mathrm{C})$. LRMS $(70 \mathrm{eV}, \mathrm{EI}) \mathrm{m} / z(\%) 329\left(\mathrm{M}^{+}, 100\right)$.

HRMS $\left(\mathrm{EI}^{+}\right)$calcd for $\mathrm{C}_{22} \mathrm{H}_{19} \mathrm{NO}_{2}, 329.1416$, found, 329.1417.

1-(4-(1,2-Dimethyl-1H-indol-3-yl)-2-methyl-5-phenylfuran-3-yl)ethanone (26c).

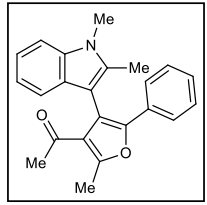

Yellow solid; yield $=84 \%$; m.p. $181-183{ }^{\circ} \mathrm{C}$.

${ }^{1} \mathbf{H}$ NMR $\left(300 \mathrm{MHz}, \mathrm{CDCl}_{3}\right) \delta(\mathrm{ppm})=1.78(\mathrm{~s}, 3 \mathrm{H}), 2.19(\mathrm{~s}, 3 \mathrm{H}), 2.71$

(s, 3H), $3.77(\mathrm{~s}, 3 \mathrm{H}), 7.02-7.10(\mathrm{~m}, 1 \mathrm{H}), 7.12-7.21(\mathrm{~m}, 3 \mathrm{H}), 7.22-7.26$ $(\mathrm{m}, 1 \mathrm{H}), 7.31(\mathrm{~d}, J=7.8 \mathrm{~Hz}, 1 \mathrm{H}), 7.34-7.41(\mathrm{~m}, 3 \mathrm{H})$.

${ }^{13}$ C NMR $\left(75.4 \mathrm{MHz}, \mathrm{CDCl}_{3}\right) \delta(\mathrm{ppm})=11.0\left(\mathrm{CH}_{3}\right), 14.9\left(\mathrm{CH}_{3}\right), 29.8\left(\mathrm{CH}_{3}\right), 30.0\left(\mathrm{CH}_{3}\right)$, $104.8(\mathrm{C}), 109.0(\mathrm{CH}), 113.6(\mathrm{C}), 119.2(\mathrm{CH}), 120.1(\mathrm{CH}), 121.5(\mathrm{CH}), 124.8(2 \times \mathrm{CH})$, $125.4(\mathrm{C}), 127.2(\mathrm{CH}), 128.1(\mathrm{C}), 128.5(2 \times \mathrm{CH}), 131.0(\mathrm{C}), 134.9(\mathrm{C}), 137.3(\mathrm{C}), 148.5$ (C), 158.0 (C), 196.8 (C).

LRMS (70 eV, EI) $\mathrm{m} / z(\%) 343\left(\mathbf{M}^{+}, 100\right)$.

HRMS $\left(\mathrm{EI}^{+}\right)$calcd for $\mathrm{C}_{23} \mathrm{H}_{21} \mathrm{NO}_{2}, 343.1572$, found, 343.1574 .

Ethyl 4-(1H-indol-3-yl)-2-methyl-5-phenylfuran-3-carboxylate (26d).

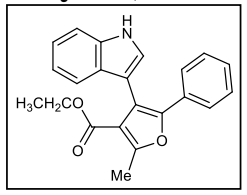

Brown solid; yield $=67 \%$; m.p. $179-181{ }^{\circ} \mathrm{C}$.

${ }^{1} \mathbf{H}$ NMR $\left(300 \mathrm{MHz}, \mathrm{CDCl}_{3}\right) \delta(\mathrm{ppm})=0.85(\mathrm{t}, J=7.1 \mathrm{~Hz}, 3 \mathrm{H}), 2.72$ $(\mathrm{s}, 3 \mathrm{H}), 4.01(\mathrm{q}, J=7.1 \mathrm{~Hz}, 2 \mathrm{H}), 7.04$ (at, $J=7.5 \mathrm{~Hz}, 1 \mathrm{H}), 7.11-7.23$ $(\mathrm{m}, 5 \mathrm{H}), 7.32(\mathrm{~d}, J=7.9 \mathrm{~Hz}, 1 \mathrm{H}), 7.38-7.48(\mathrm{~m}, 3 \mathrm{H}), 8.27(\mathrm{~s}, 1 \mathrm{H})$.

${ }^{13}$ C NMR (75.4 MHz, $\left.\mathrm{CDCl}_{3}\right) \delta(\mathrm{ppm})=13.7\left(\mathrm{CH}_{3}\right), 14.5\left(\mathrm{CH}_{3}\right), 59.9\left(\mathrm{CH}_{2}\right), 108.5(\mathrm{C})$, $111.1(\mathrm{CH}), 114.4(\mathrm{C}), 116.6(\mathrm{C}), 119.8(\mathrm{CH}), 120.3(\mathrm{CH}), 122.1(\mathrm{CH}), 123.9(\mathrm{CH}), 125.5(2 \times$ $\mathrm{CH}), 127.3(\mathrm{CH}), 127.9(\mathrm{C}), 128.3(2 \times \mathrm{CH}), 130.8(\mathrm{C}), 136.2(\mathrm{C}), 148.6(\mathrm{C}), 158.4(\mathrm{C}), 164.4(\mathrm{C})$.

LRMS $(70 \mathrm{eV}, \mathrm{EI}) \mathrm{m} / z$ (\%) $345\left(\mathbf{M}^{+}, 100\right)$.

HRMS $\left(\mathrm{EI}^{+}\right)$calcd for $\mathrm{C}_{22} \mathrm{H}_{19} \mathrm{~N}_{3}, 345.1365$; found, 345.1368 .

3-(4,5-Dimethyl-2-phenylfuran-3-yl)-1 $H$-indole (26i).

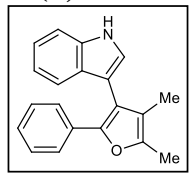

Yellow solid; yield $=58 \%$; m.p. $116-118{ }^{\circ} \mathrm{C}$.

${ }^{1} \mathbf{H}$ NMR $\left(300 \mathrm{MHz}, \mathrm{CDCl}_{3}\right) \delta(\mathrm{ppm})=1.86(\mathrm{~s}, 3 \mathrm{H}), 2.40(\mathrm{~s}, 3 \mathrm{H}), 7.06-$ $7.21(\mathrm{~m}, 5 \mathrm{H}), 7.26(\mathrm{at}, J=7.5 \mathrm{~Hz}, 1 \mathrm{H}), 7.37(\mathrm{~d}, J=7.8 \mathrm{~Hz}, 1 \mathrm{H}), 7.44(\mathrm{~d}$, $J=8.1 \mathrm{~Hz}, 1 \mathrm{H}), 7.50(\mathrm{~d}, J=7.8 \mathrm{~Hz}, 2 \mathrm{H}), 8.21(\mathrm{~s}, 1 \mathrm{H})$.

${ }^{13} \mathbf{C ~ N M R}\left(75.4 \mathrm{MHz}, \mathrm{CDCl}_{3}\right) \delta(\mathrm{ppm})=9.1\left(\mathrm{CH}_{3}\right), 12.0\left(\mathrm{CH}_{3}\right), 109.5(\mathrm{C}), 111.2(\mathrm{CH})$, $116.5(\mathrm{C}), 118.1(\mathrm{C}), 119.9(\mathrm{CH}), 120.6(\mathrm{CH}), 122.3(\mathrm{CH}), 123.3(\mathrm{CH}), 124.8(2 \times \mathrm{CH})$, $126.3(\mathrm{CH}), 127.1(\mathrm{C}), 128.2(2 \times \mathrm{CH}), 131.9(\mathrm{C}), 136.3(\mathrm{C}), 146.6(\mathrm{C}), 147.1(\mathrm{C})$.

LRMS $\left(70 \mathrm{eV}\right.$, EI) $\mathrm{m} / \mathrm{z}(\%) 287\left(\mathrm{M}^{+}, 100\right)$.

HRMS $\left(\mathrm{EI}^{+}\right)$calcd for $\mathrm{C}_{20} \mathrm{H}_{17} \mathrm{NO}, 287.1310$; found, 287.1310 


\subsection{Synthesis of $\alpha$-(Trimethoxyphenyl) Carbonyl Compound 27a}

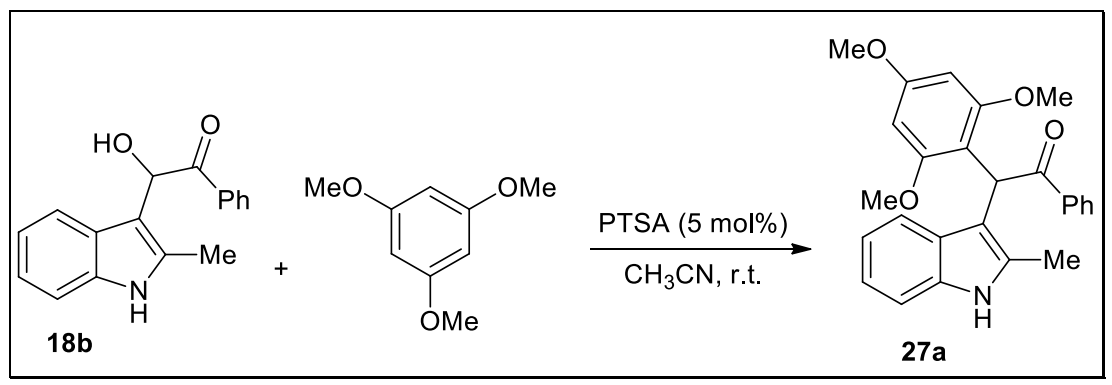

General Procedure: PTSA ( $9 \mathrm{mg}, 5 \mathrm{~mol} \%$ ) was added to a solution of the corresponding $\alpha$-acyloin $\mathbf{1 8 b}$ (265.3 mg, $1 \mathrm{mmol}$ ) 1,3,5-trimethoxybenzene (168.2 $\mathrm{mg}, 1$ $\mathrm{mmol})$ in $\mathrm{MeCN}(2 \mathrm{ml})$. The resulting reaction mixture was stirred at r.t. until the alcohol was consumed as determined by TLC. The crude mixture was quenched with aqueous $\mathrm{NaOH}(0.5 \mathrm{M})$ and extracted with EtOAc $(3 \times 15 \mathrm{ml})$, and the combined organic layers were dried over anhydrous $\mathrm{Na}_{2} \mathrm{SO}_{4}$ and concentrated at reduced pressure. The residue was purified by flash chromatography using mixtures of hexane and EtOAc as eluents to obtain the corresponding $\alpha$-(indol-3-yl) carbonyl compounds derivatives $\mathbf{2 7 a}$.

\section{2-(2-Methyl-1H-indol-3-yl)-1-phenyl-2-(2,4,6-trimethoxyphenyl)ethanone (27a).}

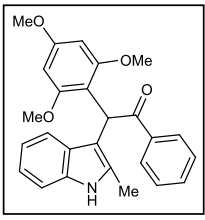

White foam; yield $=38 \% ; R_{f}=0.19$ (hexane/EtOAc, $\left.1: 1\right)$.

${ }^{1} \mathbf{H}$ NMR $\left(300 \mathrm{MHz}, \mathrm{CDCl}_{3}\right) \delta(\mathrm{ppm})=2.24(\mathrm{~s}, 3 \mathrm{H}), 3.65(\mathrm{~s}, 6 \mathrm{H}), 3.74$ $(\mathrm{s}, 3 \mathrm{H}), 6.07(\mathrm{~s}, 2 \mathrm{H}), 6.21(\mathrm{~s}, 1 \mathrm{H}), 6.98-7.04(\mathrm{~m}, 2 \mathrm{H}), 7.12-7.20(\mathrm{~m}$, $1 \mathrm{H}), 7.24-7.34(\mathrm{~m}, 2 \mathrm{H}), 7.35-7.42(\mathrm{~m}, 1 \mathrm{H}), 7.52(\mathrm{~d}, J=7.5 \mathrm{~Hz}, 1 \mathrm{H})$, $7.77(\mathrm{~s}, 1 \mathrm{H}), 7.86-7.81(\mathrm{~m}, 2 \mathrm{H})$.

${ }^{13} \mathrm{C}$ NMR $\left(75.4 \mathrm{MHz}, \mathrm{CDCl}_{3}\right) \delta(\mathrm{ppm})=12.6\left(\mathrm{CH}_{3}\right), 42.3(\mathrm{CH}), 55.3\left(\mathrm{CH}_{3}\right), 55.6(2 \times$ $\left.\mathrm{CH}_{3}\right), 91.1(2 \times \mathrm{CH}), 109.5(\mathrm{C}), 110.0(\mathrm{C}), 110.4(\mathrm{CH}), 119.1(\mathrm{CH}), 119.5(\mathrm{CH}), 128.08$ $(2 \times \mathrm{CH}), 128.12(2 \times \mathrm{CH}), 129.1(\mathrm{C}), 131.8(\mathrm{CH}), 132.7(\mathrm{C}), 135.2(\mathrm{C}), 137.6(\mathrm{C}), 158.3$ $(2 \times \mathrm{C}), 160.3(\mathrm{C}), 198.7(\mathrm{C})$.

LRMS (70 eV, EI): $m / z(\%) 415\left(\mathbf{M}^{+}, 9\right), 310$ (100).

HRMS $\left(\mathrm{EI}^{+}\right)$calcd for $\mathrm{C}_{26} \mathrm{H}_{25} \mathrm{NO}_{4}, 415.1784$; found, 415.1779 .

\subsection{Synthesis of $\alpha$-(Indol-3-yl) Carbonyl Compounds 28}

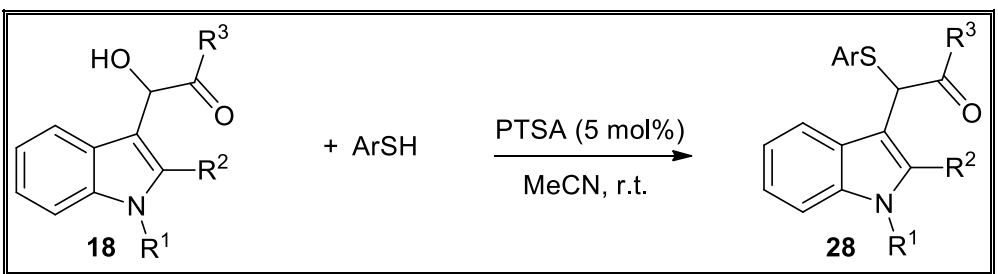


General Procedure: PTSA ( $9 \mathrm{mg}, 5 \mathrm{~mol} \%$ ) was added to a solution of the corresponding $\alpha$-acyloin 18 ( $1 \mathrm{mmol})$ and tiophenol $(1 \mathrm{mmol})$ in $\mathrm{MeCN}(2 \mathrm{ml})$. The resulting reaction mixture was stirred at r.t. until the alcohol was consumed as determined by TLC. The crude mixture was quenched with aqueous $\mathrm{NaOH}(0.5 \mathrm{M})$ and extracted with $\mathrm{CH}_{2} \mathrm{Cl}_{2}(3 \times 10 \mathrm{ml})$, and the combined organic layers were dried over anhydrous $\mathrm{Na}_{2} \mathrm{SO}_{4}$ and concentrated at reduced pressure. The residue was purified by flash chromatography using mixtures of hexane and EtOAc as eluents to obtain the corresponding $\alpha$-(indol-3-yl) carbonyl compounds derivatives 28.

\section{2-(1H-Indol-3-yl)-1-phenyl-2-(p-tolylthio)ethanone (28a).}

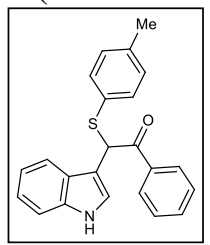

White solid; yield $=87 \%$; m.p. $113-115^{\circ} \mathrm{C}$.

${ }^{1} \mathbf{H}$ NMR $\left(300 \mathrm{MHz}, \mathrm{CDCl}_{3}\right) \delta(\mathrm{ppm})=2.29(\mathrm{~s}, 3 \mathrm{H}), 6.22(\mathrm{~s}, 1 \mathrm{H}), 7.02$ $(\mathrm{d}, J=7.8 \mathrm{~Hz}, 2 \mathrm{H}), 7.10(\mathrm{~d}, J=2.5 \mathrm{~Hz}, 1 \mathrm{H}), 7.18-7.27(\mathrm{~m}, 4 \mathrm{H}), 7.32$ $7.42(\mathrm{~m}, 3 \mathrm{H}), 7.51(\mathrm{at}, J=7.3 \mathrm{~Hz}, 1 \mathrm{H}), 7.82-7.86(\mathrm{~m}, 1 \mathrm{H}), 8.02(\mathrm{ad}, J=$ $7.7 \mathrm{~Hz}, 2 \mathrm{H}), 8.39$ (s, 1H).

${ }^{13} \mathrm{C}$ NMR $\left(75.4 \mathrm{MHz}, \mathrm{CDCl}_{3}\right) \delta(\mathrm{ppm})=21.2\left(\mathrm{CH}_{3}\right), 51.4(\mathrm{CH}), 110.0(\mathrm{C}), 111.7(\mathrm{CH})$, $119.0(\mathrm{CH}), 120.1(\mathrm{CH}), 122.5(\mathrm{CH}), 125.0(\mathrm{CH}), 126.0(\mathrm{C}), 128.6(2 \times \mathrm{CH}), 128.8(2 \times \mathrm{CH})$, $129.6(2 \times \mathrm{CH}), 130.4(\mathrm{C}), 133.2(\mathrm{CH}), 134.0(2 \times \mathrm{CH}), 136.1(\mathrm{C}), 136.3(\mathrm{C}), 138.3(\mathrm{C}), 194.9(\mathrm{C})$.

LRMS (70 eV, EI) $m / z$ (\%) $357\left(\mathrm{M}^{+}, 4\right), 234$ (100).

HRMS $\left(\mathrm{EI}^{+}\right)$calcd for $\mathrm{C}_{23} \mathrm{H}_{19} \mathrm{NOS}$, 357.1187; found, 357.1185.

\section{2-(1H-Indol-3-yl)-2-((4-methoxyphenyl)thio)-1-phenylethanone (28b).}

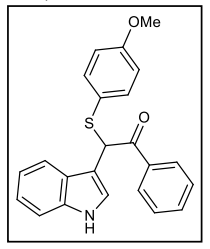

Brown solid; yield $=83 \% ; R_{f}=0.25$ (hexane/EtOAc, 6:1).

${ }^{1} \mathbf{H}$ NMR $\left(300 \mathrm{MHz},\left(\mathrm{CD}_{3}\right)_{2} \mathrm{CO}\right) \delta(\mathrm{ppm})=3.73(\mathrm{~s}, 3 \mathrm{H}), 6.45(\mathrm{~s}, 1 \mathrm{H})$, 6.73-6.81 (m, 2H), 7.06-7.26 (m, 4H), $7.29(\mathrm{~d}, J=2.6 \mathrm{~Hz}, 1 \mathrm{H})$, $7.37-7.56(\mathrm{~m}, 4 \mathrm{H}), 7.90(\mathrm{~d}, J=7.6 \mathrm{~Hz}, 1 \mathrm{H}), 8.08-8.12(\mathrm{~m}, 1 \mathrm{H}), 10.27(\mathrm{~s}, 1 \mathrm{H})$.

${ }^{13} \mathrm{C}$ NMR $\left(75.4 \mathrm{MHz},\left(\mathrm{CD}_{3}\right)_{2} \mathrm{CO}\right) \delta(\mathrm{ppm})=52.9\left(\mathrm{CH}_{3}\right), 55.5(\mathrm{CH})$, $110.4(\mathrm{C}), 112.4(\mathrm{CH}), 114.9(2 \times \mathrm{CH}), 120.1(\mathrm{CH}), 120.2(\mathrm{CH}), 122.6(\mathrm{CH}), 125.3(\mathrm{C})$, $126.4(\mathrm{CH}), 127.0(\mathrm{C}), 129.3(2 \times \mathrm{CH}), 129.5(2 \times \mathrm{CH}), 133.7(\mathrm{CH}), 137.0(2 \times \mathrm{CH})$, 137.1 (C), $137.5(\mathrm{C}), 160.8(\mathrm{C}), 195.1(\mathrm{C})$.

LRMS (70 eV, EI) $m / z(\%) 373\left(\mathrm{M}^{+}, 3\right), 234$ (100).

HRMS $\left(\mathrm{EI}^{+}\right)$calcd for $\mathrm{C}_{23} \mathrm{H}_{19} \mathrm{NO}_{2} \mathrm{~S}, 373.1136$; found, 373.1136.

2-((2,5-Dimethoxyphenyl)thio)-2-(1H-indol-3-yl)-1-phenylethanone (28c).

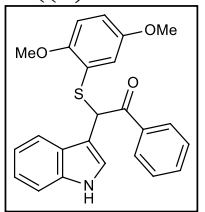

White foam; yield $=76 \% ; R_{f}=0.25$ (hexane/EtOAc, $4: 1$ ).

${ }^{1} \mathbf{H}$ NMR $\left(300 \mathrm{MHz}, \mathrm{CDCl}_{3}\right) \delta(\mathrm{ppm})=3.53(\mathrm{~s}, 3 \mathrm{H}), 3.68(\mathrm{~s}, 3 \mathrm{H}), 6.45$ $(\mathrm{d}, J=3.0 \mathrm{~Hz}, 1 \mathrm{H}), 6.73(\mathrm{~s}, 2 \mathrm{H}), 6.81(\mathrm{~d}, J=1.5 \mathrm{~Hz}, 1 \mathrm{H}), 7.11-7.23(\mathrm{~m}$, $3 \mathrm{H}), 7.25-7.40(\mathrm{~m}, 3 \mathrm{H}), 7.46$ (at, $J=7.3 \mathrm{~Hz}, 1 \mathrm{H}), 7.79-7.84(\mathrm{~m}, 1 \mathrm{H})$, $7.98(\mathrm{ad}, J=7.9 \mathrm{~Hz}, 2 \mathrm{H}), 8.56(\mathrm{~s}, 1 \mathrm{H})$. 
${ }^{13} \mathrm{C} \mathrm{NMR}\left(75.4 \mathrm{MHz}, \mathrm{CDCl}_{3}\right) \delta(\mathrm{ppm})=49.2(\mathrm{CH}), 55.7\left(\mathrm{CH}_{3}\right), 56.2\left(\mathrm{CH}_{3}\right), 110.0(\mathrm{C})$, $111.6(\mathrm{CH}), 111.9(\mathrm{CH}), 114.7(\mathrm{CH}), 119.0(\mathrm{CH}), 119.2(\mathrm{CH}), 120.1(\mathrm{CH}), 122.5(\mathrm{CH})$, $123.6(\mathrm{C}), 124.7(\mathrm{CH}), 126.2(\mathrm{C}), 128.6(2 \times \mathrm{CH}), 128.7(2 \times \mathrm{CH}), 133.1(\mathrm{CH}), 136.2$ (C), $136.4(\mathrm{C}), 153.2(\mathrm{C}), 153.3(\mathrm{C}), 195.4(\mathrm{C})$.

LRMS (70 eV, EI) $\mathrm{m} / z$ (\%) 387 [(M-O) $\left.{ }^{+}, 25\right], 282$ (100).

HRMS $\left(\mathrm{EI}^{+}\right)$calcd for $\mathrm{C}_{24} \mathrm{H}_{21} \mathrm{NO}_{3} \mathrm{~S}(\mathrm{M}-\mathrm{O})^{+}, 387.1293$, found, 387.1295.

\section{2-((3,4-Dimethoxyphenyl)thio)-2-(1H-indol-3-yl)-1-phenylethanone (28d).}

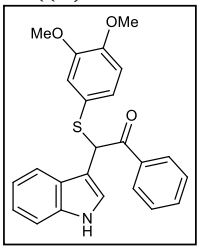

Orange oil; yield $=75 \% ; R_{f}=0.34$ (hexane/EtOAc, $5: 1$ ).

${ }^{1} \mathbf{H}$ NMR $\left(300 \mathrm{MHz}, \mathrm{CDCl}_{3}\right) \delta(\mathrm{ppm})=3.48(\mathrm{~s}, 3 \mathrm{H}), 3.81(\mathrm{~s}, 3 \mathrm{H}), 6.14$ $(\mathrm{s}, 1 \mathrm{H}), 6.54(\mathrm{~d}, J=1.8 \mathrm{~Hz}, 1 \mathrm{H}), 6.70(\mathrm{~d}, J=8.3 \mathrm{~Hz}, 1 \mathrm{H}), 6.94(\mathrm{dd}, J=$ 8.3, 2.0 Hz, 1H), 7.09 (d, $J=2.5 \mathrm{~Hz}, 1 \mathrm{H}), 7.17-7.28(\mathrm{~m}, 2 \mathrm{H}), 7.31-7.44$ $(\mathrm{m}, 3 \mathrm{H}), 7.51$ (at, $J=7.3 \mathrm{~Hz}, 1 \mathrm{H}), 7.78-7.83(\mathrm{~m}, 1 \mathrm{H}), 8.00(\mathrm{~d}, J=7.6$

$\mathrm{Hz}, 2 \mathrm{H}), 8.43$ (s, 1H).

${ }^{13} \mathrm{C}$ NMR $\left(75.4 \mathrm{MHz}, \mathrm{CDCl}_{3}\right) \delta(\mathrm{ppm})=51.3\left(\mathrm{CH}_{3}\right), 55.6\left(\mathrm{CH}_{3}\right), 55.9\left(\mathrm{CH}_{3}\right), 109.9(\mathrm{C})$, $111.1(\mathrm{CH}), 111.5(\mathrm{CH}), 118.3(\mathrm{CH}), 119.1(\mathrm{CH}), 120.1(\mathrm{CH}), 122.6(\mathrm{CH}), 124.2(\mathrm{C})$, $125.2(\mathrm{CH}), 126.2(\mathrm{C}), 128.4(\mathrm{CH}), 128.7(2 \times \mathrm{CH}), 128.8(2 \times \mathrm{CH}), 133.2(\mathrm{CH}), 136.1$ (C), 136.2 (C), 148.3 (C), 149.6 (C), 194.9 (C).

LRMS (70 eV, EI) $m / z(\%) 387$ [(M-O)+, 19], 282 (100).

HRMS $\left(\mathrm{EI}^{+}\right)$calcd for $\mathrm{C}_{24} \mathrm{H}_{21} \mathrm{NO}_{3} \mathrm{~S}(\mathrm{M}-\mathrm{O})^{+}, 387.1293$; found, 387.1294 .

2-((2-Bromophenyl)thio)-2-(2-methyl-1H-indol-3-yl)-1-phenylethanone (28e): Black

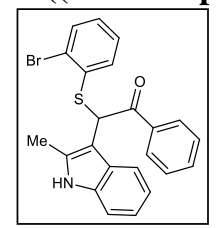
solid; yield $=78 \%$; m.p. $99-101{ }^{\circ} \mathrm{C}$.

${ }^{1} \mathbf{H}$ NMR $\left(300 \mathrm{MHz}, \mathrm{CDCl}_{3}\right) \delta(\mathrm{ppm})=2.21(\mathrm{~s}, 3 \mathrm{H}), 6.38(\mathrm{~s}, 1 \mathrm{H}), 6.95-$ $7.05(\mathrm{~m}, 2 \mathrm{H}), 7.06-7.13(\mathrm{~m}, 3 \mathrm{H}), 7.16-7.21(\mathrm{~m}, 1 \mathrm{H}), 7.31$ (at, $J=7.5 \mathrm{~Hz}$, $2 \mathrm{H}), 7.43(\mathrm{dd}, J=8.3,6.4 \mathrm{~Hz}, 1 \mathrm{H}), 7.56(\mathrm{dd}, J=7.6,1.6 \mathrm{~Hz}, 1 \mathrm{H}), 7.71$ $(\mathrm{dd}, J=5.9,3.2 \mathrm{~Hz}, 1 \mathrm{H}), 7.86(\mathrm{~s}, 1 \mathrm{H}), 7.90-7.94(\mathrm{~m}, 2 \mathrm{H})$.

${ }^{13} \mathrm{C} \mathrm{NMR}\left(75.4 \mathrm{MHz}, \mathrm{CDCl}_{3}\right) \delta(\mathrm{ppm})=12.0\left(\mathrm{CH}_{3}\right), 52.8(\mathrm{CH}), 105.7(\mathrm{C}), 110.5(\mathrm{CH})$, $119.0(\mathrm{CH}), 120.3(\mathrm{CH}), 121.7(\mathrm{CH}), 127.1(\mathrm{C}), 127.6(\mathrm{CH}), 128.66(2 \times \mathrm{CH}), 128.70(2$ $\times \mathrm{CH}), 128.9(\mathrm{C}), 129.2(\mathrm{CH}), 133.0(\mathrm{CH}), 133.2(\mathrm{CH}), 134.1(\mathrm{C}), 135.3(\mathrm{C}), 135.6(\mathrm{C})$, $135.7(\mathrm{CH}), 135.9(\mathrm{C}), 194.4(\mathrm{C})$.

LRMS (70 eV, EI) $m / z(\%) 435\left[(\mathrm{M}+2)^{+}, 3\right], 437\left(\mathrm{M}^{+}, 3\right), 248$ (100).

HRMS $\left(\mathrm{EI}^{+}\right)$calcd for $\mathrm{C}_{23} \mathrm{H}_{18} \mathrm{BrNOS}$, 435.0292; found, 435.0291 .

2-((2-Bromophenyl)thio)-2-(1-methyl-1H-indol-3-yl)-1-phenylethanone (28f).

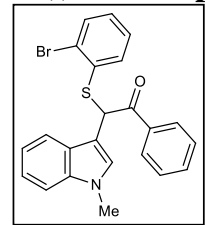

Orange solid; yield $=86 \%$; m.p. $129-131{ }^{\circ} \mathrm{C}$.

${ }^{1} \mathbf{H}$ NMR $\left(300 \mathrm{MHz}, \mathrm{CDCl}_{3}\right) \delta(\mathrm{ppm})=3.67(\mathrm{~s}, 3 \mathrm{H}), 6.51(\mathrm{~s}, 1 \mathrm{H}), 7.00$ $7.09(\mathrm{~m}, 2 \mathrm{H}), 7.10(\mathrm{~s}, 1 \mathrm{H}), 7.21(\mathrm{ddd}, J=7.8,6.6,3.8 \mathrm{~Hz}, 1 \mathrm{H}), 7.26-7.31$ (m, 3H), 7.37 (at, $J=7.8 \mathrm{~Hz}, 2 \mathrm{H}), 7.49$ (at, $J=7.4 \mathrm{~Hz}, 1 \mathrm{H}$ ), 7.55-7.59 (m, 1H), 7.80-7.86 (m, 1H), 7.98-8.04 (m, 2H). 
${ }^{13} \mathrm{C} \mathrm{NMR}\left(75.4 \mathrm{MHz}, \mathrm{CDCl}_{3}\right) \delta(\mathrm{ppm})=33.0\left(\mathrm{CH}_{3}\right), 50.1(\mathrm{CH}), 107.7(\mathrm{C}), 109.7(\mathrm{CH})$, $119.1(\mathrm{CH}), 120.0(\mathrm{CH}), 122.3(\mathrm{CH}), 126.6(\mathrm{C}), 126.8(\mathrm{C}), 127.8(\mathrm{CH}), 128.6(\mathrm{CH}), 128.7$ $(2 \times \mathrm{CH}), 128.8(2 \times \mathrm{CH}), 129.3(\mathrm{CH}), 133.1(\mathrm{CH}), 133.3(\mathrm{CH}), 135.9(\mathrm{C}), 136.2(\mathrm{C})$, $137.2(\mathrm{C}), 194.4(\mathrm{C})$, one aromatic carbon peak was misssing due to overlapping.

LRMS (70 eV, EI) $m / z(\%) 435\left[(\mathrm{M}+2)^{+}, 1\right], 437\left(\mathrm{M}^{+}, 1\right), 248(100)$.

HRMS $\left(\mathrm{EI}^{+}\right)$calcd for $\mathrm{C}_{23} \mathrm{H}_{18} \mathrm{BrNOS}$, 435.0292; found, 435.0293 .

2-((4-Chlorophenyl)thio)-2-(1-methyl-1H-indol-3-yl)-1-phenylethanone (28g).

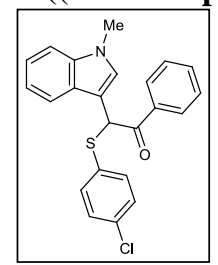

White solid; yield $=89 \%$; m.p. $114-116^{\circ} \mathrm{C}$.

${ }^{1} \mathbf{H}$ NMR $\left(300 \mathrm{MHz}, \mathrm{CDCl}_{3}\right) \delta(\mathrm{ppm})=3.67(\mathrm{~s}, 3 \mathrm{H}), 6.25(\mathrm{~s}, 1 \mathrm{H}), 7.04$ (s, 1H), 7.14-7.28 (m, 5H), 7.28-7.34 (m, 2H), 7.36-7.44 (m, 2H), 7.48$7.55(\mathrm{~m}, 1 \mathrm{H}), 7.77-7.83(\mathrm{~m}, 1 \mathrm{H}), 7.98-8.03(\mathrm{~m}, 2 \mathrm{H})$.

${ }^{13} \mathrm{C}$ NMR (75.4 MHz, $\left.\mathrm{CDCl}_{3}\right) \delta(\mathrm{ppm})=32.9\left(\mathrm{CH}_{3}\right), 51.1(\mathrm{CH}), 108.0$ (C), $109.7(\mathrm{CH}), 119.0(\mathrm{CH}), 119.9(\mathrm{CH}), 122.3(\mathrm{CH}), 126.4(\mathrm{C}), 128.7(2 \times \mathrm{CH}), 128.8$ $(2 \times \mathrm{CH}), 128.9(2 \times \mathrm{CH}), 129.4(\mathrm{CH}), 132.7(\mathrm{C}), 133.3(\mathrm{CH}), 134.2(\mathrm{C}), 135.0(2 \times \mathrm{CH})$, 135.9 (C), $137.1(\mathrm{C}), 194.3(\mathrm{C})$.

LRMS (70 eV, EI) m/z (\%) $393\left[(\mathrm{M}+2)^{+}, 1\right], 391\left(\mathrm{M}^{+}, 3\right), 248(100)$.

HRMS $\left(\mathrm{EI}^{+}\right)$calcd for $\mathrm{C}_{23} \mathrm{H}_{18} \mathrm{ClNOS}, 391.0798$; found, 391.0799 .

2-((4-Methoxyphenyl)thio)-2-(1-methyl-1H-indol-3-yl)-1-phenylethanone (28h).

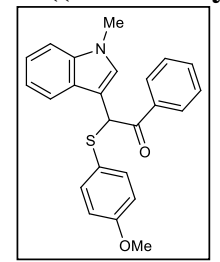

Yellow solid; yield $=87 \%$; m.p. $145-147{ }^{\circ} \mathrm{C}$.

${ }^{1} \mathbf{H}$ NMR $\left(300 \mathrm{MHz}, \mathrm{CDCl}_{3}\right) \delta(\mathrm{ppm})=3.67(\mathrm{~s}, 3 \mathrm{H}), 3.76(\mathrm{~s}, 3 \mathrm{H}), 6.17$ (s, 1H), 6.72-6.78 (m, 2H). $7.06(\mathrm{~s}, 1 \mathrm{H}), 7.20-7.27(\mathrm{~m}, 3 \mathrm{H}), 7.28-7.33$ $(\mathrm{m}, 2 \mathrm{H}), 7.40$ (at, $J=7.7 \mathrm{~Hz}, 2 \mathrm{H}), 7.51$ (at, $J=7.0 \mathrm{~Hz}, 1 \mathrm{H}), 7.80-7.84$ $(\mathrm{m}, 1 \mathrm{H}), 8.02(\mathrm{~d}, J=7.6 \mathrm{~Hz}, 2 \mathrm{H})$.

${ }^{13}$ C NMR $\left(75.4 \mathrm{MHz}, \mathrm{CDCl}_{3}\right) \delta 32.8\left(\mathrm{CH}_{3}\right), 51.3(\mathrm{CH}), 55.3\left(\mathrm{CH}_{3}\right), 108.4(\mathrm{C}), 109.5$ $(\mathrm{CH}), 114.2(2 \times \mathrm{CH}), 119.0(\mathrm{CH}), 119.7(\mathrm{CH}), 122.1(\mathrm{CH}), 124.2(\mathrm{C}), 126.6(\mathrm{CH}), 128.6$ $(2 \times \mathrm{CH}), 128.7(2 \times \mathrm{CH}), 129.4(\mathrm{C}), 133.0(\mathrm{CH}), 136.2(\mathrm{C}), 136.8(2 \times \mathrm{CH}), 136.9(\mathrm{C})$, 160.1 (C), $194.6(\mathrm{C})$.

LRMS (70 eV, EI) $m / z$ (\%) $387\left(\mathrm{M}^{+}, 1\right), 139$ (100).

HRMS $\left(\mathrm{EI}^{+}\right)$calcd for $\mathrm{C}_{24} \mathrm{H}_{21} \mathrm{NO}_{2} \mathrm{~S}\left(\mathrm{M}-\mathrm{C}_{7} \mathrm{H}_{5} \mathrm{O}\right)^{+}, 282.0953$; found, 282.0951 .

1-(1-Methyl-1H-indol-3-yl)-1-(p-tolylthio)propan-2-one (28i).

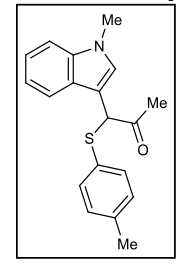

Yellow foam; yield $=70 \% ; R_{f}=0.30$ (hexane/EtOAc, 5/1).

${ }^{1} \mathbf{H}$ NMR $\left(300 \mathrm{MHz}, \mathrm{CDCl}_{3}\right) \delta(\mathrm{ppm})=2.28(\mathrm{~s}, 3 \mathrm{H}), 2.35(\mathrm{~s}, 3 \mathrm{H}), 3.74(\mathrm{~s}$, $3 \mathrm{H}), 5.29(\mathrm{~s}, 1 \mathrm{H}), 7.10(\mathrm{~s}, 1 \mathrm{H}), 7.12-7.15(\mathrm{~m}, 2 \mathrm{H}), 7.21$ (ddd, $J=8.0,6.5$, $1.6 \mathrm{~Hz}, 1 \mathrm{H}), 7.27-7.37(\mathrm{~m}, 4 \mathrm{H}), 7.71-7.75(\mathrm{~m}, 1 \mathrm{H})$.

${ }^{13} \mathbf{C}$ NMR $\left(75.4 \mathrm{MHz}, \mathrm{CDCl}_{3}\right) \delta(\mathrm{ppm})=21.1\left(\mathrm{CH}_{3}\right), 26.8\left(\mathrm{CH}_{3}\right), 32.8$ $\left(\mathrm{CH}_{3}\right), 56.0(\mathrm{CH}), 107.9(\mathrm{C}), 109.5(\mathrm{CH}), 119.1(\mathrm{CH}), 119.7(\mathrm{CH}), 122.2$ $(\mathrm{CH}), 126.6(\mathrm{C}), 128.4(\mathrm{CH}), 129.7(2 \times \mathrm{CH}), 130.2(\mathrm{C}), 133.0(2 \times \mathrm{CH}), 137.0(\mathrm{C}), 138.0$ (C), 203.3 (C).

LRMS (70 eV, EI) m/z (\%) $309\left(\mathrm{M}^{+}, 2\right), 186$ (100).

HRMS $\left(\mathrm{EI}^{+}\right)$calcd for $\mathrm{C}_{19} \mathrm{H}_{19} \mathrm{NOS}, 309.1187$, found 309.1187 . 


\subsection{Synthesis of $\alpha$-(Indol-3-yl) Carbonyl Compounds 29}

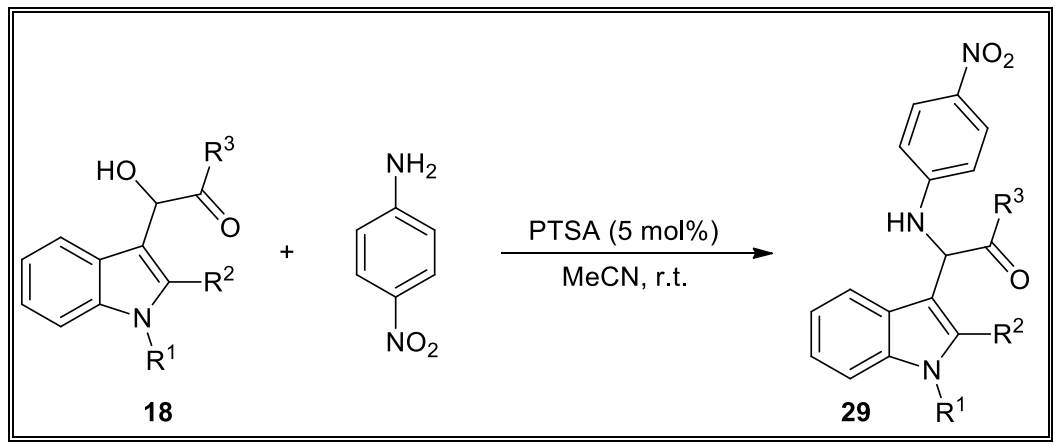

General Procedure: PTSA ( $9 \mathrm{mg}, 5 \mathrm{~mol} \%$ ) was added to a solution of the corresponding $\alpha$-acyloin 18 (1 mmol) and 4-nitroaniline (151.8 mg, 1,1 mmol) in MeCN $(2 \mathrm{ml})$. The resulting reaction mixture was stirred at r.t. until the alcohol was consumed as determined by TLC. The crude mixture was quenched with aqueous $\mathrm{NaOH}(0.5 \mathrm{M})$ and extracted with $\mathrm{CH}_{2} \mathrm{Cl}_{2}(3 \times 10 \mathrm{ml})$, and the combined organic layers were dried over anhydrous $\mathrm{Na}_{2} \mathrm{SO}_{4}$ and concentrated at reduced pressure. The residue was purified by flash chromatography using mixtures of hexane and EtOAc as eluents to obtain the corresponding $\alpha$-(indol-3-yl) carbonyl compounds derivatives 29

\section{2-(1H-Indol-3-yl)-2-((4-nitrophenyl)amino)-1-phenylethanone (29a).}

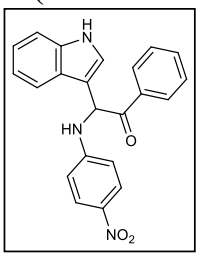

Yellow foam; yield $=65 \% ; R_{f}=0.25$ (hexane/EtOAc, $2: 1$ ).

${ }^{1} \mathbf{H}$ NMR $\left(300 \mathrm{MHz}, \mathrm{CDCl}_{3}\right) \delta(\mathrm{ppm})=6.05(\mathrm{~d}, J=6.3 \mathrm{~Hz}, 1 \mathrm{H}), 6.40(\mathrm{~d}, J=6.3 \mathrm{~Hz}$, $1 \mathrm{H}), 6.56-6.67(\mathrm{~m}, 2 \mathrm{H}), 7.15-7.28(\mathrm{~m}, 3 \mathrm{H}), 7.31-7.44(\mathrm{~m}, 3 \mathrm{H}), 7.47-7.56(\mathrm{~m}, 1 \mathrm{H})$, 7.73-7.81 (m, 1H), 7.95-8.09 (m, 4H), 8.44 (s, 1H).

${ }^{13} \mathbf{C N M R}\left(75.4 \mathrm{MHz}, \mathrm{CDCl}_{3}\right) \delta(\mathrm{ppm})=55.1(\mathrm{CH}), 111.0(\mathrm{CH}), 111.96(\mathrm{CH}), 112.03$ $(\mathrm{CH}), 113.5(\mathrm{C}), 118.8(\mathrm{CH}), 120.9(\mathrm{CH}), 123.1(\mathrm{CH}), 124.7(\mathrm{CH}), 125.4(\mathrm{C}), 126.4(\mathrm{CH}), 126.5(\mathrm{CH})$, $128.8(2 \times \mathrm{CH}), 128.9(2 \times \mathrm{CH}), 133.9(\mathrm{CH}), 134.5(\mathrm{C}), 136.5(\mathrm{C}), 138.4(\mathrm{C}), 151.8(\mathrm{C}), 195.3(\mathrm{C})$.

LRMS $(70 \mathrm{eV}, \mathrm{EI}) \mathrm{m} / \mathrm{z}(\%) 266\left[\left(\mathrm{M}-\mathrm{C}_{7} \mathrm{H}_{5} \mathrm{O}\right)^{+}, 100\right]$.

HRMS $\left(\mathrm{EI}^{+}\right)$calcd for $\mathrm{C}_{22} \mathrm{H}_{17} \mathrm{~N}_{3} \mathrm{O}_{3}\left(\mathrm{M}-\mathrm{C}_{7} \mathrm{H}_{5} \mathrm{O}\right)^{+}, 266.0930$; found, 266.0930.

\section{2-(2-Methyl-1H-indol-3-yl)-2-((4-nitrophenyl)amino)-1-phenylethanone (29b).}

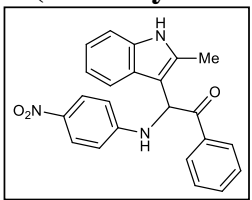

Yellow solid; yield $=88 \%$; m.p. $95-97^{\circ} \mathrm{C}$.

${ }^{1} \mathbf{H}$ NMR $\left(300 \mathrm{MHz}, \mathrm{CDCl}_{3}\right) \delta(\mathrm{ppm})=2.46(\mathrm{~s}, 3 \mathrm{H}), 6.21-6.33(\mathrm{~m}$, $2 \mathrm{H}), 6.56(\mathrm{~d}, J=9.1 \mathrm{~Hz}, 2 \mathrm{H}), 7.09-7.26(\mathrm{~m}, 3 \mathrm{H}), 7.35$ (at, $J=7.4$ $\mathrm{Hz}, 2 \mathrm{H}), 7.47$ (at, $J=7.3 \mathrm{~Hz}, 1 \mathrm{H}), 7.74(\mathrm{~d}, J=7.5 \mathrm{~Hz}, 1 \mathrm{H}), 7.92$ $8.01(\mathrm{~m}, 4 \mathrm{H}), 8.18(\mathrm{~s}, 1 \mathrm{H})$.

${ }^{13} \mathrm{C} \mathrm{NMR}\left(75.4 \mathrm{MHz}, \mathrm{CDCl}_{3}\right) \delta(\mathrm{ppm})=12.5\left(\mathrm{CH}_{3}\right), 54.9(\mathrm{CH}), 105.7(\mathrm{C}), 111.1(\mathrm{CH})$, $112.0(2 \times \mathrm{CH}), 117.7(\mathrm{CH}), 120.6(\mathrm{CH}), 121.9(\mathrm{CH}), 126.4(2 \times \mathrm{CH}), 126.7(\mathrm{C}), 128.4$ $(2 \times \mathrm{CH}), 128.7(2 \times \mathrm{CH}), 133.7(\mathrm{CH}), 134.1(\mathrm{C}), 134.8(\mathrm{C}), 135.3(\mathrm{C}), 138.1(\mathrm{C}), 151.7$ (C), $194.6(\mathrm{C})$.

LRMS $(70 \mathrm{eV}, \mathrm{EI}) \mathrm{m} / z(\%) 280\left[\left(\mathrm{M}-\mathrm{C}_{7} \mathrm{H}_{5} \mathrm{O}\right)^{+}, 100\right]$.

HRMS $\left(\mathrm{EI}^{+}\right)$: calcd for $\mathrm{C}_{23} \mathrm{H}_{19} \mathrm{~N}_{3} \mathrm{O}_{3}\left(\mathrm{M}-\mathrm{C}_{7} \mathrm{H}_{5} \mathrm{O}\right)^{+}, 280.1086$; found, 280.1081 . 
1-(1-Methyl-1H-indol-3-yl)-1-((4-nitrophenyl)amino)propan-2-one (29c).

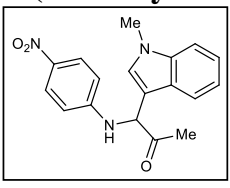

Slightly contaminated with $p$-nitroaniline. Yellow foam; yield $=67 \%$;

$R_{f}=0.25$ (hexane/EtOAc, 4:1).

${ }^{1} \mathbf{H}$ NMR $\left(300 \mathrm{MHz}, \mathrm{CDCl}_{3}\right) \delta(\mathrm{ppm})=2.20(\mathrm{~s}, 3 \mathrm{H}), 3.78(\mathrm{~s}, 3 \mathrm{H}), 5.40$

$(\mathrm{d}, J=4.5 \mathrm{~Hz}, 1 \mathrm{H}), 6.22(\mathrm{~d}, J=4.5 \mathrm{~Hz}, 1 \mathrm{H}), 6.49-6.56(\mathrm{~m}, 2 \mathrm{H}), 7.13$

(s, 1H), 7.17-7.38 (m, 3H), $7.67(\mathrm{dt}, J=7.9,1.1 \mathrm{~Hz}, 1 \mathrm{H}), 7.94-7.98(\mathrm{~m}, 2 \mathrm{H})$.

${ }^{13} \mathbf{C ~ N M R}\left(75.4 \mathrm{MHz}, \mathrm{CDCl}_{3}\right) \delta(\mathrm{ppm})=26.7\left(\mathrm{CH}_{3}\right), 33.2\left(\mathrm{CH}_{3}\right), 59.5(\mathrm{CH}), 109.0(\mathrm{C})$, $110.2(\mathrm{CH}), 112.1(2 \times \mathrm{CH}), 118.7(\mathrm{CH}), 120.4(\mathrm{CH}), 122.7(\mathrm{CH}), 126.1(\mathrm{C}), 126.3(2 \times$ $\mathrm{CH}), 128.4(\mathrm{CH}), 137.5(\mathrm{C}), 138.4(\mathrm{C}), 151.4(\mathrm{C}), 203.1(\mathrm{C})$.

LRMS (70 eV, EI) $\mathrm{m} / z$ (\%) $323\left(\mathrm{M}^{+}, 5\right), 280(100)$.

HRMS $\left(\mathrm{EI}^{+}\right)$calcd for $\mathrm{C}_{18} \mathrm{H}_{17} \mathrm{~N}_{3} \mathrm{O}_{3}, 323.1270$; found, 323.1271 .

\subsection{Synthesis of Tryptophol Derivatives 30}

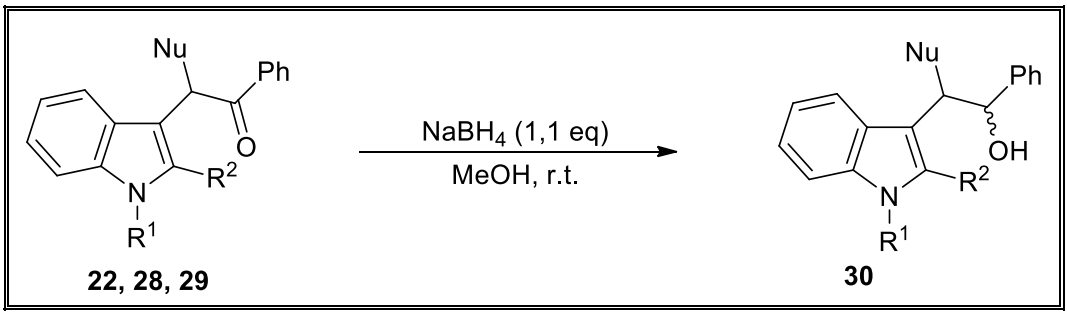

General Procedure: To a stirred solution of the corresponding $\alpha$-(indol-3-yl) carbonyl compound derivative 22, 28, or $29(0.5 \mathrm{mmol})$ in $\mathrm{MeOH}(5 \mathrm{ml}), \mathrm{NaBH}_{4}(20.8$ $\mathrm{mg}, 0.6 \mathrm{mmol}$ ) was added portionwise at $0{ }^{\circ} \mathrm{C}$. After $1 \mathrm{~h}$ at r.t. the crude mixture was quenched with a saturated aqueous solution of $\mathrm{NH}_{4} \mathrm{Cl}(5 \mathrm{ml})$ and extracted with $\mathrm{CH}_{2} \mathrm{Cl}_{2}$ $(3 \times 10 \mathrm{ml})$. The combined organic layers were dried over anhydrous $\mathrm{Na}_{2} \mathrm{SO}_{4}$ and concentrated at reduced pressure. The residue was purified by flash chromatography using mixtures of hexane and EtOAc as eluents to obtain the corresponding tryptophol derivatives $\mathbf{3 0}$.

\section{2-(1H-Indol-3-yl)-1-phenyl-2-(p-tolylthio)ethanol (30a).}

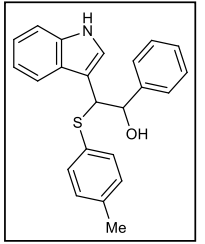

Generated and isolated as a ca. 2:1 mixture of diastereoisomers. Yellow solid; yield $=78 \%$; m.p. $151-153{ }^{\circ} \mathrm{C}$.

${ }^{1} \mathbf{H}$ NMR $\left(300 \mathrm{MHz}, \mathrm{CDCl}_{3}\right) \delta(\mathrm{ppm})=2.29$ (s, 3H, one diast), 2.32 (s, $3 \mathrm{H}$, one diast), 3.02 (bs, 1H, one diast), 3.64 (bs, $1 \mathrm{H}$, one diast), 4.71 (d, $J=8.3 \mathrm{~Hz}, 1 \mathrm{H}$, one diast), $4.84(\mathrm{~d}, J=4.8 \mathrm{~Hz}, 1 \mathrm{H}$, one diast), 5.08 (d, $J$ $=8.4 \mathrm{~Hz}, 1 \mathrm{H}$, one diast), $5.12(\mathrm{~d}, J=4.8 \mathrm{~Hz}, 1 \mathrm{H}$, one diast), $6.63(\mathrm{~d}, J=2.4 \mathrm{~Hz}, 1 \mathrm{H}$, one diast), 6.99 (d, $J=8.3 \mathrm{~Hz}, 1 \mathrm{H}$, one diast), 7.06-7.12 (m, 7H), 7.13-7.23 (m, 10H), 7.23$7.29(\mathrm{~m}, 3 \mathrm{H}), 7.31(\mathrm{~d}, J=8.0 \mathrm{~Hz}, 2 \mathrm{H}), 7.55(\mathrm{~d}, J=7.9 \mathrm{~Hz}, 1 \mathrm{H}$, one diast), 7.69 (d, $J=$ $7.6 \mathrm{~Hz}, 1 \mathrm{H}$, one diast), 7.87 (s, 1H, one diast), 8.07 (s, 1H, one diast).

${ }^{13} \mathrm{C}$ NMR $\left(75.4 \mathrm{MHz}, \mathrm{CDCl}_{3}\right) \delta(\mathrm{ppm})=21.2\left(\mathrm{CH}_{3}\right), 21.3\left(\mathrm{CH}_{3}\right), 54.2(\mathrm{CH}), 56.4(\mathrm{CH})$, $74.4(\mathrm{CH}), 75.1(\mathrm{CH}), 111.29(\mathrm{CH}), 111.32(\mathrm{CH}), 111.4(\mathrm{C}), 113.63(\mathrm{C}), 119.3(\mathrm{CH})$, $119.5(\mathrm{CH}), 119.76(\mathrm{CH}), 119.79(\mathrm{CH}), 122.3(\mathrm{CH}), 123.5(\mathrm{CH}), 124.5(\mathrm{CH}), 126.3(\mathrm{C})$, $126.6(2 \times \mathrm{CH}), 126.9(\mathrm{C}), 127.0(\mathrm{CH}), 127.6(\mathrm{CH}), 127.7(\mathrm{CH}), 128.0(2 \times \mathrm{CH}), 128.1$ 
$(2 \times \mathrm{CH}), 129.6(2 \times \mathrm{CH}), 129.9(2 \times \mathrm{CH}), 131.2(\mathrm{C}), 133.1(2 \times \mathrm{CH}), 133.7(2 \times \mathrm{CH})$, 136.0 (C), 136.1 (C), 137.79 (C), 137.82 (C), 140.9 (C), 141.2 (C).

LRMS (70 eV, EI) $m / z(\%) 252\left[\left(\mathrm{M}-\mathrm{C}_{7} \mathrm{H}_{7} \mathrm{O}\right)^{+}, 100\right]$.

HRMS $\left(\mathrm{EI}^{+}\right)$calcd for $\mathrm{C}_{23} \mathrm{H}_{21} \mathrm{NO}_{2} \mathrm{~S}\left(\mathrm{M}-\mathrm{C}_{7} \mathrm{H}_{7} \mathrm{O}\right)^{+}, 252.0847$; found, 252.0847.

\section{2-(2-Methyl-1H-indol-3-yl)-2-(5-methylfuran-2-yl)-1-phenylethanol (30b).}

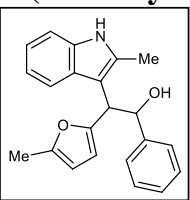

Generated as ca. 4:1 mixture of diastereoisomers. The major one could be isolated and characterized. Yellow solid; yield $=80 \%$; m.p. $165-167{ }^{\circ} \mathrm{C}$.

${ }^{1} \mathbf{H}$ NMR $\left(300 \mathrm{MHz}, \mathrm{CDCl}_{3}\right) \delta(\mathrm{ppm})=2.13(\mathrm{~s}, 3 \mathrm{H}), 2.19(\mathrm{~s}, 3 \mathrm{H}), 2.32$ (bs, $1 \mathrm{H}), 4.40(\mathrm{~d}, J=7.2 \mathrm{~Hz}, 1 \mathrm{H}), 5.60(\mathrm{~d}, J=7.2 \mathrm{~Hz}, 1 \mathrm{H}), 5.80(\mathrm{dd}, J=$ 3.0, $1.0 \mathrm{~Hz}, 1 \mathrm{H}), 5.96(\mathrm{~d}, J=2.9 \mathrm{~Hz}, 1 \mathrm{H}), 7.07-7.28(\mathrm{~m}, 8 \mathrm{H}), 7.74(\mathrm{~d}, J=7.6 \mathrm{~Hz}, 1 \mathrm{H})$, $7.91(\mathrm{~s}, 1 \mathrm{H})$.

${ }^{13} \mathbf{C ~ N M R}\left(75.4 \mathrm{MHz}, \mathrm{CDCl}_{3}\right) \delta(\mathrm{ppm})=11.9\left(\mathrm{CH}_{3}\right), 13.7\left(\mathrm{CH}_{3}\right), 46.3(\mathrm{CH}), 75.2(\mathrm{CH}), 106.0$ $(\mathrm{CH}), 107.3(\mathrm{C}), 107.8(\mathrm{CH}), 110.5(\mathrm{CH}), 119.6(\mathrm{CH}), 120.1(\mathrm{CH}), 121.3(\mathrm{CH}), 126.6(2 \times \mathrm{CH})$, $127.5(\mathrm{CH}), 127.9(\mathrm{C}), 128.1(2 \times \mathrm{CH}), 134.0(\mathrm{C}), 135.5(\mathrm{C}), 142.9(\mathrm{C}), 150.5(\mathrm{C}), 152.8(\mathrm{C})$.

LRMS $(70 \mathrm{eV}, \mathrm{EI}) \mathrm{m} / z(\%) 224\left[\left(\mathrm{M}-\mathrm{C}_{7} \mathrm{H}_{7} \mathrm{O}\right)^{+}, 100\right]$.

HRMS $\left(\mathrm{EI}^{+}\right)$calcd for $\mathrm{C}_{22} \mathrm{H}_{21} \mathrm{NO}_{2}\left(\mathrm{M}-\mathrm{C}_{7} \mathrm{H}_{7} \mathrm{O}\right)^{+}, 224.1075$; found, 224.1072 .

\section{2-(2-Methyl-1H-indol-3-yl)-2-((4-nitrophenyl)amino)-1-phenylethanol (30c).}

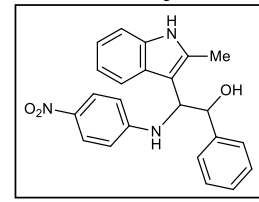

Generated as ca. 2:1 mixture of diastereoisomers. The major one could be isolated and characterized. Yellow solid; yield $=81 \%$; m.p. $184-186^{\circ} \mathrm{C}$.

${ }^{1} \mathbf{H}$ NMR $\left(300 \mathrm{MHz}, \mathrm{CDCl}_{3}\right) \delta(\mathrm{ppm})=1.90(\mathrm{~s}, 3 \mathrm{H}), 2.35(\mathrm{~d}, J=5.4$ $\mathrm{Hz}, 1 \mathrm{H}), 4.85(\mathrm{dd}, J=6.1,4.7 \mathrm{~Hz}, 1 \mathrm{H}), 5.28($ at, $J=4.7 \mathrm{~Hz}, 1 \mathrm{H}), 5.51$ $(\mathrm{d}, J=6.1 \mathrm{~Hz}, 1 \mathrm{H}), 6.42(\mathrm{ad}, J=9.2 \mathrm{~Hz}, 2 \mathrm{H}), 6.98-7.17(\mathrm{~m}, 4 \mathrm{H}), 7.22-7.35(\mathrm{~m}, 4 \mathrm{H})$, $7.62(\mathrm{~d}, J=7.7 \mathrm{~Hz}, 1 \mathrm{H}), 7.87-7.96(\mathrm{~m}, 3 \mathrm{H})$.

${ }^{13} \mathrm{C} \mathrm{NMR}\left(75.4 \mathrm{MHz}, \mathrm{CDCl}_{3}\right) \delta(\mathrm{ppm})=11.8\left(\mathrm{CH}_{3}\right), 57.7(\mathrm{CH}), 77.3(\mathrm{CH}), 105.8(\mathrm{C}), 110.8$ $(\mathrm{CH}), 111.8(2 \times \mathrm{CH}), 119.0(\mathrm{CH}), 120.1(\mathrm{CH}), 121.6(\mathrm{CH}), 126.2(2 \times \mathrm{CH}), 126.5(2 \times \mathrm{CH})$, $127.4(\mathrm{C}), 128.3(\mathrm{CH}), 128.5(2 \times \mathrm{CH}), 134.2(\mathrm{C}), 135.4(\mathrm{C}), 138.1(\mathrm{C}), 140.2(\mathrm{C}), 152.6(\mathrm{C})$.

LRMS $(70 \mathrm{eV}, \mathrm{EI}) \mathrm{m} / \mathrm{z}(\%) 280\left[\left(\mathrm{M}-\mathrm{C}_{7} \mathrm{H}_{7} \mathrm{O}\right)^{+}, 100\right]$.

HRMS $\left(\mathrm{EI}^{+}\right)$calcd for $\mathrm{C}_{23} \mathrm{H}_{21} \mathrm{~N}_{3} \mathrm{O}_{3}\left(\mathrm{M}-\mathrm{C}_{7} \mathrm{H}_{7} \mathrm{O}\right)^{+}, 280.1086$; found, 280.1088. 


\section{SYNTHESIS OF BENZO $[b]$ CARBAZOLES AND HETEROARYL[b]CARBAZOLES}

\subsection{Preparation of Starting Materials}

\subsubsection{Synthesis of acetals $31 \mathrm{~b}, 34$}

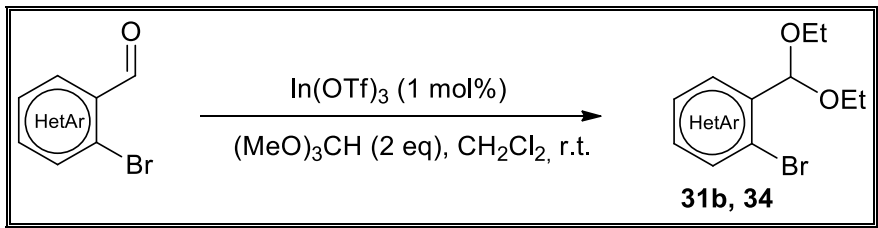

General Procedure: To a mixture of the corresponding aldehyde $(10 \mathrm{mmol})$, and trimethylorthoformate $(20 \mathrm{mmol})$ in $\mathrm{CH}_{2} \mathrm{Cl}_{2}(20 \mathrm{ml})$ at r.t. was added $\mathrm{In}(\mathrm{OTf})_{3}(28 \mathrm{mg}$, $0.5 \mathrm{~mol} \%$ ), and the reaction mixture stirred at r.t. for $3 \mathrm{~min}$. A further portion of the catalyst ( $28 \mathrm{mg}, 0.5 \mathrm{~mol} \%$ ), was added at this time and the reaction mixture stirred for a further $2 \mathrm{~min}$. Next, the mixture was passed through a short plug of neutral alumina which was then washed with additional $\mathrm{CH}_{2} \mathrm{Cl}_{2}(15 \mathrm{ml})$ and the solvent was removed under reduced pressure to give the product $\mathbf{3 1 b}, \mathbf{3 4}$.

1-Bromo-2-(diethoxymethyl)-4-methoxybenzene (31b).

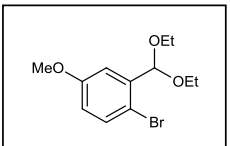

Yellow oil; yield $=99 \%$.

${ }^{1} \mathbf{H}$ NMR $\left(300 \mathrm{MHz}, \mathrm{CDCl}_{3}\right) \delta(\mathrm{ppm})=1.25(\mathrm{t}, J=7.1 \mathrm{~Hz}, 1 \mathrm{H})$, $3.52-3.63(\mathrm{~m}, 2 \mathrm{H}), 3.64-3.75(\mathrm{~m}, 2 \mathrm{H}), 3.79(\mathrm{~s}, 3 \mathrm{H}), 5.60(\mathrm{~s}, 1 \mathrm{H}), 6.74$ $(\mathrm{dd}, J=8.7,3.1 \mathrm{~Hz}, 1 \mathrm{H}), 7.20(\mathrm{~d}, J=3.1 \mathrm{~Hz}, 1 \mathrm{H}), 7.41(\mathrm{~d}, J=8.7 \mathrm{~Hz}, 1 \mathrm{H})$ ${ }^{13} \mathbf{C ~ N M R}\left(75.4 \mathrm{MHz}, \mathrm{CDCl}_{3}\right) \delta(\mathrm{ppm})=15.3\left(\mathrm{CH}_{3}\right), 55.6\left(\mathrm{CH}_{3}\right), 62.8\left(\mathrm{CH}_{2}\right), 101.5(\mathrm{CH})$, $113.4(\mathrm{CH}), 116.3(\mathrm{CH}), 133.5(\mathrm{C}), 139.0(\mathrm{C}), 151.1(\mathrm{C})$.

\section{3-Bromo-2-(diethoxymethyl)benzo $[b]$ thiophene (34).}

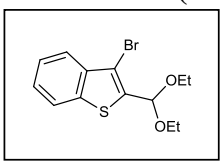

Yellow oil; yield $=66 \%$;

${ }^{1} \mathbf{H}$ NMR $\left(300 \mathrm{MHz}, \mathrm{CDCl}_{3}\right) \delta(\mathrm{ppm})=1.28(\mathrm{t}, J=7.1 \mathrm{~Hz}, 3 \mathrm{H})$, 3.61-3.80 (m, 4H), $5.91(\mathrm{~s}, 1 \mathrm{H}), 7.34-7.55(\mathrm{~m}, 2 \mathrm{H}), 7.77-7.86(\mathrm{~m}, 2 \mathrm{H})$.

${ }^{13}$ C NMR (75.4 MHz, $\left.\mathrm{CDCl}_{3}\right) \delta(\mathrm{ppm})=15.2\left(\mathrm{CH}_{3}\right), 62.2\left(\mathrm{CH}_{2}\right), 98.3(\mathrm{CH}), 106.4(\mathrm{C})$, $122.7(\mathrm{CH}), 123.1(\mathrm{CH}), 125.0(\mathrm{CH}), 127.7(\mathrm{CH}), 137.9(\mathrm{C}), 138.1(\mathrm{C}), 138.3(\mathrm{C})$.

\subsubsection{Synthesis of acetals 36a-d}

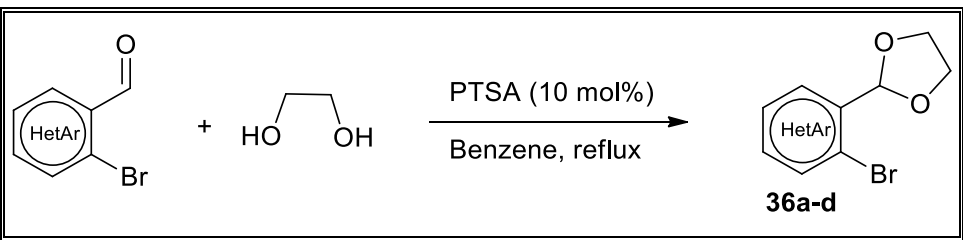


General Procedure: A flask equipped with a Dean-Stark trap was charged with a solution of the corresponding aldehyde $(5 \mathrm{mmol})$, ethylene glycol $(1.5 \mathrm{~g}, 25 \mathrm{mmol})$ and PTSA (9.5 mg $10 \mathrm{~mol} \%)$, in benzene $(20 \mathrm{ml})$. The reaction mixture was refluxed for $4 \mathrm{~h}$, cooled to r.t. and washed with a saturated solution $\mathrm{NaHCO}_{3}$. The organic layer was collected and the aqueous layer extracted with EtOAc $(3 \times 20 \mathrm{ml})$. The combine organic layers were washed with brine $(20 \mathrm{ml})$, dried over $\mathrm{MgSO}_{4}$, filtered, and concentrated in vacuo.

\section{2-(Thiophen-3-yl)-1,3-dioxolane (36a).}

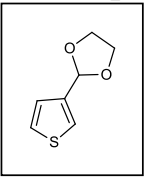

Yellow oil; yield $=95 \%$.

${ }^{1} \mathbf{H}$ NMR $\left(300 \mathrm{MHz}, \mathrm{CDCl}_{3}\right) \delta(\mathrm{ppm})=3.93-4.18(\mathrm{~m}, 4 \mathrm{H}), 5.90(\mathrm{~s}, 1 \mathrm{H})$, $7.16(\mathrm{dd}, J=5.0,1.3 \mathrm{~Hz}, 1 \mathrm{H}), 7.31(\mathrm{dd}, J=5.0,3.0 \mathrm{~Hz}, 1 \mathrm{H}), 7.40-7.45(\mathrm{~m}, 1 \mathrm{H})$. ${ }^{13} \mathrm{C} \mathrm{NMR}\left(75.4 \mathrm{MHz}, \mathrm{CDCl}_{3}\right) \delta(\mathrm{ppm})=65.1\left(2 \times \mathrm{CH}_{2}\right), 100.5(\mathrm{CH}), 123.7$ $(\mathrm{CH}), 125.6(\mathrm{CH}), 126.4(\mathrm{CH}), 140.0(\mathrm{C})$.

\section{3-Bromo-2-(1,3-dioxolan-2-yl)benzofuran (36b).}

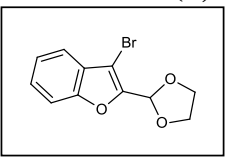

Yellow foam; yield $=89 \%$.

${ }^{1} \mathbf{H}$ NMR $\left(300 \mathrm{MHz}, \mathrm{CDCl}_{3}\right) \delta(\mathrm{ppm})=4.02-4.15(\mathrm{~m}, 2 \mathrm{H}), 4.27-4.33$ $(\mathrm{m}, 2 \mathrm{H}), 6.23(\mathrm{~s}, 1 \mathrm{H}), 7.28-7.42(\mathrm{~m}, 2 \mathrm{H}), 7.47-7.59(\mathrm{~m}, 2 \mathrm{H})$.

${ }^{13} \mathrm{C} \mathrm{NMR}\left(75.4 \mathrm{MHz}, \mathrm{CDCl}_{3}\right) \delta(\mathrm{ppm})=65.9\left(2 \times \mathrm{CH}_{2}\right), 96.7(\mathrm{CH}), 98.0(\mathrm{C}), 112.0(\mathrm{CH})$, $120.3(\mathrm{CH}), 123.7(\mathrm{CH}), 126.5(\mathrm{CH}), 127.6(\mathrm{C}), 148.9(\mathrm{C}), 153.9(\mathrm{C})$.

\section{2-Bromo-3-(1,3-dioxolan-2-yl)pyridine (36c).}

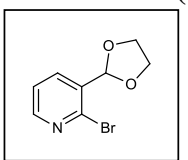

Yellow foam; yield $=93 \%$.

${ }^{1} \mathbf{H}$ NMR $\left(300 \mathrm{MHz}, \mathrm{CDCl}_{3}\right) \delta(\mathrm{ppm})=3.99-4.18(\mathrm{~m}, 4 \mathrm{H}), 6.01(\mathrm{~s}, 1 \mathrm{H})$, $7.27(\mathrm{dd}, J=7.1,2.2 \mathrm{~Hz}, 1 \mathrm{H}), 7.82-7.91(\mathrm{~m}, 1 \mathrm{H}), 8.29-8.38(\mathrm{~m}, 1 \mathrm{H})$.

${ }^{13} \mathrm{C} \mathrm{NMR}\left(75.4 \mathrm{MHz}, \mathrm{CDCl}_{3}\right) \delta(\mathrm{ppm})=65.7\left(2 \times \mathrm{CH}_{2}\right), 101.8(\mathrm{CH}), 123.0(\mathrm{CH}), 134.3$ (C), $136.5(\mathrm{CH}), 142.5(\mathrm{C}), 150.6(\mathrm{CH})$.

\section{3-(1,3-dioxolan-2-yl)-1-tosyl-1H-indole (36d).}

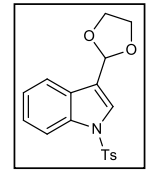

Yellow oil; yield $=88 \%$.

${ }^{1} \mathbf{H}$ NMR $\left(300 \mathrm{MHz}, \mathrm{CDCl}_{3}\right) \delta(\mathrm{ppm})=2.33(\mathrm{~s}, 3 \mathrm{H}), 4.00-4.12(\mathrm{~m}, 2 \mathrm{H})$, 4.10-4.17 (m, 2H), 6.08 (s 1H), 7.18-7.38 (m, 4H), 7.64-7.70 (m, 2H), 7.75-7.82 (m, 2H), 7.95-8.00 (m, 1H).

${ }^{13} \mathrm{C} \mathrm{NMR}\left(75.4 \mathrm{MHz}, \mathrm{CDCl}_{3}\right) \delta(\mathrm{ppm})=21.7\left(\mathrm{CH}_{3}\right), 65.3\left(\mathrm{CH}_{2}\right), 99.5(\mathrm{CH}), 113.7(\mathrm{CH})$, $120.0(\mathrm{C}), 120.8(\mathrm{CH}), 123.5(\mathrm{CH}), 125.0(\mathrm{CH}), 125.1(\mathrm{CH}), 127.0(2 \times \mathrm{CH}), 128.3(\mathrm{C})$, $130.1(2 \times \mathrm{CH}), 135.3(\mathrm{C}), 135.5(\mathrm{C}), 145.2(\mathrm{C})$. 


\subsubsection{Synthesis of hydroxy-functionalized acetals 32, 33, 35a, 38 and/or cyclic acetals 32', 33' and 35b}

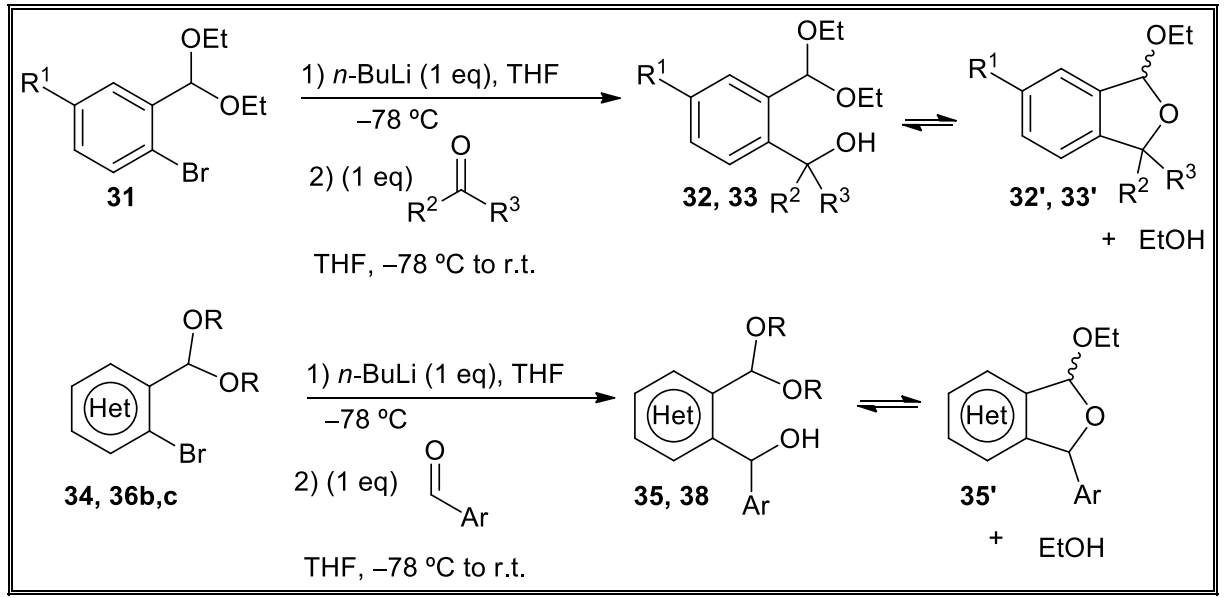

General Procedure: To a solution of the corresponding aldehyde dialkyl acetal 31, 34, 36a-d (10 mmol, for 31a, $5 \mathrm{mmol}$ for 31b, 34, 36a-d) in THF $(20 \mathrm{ml})$, at $-78^{\circ} \mathrm{C}$, was added $n$-BuLi $(6.25 \mathrm{ml}, 10 \mathrm{mmol}$, for 31a; $3.12 \mathrm{ml}, 5 \mathrm{mmol}$, for 31b, 34, and 36b,c; 1.6 $\mathrm{M}$ in hexanes). The solution was stirred at $-78{ }^{\circ} \mathrm{C}$ for $45 \mathrm{~min}$, then the appropriate aldehyde or ketone was added. The resulting mixture was stirred at r.t. until the corresponding bromoaldehyde dialkyl acetal was consumed as determined by TLC or GC-MS. The reaction was quenched with a saturated $\mathrm{NH}_{4} \mathrm{Cl}$ solution and extracted with $\mathrm{Et}_{2} \mathrm{O}(3 \times 30 \mathrm{ml})$. The combined organic layers were dried over anhydrous $\mathrm{Na}_{2} \mathrm{SO}_{4}$ and concentrated at reduced pressure. The residue was purified by flash chromatography using mixtures of hexane and EtOAc as eluents to obtain the corresponding hydroxyfunctionalized acetals $\mathbf{3 2}, \mathbf{3 3}, \mathbf{3 5}, \mathbf{3 8}$. In some cases these acetals were characterized as cyclic acetals 32', 33' and 35', or as mixtures of both compounds.

\section{(2-(Diethoxymethyl)phenyl)(phenyl)methanol (32a).}

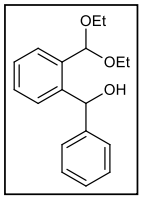

Yellow oil; yield $=66 \% ; R_{f}=0.23($ hex/EtOAc, $5: 1)$

${ }^{1} \mathbf{H}$ NMR $\left(300 \mathrm{MHz}, \mathrm{CDCl}_{3}\right) \delta(\mathrm{ppm})=1.19(\mathrm{t}, J=7.1 \mathrm{~Hz} ., 3 \mathrm{H}), 1.23(\mathrm{t}, J=$ $7.1 \mathrm{~Hz}, 3 \mathrm{H}), 3.41-3.71(\mathrm{~m}, 4 \mathrm{H}), 3.81(\mathrm{~d}, J=4.7 \mathrm{~Hz}, 1 \mathrm{H}), 5.53(\mathrm{~s}, 1 \mathrm{H}), 6.29$ $(\mathrm{d}, J=4.7 \mathrm{~Hz}, 1 \mathrm{H}), 7.18-7.42(\mathrm{~m}, 8 \mathrm{H}), 7.55-7.60(\mathrm{~m}, 1 \mathrm{H})$.

${ }^{13} \mathrm{C}$ NMR $\left(75.4 \mathrm{MHz}, \mathrm{CDCl}_{3}\right) \delta(\mathrm{ppm})=15.2\left(2 \times \mathrm{CH}_{3}\right), 62.1\left(\mathrm{CH}_{2}\right), 62.3\left(\mathrm{CH}_{2}\right), 72.6$ $(\mathrm{CH}), 101.2(\mathrm{CH}), 126.6(2 \times \mathrm{CH}), 127.1(\mathrm{CH}), 127.4(\mathrm{CH}), 127.6(\mathrm{CH}), 128.2(2 \times \mathrm{CH})$, $129.0(\mathrm{CH}), 129.3(\mathrm{CH}), 136.5(\mathrm{C}), 142.3(\mathrm{C}), 143.0(\mathrm{C})$.

LRMS (EI): $m / z(\%) 240$ [(M- $\left.\left.\mathrm{C}_{2} \mathrm{H}_{6} \mathrm{O}\right)^{+}, 5\right], 239$ (23), 196 (23), 195 (100), 165 (38).

HRMS (EI) for $\mathrm{C}_{16} \mathrm{H}_{16} \mathrm{O}_{2}\left(\mathrm{M}-\mathrm{C}_{2} \mathrm{H}_{6} \mathrm{O}\right)^{+}$, 239.1072; found, 239.1075 . 


\section{1-(4-Chlorophenyl)-3-ethoxy-1,3-dihydroisobenzofuran (32'b).}

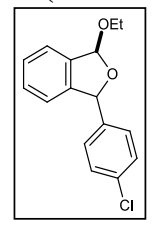

Isolated as a ca. 1.4:1 mixture of diastereoisomers along with EtOH. Yellow oil; yield $=77 \% ; R_{f}=0.31($ hex/EtOAc, $10: 1)$.

${ }^{1} \mathbf{H}$ NMR $\left(300 \mathrm{MHz}, \mathrm{CDCl}_{3}\right) \delta(\mathrm{ppm})=1.29$ (t, $J=7.1 \mathrm{~Hz}, 3 \mathrm{H}$, minor diast.), 1.30 (t, $J=7.1 \mathrm{~Hz}, 3 \mathrm{H}$, major diast.), 3.70-4.05 (m, 4H, minor diast.), 6.06 (s, $1 \mathrm{H}$, major diast.), 6.25 (d, $J=1.9 \mathrm{~Hz}, 1 \mathrm{H}$ minor diast.), 6.30 (s, $1 \mathrm{H}$, major diast.), 6.43 (d, $J=1.9 \mathrm{~Hz}, 1 \mathrm{H}$ minor diast.), 6.95-7.05 (m, 2H, both diast.), 7.20-7.37 (m, 12H, both diast.), 7.40-7.47 (m, 2H, both diast.).

${ }^{13} \mathrm{C} \mathrm{NMR}\left(75.4 \mathrm{MHz}, \mathrm{CDCl}_{3}\right) \delta(\mathrm{ppm})=15.4\left(\mathrm{CH}_{3}\right), 15.5\left(\mathrm{CH}_{3}\right), 63.7\left(\mathrm{CH}_{2}\right), 64.2\left(\mathrm{CH}_{2}\right)$, $84.2(\mathrm{CH}), 85.1(\mathrm{CH}), 106.3(\mathrm{CH}), 106.6(\mathrm{CH}), 122.06(\mathrm{CH}), 122.09(\mathrm{CH}), 122.9(\mathrm{CH})$, $123.1(\mathrm{CH}), 128.26(\mathrm{CH}), 128.29(\mathrm{CH}), 128.56(2 \times \mathrm{CH}), 128.61(2 \times \mathrm{CH}), 128.7(2 \times$ CH) $128.8(2 \times \mathrm{CH}), 129.5(2 \times \mathrm{CH}), 133.7(\mathrm{C}), 134.1(\mathrm{C}), 137.4(\mathrm{C}), 137.8(\mathrm{C}), 139.4$ (C), $140.5(\mathrm{C}), 142.5(\mathrm{C}), 142.8(\mathrm{C})$.

LRMS (EI): $m / z$ (\%) 276 [(M+2)+, 8], $274\left(\mathrm{M}^{+}, 26\right), 245$ (66) 229 (100), 165 (80).

HRMS (EI) for $\mathrm{C}_{16} \mathrm{H}_{15} \mathrm{O}_{2} \mathrm{Cl}, 274.0761$; found, 274.0749.

\section{1-(4-Bromophenyl)-3-ethoxy-1,3-dihydroisobenzofuran (32'c).}

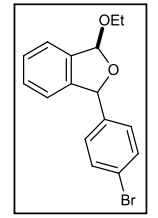

Isolated as a ca. 1.1:1 mixture of diastereoisomers along with EtOH. Yellow oil; yield $=81 \% ; R_{f}=0.29($ hex/EtOAc, $5: 1)$.

${ }^{1} \mathbf{H}$ NMR $\left(300 \mathrm{MHz}, \mathrm{CDCl}_{3}\right) \delta$ (ppm) $=1.28$ (t, $J=7.0 \mathrm{~Hz}, 3 \mathrm{H}$, one diast.), 1.30 (t, $J=7.1 \mathrm{~Hz}, 3 \mathrm{H}$, one diast.), 3.70-4.02 (m, 4H, both diast.), 6.05 (s, $1 \mathrm{H}$, one diast.), 6.24 (d, $J=1.9 \mathrm{~Hz}, 1 \mathrm{H}$, one diast.), 6.29 (s, 1H, one diast.), 6.43 (d, $J=1.9 \mathrm{~Hz}$, one diast.), 6.95-7.05 (m, 2H, both diast.) 7.15-7.19 (m, 2H), 7.27-7.37 (m, 4H, both diast.), 7.41-7.49 (m, 6H, both diast.).

${ }^{13} \mathrm{C} \mathrm{NMR}\left(75.4 \mathrm{MHz}, \mathrm{CDCl}_{3}\right) \delta(\mathrm{ppm})=15.5\left(\mathrm{CH}_{3}\right), 15.6\left(\mathrm{CH}_{3}\right), 63.8\left(\mathrm{CH}_{2}\right), 64.3\left(\mathrm{CH}_{2}\right)$, $84.3(\mathrm{CH}), 85.2(\mathrm{CH}), 106.4(\mathrm{CH}), 106.7(\mathrm{CH}), 122.0(\mathrm{CH}), 122.1(\mathrm{CH}+\mathrm{C}), 122.3(\mathrm{C})$, 123.0 (CH), $123.1(\mathrm{CH}), 128.3(2 \times \mathrm{CH}), 129.0(4 \times \mathrm{CH}), 129.6(2 \times \mathrm{CH}), 131.7(2 \times \mathrm{CH})$, $131.9(2 \times \mathrm{CH}), 137.5(\mathrm{C}), 138.0(\mathrm{C}), 140.1(\mathrm{C}), 141.1(\mathrm{C}), 142.5(\mathrm{C}), 142.8(\mathrm{C})$.

LRMS (EI): $m / z$ (\%) 319 [(M+2) $\left.)^{+}, 14\right], 317\left(\mathrm{M}^{+}, 14\right), 274$ (69), 272 (76), 194 (100).

HRMS (EI) for $\mathrm{C}_{16} \mathrm{H}_{14} \mathrm{O}_{2} \mathrm{Br}, 317.0177$; found, 317.0181 .

\section{(2-(Diethoxymethyl)phenyl)(4-methoxyphenyl)methanol (32d).}

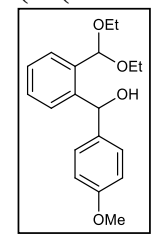

Yellow oil; yield $=67 \% ; R_{f}=0.15($ hex/EtOAc, $5: 1)$.

${ }^{1} \mathbf{H}$ NMR $\left(300 \mathrm{MHz}, \mathrm{CDCl}_{3}\right) \delta(\mathrm{ppm})=1.20(\mathrm{t}, J=7.1 \mathrm{~Hz}, 6 \mathrm{H}), 3.41-3.68$ (m, 4H), 3.69-3.81 (m, 1H), $3.79(\mathrm{~s}, 3 \mathrm{H}), 5.54(\mathrm{~s}, 1 \mathrm{H}), 6.23(\mathrm{~d}, J=4.3 \mathrm{~Hz}$, $1 \mathrm{H}), 6.88(\mathrm{~d}, J=8.7 \mathrm{~Hz}, 2 \mathrm{H}), 7.20-7.36(\mathrm{~m}, 5 \mathrm{H}), 7.57-7.60(\mathrm{~m} \mathrm{1H})$.

${ }^{13} \mathrm{C} \mathrm{NMR}\left(75.4 \mathrm{MHz}, \mathrm{CDCl}_{3}\right) \delta(\mathrm{ppm})=15.1\left(2 \times \mathrm{CH}_{3}\right), 55.3\left(\mathrm{CH}_{3}\right), 61.9$ $\left(\mathrm{CH}_{2}\right), 62.3\left(\mathrm{CH}_{2}\right), 72.1(\mathrm{CH}), 100.9(\mathrm{CH}), 113.6(2 \times \mathrm{CH}), 127.3(\mathrm{CH}), 127.4(\mathrm{CH})$, $127.9(2 \times \mathrm{CH}), 128.8(\mathrm{CH}), 128.9(\mathrm{CH}), 135.2(\mathrm{C}), 136.3(\mathrm{C}), 142.4(\mathrm{C}), 158.7(\mathrm{C})$.

LRMS (EI): $m / z$ (\%) 270 [(M- $\left.\left.\mathrm{C}_{2} \mathrm{H}_{6} \mathrm{O}^{+}\right), 15\right], 241$ (28), 225 (40), 133 (100).

HRMS (EI) for $\mathrm{C}_{17} \mathrm{H}_{18} \mathrm{O}_{3}\left(\mathrm{M}-\mathrm{C}_{2} \mathrm{H}_{6} \mathrm{O}\right)^{+}, 270.1256$; found, 270.1249. 
(2-(Diethoxymethyl)phenyl)(2,3,4-trimethoxyphenyl)methanol (32e).

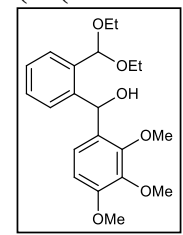

Yellow oil; yield $=69 \% ; R_{f}=0.21($ hex/EtOAc, $5: 1)$.

${ }^{1} \mathbf{H}$ NMR $\left(300 \mathrm{MHz}, \mathrm{CDCl}_{3}\right) \delta(\mathrm{ppm})=1.21(\mathrm{t}, J=7.1 \mathrm{~Hz}, 6 \mathrm{H}), 3.50-3.62$ $(\mathrm{m}, 5 \mathrm{H}), 3.58(\mathrm{~s}, 3 \mathrm{H}), 3.83(\mathrm{~s}, 3 \mathrm{H}), 3.86(\mathrm{~s}, 3 \mathrm{H}), 5.68(\mathrm{~s}, 1 \mathrm{H}), 6.46(\mathrm{~d}, J=$ $3.5 \mathrm{~Hz}, 1 \mathrm{H}), 6.69(\mathrm{~d}, J=8.7 \mathrm{~Hz}, 1 \mathrm{H}), 7.13-7.18(\mathrm{~m}, 2 \mathrm{H}), 7.24-7.27(\mathrm{~m}$, $2 \mathrm{H}), 7.54-7.57(\mathrm{~m}, 1 \mathrm{H})$.

${ }^{13} \mathrm{C}$ NMR $\left(75.4 \mathrm{MHz}, \mathrm{CDCl}_{3}\right) \delta(\mathrm{ppm})=15.17\left(\mathrm{CH}_{3}\right), 15.20\left(\mathrm{CH}_{3}\right) 56.0\left(\mathrm{CH}_{3}\right), 60.5$ $\left(\mathrm{CH}_{3}\right), 60.8\left(\mathrm{CH}_{3}\right), 61.6\left(\mathrm{CH}_{2}\right), 63.1\left(\mathrm{CH}_{2}\right), 67.0(\mathrm{CH}), 101.3(\mathrm{CH}), 106.8(\mathrm{CH}), 121.9$ $(\mathrm{CH}), 127.0(\mathrm{CH}), 127.3(\mathrm{CH}), 127.8(\mathrm{CH}), 128.8(\mathrm{CH}), 128.9(\mathrm{C}), 136.2(\mathrm{C}), 142.1(\mathrm{C})$, $142.3(\mathrm{C}), 150.9$ (C), $153.2(\mathrm{C})$.

\section{(2-(Diethoxymethyl)phenyl)(naphthalen-2-yl)methanol (32f).}

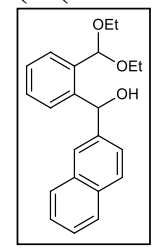

White solid; yield $=85 \%$; m.p. $=105-106{ }^{\circ} \mathrm{C} ; R_{f}=0.32($ hex/EtOAc, $5: 1)$.

${ }^{1} \mathbf{H}$ NMR $\left(300 \mathrm{MHz}, \mathrm{CDCl}_{3}\right) \delta(\mathrm{ppm})=1.23(\mathrm{t}, J=7.0 \mathrm{~Hz}, 3 \mathrm{H}), 1.28(\mathrm{t}, J=$ $7.0 \mathrm{~Hz}, 3 \mathrm{H}), 3.45-3.79(\mathrm{~m}, 4 \mathrm{H}), 4.10(\mathrm{bs}, 1 \mathrm{H}), 5.64(\mathrm{~s}, 1 \mathrm{H}), 6.52(\mathrm{~d}, J=3.6$ $\mathrm{Hz}, 1 \mathrm{H}), 7.18-7.25(\mathrm{~m}, 1 \mathrm{H}), 7.25-7.37(\mathrm{~m}, 2 \mathrm{H}), 7.39-7.45(\mathrm{~m}, 1 \mathrm{H})$, 7.46-7.54 (m, 2H), 7.59-7.64 (m, 1H), 7.80-7.90 (m, 3H), $8.05(\mathrm{~s}, 1 \mathrm{H})$.

${ }^{13} \mathrm{C} \mathrm{NMR}\left(75.4 \mathrm{MHz}, \mathrm{CDCl}_{3}\right) \delta(\mathrm{ppm})=15.1\left(\mathrm{CH}_{3}\right), 15.2\left(\mathrm{CH}_{3}\right), 62.1\left(\mathrm{CH}_{2}\right), 62.6\left(\mathrm{CH}_{2}\right)$, $72.3(\mathrm{CH}), 101.5(\mathrm{CH}), 124.9(\mathrm{CH}), 125.2(\mathrm{CH}), 125.8(\mathrm{CH}), 126.1(\mathrm{CH}), 127.4(\mathrm{CH})$, 127.6 (CH), $127.7(\mathrm{CH}), 127.8(\mathrm{CH}), 128.2(\mathrm{CH}), 129.0(\mathrm{CH}), 129.4(\mathrm{CH}), 132.7(\mathrm{C})$, $133.3(\mathrm{C}), 136.6(\mathrm{C}), 140.4(\mathrm{C}), 142.1(\mathrm{C})$.

LRMS (EI): $m / z(\%) 290$ [(M- $\left.\left.\mathrm{C}_{2} \mathrm{H}_{6} \mathrm{O}\right)^{+}, 23\right], 246$ (23), 245 (100), 244 (56), 215 (60).

HRMS (EI) for $\mathrm{C}_{20} \mathrm{H}_{18} \mathrm{O}_{2}\left(\mathrm{M}-\mathrm{C}_{2} \mathrm{H}_{6} \mathrm{O}\right)^{+}, 290.1370$; found; 290.1296.

(2-(Diethoxymethyl)phenyl)(thiophen-2-yl)methanol (32g).

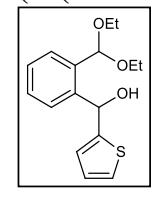

Yellow oil; yield $=88 \% ; R_{f}=0.20($ hex/EtOAc, $5: 1)$.

${ }^{1} \mathbf{H}$ NMR $\left(300 \mathrm{MHz}, \mathrm{CDCl}_{3}\right) \delta(\mathrm{ppm})=1.19(\mathrm{t}, J=7.1 \mathrm{~Hz}, 6 \mathrm{H}), 3.40-3.65$ $(\mathrm{m}, 5 \mathrm{H}), 4.07(\mathrm{~d}, J=5.3 \mathrm{~Hz}, 1 \mathrm{H}), 5.54(\mathrm{~s}, 1 \mathrm{H}), 6.42(\mathrm{~d}, J=5.3 \mathrm{~Hz}, 1 \mathrm{H})$, 6.82-6.84 (m, 1H), 6.94-6.98 (m, 1H), 7.25-7.27 (m, 1H), 7.33-7.37 (m, $1 \mathrm{H}), 7.41-7.44(\mathrm{~m}, 1 \mathrm{H}), 7.56-7.62(\mathrm{~m}, 1 \mathrm{H})$.

${ }^{13} \mathrm{C} \mathrm{NMR}\left(75.4 \mathrm{MHz}, \mathrm{CDCl}_{3}\right) \delta(\mathrm{ppm})=15.0\left(2 \times \mathrm{CH}_{3}\right), 61.9\left(\mathrm{CH}_{2}\right), 62.2\left(\mathrm{CH}_{2}\right), 69.8$ $(\mathrm{CH}), 100.6(\mathrm{CH}), 124.4(\mathrm{CH}), 124.7(\mathrm{CH}), 126.7(\mathrm{CH}), 127.3(\mathrm{CH}), 127.8(\mathrm{CH}), 128.4$ $(\mathrm{CH}), 129.0(\mathrm{CH}), 136.0(\mathrm{C}), 141.5(\mathrm{C}), 147.9(\mathrm{C})$.

LRMS (EI): $m / z(\%) 246$ [(M- $\left.\left.\mathrm{C}_{2} \mathrm{H}_{6} \mathrm{O}\right)^{+}, 5\right], 216$ (41), 201 (100), 171 (41), 162 (90), 133 (89). HRMS (EI) for $\mathrm{C}_{14} \mathrm{H}_{14} \mathrm{O}_{2} \mathrm{~S}\left(\mathrm{M}-\mathrm{C}_{2} \mathrm{H}_{6} \mathrm{O}\right)^{+}$, 246.0715; found, 246.0719 . 


\section{1-Ethoxy-3-(3-methylthiophen-2-yl)-1,3-dihydroisobenzofuran (32'h).}

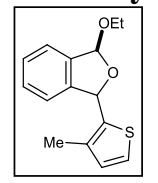

Isolated as a ca. 2:1 mixture of diasteroisomers. Yellow oil; yield $=69 \% ; R_{f}$ $=0.23($ hex/EtOAc, $5: 1)$.

${ }^{1} \mathbf{H}$ NMR (300 MHz, $\left.\mathrm{CDCl}_{3}\right) \delta(\mathrm{ppm})=1.20-1.36$ (m, 6H, both diast.), 2.36 (s, 3H, major diast.), 2.41 (s, 3H, minor diast.), 3.62-4.02 ( $\mathrm{m}, 4 \mathrm{H}$, both diast.), 6.33 (s, $1 \mathrm{H}$, minor diast.), 6.40 (d, $J=1.6 \mathrm{~Hz}, 1 \mathrm{H}$, major diast.), 6.48 (s, $1 \mathrm{H}$, minor diast.), 6.67 (bs, 1H, major diast.), 6.83-6.89 (m, 2H), 7.14-7.20 (m, 4H), 7.33-7.43 (m, 4H), 7.44-7.50 (m, 2H).

${ }^{13}$ C NMR (75.4 MHz, $\left.\mathrm{CDCl}_{3}\right) \delta(\mathrm{ppm})=13.98\left(\mathrm{CH}_{3}\right), 14.01\left(\mathrm{CH}_{3}\right), 15.4\left(\mathrm{CH}_{3}\right), 15.5$ $\left(\mathrm{CH}_{3}\right), 63.0\left(\mathrm{CH}_{2}\right), 63.9\left(\mathrm{CH}_{2}\right), 78.3(\mathrm{CH}), 78.4(\mathrm{CH}), 105.8(\mathrm{CH}), 105.9(\mathrm{CH}), 122.31$ $(\mathrm{CH}), 122.33(\mathrm{CH}), 122.9(\mathrm{CH}), 123.0(\mathrm{CH}), 124.5(\mathrm{CH}), 124.8(\mathrm{CH}), 128.4(2 \times \mathrm{CH})$, $129.4(2 \times \mathrm{CH}), 129.9(\mathrm{CH}), 130.2(\mathrm{CH}), 135.2(\mathrm{C}), 136.0(\mathrm{C}), 137.3(\mathrm{C}), 137.7(\mathrm{C})$, 138.1 (C), $138.9(\mathrm{C}), 142.4(\mathrm{C}), 142.7(\mathrm{C})$.

LRMS (EI): $m / z$ (\%) $260\left(\mathrm{M}^{+}, 8\right), 215$ (82), 214 (42), 162 (65), 133 (100), 83 (24).

HRMS (EI) for $\mathrm{C}_{15} \mathrm{H}_{16} \mathrm{O}_{2} \mathrm{~S}, 260.0871$; found, 260.0864 .

(2-(Diethoxymethyl)phenyl)(5-methylfuran-2-yl)methanol (32i).

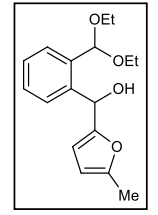

Yellow oil; yield $=78 \% ; R_{f}=0.20($ hex/EtOAc, $5: 1)$.

${ }^{1} \mathbf{H}$ NMR $\left(300 \mathrm{MHz}, \mathrm{CDCl}_{3}\right) \delta(\mathrm{ppm})=1.20(\mathrm{t}, J=7.1 \mathrm{~Hz}, 3 \mathrm{H}), 1.17(\mathrm{t}, J=$ $7.1 \mathrm{~Hz}, 3 \mathrm{H}), 2.26(\mathrm{~s}, 3 \mathrm{H}), 3.42-3.66(\mathrm{~m}, 5 \mathrm{H}), 5.60(\mathrm{~s}, 1 \mathrm{H}), 5.87-5.92(\mathrm{~m}$, $1 \mathrm{H}), 5.98-6.03(\mathrm{~m}, 1 \mathrm{H}), 6.19(\mathrm{bs}, 1 \mathrm{H}), 7.24-7.38(\mathrm{~m}, 2 \mathrm{H}), 7.44-7.46(\mathrm{~m}$, 1H), 7.57-7.60 (m, 1H).

${ }^{13} \mathrm{C}$ NMR $\left(75.4 \mathrm{MHz}, \mathrm{CDCl}_{3}\right) \delta(\mathrm{ppm})=13.7\left(\mathrm{CH}_{3}\right), 15.0\left(\mathrm{CH}_{3}\right), 15.1\left(\mathrm{CH}_{3}\right), 61.86$ $\left(\mathrm{CH}_{2}\right), 61.93\left(\mathrm{CH}_{2}\right), 67.2(\mathrm{CH}), 100.5(\mathrm{CH}), 106.2(\mathrm{CH}), 108.3(\mathrm{CH}), 127.1(\mathrm{CH}), 127.7$ $(\mathrm{CH}), 128.2(\mathrm{CH}), 128.9(\mathrm{CH}), 136.1(\mathrm{C}), 139.6(\mathrm{C}), 151.9(\mathrm{C}), 153.7(\mathrm{C})$.

LRMS (EI): $m / z$ (\%) 244 [(M- $\left.\left.\mathrm{C}_{2} \mathrm{H}_{6} \mathrm{O}\right)^{+}, 4\right], 214$ (38), 171 (50), 163 (34), 162 (23), 135 (100).

HRMS (EI) for $\mathrm{C}_{15} \mathrm{H}_{16} \mathrm{O}_{3}\left(\mathrm{M}-\mathrm{C}_{2} \mathrm{H}_{6} \mathrm{O}\right)^{+}, 244.1099$; found, 244.1087.

\section{1-(2-(Diethoxymethyl)phenyl)-3-phenylprop-2-yn-1-ol (32j).}

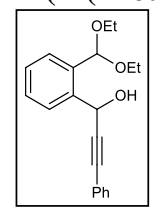

Yellow oil; yield $=60 \%$.

${ }^{1} \mathbf{H}$ NMR $\left(300 \mathrm{MHz}, \mathrm{CDCl}_{3}\right) \delta(\mathrm{ppm})=1.21-1.31(\mathrm{~m}, 6 \mathrm{H}), 3.47-3.80(\mathrm{~m}$, $4 \mathrm{H}), 4.24(\mathrm{~s}, 1 \mathrm{H}), 5.89(\mathrm{~s}, 1 \mathrm{H}), 6.15(\mathrm{~s}, 1 \mathrm{H}), 7.29-7.40(\mathrm{~m}, 6 \mathrm{H}), 7.46-7.54$ $(\mathrm{m}, 2 \mathrm{H}), 7.56-7.61(\mathrm{~m}, 1 \mathrm{H})$.

${ }^{13} \mathrm{C}$ NMR $\left(75.4 \mathrm{MHz}, \mathrm{CDCl}_{3}\right) \delta(\mathrm{ppm})=15.16\left(\mathrm{CH}_{3}\right), 15.19\left(\mathrm{CH}_{3}\right), 62.4\left(\mathrm{CH}_{2}\right), 62.5$ $\left(\mathrm{CH}_{2}\right), 88.4(\mathrm{C}), 88.6(\mathrm{C}), 101.7(\mathrm{CH}), 127.7(\mathrm{CH}), 128.2(\mathrm{CH}), 128.4(2 \times \mathrm{CH}), 128.5$ $(\mathrm{CH}), 128.9(\mathrm{CH}), 129.3(\mathrm{CH}), 131.8(2 \times \mathrm{CH}), 132.2(\mathrm{C}), 136.1(\mathrm{C}), 139.0(\mathrm{C})$. 


\section{3-Ethoxy-1-(4-methoxyphenyl)-1-methyl-1,3-dihydroisobenzofuran (32'm).}

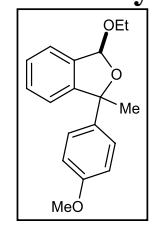

Isolated as a ca. 1:1 mixture of diastereoisomers along with EtOH. Yellow oil; yield $=82 \% ; R_{f}=0.13($ hex/EtOAc, $5: 1)$.

${ }^{1} \mathbf{H}$ NMR $\left(300 \mathrm{MHz}, \mathrm{CDCl}_{3}\right) \delta(\mathrm{ppm})=1.24(\mathrm{t}, J=7.1 \mathrm{~Hz}, 3 \mathrm{H}), 1.31(\mathrm{t}, J=$ $7.1 \mathrm{~Hz}, 3 \mathrm{H}), 1.87(\mathrm{~s}, 3 \mathrm{H}), 1.97(\mathrm{~s}, 3 \mathrm{H}), 3.64-3.78(\mathrm{~m}, 2 \mathrm{H}), 3.77(\mathrm{~s}, 6 \mathrm{H})$, $3.87-4.00(\mathrm{~m}, 2 \mathrm{H}), 6.30(\mathrm{~s}, 1 \mathrm{H}), 6.37(\mathrm{~s}, 1 \mathrm{H}), 6.81-6.88(\mathrm{~m}, 4 \mathrm{H}), 7.08-7.21$ (m, 2H), 7.28-7.42 (m, 8H), 7.44-7.50 (m, 2H).

${ }^{13} \mathrm{C}$ NMR $\left(75.4 \mathrm{MHz}, \mathrm{CDCl}_{3}\right) \delta(\mathrm{ppm})=15.5\left(\mathrm{CH}_{3}\right), 15.6\left(\mathrm{CH}_{3}\right), 29.20\left(\mathrm{CH}_{3}\right), 29.24$ $\left(\mathrm{CH}_{3}\right), 55.28\left(\mathrm{CH}_{3}\right), 55.31\left(\mathrm{CH}_{3}\right), 63.3\left(\mathrm{CH}_{2}\right), 63.8\left(\mathrm{CH}_{2}\right), 88.4(\mathrm{C}), 88.7(\mathrm{C}), 105.4(\mathrm{CH})$, 105.6 $(\mathrm{CH}), 113.4(2 \times \mathrm{CH}), 113.6(2 \times \mathrm{CH}), 121.8(\mathrm{CH}), 121.9(\mathrm{CH}), 123.0(\mathrm{CH}), 123.2$ $(\mathrm{CH}), 126.9(2 \times \mathrm{CH}), 129.95(2 \times \mathrm{CH}), 127.9(\mathrm{CH}), 128.0(\mathrm{CH}), 129.5(\mathrm{CH}), 129.55$ $(\mathrm{CH}), 137.1(\mathrm{C}), 137.4(\mathrm{C}), 137.6(\mathrm{C}), 138.2(\mathrm{C}), 147.1(\mathrm{C}), 147.7(\mathrm{C}), 158.6(\mathrm{C}), 158.8(\mathrm{C})$. LRMS (EI): m/z (\%) 284 (M+, 5), 269 (100), 239 (28), 147 (37), 133 (48).

\section{3-Ethoxy-1-(4-methoxyphenyl)-1-methyl-1,3-dihydroisobenzofuran (32'n).}

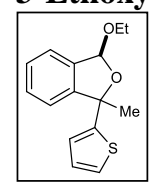

Isolated as a ca. 1:1 mixture of diastereoisomers along with EtOH. Yellow oil; yield $=82 \% ; R_{f}=0.13($ hex/EtOAc, $5: 1)$.

${ }^{1} \mathbf{H}$ NMR $\left(300 \mathrm{MHz}, \mathrm{CDCl}_{3}\right) \delta(\mathrm{ppm})=1.24(\mathrm{t}, J=7.1 \mathrm{~Hz}, 3 \mathrm{H}), 1.31(\mathrm{t}, J=$ $7.1 \mathrm{~Hz}, 3 \mathrm{H}), 1.87(\mathrm{~s}, 3 \mathrm{H}), 1.97(\mathrm{~s}, 3 \mathrm{H}), 3.64-3.78(\mathrm{~m}, 2 \mathrm{H}), 3.77(\mathrm{~s}, 6 \mathrm{H})$, 3.87-4.00 (m, 2H), $6.30(\mathrm{~s}, 1 \mathrm{H}), 6.37(\mathrm{~s}, 1 \mathrm{H}), 6.81-6.88(\mathrm{~m}, 4 \mathrm{H}), 7.08-7.21(\mathrm{~m}, 2 \mathrm{H})$, 7.28-7.42 (m, 8H), 7.44-7.50 (m, 2H).

${ }^{13} \mathrm{C}$ NMR $\left(75.4 \mathrm{MHz}, \mathrm{CDCl}_{3}\right) \delta(\mathrm{ppm})=15.5\left(\mathrm{CH}_{3}\right), 15.6\left(\mathrm{CH}_{3}\right), 29.20\left(\mathrm{CH}_{3}\right), 29.24$ $\left(\mathrm{CH}_{3}\right), 55.28\left(\mathrm{CH}_{3}\right), 55.31\left(\mathrm{CH}_{3}\right), 63.3\left(\mathrm{CH}_{2}\right), 63.8\left(\mathrm{CH}_{2}\right), 88.4(\mathrm{C}), 88.7(\mathrm{C}), 105.4(\mathrm{CH})$, $105.6(\mathrm{CH}), 113.4(2 \times \mathrm{CH}), 113.6(2 \times \mathrm{CH}), 121.8(\mathrm{CH}), 121.9(\mathrm{CH}), 123.0(\mathrm{CH}), 123.2$ $(\mathrm{CH}), 126.9(2 \times \mathrm{CH}), 129.95(2 \times \mathrm{CH}), 127.9(\mathrm{CH}), 128.0(\mathrm{CH}), 129.5(\mathrm{CH}), 129.55$ $(\mathrm{CH}), 137.1(\mathrm{C}), 137.4(\mathrm{C}), 137.6(\mathrm{C}), 138.2(\mathrm{C}), 147.1(\mathrm{C}), 147.7(\mathrm{C}), 158.6(\mathrm{C}), 158.8(\mathrm{C})$. LRMS (EI): $m / z$ (\%) 284 (M+, 5), 269 (100), 239 (28), 147 (37), 133 (48).

\section{3-Ethoxy-1-methyl-1-(phenylethynyl)-1,3-dihydroisobenzofuran (32'o).}

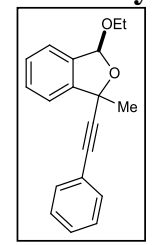

Isolated as ca. 1.1:1 mixture of diastereoisomers. Yellow oil; yield $=79 \% ; R_{f}$ $=0.16($ hex/EtOAc, 10:1).

${ }^{1} \mathbf{H}$ NMR $\left(300 \mathrm{MHz}, \mathrm{CDCl}_{3}\right) \delta(\mathrm{ppm})=1.29(\mathrm{t}, J=7.0 \mathrm{~Hz}, 3 \mathrm{H}), 1.31(\mathrm{t}, J=$ $7.1 \mathrm{~Hz}, 3 \mathrm{H}), 1.89$ (s, 3H), 1.96 (s, 3H), 3.71-4.04 (m, 4H), 6.31 (s, 1H), 6.33 (s, 1H), 7.22-7.53 (m, 18H).

${ }^{13} \mathrm{C} \mathrm{NMR}\left(75.4 \mathrm{MHz}, \mathrm{CDCl}_{3}\right) \delta(\mathrm{ppm})=15.5\left(2 \times \mathrm{CH}_{3}\right), 30.0\left(\mathrm{CH}_{3}\right), 31.7\left(\mathrm{CH}_{3}\right), 62.3$ $\left(\mathrm{CH}_{2}\right), 63.9\left(\mathrm{CH}_{2}\right), 79.7(\mathrm{C}), 81.0(\mathrm{C}), 84.3(\mathrm{C}), 84.8(\mathrm{C}), 90.5(\mathrm{C}), 90.9(\mathrm{C}), 105.2(\mathrm{CH})$, $105.8(\mathrm{CH}), 121.4(\mathrm{CH}), 121.5(\mathrm{CH}), 122.5(\mathrm{C}), 122.8(\mathrm{C}), 123.05(\mathrm{CH}), 123.09(\mathrm{CH})$, $128.15(2 \times \mathrm{CH}), 128.19(2 \times \mathrm{CH}), 128.3(\mathrm{CH}), 128.4(\mathrm{CH}), 128.6(2 \times \mathrm{CH}), 129.76(\mathrm{CH})$, $129.79(\mathrm{CH}), 131.7(2 \times \mathrm{CH}), 131.8(2 \times \mathrm{CH}), 137.0(\mathrm{C}), 137.2(\mathrm{C}), 145.0(2 \times \mathrm{C})$. 


\section{1-Cyclopropyl-3-ethoxy-1-methyl-1,3-dihydroisobenzofuran (32'p).}

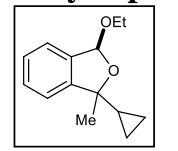

Isolated as ca. 1:1 mixture of diastereoisomers. Yellow oil; yield $=78 \% ; R_{f}$ $=0.25($ hex $/$ EtOAc, $5: 1)$.

${ }^{1} \mathbf{H}$ NMR $\left(300 \mathrm{MHz}, \mathrm{CDCl}_{3}\right) \delta(\mathrm{ppm})=0.22-0.48(\mathrm{~m}, 8 \mathrm{H}), 1.12-1.32(\mathrm{~m}$, $6 \mathrm{H}), 1.50(\mathrm{~s}, 3 \mathrm{H}), 1.53(\mathrm{~s}, 3 \mathrm{H}), 3.58-3.77(\mathrm{~m}, 4 \mathrm{H}), 3.82-3.95(\mathrm{~m}, 1 \mathrm{H}), 6.08(\mathrm{~s}, 1 \mathrm{H}), 6.13$ (s, 1H), 7.14-7.22 (m, 2H), 7.26-7.40 (m, 6H).

${ }^{13} \mathrm{C} \mathrm{NMR}\left(75.4 \mathrm{MHz}, \mathrm{CDCl}_{3}\right) \delta(\mathrm{ppm})=0.98\left(\mathrm{CH}_{2}\right), 1.14\left(\mathrm{CH}_{2}\right), 1.28\left(\mathrm{CH}_{2}\right), 1.50\left(\mathrm{CH}_{2}\right)$, $15.51\left(\mathrm{CH}_{3}\right), 15.57\left(\mathrm{CH}_{3}\right), 18.4\left(\mathrm{CH}_{3}\right), 21.2\left(\mathrm{CH}_{3}\right), 27.3(\mathrm{CH}), 27.4(\mathrm{CH}), 62.6\left(\mathrm{CH}_{2}\right)$, $63.8\left(\mathrm{CH}_{2}\right), 86.8(\mathrm{C}), 87.4(\mathrm{C}), 104.9(\mathrm{CH}), 105.3(\mathrm{CH}), 120.96(\mathrm{CH}), 121.01(\mathrm{CH})$, $122.98(\mathrm{CH}), 123.05(\mathrm{CH}), 127.85(\mathrm{CH}), 129.20(\mathrm{CH}), 129.22(\mathrm{CH}), 137.5(\mathrm{C}), 137.7$ (C), 146.9 (C), $147.1(\mathrm{C})$.

\section{(E)-3-Ethoxy-1-methyl-1-styryl-1,3-dihydroisobenzofuran (32'q).}

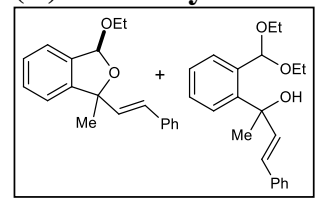
Isolated as ca. 1:1 mixture of diastereoisomers along with 32q. Yellow oil; yield $=58 \% ; R_{f}=0.23$ (hex/EtOAc, 5:1).

${ }^{1} \mathbf{H}$ NMR (300 MHz, $\left.\mathrm{CDCl}_{3}\right): \delta(\mathrm{ppm})=1.19-1.42(\mathrm{~m}, 6 \mathrm{H}), 1.76$ $(\mathrm{s}, 3 \mathrm{H}), 1.83(\mathrm{~s}, 3 \mathrm{H}), 3.47-3.84(\mathrm{~m}, 2 \mathrm{H}), 5.55(\mathrm{~s}, 1 \mathrm{H}), 6.23-6.57$ (m, 4H), 6.60-6.77 (m, 2H), 7.09-7.57 (m, 20H).

${ }^{13} \mathrm{C}$ NMR $\left(75.4 \mathrm{MHz}, \mathrm{CDCl}_{3},\right) \delta(\mathrm{ppm})=15.1\left(\mathrm{CH}_{3}\right), 15.48\left(\mathrm{CH}_{3}\right), 15.50\left(\mathrm{CH}_{3}\right), 27.0$ $\left(\mathrm{CH}_{3}\right), 28.1\left(\mathrm{CH}_{3}\right), 60.8\left(\mathrm{CH}_{2}\right), 63.1\left(\mathrm{CH}_{2}\right), 63.3\left(\mathrm{CH}_{2}\right), 87.0(\mathrm{C}), 87.2(\mathrm{C}), 101.4(\mathrm{CH})$, 105.2 $(\mathrm{CH}), 105.3(\mathrm{CH}), 121.27(\mathrm{CH}), 121.32(\mathrm{CH}), 123.07(\mathrm{CH}), 123.13(\mathrm{CH}), 126.5(2$ $\times \mathrm{CH}), 126.53(2 \times \mathrm{CH}), 127.4(\mathrm{CH}), 127.5(\mathrm{CH}), 127.6(\mathrm{CH}), 127.9(\mathrm{CH}), 128.0(\mathrm{CH})$, $128.2(\mathrm{CH}), 128.36(\mathrm{CH}), 128.40(\mathrm{CH}), 133.5(\mathrm{C}), 134.3(\mathrm{C}), 136.56(\mathrm{C}), 136.73(\mathrm{C})$, 137.3 (C), 137.4 (C), 139.0 (C), 145.8 (C), 145.9 (C).

\section{1,1-Bis(4-chlorophenyl)-3-ethoxy-1,3-dihydroisobenzofuran (32s).}

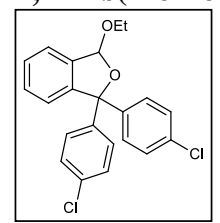

Yellow oil; yield $=90 \% ; R_{f}=0.19($ hex/EtOAc, 5:1).

${ }^{1} \mathbf{H}$ NMR $\left(300 \mathrm{MHz}, \mathrm{CDCl}_{3}\right) \delta(\mathrm{ppm})=1.21(\mathrm{t}, J=7.1 \mathrm{~Hz}, 1 \mathrm{H})$, 3.64-3.78 (m, 2H), 3.83-3.97 (m, 2H), $6.40(\mathrm{~s}, 1 \mathrm{H}), 7.20-7.52(\mathrm{~m}, 12 \mathrm{H})$. ${ }^{13} \mathrm{C} \mathrm{NMR}\left(75.4 \mathrm{MHz}, \mathrm{CDCl}_{3},\right) \delta(\mathrm{ppm})=15.4\left(\mathrm{CH}_{3}\right), 63.9\left(\mathrm{CH}_{2}\right), 92.1$ (C), $105.8(\mathrm{CH}), 123.5(\mathrm{CH}), 123.7(\mathrm{CH}), 128.2(2 \times \mathrm{CH}), 128.4(2 \times$ $\mathrm{CH}), 128.7(2 \times \mathrm{CH}), 128.8(2 \times \mathrm{CH}), 128.9(\mathrm{CH}), 129.5(\mathrm{CH}), 133.4(\mathrm{C}), 133.7(\mathrm{C})$, 138.1 (C), 143.4 (C), 143.6 (C), 144.0 (C). 
(2-(Diethoxymethyl)-4-methoxyphenyl)(phenyl)methanol (32t).

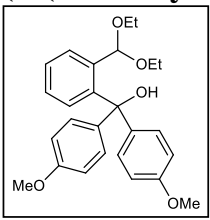

Yellow oil; yield $=58 \% ; R_{f}=0.19($ hex/EtOAc, $5: 1)$.

${ }^{1} \mathbf{H}$ NMR $\left(300 \mathrm{MHz}, \mathrm{CDCl}_{3}\right) \delta(\mathrm{ppm})=1.12(\mathrm{t}, J=7.0 \mathrm{~Hz}, 1 \mathrm{H})$, $3.20-3.52(\mathrm{~m}, 2 \mathrm{H}), 3.80(\mathrm{~s}, 3 \mathrm{H}), 3.88(\mathrm{~s}, 3 \mathrm{H}), 5.31(\mathrm{~s}, 1 \mathrm{H}), 5.69(\mathrm{~s}, 1 \mathrm{H})$, 6.64-6.74 (m, 1H), 6.79-6.91 (m, 2H), 6.02-7.09 (m, 2H), 7.11-7.37 $(\mathrm{m}, 4 \mathrm{H}), 7.74-7.90(\mathrm{~m}, 2 \mathrm{H})$.

${ }^{13} \mathbf{C ~ N M R}\left(75.4 \mathrm{MHz}, \mathrm{CDCl}_{3},\right) \delta(\mathrm{ppm})=14.9\left(\mathrm{CH}_{3}\right), 55.4\left(\mathrm{CH}_{3}\right), 55.6\left(\mathrm{CH}_{3}\right), 62.0\left(\mathrm{CH}_{2}\right)$, $81.6(\mathrm{C}), 98.9(\mathrm{CH}), 113.2(2 \times \mathrm{CH}), 113.5(2 \times \mathrm{CH}), 127.7(\mathrm{CH}), 128.0(\mathrm{CH}), 129.1(2 \times \mathrm{CH})$, $130.1(\mathrm{CH}), 130.8(\mathrm{CH}), 132.3(2 \times \mathrm{CH}), 136.8(\mathrm{C}), 139.8(2 \times \mathrm{C}), 146.1(\mathrm{C}), 158.6(\mathrm{C}), 162.9(\mathrm{C})$.

(2-(Diethoxymethyl)-4-methoxyphenyl)(phenyl)methanol (33a).

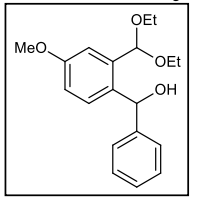

Yellow oil; yield $=58 \% ; R_{f}=0.19($ hex/EtOAc, 5:1)

${ }^{1} \mathbf{H}$ NMR $\left(300 \mathrm{MHz}, \mathrm{CDCl}_{3}\right) \delta(\mathrm{ppm})=1.19(\mathrm{t}, J=7.1 \mathrm{~Hz}, 3 \mathrm{H}), 1.22(\mathrm{t}$, $J=7.1 \mathrm{~Hz}, 3 \mathrm{H}), 3.40-3.77(\mathrm{~m}, 5 \mathrm{H}), 3.80(\mathrm{~s}, 3 \mathrm{H}), 5.51(\mathrm{~s}, 1 \mathrm{H}), 6.19(\mathrm{~d}, J$ $=4.4 \mathrm{~Hz}, 1 \mathrm{H}), 6.80(\mathrm{~d}, J=8.5,2.8 \mathrm{~Hz}, 1 \mathrm{H}), 7.11(\mathrm{~d}, J=8.5 \mathrm{~Hz}, 1 \mathrm{H}), 7.17$ (d, $J=2.8 \mathrm{~Hz}, 1 \mathrm{H}), 7.23-7.42(\mathrm{~m}, 5 \mathrm{H})$.

${ }^{13} \mathrm{C}$ NMR (75.4 MHz, $\left.\mathrm{CDCl}_{3},\right) \delta(\mathrm{ppm})=15.11\left(\mathrm{CH}_{3}\right), 15.15\left(\mathrm{CH}_{3}\right), 55.4\left(\mathrm{CH}_{3}\right), 62.1$ $\left(\mathrm{CH}_{2}\right), 62.3\left(\mathrm{CH}_{2}\right), 72.2(\mathrm{CH}), 100.5(\mathrm{CH}), 113.2(\mathrm{CH}), 113.6(\mathrm{CH}), 126.5(2 \times \mathrm{CH})$, $127.0(\mathrm{CH}), 128.2(2 \times \mathrm{CH}), 130.7(\mathrm{CH}), 134.5(\mathrm{C}), 138.0(\mathrm{C}), 143.4(\mathrm{C}), 158.9(\mathrm{C})$.

LRMS (EI): $m / z(\%) 270$ [(M- $\left.\left.\mathrm{C}_{2} \mathrm{H}_{6} \mathrm{O}\right)^{+}, 15\right], 225$ (70), 165 (100), 163 (43).

HRMS (EI) for $\mathrm{C}_{17} \mathrm{H}_{18} \mathrm{O}_{3}\left(\mathrm{M}-\mathrm{C}_{2} \mathrm{H}_{6} \mathrm{O}\right)^{+}, 270.1256$; found, 270.1254.

(4-Chlorophenyl)(2-(diethoxymethyl)-4-methoxyphenyl)metanol (33b).

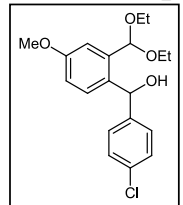

Yellow oil; yield $=73 \% ; R_{f}=0.11($ hex/EtOAc, 5:1).

${ }^{1} \mathbf{H}$ NMR $\left(300 \mathrm{MHz}, \mathrm{CDCl}_{3}\right) \delta(\mathrm{ppm})=1.17-1.26(\mathrm{~m}, 6 \mathrm{H}), 3.41-3.73(\mathrm{~m}$, $4 \mathrm{H}), 3.80(\mathrm{~s}, 3 \mathrm{H}), 3.80-3.85(\mathrm{~m}, 1 \mathrm{H}), 5.48(\mathrm{~s}, 1 \mathrm{H}), 6.17(\mathrm{~d}, J=4.4 \mathrm{~Hz}, 1 \mathrm{H})$, 6.76-6.82 (m, 1H), $7.03(\mathrm{dd}, J=8.5,3.0 \mathrm{~Hz}, 1 \mathrm{H}), 7.11-7.15(\mathrm{~m}, 1 \mathrm{H})$, 7.27-7.39 (m, 4H).

${ }^{13} \mathrm{C} \mathrm{NMR}\left(75.4 \mathrm{MHz}, \mathrm{CDCl}_{3}\right) \delta(\mathrm{ppm})=15.1\left(\mathrm{CH}_{3}\right), 15.2\left(\mathrm{CH}_{3}\right), 55.4\left(\mathrm{CH}_{3}\right), 62.2\left(\mathrm{CH}_{2}\right)$, $62.4\left(\mathrm{CH}_{2}\right), 71.5(\mathrm{CH}), 101.0(\mathrm{CH}), 113.5(\mathrm{CH}), 113.6(\mathrm{CH}), 128.0(2 \times \mathrm{CH}), 128.3(2 \times$ $\mathrm{CH}), 130.7(\mathrm{CH}), 132.7(\mathrm{C}), 134.1(\mathrm{C}), 138.0(\mathrm{C}), 142.0(\mathrm{C}), 159.0(\mathrm{C})$.

LRMS (EI): $m / z(\%) 306$ [(M+2- $\left.\left.\mathrm{C}_{2} \mathrm{H}_{6} \mathrm{O}\right)^{+}, 11\right], 304$ [(M- $\left.\left.\mathrm{C}_{2} \mathrm{H}_{6} \mathrm{O}\right)^{+}, 35\right], 277$ (45), 275 (100). HRMS (EI) for $\mathrm{C}_{17} \mathrm{H}_{17} \mathrm{ClO}_{3}\left(\mathrm{M}-\mathrm{C}_{2} \mathrm{H}_{6} \mathrm{O}\right)^{+}, 304.0866$; found, 304.0868 . 


\section{3-Ethoxy-5-methoxy-1-(4-methoxyphenyl)-1,3-dihydroisobenzofuran (33'c).}

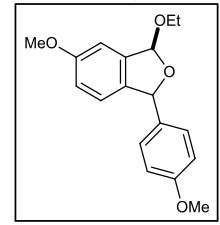

Isolated as a ca. 1.4:1 mixture of diastereoisomers along with EtOH. Yellow oil; yield $=69 \% ; R_{f}=0.30($ hex/EtOAc, $5: 1)$.

${ }^{1} \mathbf{H}$ NMR $\left(300 \mathrm{MHz}, \mathrm{CDCl}_{3}\right) \delta(\mathrm{ppm})=1.26-1.31$ (m, 6H, both diast.), 3.63-3.98 (m, 4H, both diast.), $3.76(\mathrm{~s}, 6 \mathrm{H}), 3.80(\mathrm{~s}, 6 \mathrm{H}), 6.01(\mathrm{~s}, 1 \mathrm{H}$, minor diast.), 6.20 (s, $1 \mathrm{H}$, major diast.), 6.23 (s, $1 \mathrm{H}$, minor diast.), 6.35

(s, 1H, major diast.), 6.81-6.97 (m, 10H, both diast.), 7.18-7.21 (m, 2H,

${ }^{13} \mathrm{C} \mathrm{NMR}\left(75.4 \mathrm{MHz}, \mathrm{CDCl}_{3}\right) \delta(\mathrm{ppm})=15.4\left(\mathrm{CH}_{3}\right), 15.5\left(\mathrm{CH}_{3}\right), 55.2\left(\mathrm{CH}_{3}\right), 55.3\left(\mathrm{CH}_{3}\right)$, $55.5\left(2 \times \mathrm{CH}_{3}\right), 63.5\left(\mathrm{CH}_{2}\right), 63.7\left(\mathrm{CH}_{2}\right), 84.4(\mathrm{CH}), 85.2(\mathrm{CH}), 105.8(\mathrm{CH}), 106.1(\mathrm{CH})$, $106.7(\mathrm{CH}), 107.0(\mathrm{CH}), 113.8(2 \times \mathrm{CH}), 114.0(2 \times \mathrm{CH}), 116.5(\mathrm{CH}), 116.8(\mathrm{CH}), 123.05$ $(\mathrm{CH}), 123.10(\mathrm{CH}), 128.6(2 \times \mathrm{CH}), 128.7(2 \times \mathrm{CH}), 133.2(\mathrm{C}), 134.3(\mathrm{C}), 135.2(\mathrm{C})$, 135.5 (C), 139.0 (C), $139.6(\mathrm{C}), 159.3$ (C), $159.6(\mathrm{C}), 159.90$ (C), 159.93 (C).

LRMS (EI): $m / z$ (\%) 300 (M+1 10), 269 (100), 163 (61), 137 (73), 135 (39).

HRMS (EI) for $\mathrm{C}_{18} \mathrm{H}_{20} \mathrm{O}_{4}, 300.1362$; found, 300.1363 .

(2-(Diethoxymethyl)-4-methoxyphenyl)(2,3,4-trimethoxyphenyl)metanol (33d).

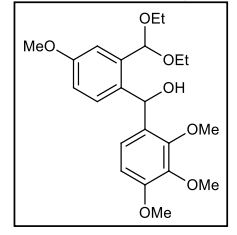

Yellow oil; yield $=71 \% ; R_{f}=0.15($ hex/EtOAc, $5: 1)$.

${ }^{1} \mathbf{H}$ NMR $\left(300 \mathrm{MHz}, \mathrm{CDCl}_{3}\right) \delta(\mathrm{ppm})=1.16-1.21(\mathrm{~m}, 6 \mathrm{H}), 3.44-3.72$ $(\mathrm{m}, 5 \mathrm{H}), 3.55(\mathrm{~s}, 3 \mathrm{H}), 3.74(\mathrm{~s}, 3 \mathrm{H}), 3.79(\mathrm{~s}, 3 \mathrm{H}), 3.81(\mathrm{~s}, 3 \mathrm{H}), 5.65(\mathrm{~s}$, $1 \mathrm{H}), 6.33(\mathrm{~d}, J=3.3 \mathrm{~Hz}, 1 \mathrm{H}), 6.66(\mathrm{~d}, J=8.7 \mathrm{~Hz}, 1 \mathrm{H}), 6.72(\mathrm{dd}, J=$ 8.6, $2.7 \mathrm{~Hz}, 1 \mathrm{H}), 7.03(\mathrm{~d}, J=8.5 \mathrm{~Hz}, 1 \mathrm{H}), 7.08-7.19(\mathrm{~m}, 2 \mathrm{H})$.

${ }^{13} \mathbf{C ~ N M R}\left(75.4 \mathrm{MHz}, \mathrm{CDCl}_{3}\right) \delta(\mathrm{ppm})=15.0\left(\mathrm{CH}_{3}\right), 15.1\left(\mathrm{CH}_{3}\right), 55.2\left(\mathrm{CH}_{3}\right), 55.9\left(\mathrm{CH}_{3}\right)$, $60.4\left(\mathrm{CH}_{3}\right), 60.6\left(\mathrm{CH}_{2}\right), 61.5\left(\mathrm{CH}_{3}\right), 62.9\left(\mathrm{CH}_{2}\right), 66.5(\mathrm{CH}), 100.6(\mathrm{CH}), 106.7(\mathrm{CH})$, $112.5(\mathrm{CH}), 113.4(\mathrm{CH}), 121.7(\mathrm{CH}), 129.08(\mathrm{C}), 129.14(\mathrm{CH}), 134.4(\mathrm{C}), 137.6(\mathrm{C})$, 141.9 (C), 150.7 (C), 152.9 (C), $158.6(\mathrm{C})$.

LRMS (EI): $m / z(\%) 360$ [(M- $\left.\left.\mathrm{C}_{2} \mathrm{H}_{6} \mathrm{O}\right)^{+}, 68\right], 329$ (30), 314 (23), 195 (87), 165 (25), 163 (100).

HRMS (EI) for $\mathrm{C}_{22} \mathrm{H}_{28} \mathrm{O}_{6}\left(\mathrm{M}-\mathrm{H}_{2} \mathrm{O}\right)^{+}, 388.1886$; found, 388.1880.

(2-(Diethoxymethyl)-4-methoxyphenyl)(thiophen-2-yl)methanol (33e).

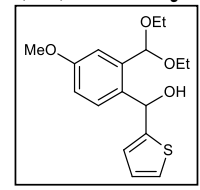

Yellow oil; yield $=79 \% ; R_{f}=0.18($ hex/EtOAc, $5: 1)$.

${ }^{1} \mathbf{H}$ NMR (300 MHz, $\left.\mathrm{CDCl}_{3}\right) \delta(\mathrm{ppm})=1.15-1.20(\mathrm{~m}, 6 \mathrm{H}), 3.41-3.60(\mathrm{~m}$, $4 \mathrm{H}), 3.80(\mathrm{~s}, 3 \mathrm{H}), 4.14(\mathrm{bs}, 1 \mathrm{H}), 5.52(\mathrm{~s}, 1 \mathrm{H}), 6.30(\mathrm{bs}, 1 \mathrm{H}), 6.80-6.86$ $(\mathrm{m}, 2 \mathrm{H}), 6.91-6.95(\mathrm{~m}, 1 \mathrm{H}), 7.17(\mathrm{~d}, J=2.7 \mathrm{~Hz}, 1 \mathrm{H}), 7.21-7.24(\mathrm{~m}, 1 \mathrm{H})$,

$7.34(\mathrm{~d}, J=8.5 \mathrm{~Hz}, 1 \mathrm{H})$.

${ }^{13} \mathrm{C}$ NMR (75.4 MHz, $\left.\mathrm{CDCl}_{3}\right) \delta(\mathrm{ppm})=14.97\left(\mathrm{CH}_{3}\right), 15.00\left(\mathrm{CH}_{3}\right), 55.2\left(\mathrm{CH}_{3}\right), 61.8$ $\left(\mathrm{CH}_{2}\right), 62.2\left(\mathrm{CH}_{2}\right), 69.6(\mathrm{CH}), 100.0(\mathrm{CH}), 113.0(\mathrm{CH}), 113.5(\mathrm{CH}), 124.2(\mathrm{CH}), 124.6$ $(\mathrm{CH}), 126.6(\mathrm{CH}), 129.9(\mathrm{CH}), 133.7(\mathrm{C}), 137.6(\mathrm{C}), 148.4(\mathrm{C}), 159.0(\mathrm{C})$.

LRMS (EI): $m / z(\%) 276$ [(M- $\left.\left.\mathrm{C}_{2} \mathrm{H}_{6} \mathrm{O}\right)^{+}, 15\right], 231$ (55), 192 (58), 165 (38), 163 (100).

HRMS (EI) for $\mathrm{C}_{15} \mathrm{H}_{16} \mathrm{O}_{3} \mathrm{~S}\left(\mathrm{M}-\mathrm{C}_{2} \mathrm{H}_{6} \mathrm{O}\right)^{+}, 276.0820$; found, 276.0818. 
1-(2-(Diethoxymethyl)-4-methoxyphenyl)-1-(4-methoxyphenyl)ethanol (33f).

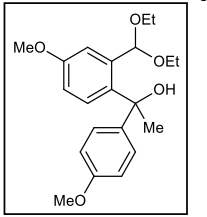

Isolated along with minor amounts of 33'f. Yellow oil; yield $=88 \% ; R_{f}$ $=0.11($ hex $/$ EtOAc, $5: 1)$.

${ }^{1} \mathbf{H}$ NMR $\left(300 \mathrm{MHz}, \mathrm{CDCl}_{3}\right) \delta(\mathrm{ppm})=0.98(\mathrm{t}, J=7.1 \mathrm{~Hz}, 3 \mathrm{H}), 1.16(\mathrm{t}$, $J=7.1 \mathrm{~Hz}, 3 \mathrm{H}), 1.81(\mathrm{~s}, 3 \mathrm{H}), 2.99-3.24(\mathrm{~m}, 2 \mathrm{H}), 3.35-3.54(\mathrm{~m}, 2 \mathrm{H}), 3.77$ (s, 3H), $3.83(\mathrm{~s}, 3 \mathrm{H}), 4.89(\mathrm{~s}, 1 \mathrm{H}), 5.08(\mathrm{~s}, 1 \mathrm{H}), 6.77-6.83(\mathrm{~m}, 2 \mathrm{H}), 6.89$ (dd, $J=8.7,2.9 \mathrm{~Hz}, 1 \mathrm{H}), 7.20-7.28(\mathrm{~m}, 2 \mathrm{H}), 7.30(\mathrm{~d}, J=2.9 \mathrm{~Hz}, 1 \mathrm{H}), 7.60(\mathrm{~d}, J=8.7 \mathrm{~Hz}, 1 \mathrm{H})$. ${ }^{13} \mathbf{C ~ N M R}\left(75.4 \mathrm{MHz}, \mathrm{CDCl}_{3}\right) \delta(\mathrm{ppm})=14.8\left(\mathrm{CH}_{3}\right), 15.0\left(\mathrm{CH}_{3}\right), 33.3\left(\mathrm{CH}_{3}\right), 55.39\left(\mathrm{CH}_{3}\right)$, $55.41\left(\mathrm{CH}_{3}\right), 60.4\left(\mathrm{CH}_{2}\right), 63.3\left(\mathrm{CH}_{2}\right), 75.6(\mathrm{CH}), 98.3(\mathrm{CH}), 113.0(\mathrm{CH}), 113.4(2 \times \mathrm{CH}), 113.7(\mathrm{CH})$, $126.3(2 \times \mathrm{CH}), 128.2(\mathrm{CH}), 137.2(\mathrm{C}), 138.3(\mathrm{C}), 142.7(\mathrm{C}), 158.3(\mathrm{C}), 158.9(\mathrm{C})$.

(2-(Diethoxymethyl)thiophen-3-yl)(2,3,4-trimethoxyphenyl)metanol (35a).

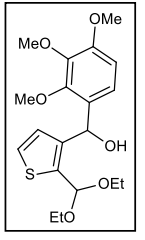

Yellow oil; yield $=70 \% ; R_{f}=0.26($ hex/EtOAc, $2: 1)$.

${ }^{1} \mathbf{H}$ NMR $\left(300 \mathrm{MHz}, \mathrm{CDCl}_{3}\right) \delta(\mathrm{ppm})=1.12-1.26(\mathrm{~m}, 6 \mathrm{H}), 3.51-3.70(\mathrm{~m}$, $7 \mathrm{H}), 3.82(\mathrm{~s}, 6 \mathrm{H}), 5.81(\mathrm{~s}, 1 \mathrm{H}), 6.14(\mathrm{~d}, J=4.4 \mathrm{~Hz}, 1 \mathrm{H}), 6.59-6.67(\mathrm{~m}, 1 \mathrm{H})$, $6.81(\mathrm{~d}, J=5.2 \mathrm{~Hz}, 1 \mathrm{H}), 7.07(\mathrm{~d}, J=8.7 \mathrm{~Hz}, 1 \mathrm{H}), 7.11(\mathrm{~d}, J=5.1, \mathrm{~Hz}, 1 \mathrm{H})$.

${ }^{13} \mathrm{C} \mathrm{NMR}\left(75.4 \mathrm{MHz}, \mathrm{CDCl}_{3}\right) \delta(\mathrm{ppm})=15.1\left(\mathrm{CH}_{3}\right), 15.2\left(\mathrm{CH}_{3}\right), 56.1\left(\mathrm{CH}_{3}\right)$, $60.7\left(\mathrm{CH}_{3}\right), 60.8\left(\mathrm{CH}_{3}\right), 61.1\left(\mathrm{CH}_{2}\right), 61.9\left(\mathrm{CH}_{2}\right), 66.4(\mathrm{CH}), 97.7(\mathrm{CH}), 106.9(\mathrm{CH}), 121.6$ (CH), $124.1(\mathrm{CH}), 128.2(\mathrm{CH}), 129.2(\mathrm{C}), 137.7(\mathrm{C}), 142.0(\mathrm{C}), 142.1(\mathrm{C}), 151.1(\mathrm{C}), 153.3(\mathrm{C})$.

LRMS (EI): $m / z$ (\%) $336\left(\mathrm{M}^{+}, 61\right), 291$ (19), 138 (100).

HRMS (EI) for $\mathrm{C}_{19} \mathrm{H}_{26} \mathrm{O}_{6} \mathrm{~S}, 382.1451$; found, 382.1450 .

\section{3-Ethoxy-1-(4-methoxyphenyl)-1,3-dihydrobenzo[4,5]thieno[2,3-c]furan (35b).}

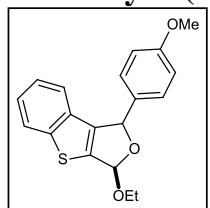
Isolated as ca. 1.7:1 mixture of diastereoisomers. Yellow oil; yield $=$ $40 \% ; R_{f}=0.19($ hex/EtOAc, 10:1).

${ }^{1} \mathbf{H}$ NMR $\left(300 \mathrm{MHz}, \mathrm{CDCl}_{3}\right) \delta(\mathrm{ppm})=1.24-1.34$ (m, 6H, both diast.), $3.67-3.93(\mathrm{~m}, 10 \mathrm{H}$, both diast.), 6.15 (s, 1H, major diast.), 6.38 (d, $J=$ $3.2 \mathrm{~Hz}, 1 \mathrm{H}$, minor diast.), 6.42 (s, $1 \mathrm{H}$, major diast.), 6.55 (d, $J=3.2 \mathrm{~Hz}$, minor diast.), 6.85-6.93 (m, 3H), 7.22-7.33 (m, 7H), 7.38-7.43 (m, 2H), 7.76-7.87 (m, 2H).

${ }^{13} \mathrm{C} \mathrm{NMR}\left(75.4 \mathrm{MHz}, \mathrm{CDCl}_{3}\right) \delta(\mathrm{ppm})=15.46\left(\mathrm{CH}_{3}\right), 15.53\left(\mathrm{CH}_{3}\right), 55.34\left(\mathrm{CH}_{3}\right), 55.39$ $\left(\mathrm{CH}_{3}\right), 63.0\left(\mathrm{CH}_{2}\right), 63.5\left(\mathrm{CH}_{2}\right), 82.9(\mathrm{CH}), 83.3(\mathrm{CH}), 103.7(\mathrm{CH}), 103.9(\mathrm{CH}), 114.0(2$ $\times \mathrm{CH}), 114.2(2 \times \mathrm{CH}), 122.2(\mathrm{CH}), 122.4(\mathrm{CH}), 123.9(2 \times \mathrm{CH}), 124.76(\mathrm{CH}), 124.78(\mathrm{CH})$, $124.85(\mathrm{CH}), 124.93(\mathrm{CH}), 129.0(2 \times \mathrm{CH}), 129.2(2 \times \mathrm{CH}), 131.3(\mathrm{C}), 131.87(\mathrm{C}), 131.89(\mathrm{C})$, 132.03 (C), 138.7 (C), 139.0 (C), 142.9 (C), 143.2 (C), 146.6 (C), 146.8 (C), 159.8 (C), 160.0 (C). 


\section{(2-(1,3-Dioxolan-2-yl)benzofuran-3-yl)(4-methoxyphenyl)metanol (38).}

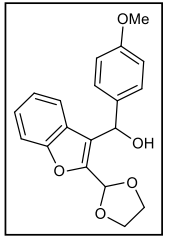

Yellow oil; yield $=65 \% ; R_{f}=0.20($ hex/EtOAc, $3: 1)$.

${ }^{1} \mathbf{H}$ NMR $\left(300 \mathrm{MHz}, \mathrm{CDCl}_{3}\right) \delta(\mathrm{ppm})=3.73(\mathrm{~s}, 3 \mathrm{H}), 3.94-4.17(\mathrm{~m}, 5 \mathrm{H})$, $6.15(\mathrm{~s}, 1 \mathrm{H}), 6.27(\mathrm{~s}, 1 \mathrm{H}), 6.80-6.86(\mathrm{~m}, 2 \mathrm{H}), 7.07-7.14(\mathrm{~m}, 1 \mathrm{H}), 7.22-7.30$ (m, 1H), 7.33-7.40 (m, 3H), $7.46(\mathrm{~d}, 8.3 \mathrm{~Hz}, 1 \mathrm{H})$.

${ }^{13} \mathbf{C}$ NMR $\left(75.4 \mathrm{MHz}, \mathrm{CDCl}_{3}\right) \delta(\mathrm{ppm})=55.2\left(\mathrm{CH}_{3}\right), 65.49\left(\mathrm{CH}_{2}\right), 65.54$ $\left(\mathrm{CH}_{2}\right), 67.8(\mathrm{CH}), 97.5(\mathrm{CH}), 111.5(\mathrm{CH}), 113.7(2 \times \mathrm{CH}), 121.5(\mathrm{CH}), 122.1(\mathrm{C}), 122.8$ $(\mathrm{CH}), 125.2(\mathrm{CH}), 126.7(\mathrm{C}), 127.5(2 \times \mathrm{CH}), 134.5(\mathrm{C}), 148.2(\mathrm{C}), 154.3(\mathrm{C}), 158.9(\mathrm{C})$. LRMS (EI): $m / z$ (\%) $326\left(\mathbf{M}^{+}, 31\right), 242$ (19), 173 (100).

HRMS (EI) for $\mathrm{C}_{19} \mathrm{H}_{18} \mathrm{O}_{5}, 326.1152$; found, 326.1154 .

\subsubsection{Synthesis of hydroxy-functionalized acetals 36a, 37, 40 and/or cyclic acetals}

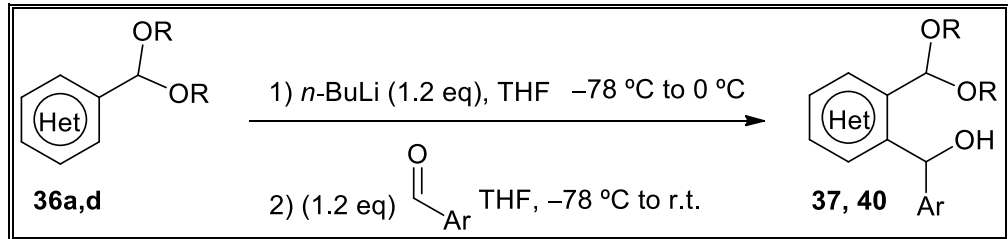

To a solution of the corresponding aldehyde dialkyl acetal 36a, 36d (5 mmol) in THF (10 ml), at $-78{ }^{\circ} \mathrm{C}$, was added $n$-BuLi $(3.75 \mathrm{ml}, 6 \mathrm{mmol}, 1.6 \mathrm{M}$ in hexanes). The solution was stirred at $0{ }^{\circ} \mathrm{C}$ for $30 \mathrm{~min}$, then the appropriate aldehyde $(1.2 \mathrm{eq})$ was added at -78 ${ }^{\circ} \mathrm{C}$. The resulting mixture was stirred at r.t. until the corresponding aldehyde dialkyl acetal was consumed as determined by TLC or GC-MS. The reaction was quenched with a saturated aqueous solution of $\mathrm{NH}_{4} \mathrm{Cl}$ and extracted with $\mathrm{Et}_{2} \mathrm{O}(3 \times 15 \mathrm{ml})$. The combined organic layers were dried over anhydrous $\mathrm{Na}_{2} \mathrm{SO}_{4}$ and concentrated at reduced pressure. The residue was purified by flash chromatography using mixtures of hexane and EtOAc as eluents to obtain the corresponding hydroxy-functionalized acetals $\mathbf{3 7}$ and $\mathbf{4 0 .}$

\section{(3-(Diethoxymethyl)thiophen-2-yl)(4-methoxyphenyl)methanol (36a).}

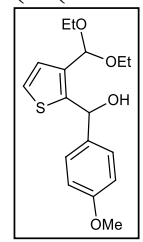

Yellow oil; yield $=30 \% ; R_{f}=0.73($ hex/EtOAc, $5: 1)$.

${ }^{1} \mathbf{H}$ NMR $\left(300 \mathrm{MHz}, \mathrm{CDCl}_{3}\right) \delta(\mathrm{ppm})=1.21(\mathrm{t}, J=7.1 \mathrm{~Hz}, 3 \mathrm{H}), 1.23(\mathrm{t}, J=$ $7.0 \mathrm{~Hz}, 3 \mathrm{H}), 3.43-3.69(\mathrm{~m}, 4 \mathrm{H}), 3.81(\mathrm{~s}, 3 \mathrm{H}), 3.84(\mathrm{~d}, J=3.3 \mathrm{~Hz}, 1 \mathrm{H}), 5.58$ $(\mathrm{s}, 1 \mathrm{H}), 6.16(\mathrm{~d}, J=3.3 \mathrm{~Hz}, 1 \mathrm{H}), 6.87-6.90(\mathrm{~m}, 2 \mathrm{H}), 7.07(\mathrm{~d}, J=5.2 \mathrm{~Hz}, 1 \mathrm{H})$, $7.10(\mathrm{~d}, J=5.2 \mathrm{~Hz}, 1 \mathrm{H}), 7.38-7.41(\mathrm{~m}, 2 \mathrm{H})$.

${ }^{13} \mathrm{C}$ NMR $\left(75.4 \mathrm{MHz}, \mathrm{CDCl}_{3}\right) \delta(\mathrm{ppm})=15.20\left(\mathrm{CH}_{3}\right), 15.25\left(\mathrm{CH}_{3}\right), 55.4\left(\mathrm{CH}_{3}\right), 61.2$ $\left(\mathrm{CH}_{2}\right), 61.9\left(\mathrm{CH}_{2}\right), 69.4(\mathrm{CH}), 98.8(\mathrm{CH}), 113.6(2 \times \mathrm{CH}), 123.5(\mathrm{CH}), 127.9(2 \times \mathrm{CH})$, $128.0(\mathrm{CH}), 134.8(\mathrm{C}), 136.6(\mathrm{C}), 146.2(\mathrm{C}), 159.3(\mathrm{C})$ 
(3-(Diethoxymethyl)thiophen-2-yl)(4-methoxyphenyl)methanol (37).

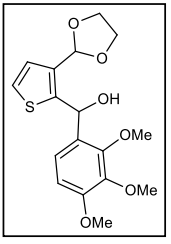

Yellow oil; yield $=59 \% ; R_{f}=0.16($ hex/EtOAc, $5: 1)$.

${ }^{1} \mathbf{H}$ NMR $\left(300 \mathrm{MHz}, \mathrm{CDCl}_{3}\right) \delta(\mathrm{ppm})=3.72(\mathrm{~s}, 3 \mathrm{H}), 3.84(\mathrm{~s}, 3 \mathrm{H}), 3.86(\mathrm{~s}$, $3 \mathrm{H}), 3.97-4.14(\mathrm{~m}, 5 \mathrm{H}), 5.96(\mathrm{~s}, 1 \mathrm{H}), 6.40(\mathrm{~d}, J=3.8 \mathrm{~Hz}, 1 \mathrm{H}), 6.69(\mathrm{~d}, J=8.7 \mathrm{~Hz}$, $1 \mathrm{H}), 7.08(\mathrm{~d}, J=5.2 \mathrm{~Hz}, 1 \mathrm{H}), 7.12(\mathrm{~d}, J=5.2 \mathrm{~Hz}, 1 \mathrm{H}), 7.20(\mathrm{~d}, J=8.7 \mathrm{~Hz}, 1 \mathrm{H})$.

${ }^{13} \mathrm{C}$ NMR $\left(75.4 \mathrm{MHz}, \mathrm{CDCl}_{3}\right) \delta(\mathrm{ppm})=56.0\left(\mathrm{CH}_{3}\right), 60.77\left(\mathrm{CH}_{2}\right), 60.82$ $\left(\mathrm{CH}_{2}\right), 65.0(\mathrm{CH}), 65.1\left(\mathrm{CH}_{3}\right), 65.2\left(\mathrm{CH}_{3}\right), 99.8(\mathrm{CH}), 106.8(\mathrm{CH}), 121.5(\mathrm{CH}), 123.7$ $(\mathrm{CH}), 126.9(\mathrm{CH}), 128.7(\mathrm{C}), 134.9(\mathrm{C}), 141.9(\mathrm{C}), 147.6(\mathrm{C}), 151.0(\mathrm{C}), 153.6(\mathrm{C})$.

\section{(3-(1,3-Dioxolan-2-yl)-1-tosyl-1H-indol-2-yl)(phenyl)methanol (40).}

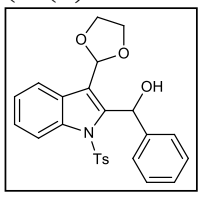

Yellow oil; yield $=55 \% ; R_{f}=0.20($ hex/EtOAc, $3: 1)$.

${ }^{1} \mathbf{H}$ NMR $\left(300 \mathrm{MHz}, \mathrm{CDCl}_{3}\right) \delta(\mathrm{ppm})=2.30(\mathrm{~s}, 3 \mathrm{H}), 3.90-4.08(\mathrm{~m}, 4 \mathrm{H})$, $4.63(\mathrm{~d}, J=10.6 \mathrm{~Hz}, 1 \mathrm{H}), 6.04(\mathrm{~s}, 1 \mathrm{H}), 6.77(\mathrm{~d}, J=10.6 \mathrm{~Hz}, 1 \mathrm{H}), 7.02-$ $7.10(\mathrm{~m}, 2 \mathrm{H}), 7.15-7.47(\mathrm{~m}, 8 \mathrm{H}), 7.77-7.85(\mathrm{~m}, 1 \mathrm{H}), 8.11-8.25(\mathrm{~m}, 1 \mathrm{H})$.

${ }^{13} \mathrm{C} \mathrm{NMR}\left(75.4 \mathrm{MHz}, \mathrm{CDCl}_{3}\right) \delta(\mathrm{ppm})=21.6\left(\mathrm{CH}_{3}\right), 65.1\left(\mathrm{CH}_{2}\right), 65.2\left(\mathrm{CH}_{2}\right), 67.4(\mathrm{CH})$, $99.7(\mathrm{CH}), 115.0(\mathrm{CH}), 119.2(\mathrm{C}), 121.2(\mathrm{CH}), 124.0(\mathrm{CH}), 125.6(\mathrm{CH}), 126.6(2 \times \mathrm{CH}), 127.7$ $(2 \times \mathrm{CH}), 128.3(2 \times \mathrm{CH}), 129.8(2 \times \mathrm{CH}), 133.1(\mathrm{C}), 135.4(\mathrm{C}), 136.5(\mathrm{C}), 140.2(\mathrm{C}), 140.6$ (C), $145.2(\mathrm{C})$, one quaternary carbon peak is not observed, probably due to overlapping.

\subsection{Synthesis of Benzo $[b]$ carbazoles and Heteroaryl $[b]$ carbazoles $41,44,45-51$}

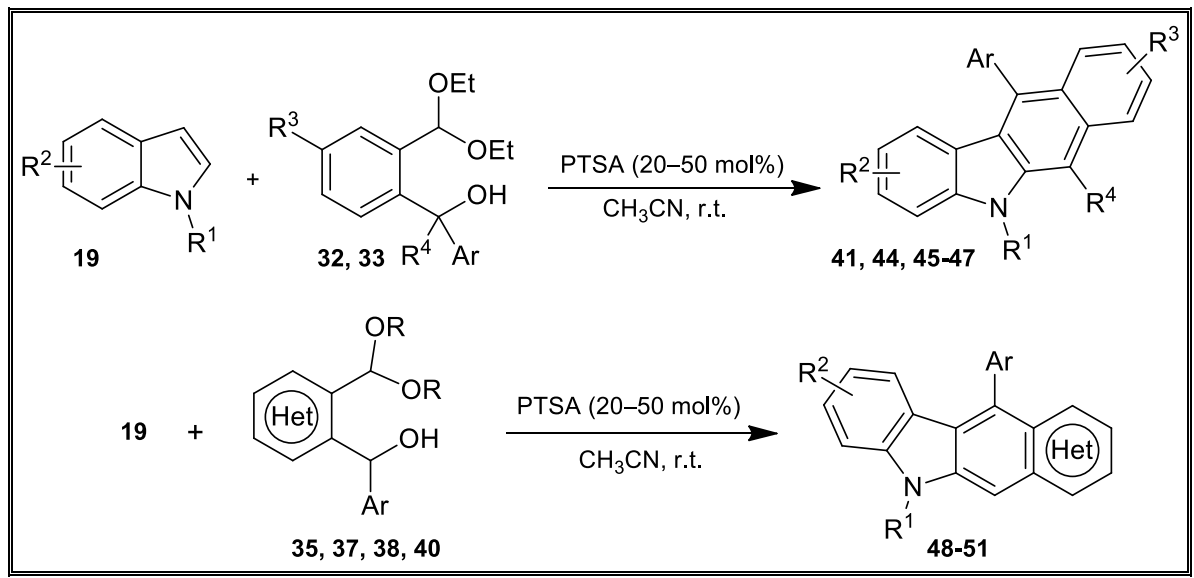

General Procedure: To a mixture of the corresponding acetal derivative 32, 33, 35, 37, 38, 40 (1 mmol) and the corresponding indole 19 (1 mmol), in $\mathrm{MeCN}(1 \mathrm{ml})$ was added PTSA (38-95 mg, 20-50 mol\%). The reaction mixture was stirred for $0.5-24 \mathrm{~h}$ at r.t., then was quenched with a $\mathrm{NaOH}$ solution $(0.5 \mathrm{M})$, and extracted with EtOAc $(3 \times 15$ $\mathrm{ml}$ ). The combined organic layers were dried over anhydrous $\mathrm{Na}_{2} \mathrm{SO}_{4}$ and concentrated at reduced pressure. The residue was purified by flash chromatography using mixtures of hexane and EtOAc as eluents to obtain the corresponding carbazoles 41, 44, 45-51. In some cases the final product precipitates from the reaction mixture and could be isolated by simple filtration in pure form. Data for $\mathbf{4 1}, \mathbf{4 4 , 4 5 - 5 1}$ are shown below. 


\section{5-Methyl-11-phenyl-5H-benzo[b]carbazole (41ca).}

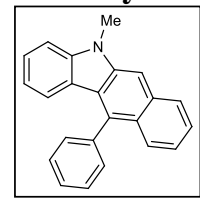

Yellow solid; yield $=78 \%$; m.p. $158-160{ }^{\circ} \mathrm{C} ; R_{f}=0.49($ hex/EtOAc, $5: 1)$.

${ }^{1} \mathbf{H}$ NMR $\left(400 \mathrm{MHz}, \mathrm{CDCl}_{3}\right) \delta(\mathrm{ppm})=3.90(\mathrm{~s}, 3 \mathrm{H}), 6.95-6.99(\mathrm{~m}, 2 \mathrm{H})$, 7.32-7.38 (m, 2H), 7.45-7.57 (m, 4H), 7.63-7.70 (m, 3H), $7.74(\mathrm{~s}, 1 \mathrm{H})$, $7.78(\mathrm{~d}, J=8.5 \mathrm{~Hz}, 1 \mathrm{H}), 8.06(\mathrm{~d}, J=8.3 \mathrm{~Hz}, 1 \mathrm{H})$.

${ }^{13} \mathrm{C} \mathrm{NMR}\left(75.4 \mathrm{MHz}, \mathrm{CDCl}_{3}\right) \delta(\mathrm{ppm})=29.3\left(\mathrm{CH}_{3}\right), 102.7(\mathrm{CH}), 107.7(\mathrm{CH}), 118.7$ $(\mathrm{CH}), 122.6(\mathrm{CH}), 122.9(\mathrm{C}), 123.2(\mathrm{CH}+\mathrm{C}), 125.1(\mathrm{CH}), 126.5(\mathrm{CH}), 127.0(\mathrm{CH}), 127.2$ $(\mathrm{CH}), 127.5(\mathrm{C}), 127.9(\mathrm{CH}), 129.0(2 \times \mathrm{CH}), 130.3(2 \times \mathrm{CH}), 132.6(\mathrm{C}), 134.0(\mathrm{C}), 139.1$ (C), $140.7(\mathrm{C}), 143.8(\mathrm{C})$.

LRMS (EI): $m / z(\%) 307\left(\mathbf{M}^{+}, 100\right), 291$ (13).

HRMS (EI) for $\mathrm{C}_{23} \mathrm{H}_{17} \mathrm{~N}$, 307.1361; found, 307.1360.

\section{1-(4-Chlorophenyl)-5-methyl-5 $H$-benzo $[b]$ carbazole $(41 \mathrm{cb})$.}

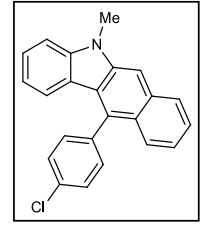

Yellow solid; yield $=89 \%$; m.p. $177-179{ }^{\circ} \mathrm{C} ; R_{f}=0.40($ hex/EtOAc, $5: 1)$. ${ }^{1} \mathbf{H}$ NMR $\left(400 \mathrm{MHz}, \mathrm{CDCl}_{3}\right) \delta(\mathrm{ppm})=3.90(\mathrm{~s}, 3 \mathrm{H}), 6.95-7.00(\mathrm{~m}, 2 \mathrm{H})$, $7.30-7.37(\mathrm{~m}, 2 \mathrm{H}), 7.43-7.53(\mathrm{~m}, 4 \mathrm{H}), 7.59-7.63(\mathrm{~m}, 2 \mathrm{H}), 7.68(\mathrm{~d}, J=$ $8.6 \mathrm{~Hz}, 1 \mathrm{H}), 7.73(\mathrm{~s}, 1 \mathrm{H}), 8.03(\mathrm{dd}, J=8.3,0.5 \mathrm{~Hz}, 1 \mathrm{H})$.

${ }^{13} \mathrm{C}$ NMR $\left(75.4 \mathrm{MHz}, \mathrm{CDCl}_{3}\right) \delta(\mathrm{ppm})=29.3\left(\mathrm{CH}_{3}\right), 103.1(\mathrm{CH}), 107.9$ $(\mathrm{CH}), 118.8(\mathrm{CH}), 122.6(\mathrm{C}), 122.8(\mathrm{CH}), 123.0(\mathrm{CH}), 123.1(\mathrm{C}), 125.2(\mathrm{CH}), 126.1(\mathrm{CH})$, $127.20(\mathrm{C}), 127.24(\mathrm{CH}), 127.3(\mathrm{CH}), 129.4(2 \times \mathrm{CH}), 131.8(2 \times \mathrm{CH}), 132.4(\mathrm{C}), 132.6$ (C), 133.9 (C), $137.6(\mathrm{C}), 140.7$ (C) 143.9 (C).

LRMS (EI): $m / z(\%) 343\left[(\mathrm{M}+2)^{+}, 36\right], 341\left(\mathrm{M}^{+}, 100\right), 342(29)$.

HRMS (EI) for $\mathrm{C}_{23} \mathrm{H}_{16} \mathrm{ClN}$, 341.0971; found, 341.0963.

\section{1-(4-Bromophenyl)-5-methyl-5H-benzo[b]carbazole (41cc).}

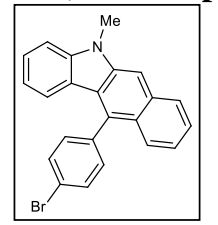

Yellow solid; yield $=65 \%$; m.p. $192-194{ }^{\circ} \mathrm{C} ; R_{f}=0.45($ hex/EtOAc, $5: 1)$.

${ }^{1} \mathbf{H}$ NMR $\left(400 \mathrm{MHz}, \mathrm{CDCl}_{3}\right) \delta(\mathrm{ppm})=3.89(\mathrm{~s}, 3 \mathrm{H}), 6.97-7.02(\mathrm{~m}, 2 \mathrm{H})$, 7.31-7.37 (m, 2H), 7.37-7.41 (m, 2H), 7.46-7.54 (m, 2H), 7.67-7.70 (m, $1 \mathrm{H}), 7.73(\mathrm{~s}, 1 \mathrm{H}), 7.76-7.80(\mathrm{~m}, 2 \mathrm{H}), 8.02-8.05(\mathrm{~m}, 1 \mathrm{H})$.

${ }^{13}$ C NMR $\left(100.6 \mathrm{MHz}, \mathrm{CDCl}_{3}\right) \delta(\mathrm{ppm})=29.3\left(\mathrm{CH}_{3}\right), 103.1(\mathrm{CH}), 107.9$ $(\mathrm{CH}), 118.8(\mathrm{CH}), 122.1(\mathrm{C}), 122.6(\mathrm{C}), 122.8(\mathrm{CH}), 123.0(\mathrm{CH}+\mathrm{C}), 125.2(\mathrm{CH}), 126.1$ $(\mathrm{CH}), 127.1(\mathrm{C}), 127.2(\mathrm{CH}), 127.3(\mathrm{CH}), 132.1(2 \times \mathrm{CH}), 132.3(2 \times \mathrm{CH}), 132.4(\mathrm{C})$, 132.6 (C), $138.1(\mathrm{C}), 140.6(\mathrm{C}), 143.9(\mathrm{C})$.

LRMS (EI): $m / z(\%) 387$ [(M+2) $\left.{ }^{+}, 97\right], 385\left(\mathrm{M}^{+}, 100\right), 291$ (21), 153 (25).

HRMS (EI) for $\mathrm{C}_{23} \mathrm{H}_{16} \mathrm{BrN}$, 385.0466; found, 385.0457. 
11-(4-Methoxyphenyl)-5-methyl-5H-benzo[b]carbazole (41cd).

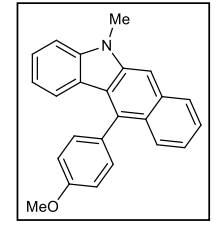

Yellow solid; yield $=85 \% ;$ m.p. $=172-174{ }^{\circ} \mathrm{C} ; R_{f}=0.44($ hex/EtOAc, $5: 1)$. ${ }^{1} \mathbf{H}$ NMR $\left(400 \mathrm{MHz}, \mathrm{CDCl}_{3}\right) \delta(\mathrm{ppm})=3.90(\mathrm{~s}, 3 \mathrm{H}), 3.99$ (s, 3H), 6.96 (ddd, $J=7.9,7.1,1.0 \mathrm{~Hz}, 1 \mathrm{H}), 7.04(\mathrm{ddd}, J=7.9,1.3,0.7,1 \mathrm{H}), 7.16-7.20$ $(\mathrm{m}, 2 \mathrm{H}), 7.29-7.36(\mathrm{~m}, 2 \mathrm{H}), 741-7.51(\mathrm{~m}, 4 \mathrm{H}), 7.71(\mathrm{~s}, 1 \mathrm{H}), 7.76-7.79$ $(\mathrm{m}, 1 \mathrm{H}), 8.01-8.04(\mathrm{~m}, 1 \mathrm{H})$.

${ }^{13} \mathrm{C}$ NMR $\left(100.6 \mathrm{MHz}, \mathrm{CDCl}_{3}\right) \delta(\mathrm{ppm})=29.2\left(\mathrm{CH}_{3}\right), 55.4\left(\mathrm{CH}_{3}\right), 102.6(\mathrm{CH}), 107.7$ $(\mathrm{CH}), 114.4(2 \times \mathrm{CH}), 118.6(\mathrm{CH}), 122.5(\mathrm{CH}), 123.0(\mathrm{C}), 123.2(\mathrm{CH}), 123.4(\mathrm{C}), 125.0$ $(\mathrm{CH}), 126.5(\mathrm{CH}), 126.9(\mathrm{CH}), 127.2(\mathrm{CH}), 127.7(\mathrm{C}), 131.2(\mathrm{C}), 131.3(2 \times \mathrm{CH}), 132.6$ (C), 133.7 (C), 140.7 (C), 143.7 (C), 159.3 (C).

LRMS (EI): $m / z$ (\%) 337 (M+1 100), 292 (9), 278 (10).

HRMS (EI) for $\mathrm{C}_{24} \mathrm{H}_{19} \mathrm{NO}, 337.1467$; found, 337.1480 .

\section{5-Methyl-11-(2,3,4-trimethoxyphenyl)-5H-benzo[b]carbazole (41ce).}

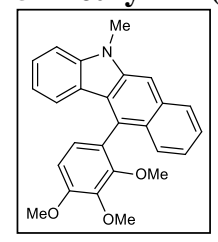

Yellow solid; yield $=90 \%$; m.p. $=245-248^{\circ} \mathrm{C}$.

${ }^{1} \mathbf{H}$ NMR $\left(400 \mathrm{MHz}, \mathrm{CDCl}_{3}\right) \delta(\mathrm{ppm})=3.38(\mathrm{~s}, 3 \mathrm{H}), 3.90(\mathrm{~s}, 3 \mathrm{H}), 4.01$ $(\mathrm{s}, 3 \mathrm{H}), 4.03(\mathrm{~s}, 3 \mathrm{H}), 6.92(\mathrm{~d}, J=8.5 \mathrm{~Hz}, 1 \mathrm{H}), 6.96(\mathrm{at}, J=7.6 \mathrm{~Hz}, 1 \mathrm{H})$, $7.02(\mathrm{~d}, J=8.4 \mathrm{~Hz}, 1 \mathrm{H}), 7.04(\mathrm{~d}, J=7.4 \mathrm{~Hz}, 1 \mathrm{H}), 7.29-7.35(\mathrm{~m}, 2 \mathrm{H}), 7.42-7.50$ $(\mathrm{m}, 2 \mathrm{H}), 7.72(\mathrm{~s}, 1 \mathrm{H}), 7.74(\mathrm{~d}, J=8.7 \mathrm{~Hz}, 1 \mathrm{H}), 8.01(\mathrm{~d}, J=8.2 \mathrm{~Hz}, 1 \mathrm{H})$.

${ }^{13} \mathrm{C}$ NMR $\left(100.6 \mathrm{MHz}, \mathrm{CDCl}_{3}\right) \delta(\mathrm{ppm})=29.3\left(\mathrm{CH}_{3}\right), 56.3\left(\mathrm{CH}_{3}\right), 61.1\left(\mathrm{CH}_{3}\right), 61.4$ $\left(\mathrm{CH}_{3}\right), 102.8(\mathrm{CH}), 107.8(\mathrm{CH}), 108.0(\mathrm{CH}), 118.8(\mathrm{CH}), 122.7(\mathrm{CH}), 122.9(\mathrm{CH}), 123.0$ $(\mathrm{C}), 123.8(\mathrm{C}), 125.1(\mathrm{CH}), 125.4(\mathrm{C}), 125.9(\mathrm{CH}), 126.3(\mathrm{CH}), 127.0(\mathrm{CH}), 127.2(\mathrm{CH})$, 127.8 (C), 130.1 (C), $132.6(\mathrm{C}), 140.8$ (C), 143.0 (C), 143.8 (C), 152.5 (C), 153.8 (C).

LRMS (EI): $m / z$ (\%) 397 (M+1 100), 268 (9), 198 (7).

HRMS (EI) for $\mathrm{C}_{26} \mathrm{H}_{23} \mathrm{NO}_{3}, 397.1678$; found, 397.1633 .

\section{5-Methyl-11-(naphthalen-2-yl)-5H-benzo[b]carbazole (41cf).}

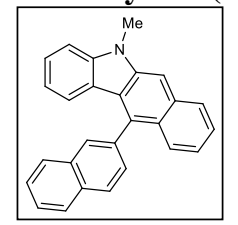

Yellow solid; yield $=58 \%$, m.p. $174-176^{\circ} \mathrm{C} ; R_{f}=0.44($ hex/EtOAc, $5: 1)$.

${ }^{1} \mathbf{H}$ NMR $\left(400 \mathrm{MHz}, \mathrm{CDCl}_{3}\right) \delta(\mathrm{ppm})=3.93(\mathrm{~s}, 3 \mathrm{H}), 6.89-6.94(\mathrm{~m}, 1 \mathrm{H})$, 7.01-7.04 (m, 1H), 7.35-7.40 (m, 2H), 7.46-7.52 (m, 1H), 7.56-7.61 $(\mathrm{m}, 1 \mathrm{H}), 7.64-7.75(\mathrm{~m}, 3 \mathrm{H}) 7.82(\mathrm{~s}, 1 \mathrm{H}), 7.86(\mathrm{~d}, J=8.6 \mathrm{~Hz}, 1 \mathrm{H}), 7.99$ $(\mathrm{d}, J=7.9 \mathrm{~Hz}, 1 \mathrm{H}), 8.11-8.15(\mathrm{~m}, 3 \mathrm{H}), 8.19(\mathrm{~d}, J=8.3 \mathrm{~Hz}, 1 \mathrm{H})$.

${ }^{13} \mathbf{C ~ N M R}\left(\mathrm{CDCl}_{3}, 100.6 \mathrm{MHz}\right) \delta(\mathrm{ppm})=29.2\left(\mathrm{CH}_{3}\right), 102.9(\mathrm{CH}), 107.8(\mathrm{CH}), 118.7$ $(\mathrm{CH}), 122.7(\mathrm{CH}), 122.8(\mathrm{C}), 123.21(\mathrm{CH}), 123.24(\mathrm{C}), 125.2(\mathrm{CH}), 126.3(\mathrm{CH}), 126.4$ $(\mathrm{CH}), 126.5(\mathrm{CH}), 127.1(\mathrm{CH}), 127.2(\mathrm{CH}), 127.5(\mathrm{C}), 128.1(\mathrm{CH}), 128.4(\mathrm{CH}), 128.6$ $(\mathrm{CH}), 128.7(\mathrm{CH}), 129.2(\mathrm{CH}), 132.6(\mathrm{C}), 133.0(\mathrm{C}), 133.7(\mathrm{C}), 133.8(\mathrm{C}), 136.6(\mathrm{C})$, 140.7 (C), 143.8 (C).

LRMS (EI): $m / z$ (\%) $357\left(\mathbf{M}^{+}, 100\right), 356$ (19), 341 (15).

HRMS (EI) for $\mathrm{C}_{27} \mathrm{H}_{19} \mathrm{~N}$, 357.1517; found, 357.1511. 


\section{5-Methyl-11-(thiophen-2-yl)-5H-benzo[b]carbazole (41cg).}

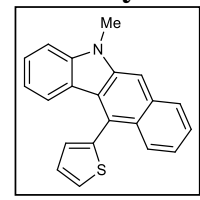

Yellow solid; yield $=73 \%$; m.p. $189-192{ }^{\circ} \mathrm{C} ; R_{f}=0.47($ hex/EtOAc, $5: 1)$.

${ }^{1} \mathbf{H}$ NMR $\left(400 \mathrm{MHz}, \mathrm{CDCl}_{3}\right) \delta(\mathrm{ppm})=3.88(\mathrm{~s}, 3 \mathrm{H}), 7.01-7.09(\mathrm{~m}, 2 \mathrm{H})$, $7.24(\mathrm{dd}, J=3.4,1.1 \mathrm{~Hz}, 1 \mathrm{H}), 7.33-7.41(\mathrm{~m}, 3 \mathrm{H}), 7.47-7.54(\mathrm{~m}, 2 \mathrm{H})$, $7.67(\mathrm{dd}, J=5.0,1.0 \mathrm{~Hz}, 1 \mathrm{H}), 7.76(\mathrm{~s}, 1 \mathrm{H}), 7.94(\mathrm{~d}, J=8.6 \mathrm{~Hz}, 1 \mathrm{H}), 8.03$

(d, $J=8.3 \mathrm{~Hz}, 1 \mathrm{H})$.

${ }^{13} \mathrm{C}$ NMR $\left(75.4 \mathrm{MHz}, \mathrm{CDCl}_{3}\right) \delta(\mathrm{ppm})=29.3\left(\mathrm{CH}_{3}\right), 104.0(\mathrm{CH}), 107.9(\mathrm{CH}), 119.0$ $(\mathrm{CH}), 122.5(\mathrm{C}), 123.1(\mathrm{CH}), 123.3(\mathrm{CH}), 125.1(\mathrm{C}), 125.3(\mathrm{CH}), 125.6(\mathrm{C}), 126.2(\mathrm{CH})$, $126.8(\mathrm{CH}), 127.2(\mathrm{CH}), 127.4(\mathrm{CH}), 127.8(\mathrm{CH}), 128.1(\mathrm{CH}), 128.8(\mathrm{C}), 132.3(\mathrm{C}), 139.3$ (C), $140.5(\mathrm{C}), 143.9(\mathrm{C})$.

LRMS (EI): $m / z$ (\%) 313 (M+1 100), 312 (9), 297 (11).

HRMS (EI) for $\mathrm{C}_{21} \mathrm{H}_{15} \mathrm{NS}, 313.0925$; found, 313.0924 .

\section{5-Methyl-11-(3-methylthiophen-2-yl)-5H-benzo[b]carbazole (41ch).}

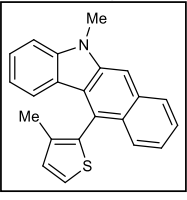

Yellow solid; yield $=71 \%$; m.p. $207-209^{\circ} \mathrm{C} ; R_{f}=0.46($ hex/EtOAc, $5: 1)$. ${ }^{1} \mathbf{H}$ NMR $\left(400 \mathrm{MHz}, \mathrm{CDCl}_{3}\right) \delta(\mathrm{ppm})=1.95(\mathrm{~s}, 3 \mathrm{H}), 3.90(\mathrm{~s}, 3 \mathrm{H})$, 7.03-7.07 (m, 2H), $7.21(\mathrm{~d}, J=5.1 \mathrm{~Hz}, 1 \mathrm{H}), 7.34-7.41(\mathrm{~m}, 2 \mathrm{H})$, $7.47-7.54(\mathrm{~m}, 2 \mathrm{H}), 7.56(\mathrm{~d}, J=5.1, \mathrm{~Hz}, 1 \mathrm{H}), 7.76(\mathrm{~s}, 1 \mathrm{H}), 7.87(\mathrm{~d}, J=8.5$ $\mathrm{Hz}, 1 \mathrm{H}), 8.04(\mathrm{~d}, J=8.0 \mathrm{~Hz}, 1 \mathrm{H})$.

${ }^{13} \mathrm{C} \mathrm{NMR}\left(75.4 \mathrm{MHz}, \mathrm{CDCl}_{3}\right) \delta(\mathrm{ppm})=14.1\left(\mathrm{CH}_{3}\right), 29.3\left(\mathrm{CH}_{3}\right), 103.9(\mathrm{CH}), 107.8(\mathrm{CH})$, $119.2(\mathrm{CH}), 122.7(\mathrm{C}), 123.07(\mathrm{CH}), 123.09(\mathrm{CH}), 125.1(\mathrm{C}), 125.2(\mathrm{C}), 125.3(\mathrm{CH})$, 125.4 (CH), $126.1(\mathrm{CH}), 127.3(\mathrm{CH}), 127.4(\mathrm{CH}), 128.6(\mathrm{C}), 130.1(\mathrm{CH}), 132.5(\mathrm{C}), 133.4$ (C), $136.4(\mathrm{C}), 140.6(\mathrm{C}), 143.9(\mathrm{C})$.

LRMS (EI): $m / z$ (\%) $327\left(\mathrm{M}^{+}, 100\right), 215$ (11), 133 (13).

HRMS (EI) for $\mathrm{C}_{22} \mathrm{H}_{17} \mathrm{~S}$, 327.1082; found, 327.1214 .

\section{5-Methyl-11-(5-methylfuran-2-yl)-5H-benzo[b]carbazole (41ci).}

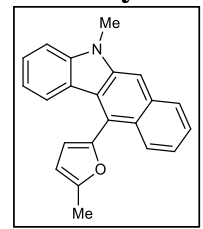

Yellow solid; yield $=51 \%$; m.p. $172-174{ }^{\circ} \mathrm{C} ; R_{f}=0.18($ hex/EtOAc, $5: 1)$. ${ }^{1} \mathbf{H}$ NMR $\left(400 \mathrm{MHz}, \mathrm{CDCl}_{3}\right) \delta(\mathrm{ppm})=2.50(\mathrm{~d}, J=0.6 \mathrm{~Hz}, 3 \mathrm{H}), 3.88(\mathrm{~s}$, $3 \mathrm{H}), 6.36-6.38(\mathrm{~m}, 1 \mathrm{H}), 6.60(\mathrm{~d}, J=3.0 \mathrm{~Hz}, 1 \mathrm{H}), 7.07-7.12(\mathrm{~m}, 1 \mathrm{H})$, 7.33-7.41 (m, 3H), 7.46-7.53 (m, 2H), $7.75(\mathrm{~s}, 1 \mathrm{H}), 8.00(\mathrm{~d}, J=8.3 \mathrm{~Hz}$, $1 \mathrm{H}), 8.10(\mathrm{~d}, J=8.2 \mathrm{~Hz}, 1 \mathrm{H})$.

${ }^{13} \mathbf{C ~ N M R}\left(75.4 \mathrm{MHz}, \mathrm{CDCl}_{3}\right) \delta(\mathrm{ppm})=13.9\left(\mathrm{CH}_{3}\right), 29.1\left(\mathrm{CH}_{3}\right), 104.5(\mathrm{CH}), 107.3(\mathrm{CH})$, $107.9(\mathrm{CH}), 111.7(\mathrm{CH}), 118.9(\mathrm{CH}), 122.3(\mathrm{C}), 122.4(\mathrm{C}), 123.15(\mathrm{CH}), 123.20(\mathrm{CH})$, $125.2(\mathrm{CH}), 126.0(\mathrm{CH}), 127.3(\mathrm{CH}), 127.4(\mathrm{CH}), 128.0(\mathrm{C}), 132.5(\mathrm{C}), 140.6(\mathrm{C}), 143.9(\mathrm{C})$, $148.6(\mathrm{C}), 152.4(\mathrm{C})$, one quaternary carbon peak is not observed, probably due to overlapping. LRMS (EI): $m / z$ (\%) $311\left(\mathrm{M}^{+}, 100\right), 268$ (13), 253 (12).

HRMS (EI) for $\mathrm{C}_{22} \mathrm{H}_{17} \mathrm{NO}, 311.1310$; found, 311.1319 . 


\section{1-Phenyl-5H-benzo[b]carbazole (41aa).}

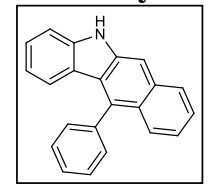

Yellow solid; yield $=65 \%$; m.p. $260-262^{\circ} \mathrm{C} ; R_{f}=0.29($ hex $/$ EtOAc, $5: 1)$.

${ }^{1} \mathbf{H}$ NMR $\left(400 \mathrm{MHz}, \mathrm{CDCl}_{3}\right) \delta(\mathrm{ppm})=6.86-6.95(\mathrm{~m}, 2 \mathrm{H}), 7.27-7.40$ (m, 3H), 7.45-7.53 (m, 3H), 7.59-7.66 (m, 3H), 7.70-7.74 (m, 1H), 7.75 (s, 1H), 7.94-7.96 (m, 2H).

${ }^{13} \mathrm{C} \mathrm{NMR}\left(100.6 \mathrm{MHz}, \mathrm{CDCl}_{3}\right) \delta(\mathrm{ppm})=104.9(\mathrm{CH}), 110.0(\mathrm{CH}), 119.3(\mathrm{CH}), 122.8$ $(\mathrm{CH}), 123.3(\mathrm{CH}), 123.4(\mathrm{C}), 123.8(\mathrm{C}), 125.2(\mathrm{CH}), 126.5(\mathrm{CH}), 127.06(\mathrm{CH}), 127.12$ $(\mathrm{CH}), 127.7(\mathrm{C}), 127.9(\mathrm{CH}), 129.1(2 \times \mathrm{CH}), 130.3(2 \times \mathrm{CH}), 132.7(\mathrm{C}), 134.0(\mathrm{C}), 139.1$ $(2 \times \mathrm{C}), 142.3(\mathrm{C})$.

LRMS (EI): $m / z$ (\%) $293\left(\mathbf{M}^{+}, 100\right), 291$ (22), 145 (13).

HRMS (EI) for $\mathrm{C}_{22} \mathrm{H}_{15} \mathrm{~N}$, 293.1204; found, 293.1207.

\section{1-(Naphthalen-2-yl)-5H-benzo[b]carbazole (41af).}

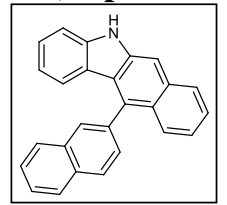

Yellow solid; yield $=50 \%$; m.p. $160-162^{\circ} \mathrm{C} ; R_{f}=0.29$ (hex/EtOAc, 5:1).

${ }^{1} \mathbf{H}$ NMR $\left(400 \mathrm{MHz}, \mathrm{CDCl}_{3}\right) \delta(\mathrm{ppm})=6.83(\mathrm{ddd}, J=8.0,6.8,1.3 \mathrm{~Hz}$, $1 \mathrm{H}), 6.90(\mathrm{~d}, J=7.9 \mathrm{~Hz}, 1 \mathrm{H}), 7.28-7.33(\mathrm{~m}, 2 \mathrm{H}), 7.36$ (ddd, $J=8.1$, 6.8, $1.3 \mathrm{~Hz}, 1 \mathrm{H}), 7.50(\mathrm{ddd}, J=8.2,6.6,1.2 \mathrm{~Hz}, 1 \mathrm{H}), 7.57-7.66(\mathrm{~m}$, $3 \mathrm{H}), 7.74(\mathrm{~s}, 1 \mathrm{H}), 7.76(\mathrm{dd}, J=8.6,0.7 \mathrm{~Hz}, 1 \mathrm{H}), 7.88(\mathrm{bs}, 1 \mathrm{H}), 7.92(\mathrm{~d}, J=8.0 \mathrm{~Hz}, 1 \mathrm{H})$, $7.96(\mathrm{dd}, J=8.3,0.5 \mathrm{~Hz}, 1 \mathrm{H}), 8.04(\mathrm{~s}, 1 \mathrm{H}), 8.07(\mathrm{~d}, J=8.0 \mathrm{~Hz}, 1 \mathrm{H}), 8.13(\mathrm{~d}, J=8.3 \mathrm{~Hz}, 1 \mathrm{H})$. ${ }^{13}$ C NMR $\left(100.6 \mathrm{MHz}, \mathrm{CDCl}_{3}\right) \delta(\mathrm{ppm})=105.1(\mathrm{CH}), 110.0(\mathrm{CH}), 119.4(\mathrm{CH}), 122.9$ $(\mathrm{CH}), 123.3(\mathrm{CH}), 123.4(\mathrm{C}), 123.8(\mathrm{C}), 125.2(\mathrm{CH}), 126.4(\mathrm{CH}), 126.45(\mathrm{CH}), 126.53$ $(\mathrm{CH}), 127.1(\mathrm{CH}), 127.2(\mathrm{CH}), 127.8(\mathrm{C}), 128.1(\mathrm{CH}), 128.4(\mathrm{CH}), 128.6(\mathrm{CH}), 128.7$ $(\mathrm{CH}), 129.2(\mathrm{CH}), 132.7(\mathrm{C}), 133.1(\mathrm{C}), 133.7(\mathrm{C}), 133.9(\mathrm{C}), 136.5(\mathrm{C}), 139.1(\mathrm{C}), 142.3(\mathrm{C})$.

LRMS (EI): $m / z$ (\%) 343 (M+, 100), 342 (36), 341 (25).

HRMS (EI) for $\mathrm{C}_{26} \mathrm{H}_{17} \mathrm{~N}, 343.1361$; found, 343.1344.

\section{1-(4-Methoxyphenyl)-5H-benzo[b]carbazole (41ad).}

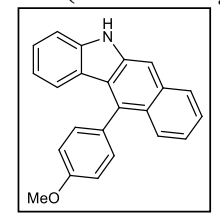

Yellow solid; yield $=92 \%$; m.p. $261-263{ }^{\circ} \mathrm{C} ; R_{f}=0.20($ hex/EtOAc, $5: 1)$.

${ }^{1} \mathbf{H}$ NMR $\left(400 \mathrm{MHz}, \mathrm{CDCl}_{3}\right) \delta(\mathrm{ppm})=3.98(\mathrm{~s}, 3 \mathrm{H}), 6.94(\mathrm{ddd}, J=8.0$, 6.5, 1.6 Hz, 1H), $7.00(\mathrm{~d}, J=7.8 \mathrm{~Hz}, 1 \mathrm{H}), 7.15-7.18(\mathrm{~m}, 2 \mathrm{H}), 7.28-7.32$ $(\mathrm{m}, 1 \mathrm{H}), 7.33$ (ddd, $J=8.2,6.8,1.0 \mathrm{~Hz}, 2 \mathrm{H}), 7.40-7.48(\mathrm{~m}, 3 \mathrm{H}), 7.74(\mathrm{~s}$,

$1 \mathrm{H}), 7.76(\mathrm{~d}, J=8.8 \mathrm{~Hz}, 1 \mathrm{H}), 7.91-7.97(\mathrm{~m}, 2 \mathrm{H})$.

${ }^{13}$ C NMR (75.4 MHz, $\left.\mathrm{CDCl}_{3}\right) \delta(\mathrm{ppm})=55.5\left(\mathrm{CH}_{3}\right), 104.8(\mathrm{CH}), 110.0(\mathrm{CH}), 114.5(2$ $\times \mathrm{CH}), 119.3(\mathrm{CH}), 122.8(\mathrm{CH}), 123.3(\mathrm{CH}), 123.6(\mathrm{C}), 124.1(\mathrm{C}), 125.1(\mathrm{CH}), 126.5$ $(\mathrm{CH}), 127.06(\mathrm{CH}), 127.08(\mathrm{CH}), 128.0(\mathrm{C}), 131.2(\mathrm{C}), 131.4(2 \times \mathrm{CH}), 132.7(\mathrm{C}), 133.8$ (C), 139.1 (C), $142.3(\mathrm{C}), 159.4(\mathrm{C})$.

LRMS (EI): $m / z$ (\%) $323\left(\mathrm{M}^{+}, 100\right), 279$ (8), 278 (10).

HRMS (EI) for $\mathrm{C}_{23} \mathrm{H}_{17} \mathrm{NO}, 323.1310$; found, 323.1308. 
11-(2,3,4-Trimethoxyphenyl)-5 $\boldsymbol{H}$-benzo[b]carbazole (41ae).

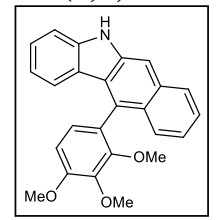

Yellow solid; yield $=98 \%$, m.p. $292-295^{\circ} \mathrm{C}$.

${ }^{1} \mathbf{H}$ NMR $\left(400 \mathrm{MHz}, \mathrm{CDCl}_{3}\right) \delta(\mathrm{ppm})=3.39(\mathrm{~s}, 3 \mathrm{H}), 4.00(\mathrm{~s}, 3 \mathrm{H}), 4.02$ $(\mathrm{s}, 3 \mathrm{H}), 6.92(\mathrm{~d}, J=8.5 \mathrm{~Hz}, 1 \mathrm{H}), 6.92-6.97(\mathrm{~m}, 1 \mathrm{H}), 7.00-7.04(\mathrm{~m}, 2 \mathrm{H}), 7.31$ (ddd, $J=8.1,6.7,1.3 \mathrm{~Hz}, 1 \mathrm{H}), 7.34-7.39(\mathrm{~m}, 2 \mathrm{H}), 7.46$ (ddd, $J=8.0,6.6$, $1.1 \mathrm{~Hz}, 1 \mathrm{H}), 7.73(\mathrm{~d}, J=8.5 \mathrm{~Hz}, 1 \mathrm{H}), 7.76(\mathrm{~s}, 1 \mathrm{H}), 7.94(\mathrm{~d}, J=8.5 \mathrm{~Hz}, 1 \mathrm{H}), 7.99$ (bs, 1H).

${ }^{13}$ C NMR (100.6 MHz, DMSO-d $) \delta(\mathrm{ppm})=55.9\left(\mathrm{CH}_{3}\right), 60.4\left(\mathrm{CH}_{3}\right), 60.7\left(\mathrm{CH}_{3}\right), 104.8$ $(\mathrm{CH}), 108.5(\mathrm{CH}), 110.4(\mathrm{CH}), 118.2(\mathrm{CH}), 122.0(\mathrm{CH}), 122.2(\mathrm{CH}), 122.4(\mathrm{C}), 123.6$ (C), $124.57(\mathrm{C}), 124.59(\mathrm{CH}), 125.4(\mathrm{CH}), 125.6(\mathrm{CH}), 126.8(\mathrm{C}), 126.9(\mathrm{CH}), 127.0$ (CH), 129.2 (C), $132.1(\mathrm{C}), 139.2$ (C), 142.3 (C), 142.6 (C), 151.6 (C), 153.5 (C).

LRMS (EI): $m / z$ (\%) $383\left(\mathrm{M}^{+}, 100\right), 254$ (6), 127 (5).

HRMS (EI) for $\mathrm{C}_{25} \mathrm{H}_{21} \mathrm{NO}_{3}, 383.1521$; found, 383.1517 .

\section{1-(5-Methylfuran-2-yl)-5H-benzo[b]carbazole (41ai).}

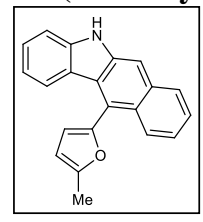

Yellow solid; yield $=68 \%$, m.p. $193-195^{\circ} \mathrm{C} ; R_{f}=0.25($ hex/EtOAc, 5:1). ${ }^{1} \mathbf{H}$ NMR $\left(400 \mathrm{MHz}, \mathrm{CDCl}_{3}\right) \delta(\mathrm{ppm})=2.50(\mathrm{~d}, J=0.6 \mathrm{~Hz}, 3 \mathrm{H})$, 6.36-6.40 (m, 1H), $6.61(\mathrm{~d}, J=3.0 \mathrm{~Hz}, 1 \mathrm{H}), 7.10(\mathrm{ddd}, J=8.1,7.0,1.2$ $\mathrm{Hz}, 1 \mathrm{H}), 7.33(\mathrm{~d}, J=7.9 \mathrm{~Hz}, 1 \mathrm{H}), 7.35-7.52(\mathrm{~m}, 4 \mathrm{H}), 7.79(\mathrm{~s}, 1 \mathrm{H})$, 7.91-7.96 (m, 1H), 7.99 (bs, 1H), 8.08-8.14 (m, 1H).

${ }^{13} \mathrm{C}$ NMR $\left(75.4 \mathrm{MHz}, \mathrm{CDCl}_{3}\right) \delta(\mathrm{ppm})=14.0\left(\mathrm{CH}_{3}\right), 106.7(\mathrm{CH}), 107.4(\mathrm{CH}), 110.2$ $(\mathrm{CH}), 111.7(\mathrm{CH}), 119.5(\mathrm{CH}), 122.4(\mathrm{C}), 122.8(\mathrm{C}), 123.3(\mathrm{CH}), 123.4(\mathrm{CH}), 125.2(\mathrm{CH})$, $125.7(\mathrm{C}), 126.1(\mathrm{CH}), 127.2(\mathrm{CH}), 127.5(\mathrm{CH}), 128.3(\mathrm{C}), 132.6(\mathrm{C}), 138.9(\mathrm{C}), 142.4$ (C), $148.4(\mathrm{C}), 152.4(\mathrm{C})$.

LRMS (EI): $m / z$ (\%) $297\left(\mathbf{M}^{+}, 100\right), 254$ (17), 253 (7).

HRMS (EI) for $\mathrm{C}_{21} \mathrm{H}_{15} \mathrm{NO}, 297.1154$; found, 297.1152 .

\section{2-Bromo-11-(4-methoxyphenyl)-5H-benzo $[b]$ carbazole (41ed).}

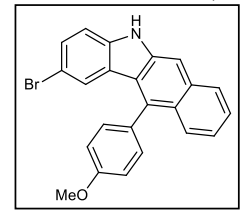

Yellow solid; yield $=48 \%$; m.p. $209-211^{\circ} \mathrm{C} ; R_{f}=0.13$ (hex/EtOAc, 5:1). ${ }^{1} \mathbf{H}$ NMR $\left(400 \mathrm{MHz}, \mathrm{CDCl}_{3}\right) \delta(\mathrm{ppm})=3.98(\mathrm{~s}, 3 \mathrm{H}), 7.07$ (d, $J=1.9$ $\mathrm{Hz}, 1 \mathrm{H}), 7.16-7.19(\mathrm{~m}, 2 \mathrm{H}), 7.21(\mathrm{~d}, J=8.5 \mathrm{~Hz}, 1 \mathrm{H}), 7.30$ (ddd, $J=$ 8.2, 6.6, 1.3 Hz, 1H), 7.37-7.40 (m, 2H), 7.43-7.49 (m, 2H), 7.72-7.77 (m, 1H), $7.74(\mathrm{~s}, 1 \mathrm{H}), 7.93(\mathrm{~d}, J=8.0 \mathrm{~Hz}, 1 \mathrm{H}), 7.79(\mathrm{bs}, 1 \mathrm{H})$.

${ }^{13} \mathbf{C}$ NMR $\left(100.6 \mathrm{MHz}, \mathrm{CDCl}_{3},\right) \delta(\mathrm{ppm})=55.7\left(\mathrm{CH}_{3}\right), 105.1(\mathrm{CH}), 111.3(\mathrm{CH}), 111.9$ (C), $114.7(2 \times \mathrm{CH}), 123.05(\mathrm{C}), 123.08(\mathrm{CH}), 125.47(\mathrm{C}), 125.52(\mathrm{CH}), 126.0(\mathrm{CH})$, $126.7(\mathrm{CH}), 127.1(\mathrm{CH}), 128.1(\mathrm{C}), 129.7(\mathrm{CH}), 130.5(\mathrm{C}), 131.2(2 \times \mathrm{CH}), 133.0(\mathrm{C})$, 134.4 (C), $139.2(\mathrm{C}), 140.9$ (C), 159.7 (C).

LRMS (EI): $m / z(\%) 403\left[(\mathrm{M}+2)^{+}, 100\right], 401\left(\mathrm{M}^{+}, 98\right), 278$ (31).

HRMS (EI) for $\mathrm{C}_{23} \mathrm{H}_{16} \mathrm{BrNO}, 401.0415$; found, 401.0414. 


\section{2-Nitro-11-(2,3,4-trimethoxyphenyl)-5H-benzo[b]carbazole (41fe).}

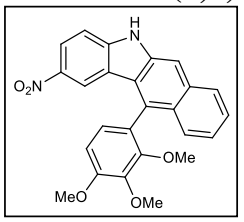

Yellow solid; yield $=85 \%$; m.p. $268-270{ }^{\circ} \mathrm{C}$.

${ }^{1} \mathbf{H}$ NMR $\left(400 \mathrm{MHz}, \mathrm{CDCl}_{3}\right) \delta(\mathrm{ppm})=3.48(\mathrm{~s}, 3 \mathrm{H}), 4.06(\mathrm{~s}, 6 \mathrm{H}), 6.99$ $(\mathrm{d}, J=8.5 \mathrm{~Hz}, 1 \mathrm{H}), 7.03(\mathrm{~d}, J=8.5 \mathrm{~Hz}, 1 \mathrm{H}), 7.23-7.29(\mathrm{~m}, 1 \mathrm{H})$, $7.36-7.44(\mathrm{~m}, 1 \mathrm{H}), 7.50-7.58(\mathrm{~m}, 1 \mathrm{H}), 7.74(\mathrm{~s}, 1 \mathrm{H}), 7.86(\mathrm{~d}, J=8.6$ $\mathrm{Hz}, 1 \mathrm{H}), 7.91(\mathrm{~s}, 1 \mathrm{H}), 7.96(\mathrm{~d}, J=8.2 \mathrm{~Hz}, 1 \mathrm{H}), 8.26(\mathrm{~d}, J=8.9 \mathrm{~Hz}, 1 \mathrm{H}), 8.45(\mathrm{bs}, 1 \mathrm{H})$. ${ }^{13}$ C NMR (75.4 MHz, DMSO-d 6$) \delta(\mathrm{ppm})=56.2\left(\mathrm{CH}_{3}\right), 60.6\left(\mathrm{CH}_{3}\right), 60.8\left(\mathrm{CH}_{3}\right), 106.6$ $(\mathrm{CH}), 109.1(\mathrm{CH}), 110.4(\mathrm{CH}), 118.3(\mathrm{CH}), 122.2(\mathrm{C}), 122.8(\mathrm{C}), 123.0(\mathrm{CH}), 123.4(\mathrm{C})$, $123.5(\mathrm{CH}), 125.3(\mathrm{CH}), 125.6(\mathrm{CH}), 125.8(\mathrm{CH}), 127.5(\mathrm{CH}+\mathrm{C}), 130.4(\mathrm{C}), 132.9(\mathrm{C})$, 139.2 (C), 139.6 (C), 142.7 (C), 146.5 (C), 151.5 (C), 154.0 (C).

LRMS (EI): $m / z(\%) 428\left(\mathrm{M}^{+}, 100\right), 398$ (4).

HRMS (EI) for $\mathrm{C}_{25} \mathrm{H}_{20} \mathrm{~N}_{2} \mathrm{O}_{5}, 428.1372$; found, 428.1372 .

\section{2-Chloro-11-(2,3,4-trimethoxyphenyl)-5H-benzo[b]carbazole (41ge).}

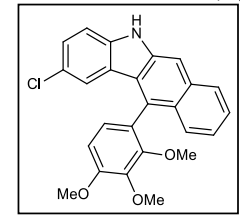

Yellow solid; yield $=94 \%$; m.p. $245-247^{\circ} \mathrm{C} ; R_{f}=0.30($ hex/EtOAc, $5: 1$ ). ${ }^{1} \mathbf{H}$ NMR $\left(400 \mathrm{MHz}, \mathrm{CDCl}_{3}\right) \delta(\mathrm{ppm})=3.41(\mathrm{~s}, 3 \mathrm{H}), 4.02(\mathrm{~s}, 3 \mathrm{H}), 4.03$ (s, 3H), 6.92-6.96 (m, 2H), $7.01(\mathrm{~d}, J=8.5 \mathrm{~Hz}, 1 \mathrm{H}), 7.19(\mathrm{~d}, J=8.5 \mathrm{~Hz}$, $1 \mathrm{H}), 7.30(\mathrm{dd}, J=8.5,2.0 \mathrm{~Hz}, 1 \mathrm{H}), 7.30-7.35(\mathrm{~m}, 1 \mathrm{H}), 7.47$ (ddd, $J=8.2$, 6.6, 1.2 Hz, 1H), $7.68(\mathrm{~s}, 1 \mathrm{H}), 7.76(\mathrm{~d}, J=7.7 \mathrm{~Hz}, 1 \mathrm{H}), 7.91(\mathrm{~d}, J=8.3 \mathrm{~Hz}, 1 \mathrm{H}), 7.95(\mathrm{bs}, 1 \mathrm{H})$. ${ }^{13} \mathbf{C}$ NMR $\left(100.6 \mathrm{MHz}, \mathrm{CDCl}_{3}\right) \delta(\mathrm{ppm})=56.4\left(\mathrm{CH}_{3}\right), 61.2\left(\mathrm{CH}_{3}\right), 61.5\left(\mathrm{CH}_{3}\right), 105.3$ $(\mathrm{CH}), 108.3(\mathrm{CH}), 110.9(\mathrm{CH}), 122.6(\mathrm{CH}), 123.2(\mathrm{CH}), 123.5(\mathrm{C}), 124.69(\mathrm{C}), 124.72$ $(\mathrm{C}), 124.8(\mathrm{C}), 125.5(\mathrm{CH}), 125.8(\mathrm{CH}), 126.4(\mathrm{CH}), 127.0(\mathrm{CH}), 127.2(\mathrm{CH}), 128.1(\mathrm{C})$, 130.5 (C), 133.0 (C), 139.4 (C), 140.6 (C), 143.2 (C), 152.5 (C), 154.2 (C).

LRMS (EI): $m / z(\%) 419\left[(\mathrm{M}+2)^{+}, 33\right], 417\left(\mathbf{M}^{+}, 100\right), 253$ (5).

HRMS (EI) for $\mathrm{C}_{25} \mathrm{H}_{20} \mathrm{ClNO}_{3}, 417.1132$; found, 417.1132 .

Methyl 11-(2,3,4-trimethoxyphenyl)-5H-benzo[b]carbazole-2-carboxylate (41he).

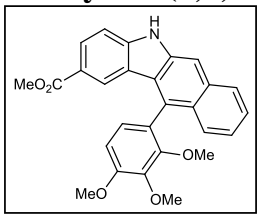

Yellow solid; yield $=80 \%$, m.p. $215-217^{\circ} \mathrm{C} ; R_{f}=0.25($ hex/EtOAc, $2: 1)$.

${ }^{1} \mathbf{H}$ NMR $\left(400 \mathrm{MHz}, \mathrm{CDCl}_{3}\right) \delta(\mathrm{ppm})=3.42(\mathrm{~s}, 3 \mathrm{H}), 3.81(\mathrm{~s}, 3 \mathrm{H}), 4.03$ $(\mathrm{s}, 3 \mathrm{H}), 4.04(\mathrm{~s}, 3 \mathrm{H}), 6.96(\mathrm{~d}, J=8.5 \mathrm{~Hz}, 1 \mathrm{H}), 7.03(\mathrm{~d}, J=8.5 \mathrm{~Hz}, 1 \mathrm{H})$, $7.16(\mathrm{~d}, J=8.5 \mathrm{~Hz}, 1 \mathrm{H}), 7.36(\mathrm{ddd}, J=8.2,6.6,1.3 \mathrm{~Hz}, 1 \mathrm{H}), 7.48$ (ddd, $J=8.1,6.7,1.2 \mathrm{~Hz}, 1 \mathrm{H}), 7.59(\mathrm{~s}, 1 \mathrm{H}), 7.71(\mathrm{~d}, J=1.6 \mathrm{~Hz}, 1 \mathrm{H}), 7.82$ $(\mathrm{d}, J=8.5 \mathrm{~Hz}, 1 \mathrm{H}), 7.88-7.89(\mathrm{~m}, 1 \mathrm{H}), 8.04(\mathrm{dd}, J=8.5,1.6 \mathrm{~Hz}, 1 \mathrm{H}), 8.19(\mathrm{bs}, 1 \mathrm{H})$.

${ }^{13} \mathrm{C}$ NMR $\left(100.6 \mathrm{MHz}, \mathrm{CDCl}_{3}\right) \delta(\mathrm{ppm})=51.9\left(\mathrm{CH}_{3}\right), 56.4\left(\mathrm{CH}_{3}\right), 61.3\left(\mathrm{CH}_{3}\right), 61.5$ $\left(\mathrm{CH}_{3}\right), 105.6(\mathrm{CH}), 108.4(\mathrm{CH}), 109.6(\mathrm{CH}), 109.9(\mathrm{C}), 121.2(\mathrm{C}), 123.3(\mathrm{C}), 123.4(\mathrm{CH})$, $124.0(\mathrm{C}), 124.8(\mathrm{C}), 125.0(\mathrm{CH}), 125.4(\mathrm{CH}), 125.8(\mathrm{CH}), 126.4(\mathrm{CH}), 127.3(\mathrm{CH}), 128.4$ (C), $129.0(\mathrm{CH}), 130.5(\mathrm{C}), 133.0(\mathrm{C}), 139.2(\mathrm{C}), 143.4(\mathrm{C}), 152.5(\mathrm{C}), 154.2(\mathrm{C}), 167.6(\mathrm{C})$. LRMS (EI): $m / z$ (\%) $441\left(\mathrm{M}^{+}, 100\right), 253$ (4).

HRMS (EI) for $\mathrm{C}_{27} \mathrm{H}_{23} \mathrm{NO}_{5}, 441.1576$; found, 441.1581 . 
5-Methyl-6-(5-methylfuran-2-yl)-5H-benzo[b]carbazole (41'ci).

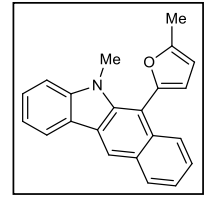

Yellow foam; yield $=10 \% ; R_{f}=0.30($ hex/EtOAc, 5:1).

${ }^{1} \mathbf{H}$ NMR $\left(300 \mathrm{MHz}, \mathrm{CDCl}_{3}\right) \delta(\mathrm{ppm})=2.48(\mathrm{~s}, 3 \mathrm{H}), 3.44(\mathrm{~s}, 3 \mathrm{H}), 6.28-6.32$ $(\mathrm{m}, 1 \mathrm{H}), 6.53(\mathrm{~d}, J=3.0 \mathrm{~Hz}, 1 \mathrm{H}), 7.25-7.36(\mathrm{~m}, 2 \mathrm{H}), 7.39-7.59(\mathrm{~m}, 3 \mathrm{H})$, 7.90-7.95 (m, 1H), 8.04-8.09 (m, 1H), 8.21-8.26 (m, 1H), $8.64(\mathrm{~s}, 1 \mathrm{H})$.

${ }^{13} \mathrm{C} \mathrm{NMR}\left(100.6 \mathrm{MHz}, \mathrm{CDCl}_{3}\right) \delta(\mathrm{ppm})=14.1\left(\mathrm{CH}_{3}\right), 30.9\left(\mathrm{CH}_{3}\right), 107.2(\mathrm{CH}), 107.4(\mathrm{C})$, $108.5(\mathrm{CH}), 113.7(\mathrm{CH}), 119.3(\mathrm{CH}), 120.3(\mathrm{CH}), 120.7(\mathrm{CH}), 122.6(\mathrm{C}), 122.8(\mathrm{CH})$, 124.6 (CH), $125.6(\mathrm{C}), 125.7(\mathrm{CH}), 127.5(\mathrm{CH}), 127.7(\mathrm{C}), 128.5(\mathrm{CH}), 133.5(\mathrm{C}), 144.4$ (C), $147.0(\mathrm{C}), 152.1(\mathrm{C})$, one quaternary $\mathrm{C}$ peak is not observed, probably due to overlapping. LRMS (EI): $m / z$ (\%) $311\left(\mathrm{M}^{+}, 100\right), 254$ (70), 149 (60).

HRMS (EI) for $\mathrm{C}_{22} \mathrm{H}_{17} \mathrm{NO}, 311.1310$; found, 311.1303 .

\section{6-(5-Methylfuran-2-yl)-5H-benzo[b]carbazole (41'ai).}

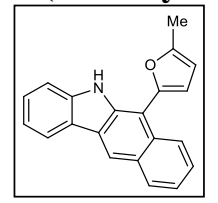

Yellow foam; yield $=7 \% ; R_{f}=0.33$ (hex/EtOAc, 5:1).

${ }^{1} \mathbf{H}$ NMR $\left(400 \mathrm{MHz}, \mathrm{CDCl}_{3}\right) \delta(\mathrm{ppm})=2.55(\mathrm{~d}, J=0.6 \mathrm{~Hz}, 3 \mathrm{H})$, $6.30-6.33(\mathrm{~m}, 1 \mathrm{H}), 6.77(\mathrm{~d}, J=3.3 \mathrm{~Hz}, 1 \mathrm{H}), 7.26-7.29(\mathrm{~m}, 1 \mathrm{H})$, $7.40-7.55(\mathrm{~m}, 4 \mathrm{H}), 8.07(\mathrm{~d}, J=8.3 \mathrm{~Hz}, 1 \mathrm{H}), 8.20(\mathrm{~d}, J=7.9 \mathrm{~Hz}, 1 \mathrm{H})$, $8.43(\mathrm{~d}, J=9.0 \mathrm{~Hz}, 1 \mathrm{H}), 8.53(\mathrm{~s}, 1 \mathrm{H}), 8.67$ (bs, 1H).

${ }^{13} \mathrm{C} \mathrm{NMR}\left(100.6 \mathrm{MHz}, \mathrm{CDCl}_{3}\right) \delta(\mathrm{ppm})=14.2\left(\mathrm{CH}_{3}\right), 107.7(\mathrm{C}), 107.9(\mathrm{CH}), 110.5(\mathrm{CH})$, $111.6(\mathrm{CH}), 119.4(\mathrm{CH}), 119.7(\mathrm{CH}), 121.2(\mathrm{CH}), 122.9(\mathrm{CH}), 123.2(\mathrm{C}), 124.5(\mathrm{CH})$, $125.5(\mathrm{C}), 125.9(\mathrm{CH}), 127.5(\mathrm{CH}), 128.9(\mathrm{C}), 129.2(\mathrm{CH}), 129.7(\mathrm{C}), 137.7(\mathrm{C}), 141.9$ (C), 149.1 (C), $152.1(\mathrm{C})$.

LRMS (EI): $m / z$ (\%) $297\left(\mathrm{M}^{+}, 100\right), 245$ (70), 149 (60).

HRMS (EI) for $\mathrm{C}_{21} \mathrm{H}_{15} \mathrm{NO}, 297.1154$; found, 297.1164 .

\section{8-Methoxy-5-methyl-11-phenyl-5H-benzo $[b]$ carbazole (44a).}

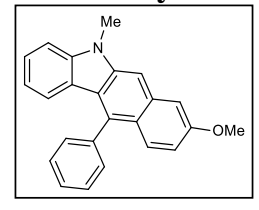

Yellow foam; yield $=60 \%$; m.p. $175-177^{\circ} \mathrm{C} ; R_{f}=0.45$ (hex/EtOAc, $\left.5: 1\right)$. ${ }^{1} \mathbf{H}$ NMR $\left(400 \mathrm{MHz}, \mathrm{CDCl}_{3}\right) \delta(\mathrm{ppm})=3.87(\mathrm{~s}, 3 \mathrm{H}), 3.98(\mathrm{~s}, 3 \mathrm{H})$, 6.87-6.94 (m, 2H), $7.00(\mathrm{dd}, J=9.2,2.6 \mathrm{~Hz}, 1 \mathrm{H}), 7.30-7.33(\mathrm{~m}, 1 \mathrm{H})$, $7.33(\mathrm{~s}, 1 \mathrm{H}), 7.42(\mathrm{ddd}, J=8.3,6.6,1.8,1 \mathrm{H}), 7.50-7.52(\mathrm{~m}, 2 \mathrm{H})$,

7.59-7.66 (m, 5H).

${ }^{13} \mathrm{C}$ NMR $\left(100.6 \mathrm{MHz}, \mathrm{CDCl}_{3}\right) \delta(\mathrm{ppm})=29.2\left(\mathrm{CH}_{3}\right), 55.4\left(\mathrm{CH}_{3}\right), 101.6(\mathrm{CH}), 104.7$ $(\mathrm{CH}), 107.7(\mathrm{CH}), 115.9(\mathrm{CH}), 118.7(\mathrm{CH}), 121.3(\mathrm{C}), 122.7(\mathrm{CH}), 123.13(\mathrm{C}), 123.15$ (C), $126.5(\mathrm{CH}), 127.9(\mathrm{CH}), 128.1(\mathrm{CH}), 129.0(2 \times \mathrm{CH}), 130.2(2 \times \mathrm{CH}), 134.0(\mathrm{C})$, 134.2 (C), 139.2 (C), 141.4 (C), 143.5 (C), 157.4 (C).

LRMS (EI): $m / z$ (\%) $337\left(\mathrm{M}^{+}, 100\right), 294$ (36), 278 (11).

HRMS (EI) for $\mathrm{C}_{24} \mathrm{H}_{19} \mathrm{NO}, 337.1467$; found, 337.1465 . 
11-(4-Chlorophenyl)-8-methoxy-5-methyl-5H-benzo[ $b]$ carbazole (44b).

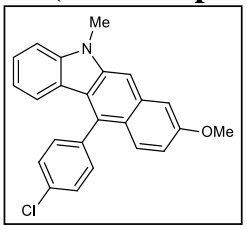

Yellow solid; yield $=68 \%$; m.p. $202-204^{\circ} \mathrm{C} ; R_{f}=0.52($ hex/EtOAc, $5: 1)$.

${ }^{1} \mathbf{H}$ NMR $\left(400 \mathrm{MHz}, \mathrm{CDCl}_{3}\right) \delta(\mathrm{ppm})=3.87(\mathrm{~s}, 3 \mathrm{H}), 3.98(\mathrm{~s}, 3 \mathrm{H})$, $6.95(\mathrm{~d}, J=0.8 \mathrm{~Hz}, 1 \mathrm{H}), 6.95-6.96(\mathrm{~m}, 1 \mathrm{H}), 7.00(\mathrm{dd}, J=9.3,2.6 \mathrm{~Hz}$, $1 \mathrm{H}), 7.31-7.34(\mathrm{~m}, 2 \mathrm{H}), 7.41-7.46(\mathrm{~m}, 3 \mathrm{H}), 7.56(\mathrm{~d}, J=9.3 \mathrm{~Hz}, 1 \mathrm{H})$, $7.58-7.62(\mathrm{~m}, 3 \mathrm{H})$.

${ }^{13} \mathrm{C}$ NMR $\left(100.6 \mathrm{MHz}, \mathrm{CDCl}_{3}\right) \delta(\mathrm{ppm})=29.3\left(\mathrm{CH}_{3}\right), 55.5\left(\mathrm{CH}_{3}\right), 102.0(\mathrm{CH}), 104.8$ $(\mathrm{CH}), 107.8(\mathrm{CH}), 116.1(\mathrm{CH}), 118.8(\mathrm{CH}), 121.3(\mathrm{C}), 122.6(\mathrm{CH}), 122.9(\mathrm{C}), 123.0(\mathrm{C})$, $126.7(\mathrm{CH}), 127.8(\mathrm{CH}), 129.3(2 \times \mathrm{CH}), 131.7(2 \times \mathrm{CH}), 132.6(\mathrm{C}), 133.9(\mathrm{C}), 134.0$ (C), 137.7 (C), 141.3 (C), 143.5 (C), 157.4 (C).

LRMS (EI): $m / z(\%) 373\left[(\mathrm{M}+2)^{+}, 33\right], 371\left(\mathrm{M}^{+}, 100\right), 328(23)$.

HRMS (EI) for $\mathrm{C}_{24} \mathrm{H}_{18} \mathrm{CINO}$, 371.1077; found, 371.1090.

\section{8-Methoxy-11-(4-methoxyphenyl)-5-methyl-5H-benzo[b]carbazole (44c).}

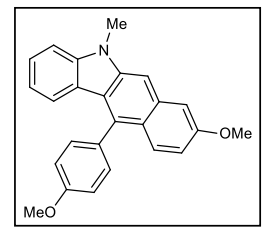

Yellow solid; yield $=73 \%$; m.p. $190-192^{\circ} \mathrm{C} ; R_{f}=0.25$ (hex/EtOAc, $\left.5: 1\right)$. ${ }^{1} \mathbf{H}$ NMR $\left(400 \mathrm{MHz}, \mathrm{CDCl}_{3}\right) \delta(\mathrm{ppm})=3.86(\mathrm{~s}, 3 \mathrm{H}), 3.99(\mathrm{~s}, 3 \mathrm{H}), 4.00(\mathrm{~s}$, $3 \mathrm{H}), 6.93-6.98(\mathrm{~m}, 1 \mathrm{H}), 6.99-7.04(\mathrm{~m}, 2 \mathrm{H}), 7.15-7.20(\mathrm{~m}, 2 \mathrm{H}), 7.30-7.34$ (m, 2H), 7.40-7.46 (m, 3H), $7.60(\mathrm{~s}, 1 \mathrm{H}), 7.69(\mathrm{~d}, J=9.3 \mathrm{~Hz}, 1 \mathrm{H})$.

${ }^{13} \mathbf{C ~ N M R}\left(100.6 \mathrm{MHz}, \mathrm{CDCl}_{3}\right) \delta(\mathrm{ppm})=29.2\left(\mathrm{CH}_{3}\right), 55.4\left(\mathrm{CH}_{3}\right)$, $55.5\left(\mathrm{CH}_{3}\right), 101.5(\mathrm{CH}), 104.7(\mathrm{CH}), 107.6(\mathrm{CH}), 114.4(2 \times \mathrm{CH}), 115.7(\mathrm{CH}), 118.7$ $(\mathrm{CH}), 121.7(\mathrm{C}), 122.7(\mathrm{CH}), 123.3(\mathrm{C}), 123.5(\mathrm{C}), 126.4(\mathrm{CH}), 128.2(\mathrm{CH}), 131.29(\mathrm{C})$, $131.31(2 \times \mathrm{CH}), 133.97(\mathrm{C}), 134.01(\mathrm{C}), 141.4(\mathrm{C}), 143.4(\mathrm{C}), 157.4(\mathrm{C}), 159.3(\mathrm{C})$.

LRMS (EI): $m / z(\%) 367\left(\mathrm{M}^{+}, 100\right), 324$ (22).

HRMS (EI) for $\mathrm{C}_{25} \mathrm{H}_{21} \mathrm{NO}_{2}, 367.1572$; found, 367.1572 .

9-Methoxy-5-methyl-11-(2,3,4-trimethoxyphenyl)-5H-benzo[b]carbazole (45d).

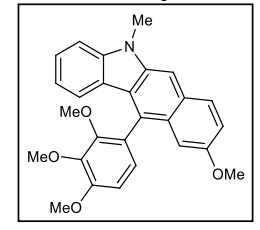

Yellow foam; yield $=82 \%$ (for the mixture with $44 d$ ); $R_{f}=0.28$ (hex/EtOAc, 2:1).

${ }^{1} \mathbf{H}$ NMR $\left(400 \mathrm{MHz}, \mathrm{CDCl}_{3}\right) \delta(\mathrm{ppm})=3.40(\mathrm{~s}, 3 \mathrm{H}), 3.76(\mathrm{~s}, 3 \mathrm{H})$, $3.88(\mathrm{~s}, 3 \mathrm{H}), 4.00(\mathrm{~s}, 3 \mathrm{H}), 4.03(\mathrm{~s}, 3 \mathrm{H}), 6.92(\mathrm{~d}, J=8.5 \mathrm{~Hz}, 1 \mathrm{H})$, 6.92-6.97 (m, 1H), 7.01-7.04 (m, 3H), $7.19(\mathrm{dd}, J=9.0,2.6 \mathrm{~Hz}, 1 \mathrm{H})$,

$7.32(\mathrm{~d}, J=8.1 \mathrm{~Hz}, 1 \mathrm{H}), 7.40-7.45(\mathrm{~m}, 1 \mathrm{H}), 7.68(\mathrm{~s}, 1 \mathrm{H}), 7.92(\mathrm{~d}, J=9.0 \mathrm{~Hz}, 1 \mathrm{H})$.

${ }^{13} \mathrm{C} \mathrm{NMR}\left(100.6 \mathrm{MHz}, \mathrm{CDCl}_{3}\right) \delta(\mathrm{ppm})=29.3\left(\mathrm{CH}_{3}\right), 55.3\left(\mathrm{CH}_{3}\right), 56.2\left(\mathrm{CH}_{3}\right), 61.1\left(\mathrm{CH}_{3}\right)$, $61.4\left(\mathrm{CH}_{3}\right), 103.1(\mathrm{CH}), 104.3(\mathrm{CH}), 107.7(\mathrm{CH}), 108.1(\mathrm{CH}), 118.3(\mathrm{CH}), 118.6(\mathrm{CH}), 122.87$ $(\mathrm{CH}), 122.89(\mathrm{C}), 124.0(\mathrm{C}), 125.6(\mathrm{C}), 126.0(\mathrm{CH}), 126.9(\mathrm{CH}), 128.4(\mathrm{C}), 128.5(\mathrm{C}), 128.70$ (C), $128.73(\mathrm{CH}), 139.6(\mathrm{C}), 143.0(\mathrm{C}), 143.8(\mathrm{C}), 152.5(\mathrm{C}), 153.7$ (C), $155.5(\mathrm{C})$.

LRMS (EI): $m / z$ (\%) $427\left(\mathrm{M}^{+}, 100\right), 371$ (75), 242 (34).

HRMS (EI) for $\mathrm{C}_{27} \mathrm{H}_{25} \mathrm{NO}_{4}, 427.1784$; found, 427.1787 . 


\section{9-Methoxy-5-methyl-11-(thiophen-2-yl)-5H-benzo[b]carbazole (45e).}

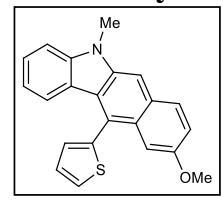

Yellow foam; yield $=19 \% ; R_{f}=0.34($ hex/EtOAc, 5:1).

${ }^{1} \mathbf{H}$ NMR $\left(400 \mathrm{MHz}, \mathrm{CDCl}_{3}\right) \delta(\mathrm{ppm})=3.79(\mathrm{~s}, 3 \mathrm{H}), 3.88(\mathrm{~s}, 3 \mathrm{H})$, 6.95-7.02 (m, 2H), 7.16-7.21 (m, 3H), 7.32-7.37 (m, 2H), 7.43-7.48 $(\mathrm{m}, 1 \mathrm{H}), 7.63-7.66(\mathrm{~m}, 1 \mathrm{H}), 7.71(\mathrm{~s}, 1 \mathrm{H}), 7.92(\mathrm{~d}, J=8.8 \mathrm{~Hz}, 1 \mathrm{H})$.

${ }^{13} \mathbf{C}$ NMR $\left(100.6 \mathrm{MHz}, \mathrm{CDCl}_{3}\right) \delta(\mathrm{ppm})=29.3\left(\mathrm{CH}_{3}\right), 55.3\left(\mathrm{CH}_{3}\right), 104.1(\mathrm{CH}), 104.4$ $(\mathrm{CH}), 107.8(\mathrm{CH}), 118.6(\mathrm{CH}), 118.8(\mathrm{CH}), 122.4(\mathrm{C}), 123.3(\mathrm{CH}), 124.1(\mathrm{C}), 125.4(\mathrm{C})$, $126.8(\mathrm{CH}), 127.3(\mathrm{CH}), 127.8(\mathrm{CH}), 127.9(\mathrm{CH}), 128.2(\mathrm{C}), 128.7(\mathrm{CH}), 129.7(\mathrm{C}), 139.3$ (C), $139.6(\mathrm{C}), 143.8(\mathrm{C}), 155.8(\mathrm{C})$.

LRMS (EI): $m / z(\%) 343\left(\mathbf{M}^{+}, 100\right), 300$ (28).

HRMS (EI) for $\mathrm{C}_{22} \mathrm{H}_{17} \mathrm{NOS}, 343.1031$; found, 343.1030.

8-Methoxy-5-methyl-11-(thiophen-2-yl)-5H-benzo[b]carbazole (44e).

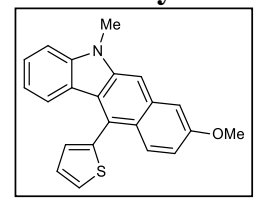

Yellow solid; yield $=56 \%$; m.p. $156-158^{\circ} \mathrm{C} ; R_{f}=0.27($ hex/EtOAc, $5: 1)$.

${ }^{1} \mathbf{H}$ NMR $\left(400 \mathrm{MHz}, \mathrm{CDCl}_{3}\right) \delta(\mathrm{ppm})=3.84(\mathrm{~s}, 3 \mathrm{H}), 3.97(\mathrm{~s}, 3 \mathrm{H})$, 6.98-7.05 (m, 2H), $7.06(\mathrm{dd}, J=9.3,2.6 \mathrm{~Hz}, 1 \mathrm{H}), 7.22(\mathrm{dd}, J=3.4$, $1.2 \mathrm{~Hz}, 1 \mathrm{H}), 7.29(\mathrm{~d}, J=2.6 \mathrm{~Hz}, 1 \mathrm{H}), 7.32(\mathrm{~d}, J=8.1 \mathrm{~Hz}, 1 \mathrm{H}), 7.36$ $(\mathrm{dd}, J=5.2,3.4 \mathrm{~Hz}, 1 \mathrm{H}), 7.45(\mathrm{ddd}, J=8.3,6.3,2.1 \mathrm{~Hz}, 1 \mathrm{H}), 7.62(\mathrm{~s}, 1 \mathrm{H}), 7.65(\mathrm{dd}, J=$ $5.2,1.2 \mathrm{~Hz}, 1 \mathrm{H}), 7.82(\mathrm{~d}, J=9.3 \mathrm{~Hz}, 1 \mathrm{H})$.

${ }^{13} \mathbf{C ~ N M R}\left(100.6 \mathrm{MHz}, \mathrm{CDCl}_{3}\right) \delta(\mathrm{ppm})=29.2\left(\mathrm{CH}_{3}\right), 55.4\left(\mathrm{CH}_{3}\right), 102.9(\mathrm{CH}), 104.7$ $(\mathrm{CH}), 107.8(\mathrm{CH}), 116.3(\mathrm{CH}), 119.0(\mathrm{CH}), 122.77(\mathrm{C}), 122.84(\mathrm{CH}), 123.3(\mathrm{C}), 124.6$ (C), $125.7(\mathrm{C}), 126.7(\mathrm{CH}), 126.8(\mathrm{CH}), 127.7(\mathrm{CH}), 127.8(\mathrm{CH}), 128.0(\mathrm{CH}), 133.7(\mathrm{C})$, $139.4(\mathrm{C}), 141.1(\mathrm{C}), 143.5(\mathrm{C}), 157.4(\mathrm{C})$.

LRMS (EI): $m / z(\%) 343\left(\mathrm{M}^{+}, 100\right), 328$ (23).

HRMS (EI) for $\mathrm{C}_{22} \mathrm{H}_{17} \mathrm{NOS}, 343.1031$; found, 343.1030 .

9-Methoxy-5-methyl-6-phenyl-5H-benzo[b]carbazole (44'a).

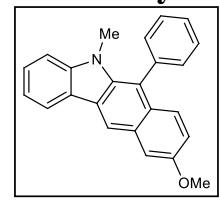

Yellow foam; yield $=4 \% ; R_{f}=0.50($ hex/EtOAc, 5:1).

${ }^{1} \mathbf{H}$ NMR $\left(400 \mathrm{MHz}, \mathrm{CDCl}_{3}\right) \delta(\mathrm{ppm})=3.22(\mathrm{~s}, 3 \mathrm{H}), 3.96(\mathrm{~s}, 3 \mathrm{H}), 7.05$ (dd, $J=9.4,2.7 \mathrm{~Hz}, 1 \mathrm{H}), 7.22-7.26(\mathrm{~m}, 2 \mathrm{H}), 7.37(\mathrm{~d}, J=2.6 \mathrm{~Hz}, 1 \mathrm{H})$, $7.45-7.54(\mathrm{~m}, 7 \mathrm{H}), 8.20-8.23(\mathrm{~m}, 1 \mathrm{H}), 8.51(\mathrm{~s}, 1 \mathrm{H})$.

${ }^{13} \mathrm{C}$ NMR $\left(100.6 \mathrm{MHz}, \mathrm{CDCl}_{3}\right) \delta(\mathrm{ppm})=32.2\left(\mathrm{CH}_{3}\right), 55.4\left(\mathrm{CH}_{3}\right), 105.7(\mathrm{CH}), 108.3$ $(\mathrm{CH}), 116.8(\mathrm{CH}), 118.3(\mathrm{CH}), 118.8(\mathrm{CH}), 119.1(\mathrm{C}), 120.6(\mathrm{CH}), 122.4(\mathrm{C}), 126.0(\mathrm{C})$, $126.8(\mathrm{CH}), 127.3(\mathrm{CH}), 127.7(\mathrm{CH}), 128.0(\mathrm{C}), 128.2(2 \times \mathrm{CH}), 128.7(\mathrm{C}), 131.9(2 \times$ $\mathrm{CH}), 136.9(\mathrm{C}), 138.1(\mathrm{C}), 144.5(\mathrm{C}), 155.4(\mathrm{C})$.

LRMS (EI): $m / z$ (\%) $337\left(\mathrm{M}^{+}, 100\right), 294$ (48).

HRMS (EI) for $\mathrm{C}_{24} \mathrm{H}_{19} \mathrm{NO}, 337.1467$; found, 337.1476 . 
11-(4-Methoxyphenyl)-5,6-dimethyl-5H-benzo[b]carbazole (46a).

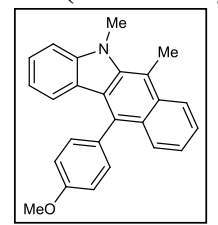

Yellow solid; yield $=65 \%$; m.p. $=207-210^{\circ} \mathrm{C} ; R_{f}=0.37($ hex $/$ EtOAc, $5: 1)$.

${ }^{1} \mathbf{H}$ NMR $\left(400 \mathrm{MHz}, \mathrm{CDCl}_{3}\right) \delta(\mathrm{ppm})=3.18(\mathrm{~s}, 3 \mathrm{H}), 4.00$ (s, 3H), 4.14 $(\mathrm{s}, 3 \mathrm{H}), 6.87-6.91(\mathrm{~m}, 1 \mathrm{H}), 6.92-6.97(\mathrm{~m}, 1 \mathrm{H}), 7.17-7.21(\mathrm{~m}, 2 \mathrm{H})$, 7.31-7.47 (m, 5H), 7.54-7.59 (m, 1H), 7.77-7.80 (m, 1H), 8.23-8.26 (m, 1H).

${ }^{13} \mathrm{C} \mathrm{NMR}\left(100.6 \mathrm{MHz}, \mathrm{CDCl}_{3}\right) \delta(\mathrm{ppm})=14.8\left(\mathrm{CH}_{3}\right), 34.6\left(\mathrm{CH}_{3}\right), 55.5$ $\left(\mathrm{CH}_{3}\right), 108.3(\mathrm{CH}), 111.8(\mathrm{C}), 114.5(2 \times \mathrm{CH}), 118.9(\mathrm{CH}), 122.4(\mathrm{CH}), 123.0(\mathrm{CH})$, $123.2(\mathrm{CH}), 123.4(\mathrm{C}), 124.3(\mathrm{C}), 124.9(\mathrm{CH}), 126.9(\mathrm{CH}), 127.0(\mathrm{CH}), 128.3(\mathrm{C}), 131.5$ $(2 \times \mathrm{CH}), 131.6(\mathrm{C}), 131.8(\mathrm{C}), 132.2(\mathrm{C}), 139.9(\mathrm{C}), 145.7(\mathrm{C}), 159.3(\mathrm{C})$.

LRMS (EI): $m / z(\%) 351\left(\mathrm{M}^{+}, 100\right), 336$ (9), 292 (11).

HRMS (EI) for $\mathrm{C}_{25} \mathrm{H}_{21} \mathrm{NO}, 351.1623$; found, 351.1622 .

\section{5,6-Dimethyl-11-(2-phenylethynyl)-5H-benzo[b]carbazole (46b).}

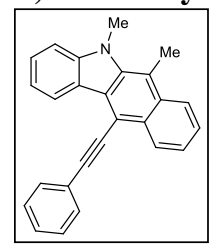

Yellow solid; yield $=67 \% ; \mathrm{m} . \mathrm{p} .=180-182^{\circ} \mathrm{C} ; R_{f}=0.38($ hex $/$ EtOAc, $5: 1)$. ${ }^{1} \mathbf{H}$ NMR $\left(400 \mathrm{MHz}, \mathrm{CDCl}_{3}\right) \delta(\mathrm{ppm})=3.14(\mathrm{~s}, 3 \mathrm{H}), 4.12(\mathrm{~s}, 3 \mathrm{H})$, 7.26-7.31 (m, 1H), $7.36(\mathrm{~d}, J=8.2 \mathrm{~Hz}, 1 \mathrm{H}), 7.42-7.60(\mathrm{~m}, 6 \mathrm{H}), 7.79-7.83$ (m, 2H), 8.17-8.20 (m, 1H), 8.69-8.72 (m, 1H), 8.97-9.02 (m, 1H).

${ }^{13} \mathbf{C ~ N M R}\left(100.6 \mathrm{MHz}, \mathrm{CDCl}_{3}\right) \delta(\mathrm{ppm})=15.0\left(\mathrm{CH}_{3}\right), 34.5\left(\mathrm{CH}_{3}\right), 87.7$ (C), $99.4(\mathrm{C}), 108.4(\mathrm{CH}), 109.9(\mathrm{C}), 114.3(\mathrm{C}), 119.4(\mathrm{CH}), 123.2(\mathrm{C}), 123.39(\mathrm{CH})$, $123.41(\mathrm{CH}), 123.6(\mathrm{CH}), 124.1(\mathrm{C}), 125.4(\mathrm{CH}), 126.6(\mathrm{C}), 126.7(\mathrm{CH}), 127.9(\mathrm{CH})$, $128.5(\mathrm{CH}), 128.7(2 \times \mathrm{CH}), 129.4(\mathrm{C}), 131.7(2 \times \mathrm{CH}), 132.0(\mathrm{C}), 139.8(\mathrm{C}), 145.7(\mathrm{C})$. LRMS (EI): $m / z$ (\%) $345\left(\mathrm{M}^{+}, 100\right), 330$ (15), 172 (13).

HRMS (EI) for $\mathrm{C}_{26} \mathrm{H}_{19} \mathrm{~N}, 345.1517$; found, 345.1514.

\section{9-Methoxy-11-(4-methoxyphenyl)-5,6-dimethyl-5H-benzo[b]carbazole (47).}

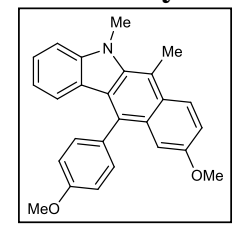

Yellow solid; yield $=70 \%$; m.p. $=166-168^{\circ} \mathrm{C} ; R_{f}=0.37($ hex/EtOAc, $5: 1)$. ${ }^{1} \mathbf{H}$ NMR $\left(400 \mathrm{MHz}, \mathrm{CDCl}_{3}\right) \delta(\mathrm{ppm})=3.16(\mathrm{~s}, 3 \mathrm{H}), 3.73(\mathrm{~s}, 3 \mathrm{H}), 3.98$ $(\mathrm{s}, 3 \mathrm{H}), 4.13(\mathrm{~s}, 3 \mathrm{H}), 6.79-6.83(\mathrm{~m}, 1 \mathrm{H}), 6.88(\mathrm{ddd}, J=8.0,7.1,1.0 \mathrm{~Hz}$, 1H), $7.01(\mathrm{~d}, J=2.7 \mathrm{~Hz}, 1 \mathrm{H}), 7.14-7.18(\mathrm{~m}, 2 \mathrm{H}), 7.23(\mathrm{dd}, J=9.4,2.7 \mathrm{~Hz}$, $1 \mathrm{H}), 7.29(\mathrm{~d}, J=8.2 \mathrm{~Hz}, 1 \mathrm{H}), 7.35-7.42(\mathrm{~m}, 3 \mathrm{H}), 8.14(\mathrm{~d}, J=9.4 \mathrm{~Hz}, 1 \mathrm{H})$.

${ }^{13} \mathbf{C}$ NMR $\left(100.6 \mathrm{MHz}, \mathrm{CDCl}_{3}\right) \delta(\mathrm{ppm})=14.9\left(\mathrm{CH}_{3}\right), 34.6\left(\mathrm{CH}_{3}\right), 55.3\left(\mathrm{CH}_{3}\right), 55.5$ $\left(\mathrm{CH}_{3}\right), 104.9(\mathrm{CH}), 108.3(\mathrm{CH}), 112.3(\mathrm{C}), 114.7(2 \times \mathrm{CH}), 117.7(\mathrm{CH}), 118.7(\mathrm{CH})$, $123.2(\mathrm{CH}), 123.4(\mathrm{C}), 124.6(\mathrm{CH}), 124.8(\mathrm{C}), 126.9(\mathrm{CH}), 127.9(\mathrm{C}), 129.2(\mathrm{C}), 130.5$ (C), $131.5(2 \times \mathrm{CH}), 131.9(\mathrm{C}), 138.7$ (C), 145.7 (C), 155.2 (C), $159.2(\mathrm{C})$.

LRMS (EI): $m / z(\%) 381\left(\mathbf{M}^{+}, 100\right), 351$ (19).

HRMS (EI) for $\mathrm{C}_{26} \mathrm{H}_{23} \mathrm{NO}_{2}, 381.1729$; found, 381.1726 . 
10-(4-Methoxyphenyl)-5-methyl-5 $H$-thieno[3,2-b]carbazole (48a).

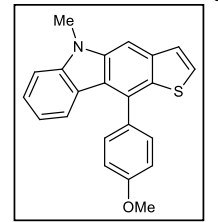

Yellow solid; yield $=53 \%$; m.p. $201-203{ }^{\circ} \mathrm{C} ; R_{f}=0.23($ hex/EtOAc, $5: 1)$. ${ }^{1} \mathbf{H}$ NMR $\left(400 \mathrm{MHz}, \mathrm{CDCl}_{3}\right) \delta(\mathrm{ppm})=3.87(\mathrm{~s}, 3 \mathrm{H}), 3.97$ (s, 3H), 7.0 (ddd, $J=8.1,7.2,1.1 \mathrm{~Hz}, 1 \mathrm{H}), 7.15-7.19(\mathrm{~m}, 2 \mathrm{H}), 7.35-7.38(\mathrm{~m}, 2 \mathrm{H})$, 7.44 (ddd, $J=8.1,7.1,1.1 \mathrm{~Hz}, 1 \mathrm{H}), 7.48(\mathrm{~d}, J=5.5 \mathrm{~Hz}, 1 \mathrm{H}), 7.50(\mathrm{~d}, J=$ $5.5 \mathrm{~Hz}, 1 \mathrm{H}), 7.60-7.63(\mathrm{~m}, 2 \mathrm{H}), 7.73(\mathrm{~s}, 1 \mathrm{H})$.

${ }^{13} \mathrm{C} \mathrm{NMR}\left(100.6 \mathrm{MHz}, \mathrm{CDCl}_{3}\right) \delta(\mathrm{ppm})=29.3\left(\mathrm{CH}_{3}\right), 55.5\left(\mathrm{CH}_{3}\right), 100.6(\mathrm{CH}), 107.9$ $(\mathrm{CH}), 114.6(2 \times \mathrm{CH}), 118.5(\mathrm{CH}), 120.2(\mathrm{C}), 122.2(\mathrm{C}), 122.4(\mathrm{CH}), 124.0(\mathrm{CH}), 126.0$ $(\mathrm{CH}), 127.5(\mathrm{CH}), 130.6(2 \times \mathrm{CH}), 130.7(\mathrm{C}), 131.6(\mathrm{C}), 133.5(\mathrm{C}), 138.1(\mathrm{C}), 141.0(\mathrm{C})$, $142.6(\mathrm{C}), 159.7(\mathrm{C})$.

LRMS (EI): $m / z(\%) 343\left(\mathrm{M}^{+}, 100\right), 328$ (11).

HRMS (EI) for $\mathrm{C}_{22} \mathrm{H}_{17} \mathrm{NOS}, 343.1031$; found, 343.1031.

\section{5-Methyl-10-(2,3,4-trimethoxyphenyl)-5H-thieno[3,2-b]carbazole (48b).}

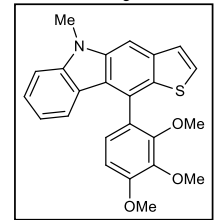

Yellow solid; yield $=94 \%$ m.p. $=215-217^{\circ} \mathrm{C} ; R_{f}=0.17($ hex $/$ EtOAc, $5: 1)$.

${ }^{1} \mathbf{H}$ NMR $\left(400 \mathrm{MHz}, \mathrm{CDCl}_{3}\right) \delta(\mathrm{ppm})=3.47(\mathrm{~s}, 3 \mathrm{H}), 3.89(\mathrm{~s}, 3 \mathrm{H}), 4.01$ $(\mathrm{s}, 6 \mathrm{H}), 6.89(\mathrm{~d}, J=8.5 \mathrm{~Hz}, 1 \mathrm{H}), 6.95-7.01(\mathrm{~m}, 1 \mathrm{H}), 7.14(\mathrm{~d}, J=8.5 \mathrm{~Hz}$, $1 \mathrm{H}), 7.20(\mathrm{~d}, J=7.7 \mathrm{~Hz}, 1 \mathrm{H}), 7.35(\mathrm{~d}, J=8.0 \mathrm{~Hz}, 1 \mathrm{H}), 7.39-7.44(\mathrm{~m}$, $1 \mathrm{H}), 7.46(\mathrm{~d}, J=5.5 \mathrm{~Hz}, 1 \mathrm{H}), 7.48(\mathrm{~d}, J=5.5 \mathrm{~Hz}, 1 \mathrm{H}), 7.76(\mathrm{~s}, 1 \mathrm{H})$.

${ }^{13} \mathrm{C}$ NMR $\left(100.6 \mathrm{MHz}, \mathrm{CDCl}_{3}\right) \delta(\mathrm{ppm})=29.4\left(\mathrm{CH}_{3}\right), 56.2\left(\mathrm{CH}_{3}\right), 61.3\left(\mathrm{CH}_{3}\right), 61.4$ $\left(\mathrm{CH}_{3}\right), 100.8(\mathrm{CH}), 107.9(\mathrm{CH}), 108.0(\mathrm{CH}), 118.7(\mathrm{CH}), 120.9(\mathrm{C}), 122.1(\mathrm{CH}), 122.3$ (C), $123.9(\mathrm{CH}), 125.2(\mathrm{CH}), 125.7(\mathrm{C}), 126.0(\mathrm{CH}), 127.0(\mathrm{C}), 127.3(\mathrm{CH}), 133.8(\mathrm{C})$, 138.0 (C), 140.7 (C), 142.6 (C), 142.9 (C), 152.2 (C), 154.1 (C).

LRMS (EI): $m / z$ (\%) $403\left(\mathrm{M}^{+}, 100\right), 357$ (9).

HRMS (EI) for $\mathrm{C}_{24} \mathrm{H}_{21} \mathrm{NO}_{3} \mathrm{~S}, 403.1242$; found, 403.1244 .

\section{9-Methyl-4-(2,3,4-trimethoxyphenyl)-9H-thieno[2,3-b]carbazole (49).}

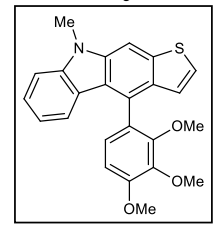

White solid; yield $=80 \%$ m.p. $213-215^{\circ} \mathrm{C} ; R_{f}=0.20$ (hex/EtOAc, 5:1). ${ }^{1} \mathbf{H}$ NMR $\left(400 \mathrm{MHz}, \mathrm{CDCl}_{3}\right) \delta(\mathrm{ppm})=3.42(\mathrm{~s}, 3 \mathrm{H}), 3.88(\mathrm{~s}, 3 \mathrm{H}), 4.01$ $(\mathrm{s}, 3 \mathrm{H}), 6.87(\mathrm{~d}, J=8.5 \mathrm{~Hz}, 1 \mathrm{H}), 6.95-7.00(\mathrm{~m}, 1 \mathrm{H}), 7.07-7.09(\mathrm{~m}, 1 \mathrm{H})$, $7.10-7.13(\mathrm{~m}, 1 \mathrm{H}), 7.17-7.20(\mathrm{~m}, 1 \mathrm{H}), 7.23(\mathrm{dd}, J=5.6,0.5 \mathrm{~Hz}, 1 \mathrm{H})$, $7.36(\mathrm{~d}, J=8.0 \mathrm{~Hz}, 1 \mathrm{H}), 7.39-7.44(\mathrm{~m}, 1 \mathrm{H}), 7.83(\mathrm{~s}, 1 \mathrm{H})$.

${ }^{13} \mathrm{C}$ NMR $\left(100.6 \mathrm{MHz}, \mathrm{CDCl}_{3}\right) \delta(\mathrm{ppm})=29.3\left(\mathrm{CH}_{3}\right), 56.2\left(\mathrm{CH}_{3}\right), 61.2\left(\mathrm{CH}_{2}\right), 61.3$ $\left(\mathrm{CH}_{2}\right), 100.0(\mathrm{CH}), 107.7(\mathrm{CH}), 108.1(\mathrm{C}), 118.7(\mathrm{CH}), 120.8(\mathrm{C}), 122.1(\mathrm{CH}), 122.6$ $(\mathrm{CH}), 123.0(\mathrm{CH}), 123.5(\mathrm{CH}), 125.6(\mathrm{CH}), 125.8(\mathrm{C}), 125.9(\mathrm{CH}), 127.8(\mathrm{C}), 133.6(\mathrm{C})$, 138.4 (C), 140.5 (C), 142.4 (C), 142.8 (C), 152.3 (C), 153.8 (C).

LRMS (EI): $m / z(\%) 403\left(\mathrm{M}^{+}, 100\right), 201$ (8).

HRMS (EI) for $\mathrm{C}_{24} \mathrm{H}_{21} \mathrm{NO}_{3} \mathrm{~S}$, 403.1242; found, 403.1242 . 
12-(4-Methoxyphenyl)-7-methyl-7H-benzo[4,5]thieno[2,3-b]carbazole (50).

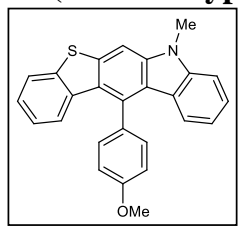

Black foam; yield $=51 \% ; R_{f}=0.36($ hex/EtOAc, $4: 1)$.

${ }^{1} \mathbf{H}$ NMR $\left(400 \mathrm{MHz}, \mathrm{CDCl}_{3}\right) \delta(\mathrm{ppm})=3.88(\mathrm{~s}, 3 \mathrm{H}), 402(\mathrm{~s}, 3 \mathrm{H}), 6.86$ $(\mathrm{d}, J=7.5 \mathrm{~Hz}, 1 \mathrm{H}), 6.93-7.01(\mathrm{~m}, 2 \mathrm{H}), 7.06-7.12(\mathrm{~m}, 1 \mathrm{H}), 7.18-7.24$ $(\mathrm{m}, 2 \mathrm{H}), 7.26-7.31(\mathrm{~m}, 1 \mathrm{H}), 7.36(\mathrm{~d}, J=7.6 \mathrm{~Hz}, 1 \mathrm{H}), 7.39-7.46(\mathrm{~m}$, $3 \mathrm{H}), 7.76-7.81(\mathrm{~m}, 2 \mathrm{H})$.

${ }^{13} \mathbf{C ~ N M R}\left(100.6 \mathrm{MHz}, \mathrm{CDCl}_{3}\right) \delta(\mathrm{ppm})=29.4\left(\mathrm{CH}_{3}\right), 55.6\left(\mathrm{CH}_{3}\right), 100.5(\mathrm{CH}), 108.2$ $(\mathrm{CH}), 115.2(2 \times \mathrm{CH}), 119.1(\mathrm{CH}), 121.3(\mathrm{C}), 122.4(\mathrm{CH}), 122.5(\mathrm{CH}), 123.3(\mathrm{C}), 124.0$ $(\mathrm{CH}), 124.1(\mathrm{CH}), 125.1(\mathrm{CH}), 125.8(\mathrm{CH}), 126.6(\mathrm{C}), 130.3(2 \times \mathrm{CH}), 131.9(\mathrm{C}), 133.5$ (C), 136.6 (C), 138.5 (C), 138.7 (C), 140.8 (C), 142.1 (C), 159.7 (C).

LRMS (EI): $m / z$ (\%) $393\left(\mathrm{M}^{+}, 100\right), 348$ (5), 196 (4).

HRMS (EI) for $\mathrm{C}_{26} \mathrm{H}_{19} \mathrm{NOS}, 393.1190$; found, 393.1187 .

\section{2-(4-Methoxyphenyl)-7-methyl-7H-benzofuro[2,3-b]carbazole (51).}

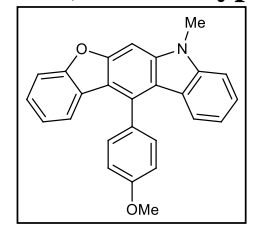

Yellow solid; yield $=34 \% ; R_{f}=0.30($ hex/EtOAc, 20:1).

${ }^{1} \mathbf{H}$ NMR $\left(400 \mathrm{MHz}, \mathrm{CDCl}_{3}\right) \delta(\mathrm{ppm})=3.91(\mathrm{~s}, 3 \mathrm{H}), 4.01(\mathrm{~s}, 3 \mathrm{H}), 6.98$ (ddd, $J=8.0,5.0,3.1 \mathrm{~Hz}, 1 \mathrm{H}), 7.03-7.09(\mathrm{~m}, 2 \mathrm{H}), 7.16-7.22(\mathrm{~m}, 3 \mathrm{H})$, 7.28-7.34 (m, 1H), 7.37-7.40 (m, 2H), $7.46(\mathrm{~s}, 1 \mathrm{H}), 7.50-7.56(\mathrm{~m}, 3 \mathrm{H})$. ${ }^{13} \mathrm{C}$ NMR $\left(100.6 \mathrm{MHz}, \mathrm{CDCl}_{3}\right): \delta(\mathrm{ppm})=29.6\left(\mathrm{CH}_{3}\right), 55.5\left(\mathrm{CH}_{3}\right)$, $89.8(\mathrm{CH}), 108.2(\mathrm{CH}), 111.1(\mathrm{CH}), 114.7(2 \times \mathrm{CH}), 116.6(\mathrm{C}), 118.5(\mathrm{C}), 119.0(\mathrm{CH})$, $121.4(\mathrm{CH}), 121.9(\mathrm{CH}), 122.4(\mathrm{CH}), 123.1(\mathrm{C}), 125.17(\mathrm{CH}), 125.21(\mathrm{C}), 125.6(\mathrm{CH})$, $130.5(2 \times \mathrm{CH}), 130.7$ (C), $131.3(\mathrm{C}), 141.7$ (C), 142.0 (C), 155.9 (C), 156.7 (C), 159.7 (C). LRMS (EI): $m / z$ (\%) $377\left(\mathbf{M}^{+}, 100\right), 331$ (5).

HRMS (EI) for $\mathrm{C}_{26} \mathrm{H}_{19} \mathrm{NO}_{2}, 377.1423$; found, 377.1420 .

\section{6-(4-Methoxyphenyl)-7-methyl-7H-benzofuro[2,3-b]carbazole (51').}

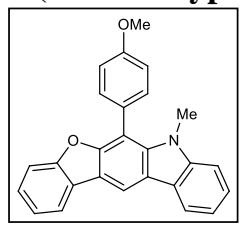

Yellow foam; yield $=22 \% ; R_{f}=0.23($ hex/EtOAc, 20:1).

${ }^{1} \mathbf{H}$ NMR $\left(400 \mathrm{MHz}, \mathrm{CDCl}_{3}\right) \delta(\mathrm{ppm})=3.40(\mathrm{~s}, 3 \mathrm{H}), 3.98(\mathrm{~s}, 3 \mathrm{H}), 6.78$ (ddd, $J=7.8,1.3,0.6 \mathrm{~Hz}, 1 \mathrm{H}), 7.03(\mathrm{~m}, 1 \mathrm{H}), 7.22-7.28(\mathrm{~m}, 2 \mathrm{H})$, $7.31-7.38(\mathrm{~m}, 2 \mathrm{H}), 7.46-7.51(\mathrm{~m}, 3 \mathrm{H}), 7.52-7.55(\mathrm{~m}, 1 \mathrm{H}), 8.17$ (ddd, $J=7.7,1.1,0.6 \mathrm{~Hz}, 1 \mathrm{H}), 8.20(\mathrm{~s}, 1 \mathrm{H})$.

${ }^{13} \mathrm{C}$ NMR $\left(100.6 \mathrm{MHz}, \mathrm{CDCl}_{3}\right) \delta(\mathrm{ppm})=32.4\left(\mathrm{CH}_{3}\right), 55.5\left(\mathrm{CH}_{3}\right), 100.9(\mathrm{CH}), 108.7$ $(\mathrm{CH}), 111.3(\mathrm{CH}), 114.2(2 \times \mathrm{CH}), 118.76(\mathrm{C}), 118.81(\mathrm{CH}), 120.4(\mathrm{CH}), 122.0(\mathrm{CH})$, $122.2(\mathrm{CH}), 122.7(\mathrm{C}), 123.0(\mathrm{C}), 123.9(\mathrm{C}), 125.3(\mathrm{C}), 126.3(\mathrm{CH}), 126.6(\mathrm{CH}), 129.5$ (C), $131.7(2 \times \mathrm{CH}), 135.7$ (C), $143.2(\mathrm{C}), 150.5$ (C), 157.2 (C), 159.7(C).

LRMS (EI): $m / z$ (\%) $377\left(\mathrm{M}^{+}, 100\right), 318(8)$.

HRMS (EI) for $\mathrm{C}_{26} \mathrm{H}_{19} \mathrm{NO}_{2}, 377.1423$; found, 377.1416. 


\subsection{Synthesis of Isobenzofurans 42 and Bisindole 43}

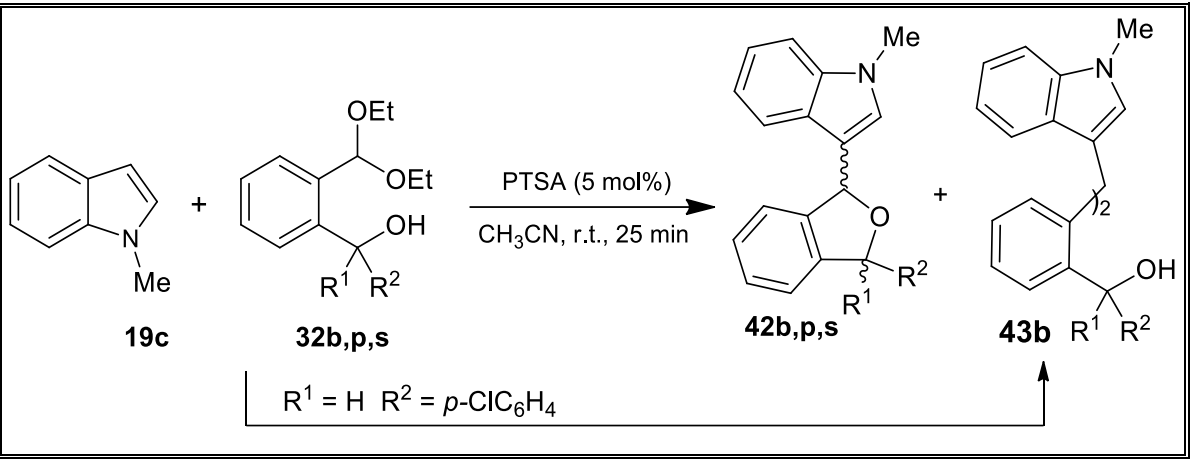

General Procedure: To a mixture of acetal $32(1 \mathrm{mmol})$ and $N$-methylindole 19c (131.2 mg, $1 \mathrm{mmol})$, in $\mathrm{MeCN}(1 \mathrm{ml})$ was added PTSA (10 mg, $5 \mathrm{~mol} \%)$. The reaction mixture was stirred for $25 \mathrm{~min}$ at r.t., then was quenched with a $0.5 \mathrm{M} \mathrm{NaOH}$ solution and extracted with EtOAc $(3 \times 15 \mathrm{ml})$. The combined organic layers were dried over anhydrous $\mathrm{Na}_{2} \mathrm{SO}_{4}$ and concentrated at reduced pressure. The residue was purified by flash chromatography of hexane and EtOAc as eluent to obtain isobenzofurans derivatives 42 and bisindolylmethane $\mathbf{4 3 b}$.

\section{3-(3-(4-Chlorophenyl)-1,3-dihydroisobenzofuran-1-yl)-1-methyl-1H-indole (42b).}

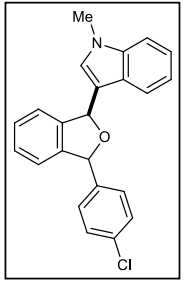

Isolated as a ca. 1.2:1 mixture of diastereoisomers. Yellow foam; yield $=$ $38 \% ; R_{f}=0.28$ (hex/EtOAc, 5:1).

${ }^{1} \mathbf{H}$ NMR $\left(300 \mathrm{MHz}, \mathrm{CDCl}_{3}\right) \delta(\mathrm{ppm})=3.76(\mathrm{~s}, 3 \mathrm{H}$, one diast.), 3.81 (s, $3 \mathrm{H}$, one diast.), 6.19 (d, $J=2.6 \mathrm{~Hz}, 1 \mathrm{H}$, one diast.), 6.35 (d, $J=2.6 \mathrm{~Hz}, 1 \mathrm{H}$, one diast.), 6.60 (d, $J=2.6 \mathrm{~Hz}, 1 \mathrm{H}$, one diast.), $6.78(\mathrm{~d}, J=2.6 \mathrm{~Hz}, 1 \mathrm{H}$, one diast.), 6.98-7.08 ( $\mathrm{m}, 4 \mathrm{H}$, both diast.), 7.11-7.40 (m, $22 \mathrm{H}$, both diast.).

${ }^{13} \mathrm{C} \mathrm{NMR}\left(75.4 \mathrm{MHz}, \mathrm{CDCl}_{3}\right) \delta(\mathrm{ppm})=32.9\left(\mathrm{CH}_{3}\right), 33.0\left(\mathrm{CH}_{3}\right), 79.2(\mathrm{CH}), 79.6(\mathrm{CH})$, $84.2(\mathrm{CH}), 84.4(\mathrm{CH}), 109.56(\mathrm{CH}), 109.64(\mathrm{CH}), 114.5(\mathrm{C}), 115.1(\mathrm{C}), 119.6(\mathrm{CH}), 119.7$ $(2 \times \mathrm{CH}), 120.1(\mathrm{CH}), 122.06(\mathrm{CH}), 122.09(\mathrm{CH}), 122.14(\mathrm{CH}), 122.3(\mathrm{CH}), 122.65(\mathrm{CH})$, $122.68(\mathrm{CH}), 126.7(\mathrm{C}), 126.8(\mathrm{C}), 128.0(2 \times \mathrm{CH}), 128.1(\mathrm{CH}), 128.2(\mathrm{CH}), 128.4(\mathrm{CH})$, $128.6(2 \times \mathrm{CH}), 128.71(2 \times \mathrm{CH}), 128.74(2 \times \mathrm{CH}), 128.8(2 \times \mathrm{CH}), 129.2(\mathrm{CH}), 133.77$ (C), $133.80(\mathrm{C}), 137.8(2 \times \mathrm{C}), 140.5(\mathrm{C}), 141.1(\mathrm{C}), 141.5(\mathrm{C}), 141.7$ (C), 142.1 (C), 142.9 (C). LRMS (EI): $m / z$ (\%) 359 (M+1 100), 361 [(M+2)+, 34], 358 (47), 230 (26), 229 (30), 228 (73), 193 (87), 165 (40), 158 (65), 131 (24).

HRMS (EI) for $\mathrm{C}_{23} \mathrm{H}_{18} \mathrm{NOCl}$, 359.1077; found, 359.1079. 


\section{3-(3-Cyclopropyl-3-methyl-1,3-dihydroisobenzofuran-1-yl)-1-methyl-1 $H$-indole (42p).}

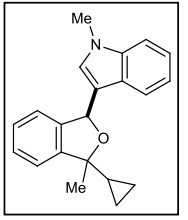

Isolated as a ca. 1:1 mixture of diastereoisomers. Yellow foam; yield $=$ $70 \% ; R_{f}=0.30($ hex/EtOAc, $6: 1)$.

${ }^{1} \mathbf{H}$ NMR $\left(300 \mathrm{MHz}, \mathrm{CDCl}_{3}\right) \delta(\mathrm{ppm})=0.38-0.62(\mathrm{~m}, 6 \mathrm{H}$, both diast), $0.87-1.05$ ( $\mathrm{m}, 2 \mathrm{H}$, both diast), 1.34-1.52 (m, $2 \mathrm{H}$, both diast), 1.59 (s, $3 \mathrm{H}$, one diast), 1.78 (s, 3H, one diast), $3.78(\mathrm{~s}, 3 \mathrm{H}), 3.79(\mathrm{~s}, 3 \mathrm{H}), 6.56(\mathrm{~s}, 1 \mathrm{H}$, one diast), 6.58 (s, 1H, one diast), 7.01-7.20 (m, 4H), 7.23-7.47 (m, 8H).

${ }^{13} \mathrm{C} \mathrm{NMR}\left(75.4 \mathrm{MHz}, \mathrm{CDCl}_{3}\right) \delta(\mathrm{ppm})=1.1\left(\mathrm{CH}_{2}\right), 1.18\left(\mathrm{CH}_{2}\right), 1.23\left(\mathrm{CH}_{2}\right), 1.4\left(\mathrm{CH}_{2}\right)$, $21.1(\mathrm{CH}), 21.3(\mathrm{CH}), 25.5\left(\mathrm{CH}_{3}\right), 27.3\left(\mathrm{CH}_{3}\right), 32.70\left(\mathrm{CH}_{3}\right), 32.74\left(\mathrm{CH}_{3}\right), 76.9(\mathrm{C}), 78.3$ $(\mathrm{C}), 85.7(\mathrm{CH}), 86.3(\mathrm{CH}), 109.35(\mathrm{CH}), 109.39(\mathrm{CH}), 115.2(\mathrm{C}), 119.2(\mathrm{CH}), 119.3(\mathrm{CH})$, $119.9(\mathrm{CH}), 120.2(\mathrm{CH}), 120.9(\mathrm{CH}), 121.4(\mathrm{CH}), 121.73(\mathrm{CH}), 121.76(\mathrm{CH}), 122.4(\mathrm{CH})$, $122.5(\mathrm{CH}), 125.4(\mathrm{C}), 126.4(\mathrm{C}), 127.4(\mathrm{CH}), 127.60(\mathrm{CH}), 127.64(\mathrm{CH}), 128.3(\mathrm{CH})$, $128.6(\mathrm{CH}), 129.1(\mathrm{CH}), 137.7(\mathrm{C}), 137.8(\mathrm{C}), 141.3(\mathrm{C}), 142.2(\mathrm{C}), 145.5(\mathrm{C}), 147.5(\mathrm{C})$.

\section{3-(3,3-Bis(4-chlorophenyl)-1,3-dihydroisobenzofuran-1-yl)-1-methyl-1 $H$-indole (42s).}

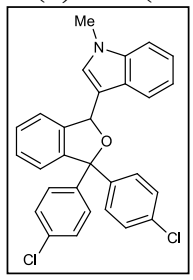

Yellow foam; yield $=60 \% ; R_{f}=0.28($ hex/EtOAc, 5:1).

${ }^{1} \mathbf{H}$ NMR $\left(300 \mathrm{MHz}, \mathrm{CDCl}_{3}\right) \delta(\mathrm{ppm})=3.82(\mathrm{~s}, 3 \mathrm{H}), 6.45(\mathrm{~s}, 1 \mathrm{H})$, 7.01-7.09 (m, 1H), 7.14-7.22 (m, 3H), 7.25-7.48 (m, 13H).

${ }^{13} \mathrm{C} \mathrm{NMR}\left(75.4 \mathrm{MHz}, \mathrm{CDCl}_{3}\right) \delta(\mathrm{ppm})=32.9\left(\mathrm{CH}_{3}\right), 77.6(\mathrm{C}), 90.8(\mathrm{CH})$, $109.6(\mathrm{CH}), 113.4(\mathrm{C}), 119.5(\mathrm{CH}), 120.1(\mathrm{CH}), 122.1(\mathrm{CH}), 122.9(\mathrm{CH})$, $123.5(\mathrm{CH}), 126.6(\mathrm{C}), 127.8(\mathrm{CH}), 128.2(2 \times \mathrm{CH}), 128.29(\mathrm{CH}), 128.34$ $(2 \times \mathrm{CH}), 128.7(2 \times \mathrm{CH}), 129.3(2 \times \mathrm{CH}), 129.5(\mathrm{CH}), 133.3(\mathrm{C}), 133.6(\mathrm{C}), 137.8(\mathrm{C})$, 142.1 (C), 142.5 (C), 143.8 (C), 143.9 (C).

(2-(Bis(1-methyl-1H-indol-3-yl)methyl)phenyl)(4-chlorophenyl)metanol (43b).

Red foam; yield $=32 \% ; R_{f}=0.13($ hex/EtOAc, $5: 1)$

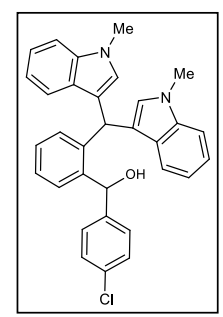

${ }^{1} \mathbf{H}$ NMR $\left(300 \mathrm{MHz}, \mathrm{CDCl}_{3}\right) \delta(\mathrm{ppm})=2.22(\mathrm{bs}, 1 \mathrm{H}), 3.61(\mathrm{~s}, 3 \mathrm{H}), 3.69$ (s, 3H), 6.09 (s, 1H), 6.16 (s, 1H), 6.33 (s, 1H), 6.47 (s, 1H), 6.83-7.09 (m, 3H), 7.13-7.38 (m, $12 \mathrm{H}), 7.66(\mathrm{~d}, J=7.8 \mathrm{~Hz}, 1 \mathrm{H})$.

${ }^{13} \mathrm{C}$ NMR $\left(75.4 \mathrm{MHz}, \mathrm{CDCl}_{3}\right) \delta(\mathrm{ppm})=32.7\left(\mathrm{CH}_{3}\right), 32.8\left(\mathrm{CH}_{3}\right), 35.5$ $(\mathrm{CH}), 72.4(\mathrm{CH}), 109.1(\mathrm{CH}), 109.3(\mathrm{CH}), 117.3(\mathrm{C}), 117.6(\mathrm{C}), 118.8$ $(\mathrm{CH}), 118.9(\mathrm{CH}), 119.7(\mathrm{CH}), 119.9(\mathrm{CH}), 121.6(\mathrm{CH}), 121.8(\mathrm{CH})$, $126.66(\mathrm{CH}), 126.71(\mathrm{CH}), 127.2(\mathrm{C}), 127.4(\mathrm{C}), 127.8(\mathrm{CH}), 128.5(2$ $\times \mathrm{CH}), 128.6(\mathrm{CH}), 128.8(2 \times \mathrm{CH}), 129.0(\mathrm{CH}), 129.2(\mathrm{CH}), 133.3(\mathrm{C}), 137.48(\mathrm{C}), 137.53$ (C), 140.7 (C), $141.3(\mathrm{C}), 141.9(\mathrm{C})$.

LRMS (EI): $m / z$ (\%) 361 (32), 360 (32), 359 (100), 165 (35), 158 (47), 131 (28).

HRMS (EI) for $\mathrm{C}_{32} \mathrm{H}_{25} \mathrm{~N}_{2} \mathrm{ClO}, 488.1655$; found, 488.1655 


\section{SYNTHESIS OF 1-INDOL-3-YLCARBAZOLES AND $\alpha$ - INDOL-3-YL- $\alpha$-ALKENYLACETOPHENONES}

\subsection{Synthesis of 1-Indol-3-ylcarbazol}

\subsubsection{Synthesis of $\alpha, \alpha$-Bis(indol-3-yl) Ketones 52}

Starting $\alpha, \alpha$-bis(indol-3-yl) ketones 52 were prepared by reaction of phenyl glyoxal or pyruvic aldehyde, with the corresponding indole in $\mathrm{CH}_{3} \mathrm{CN}$ catalized by PTSA following a procedure previously described by our group. Characterization data for $\alpha, \alpha-$ bis(indol-3-yl) ketones 52cc, 52aa and 52ae have been previously reported. ${ }^{112}$

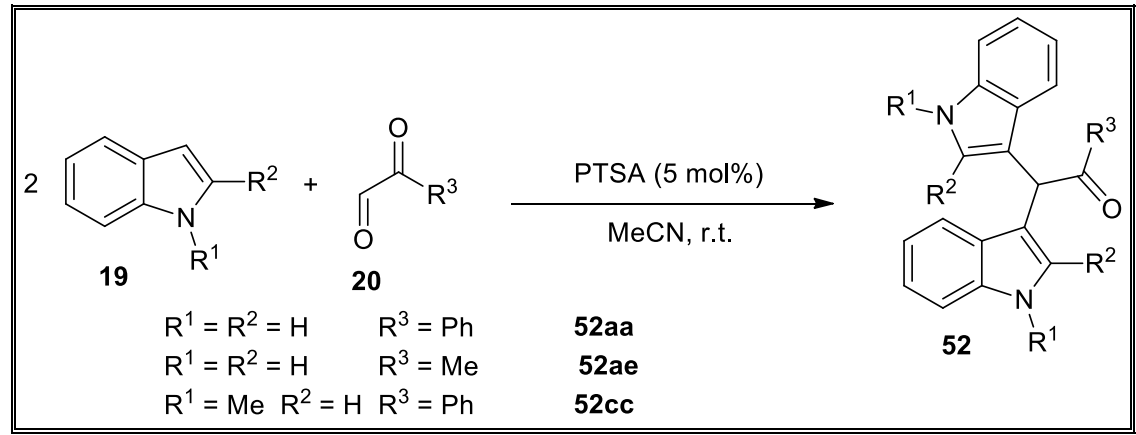

\subsubsection{Synthesis of Alcohols 53a-k and 54}

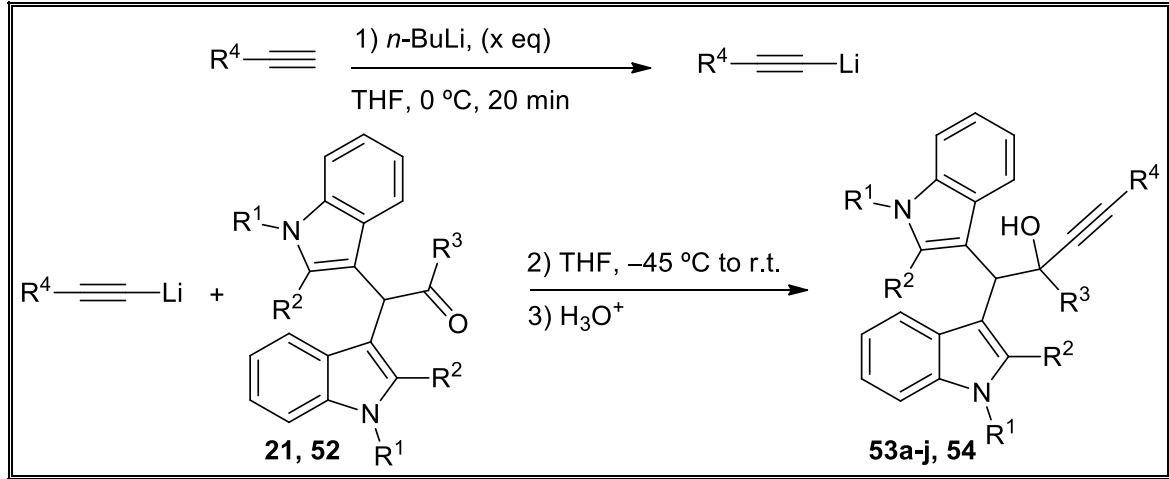

General Procedure: To a solution of the corresponding alkyne (2 eq, $6 \mathrm{mmol}$ for 52cc and 21cd; $3 \mathrm{eq}, 9 \mathrm{mmol}$ for 21ac; $4 \mathrm{eq}, 12 \mathrm{mmol}$ for 52aa,21ba, and $5 \mathrm{eq}, 15 \mathrm{mmol}$ for 52ae) in THF (12-30 ml), at $0{ }^{\circ} \mathrm{C}$, was added $n$-BuLi (1.6 M in hexanes) $(3.75 \mathrm{ml}, 2$ eq, $6 \mathrm{mmol}$, for $\mathbf{5 2 c c}$ and 21cd; $5.6 \mathrm{ml}, 3 \mathrm{eq}, 9 \mathrm{mmol}$, for $21 \mathrm{ac} ; 7.5 \mathrm{ml}, 4 \mathrm{eq}, 12 \mathrm{mmol}$, for 52aa, $21 \mathbf{b a}$ and $9.4 \mathrm{ml}, 5 \mathrm{eq}, 15 \mathrm{mmol}$, for 52ae). The solution was stirred at $0{ }^{\circ} \mathrm{C}$ for $20 \mathrm{~min}$, then the appropriate ketone $\mathbf{5 2}$ or $\mathbf{2 1}$ was added ( $1 \mathrm{eq}, 3 \mathrm{mmol})$ at $-45^{\circ} \mathrm{C}$. The resulting mixture was stirred at r.t. until ketone was consumed as determined by TLC. The reaction was quenched with a saturated $\mathrm{NH}_{4} \mathrm{Cl}$ aqueous solution and extracted with $\mathrm{Et}_{2} \mathrm{O}(3 \times 20 \mathrm{ml})$. The combined organic layers were dried over anhydrous $\mathrm{Na}_{2} \mathrm{SO}_{4}$ and 
concentrated at reduced pressure. The residue was purified by flash chromatography using mixtures of hexane and EtOAc as eluents to obtain the alkynols 53a-j and $\mathbf{5 4}$.

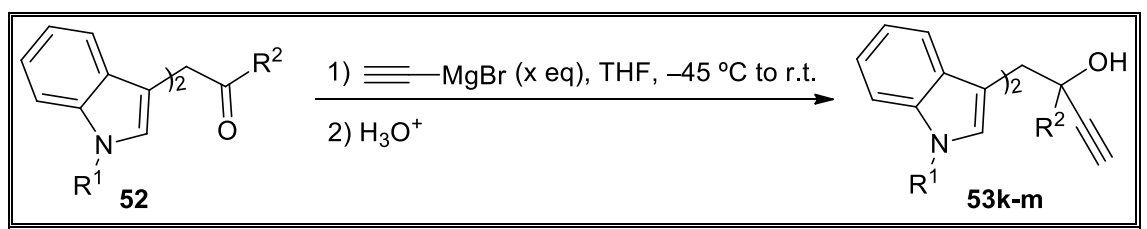

General Procedure: To a solution of the corresponding ketone 52 (5 mmol, 1 eq), in THF (20-30 ml), at $-45^{\circ} \mathrm{C}$, was added ethynylmagnesium bromide ( $0.5 \mathrm{M}$ in THF) (10 mmol, 2 eq for 52cc, $20 \mathrm{mmol}, 4 \mathrm{eq}$ for $\mathbf{5 2 a a}$, and $25 \mathrm{mmol}, 5 \mathrm{eq}$ for 52ae). The resulting mixture was stirred at r.t. until ketone $\mathbf{5 2}$ was consumed as determined by TLC. Then, the reaction was quenched with a saturated $\mathrm{NH}_{4} \mathrm{Cl}$ aqueous solution and extracted with $\mathrm{Et}_{2} \mathrm{O}(3 \times 25 \mathrm{ml})$. The combined organic layers were dried over anhydrous $\mathrm{Na}_{2} \mathrm{SO}_{4}$ and concentrated at reduced pressure. The residue was purified by flash chromatography using mixtures of hexane and EtOAc as eluents to obtain the alkynols 53k-m.

\section{1,1-Bis(1-methyl-1H-indol-3-yl)-2-phenyloct-3-yn-2-ol (53a).}

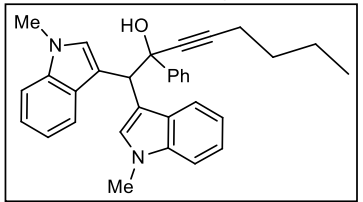

White solid; yield $=75 \%$; m.p. $136-138^{\circ} \mathrm{C}$.

${ }^{1} \mathbf{H}$ NMR $\left(300 \mathrm{MHz}, \mathrm{CDCl}_{3}\right) \delta(\mathrm{ppm})=0.96(\mathrm{t}, J=7.2 \mathrm{~Hz}, 3 \mathrm{H})$, $1.33-1.60(\mathrm{~m}, 4 \mathrm{H}), 2.33(\mathrm{t}, J=6.9 \mathrm{~Hz}, 2 \mathrm{H}), 3.10(\mathrm{~s}, 1 \mathrm{H}), 3.72(\mathrm{~s}, 3 \mathrm{H})$, $3.77(\mathrm{~s}, 3 \mathrm{H}), 5.20(\mathrm{~s}, 1 \mathrm{H}), 6.86-6.98(\mathrm{~m}, 1 \mathrm{H}), 7.04-7.10(\mathrm{~m}, 1 \mathrm{H})$, 7.11-7.16 (m, 1H), 7.16-7.30 (m, 8H), 7.38 (s, 1H), 7.63 (dt, J=7.9, 1.0 Hz, 1H), 7.67-7.71 (m, 2H). ${ }^{13} \mathbf{C ~ N M R}\left(75.4 \mathrm{MHz}, \mathrm{CDCl}_{3}\right) \delta(\mathrm{ppm})=13.8\left(\mathrm{CH}_{3}\right), 18.8\left(\mathrm{CH}_{2}\right), 22.1\left(\mathrm{CH}_{2}\right), 30.7\left(\mathrm{CH}_{2}\right)$, $32.76\left(\mathrm{CH}_{3}\right), 32.84\left(\mathrm{CH}_{3}\right), 47.0(\mathrm{CH}), 76.5(\mathrm{C}), 83.6(\mathrm{C}), 87.8(\mathrm{C}), 108.7(\mathrm{CH}), 109.0$ $(\mathrm{CH}), 114.0(\mathrm{C}), 114.5(\mathrm{C}), 118.5(\mathrm{CH}), 119.0(\mathrm{CH}), 119.3(\mathrm{CH}), 119.5(\mathrm{CH}), 121.1(\mathrm{CH})$, $121.5(\mathrm{CH}), 126.6(2 \times \mathrm{CH}), 127.3(\mathrm{CH}), 127.6(2 \times \mathrm{CH}), 128.5(\mathrm{CH}), 136.3(\mathrm{C}), 136.6$ (C), $144.1(\mathrm{C})$, one aromatic carbon peak was misssing due to overlapping.

EI-LRMS $m / z 273$ (100).

\section{4-Cyclopropyl-1,1-bis(1-methyl-1H-indol-3-yl)-2-phenylbut-3-yn-2-ol (53b).}

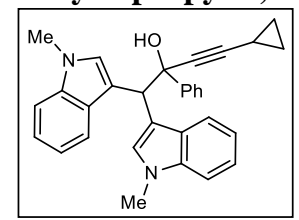

White solid; yield $=50 \%$; m.p. $215-217^{\circ} \mathrm{C}$.

${ }^{1} \mathbf{H}$ NMR $\left(300 \mathrm{MHz}, \mathrm{CDCl}_{3}\right) \delta(\mathrm{ppm})=1.05-1.22(\mathrm{~m}, 2 \mathrm{H}), 1.23-$ $1.38(\mathrm{~m}, 1 \mathrm{H}), 2.56(\mathrm{~s}, 1 \mathrm{H}), 3.60(\mathrm{~s}, 3 \mathrm{H}), 3.72(\mathrm{~s}, 3 \mathrm{H}), 5.24(\mathrm{~s}, 1 \mathrm{H})$, 6.93 (ddd, $J=8.0,5.2,1.8 \mathrm{~Hz}, 1 \mathrm{H}), 7.02-7.18(\mathrm{~m}, 5 \mathrm{H}), 7.21-7.38$ $(\mathrm{m}, 6 \mathrm{H}), 7.48-7.56(\mathrm{~m}, 2 \mathrm{H}), 7.89-7.94(\mathrm{~m}, 1 \mathrm{H})$.

${ }^{13} \mathrm{C} \mathrm{NMR}\left(75.4 \mathrm{MHz}, \mathrm{CDCl}_{3}\right) \delta(\mathrm{ppm})=14.2\left(\mathrm{CH}_{2}\right), 23.1\left(\mathrm{CH}_{2}\right), 26.2(\mathrm{CH}), 32.7\left(\mathrm{CH}_{3}\right)$, $32.9\left(\mathrm{CH}_{3}\right), 42.5(\mathrm{CH}), 44.4(\mathrm{CH}), 79.6(\mathrm{C}), 108.7(\mathrm{CH}), 109.3(\mathrm{CH}), 115.2(\mathrm{C}), 115.3$ $(\mathrm{C}), 118.4(\mathrm{CH}), 119.1(\mathrm{CH}), 119.3(\mathrm{CH}), 119.7(\mathrm{CH}), 120.9(\mathrm{CH}), 121.5(\mathrm{CH}), 125.6$ $(\mathrm{CH}), 126.0(2 \times \mathrm{CH}), 127.6(2 \times \mathrm{CH}), 128.3(\mathrm{C}), 128.56(\mathrm{CH}), 128.63(\mathrm{CH}), 128.1(\mathrm{C})$, $136.2(\mathrm{C}), 136.8(\mathrm{C}), 145.6(\mathrm{C})$, two quaternary carbon peaks were misssing probably due to overlapping with $\mathrm{CDCl}_{3}$ signals.

EI-LRMS $m / z 274$ (25), 273 (100). 
1,1-Bis(1-methyl-1H-indol-3-yl)-2,6-diphenylhex-3-yn-2-ol (53c).

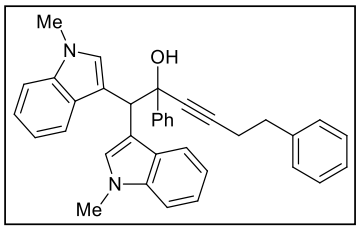

White solid; yield $=70 \%$; m.p. $175-177^{\circ} \mathrm{C}$.

${ }^{1} \mathbf{H}$ NMR $\left(300 \mathrm{MHz}, \mathrm{CDCl}_{3}\right) \delta(\mathrm{ppm})=2.60(\mathrm{t}, J=7.4 \mathrm{~Hz}$, $1 \mathrm{H}), 2.79(\mathrm{t}, J=7.2 \mathrm{~Hz}, 1 \mathrm{H}), 3.08(\mathrm{~s}, 1 \mathrm{H}), 3.69(\mathrm{~s}, 3 \mathrm{H}), 3.73(\mathrm{~s}, 3 \mathrm{H})$, $5.19(\mathrm{~s}, 1 \mathrm{H}), 6.88-7.00(\mathrm{~m}, 1 \mathrm{H}), 7.02-7.08(\mathrm{~m}, 1 \mathrm{H}), 7.09-7.14(\mathrm{~m}$, 2H), 7.15-7.24 (m, 7H), 7.25-7.30 (m, 6H), 7.54-7.66 (m, 3H).

${ }^{13} \mathrm{C} \mathrm{NMR}\left(75.4 \mathrm{MHz}, \mathrm{CDCl}_{3}\right) \delta(\mathrm{ppm})=21.1\left(\mathrm{CH}_{2}\right), 32.9\left(\mathrm{CH}_{3}\right), 33.0\left(\mathrm{CH}_{3}\right), 34.7\left(\mathrm{CH}_{2}\right)$, $46.9(\mathrm{CH}), 76.3(\mathrm{C}), 84.4(\mathrm{C}), 87.0(\mathrm{C}), 108.8(\mathrm{CH}), 109.0(\mathrm{CH}), 113.8(\mathrm{C}), 114.4(\mathrm{C})$, $118.5(\mathrm{CH}), 119.0(\mathrm{CH}), 119.5(\mathrm{CH}), 121.1(\mathrm{CH}), 121.5(\mathrm{CH}), 126.4(\mathrm{CH}), 126.5(2 \times \mathrm{CH})$, $127.3(\mathrm{CH}), 127.6(2 \times \mathrm{CH}), 128.4(\mathrm{CH}), 128.5(2 \times \mathrm{CH}), 128.6(2 \times \mathrm{CH}), 128.7(\mathrm{C})$, $136.3(\mathrm{C}), 136.6(\mathrm{C}), 140.7(\mathrm{C}), 143.8(\mathrm{C})$, three aromatic carbon peaks were misssing due to overlapping.

EI-LRMS $m / z, 273$ (100), $508\left(\mathbf{M}^{+}, 20\right)$.

HRMS calcd. for $\mathrm{C}_{36} \mathrm{H}_{32} \mathrm{~N}_{2} \mathrm{O}, 508.2515$; found, 508.2516.

\section{1,1-Bis(1-methyl-1H-indol-3-yl)-2,4-diphenylbut-3-yn-2-ol (53d).}

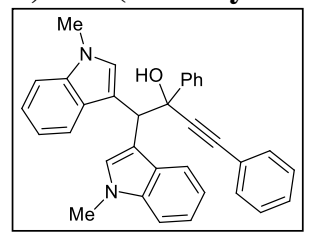

White solid; yield $=90 \%$ yield; m.p. $199-201{ }^{\circ} \mathrm{C}$.

${ }^{1} \mathbf{H}$ NMR $\left(300 \mathrm{MHz}, \mathrm{CDCl}_{3}\right) \delta(\mathrm{ppm})=3.32(\mathrm{~s}, 1 \mathrm{H}), 3.77(\mathrm{~s}, 3 \mathrm{H})$, $3.78(\mathrm{~s}, 3 \mathrm{H}), 5.34(\mathrm{~s}, 1 \mathrm{H}), 6.91-7.00(\mathrm{~m}, 1 \mathrm{H}), 7.07-7.19(\mathrm{~m}, 2 \mathrm{H})$, 7.20-7.51 (m, 13H), 7.67-7.73 (m, 1H), 7.75-7.82 (m, 2H).

${ }^{13} \mathbf{C ~ N M R}\left(75.4 \mathrm{MHz}, \mathrm{CDCl}_{3}\right) \delta(\mathrm{ppm})=32.8\left(\mathrm{CH}_{3}\right), 32.9\left(\mathrm{CH}_{3}\right)$, $47.2(\mathrm{CH}), 76.9(\mathrm{C}), 87.1(\mathrm{C}), 92.9(\mathrm{C}), 108.8(\mathrm{CH}), 109.1(\mathrm{CH}), 113.8(\mathrm{C}), 114.3(\mathrm{C})$, $118.7(\mathrm{CH}), 119.1(\mathrm{CH}), 119.3(\mathrm{CH}), 119.4(\mathrm{CH}), 121.2(\mathrm{CH}), 121.6(\mathrm{CH}), 123.0(\mathrm{C})$, $126.6(2 \times \mathrm{CH}), 127.4(\mathrm{CH}), 127.5(\mathrm{CH}), 127.8(2 \times \mathrm{CH}), 128.3(\mathrm{C}), 128.39(2 \times \mathrm{CH})$, $128.46(\mathrm{CH}), 131.7(2 \times \mathrm{CH}), 132.2(\mathrm{CH}), 136.3(\mathrm{C}), 136.6(\mathrm{C}), 143.5(\mathrm{C})$.

\section{4-(4-Methoxyphenyl)-1,1-bis(1-methyl-1H-indol-3-yl)-2-phenylbut-3-yn-2-ol (53e).}

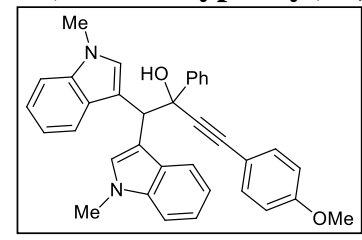

White solid; yield $=60 \%$; m.p. $207-209^{\circ} \mathrm{C}$.

${ }^{1} \mathbf{H}$ NMR $\left(300 \mathrm{MHz}, \mathrm{CDCl}_{3}\right) \delta(\mathrm{ppm})=3.29(\mathrm{~s}, 1 \mathrm{H}), 3.71(\mathrm{~s}$, $3 \mathrm{H}), 3.77(\mathrm{~s}, 3 \mathrm{H}), 3.79(\mathrm{~s}, 3 \mathrm{H}), 5.30(\mathrm{~s}, 1 \mathrm{H}), 6.87-6.97(\mathrm{~m}, 3 \mathrm{H})$, 6.98-7.03 (m, 1H), 7.04-7.17 (m, 2H), 7.17-7.35 (m, 9H), $7.45(\mathrm{~d}$, $J=1.9 \mathrm{~Hz}, 1 \mathrm{H}), 7.63-7.68(\mathrm{~m}, 1 \mathrm{H}), 7.72-7.72(\mathrm{~m}, 2 \mathrm{H})$.

${ }^{13} \mathrm{C} \mathrm{NMR}\left(75.4 \mathrm{MHz}, \mathrm{CDCl}_{3}\right) \delta(\mathrm{ppm})=32.9\left(\mathrm{CH}_{3}\right), 33.0\left(\mathrm{CH}_{3}\right), 47.2(\mathrm{CH}), 55.4\left(\mathrm{CH}_{3}\right)$, $76.9(\mathrm{C}), 87.0(\mathrm{C}), 92.7(\mathrm{C}), 108.8(\mathrm{CH}), 109.1(\mathrm{CH}), 113.8(\mathrm{C}), 114.3(\mathrm{C}), 115.1(\mathrm{CH})$, $116.6(\mathrm{CH}), 118.8(\mathrm{CH}), 119.2(\mathrm{CH}), 119.4(\mathrm{CH}), 119.5(\mathrm{CH}), 121.2(\mathrm{CH}), 121.7(\mathrm{CH})$, $124.1(\mathrm{C}), 124.2(\mathrm{CH}), 126.6(2 \times \mathrm{CH}), 127.6(\mathrm{CH}), 127.8(2 \times \mathrm{CH}), 128.4(\mathrm{CH}), 128.5$ (C), $128.6(\mathrm{CH}), 128.8(\mathrm{C}), 129.5(\mathrm{CH}), 136.4(\mathrm{C}), 136.7(\mathrm{C}), 143.4(\mathrm{C}), 159.4(\mathrm{C})$.

EI-LRMS $m / z, 510\left(\mathrm{M}^{+}, 17\right), 405$ (35), 366 (100).

HRMS calcd. for $\mathrm{C}_{35} \mathrm{H}_{30} \mathrm{~N}_{2} \mathrm{O}_{2}, 510.2307$; found, 510.2307 . 


\section{1,1-Bis(1-methyl-1H-indol-3-yl)-2-phenyl-4-(thiophen-3-yl)but-3-yn-2-ol (53f).}

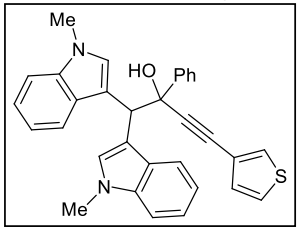

Brown solid; yield $=70 \%$; m.p. $208-210^{\circ} \mathrm{C}$.

${ }^{1} \mathbf{H}$ NMR $\left(300 \mathrm{MHz}, \mathrm{CDCl}_{3}\right) \delta(\mathrm{ppm})=3.23(\mathrm{~s}, 1 \mathrm{H}), 3.70(\mathrm{~s}, 3 \mathrm{H})$, $3.76(\mathrm{~s}, 3 \mathrm{H}), 5.27(\mathrm{~s}, 1 \mathrm{H}), 6.92$ (ddd, $J=8.1,6.9,1.2 \mathrm{~Hz}, 1 \mathrm{H})$, 6.98-7.08 (m, 2H), 7.08-7.10 (m, 1H), 7.16-7.28 (m, 8H), 7.29-7.37 $(\mathrm{m}, 2 \mathrm{H}), 7.39(\mathrm{~s}, 1 \mathrm{H}), 7.60(\mathrm{dt}, J=8.0,1.0 \mathrm{~Hz}, 1 \mathrm{H}), 7.67-7.73(\mathrm{~m}, 2 \mathrm{H})$.

${ }^{13} \mathbf{C ~ N M R}\left(100.6 \mathrm{MHz}, \mathrm{CDCl}_{3}\right) \delta(\mathrm{ppm})=32.95\left(\mathrm{CH}_{3}\right), 33.01\left(\mathrm{CH}_{3}\right), 47.2(\mathrm{CH}), 76.8(\mathrm{C})$, $82.3(\mathrm{C}), 92.5(\mathrm{C}), 108.9(\mathrm{CH}), 109.1(\mathrm{CH}), 113.7(\mathrm{C}), 114.4(\mathrm{C}), 118.8(\mathrm{CH}), 119.1$ $(\mathrm{CH}), 119.5(2 \times \mathrm{CH}), 121.3(\mathrm{CH}), 121.7(\mathrm{CH}), 122.1(\mathrm{C}), 125.4(\mathrm{CH}), 126.6(2 \times \mathrm{CH})$, $127.5(\mathrm{CH}), 127.8(2 \times \mathrm{CH}), 128.3(\mathrm{CH}), 128.5(\mathrm{C}), 128.6(\mathrm{CH}), 128.8(\mathrm{C}), 129.0(\mathrm{CH})$, $129.9(\mathrm{CH}), 136.4(\mathrm{C}), 136.6(\mathrm{C}), 143.4(\mathrm{C})$.

EI-LRMS $m / z, 486\left(\mathrm{M}^{+}, 1\right), 274$ (20), 273 (100).

HRMS calcd. for $\mathrm{C}_{32} \mathrm{H}_{26} \mathrm{~N}_{2} \mathrm{OS}, 486.1768$; found, 486.1766 .

4-(Cyclohex-1-en-1-yl)-1,1-bis(1-methyl-1H-indol-3-yl)-2-phenylbut-3-yn-2-ol (53g).

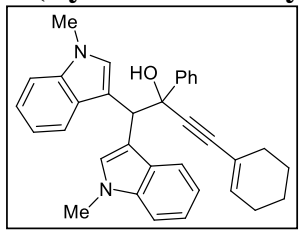

Brown solid; yield $=80 \%$; m.p. $216-218^{\circ} \mathrm{C}$.

${ }^{1} \mathbf{H}$ NMR $\left(300 \mathrm{MHz}, \mathrm{CDCl}_{3}\right) \delta(\mathrm{ppm})=1.70-1.87(\mathrm{~m}, 4 \mathrm{H}), 2.22-$ $2.34(\mathrm{~m}, 4 \mathrm{H}), 3.33(\mathrm{~s}, 1 \mathrm{H}), 3.73(\mathrm{~s}, 3 \mathrm{H}), 3.79(\mathrm{~s}, 3 \mathrm{H}), 5.39(\mathrm{~s}, 1 \mathrm{H}), 6.25$ $6.29(\mathrm{~m}, 1 \mathrm{H}), 7.05(\mathrm{ddd}, J=8.0,6.3,1.8 \mathrm{~Hz}, 1 \mathrm{H}), 7.19-7.27(\mathrm{~m}, 3 \mathrm{H})$, $7.28-7.34(\mathrm{~m}, 2 \mathrm{H}), 7.35-7.42(\mathrm{~m}, 5 \mathrm{H}), 7.55(\mathrm{~s}, 1 \mathrm{H}), 7.80-7.89(\mathrm{~m}, 3 \mathrm{H})$.

${ }^{13} \mathbf{C ~ N M R}\left(100.6 \mathrm{MHz}, \mathrm{CDCl}_{3}\right) \delta(\mathrm{ppm})=21.5\left(\mathrm{CH}_{2}\right), 22.3\left(\mathrm{CH}_{2}\right), 25.7\left(\mathrm{CH}_{2}\right), 29.0$ $\left(\mathrm{CH}_{2}\right), 32.7\left(\mathrm{CH}_{3}\right), 32.8\left(\mathrm{CH}_{3}\right), 47.0(\mathrm{CH}), 76.8(\mathrm{C}), 89.0(\mathrm{C}), 89.9(\mathrm{C}), 108.6(\mathrm{CH}), 109.0$ $(\mathrm{CH}), 113.8(\mathrm{C}), 114.2(\mathrm{C}), 118.5(\mathrm{CH}), 119.0(\mathrm{CH}), 119.2(\mathrm{CH}), 119.3(\mathrm{CH}), 120.4(\mathrm{C})$, $120.9(\mathrm{CH}), 121.5(\mathrm{CH}), 126.5(2 \times \mathrm{CH}), 127.3(\mathrm{CH}), 127.6(2 \times \mathrm{CH}), 128.29(\mathrm{C}), 128.31$ $(\mathrm{CH}), 128.4(\mathrm{CH}), 128.7(\mathrm{CH}), 135.0(\mathrm{C}), 136.1(\mathrm{C}), 136.5(\mathrm{C}), 143.7(\mathrm{C})$.

EI-LRMS $m / z 273(100), 484\left(\mathrm{M}^{+}, 15\right)$.

HRMS calcd. for $\mathrm{C}_{34} \mathrm{H}_{32} \mathrm{~N}_{2} \mathrm{O}, 484.2515$; found, 484.2503.

1,1-Di(1H-indol-3-yl)-2,4-diphenylbut-3-yn-2-ol (53h).

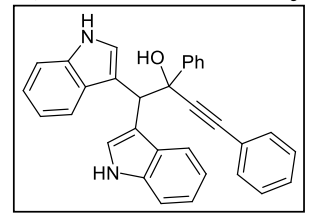

Brown solid; yield $=90 \%$; m.p. $178-180{ }^{\circ} \mathrm{C}$.

${ }^{1} \mathbf{H}$ NMR $\left(400 \mathrm{MHz},\left(\mathrm{CD}_{3}\right)_{2} \mathrm{SO}\right) \delta(\mathrm{ppm})=5.09(\mathrm{~s}, 1 \mathrm{H}), 6.15(\mathrm{~s}$, $1 \mathrm{H}), 6.77-6.82(\mathrm{~m}, 2 \mathrm{H}), 6.88-6.97(\mathrm{~m}, 2 \mathrm{H}), 7.07$ (t, $J=7.3 \mathrm{~Hz}$, $1 \mathrm{H}), 7.15$ (at, $J=7.5 \mathrm{~Hz}, 2 \mathrm{H}), 7.18-7.25(\mathrm{~m}, 4 \mathrm{H}), 7.29-7.34(\mathrm{~m}$, $3 \mathrm{H}), 7.37(\mathrm{~d}, J=2.4 \mathrm{~Hz}, 1 \mathrm{H}), 7.43-7.52(\mathrm{~m}, 3 \mathrm{H}), 7.63(\mathrm{~d}, J=7.6$

$\mathrm{Hz}, \mathrm{H}), 10.64-10.76$ (m, 2H).

${ }^{13} \mathrm{C}$ NMR $\left(100.6 \mathrm{MHz},\left(\mathrm{CD}_{3}\right)_{2} \mathrm{SO}\right) \delta(\mathrm{ppm})=46.2(\mathrm{CH}), 75.6(\mathrm{C}), 85.0(\mathrm{C}), 94.7(\mathrm{C})$, $110.86(\mathrm{CH}), 110.91(\mathrm{CH}), 115.0(\mathrm{C}), 115.4(\mathrm{C}), 117.8(\mathrm{CH}), 117.9(\mathrm{CH}), 118.9(\mathrm{C})$, $119.0(\mathrm{C}), 120.2(\mathrm{CH}), 122.7(\mathrm{CH}), 124.1(\mathrm{CH}), 124.3(\mathrm{CH}), 126.3(2 \times \mathrm{CH}), 126.6(\mathrm{C})$, $127.1(2 \times \mathrm{CH}), 127.9(\mathrm{CH}), 128.1(\mathrm{CH}), 128.3(\mathrm{CH}), 128.5(2 \times \mathrm{CH}), 131.1(2 \times \mathrm{CH})$, $135.2(\mathrm{C}), 135.3(\mathrm{C}), 145.8(\mathrm{C})$, one aromatic carbon peak was misssing due to overlapping. EI-LRMS $m / z, 452\left(\mathrm{M}^{+}, 2\right), 435$ (43), 434 (100).

HRMS calcd. for $\mathrm{C}_{32} \mathrm{H}_{24} \mathrm{~N}_{2} \mathrm{O}, 452.1883$; found, 452.1884 . 


\section{4-(Cyclohex-1-en-1-yl)-1,1-di(1H-indol-3-yl)-2-phenylbut-3-yn-2-ol (53i).}

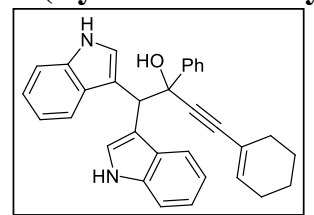

Brown solid; yield $=85 \%$; m.p. $=216-218^{\circ} \mathrm{C}$.

${ }^{1} \mathbf{H}$ NMR $\left(400 \mathrm{MHz},\left(\mathrm{CD}_{3}\right)_{2} \mathrm{CO}\right) \delta(\mathrm{ppm})=1.46-1.63(\mathrm{~m}, 5 \mathrm{H})$, $4.52(\mathrm{~s}, 1 \mathrm{H}), 5.21(\mathrm{~s}, 1 \mathrm{H}), 5.96(\mathrm{dt}, J=4.0,2.1 \mathrm{~Hz}, 1 \mathrm{H}), 6.81(\mathrm{ddd}$, $J=8.1,7.0,1.0 \mathrm{~Hz}, 1 \mathrm{H}), 6.87(\mathrm{ddd}, J=8.0,7.0,1.0 \mathrm{~Hz}, 1 \mathrm{H})$, 6.91-7.00 (m, 2H), 7.03-7.08 (m, 1H), 7.09-7.16 (m, 2H), 7.21$7.26(\mathrm{~m}, 1 \mathrm{H}), 7.26-7.30(\mathrm{~m}, 1 \mathrm{H}), 7.42(\mathrm{~d}, J=8.0 \mathrm{~Hz}, 1 \mathrm{H}), 7.48(\mathrm{~d}, J=2.5 \mathrm{~Hz}, 1 \mathrm{H}), 7.58$ $(\mathrm{d}, J=8.0 \mathrm{~Hz}, 1 \mathrm{H}), 7.62(\mathrm{~d}, J=2.5 \mathrm{~Hz}, 1 \mathrm{H}), 7.66-7.71(\mathrm{~m}, 2 \mathrm{H}), 9.90(\mathrm{~s}, 1 \mathrm{H}), 9.97$ (s, $1 \mathrm{H})$, three aliphatic signal were misssing probably due to overlapping with solvent signals.

${ }^{13} \mathbf{C}$ NMR $\left(100.6 \mathrm{MHz},\left(\mathrm{CD}_{3}\right)_{2} \mathrm{CO}\right) \delta(\mathrm{ppm})=21.3\left(\mathrm{CH}_{2}\right), 22.1\left(\mathrm{CH}_{2}\right), 25.2\left(\mathrm{CH}_{2}\right), 47.0$ $(\mathrm{CH}), 76.3(\mathrm{C}), 87.7(\mathrm{C}), 91.1(\mathrm{C}), 110.7(\mathrm{CH}), 110.8(\mathrm{CH}), 115.4(\mathrm{C}), 115.8(\mathrm{C}), 118.1$ $(\mathrm{CH}), 118.2(\mathrm{CH}), 119.0(\mathrm{CH}), 119.1(\mathrm{CH}), 120.6(\mathrm{CH}), 120.7(\mathrm{CH}), 124.2(\mathrm{CH}), 124.3$ $(\mathrm{CH}), 126.5(2 \times \mathrm{CH}), 126.6(\mathrm{CH}), 127.0(2 \times \mathrm{CH}), 128.3(\mathrm{C}), 128.6(\mathrm{C}), 133.9(\mathrm{C}), 135.8(\mathrm{C}), 136.0$ (C), $145.5(\mathrm{C})$, one aliphatic and two aromatic carbon peaks were misssing due to overlapping.

EI-LRMS $m / z, 456\left(\mathbf{M}^{+}, 20\right), 246$ (17), 245 (100).

HRMS calcd. for $\mathrm{C}_{32} \mathrm{H}_{28} \mathrm{~N}_{2} \mathrm{O}, 456.2192$; found, 456.2202.

\section{1,1-Di(1H-indol-3-yl)-2-methyl-4-phenylbut-3-yn-2-ol (53j).}

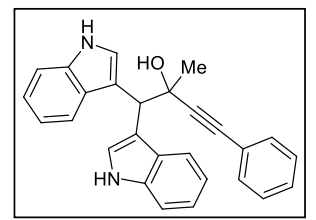

Yellow foam; yield $=65 \% ; R_{f}=0.17$ (hex/EtOAc, 3:1).

${ }^{1} \mathbf{H}$ NMR $\left(400 \mathrm{MHz}, \mathrm{CDCl}_{3}\right) \delta(\mathrm{ppm})=1.76(\mathrm{~s}, 3 \mathrm{H}), 4.94(\mathrm{~s}, 1 \mathrm{H})$, 7.10- $7.04(\mathrm{~m}, 1 \mathrm{H}), 7.14-7.11(\mathrm{~m}, 1 \mathrm{H}), 7.19-7.13(\mathrm{~m}, 2 \mathrm{H}), 7.32$ $7.28(\mathrm{~m}, 5 \mathrm{H}), 7.36-7.33(\mathrm{~m}, 2 \mathrm{H}), 7.45(\mathrm{~d}, J=2.4 \mathrm{~Hz}, 1 \mathrm{H}), 7.49$ $(\mathrm{d}, J=2.4 \mathrm{~Hz}, 1 \mathrm{H}), 7.69(\mathrm{~d}, J=7.9 \mathrm{~Hz}, 1 \mathrm{H}), 7.77(\mathrm{~d}, J=7.9 \mathrm{~Hz}$, $1 \mathrm{H}), 8.00(\mathrm{~s}, 1 \mathrm{H}), 8.05(\mathrm{~s}, 1 \mathrm{H})$.

${ }^{13} \mathrm{C} \mathrm{NMR}\left(75.4 \mathrm{MHz}, \mathrm{CDCl}_{3}\right) \delta(\mathrm{ppm})=29.0\left(\mathrm{CH}_{3}\right), 45.3(\mathrm{CH}), 72.3(\mathrm{C}), 84.7(\mathrm{C}), 93.9$ (C), $111.1(\mathrm{CH}), 111.2(\mathrm{CH}), 115.5(\mathrm{C}), 116.5(\mathrm{C}), 119.3(\mathrm{CH}), 119.4(\mathrm{CH}), 119.5(\mathrm{CH})$, $119.7(\mathrm{CH}), 122.0(\mathrm{CH}), 122.2(\mathrm{CH}), 122.96(\mathrm{C}), 123.04(\mathrm{C}), 123.4(\mathrm{CH}), 128.0(\mathrm{CH})$, $128.2(\mathrm{CH}), 128.4(2 \times \mathrm{CH}), 131.7(2 \times \mathrm{CH}), 135.7(\mathrm{C}), 135.9(\mathrm{C})$.

EI-LRMS $m / z 245$ (100).

\section{1,1-Bis(1-methyl-1H-indol-3-yl)-2-phenylbut-3-yn-2-ol (53k).}

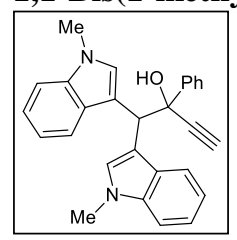

White solid; yield $=60 \%$; m.p. $113-115^{\circ} \mathrm{C}$.

${ }^{1} \mathbf{H}$ NMR $\left(300 \mathrm{MHz}, \mathrm{CDCl}_{3}\right) \delta(\mathrm{ppm})=2.76(\mathrm{~s}, 1 \mathrm{H}), 3.22(\mathrm{~s}, 1 \mathrm{H}), 3.72$ $(\mathrm{s}, 3 \mathrm{H}), 3.77(\mathrm{~s}, 3 \mathrm{H}), 5.20(\mathrm{~s}, 1 \mathrm{H}), 6.88(\mathrm{ddd}, J=8.0,6.9,1.0 \mathrm{~Hz}, 1 \mathrm{H})$, 7.01-7.11 (m, 2H), 7.11-7.14 (m, 1H), 7.15-7.24 (m, 5H), 7.25-7.31 (m, 2H), 7.39-7.41 (m, 1H), $7.60(\mathrm{dt}, J=8.0,1.0 \mathrm{~Hz}, 1 \mathrm{H}), 7.64-7.60(\mathrm{~m}, 2 \mathrm{H})$.

${ }^{13} \mathrm{C} \mathrm{NMR}\left(75.4 \mathrm{MHz}, \mathrm{CDCl}_{3}\right) \delta(\mathrm{ppm})=32.95\left(\mathrm{CH}_{3}\right), 33.03\left(\mathrm{CH}_{3}\right), 75.7(\mathrm{C}), 76.6(\mathrm{C})$, $87.1(\mathrm{C}), 108.8(\mathrm{CH}), 109.2(\mathrm{CH}), 113.5(\mathrm{C}), 113.9(\mathrm{C}), 118.6(\mathrm{CH}), 119.18(\mathrm{CH}), 119.20$ $(\mathrm{CH}), 119.3(\mathrm{CH}), 121.2(\mathrm{CH}), 121.7(\mathrm{CH}), 126.5(2 \times \mathrm{CH}), 127.7(\mathrm{C}), 127.8(2 \times \mathrm{CH})$, $128.3(\mathrm{C}), 128.4(\mathrm{CH}), 128.8(\mathrm{CH}), 136.3(\mathrm{C}), 136.6(\mathrm{C}), 143.0(\mathrm{C})$.

EI-LRMS $m / z, 404\left(\mathrm{M}^{+}, 1\right), 297$ (100).

HRMS calcd. for $\mathrm{C}_{28} \mathrm{H}_{24} \mathrm{~N}_{2} \mathrm{O}, 404.1889$; found, 404.1890. 


\section{1,1-Di(1H-indol-3-yl)-2-phenylbut-3-yn-2-ol (53I).}

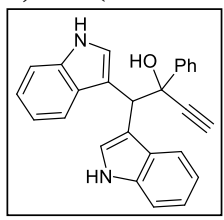

White foam; yield $=80 \%, R_{f}=0.25$ (hex/EtOAc, $\left.4: 1\right)$.

${ }^{1} \mathbf{H}$ NMR $\left(300 \mathrm{MHz},\left(\mathrm{CDCl}_{3}\right) \delta(\mathrm{ppm})=2.68(\mathrm{~s}, 1 \mathrm{H}), 3.24(\mathrm{~s}, 1 \mathrm{H}), 5.22\right.$ (s, 1H), 6.90 (ddd, $J=8.0,7.0,1.1 \mathrm{~Hz}, 1 \mathrm{H}), 7.01-7.10(\mathrm{~m}, 2 \mathrm{H})$, $7.11-7.32(\mathrm{~m}, 8 \mathrm{H}), 7.34(\mathrm{~d}, \mathrm{~J}=2.5 \mathrm{~Hz}, 1 \mathrm{H}), 7.59(\mathrm{~d}, J=7.8 \mathrm{~Hz}, 1 \mathrm{H})$, $7.63-7.71(\mathrm{~m}, 2 \mathrm{H}), 7.89(\mathrm{~s}, 1 \mathrm{H}), 8.00(\mathrm{~s}, 1 \mathrm{H})$.

${ }^{13} \mathrm{C}$ NMR (75.4.6 MHz, CDCl 3$) \delta(\mathrm{ppm})=46.8(\mathrm{CH}), 75.9(\mathrm{C}), 76.5(\mathrm{C}), 86.9(\mathrm{C}), 110.8$ $(\mathrm{CH}), 111.2(\mathrm{CH}), 114.7(\mathrm{C}), 115.2(\mathrm{C}), 119.10(\mathrm{CH}), 119.15(\mathrm{CH}), 119.21(\mathrm{CH}), 119.6$ $(\mathrm{CH}), 121.7(\mathrm{CH}), 122.1(\mathrm{CH}), 123.95(\mathrm{CH}), 124.03(\mathrm{CH}), 126.4(2 \times \mathrm{CH}), 127.75(\mathrm{CH})$, $127.78(\mathrm{CH}), 127.9(2 \times \mathrm{CH}), 128.2(\mathrm{C}), 135.4(\mathrm{C}), 135.8(\mathrm{C}), 143.0(\mathrm{C})$, one aromatic carbon peak was misssing due to overlapping.

EI-LRMS $m / z, 376\left(\mathbf{M}^{+}, 19\right), 269$ (100).

HRMS calcd. for $\mathrm{C}_{26} \mathrm{H}_{20} \mathrm{~N}_{2} \mathrm{O}, 376.1576$; found, 376.1575.

\section{1,1-Di(1H-indol-3-yl)-2-methylbut-3-yn-2-ol (53m).}

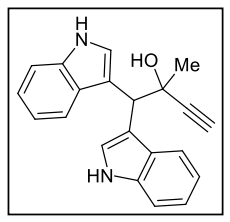

White foam; yield $=60 \% ; R_{f}=0.20($ hex/EtOAc, $2: 1)$.

${ }^{1} \mathbf{H}$ NMR $\left(300 \mathrm{MHz}, \mathrm{CDCl}_{3}\right) \delta(\mathrm{ppm})=1.70(\mathrm{~s}, 3 \mathrm{H}), 2.51(\mathrm{~s}, 1 \mathrm{H}), 2.80(\mathrm{~s}$, $1 \mathrm{H}), 4.89$ (s, 1H), 7.16-7.04 (m, 2H), 7.23-7.14 (m, 2H), 7.38-7.25 (m, 3H), $7.43(\mathrm{~s}, 1 \mathrm{H}), 7.67(\mathrm{~d}, J=7.9 \mathrm{~Hz}, 1 \mathrm{H}), 7.76(\mathrm{~d}, J=8.0 \mathrm{~Hz}, 1 \mathrm{H}), 8.01(\mathrm{~s}, 1 \mathrm{H})$. ${ }^{13} \mathbf{C ~ N M R}\left(75.4 \mathrm{MHz}, \mathrm{CDCl}_{3}\right) \delta(\mathrm{ppm})=29.2\left(\mathrm{CH}_{3}\right), 44.7(\mathrm{CH}), 71.9$ (C), $73.3(\mathrm{CH}), 88.3(\mathrm{C}), 111.2(\mathrm{CH}), 111.3(\mathrm{CH}), 115.1(\mathrm{C}), 116.1(\mathrm{C}), 119.2(\mathrm{CH})$, $119.3(\mathrm{CH}), 119.5(\mathrm{CH}), 119.8(\mathrm{CH}), 122.0(\mathrm{CH}), 122.2(\mathrm{CH}), 123.1(\mathrm{CH}), 123.4(\mathrm{CH})$, 127.9 (C), $128.1(\mathrm{C}), 135.7$ (C), $135.9(\mathrm{C})$.

\section{(1H-Indol-3-yl)-1-(1-methyl-1H-indol-3-yl)-2,4-diphenylbut-3-yn-2-ol (54a).}

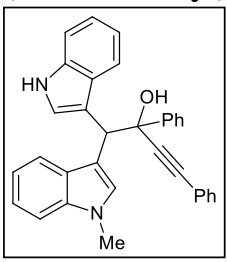

Isolated as a single diastereoisomer. White foam; yield $=65 \% ; R_{f}=$ 0.25 (hex/EtOAc, 3:1).

${ }^{1} \mathbf{H}$ NMR $\left(300 \mathrm{MHz}, \mathrm{CDCl}_{3}\right) \delta(\mathrm{ppm})=3.32(\mathrm{bs}, 1 \mathrm{H}), 3.66(\mathrm{~s}, 3 \mathrm{H})$, 5.29-5.37 (m, 1H), 6.87-6.99 (m, 1H), 7.03-7.48 (m, 17H), $7.55(\mathrm{~s}$, 1H), 7.71-7.78 (m, 1H), $8.14(\mathrm{~s}, 1 \mathrm{H})$.

${ }^{13} \mathbf{C ~ N M R}\left(75.4 \mathrm{MHz}, \mathrm{CDCl}_{3}\right) \delta(\mathrm{ppm})=32.9\left(\mathrm{CH}_{3}\right), 47.2\left(\mathrm{CH}_{3}\right), 87.1$ (C), $92.8(\mathrm{C}), 108.9(\mathrm{CH}), 111.1(\mathrm{CH}), 114.1(\mathrm{CH}), 115.3(\mathrm{CH}), 118.8(\mathrm{CH}), 119.3(\mathrm{CH})$, 119.4 (CH), $119.6(\mathrm{CH}), 121.2(\mathrm{CH}), 122.1(\mathrm{CH}), 122.9(\mathrm{C}), 123.6(\mathrm{C}), 126.4(\mathrm{C}), 126.56$ $(2 \times \mathrm{CH}), 126.63(\mathrm{C}), 127.6(\mathrm{CH}), 127.8(2 \times \mathrm{CH}), 128.4(2 \times \mathrm{CH}), 128.8(2 \times \mathrm{CH}), 129.7$ $(\mathrm{CH}), 131.7(2 \times \mathrm{CH}), 133.2(\mathrm{C}), 135.8(\mathrm{C}), 136.4(\mathrm{C}), 143.4(\mathrm{C})$.

EI-LRMS $m / z 259$ (100).

\section{(1H-Indol-3-yl)-1-(2-methyl-1H-indol-3-yl)-2,4-diphenylbut-3-yn-2-ol (54b).}

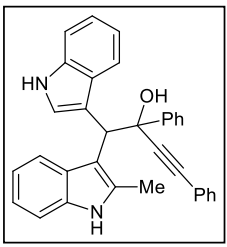

Isolated as a ca. 1.26:1 mixture of diastereoisomers. White foam; yield $=54 \% ; R_{f}=0.30($ hex/EtOAc, $5: 1)$.

${ }^{1} \mathbf{H}$ NMR $\left(300 \mathrm{MHz}, \mathrm{CDCl}_{3}\right) \delta(\mathrm{ppm})=1.92(\mathrm{~s}, 3 \mathrm{H}), 2.16(\mathrm{~s}, 3 \mathrm{H})$, 3.23-3.35 (m, 1H), 3.55-3.61 (m, 1H), $5.07(\mathrm{~s}, 1 \mathrm{H}), 5.23(\mathrm{~s}, 1 \mathrm{H})$, 
6.81-7.46 (m, 28H), 7.51-7.71 (m, 3H), 7.73-7.89 (m, 5H), $7.92(\mathrm{~d}, J=7.4 \mathrm{~Hz}, 1 \mathrm{H})$, $7.99(\mathrm{~d}, J=7.6 \mathrm{~Hz}, 2 \mathrm{H}), 8.07(\mathrm{~s}, 1 \mathrm{H})$.

${ }^{13} \mathrm{C} \mathrm{NMR}\left(75.4 \mathrm{MHz}, \mathrm{CDCl}_{3}\right) \delta(\mathrm{ppm})=11.8\left(\mathrm{CH}_{3}\right), 12.5\left(\mathrm{CH}_{3}\right), 47.6(\mathrm{CH}), 48.3(\mathrm{CH})$, $76.6(\mathrm{C}), 76.8(\mathrm{C}), 86.4(\mathrm{C}), 87.5(\mathrm{C}), 92.9(\mathrm{C}), 93.8(\mathrm{C}), 108.9(\mathrm{CH}), 109.5(\mathrm{CH}), 110.0$ $(\mathrm{CH}), 110.2(\mathrm{CH}), 110.8(\mathrm{CH}), 111.0(\mathrm{CH}), 113.8(\mathrm{CH}), 114.3(\mathrm{CH}), 118.8(\mathrm{C}), 118.9$ (C), $119.0(\mathrm{CH}), 119.1(\mathrm{CH}), 120.3(\mathrm{CH}), 128.8(\mathrm{CH}), 121.6(\mathrm{CH}), 122.0(\mathrm{CH}), 122.9$ $(\mathrm{CH}), 123.0(\mathrm{CH}), 123.1(\mathrm{CH}), 123.8(\mathrm{CH}), 126.5(2 \times \mathrm{CH}), 126.7(2 \times \mathrm{CH}), 127.4(\mathrm{C})$, $127.65(2 \times \mathrm{CH}), 127.74(\mathrm{CH}), 127.9(2 \times \mathrm{CH}), 128.2(\mathrm{CH}), 128.3(2 \times \mathrm{CH}), 128.4(2 \times$ $\mathrm{CH}), 128.46$ (C), 148.49 (C), 133.7 (C), 134.5 (C), 135.3 (C), 135.5 (C), 135.9 (C), 143.7 (C), $144.0(\mathrm{C})$, some carbon peaks were misssing due to overlapping.

EI-LRMS $m / z 335$ (5), 307 (100).

1-(1,2-Dimethyl-1H-indol-3-yl)-1-(1-methyl-1H-indol-3-yl)-2,4-diphenylbut-3-yn-2-ol (54c).

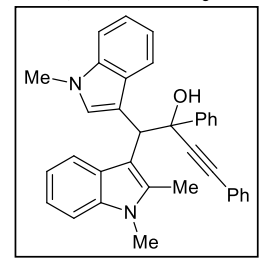

Isolated as a single diasteroisomer. White foam; yield $=65 \% ; R_{f}=$ 0.35 (hex/EtOAc, 3:1).

${ }^{1} \mathbf{H}$ NMR $\left(300 \mathrm{MHz}, \mathrm{CDCl}_{3}\right) \delta(\mathrm{ppm})=1.97(\mathrm{bs}, 1 \mathrm{H}), 3.54(\mathrm{~s}, 3 \mathrm{H})$, $3.81(\mathrm{~s}, 3 \mathrm{H}), 5.07(\mathrm{bs}, 1 \mathrm{H}), 6.83-6.96(\mathrm{~m}, 2 \mathrm{H}), 7.01-7.38(14 \mathrm{H})$, 7.53-7.62 (2H), $7.89(\mathrm{~s}, 1 \mathrm{H})$.

${ }^{13} \mathbf{C ~ N M R}\left(75.4 \mathrm{MHz}, \mathrm{CDCl}_{3}\right) \delta(\mathrm{ppm})=29.5\left(\mathrm{CH}_{3}\right), 33.5\left(\mathrm{CH}_{3}\right), 76.7$ (C), $93.9(\mathrm{C}), 108.2(\mathrm{CH}), 109.0(\mathrm{CH}), 118.4(\mathrm{CH}), 118.6(\mathrm{CH}), 119.0(\mathrm{C}), 119.8(\mathrm{CH})$, $121.5(\mathrm{CH}), 123.1(\mathrm{C}), 126.4(\mathrm{CH}), 127.2(\mathrm{C}), 127.5(\mathrm{CH}), 127.6(\mathrm{C}), 128.2(\mathrm{CH}), 131.6$ $(\mathrm{CH}), 135.3(\mathrm{C}), 136.7(\mathrm{C})$, some carbon peaks were misssing due to overlapping.

EI-LRMS $m / z, 277$ (80), 288 (100).

\subsubsection{Synthesis of 1-Indol-3-ylCarbazoles 55 and 56}

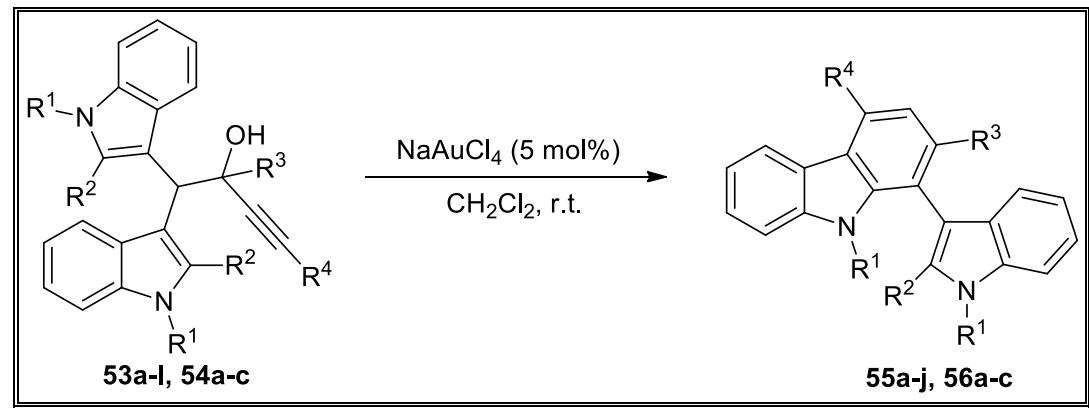

General Procedure: $\mathrm{NaAuCl}_{4}(10 \mathrm{mg}, 5 \mathrm{~mol} \%)$ was added to a solution of $\mathbf{5 3}(0.5$ mmol) in $\mathrm{CH}_{2} \mathrm{Cl}_{2}(1 \mathrm{ml})$ at r.t. The resulting reaction mixture was stirred at r.t. until $\mathbf{5 3}$ was consumed as determined by TLC. The reaction was quenched with a saturated $\mathrm{NH}_{4} \mathrm{Cl}$ aqueous solution and extracted with $\mathrm{CH}_{2} \mathrm{Cl}_{2}(3 \times 10 \mathrm{ml})$. The combined organic layers were dried over anhydrous $\mathrm{Na}_{2} \mathrm{SO}_{4}$ and concentrated at reduced pressure. The residue was purified by flash chromatography using mixtures of hexane and EtOAc as eluents to obtain the corresponding products $\mathbf{5 5}$ and $\mathbf{5 6}$. 
4-Butyl-9-methyl-1-(1-methyl-1H-indol-3-yl)-2-phenyl-9H-carbazole (55a).

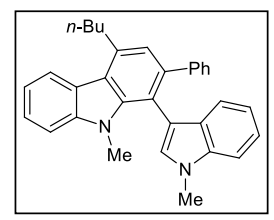

White solid; yield $=83 \%$; m.p. $109-111^{\circ} \mathrm{C}$.

${ }^{1} \mathbf{H}$ NMR $\left(300 \mathrm{MHz}, \mathrm{CDCl}_{3}\right) \delta(\mathrm{ppm})=1.07(\mathrm{t}, J=7.3 \mathrm{~Hz}, 3 \mathrm{H})$, $1.57-1.71(\mathrm{~m}, 2 \mathrm{H}), 1.93-2.03(\mathrm{~m}, 2 \mathrm{H}), 3.25(\mathrm{~s}, 3 \mathrm{H}), 3.35(\mathrm{qd}, J=$ 7.3, 6.7, 3.2 Hz, 2H), $3.73(\mathrm{~s}, 3 \mathrm{H}), 6.68(\mathrm{~s}, 1 \mathrm{H}), 7.03-7.08(\mathrm{~m}, 1 \mathrm{H})$, $7.08-7.12(\mathrm{~m}, 3 \mathrm{H}), 7.13-7.18(\mathrm{~m}, 3 \mathrm{H}), 7.22-7.29(\mathrm{~m}, 1 \mathrm{H}), 7.29$ $7.36(\mathrm{~m}, 4 \mathrm{H}), 7.48$ (ddt, $J=8.2,7.1,1.2 \mathrm{~Hz}, 1 \mathrm{H}) 8.23(\mathrm{~d}, J=8.3 \mathrm{~Hz}, 1 \mathrm{H})$.

${ }^{13} \mathbf{C ~ N M R}\left(75.4 \mathrm{MHz}, \mathrm{CDCl}_{3}\right) \delta(\mathrm{ppm})=14.3\left(\mathrm{CH}_{3}\right), 23.2\left(\mathrm{CH}_{2}\right), 31.4\left(\mathrm{CH}_{3}\right), 32.0\left(\mathrm{CH}_{2}\right)$, $32.9\left(\mathrm{CH}_{3}\right), 34.3\left(\mathrm{CH}_{2}\right), 108.8(\mathrm{CH}), 109.2(\mathrm{CH}), 112.2(\mathrm{C}), 113.7(\mathrm{C}), 119.1(\mathrm{CH}), 119.7$ $(\mathrm{CH}), 120.5(\mathrm{CH}), 120.8(\mathrm{C}), 121.7(\mathrm{CH}), 122.55(\mathrm{CH}), 122.64(\mathrm{CH}), 125.0(\mathrm{CH}), 125.8$ $(\mathrm{CH}), 127.2(2 \times \mathrm{CH}), 129.4(\mathrm{CH}), 129.7(2 \times \mathrm{CH}), 131.2(\mathrm{C}), 136.3(\mathrm{C}), 137.1(\mathrm{C}), 140.9$ (C), 141.9 (C), 142.7 (C), $143.3(\mathrm{C})$.

EI-LRMS $m / z, 442\left(\mathbf{M}^{+}, 100\right)$.

HRMS calcd. for $\mathrm{C}_{32} \mathrm{H}_{30} \mathrm{~N}_{2}, 442.2409$; found, 442.2409 .

4-Cyclopropyl-9-methyl-1-(1-methyl- $1 H$-indol-3-yl)-2-phenyl-9H-carbazole (55b).

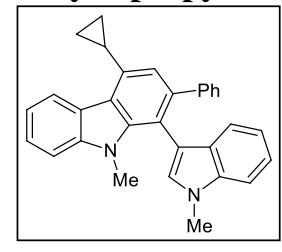
White solid; yield $=83 \%$; m.p. $103-105^{\circ} \mathrm{C}$.

${ }^{1} \mathbf{H}$ NMR $\left(300 \mathrm{MHz}, \mathrm{CDCl}_{3}\right) \delta(\mathrm{ppm})=0.95-1.8(\mathrm{~m}, 2 \mathrm{H}), 1.22(\mathrm{dt}$, $J=7.1,1.3 \mathrm{~Hz}, 2 \mathrm{H}), 2.60-2.76(\mathrm{~m}, 1 \mathrm{H}), 3.26(\mathrm{~s}, 3 \mathrm{H}), 3.72(\mathrm{~s}, 3 \mathrm{H})$, $6.67(\mathrm{~s}, 1 \mathrm{H}), 7.03-7.18(\mathrm{~m}, 7 \mathrm{H}), 7.21-7.26(\mathrm{~m}, 1 \mathrm{H}), 7.27-7.38(\mathrm{~m}$, 4H), $7.50(\mathrm{ddt}, J=8.3,7.1,1.2 \mathrm{~Hz}, 1 \mathrm{H}), 8.60(\mathrm{~d}, J=7.4 \mathrm{~Hz}, 1 \mathrm{H})$.

${ }^{13} \mathrm{C} \mathrm{NMR}\left(75.4 \mathrm{MHz}, \mathrm{CDCl}_{3}\right) \delta(\mathrm{ppm})=108.7(\mathrm{CH}), 109.2(\mathrm{CH}), 112.1(\mathrm{C}), 114.1(\mathrm{C})$, $119.0(\mathrm{CH}), 119.7(\mathrm{CH}), 120.3(\mathrm{CH}), 120.5(\mathrm{CH}), 121.7(\mathrm{CH}), 122.5(\mathrm{C}), 123.0(\mathrm{C}), 123.1$ $(\mathrm{CH}), 125.1(\mathrm{CH}), 125.9(\mathrm{CH}), 127.3(2 \times \mathrm{CH}), 129.4(\mathrm{CH}), 129.7(2 \times \mathrm{CH}), 131.2(\mathrm{C})$, 136.3 (C), 136.6 (C), 140.6 (C), 141.8 (C), 142.7 (C), 143.4 (C).

EI-LRMS $m / z, 426\left(\mathbf{M}^{+}, 100\right)$.

HRMS calcd. for $\mathrm{C}_{31} \mathrm{H}_{26} \mathrm{~N}_{2}$, 426.2096; found, 426.2096.

9-Methyl-1-(1-methyl-1H-indol-3-yl)-4-phenethyl-2-phenyl-9H-carbazole (55c).

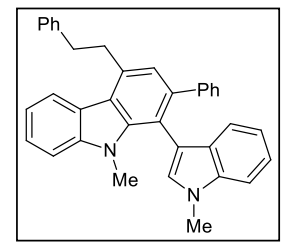

White solid; yield $=92 \%$; m.p. $84-86^{\circ} \mathrm{C}$.

${ }^{1} \mathbf{H}$ NMR $\left(300 \mathrm{MHz}, \mathrm{CDCl}_{3}\right) \delta(\mathrm{ppm})=3.25-3.33(\mathrm{~m}, 5 \mathrm{H}), 3.62-$ $3.71(\mathrm{~m}, 2 \mathrm{H}), 3.73(\mathrm{~s}, 3 \mathrm{H}), 6.70(\mathrm{~s}, 1 \mathrm{H}), 7.04-7.18(\mathrm{~m}, 8 \mathrm{H}), 7.22$ $7.38(\mathrm{~m}, 8 \mathrm{H}), 7.40-7.45(\mathrm{~m}, 4 \mathrm{H}), 7.46-7.54(\mathrm{~m}, 1 \mathrm{H}), 8.33(\mathrm{~d}, J=$ $7.8 \mathrm{~Hz}, 1 \mathrm{H})$.

${ }^{13} \mathbf{C}$ NMR $\left(75.4 \mathrm{MHz}, \mathrm{CDCl}_{3}\right) \delta(\mathrm{ppm})=31.4\left(\mathrm{CH}_{3}\right), 32.8\left(\mathrm{CH}_{3}\right)$, $36.1\left(\mathrm{CH}_{2}\right), 36.4\left(\mathrm{CH}_{2}\right), 108.9(\mathrm{CH}), 109.2(\mathrm{CH}), 112.0(\mathrm{C}), 114.1(\mathrm{C}), 119.3(\mathrm{CH}), 119.7$ $(\mathrm{CH}), 120.4(\mathrm{CH}), 120.7(\mathrm{C}), 121.7(\mathrm{CH}), 122.4(\mathrm{CH}), 122.5(\mathrm{C}), 122.6(\mathrm{CH}), 125.1(\mathrm{CH})$, $125.9(\mathrm{CH}), 126.1(\mathrm{CH}), 127.3(2 \times \mathrm{CH}), 128.6(2 \times \mathrm{CH}), 129.4(\mathrm{CH}), 129.6(2 \times \mathrm{CH})$, 131.2 (C), 135.9 (C), 136.2 (C), 140.9 (C), 142.0 (C), 142.2 (C), 142.7 (C), 143.0 (C), two carbon peaks were misssing due to overlapping.

EI-LRMS $m / z 490\left(\mathbf{M}^{+}, 5\right), 149$ (100).

HRMS calcd. for $\mathrm{C}_{36} \mathrm{H}_{30} \mathrm{~N}_{2}, 490.2409$; found, 490.2415 . 
9-Methyl-1-(1-methyl-1H-indol-3-yl)-2,4-diphenyl-9H-carbazole (55d).

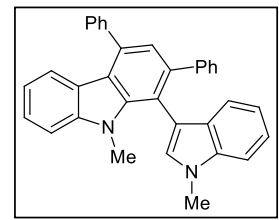

White solid; $73 \%$; m.p. $120-122^{\circ} \mathrm{C}$.

${ }^{1} \mathbf{H}$ NMR $\left(300 \mathrm{MHz}, \mathrm{CDCl}_{3}\right) \delta(\mathrm{ppm})=3.28(\mathrm{~s}, 3 \mathrm{H}), 3.74(\mathrm{~s}, 3 \mathrm{H})$, $6.72(\mathrm{~s}, 1 \mathrm{H}), 7.00(\mathrm{ddd}, J=8.1,7.1,1.1 \mathrm{~Hz}, 1 \mathrm{H}), 7.04-7.12(\mathrm{~m}, 4 \mathrm{H})$, 7.13-7.20 (m, 2H), 7.21 (s, 1H), 7.23-7.30 (m, 2H), 7.31-7.44 (m, $3 \mathrm{H}), 7.46-7.60(\mathrm{~m}, 4 \mathrm{H}), 7.69-7.78(\mathrm{~m}, 2 \mathrm{H})$.

${ }^{13} \mathbf{C ~ N M R}\left(75.4 \mathrm{MHz}, \mathrm{CDCl}_{3}\right) \delta(\mathrm{ppm})=31.5\left(\mathrm{CH}_{3}\right), 32.9\left(\mathrm{CH}_{3}\right), 108.8(\mathrm{CH}), 109.3(\mathrm{CH})$, $112.0(\mathrm{C}), 115.2(\mathrm{C}), 118.7(\mathrm{CH}), 118.8(\mathrm{CH}), 120.4(\mathrm{C}), 120.5(\mathrm{CH}), 121.8(\mathrm{CH}), 122.29$ (C), $122.32(\mathrm{CH}), 123.6(\mathrm{CH}), 125.5(\mathrm{CH}), 126.0(\mathrm{CH}), 127.3(2 \times \mathrm{CH}), 127.6(\mathrm{CH})$, $128.5(2 \times \mathrm{CH}), 129.4(\mathrm{CH}), 129.5(2 \times \mathrm{CH}), 129.7(2 \times \mathrm{CH}), 131.2(\mathrm{C}), 136.3(\mathrm{C}), 136.5$ (C), $140.9(\mathrm{C}), 141.4(\mathrm{C}), 141.8(\mathrm{C}), 142.9(2 \times \mathrm{C})$.

EI-LRMS $m / z, 462\left(\mathbf{M}^{+}, 100\right)$.

HRMS calcd. for $\mathrm{C}_{34} \mathrm{H}_{26} \mathrm{~N}_{2}$, 462.2098; found, 462.2096.

4-(4-Methoxyphenyl)-9-methyl-1-(1-methyl-1H-indol-3-yl)-2-phenyl-9H-carbazole (55e).

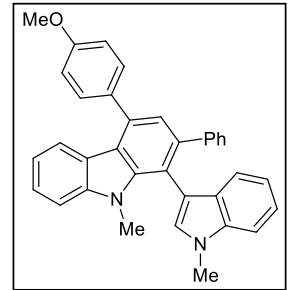

White solid; yield $=66 \%$; m.p. $170-172^{\circ} \mathrm{C}$.

${ }^{1} \mathbf{H}$ NMR $\left(300 \mathrm{MHz}, \mathrm{CDCl}_{3}\right) \delta(\mathrm{ppm})=3.28(\mathrm{~s}, 3 \mathrm{H}), 3.74(\mathrm{~s}, 3 \mathrm{H})$, $3.88(\mathrm{~s}, 3 \mathrm{H}), 6.73(\mathrm{~s}, 1 \mathrm{H}), 6.98-7.14(\mathrm{~s}, 6 \mathrm{H}), 7.15-7.21(\mathrm{~m}, 2 \mathrm{H})$, $7.22-7.32(\mathrm{~m}, 4 \mathrm{H}), 7.33-7.44(\mathrm{~m}, 4 \mathrm{H}), 7.48$ (at, $J=7.8 \mathrm{~Hz}, 1 \mathrm{H})$, $7.58(\mathrm{~d}, J=7.8 \mathrm{~Hz}, 1 \mathrm{H})$.

${ }^{13} \mathrm{C}$ NMR $\left(75.4 \mathrm{MHz}, \mathrm{CDCl}_{3}\right) \delta(\mathrm{ppm})=31.5\left(\mathrm{CH}_{3}\right), 33.0\left(\mathrm{CH}_{3}\right)$, $55.5\left(\mathrm{CH}_{3}\right), 108.8(\mathrm{CH}), 109.3(\mathrm{CH}), 112.0(\mathrm{C}), 113.7(\mathrm{CH}), 114.5(\mathrm{CH}), 115.3(\mathrm{C}), 118.8$ $(\mathrm{CH}), 119.8(\mathrm{CH}), 120.3(\mathrm{C}), 120.5(\mathrm{CH}), 121.8(\mathrm{CH}), 122.0(\mathrm{CH}), 122.2(\mathrm{C}), 122.5(\mathrm{CH})$, $123.4(\mathrm{CH}), 125.5(\mathrm{CH}), 126.0(\mathrm{CH}), 127.3(2 \times \mathrm{CH}), 129.4(\mathrm{CH}), 129.5(\mathrm{CH}), 129.7(2$ $\times \mathrm{CH}), 131.2(\mathrm{C}), 136.30(\mathrm{C}), 136.31(\mathrm{C}), 140.9$ (C), 141.8 (C), 142.8 (C), 142.89 (C), $142.92(\mathrm{C}), 159.7(\mathrm{C})$.

EI-LRMS $m / z, 492\left(\mathbf{M}^{+}, 100\right)$.

HRMS calcd. for $\mathrm{C}_{35} \mathrm{H}_{28} \mathrm{~N}_{2} \mathrm{O}, 492.2201$; found, 492.2202.

9-Methyl-1-(1-methyl-1H-indol-3-yl)-2-phenyl-4-(thiophen-3-yl)-9H-carbazole (55f).

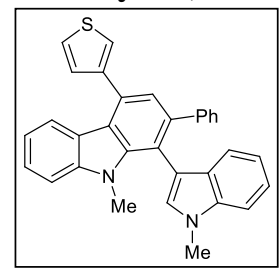

White solid; yield $=90 \%$; m.p. $155-157^{\circ} \mathrm{C}$.

${ }^{1} \mathbf{H}$ NMR $\left(300 \mathrm{MHz}, \mathrm{CDCl}_{3}\right) \delta(\mathrm{ppm})=3.28(\mathrm{~s}, 3 \mathrm{H}), 3.74(\mathrm{~s}, 3 \mathrm{H})$, $6.72(\mathrm{~s}, 1 \mathrm{H}), 7.00-7.20(\mathrm{~m}, 7 \mathrm{H}), 7.22-7.32(\mathrm{~m}, 3 \mathrm{H}), 7.33-7.60(\mathrm{~m}$, $5 \mathrm{H}), 7.62-7.73(\mathrm{~m}, 1 \mathrm{H})$.

EI-LRMS $m / z, 468\left(\mathbf{M}^{+}, 100\right)$.

HRMS calcd. for $\mathrm{C}_{32} \mathrm{H}_{24} \mathrm{~N}_{2} \mathrm{~S}$, 468.1660; found, 468.1660 . 
4-(Cyclohex-1-en-1-yl)-9-methyl-1-(1-methyl-1H-indol-3-yl)-2-phenyl-9H-carbazole (55g).

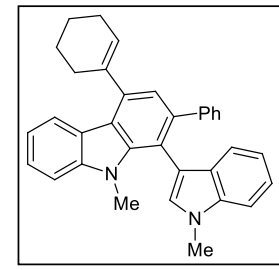

White solid; yield $=85 \%$; m.p. $91-93^{\circ} \mathrm{C}$.

${ }^{1} \mathbf{H}$ NMR $\left(300 \mathrm{MHz}, \mathrm{CDCl}_{3}\right) \delta(\mathrm{ppm})=1.92-2.05(\mathrm{~m}, 2 \mathrm{H}), 2.06-2.17$ (m, 2H), 2.41-2.51 (m, 2H), 2.69 (bs, 2H), $3.32(\mathrm{~s}, 3 \mathrm{H}), 3.75(\mathrm{~s}, 3 \mathrm{H})$, 6.11-6.18 (m, 1H), $6.75(\mathrm{~s}, 1 \mathrm{H}), 7.11-7.19(\mathrm{~m}, 4 \mathrm{H}), 7.20(\mathrm{bs}, 1 \mathrm{H})$, 7.24-7.28 (m, 2H), 7.30-7.36 (m, 3H), 7.37-7.42 (m, 1H), 7.43-7.48 $(\mathrm{m}, 1 \mathrm{H}), 7.52(\mathrm{ddd}, J=8.2,7.0,1.2 \mathrm{~Hz}, 1 \mathrm{H}), 8.33(\mathrm{~d}, J=8.3 \mathrm{~Hz}, 1 \mathrm{H})$.

${ }^{13} \mathrm{C} \mathrm{NMR}\left(75.4 \mathrm{MHz}, \mathrm{CDCl}_{3}\right) \delta(\mathrm{ppm})=22.5\left(\mathrm{CH}_{2}\right), 23.5\left(\mathrm{CH}_{2}\right), 25.7\left(\mathrm{CH}_{2}\right), 29.8\left(\mathrm{CH}_{2}\right)$, $31.4\left(\mathrm{CH}_{3}\right), 32.8\left(\mathrm{CH}_{3}\right), 108.7(\mathrm{CH}), 109.2(\mathrm{CH}), 112.1(\mathrm{C}), 114.3(\mathrm{C}), 118.9(\mathrm{CH}), 119.7$ $(\mathrm{CH}), 120.0(\mathrm{C}), 120.5(\mathrm{CH}), 121.7(\mathrm{CH}), 122.0(\mathrm{CH}), 122.4(\mathrm{CH}), 122.5(\mathrm{C}), 125.2(\mathrm{CH})$, $125.8(\mathrm{CH}), 126.0(\mathrm{CH}), 127.2(2 \times \mathrm{CH}), 129.4(\mathrm{CH}), 129.7(\mathrm{CH}), 131.2(\mathrm{C}), 136.2(\mathrm{C})$, 138.4 (C), 139.1 (C), 140.8 (C), 141.8 (C), 142.8 (C), 143.2 (C).

EI-LRMS $m / z, 466\left(\mathrm{M}^{+}, 100\right)$.

HRMS calcd. for $\mathrm{C}_{34} \mathrm{H}_{30} \mathrm{~N}_{2}, 466.2409$; found, 466.2415 .

\section{1-(1H-Indol-3-yl)-2,4-diphenyl-9H-carbazole (55h).}

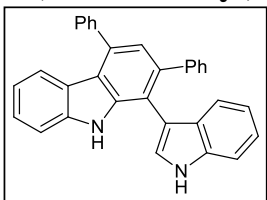

White solid; yield $=96 \%$; m.p. $145-147^{\circ} \mathrm{C}$.

${ }^{1} \mathbf{H}$ NMR $\left(300 \mathrm{MHz}, \mathrm{CDCl}_{3}\right) \delta(\mathrm{ppm})=6.84(\mathrm{~s}, 1 \mathrm{H}), 7.02(\mathrm{t}, J=7.5$ $\mathrm{Hz}, 1 \mathrm{H}), 7.11-7.39(\mathrm{~m}, 10 \mathrm{H}), 7.42-7.70(\mathrm{~m}, 6 \mathrm{H}), 7.80(\mathrm{ad}, J=7.3$ $\mathrm{Hz}, 2 \mathrm{H}), 8.14$ (s, 2H).

${ }^{13} \mathrm{C} \mathrm{NMR}\left(75.4 \mathrm{MHz}, \mathrm{CDCl}_{3}\right) \delta(\mathrm{ppm})=110.6(\mathrm{CH}), 111.7(\mathrm{CH}), 112.2(\mathrm{C}), 114.9(\mathrm{C})$, $119.1(\mathrm{CH}), 119.6(\mathrm{C}), 120.2(\mathrm{CH}), 120.4(\mathrm{CH}), 122.5(2 \times \mathrm{CH}), 123.2(\mathrm{C}), 123.8(\mathrm{CH})$, $124.8(\mathrm{CH}), 125.6(\mathrm{CH}), 126.3(\mathrm{CH}), 127.1(\mathrm{C}), 127.7(\mathrm{C}), 127.8(2 \times \mathrm{CH}), 128.6(2$ $\times \mathrm{CH}), 129.5(2 \times \mathrm{CH}), 130.0(2 \times \mathrm{CH}), 136.1(\mathrm{C}), 136.5(\mathrm{C}), 139.4(\mathrm{C}), 140.0(\mathrm{C}), 140.2$ (C), $141.2(\mathrm{C}), 142.2(\mathrm{C})$.

EI-LRMS $m / z, 434\left(\mathrm{M}^{+}, 100\right)$.

HRMS calcd. for $\mathrm{C}_{32} \mathrm{H}_{22} \mathrm{~N}_{2}$, 434.1783; found, 434.1785 .

4-(Cyclohex-1-en-1-yl)-1-(1H-indol-3-yl)-2-phenyl-9H-carbazole (55i): White solid;

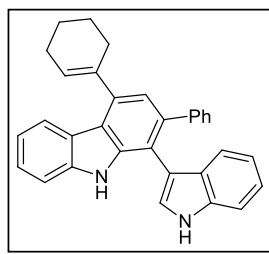

yield $=75 \%$; m.p. $127-129^{\circ} \mathrm{C}$.

${ }^{1} \mathbf{H}$ NMR $\left(300 \mathrm{MHz}, \mathrm{CDCl}_{3}\right) \delta(\mathrm{ppm})=182-191(\mathrm{~m}, 2 \mathrm{H}), 1.97(\mathrm{td}$, $J=6.0,3.8 \mathrm{~Hz}, 2 \mathrm{H}), 2.35(\mathrm{dd}, J=6.2,3.0 \mathrm{~Hz}, 2 \mathrm{H}), 2.58(\mathrm{dq}, J=6.1,3.1$ $\mathrm{Hz}, 2 \mathrm{H}), 6.06(\mathrm{at}, J=1.9 \mathrm{~Hz}, 1 \mathrm{H}), 6.83(\mathrm{dd}, J=2.5,1.1 \mathrm{~Hz}, 1 \mathrm{H}), 7.09-7.19$ (m, 5H), 7.19-7.24 (m, 1H), 7.25-7.32 (m, 5H), 7.32-7.39 (m, 1H), 7.46 $(\mathrm{dd}, J=8.1,3.9 \mathrm{~Hz}, 1 \mathrm{H}), 8.04(\mathrm{~s}, 1 \mathrm{H}), 8.16(\mathrm{~d}, J=7.8 \mathrm{~Hz}, 2 \mathrm{H})$.

${ }^{13} \mathrm{C} \mathrm{NMR}\left(75.4 \mathrm{MHz}, \mathrm{CDCl}_{3}\right) \delta(\mathrm{ppm})=22.5\left(\mathrm{CH}_{2}\right), 23.5\left(\mathrm{CH}_{2}\right), 25.7\left(\mathrm{CH}_{2}\right), 29.8\left(\mathrm{CH}_{2}\right)$, $110.6(\mathrm{CH}), 111.6(\mathrm{CH}), 112.4(\mathrm{C}), 114.1(\mathrm{C}), 119.3(\mathrm{CH}), 119.4(\mathrm{C}), 120.31(\mathrm{CH})$, $120.33(\mathrm{CH}), 122.0(\mathrm{CH}), 122.5(\mathrm{CH}), 122.6(\mathrm{CH}), 123.5(\mathrm{C}), 124.7(\mathrm{CH}), 125.3(\mathrm{CH})$, $126.2(\mathrm{CH}), 126.3(\mathrm{CH}), 127.2(\mathrm{C}), 127.7(2 \times \mathrm{CH}), 130.0(2 \times \mathrm{CH}), 136.2(\mathrm{C}), 138.1$ (C), 139.2 (C), 139.3 (C), 139.9 (C), 140.1 (C), 142.5 (C).

EI-LRMS $m / z, 438\left(\mathrm{M}^{+}, 100\right)$.

HRMS calcd. for $\mathrm{C}_{32} \mathrm{H}_{26} \mathrm{~N}_{2}$, 438.2096; found, 438.2097. 


\section{1-(1H-Indol-3-yl)-2-methyl-4-phenyl-9H-carbazole (55j).}

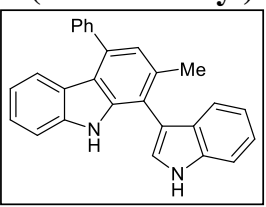

White solid; $70 \%$; m.p. $150-152^{\circ} \mathrm{C}$.

${ }^{1} \mathbf{H}$ NMR $\left(300 \mathrm{MHz}, \mathrm{CDCl}_{3}\right) \delta(\mathrm{ppm})=2.35(\mathrm{~s}, 3 \mathrm{H}), 6.75-6.85(\mathrm{~m}$, 1H), 6.90-6.99 (m, 1H), 7.04-7.12 (m, 1H), 7.20-7.38 (m, 5H), $7.42-7.50(\mathrm{~m}, 2 \mathrm{H}), 7.53-7.64(\mathrm{~m}, 3 \mathrm{H}), 7.74-7.83(\mathrm{~m}, 2 \mathrm{H}), 8.30(\mathrm{~s}$,

$1 \mathrm{H}), 8.41(\mathrm{~s}, 1 \mathrm{H})$.

${ }^{13} \mathbf{C ~ N M R}\left(75.4 \mathrm{MHz}, \mathrm{CDCl}_{3}\right) \delta(\mathrm{ppm})=20.4\left(\mathrm{CH}_{3}\right), 110.5(\mathrm{CH}), 111.6(\mathrm{CH}), 112,0(\mathrm{C})$, $115.9(\mathrm{C}), 118.3(\mathrm{C}), 118.9(\mathrm{CH}), 120.3(\mathrm{CH}), 122.2(\mathrm{CH}), 122.6(\mathrm{CH}), 123.4(\mathrm{CH}), 123.7$ $(\mathrm{CH}), 123.9(\mathrm{C}), 125.1(\mathrm{CH}), 127.0(\mathrm{CH}), 127.5(\mathrm{CH}), 128.5(2 \times \mathrm{CH}), 129.4(2 \times \mathrm{CH})$, 134.9 (C), 136.2 (C), $136.3(\mathrm{C}), 139.6(\mathrm{C}), 140.5$ (C), 141.4 (C).

EI-LRMS $m / z, 372\left(\mathbf{M}^{+}, 100\right)$.

HRMS calcd. for $\mathrm{C}_{27} \mathrm{H}_{20} \mathrm{~N}_{2}, 372.1626$; found, 372.1623 .

9-Methyl-1-(1-methyl-1H-indol-3-yl)-2-phenyl-9H-carbazole (55k).

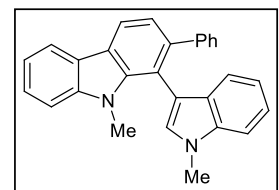

White solid; yield $=60 \%$; m.p. $132-134{ }^{\circ} \mathrm{C}$.

${ }^{1} \mathbf{H}$ NMR $\left(300 \mathrm{MHz}, \mathrm{CDCl}_{3}\right) \delta(\mathrm{ppm})=3.24(\mathrm{~s}, 3 \mathrm{H}), 3.72(\mathrm{~s}, 3 \mathrm{H})$, $6.68(\mathrm{~s}, 1 \mathrm{H}), 7.03-7.17(\mathrm{~m}, 6 \mathrm{H}), 7.20-7.28(\mathrm{~m}, 2 \mathrm{H}), 7.29-7.37$ (m, $4 \mathrm{H}), 7.46$ (ddd, $J=8.2,7.1,1.2 \mathrm{~Hz}, 1 \mathrm{H}), 8.14-8.20(\mathrm{~m}, 2 \mathrm{H})$.

${ }^{13} \mathbf{C ~ N M R}\left(75.4 \mathrm{MHz}, \mathrm{CDCl}_{3}\right) \delta(\mathrm{ppm})=31.3\left(\mathrm{CH}_{3}\right), 32.9\left(\mathrm{CH}_{3}\right), 108.9(\mathrm{CH}), 109.2(\mathrm{CH})$, $112.0(\mathrm{C}), 116.3(\mathrm{C}), 119.1(\mathrm{CH}), 119.8(\mathrm{CH}), 120.0(\mathrm{CH}), 120.5(\mathrm{CH}), 121.7(2 \times \mathrm{CH})$, $122.7(\mathrm{C}), 123.0(\mathrm{C}), 125.7(\mathrm{CH}), 125.9(\mathrm{CH}), 127.3(2 \times \mathrm{CH}), 129.3(\mathrm{CH}), 129.7(\mathrm{CH})$, $131.1(\mathrm{C}), 136.2(\mathrm{C}), 140.6(\mathrm{C}), 142.2(\mathrm{C}), 142.6(\mathrm{C}), 143.2(\mathrm{C})$, two aromatic carbon peaks were misssing due to overlapping.

EI-LRMS $m / z, 386\left(\mathbf{M}^{+}, 100\right)$.

HRMS calcd. for $\mathrm{C}_{28} \mathrm{H}_{22} \mathrm{~N}_{2}, 386.1783$; found, 386.1785 .

\section{1-(1H-Indol-3-yl)-2-phenyl-9H-carbazole (55l).}

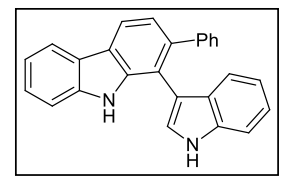

White solid; yield $=83 \%$; m.p. $148-150{ }^{\circ} \mathrm{C}$.

${ }^{1} \mathbf{H}$ NMR $\left(300 \mathrm{MHz}, \mathrm{CDCl}_{3}\right) \delta(\mathrm{ppm})=6.80-6.83(\mathrm{~m}, 1 \mathrm{H})$, 7.13-7.20 (m, 4H), 7.23-7.34 (m, 5H), 7.36-7.50 (m, 4H), $8.01(\mathrm{~s}$, $1 \mathrm{H}), 8.12-8.19(\mathrm{~m}, 3 \mathrm{H})$.

${ }^{13} \mathrm{C} \mathrm{NMR}\left(75.4 \mathrm{MHz}, \mathrm{CDCl}_{3}\right) \delta(\mathrm{ppm})=110.8(\mathrm{CH}), 111.6(\mathrm{CH}), 112.3(\mathrm{C}), 116.0(\mathrm{C})$, $119.2(\mathrm{CH}), 119.5(\mathrm{CH}), 120.1(\mathrm{CH}), 120.4(\mathrm{CH}), 120.5(\mathrm{CH}), 122.2(\mathrm{CH}), 122.3(\mathrm{C})$, $122.5(\mathrm{CH}), 123.6(\mathrm{C}), 124.7(\mathrm{CH}), 125.8(\mathrm{CH}), 126.2(\mathrm{CH}), 127.0(\mathrm{C}), 127.8(2 \times \mathrm{CH})$, $130.0(2 \times \mathrm{CH}), 136.1(\mathrm{C}), 139.6(\mathrm{C}), 139.7$ (C), 139.8 (C), $142.5(\mathrm{C})$.

EI-LRMS $m / z, 358\left(\mathbf{M}^{+}, 100\right)$.

HRMS calcd. for $\mathrm{C}_{26} \mathrm{H}_{18} \mathrm{~N}_{2}, 358.1470$; found, 358.1472. 
(1H-Indol-3-yl)-9-methyl-2,4-diphenyl-9H-carbazole (56a).

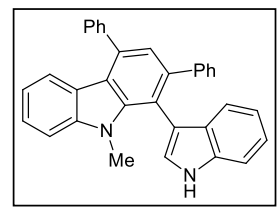

White solid; yield $=10 \%$

${ }^{1} \mathbf{H}$ NMR $\left(400 \mathrm{MHz}, \mathrm{CDCl}_{3}\right) \delta(\mathrm{ppm})=3.27(\mathrm{~s}, 3 \mathrm{H}), 6.85(\mathrm{~d}, J=2.4$ $\mathrm{Hz}, 1 \mathrm{H}), 6.97-7.03(\mathrm{~m}, 1 \mathrm{H}), 7.05-7.13(\mathrm{~m}, 4 \mathrm{H}), 7.15-7.20(\mathrm{~m}, 2 \mathrm{H})$, $7.20-7.24(\mathrm{~m}, 2 \mathrm{H}), 7.27(\mathrm{~d}, J=8.3 \mathrm{~Hz}, 1 \mathrm{H}), 7.35-7.43(\mathrm{~m}, 3 \mathrm{H})$, $7.48-7.61(\mathrm{~m}, 4 \mathrm{H}), 7.72-7.77(\mathrm{~m}, 2 \mathrm{H}), 8.06(\mathrm{~s}, 1 \mathrm{H})$.

${ }^{13} \mathbf{C ~ N M R}\left(75.4 \mathrm{MHz}, \mathrm{CDCl}_{3}\right) \delta(\mathrm{ppm})=31.3\left(\mathrm{CH}_{3}\right), 108.8(\mathrm{CH}), 111.2(\mathrm{CH}), 113.7(\mathrm{C})$, $115.0(\mathrm{C}), 118.8(\mathrm{CH}), 120.37(\mathrm{CH}), 120.39(\mathrm{CH}), 120.41(\mathrm{C}), 122.31(\mathrm{C}), 122.34(\mathrm{CH})$, $122.36(\mathrm{CH}), 123.5(\mathrm{CH}), 124.8(\mathrm{CH}), 125.5(\mathrm{CH}), 126.0(\mathrm{CH}), 127.3(2 \times \mathrm{CH}), 127.6$ $(\mathrm{CH}), 128.5(2 \times \mathrm{CH}), 129.5(2 \times \mathrm{CH}), 129.7(2 \times \mathrm{CH}), 130.7(\mathrm{C}), 135.3(\mathrm{C}), 136.6(\mathrm{C})$, 140.9 (C), 141.4 (C), 141.9 (C), 142.90, (C), 142.92 (C).

EI-LRMS $m / z, 448\left(\mathbf{M}^{+}, 100\right)$.

1-(2-Methyl-1H-indol-3-yl)-2,4-diphenyl-9H-carbazole (56b).

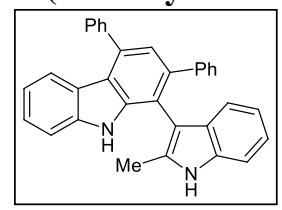

Yellow foam; yield $=14 \%$.

${ }^{1} \mathbf{H}$ NMR $\left(300 \mathrm{MHz}, \mathrm{CDCl}_{3}\right) \delta(\mathrm{ppm})=1.80(\mathrm{~s}, 3 \mathrm{H}), 6.97-7.07(\mathrm{~m}$, $1 \mathrm{H}), 7.11-7.20(\mathrm{~m}, 4 \mathrm{H}), 7.22-7.36(\mathrm{~m}, 4 \mathrm{H}), 7.38-7.47(\mathrm{~m}, 2 \mathrm{H})$, $7.48-7.70(\mathrm{~m}, 4 \mathrm{H}), 7.77-7.85(2 \mathrm{H}), 7.92(\mathrm{~s}, 1 \mathrm{H}), 8.06(\mathrm{~s}, 1 \mathrm{H})$.

${ }^{13}$ C NMR (75.4 MHz, $\left.\mathrm{CDCl}_{3}\right) \delta(\mathrm{ppm})=12.4\left(\mathrm{CH}_{3}\right), 108.6(\mathrm{C}), 110.6(\mathrm{CH}), 110.7(\mathrm{CH})$, $114.6(\mathrm{C}), 119.0(\mathrm{CH}), 119.37(\mathrm{CH}), 119.44(\mathrm{C}), 120.2(\mathrm{CH}), 121.6(\mathrm{CH}), 122.5(\mathrm{CH})$, $123.2(\mathrm{C}), 123.7(\mathrm{CH}), 125.6(\mathrm{CH}), 126.2(\mathrm{CH}), 127.6(\mathrm{CH}), 127.9(2 \times \mathrm{CH}), 128.6(2 \times$ $\mathrm{CH}), 129.5(2 \times \mathrm{CH}), 129.6(2 \times \mathrm{CH}), 133.6(\mathrm{C}), 135.7(\mathrm{C}), 136.6(\mathrm{C}), 139.8(\mathrm{C}), 140.0(\mathrm{C})$, $140.6(\mathrm{C}), 141.4(\mathrm{C}), 142.3(\mathrm{C})$, one aromatic carbon peaks was misssing due to overlapping. EI-LRMS $m / z 448\left(\mathrm{M}^{+}, 3\right), 346$ (100).

1-(1,2-Dimethyl-1H-indol-3-yl)-9-methyl-2,4-diphenyl-9H-carbazole (56c).

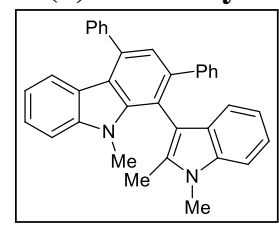

White foam; yield $=12 \%$. ${ }^{1} \mathrm{H}$ NMR was consistent with the formation of rotamers.

${ }^{1} \mathbf{H}$ NMR $\left(300 \mathrm{MHz}, \mathrm{CDCl}_{3}\right) \delta(\mathrm{ppm})=1.88(\mathrm{~s}, 3 \mathrm{H}), 3.57(\mathrm{~s}, 3 \mathrm{H})$, $3.58(\mathrm{~s}, 3 \mathrm{H}), 6.57(\mathrm{~s}, 1 \mathrm{H}), 6.87-7.00(\mathrm{~m}, 2 \mathrm{H}), 7.10-7.30(\mathrm{~m}, 14 \mathrm{H})$, $7.55-7.70(\mathrm{~m}, 4 \mathrm{H})$.

${ }^{13} \mathrm{C} \mathrm{NMR}\left(75.4 \mathrm{MHz}, \mathrm{CDCl}_{3}\right) \delta(\mathrm{ppm})=11.1\left(\mathrm{CH}_{3}\right), 14.3\left(\mathrm{CH}_{3}\right), 22.8\left(\mathrm{CH}_{3}\right), 29.8\left(\mathrm{CH}_{3}\right)$, $31.7\left(\mathrm{CH}_{3}\right), 32.8\left(\mathrm{CH}_{3}\right), 104.7(\mathrm{C}), 107.0(\mathrm{C}), 108.5(\mathrm{CH}), 109.0(\mathrm{CH}), 118.9(\mathrm{C}), 119.1$ $(\mathrm{CH}), 119.3(\mathrm{CH}), 119.58(\mathrm{C}), 119.62(\mathrm{CH}), 120.5(\mathrm{CH}), 120.8(\mathrm{CH}), 121.3(\mathrm{CH}), 124.9$ $(2 \times \mathrm{CH}), 125.5(2 \times \mathrm{CH}), 126.7(\mathrm{CH}), 126.8(\mathrm{CH}), 127.2(\mathrm{C}), 128.27(\mathrm{C}), 128.31(2 \times$ $\mathrm{CH}), 128.33(\mathrm{C}), 128.4(2 \times \mathrm{CH}), 131.7(\mathrm{CH}), 135.3(\mathrm{C}), 136.9(\mathrm{C}), 137.1(\mathrm{C}), 140.0(\mathrm{C})$, $148.8(\mathrm{C})$, one aromatic carbon peaks was misssing due to overlapping.

EI-LRMS $m / z 476\left(\mathbf{M}^{+}, 100\right)$ 


\subsection{Synthesis of 3-Iodocarbazoles 57}

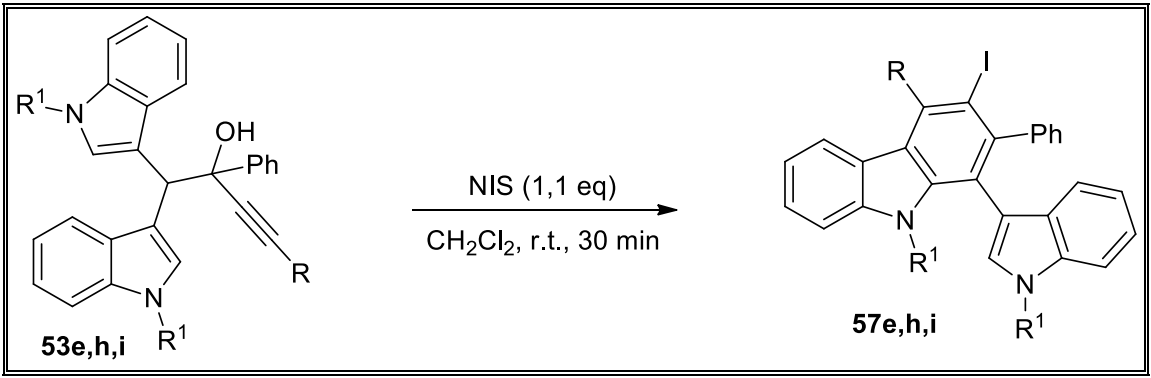

General Procedure: NIS (123.7 mg, $0.55 \mathrm{mmol})$ was added to a solution of $\mathbf{5 3}(0.5$ mmol) in $\mathrm{CH}_{2} \mathrm{Cl}_{2}(1 \mathrm{ml})$ at r.t. The resulting reaction mixture was stirred at r.t. until $\mathbf{5 3}$ was consumed as determined by TLC. The reaction was quenched with a saturated $\mathrm{Na}_{2} \mathrm{SO}_{3}$ aqueous solution and extracted with $\mathrm{CH}_{2} \mathrm{Cl}_{2}(3 \times 10 \mathrm{ml})$. The combined organic layers were dried over anhydrous $\mathrm{Na}_{2} \mathrm{SO}_{4}$ and concentrated at reduced pressure. The residue was purified by flash chromatography using mixtures of hexane and EtOAc as eluents to obtain the corresponding product 57.

3-Iodo-4-(4-methoxyphenyl)-9-methyl-1-(1-methyl-1H-indol-3-yl)-2-phenyl-9H-carbazole (57e).

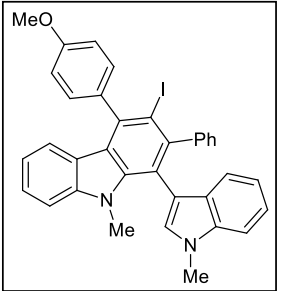

White solid; yield $=35 \% ; R_{f}=0.40($ hex/EtOAc, $4: 1)$

${ }^{1} \mathbf{H}$ NMR $\left(400 \mathrm{MHz}, \mathrm{CDCl}_{3}\right) \delta(\mathrm{ppm})=3.18(\mathrm{~s}, 3 \mathrm{H}), 3.65(\mathrm{~s}, 3 \mathrm{H})$, $3.86(\mathrm{~s}, 3 \mathrm{H}), 6.62(\mathrm{~s}, 1 \mathrm{H}), 6.66(\mathrm{~d}, J=7.8 \mathrm{~Hz}, 1 \mathrm{H}), 6.83(\mathrm{~d}, J=7.8$ $\mathrm{Hz}, 1 \mathrm{H}), 6.93$ (at, $J=7.5 \mathrm{~Hz}, 2 \mathrm{H}), 6.96-7.14(\mathrm{~m}, 8 \mathrm{H}), 7.15-7.30$ (m, 13H), 7.32-7.40 (m, 1H), 7.47-7.56 (m, 1H).

${ }^{13} \mathrm{C} \mathrm{NMR}\left(100.6 \mathrm{MHz}, \mathrm{CDCl}_{3}\right) \delta(\mathrm{ppm})=31.1\left(\mathrm{CH}_{3}\right), 32.9\left(\mathrm{CH}_{3}\right)$, $55.5\left(\mathrm{CH}_{3}\right), 95.7(\mathrm{C}), 108.7(\mathrm{CH}), 109.12(\mathrm{CH}), 109.14(\mathrm{CH}), 112.6(\mathrm{C}), 114.1(\mathrm{C}), 114.4$ $(\mathrm{CH}), 114.6(\mathrm{CH}), 114.7(\mathrm{CH}), 117.1(\mathrm{C}), 119.3(\mathrm{CH}), 119.73(\mathrm{CH}), 119.75(\mathrm{CH}), 120.29$ $(\mathrm{CH}), 120.31(\mathrm{CH}), 121.77(\mathrm{CH}), 121.83(\mathrm{CH}), 122.0(\mathrm{CH}), 122.1(\mathrm{CH}), 122.4(\mathrm{C}), 122.7$ $(\mathrm{CH}), 126.0(\mathrm{CH}), 126.5(\mathrm{CH}), 126.81(\mathrm{CH}), 126.83(\mathrm{CH}), 127.4(\mathrm{CH}), 129.15(\mathrm{CH})$, 129.22 (CH), $129.42(\mathrm{CH}), 129.45(\mathrm{CH}), 130.1(\mathrm{CH}), 130.4(\mathrm{C}), 130.95(\mathrm{CH}), 131.01(\mathrm{CH})$, 136.0 (C), 140.3 (C), 140.7 (C), 142.6 (C), 145.8 (C), 145.9 (C), 146.41 (C), 146.44 (C).

EI-LRMS $m / z 399(30), 568\left(\mathbf{M}^{+}, 100\right)$. 


\section{1-(1H-indol-3-yl)-3-iodo-2,4-diphenyl-9H-carbazole (57h).}

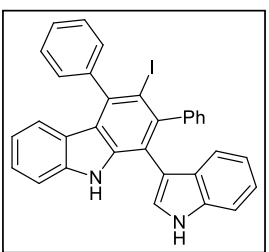

White solid; yield $=60 \% ; R_{f}=0.20($ hex/EtOAc, 5:1).

${ }^{1} \mathbf{H}$ NMR $\left(300 \mathrm{MHz}, \mathrm{CDCl}_{3}\right) \delta(\mathrm{ppm})=6.55-6.64(\mathrm{~m}, 1 \mathrm{H})$, 6.64-6.68 (m, 1H), 6.75-6.80 (m, 1H), 6.83-7.05 (m, 3H), 7.04-7.66 (m, 18H), 7.68-7.88 (m, 1H), 7.90-8.00 (m, 1H), $8.06(\mathrm{~s}, 1 \mathrm{H})$.

${ }^{13}$ C NMR (75.4 MHz, $\left.\mathrm{CDCl}_{3}\right) \delta(\mathrm{ppm})=96.3(\mathrm{C}), 110.6(\mathrm{CH})$, $111.60(\mathrm{CH}), 111.65(\mathrm{CH}), 112.2(\mathrm{C}), 112.3(\mathrm{C}), 114.9(\mathrm{CH}), 117.0$ (C), $119.1(\mathrm{CH}), 119.5(\mathrm{CH}), 119.6(\mathrm{CH}), 120.0(\mathrm{CH}), 120.2(\mathrm{CH}), 120.36(\mathrm{CH}), 120.41$ $(\mathrm{CH}), 121.8(\mathrm{CH}), 122.47(\mathrm{CH}), 122.51(\mathrm{CH}), 123.0(\mathrm{C}), 123.2(\mathrm{C}), 123.8(\mathrm{CH}), 124.8$ $(\mathrm{CH}), 125.1(\mathrm{CH}), 125.6(\mathrm{CH}), 126.1(\mathrm{CH}), 126.7(\mathrm{CH}), 126.9(\mathrm{CH}), 127.1(\mathrm{CH}), 127.7$ (C), $127.8(\mathrm{CH}), 127.9(\mathrm{CH}), 128.1(\mathrm{CH}), 128.6(\mathrm{CH}), 129.0(\mathrm{CH}), 129.5(\mathrm{CH}), 129.6$ $(\mathrm{CH}), 129.8(\mathrm{CH}), 130.0(\mathrm{C}), 131.6(\mathrm{CH}), 135.6(\mathrm{C}), 136.1(\mathrm{C}), 136.5(\mathrm{C}), 139.1(\mathrm{C})$, 139.4 (C), 139.7 (C), 140.0 (C), 140.2 (C), 140.7 (C), 141.2 (C), 142.2 (C), 143.4 (C), $145.0(\mathrm{C}), 145.9(\mathrm{C})$,

EI-LRMS $m / z 560\left(\mathbf{M}^{+}, 62\right), 434$ (100).

HRMS calcd. for $\mathrm{C}_{32} \mathrm{H}_{21} \mathrm{IN}_{2}, 560.0749$; found, 560.0750.

1-(1H-indol-3-yl)-3-iodo-2,4-diphenyl-9H-carbazole (57i).

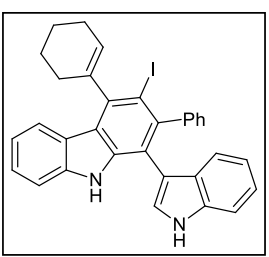

White solid; 71\%; $R_{f}=0.25$ (hex/EtOAc, 4:1).

${ }^{1} \mathbf{H}$ NMR $\left(300 \mathrm{MHz}, \mathrm{CDCl}_{3}\right) \delta(\mathrm{ppm})=1.85-2.17(\mathrm{~m}, 5 \mathrm{H})$, 2.32-2.69 (m, 4H), 5.83-5.97 (m, 1H), $6.66(\mathrm{dd}, J=8.5,2.5 \mathrm{~Hz}, 1 \mathrm{H})$, 6.85-6.91 (m, 1H), 7.00-7.06 (m, 1H), 7.07-7.12 (m, 1H), 7.15-7.26 (m, $3 \mathrm{H}), 7.30-7.42(\mathrm{~m}, 5 \mathrm{H}), 7.90(\mathrm{~s}, 1 \mathrm{H}), 7.99(\mathrm{~s}, 1 \mathrm{H}), 8.16-8.22(\mathrm{~m}, 1 \mathrm{H})$.

${ }^{13} \mathrm{C} \mathrm{NMR}\left(75.4 \mathrm{MHz}, \mathrm{CDCl}_{3}\right) \delta(\mathrm{ppm})=110.8(\mathrm{CH}), 111.6(\mathrm{CH}), 112.3(\mathrm{C}), 116.0(\mathrm{C})$, $119.2(\mathrm{CH}), 119.5(\mathrm{CH}), 120.1(\mathrm{CH}), 120.4(\mathrm{CH}), 120.5(\mathrm{CH}), 122.2(\mathrm{CH}), 122.3(\mathrm{C})$, $122.5(\mathrm{CH}), 123.6(\mathrm{C}), 124.7(\mathrm{CH}), 125.8(\mathrm{CH}), 126.2(\mathrm{CH}), 127.0(\mathrm{C}), 127.8(2 \times \mathrm{CH})$, $130.0(2 \times \mathrm{CH}), 136.1(\mathrm{C}), 139.6(\mathrm{C}), 139.7(\mathrm{C}), 139.8(\mathrm{C}), 142.5(\mathrm{C})$.

EI-LRMS $m / z 564\left(\mathbf{M}^{+}, 30\right), 438$ (100).

HRMS calcd. for $\mathrm{C}_{32} \mathrm{H}_{25} \mathrm{IN}_{2}, 564.1062$; found, 564.1063. 


\subsection{Synthesis of $\alpha$-Indolil- $\alpha$-alkenylacetophenones}

\subsubsection{Synthesis of Starting Alcohol 59a-d}

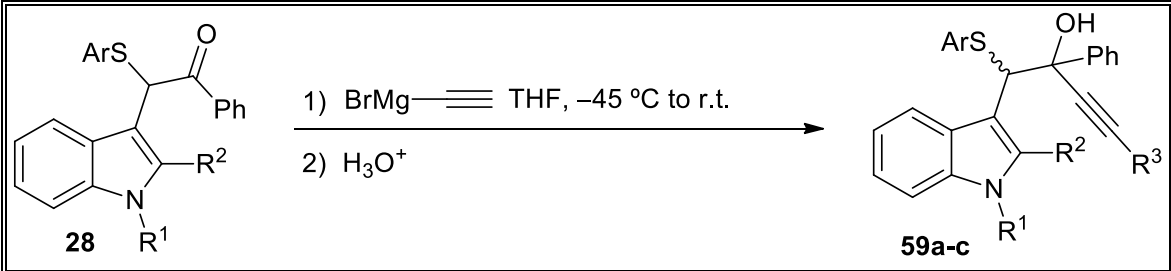

General procedure: To a solution of the corresponding ketone $\mathbf{2 8}$ ( $3 \mathrm{mmol}, 1 \mathrm{eq})$, in THF (10 ml), at $-45^{\circ} \mathrm{C}$, was added ethynylmagnesium bromide $(6.6 \mathrm{ml}, 3.3 \mathrm{mmol}, 0.5$ $\mathrm{M}$ in THF). The resulting mixture was stirred at r.t. until ketone $\mathbf{2 8}$ was consumed as determined by TLC. Then, the reaction was quenched with a saturated $\mathrm{NH}_{4} \mathrm{Cl}$ aqueous solution and extracted with $\mathrm{Et}_{2} \mathrm{O}(3 \times 15 \mathrm{ml})$. The combined organic layers were dried over anhydrous $\mathrm{Na}_{2} \mathrm{SO}_{4}$ and concentrated at reduced pressure. The residue was purified by flash chromatography using mixtures of hexane and EtOAc as eluents to obtain the alkynols 59a-c.

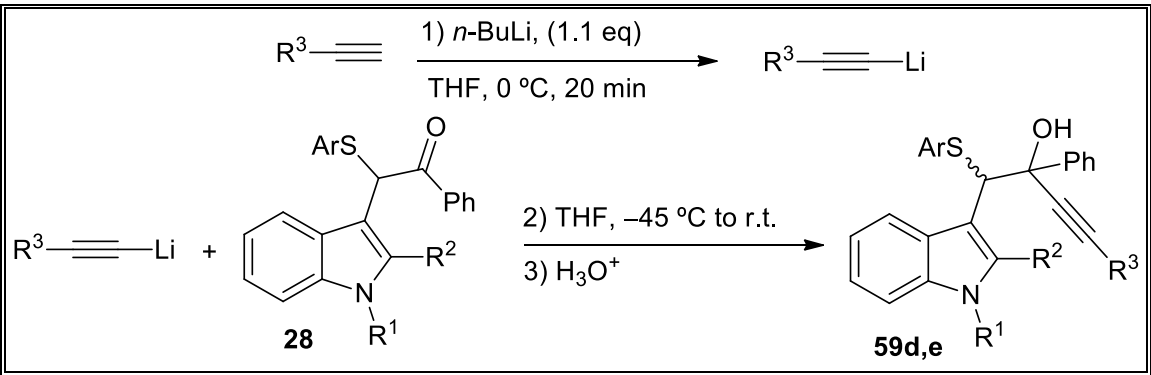

General procedure: To a solution of the corresponding alkyne (3.3 mmol, 1eq), in THF (10 ml) at $0{ }^{\circ} \mathrm{C}$ was added $n$-BuLi (3.3 mmol, $1.1 \mathrm{eq}, 2 \mathrm{ml}, 1.6 \mathrm{M}$ in hexanes). The solution was stirred at $0{ }^{\circ} \mathrm{C}$ for $20 \mathrm{~min}$, then the appropriate ketone 28 was added $(3 \mathrm{mmol}$, 1 eq) at $-45^{\circ} \mathrm{C}$. The resulting mixture was stirred at r.t. until ketone 28 was consumed as determined by TLC. The reaction was quenched with a saturated $\mathrm{NH}_{4} \mathrm{Cl}$ aqueous solution and extracted with $\mathrm{Et}_{2} \mathrm{O}(3 \times 20 \mathrm{ml})$. The combined organic layers were dried over anhydrous $\mathrm{Na}_{2} \mathrm{SO}_{4}$ and concentrated at reduced pressure. The residue was purified by flash chromatography using mixtures of hexane and EtOAc as eluents to obtain the alkynols 59d,e. 


\section{1-(1-Methyl-1H-indol-3-yl)-2-phenyl-1-( $p$-tolylthio)but-3-yn-2-ol (59a).}

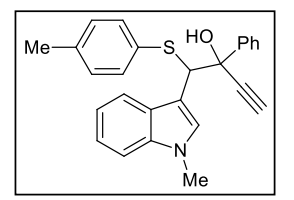

Isolated as a single diasteroisomer. White foam; yield $=50 \% ; R_{f}=$ 0.25 (hex/EtOAc, 6:1).

${ }^{1} \mathbf{H}$ NMR $\left(300 \mathrm{MHz}, \mathrm{CDCl}_{3}\right) \delta(\mathrm{ppm})=1.59(\mathrm{~d}, J=1.8 \mathrm{~Hz}, 1 \mathrm{H})$, $2.30(\mathrm{~s}, 3 \mathrm{H}), 3.70(\mathrm{~s}, 3 \mathrm{H}), 6.17(\mathrm{~d}, J=2.0 \mathrm{~Hz}, 2 \mathrm{H}), 6.97-7.06(\mathrm{~m}$, $3 \mathrm{H}), 7.14-7.23(\mathrm{~m}, 3 \mathrm{H}), 7.25-7.33(\mathrm{~m}, 2 \mathrm{H}), 7.34-7.42(\mathrm{~m}, 2 \mathrm{H}), 7.47-7.56(\mathrm{~m}, 1 \mathrm{H}), 7.75$ $(\mathrm{dt}, J=7.8,1.1 \mathrm{~Hz}, 1 \mathrm{H}), 7.93-8.00(\mathrm{~m}, 2 \mathrm{H})$.

${ }^{13} \mathrm{C}$ NMR $\left(75.4 \mathrm{MHz}, \mathrm{CDCl}_{3}\right) \delta(\mathrm{ppm})=21.1\left(\mathrm{CH}_{3}\right), 33.0\left(\mathrm{CH}_{3}\right), 58.9(\mathrm{CH}), 76.4(\mathrm{C})$, $76.6(\mathrm{CH}), 85.0(\mathrm{C}), 109.4(\mathrm{CH}), 111.2(\mathrm{C}), 119.5(\mathrm{CH}), 119.6(\mathrm{CH}), 121.9(\mathrm{CH}), 126.8$ $(2 \times \mathrm{CH}), 127.8(2 \times \mathrm{CH}), 128.1(\mathrm{CH}), 128.2(\mathrm{C}), 129.4(2 \times \mathrm{CH}), 129.5(\mathrm{CH}), 131.7(2$ $\times \mathrm{CH}), 132.5(\mathrm{C}), 136.6(\mathrm{C}), 136.8(\mathrm{C}), 141.7(\mathrm{C})$.

EI-LRMS $m / z 266$ (100), 371 (15).

\section{1-(1,2-Dimethyl-1H-indol-3-yl)-2-phenyl-1-( $p$-tolylthio)but-3-yn-2-ol (59b).}

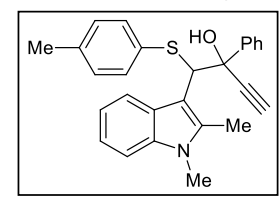

Isolated as a single diasteroisomer along with traces of the another one. White solid; yield $=55 \% ; R_{f}=0.25$ (hex/EtOAc, $5: 1$ ). ${ }^{1} \mathrm{H}$ NMR was consistent with the formation of rotamers.

${ }^{1} \mathbf{H}$ NMR $\left(300 \mathrm{MHz}, \mathrm{CDCl}_{3}\right) \delta(\mathrm{ppm})=2.06(\mathrm{~s}, 3 \mathrm{H}), 2.26(\mathrm{~s}, 3 \mathrm{H})$, $2.80(\mathrm{~s}, 1 \mathrm{H}), 3.06-3.34(\mathrm{~m}, 1 \mathrm{H}), 3.54(\mathrm{~s}, 3 \mathrm{H}), 4.57-4.73(\mathrm{~m}, 1 \mathrm{H}), 6.85-7.43(\mathrm{~m}, 10 \mathrm{H})$, 7.55-7.88 (m, 2H), 8.08-8.22 (m, 1H).

${ }^{13} \mathrm{C} \mathrm{NMR}\left(75.4 \mathrm{MHz}, \mathrm{CDCl}_{3}\right) \delta(\mathrm{ppm})=10.4\left(\mathrm{CH}_{3}\right), 21.1\left(\mathrm{CH}_{3}\right), 29.7\left(\mathrm{CH}_{3}\right), 62.3(\mathrm{CH})$, $76.1(\mathrm{C}), 76.4(\mathrm{CH}), 77.0(\mathrm{C}), 86.0(\mathrm{C}), 107.1(\mathrm{C}), 108.5(\mathrm{CH}), 118.9(\mathrm{CH}), 120.9(\mathrm{CH})$, $122.9(\mathrm{CH}), 126.7(2 \times \mathrm{CH}), 127.6(2 \times \mathrm{CH}), 127.9(\mathrm{CH}), 129.3(2 \times \mathrm{CH}), 130.7(\mathrm{C})$, $132.1(2 \times \mathrm{C}), 133.2(\mathrm{C}), 136.2(\mathrm{C}), 136.8(\mathrm{C}), 137.1(\mathrm{C}), 142.1(\mathrm{C})$.

EI-LRMS $m / z 258$ (10), 287 (100).

\section{1-((4-Chlorophenyl)thio)-1-(1,2-dimethyl-1H-indol-3-yl)-2 phenylbut-3-yn-2-ol (59c).}

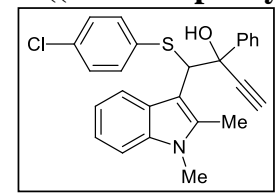

Isolated as a mixture ca. 4:1 of diasteroisomer. Yellow foam; yield $=60 \%, R_{f}=0.3($ hex/EtOAc, $2: 1)$.

${ }^{1} \mathbf{H}$ NMR $\left(300 \mathrm{MHz}, \mathrm{CDCl}_{3}\right) \delta(\mathrm{ppm})=2.02(\mathrm{~m}, 3 \mathrm{H}), 2.78(\mathrm{~s}, 1 \mathrm{H})$, $3.07(\mathrm{~s}, 1 \mathrm{H}), 3.56(\mathrm{~s}, 3 \mathrm{H}), 4.62(\mathrm{~s}, 1 \mathrm{H}), 6.84-7.34(\mathrm{~m}, 10 \mathrm{H})$,

$7.50-7.65(\mathrm{~m}, 2 \mathrm{H}), 8.13(\mathrm{~d}, J=7.9 \mathrm{~Hz}, 1 \mathrm{H})$.

${ }^{13} \mathbf{C ~ N M R}\left(75.4 \mathrm{MHz}, \mathrm{CDCl}_{3}\right) \delta(\mathrm{ppm})=10.4\left(\mathrm{CH}_{3}\right), 29.8\left(\mathrm{CH}_{3}\right), 62.0(\mathrm{CH}), 76.47(\mathrm{C})$, $76.51(\mathrm{CH}), 85.8(\mathrm{C}), 106.7(\mathrm{C}), 108.7(\mathrm{CH}), 119.1(\mathrm{CH}), 121.1(\mathrm{CH}), 122.9(\mathrm{CH}), 126.7$ $(2 \times \mathrm{CH}), 127.8(2 \times \mathrm{CH}), 128.1(\mathrm{CH}), 128.7(2 \times \mathrm{CH}), 131.6(\mathrm{C}), 132.8(\mathrm{C}), 133.2(2 \times$ $\mathrm{CH}), 135.3$ (C), $136.4(\mathrm{C}), 137.2(\mathrm{C}), 142.0(\mathrm{C})$.

EI-LRMS $m / z 259$ (100), 287 (10). 
1-(1-Methyl-1H-indol-3-yl)-2,4-diphenyl-1-(p-tolylthio)but-3-yn-2-ol (59d).

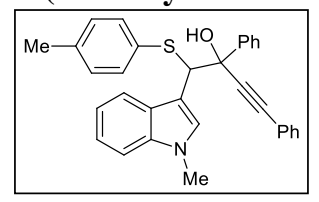

Isolated as a mixture ca. $6: 1$ of diasteroisomer. White foam; yield $=35 \% ; R_{f}=0.20($ hex/EtOAc, $5: 1)$.

${ }^{1} \mathbf{H}$ NMR $\left(300 \mathrm{MHz}, \mathrm{CDCl}_{3}\right) \delta(\mathrm{ppm})=3.20(\mathrm{~s}, 1 \mathrm{H}), 3.76(\mathrm{~s}, 3 \mathrm{H})$, $4.87(\mathrm{~s}, 1 \mathrm{H}), 6.83-6.89(\mathrm{~m}, 2 \mathrm{H}), 6.95-7.00(\mathrm{~m}, 2 \mathrm{H}), 7.09-7.20$ (m, 2H), 7.21-7.40 (m, 7H), 7.46-7.57 (m, 2H), 7.77-7.83 (m, 2H), 7.84-7.90 (m, 2H). ${ }^{13} \mathrm{C} \mathrm{NMR}\left(75.4 \mathrm{MHz}, \mathrm{CDCl}_{3}\right) \delta(\mathrm{ppm})=21.1\left(\mathrm{CH}_{3}\right), 33.1\left(\mathrm{CH}_{3}\right), 59.6(\mathrm{CH}), 77.0(\mathrm{C})$, $87.9(\mathrm{C}), 90.7(\mathrm{C}), 109.4(\mathrm{C}), 111.6(\mathrm{CH}), 119.6(\mathrm{CH}), 120.0(\mathrm{CH}), 121.9(\mathrm{CH}), 122.7$ $(\mathrm{C}), 127.0(2 \times \mathrm{CH}), 127.8(2 \times \mathrm{CH}), 128.1(\mathrm{CH}), 128.2(\mathrm{C}), 128.4(2 \times \mathrm{CH}), 128.7(\mathrm{CH})$, $129.4(2 \times \mathrm{CH}), 129.6(\mathrm{CH}), 131.6(2 \times \mathrm{CH}), 131.9(2 \times \mathrm{CH}), 132.8(\mathrm{C}), 136.7(\mathrm{C}), 136.8$ (C), $142.3(\mathrm{C})$.

EI-LRMS $m / z, 349$ (100).

1-(1,2-Dimethyl-1H-indol-3-yl)-2-phenyl-1-(p-tolylthio)oct-3-yn-2-ol (59e).

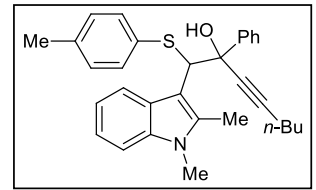
Isolated as a single diasteroisomer. Yellow foam; yield $=40 ; R_{f}$ $=0.3$ (hex/EtOAc, 5:1). ${ }^{1} \mathrm{H}$ NMR was consistent with the formation of rotamers.

${ }^{1} \mathbf{H}$ NMR $\left(300 \mathrm{MHz}, \mathrm{CDCl}_{3}\right) \delta(\mathrm{ppm})=0.92(\mathrm{t}, J=7.2 \mathrm{~Hz}, 1 \mathrm{H})$, $1.27-1.64(\mathrm{~m}, 5 \mathrm{H}), 2.28-2.37(\mathrm{~m}, 5 \mathrm{H}), 3.42-3.47(\mathrm{~s}, 5 \mathrm{H}), 4.18(\mathrm{~s}, 1 \mathrm{H}), 4.47(\mathrm{~s}, 1 \mathrm{H})$, 6.93-7.06 (m, 2H), 7.10-7.32 (m, 8H), 7.33-7.45 (m, 2H), 8.30-8.46 (m, 1H).

${ }^{13} \mathbf{C ~ N M R}\left(75.4 \mathrm{MHz}, \mathrm{CDCl}_{3}\right) \delta(\mathrm{ppm})=9.3\left(\mathrm{CH}_{3}\right), 13.8\left(\mathrm{CH}_{3}\right), 19.0\left(\mathrm{CH}_{2}\right), 21.1\left(\mathrm{CH}_{2}\right)$, $22.2\left(\mathrm{CH}_{3}\right), 29.5\left(\mathrm{CH}_{2}\right), 30.4\left(\mathrm{CH}_{3}\right), 65.7(\mathrm{CH}), 76.4(\mathrm{C}), 82.7(\mathrm{C}), 88.0(\mathrm{C}), 108.2(\mathrm{C}), 108.4(\mathrm{CH})$, $118.4(\mathrm{CH}), 120.5(\mathrm{CH}), 123.2(\mathrm{CH}), 126.7(2 \times \mathrm{CH}), 126.8(\mathrm{C}), 127.3(2 \times \mathrm{CH}), 127.4(\mathrm{CH})$, $129.6(2 \times \mathrm{CH}), 131.6(2 \times \mathrm{CH}), 133.6(\mathrm{C}), 135.5(\mathrm{C}), 136.8(\mathrm{C}), 137.0(\mathrm{C}), 142.1(\mathrm{C})$.

EI-LRMS $m / z, 467\left(\mathbf{M}^{+}, 1\right), 280$ (100).

HRMS calcd. for $\mathrm{C}_{31} \mathrm{H}_{33} \mathrm{NOS}, 467.2283$; found, 467.2276.

\subsubsection{Synthesis of 1,2-Diols 60a-c}

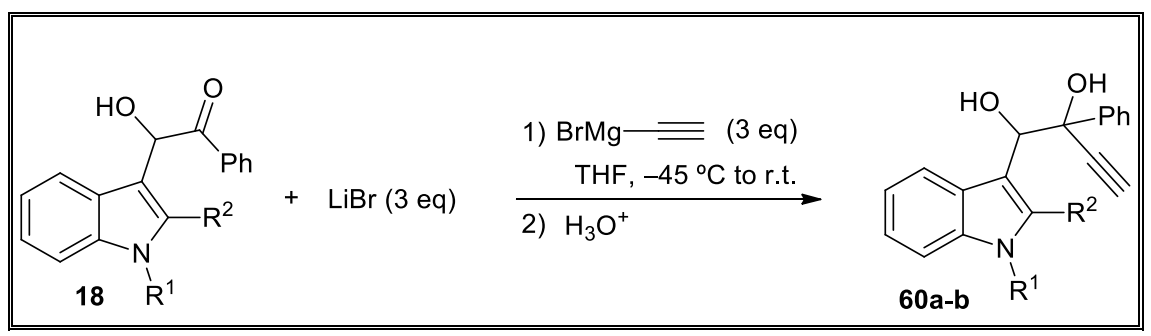

General procedure: To a solution of the corresponding acyloins 18 (3 mmol,) and dry $\mathrm{LiBr}(781.5 \mathrm{mg}, 9 \mathrm{mmol})$, in THF $(25 \mathrm{ml})$, at $-45^{\circ} \mathrm{C}$, was added ethynylmagnesium bromide (18 ml, $9 \mathrm{mmol}, 0.5 \mathrm{M}$ in THF). The resulting mixture was stirred at r.t. until acyloin 18 was consumed as determined by TLC. Then, the reaction was quenched with a saturated $\mathrm{NH}_{4} \mathrm{Cl}$ aqueous solution and extracted with $\mathrm{CH}_{2} \mathrm{Cl}_{2}(3 \times 30 \mathrm{ml})$. The combined 
organic layers were dried over anhydrous $\mathrm{Na}_{2} \mathrm{SO}_{4}$ and concentrated at reduced pressure. The residue was washed with cold $\mathrm{Et}_{2} \mathrm{O}$, and the final products were isolated by simple filtration in pure form.

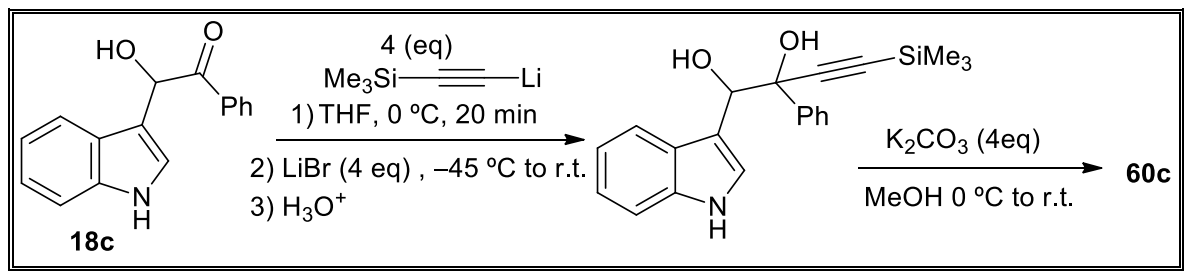

General procedure Step 1: To a solution of trimethylsilyl acetylene ( $8 \mathrm{mmol}, 4 \mathrm{eq})$, in THF ( $50 \mathrm{ml}$ ), at $0{ }^{\circ} \mathrm{C}$, was added $n$ - $\mathrm{BuLi}(5 \mathrm{ml}, 8 \mathrm{mmol}, 1.6 \mathrm{M}$ in hexanes). The solution was stirred at $0{ }^{\circ} \mathrm{C}$ for $20 \mathrm{~min}$, then ketone $18 \mathrm{c}$ was added $(502.6 \mathrm{mg}, 2 \mathrm{mmol})$ at $-45^{\circ} \mathrm{C}$. The resulting mixture was stirred at r.t. until ketone $18 \mathbf{c}$ was consumed as determined by TLC. The reaction was quenched with a saturated $\mathrm{NH}_{4} \mathrm{Cl}$ aqueous solution and extracted with EtOAc $(3 \times 20 \mathrm{ml})$. The combined organic layers were dried over anhydrous $\mathrm{Na}_{2} \mathrm{SO}_{4}$ and concentrated at reduced pressure to obtain the TMS-alkyne alkyne.

General Procedure Step 2: To a solution of $\mathrm{K}_{2} \mathrm{CO}_{3}(1.10 \mathrm{~g}, 8 \mathrm{mmol})$ in $\mathrm{MeOH}$ at 0 ${ }^{\circ} \mathrm{C}$ was added the TMS-alkyne. The solution was stirred at r.t. until the intermediate alkyne was consumed as determined by TLC. Then the reaction was quenched with a saturated $\mathrm{NH}_{4} \mathrm{Cl}$ aqueous solution and extracted with EtOAc $(3 \times 15 \mathrm{ml})$. The combined organic layers were dried over anhydrous $\mathrm{Na}_{2} \mathrm{SO}_{4}$ and concentrated at reduced pressure. The residue was purified by flash chromatography using mixtures of hexane and EtOAc as eluents to obtain the product $\mathbf{6 0 c}$.

1-(1-Methyl-1H-indol-3-yl)-2-phenylbut-3-yne-1,2-diol (60a).

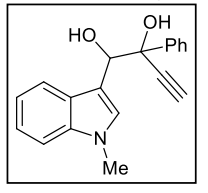

Isolated as a single diasteroisomer. White solid; yield $=60 \%$.

${ }^{1} \mathbf{H}$ NMR $\left(300 \mathrm{MHz}, \mathrm{CDCl}_{3}\right) \delta(\mathrm{ppm})=2.69(\mathrm{~s}, 1 \mathrm{H}), 3.14(\mathrm{bs}, 2 \mathrm{H}), 3.68$ $(\mathrm{s}, 3 \mathrm{H}), 5.24(\mathrm{~s}, 1 \mathrm{H}), 6.99-7.12(\mathrm{~m}, 2 \mathrm{H}), 7.18-7.34(\mathrm{~m}, 5 \mathrm{H}), 7.43-7.51$ $(\mathrm{m}, 1 \mathrm{H}), 7.57-7.67(\mathrm{~m}, 2 \mathrm{H})$.

${ }^{13} \mathbf{C ~ N M R}\left(75.4 \mathrm{MHz}, \mathrm{CDCl}_{3}\right) \delta(\mathrm{ppm})=32.8\left(\mathrm{CH}_{3}\right), 75.2(\mathrm{C}), 75.6(\mathrm{C}), 76.5(\mathrm{CH}), 109.2$ $(\mathrm{CH}), 111.3(\mathrm{C}), 119.3(\mathrm{CH}), 119.7(\mathrm{CH}), 121.6(\mathrm{CH}), 126.6(2 \times \mathrm{CH}), 127.5(\mathrm{C}), 127.8$ $(2 \times \mathrm{CH}), 128.0(\mathrm{CH}), 128.3(\mathrm{CH}), 136.4(\mathrm{C}), 140.4(\mathrm{C})$.

EI-LRMS $m / z 158$ (100), 161 (5).

1-(1,2-Dimethyl-1H-indol-3-yl)-2-phenylbut-3-yne-1,2-diol (60b).

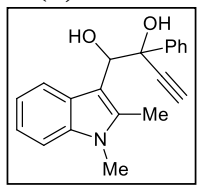

Isolated as a single diasteroisomer. White solid; yield $=65 \%$.

${ }^{1} \mathbf{H}$ NMR $\left(300 \mathrm{MHz}, \mathrm{CDCl}_{3}\right) \delta(\mathrm{ppm})=1.96(\mathrm{~s}, 1 \mathrm{H}), 2.71(\mathrm{~s}, 1 \mathrm{H}), 2.75$ $(\mathrm{d}, J=2.9 \mathrm{~Hz}, 1 \mathrm{H}), 3.14(\mathrm{~s}, 1 \mathrm{H}), 3.56(\mathrm{~s}, 3 \mathrm{H}), 5.20(\mathrm{~d}, J=2.5 \mathrm{~Hz}, 1 \mathrm{H})$, $5.29(\mathrm{~s}, 1 \mathrm{H}), 7.02(\mathrm{t}, J=7.5 \mathrm{~Hz}, 1 \mathrm{H}), 7.14(\mathrm{t}, J=7.5 \mathrm{~Hz}, 1 \mathrm{H}), 7.20-7.32$ (m, 4H), 7.48-7.52 (m, 2H), $7.68(\mathrm{~d}, J=8.0 \mathrm{~Hz}, 1 \mathrm{H})$. 
${ }^{13} \mathrm{C}$ NMR $\left(75.4 \mathrm{MHz}, \mathrm{CDCl}_{3}\right) \delta(\mathrm{ppm})=10.8\left(\mathrm{CH}_{3}\right), 29.5\left(\mathrm{CH}_{3}\right), 75.4(\mathrm{CH}), 77.5(\mathrm{C})$, $77.7(\mathrm{CH}), 85.8(\mathrm{C}), 106.8(\mathrm{C}), 108.6(\mathrm{CH}), 119.4(\mathrm{CH}), 120.77(\mathrm{CH}), 120.81(\mathrm{CH}), 126.8$ $(2 \times \mathrm{CH}), 127.0(\mathrm{C}), 127.9(2 \times \mathrm{CH}), 128.1(\mathrm{CH}), 136.3(\mathrm{C}), 136.7(\mathrm{C}), 140.5(\mathrm{C})$.

EI-LRMS $m / z, 296$ (100).

1-(1H-Indol-3-yl)-2-phenylbut-3-yne-1,2-diol (60c).

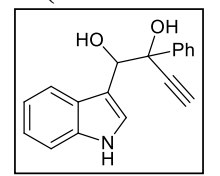

Isolated as a single diasteroisomer. White solid; yield $=60 \%$.

${ }^{1} \mathbf{H}$ NMR $\left(300 \mathrm{MHz}, \mathrm{CDCl}_{3}\right) \delta(\mathrm{ppm})=2.69(\mathrm{~s}, 1 \mathrm{H}), 2.70-2.75(\mathrm{~m}, 1 \mathrm{H})$, 3.06-3.21 (bs, 1H), 5.26 (s, 1H), 6.99-7.10 (m, 2H), 7.12-7.20 (m, $1 \mathrm{H})$, 7.21-7.32 (m, 5H), 7.46-7.52 (m, 1H), 7.54-7.62 (m, 2H), $8.19(\mathrm{~s}, 1 \mathrm{H})$. ${ }^{13} \mathrm{C} \mathrm{NMR}\left(75.4 \mathrm{MHz}, \mathrm{CDCl}_{3}\right) \delta(\mathrm{ppm})=75.5(\mathrm{CH}), 75.8(\mathrm{CH}), 76.6(\mathrm{C}), 112.2(\mathrm{CH})$, $112.7(\mathrm{C}), 119.7(\mathrm{CH}), 119.8(\mathrm{CH}), 122.0(\mathrm{CH}), 124.0(\mathrm{C}), 126.6(2 \times \mathrm{CH}), 127.96(2 \times$ $\mathrm{CH}), 128.2(\mathrm{CH}), 135.6(\mathrm{C}), 140.3(\mathrm{C})$.

EI-LRMS $m / z, 146$ (100).

HRMS calcd. for $\mathrm{C}_{18} \mathrm{H}_{15} \mathrm{NO}_{2}, 277.1103$; found, 277.1102.

\subsubsection{Synthesis of $\alpha$-Indolil- $\alpha$-alkenylacetophenones 61a-c}

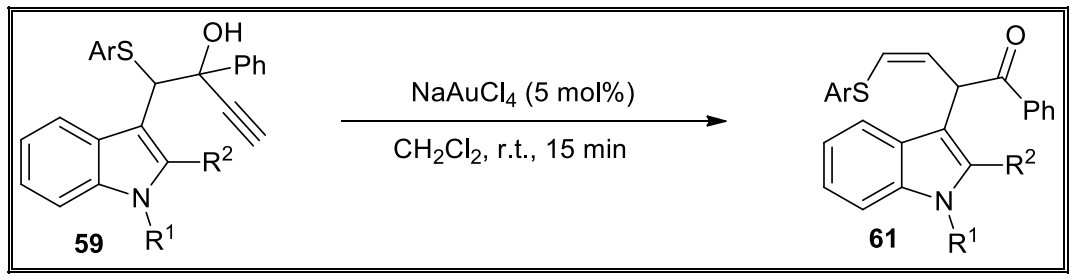

$\mathrm{NaAuCl}_{4}(10 \mathrm{mg}, 5 \mathrm{~mol} \%)$ was added to a solution of $\mathbf{5 9}(0.5 \mathrm{mmol})$ in $\mathrm{CH}_{2} \mathrm{Cl}_{2}(1$ $\mathrm{ml})$ at r.t. The resulting reaction mixture was stirred at r.t. until $\mathbf{5 9}$ was consumed as determined by TLC. The reaction was quenched with a saturated $\mathrm{NH}_{4} \mathrm{Cl}$ aqueous solution and extracted with $\mathrm{CH}_{2} \mathrm{Cl}_{2}(3 \times 10 \mathrm{ml})$. The combined organic layers were dried over anhydrous $\mathrm{Na}_{2} \mathrm{SO}_{4}$ and concentrated at reduced pressure. The residue was purified by flash chromatography using mixtures of hexane and EtOAc as eluents to obtain the corresponding product 61 .

(Z)-2-(1-Methyl-1H-indol-3-yl)-1-phenyl-4-(p-tolylthio)but-3-en-1-one (61a).

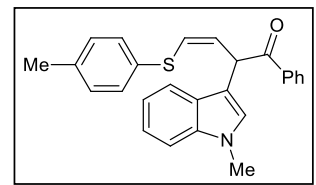

White foam; yield $=77 \% ; R_{f}=0.25$ (hex/EtOAc, 5:1).

${ }^{1} \mathbf{H}$ NMR $\left(300 \mathrm{MHz}, \mathrm{CDCl}_{3}\right) \delta(\mathrm{ppm})=2.33(\mathrm{~s}, 3 \mathrm{H}), 3.72(\mathrm{~s}, 3 \mathrm{H}), 6.13$ $(\mathrm{d}, J=9.1 \mathrm{~Hz}, 1 \mathrm{H}), 6.34(\mathrm{dd}, J=9.1,0.7 \mathrm{~Hz}, 1 \mathrm{H}), 6.41(\mathrm{t}, J=9.1 \mathrm{~Hz}$, $1 \mathrm{H}), 7.00(\mathrm{~s}, 1 \mathrm{H}), 7.11(\mathrm{~d}, J=8.0 \mathrm{~Hz}, 2 \mathrm{H}), 7.15-7.23(\mathrm{~m}, 1 \mathrm{H}), 7.24-7.31$

(m, 4H), 7.36-7.45 (m, 2H), 7.47-7.55 (m, 1H), 7.80-7.87 (m, 1H), 8.06-8.14 (m, 2H).

${ }^{13} \mathbf{C ~ N M R}\left(75.4 \mathrm{MHz}, \mathrm{CDCl}_{3}\right) \delta(\mathrm{ppm})=21.2\left(\mathrm{CH}_{3}\right), 33.0\left(\mathrm{CH}_{3}\right), 44.9(\mathrm{CH}), 109.5(\mathrm{CH})$, $111.1(\mathrm{C}), 119.5(\mathrm{CH}), 119.6(\mathrm{CH}), 122.1(\mathrm{CH}), 124.9(\mathrm{CH}), 126.7(\mathrm{C}), 127.4(\mathrm{CH}), 128.7$ $(2 \times \mathrm{CH}), 128.9((2 \times \mathrm{CH}), 129.7(2 \times \mathrm{CH}), 130.0(2 \times \mathrm{CH}), 131.1(\mathrm{CH}), 132.0(\mathrm{C}), 133.1$ (CH), $136.4(\mathrm{C}), 136.9(\mathrm{C}), 137.2(\mathrm{C}), 198.3(\mathrm{C})$.

EI-LRMS $m / z, 273$ (100). 
(Z)-2-(1,2-Dimethyl-1H-indol-3-yl)-1-phenyl-4-(p-tolylthio)but-3-en-1-one (61b).

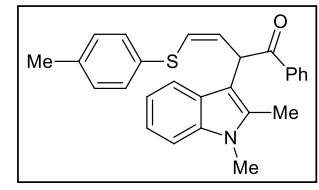

White foam; yield $=65 \% ; R_{f}=0.35$ (hex/EtOAc, $\left.5: 1\right)$.

${ }^{1} \mathbf{H}$ NMR $\left(300 \mathrm{MHz}, \mathrm{CDCl}_{3}\right) \delta(\mathrm{ppm})=2.34(\mathrm{~s}, 3 \mathrm{H}), 2.54(\mathrm{~s}, 3 \mathrm{H})$, $3.56(\mathrm{~s}, 3 \mathrm{H}), 6.04(\mathrm{dd}, J=9.2,2.4 \mathrm{~Hz}, 1 \mathrm{H}), 6.36(\mathrm{dd}, J=9.3,2.1$ $\mathrm{Hz}, 1 \mathrm{H}), 6.77(\mathrm{t}, J=9.2 \mathrm{~Hz}, 4 \mathrm{H}), 7.03-7.24(\mathrm{~m}, 5 \mathrm{H}), 7.25-7.40$ (m, 4H), 7.42-7.50 (m, 1H), 7.99-8.13 (m, 2H).

${ }^{13} \mathrm{C} \mathrm{NMR}\left(75.4 \mathrm{MHz}, \mathrm{CDCl}_{3}\right) \delta(\mathrm{ppm})=11.1\left(\mathrm{CH}_{3}\right), 21.1\left(\mathrm{CH}_{3}\right), 29.6\left(\mathrm{CH}_{3}\right), 45.4(\mathrm{CH})$, $107.7(\mathrm{C}), 108.9(\mathrm{CH}), 118.9(\mathrm{CH}), 119.5(\mathrm{CH}), 121.0(\mathrm{CH}), 124.2(\mathrm{CH}), 126.3(\mathrm{C}), 128.4$ $(2 \times \mathrm{CH}), 128.5(2 \times \mathrm{CH}), 129.5(2 \times \mathrm{CH}), 129.9(2 \times \mathrm{CH}), 130.7(\mathrm{CH}), 132.2(\mathrm{C}), 132.8$ (CH), 133.7 (C), 136.7 (C), 136.8 (C), 198.1 (C).

EI-LRMS $m / z 200$ (100), 305 (15).

(Z)-4-((4-Chlorophenyl)thio)-2-(1,2-dimethyl-1H-indol-3-yl)-1-phenylbut-3-en-1-one (61c).

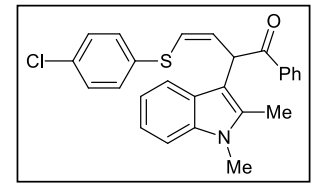

White foam; yield $=70 \% ; R_{f}=0.30$ (hex/EtOAc, 5:1).

${ }^{1} \mathbf{H}$ NMR $\left(300 \mathrm{MHz}, \mathrm{CDCl}_{3}\right) \delta(\mathrm{ppm})=2.49(\mathrm{~s}, 3 \mathrm{H}), 3.60(\mathrm{~s}, 3 \mathrm{H})$, $5.99(\mathrm{dd}, J=9.1,0.8 \mathrm{~Hz}, 1 \mathrm{H}), 6.29(\mathrm{dd}, J=9.1,0.8 \mathrm{~Hz}, 1 \mathrm{H}), 6.83$ $(\mathrm{t}, J=9.1 \mathrm{~Hz}, 1 \mathrm{H}), 7.08-7.21(\mathrm{~m}, 3 \mathrm{H}), 7.21-7.24(\mathrm{~m}, 3 \mathrm{H})$,

7.25-7.39 (m, 4H), 7.40-748 (m, 1H), 7.96-8.02 (m, 2H).

${ }^{13} \mathrm{C}$ NMR $\left(75.4 \mathrm{MHz}, \mathrm{CDCl}_{3}\right) \delta(\mathrm{ppm})=11.0\left(\mathrm{CH}_{3}\right), 29.7\left(\mathrm{CH}_{3}\right), 45.5(\mathrm{C}), 107.6(\mathrm{C})$, $108.9(\mathrm{CH}), 118.9(\mathrm{CH}), 119.7(\mathrm{CH}), 121.1(\mathrm{CH}), 122.4(\mathrm{CH}), 126.3(\mathrm{C}), 128.5(2 \times \mathrm{CH})$, $128.6(2 \times \mathrm{CH}), 129.2(2 \times \mathrm{CH}), 130.2(2 \times \mathrm{CH}), 132.5(\mathrm{C}), 132.9(\mathrm{CH}), 133.0(\mathrm{CH})$, 133.8 (C), 134.6 (C), 136.6 (C), 136.9 (C), 197.9 (C).

EI-LRMS $m / z 287$ (100).

\subsubsection{Synthesis of $\alpha$-Indolil- $\alpha$-alkenylacetophenones 61f-j}

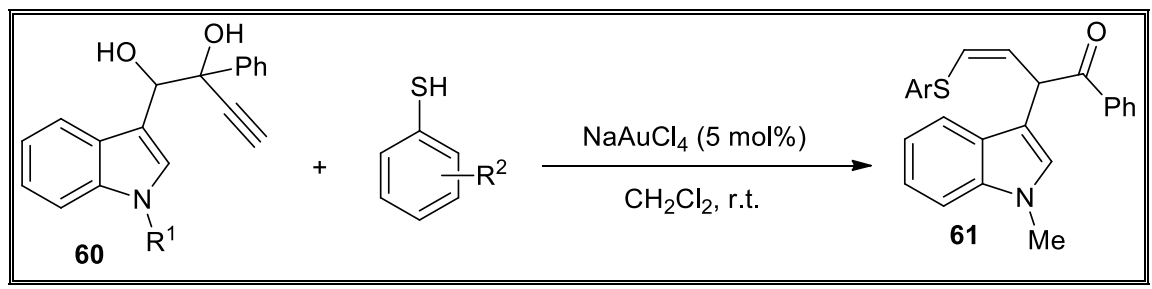

General Procedure: $\mathrm{NaAuCl}_{4}(6 \mathrm{mg}, 5 \mathrm{~mol} \%)$ was added to a solution of diol $\mathbf{6 0}$ $(0.3 \mathrm{mmol})$ and the corresponding thiophenol $(0.3 \mathrm{mmol})$ in $\mathrm{CH}_{2} \mathrm{Cl}_{2}(1 \mathrm{ml})$ at r.t. The resulting reaction mixture was stirred at r.t. until diol $\mathbf{6 0}$ was consumed as determined by TLC. The reaction was quenched with $\mathrm{NaOH}$ aqueous solution $(0.5 \mathrm{M})$ and extracted with $\mathrm{CH}_{2} \mathrm{Cl}_{2}(3 \times 5 \mathrm{ml})$. The combined organic layers were dried over anhydrous $\mathrm{Na}_{2} \mathrm{SO}_{4}$ and concentrated at reduced pressure. 
(Z)-4-((4-Methoxyphenyl)thio)-2-(1-methyl-1H-indol-3-yl)-1-phenylbut-3-en-1-one (61g).

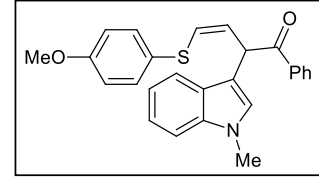

White foam; yield $=85 \%$.

${ }^{1} \mathbf{H}$ NMR $\left(300 \mathrm{MHz}, \mathrm{CD}_{2} \mathrm{Cl}_{2}\right) \delta(\mathrm{ppm})=3.73(\mathrm{~s}, 3 \mathrm{H}), 3.80(\mathrm{~s}$, $3 \mathrm{H}), 6.13(\mathrm{~d}, J=8.6 \mathrm{~Hz}, 1 \mathrm{H}), 6.31-6.45(\mathrm{~m}, 2 \mathrm{H}), 6.83-6.96(\mathrm{~m}$, $2 \mathrm{H}), 7.03-7.09(\mathrm{~m}, 1 \mathrm{H}), 7.18(\mathrm{ddd}, J=8.0,6.8,1.4 \mathrm{~Hz}, 2 \mathrm{H})$, 7.23-7.30 (m, 2H), 7.31-7.60 (m, 4H), $7.84(\mathrm{dt}, J=7.8,1.0 \mathrm{~Hz}, 2 \mathrm{H}), 8.09-8.18(\mathrm{~m}, 1 \mathrm{H})$. ${ }^{13} \mathrm{C} \mathrm{NMR}\left(75.4 \mathrm{MHz}, \mathrm{CD}_{2} \mathrm{Cl}_{2}\right) \delta(\mathrm{ppm})=33.2\left(\mathrm{CH}_{3}\right), 45.5\left(\mathrm{CH}_{3}\right), 55.9(\mathrm{CH}), 110.0(\mathrm{CH})$, $112.2(\mathrm{C}), 115.2(\mathrm{C}), 115.3(2 \times \mathrm{CH}), 119.8(\mathrm{CH}), 119.9(\mathrm{CH}), 122.4(\mathrm{CH}), 126.3(\mathrm{C})$, $126.7(\mathrm{CH}), 127.0(\mathrm{C}), 128.0(\mathrm{CH}), 129.1(2 \times \mathrm{CH}), 129.2(2 \times \mathrm{CH}), 130.1(\mathrm{CH}), 132.6$ $(2 \times \mathrm{CH}), 133.1(\mathrm{C}), 133.5(\mathrm{CH}), 136.9(\mathrm{C}), 137.7(\mathrm{C}), 159.8(\mathrm{C}), 198.3(\mathrm{C})$.

EI-LRMS $m / z 244$ (20), $273(\mathrm{M}+, 100)$.

(Z)-4-((2-Bromophenyl)thio)-2-(1-methyl-1H-indol-3-yl)-1-phenylbut-3-en-1-one (61h).

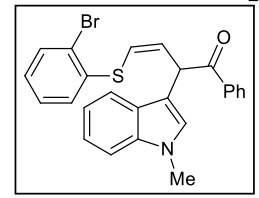
White foam; yield $=60 \%$.

${ }^{1} \mathbf{H}$ NMR $\left(300 \mathrm{MHz}, \mathrm{CDCl}_{2}\right) \delta(\mathrm{ppm})=3.72(\mathrm{~s}, 3 \mathrm{H}), 6.23(\mathrm{~d}, J=9.6$ $\mathrm{Hz}, 1 \mathrm{H}), 6.37(\mathrm{~d}, J=9.1 \mathrm{~Hz}, 1 \mathrm{H}), 6.76(\mathrm{t}, J=9.4 \mathrm{~Hz}, 1 \mathrm{H}), 6.99-7.18$ $(\mathrm{m}, 3 \mathrm{H}), 7.21-7.37(\mathrm{~m}, 4 \mathrm{H}), 7.41(\mathrm{at}, J=7.6 \mathrm{~Hz}, 2 \mathrm{H}), 7.49-7.66(\mathrm{~m}$, 2H), $7.78(\mathrm{~d}, J=8.1 \mathrm{~Hz}, 1 \mathrm{H}), 8.09(\mathrm{ad}, J=7.5 \mathrm{~Hz}, 2 \mathrm{H})$.

${ }^{13} \mathbf{C ~ N M R}\left(75.4 \mathrm{MHz}, \mathrm{CD}_{2} \mathrm{Cl}_{2}\right) \delta(\mathrm{ppm})=33.3\left(\mathrm{CH}_{3}\right), 45.5\left(\mathrm{CH}_{3}\right), 110.0(\mathrm{CH}), 111.8(\mathrm{C})$, $119.6(\mathrm{CH}), 120.0(\mathrm{CH}), 121.8(\mathrm{CH}), 122.5(\mathrm{CH}), 123.2(\mathrm{C}), 126.8(\mathrm{C}), 127.8(\mathrm{CH}), 128.0$ $(\mathrm{CH}), 128.5(\mathrm{CH}), 129.1(2 \times \mathrm{CH}), 129.2(2 \times \mathrm{CH}), 129.4(\mathrm{CH}), 133.4(\mathrm{CH}), 133.6(\mathrm{CH})$, $136.1(\mathrm{CH}), 136.7(\mathrm{C}), 137.7(\mathrm{C}), 137.8(\mathrm{C}), 198.0(\mathrm{C})$.

EI-LRMS $m / z 257$ (10), 273 (100).

(Z)-4-((2-Methoxyphenyl)thio)-2-(1-methyl-1H-indol-3-yl)-1-phenylbut-3-en-1-one (61i).

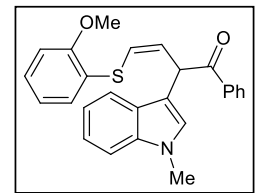

White foam; yield $=77 \%$.

${ }^{1} \mathbf{H}$ NMR $\left(300 \mathrm{MHz}, \mathrm{CD}_{2} \mathrm{Cl}_{2}\right) \delta(\mathrm{ppm})=3.75(\mathrm{~s}, 3 \mathrm{H}), 3.92(\mathrm{~s}, 3 \mathrm{H})$, $6.23(\mathrm{~d}, J=9.4 \mathrm{~Hz}, 1 \mathrm{H}), 6.41(\mathrm{~d}, J=9.0 \mathrm{~Hz}, 1 \mathrm{H}), 6.58(\mathrm{t}, J=9.2 \mathrm{~Hz}$, $1 \mathrm{H}), 6.78-7.60(\mathrm{~m}, 11 \mathrm{H}), 7.81(\mathrm{~d}, J=8.0 \mathrm{~Hz}, 1 \mathrm{H}), 8.14(\mathrm{~d}, J=7.8 \mathrm{~Hz}, 1 \mathrm{H})$. ${ }^{13} \mathrm{C} \mathrm{NMR}\left(75.4 \mathrm{MHz}, \mathrm{CDCl}_{2}\right) \delta(\mathrm{ppm})=33.3\left(\mathrm{CH}_{3}\right), 45.5\left(\mathrm{CH}_{3}\right), 56.3(\mathrm{CH}), 111.0(\mathrm{CH})$, $111.1(\mathrm{CH}), 111.3(\mathrm{CH}), 112.1(\mathrm{C}), 119.77(\mathrm{CH}), 119.84(\mathrm{CH}), 121.7(\mathrm{CH}), 122.4(\mathrm{CH})$, $123.4(\mathrm{C}), 127.0(\mathrm{C}), 128.0(\mathrm{CH}), 128.2(\mathrm{CH}), 129.1(2 \times \mathrm{CH}), 129.2(2 \times \mathrm{CH}), 129.8$ $(\mathrm{CH}), 133.0(\mathrm{CH}), 133.5(\mathrm{CH}), 136.9(\mathrm{C}), 137.7(\mathrm{C}), 157.4(\mathrm{C}), 198.3(\mathrm{C})$.

EI-LRMS $m / z 244$ (19), 273 (100). 
(Z)-2-(1H-Indol-3-yl)-1-phenyl-4-(p-tolylthio)but-3-en-1-one (61j).

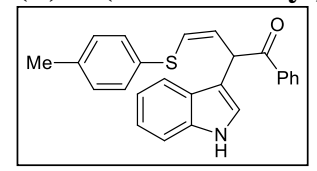

White foam; yield $=77 \%$.

${ }^{1} \mathbf{H}$ NMR $\left(300 \mathrm{MHz}, \mathrm{CD}_{2} \mathrm{Cl}_{2}\right) \delta(\mathrm{ppm})=2.34(\mathrm{~s}, 3 \mathrm{H}), 6.12(\mathrm{~d}, J=$ $8.0 \mathrm{~Hz}, 1 \mathrm{H}), 6.35-6.48(\mathrm{~m}, 2 \mathrm{H}), 7.00-7.62(\mathrm{~m}, 12 \mathrm{H}), 7.79(\mathrm{~d}, J=$ $7.8 \mathrm{~Hz}, 1 \mathrm{H}), 8.10(\mathrm{ad}, J=7.3 \mathrm{~Hz}, 2 \mathrm{H}), 8.34(\mathrm{~s}, 1 \mathrm{H})$.

${ }^{13} \mathbf{C ~ N M R}\left(75.4 \mathrm{MHz}, \mathrm{CDCl}_{3}\right) \delta(\mathrm{ppm})=21.3\left(\mathrm{CH}_{3}\right), 54.7(\mathrm{CH}), 111.9(\mathrm{CH}), 113.7(\mathrm{C})$, $119.7(\mathrm{CH}), 120.3(\mathrm{CH}), 122.9(\mathrm{CH}), 123.5(\mathrm{CH}), 125.7(\mathrm{CH}), 126.5(\mathrm{C}), 129.1(2 \times \mathrm{CH})$, $129.2(2 \times \mathrm{CH}), 130.1(2 \times \mathrm{CH}), 130.4(2 \times \mathrm{CH}), 130.9(\mathrm{CH}), 132.3(\mathrm{C}), 133.6(\mathrm{C}), 136.9$ (C), 137.5 (C), $198.5(\mathrm{C})$. 